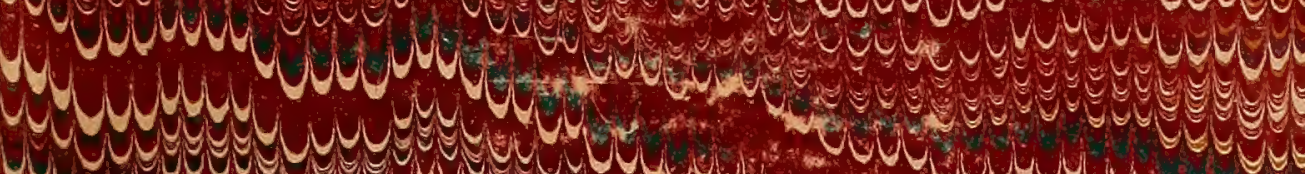

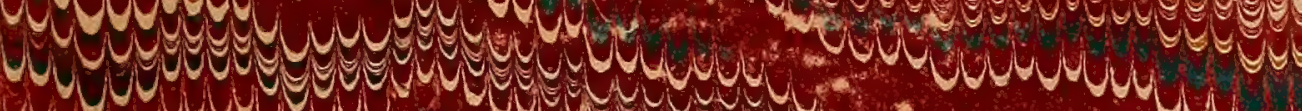

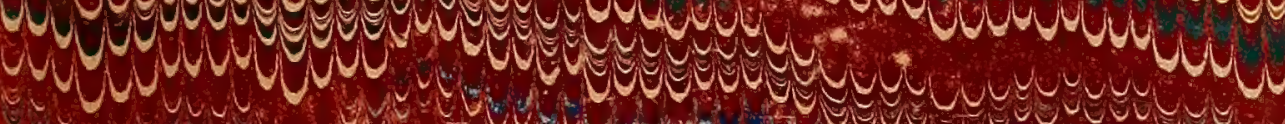

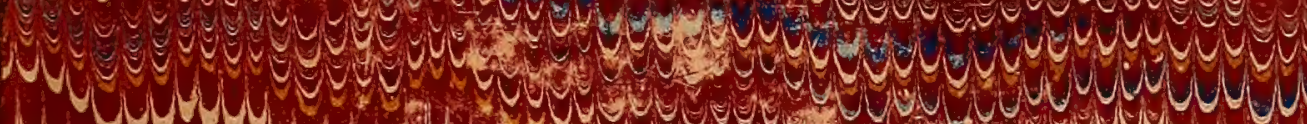
M. W M y y

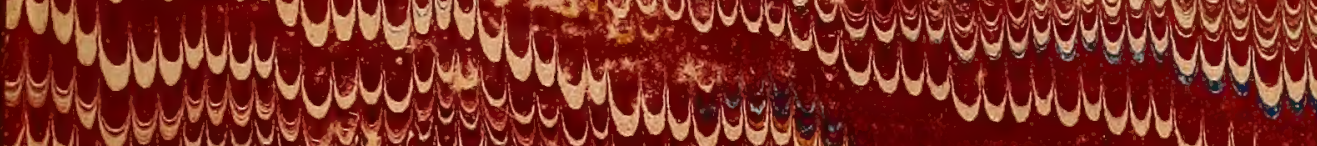

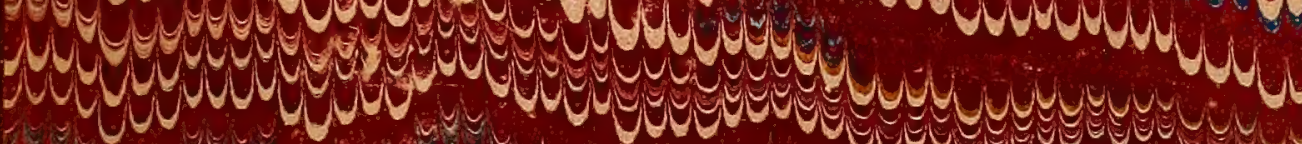

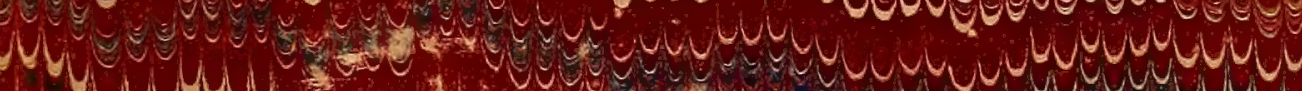

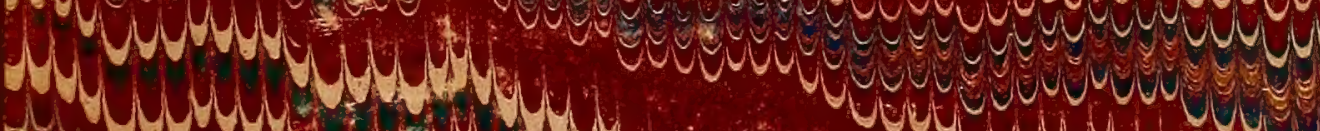
s- 1 Hy

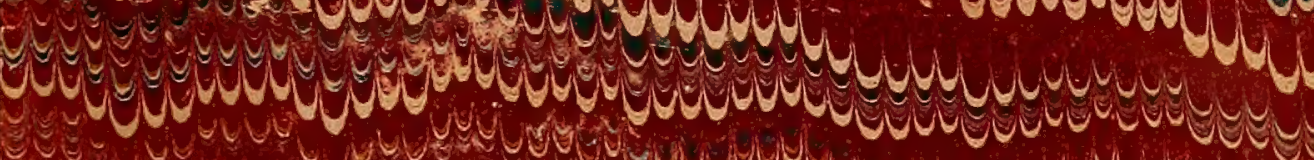

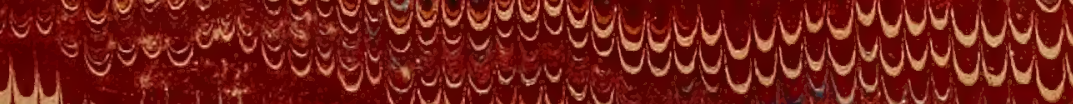

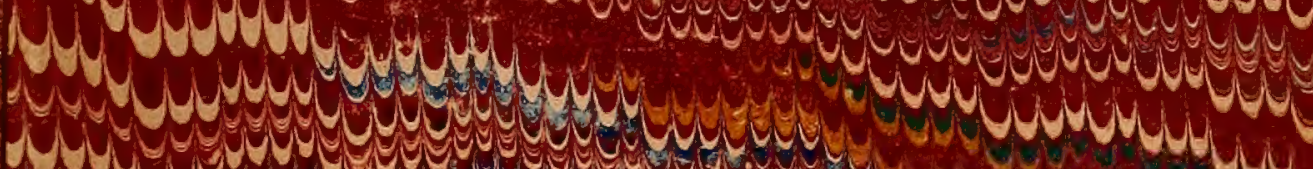
y y y y d y a

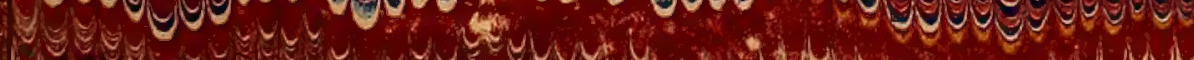

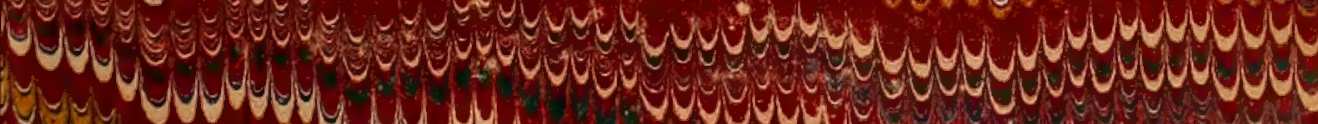
yer wa de wo

tar

Leto

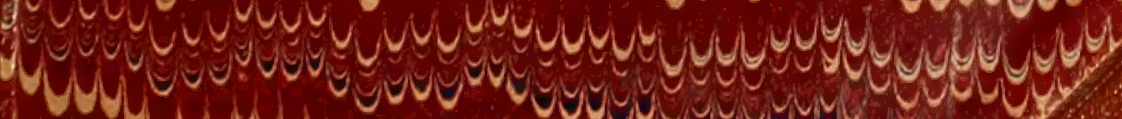

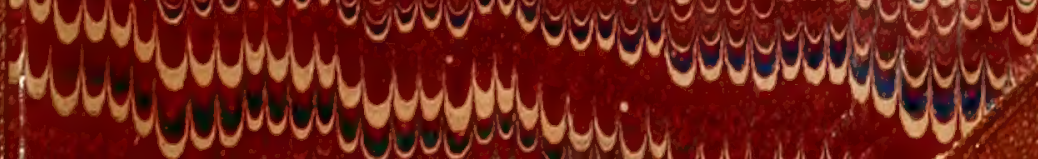




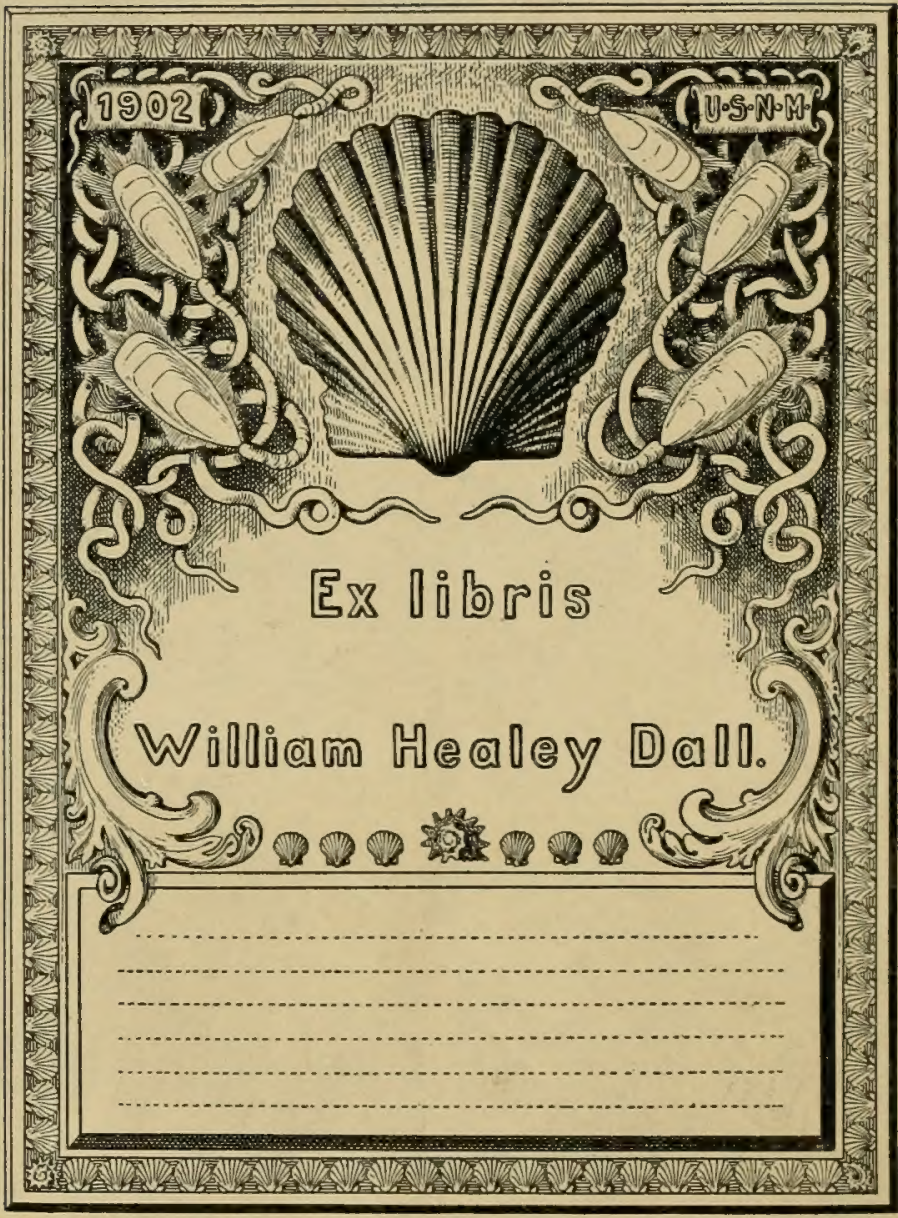




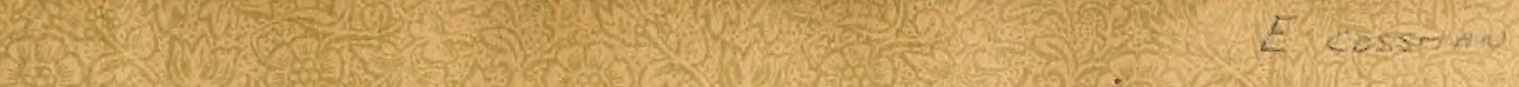

(15)

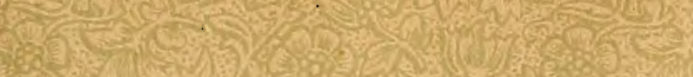

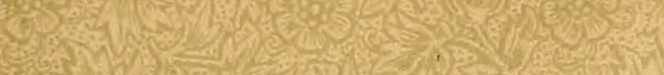
e.

(2)

$$
\text { (1) }
$$

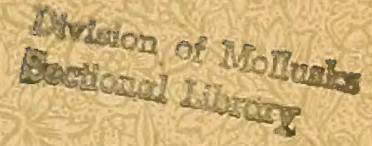

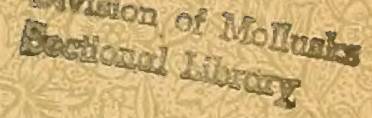

g) $(0$

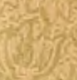

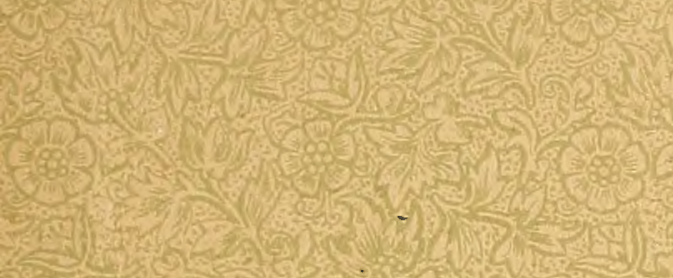

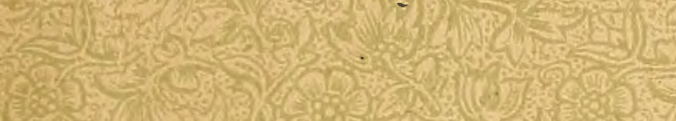

(2)

(2)

(2)

(5)

T. 





ESSAIS

\section{PALÉOCONCHOLOGIE COMPARÉE}




\section{OUVRAGES DU MÊME AUTEUR}

Catalogue illustré des coquilles fossiles de l'Eocène des environs. de Paris (1886-1892). Cinq vol. in-8, 43 planches; avec un appendice. Prix : $103 \mathrm{fr}$.

Revision sommaire de la faune du terrain oligocène marin aux environs d'Étampes (1891-1893). Trois fascicules in-8, 3 planches. Prix : 12 fr. 50.

Notes complémentaires sur la faune éocénique del'Alabama, (1893). 1 vol. in-4, 2 pl. Prix : 8 fr.

S'adresser à l'Auteur, 9ø̈, rue de Maubeuge. 


\title{
ESS A IS
}

DE

\section{PALEOCONCHOLOGIE}

\author{
GOMPAREE
}

PAR M. COSSMANN.

\section{PREMIÉRE LIVRAISON}

(Février 1895)

\section{PAR IS}

CIIEZ L'AUTEUR

9รั. nue maubeuge, 95
COMPTOIR GÉOLOGIQUE

53, rue MoxsievR-Le-PIINCE, 53
SMITHSONIAA

JUN 151988 



\section{P RÉF A CE}

La classification des mollusques fossiles présente, pour les paléontologistes, les plus grandes difficultés : non seulement ils n'ont à leur disposition que la coquille qu'habitait l'animal, mais encore la fossilisation enlève trop souvent à cette coquille les caractères qui pourraient guider l'observateur. Quand le test 'n'a pas été complètement détruit par les actions chimiques ou par la pression, il est du moins privé des couleurs qui sont si utiles pour l'élude des coquilles des mers actuelles; parfois il est empâté dans une gangue sous laquelle il faut deviner - plutôt qu'on ne les aperçoit réellement - la forme des parties les plus importantes de la coquille. Aussi, quand les malacologistes qui s'occupent de conchyliologie récente ont déjà tant de peine à se mettre d'accord sur la classification systématique d'êtres dont ils connaissent presque tous les organes, on se demande s'il est vraiment possible, en se fondant seulement sur ce principe " qu'à une modification de l'animal correspond généralement une modification de la coquille ", d'établir une méthode paléoconchologique.

Au début de la recherche des fossiles, el même dans la première moitié de ce siècle, la paléoconchologie est restée à l'état rudimentaire: les flus illustres de nos maîtres en géologie stratigraphique, se sont bornés à appliquer aux coquilles qu'ils recueil- 
laient, mîme dans les terrains les plus anciens, les noms des formes existant encore aujourd'hui dans la nature, en négligeant peutêtre à dessein, des différences qu'un examen plus attentif permet d'apercevoir. Les travaux de d'Orbigny, Deshayes, Comrar, Mreck, Gal,b, Zittel, Stoliczka, Waagen, Bayan, Gemmellarn, de Konnincli, Sacco, Ehlert, von Ammon, Koken, Kittl, Hudleston, etc..., et de beaucoup d'autres paléontologistes éminents qu'il scrait trop longr d'énumérer, ont ouvert un nouvel horizon : cessant de redouter l'introduction de nouveaux genres et de nouvellesfamilles, admetlant la nécessité de séparer complètement certaines formes rteintes après chaque période géologique, ils ont apporté, pierre à pierre, les matériaux d'un monument dont le siècle prochain verra peut-être l'achèvement.

Aiusi qu'il arrive ordinairement, une réforme de cette importance ne s'accomplit jamais sans que quelques-uns de ceux qui luttent pour la réaliser dépassent le but : on craignait autrefois de multiplier les genres, aujourd'hui on en abuse quelquefois jusqu'à l'excès. La vérité scientifique est nécessairement entre ces deux extrémités; le talent du conchyliologue consiste précisément à se maintenir dans un terme moyen, en s'inspirant de l'ensemble des faits et en accordant à chacun des caractères particuliers l'importance relative qui lui convient; c'est à celte double condition qu'on peut éviter une tendance aussi funeste pour la netteté de la classification malacologique, que l'était l'examen insuffisant a la suite duquel nos prédécesseurs réunissaient des êtres très différents.

Il semble donc que le moment est venu de résumer la siluation actuelle des connaissances paléontologiques dans une sorte de Manuel, où seraient méthodiquement discutés et comparés les rapports des familles et des genres créés jusqu'à présent, où l'on n'admettrait, avec de sérieux motifs à l'appui, que les coupes qui méritent réellement d'être conservées, enfin, où l'on proposerait la création de nourelles subdivisions chaque fois que la nécessité s'en ferait impérieusement sentir. Il existe déjà d'excellents 
Manuels de Conchyliologie, par exemple ceux de Tryon et de Fischer, encore tout récents ; on pourrait penser qu'après la publication de travaux aussi complets, il suffira désormais de les tenir au courant, en y intercalant, page par page, les noms nouveaux qu'on admet définitivement. Mais ces ouvrages sont plutột destinés aux coquilles actuelles qui y occupent une importance prépondérante, la Paléontologie n'y joue qu'un rôle en quelque sorte accessoire; en tous cas, les assertions des auteurs, relatives à l'existence des formes actuelles dans les temps géologiques, n'y ont été l'objet d'aucune vérification, de sorte que la question reste entière. Il y a ausssi de nombreux et de très bons Manuels de Paléontologie, les uns abrégés, les autres beaucoup plus développés, qui embrassent l'histoire de tous les êtres organisés fossiles, depuis les mammifères jusqu'aux plantes, de sorte que la Conchyliologie proprement dite n'y peut occuper qu'une place relativement restreinte : ainsi le meilleur et l'un des plus récents de ces Manuels, celui du savant professeur Zittel, consacre cent quatre-vingts pages aux Gastropodes; il reste done encore beaucoup à faire dans cette voie.

Voici, d'après notre: opinion, le but que devrait se proposer l'auteur d'un travail qui réaliserait complètement notre idéal sur cette question :

Reprendre, autant que possible d'après l'espèce typique, la diagnose détaillée de chaque genre, sous-genre ou section fossile, en la complétant s'il y a lieu et en l'accompagnant d'une ou de plusieurs figures qui en reproduisent fidèlement les caractères essentiels; établir, pour chacune de ces coupes, les rapports et les différences qu'elle présente avec les autres formes de la même famille; en déduire la valeur relative qu'il y a lieu de leur attribuer, soit comme genre, soit comme sous-genre, soit comme section ; faire suivre ces obșervations d'un tableau indiquant, pour chacune des coupes admises, les espèces qui attestent authentiquement son existence à tel ou tel niveau stratigraphique; en conclure, enfin, quel a été l'ordre successif 
d'apparition des divers membres d'une même famille, depuis l'époque paléozoïque la plus reculée jusqu'à l'époque actuelle.

Nous n'avons pas la prétention de croire que la publication que nous commençons aujourd'hui répondra exactement à tous les points de ce programme, car il y a toujours des matériaux qui font défaut même à ceux qui sont le mieux secondés ; aussi nous bornerons-nous à l'intituler " Essais de Paléoconchologie comPARÉE ", titre indiquant que nous nous sommes efforcés de nous rapprocher le plus possible du but consistant à établir une comparaison entre la faune fossile et celle des mers contemporaines ou de nos continents, de manière à fixer approximativement la position systématique des formes éteintes.

Pour exposer les résultats de cette étude, on peut procéder soit par analyse, soit par synthèse : nous avons été contraints de laisser de côté la méthode analytique, bien qu'elle soit plus conforme à l'ordre naturel des recherches, ainsi qu'à la réalité probable de l'évolution qu'ont subie les êtres organisés depuis leur apparition sur la terre: mais elle nous aurait conduit à une exposition peu claire, à des redites inévitables. Pour définir ce système analytique, on peut le comparer à un éventail déployé, dont les branches rayonnantes rep̣ésenteraient la subdivision plus ou moins régulière des formes ayant une même origine ancestrale: l'analyse consiste à prendre isolément l'histoire de chacune de ces branches, du centre à la circonférence; pour les passer toutes en revue il faut remonter chaque fois à l'origine; ce système est évidemment inadmissible dans un Manuel. Nous avons donc admis, comme point de départ, la classification des mollusques vivants, en y intercalant ceux qui n'existent plus ; pour adopter la même comparaison que ci-dessus, cette méthode synthétique consiste à suivre, au contraire, la circonférence de l'éventail dont les branches figurent plus ou moins exactement l'enchaînement naturel des êtres de la création. Avec les renseignements stratigraphiques accompagnant chaque définition, le paléontologiste qui n'étudie que la faune d'un seul terrain, n'a plus alors qu'à 
tracer sur l'éventail, à la hauteur qui correspond à ce terrain, le cercle intermédiaire contenant tous les mollusques dont l'existence y a été signalée.

Il y a d'ailleurs un autre motif qui oblige à ajourner cette histoire de la création successive des mollusques à une époque où l'on sera mieux fixé sur le but de chacune des parties de la coquille qu'ils habitent. Dans l'état actuel de nos connaissances, il est impossible d'expliquer pourquoi un genre est caractérisé par l'existence de plis columellaires, pourquoi le labre est incliné plutôt dans un sens que dans le sens opposé, pourquoi les tours embryonnaires ont un enroulement différent de celui des autres tours de la spire, pourquoi l'ouverture passe graduellement de la forme holostomée à la forme siphonostomée, etc., etc..., toutes cesquestions ont-elles même jamais été posées, et en admettant qu'un conchyliologue en ait cherché la solution, s'est-il suffisamment inspiré de l'anatomie ou des mœurs de l'animal pour pouvoir en conclure quelle doit être sa coquille? Inversement, l'anatomiste qui étudie les organes respiratoires ou reproducteurs, les fonctions digestives, la circulation ou le système nerveux des mollusques, en a-t-il jamais conclu quelle doit être la forme de la coquille qui l'abrite? Il est certain cependant que cette corrélation existe, qu'elle est intimement liée aux mœurs, au mode de locomotion de l'animal, qu'elle dépend des conditions de son existence, du milieu qu'il habite, de la température, de la profondeur, de l'éclairement même des masses liquides qui le recèlent.

Pour résoudre ces problèmes obscurs, il faudrait une collaboration intime entre l'anatomiste et le conchyliologue qui travaillent trop souvent indépendamment l'un de l'autre; il nous manque surtout l'observation de tous les faits dont se compose la vie du mollusque, soit qu'il se déplace, soit qu'il s'alimente, soit qu'il secrète, de manière à saisir ce que devient et à quoi peut lui servir sa coquille dans chacun de ses actes. Si toutes ces lacunes étaient comblées, il n'est pas douteux qu'en tenant compte du milieu géologique dans lequel ont dû vivre les êtres 
aujourd'hui fossiles, on trouverait que la forme de leur coquille correspond exactement à leur àge stratigraphique. Mais nous ne pouvons malheureusement qu'émettre des hypothèses sur ces questions à peine effleurées, et souhaiter que la lumière se fasse bientôt sur elles.

Quoi qu'il en soit, puisqu'il ne nous est pas donné d'apporter une solution, nous avons pensé qu'il serait du moins utile d'appeler l'attention sur les parties de la coquille qui peuvent jouer un rôle essentiel dans la distinction des familles et des genres; aussi, avant d'entrer en matière, donnons-nous ci-après quelques considérations sommaires et principalement des définitions pour fixer les idées.

\section{FORME DES GASTROPODES}

Les Gastropodes sont plus ou moins complètement enroulés, soit symétriquement par rapport à un plan qui divise la coquille en deux parties absolument pareilles, soit as ymétriquement autour d'un axe presque toujours rectiligne : il est extrèmement rare que cet axe soit courbé ou irrégulièrement tordu. L'enroulement forme une spire dont les tours sont tantôt lâches, tantôt resserrés en contact; et dans ce cas, la ligne séparative de deux tours consécutifs se nomme suture.

Dans les coquilles symétriques, la superposition des tours se fait, en général, régulièrement, de sorte que, sauf pour les genres à spire déroulée, les sutures forment, de chaque côté, une spirale identique, dont la cavité dépend de l'accroissement plus ou moins rapide de l'épaisseur de chaque tour: celte cavité, qu'on nomme o mbilic, a un galbe conique quand l'accroissement est constant, ovoüde quand cet accroissement est plus rapide pour l'épaisseur des tours que pour leur hauteur, évasé quand c'est l'inverse; les deux 
faces, toujours égales puisqu'il y a symétrie par rapport au plan médian, ne sont jamais absolument planes, et encore moins convexes, puisque les premiers tours sont nécessairement moins épais que le dernier. Les tours des coquilles symétriques se recouvrent successivement, c'est-à-dire sont embrassants, de sorte qu'on n'aperçoit leur surface dorsale que sur le dernier, et, dans chaque ombilic, une faible partie non recouverte des tours précédents.

On passe des formes symétriques aux formes asymétriques, dès que les deux ombilics ne sont plus égaux en profondeur: il y a alors le côté de la spire et la face interne ou ombilicale au centre de laquelle est censé s'élever l'axe idéal de l'enroulement. Ce n'est pas toujours la face la plus profonde des coquilles discoïdales qui est leur véritable ombilic; il y a même des individus dont la face ombilicale est saillante, comme si c'était le côté de la spire, tandis que ce dernier est en creux, comme s'il avait subi un effort de pression qui l'eût retourné à l'instar d'un gant.

Les tours des coquilles asymétriques sont entièrement embrassants, comme ceux des coquilles symétriques, quand la coquille est discoïdale, ou même quand sa spire est élevée et que son ombilic est largement ouvert; mais, à mesure que la superposition d'un tour sur le précédent se fait de moins en moins symétriquement, la paroi de chaque tour qui confine à l'ombilic, ou paroi columellaire, prend plus de développement, l'ombilic se rétrécit, ou même se ferme complètement, de sorte que les parois opposées se touchent, que l'axe idéal de la coquille se trouve matérialisé sous la forme d'une sorte de pilier creux ou plein, auquel on donne généralement le nom de columelle. Néanmoins, les tours peuvent encore être embrassants et même recouvrir toute la spire, comme cela a lieu dans les coquilles complètement involvées, dont la face de la spire est restée ombiliquée, tandis que c'est, au contraire, la face columellaire qui est saillante (Bullidex).

$\mathrm{Au}$ contraire, dans d'autres familles, les tours se superposent presque sans se recouvrir (Scalid $)$; la spire est lâche, les sutures sont alors très profondes, et quelquefois les derniers tours 
complètement détachés (Vermicularia), soit en spirale, soit dans une direction indéterminée.

Enfin, si le tube, dont l'enroulement compose la spire, est incomplètement fermé, il n'y a ni columelle, ni ombilic: les tours sont intérieurement ouverts (Scaphandridx, Haliotidx); on les aperçoit jusqu'au sommet si le pilier spiral, ou bord interne, autour duquel ils s'enroulent, n'est pas trop épaissi. On cite même un genre (Velainclla) dont le pilier spiral s'applique sur la paroi externe, de sorte que la coquille est réduite à un tube ouvert, presque comme dans les Scaphopoda.

Les Gastropodes symétriques peuvent indifféremment être posés

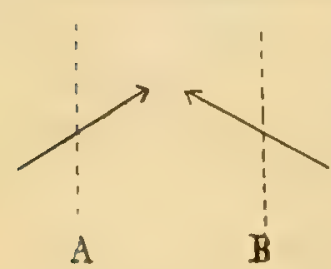

Fir. 1. à plat, d'un côlé ou de l'autre, sur un plan parallèle à leur plan de symétrie. Quant aux Gastropodes asymétriques, princinalement ceux dont la spire est saillante, on appelle coquille dextre celle dont les sutures sont orientées dans le sens d'inclinaison de la flèche A (fig. 1); on nomme, au contraire, sénestre tout Gastropode dont la suture a l'inclinaison de la flèche B, l'axe vertical étant, dans les deux cas, indiqué par la. ligne pointillée qui croise cette flèche.

Si la superposition des tours se fait avec rẻgularité, si leur croissance suit une progression dont la raison est constante, le profil de la coquille, c'est-à-dire la ligne qui enveloppe le contour extérieur des tours superposés, fussent-ils plans, convexes ou excavés, est une ligne droite également inclinée de chaque côté de l'axe vertical, de sorte que le galbe de la coquille est parfaitement conique (Calliostoma, Niso); l'angle au sommet de ce cône est ce que d'Orbigny a nommé angle spiral de la coquille. Si, au contraire, l'accroissement des tours se fait irrégulièrement, c'est-à-dire si le rapport entre les dimensions homologues des tours consécutifs varie d'un tour à l'autre, le profil de la coquillo est nécessairement curviligne: quand le rapport entre la hauteur de chaque tour (comptée dans le sens vertical) 
et sa argeur (mesurée dans le sens perpendiculaire à l'axe veltical) va en diminuant à partir du sommet, le profil est concave, et le galbe s'évase depuis le premier tour jusqu'au dernier, on dit alors qu'il est extraconique; inversement; lorsque le rapport entre la hauteur et la largeur de chaque tour va en croissant, le profil est convexe, le galbe se contracte, la coquille devient conoïde ou encore pupiforme.

Il y a, dans les Pulmonés, quelques rares exemples de coquilles dont le galbe; après avoir été extraçonique au début, devient conoïde dans les derniers tours (Eucalodium); mais il ne paraît pas qu'il existe d'exemple du phénomène inverse, à moins d'exceptions tératologiques.

La rapidité de la croissance des tours de spire est en fonction directe du nombre de ces tours; la coquille est généralement paucispirée quand cet accroissement est très rapide, multispirée ou polygyrée, quand il se fait lentement; mais c'est surtout à l'inclinaison des sutures par rapport au profil, c'est-àdire à l'angle sutural, que se mesure la rapidité de la croissance: ces sutures sont presque horizontales quand la superposition des tours est lente, très inclinées sur l'axe vertical quand la croissance est rapide; cette inclinaison augmente quelquefois au dernier tour, dont la suture remonte obliquement vers l'ouverture: on dit alors qu'elle est ascendante (Eligmoloxus, Limnxa); il est rare qu'elle soit descendante, à moins qu'il n'y ait un épanouissement de l'ouverture (Pterocera, Alaria).

\section{SOMNET EMBRYONNAIRE}

La partie initiale de la spire forme ce qu'on appelle l'embryon de la coquille. La structure de cet embryon, qui a une importance capitale, a été généralement négligée dans l'étude des fossiles, parce qu'il est bien rare, surtout dans les terrains 
secondaires et paléozoïques, qu'on trouve le test dans un état de fraicheur suffisant pour que le sommet soit complètement intact, ou encore parce que la cristallisation spathique du test ne permet pas de distinguer nettement de quoi se compose le bouton qui termine le sommet de la spire. Quelle que soit la difficulté de ces recherches, il est impossible de laisser de côté un caractère qui permet souvent de trancher la question du classement d'une forme éleinte aujourd'hui.

On sait que les larves de la plupart des Gastropodes ont une coquille embryonnaire qui, tantit ne difëre pas sensiblement de celle des adultes, tantît présente une structure tout à fait distincte. On appelle homaostrophes les embryons dont le nucléus est curoulé dans le même sens que le reste de la spire, hétérostrop hes ceux dont l'enroulement est inverse; M. Koken a proposé orthostrophe au lieu d'homrostrophe, mais cette dénomination a l'inconvénient de n'être pas l'opposé exact du mot hétérostrophe, communément admis, et de plus elle donne l'idée d'un enroulement orthogonal, qui n'est pas toujours conforme aux faits.

Eubryons hojizostrophes. - Même lorsque l'allure de l'enroulement de l'embryon est absolument conforme à celle du reste de la spire, il ne peut cependant former une pointe, dans le sens strictement géonétrique, attendu que le stade primitif de la naissance de la coquille doit être représenté par un corps minuscule, il est vrai, mais subglobuleux, qui grossit avant de commencer à s'enrouler, et qui est le nucléus apical de la coquille. Dès que le nucléus est formé, il se développe par accroissement unilatéral, avec un mouvement gyratoire et ascendant, en supposant toujours que le sommet est orienté vers le bas; il en résulte que le nucléus ne tarde pas à être en contact avec une portion de tour embryonnaire dont il est séparé par une ligne suturale qui a la même direction que les sutures de la spire de la coquille, mais dont l'inclinaison varie quelquefois.

Lorsqu'au nucléus succèdent trois ou quatre tours embryonnaires au moins, généralement lisses et brillants, bien distincts 
de la spire proprement dite qui est ornée ou qui, lorsqu'elle est lisse, n'est pas aussi brillante, on dit que l'embryon est polygyré (Ex. Seila mundula, Desh. de l'Eocène inférieur, fig. 2); quelquefois il est, en outre, régulièrement conoïdal (Ex. Suessionia exigua, Desh. de l'Eocène inférieur, fig. 3).

L'embryon est, au contraire, pa u c ispiré quand il n'existe qu'un tour ou deux entre le nucléus apical et le premier tour de spire muni de l'ornementation normale de la coquille, ou tout au moins d'une ornementation rudimentaire (Ex. Newotoniella clavus, Lamk. de l'Eocène moyen, fig. 4); cette ornementation commence subi-

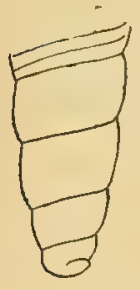

FIG. 2.

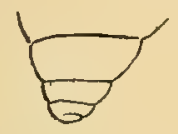

FIG. 3.

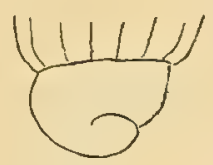

FIG. 4.

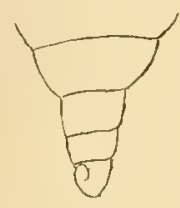

FIG. 5 .

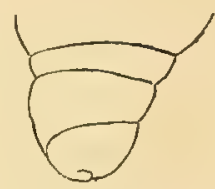

FIG. 6.

tement, sans aucune transition, soit avec son allure définitive, soit plutôt avec une exagération initiale de l'un des deux éléments aux dépens de l'autre, par exemple des costules d'accroissement quand il n'y a plus que des stries sur les individus adultes.

L'embryon polygyré n'a pas toujours le même galbe que le reste de la coquille, ainsi que cela a lieu dans l'exemple indiqué cidessus: il est styliforme lorsqu'il se compose d'une pointe étroite et subcylindrique à laquelle succède le galbe conoïdal de la spire (Ex. Stylifer pellucidus, Desh. de l'Eocène moyen, fig. 5); il est globuleux quand il forme un bourgeon plus ou moins régulier, dont le galbe subsphérique, ou même cylindro-conoïdal, n'est pas dans le prolongement du galbe du reste de la spire (Ex. Voluta fulgetrum, Sow. des mers actuelles, fig. 6, et Clavilithes deformis, Sol. de l'Eocène, fig. 7); il est mammillé quand il forme un petit bouton saillant, mucroné quand c'est une pointe. 
Les embryons paucispirés sont plus fréquents, et ils présentent une diversité d'allure qui mérite d'autant plus d'appeler l'attention que, par certains côtés, cette allure se rapproche de celle des embryons hétérostrophes; de sorte qu'il faut parfois y regarder à deux fois avant de se faire une opinion certaine sur le sens de la gyration du nucléus.

Quand il forme un bouton obtus, l'embryon paucispiré peut

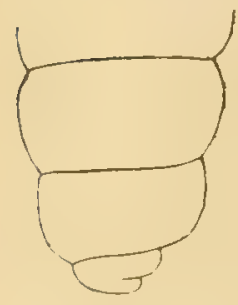

Fig. 7.

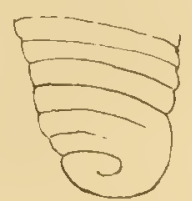

Fig. 8.

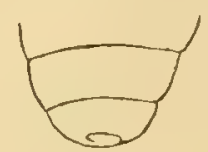

FIG. 9.

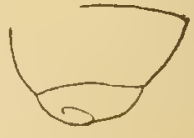

FiG. 10,

être simple (Ex. Triforis asper, Desh. de l'Eocène supérieur, fig. 8), ou déprimé, formant une calotte dite en goutle de suif (Ex. Voluta scapha, Gm. des mers actuelles, fig. 9, ou Volvaria Lamarcki de l'Eocène inférieur, fig. 10), ou tectiforme, c'està-dire en cône surbaissé (Ex. Acrophlyctis Eıgenei, Desh. de l'Eocène moyen), ou encore planorbulaire, c'est-à-dire présen-

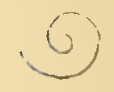

FIG. 11.

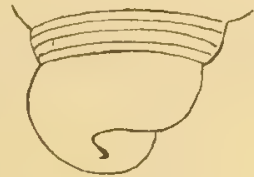

FIG. 12.

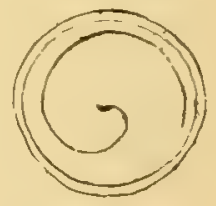

Fเa. 13.

tant un aplatissement comparable à celui de la face de la spire de certains Planorbis (Ex. Volvaria alabamiensis, Cossm. de Claiborne, fig. 11). Il y a même des genres dont le nucléus embryonnaire est au fond d'une petite dépression, l'embryon est alors dit excavé (Ex. Tudicla spirillus, Lin. des' mers actuelles, fig. 12); parfois le sommet de la coquille se détache dès qu'elle 
est adulte, l'embryon est tronqué (Ex. Nystia polita, Edw. du Ruel, fig. 13), et, dans ce cas, la cicatrice de l'occlusion de l'extrémité de la spire se fait dans une sorte de petit cirque formé par l'épiderme du premier tour, conservé intact après la chute de l'embryon.

Un grand nombre de genres sont caractérisés par un embryon dévié, c'est-à-dire que le nucléus commence son enroulement autour d'un axe qui fait uu angle avec celui de la coquille: si le nucléus n'est pas saillant, cette disposition oblique est peu visible; on s'en aperçoit seulement à ce que la suture est un peu plus

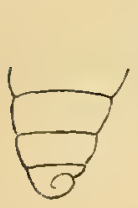

FIG. 14.

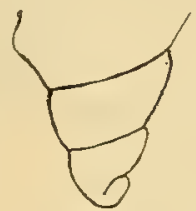

FIG. 15.

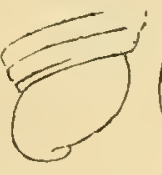

FIG. 16 .

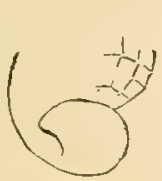

FIG. 17.

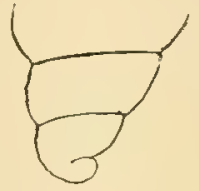

Fig. 18.

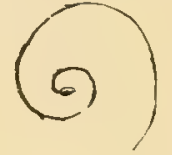

FIG. 19.

inclinée que ne le comporterait un enroulement tout à fait normal (Turritella funiculosa, Desh. de l'Focène moyen, fig. 14). Mais, quand le nucléus est à peu près disjoint dans une direction complètement oblique, et qu'il forme une sorte de crochet se raccordant avec la spire par un coude plus ou moins arqué, l'embryon est dit papilleux (Ex. Sipho tenuiplicatus, Desh. de l'Eocène moyen, fig. 15). Souvent même, l'embryon papilleux est si obliquement dévié que les tours ne sont plus en contact, il est alors détaché (Ex. Cerithioderma angulatum, Desh. de l'Eocène moyen, fig. 16 et 17, ou Homotoma striarella, Desh. de l'Eocène, fig. 18). Quand l'embryon papilleux forme un bouton globuleux à nucléus dévié, il est dit loxosphérique (Ex. Clavilithes deformis, Sol. de l'Eocène, fig. 7). Enfin, il est quelquefois nautiloïde, c'est-à-dire symétriquement enroulé autour d'un axe oblique par rapport a l'axe de la spire asymétrique (Ex. Lamellaria Berghi, Desh. de l'île Maurice, fig. 19).

Eurryons hétérostrophes. - Il n'est pas aisé de se rendre 
compte par quelle torsion géométrique se fait le raccordement entre un embryon sénestre et une coquille dextrogyre, pendant la période qui correspond au passage présumé des organes viscéraux, d'un côté à l'autre de l'axe de la coquille. Avant de montrer, sur des exemples pris d'après des sommets grossis de coquilles hétérostrophes, conment se fait cetle délicate jonction, il ne sera pas sans intérêt de représenter par un tracé géométrique les éléments du problème inconsciemment résolu par l'animal lui-même :

Soit une coquille turriculée, par exemple (fig. 20), dont les premiers tours $c d e$ s'enroulent autour d'un axe vertical MN, il s'agit d'y souder un embryon sénestre composé de deux tours a $b$, ayant le même angle sutural et le même axe; si le contour du tour embryonnaire $h$, préparé pour servir de suture au tour subséquent, suivait le tracé indiqué en pointillé sur la figure, il viemlrait couper en $b$, sous un

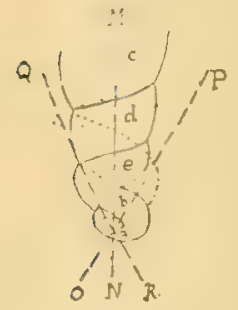

Fra. 20. angle aigu, le contour du tour de spire $e$, au lieu de reposer sur lui, de sorte que l'intersection des deux surfaces courbes se ferait dans un pli profond, partant de cet angle $b$ et s'atténuant graduellement jusqu'au côté opposé, où les deux courbures viennent en contact avec un plan tangentiel commun; cette suture idéale ne peut être tracée sur un croquis schématique, mais toute personne familiarisée avec les procédés de la géométrie descriptive peut reconstituer les projections de cette suture en plan et en rabaltement.

Or, pour peu que l'on ait observé au microscope quelques emlıryous hétérostrophes, on est en droit d'affirmer avec certitude que jamais on n'y remarque une telle sulure, et que le pli $b$, d'ailleurs incompatible avec les lois de la solidité, n'existe pas. On peut donc en conclure : d'une part, que le raccordement entre les deux éléments dont il s'agit, l'embryon et la spire, se fait par une transition graduelle, au cours de laquelle les tendances sinistroggre et dextrogyre se font d'abord équilibre, puis la première cède à la seconde ; d'autre part, que l'enroulement de l'em- 
bryon ne se fait jamais autour du mêmeaxeque celui de la coquille, comme supposait le schéma théorique, ou, en d'autres termes, que l'embryon hétérostrophe est généralement dévié, soit autour d'un axe tel que $O P$ qui augmente encore l'apparence papilleuse du nucléus, soit autour d'un axe tel que $\mathrm{QR}$, qui ramène, au contraire, ce nucléus en contact avec le reste de la spire.

On ne peut se rendre bien compte de la torsion du fragment de tour qui raccorde l'embryon avec la spire, qu'en étudiant d'abord la déviation du nucléus hétérostrophe, quoiqu'il paraisse a priori peu logique d'évaluer un effet de déviation qui se produit par rapport à l'axe d'une coquille non encore formée, et qu'en réalité il serait plus juste de dire que c'est cette dernière qui est déviée par rapport à l'axe initial de l'embryon. Mais on est tellement habitué à observer-la coquille comme l'état normal et l'embryon comme un phénomène exceptionnellement bien conservé en place, que cette interversion de termes ne surprendra personne. Le plus

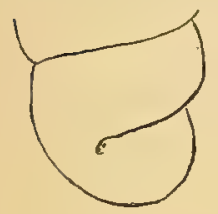

FIG. 21.

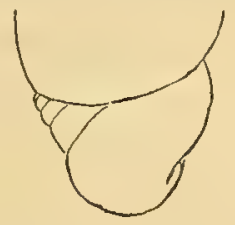

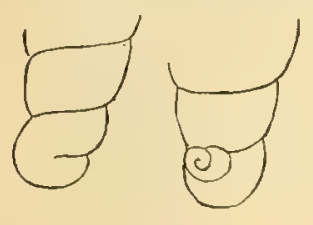

FjG. 22.

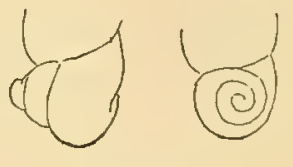

FIG. 23.

simple sera de choisir une série d'exemples parmi les inclinaisons les plus apparentes et d'examiner ce que devient la torsion de raccord, quand l'axe passe de l'inclinaison OP à l'inclinaison QR.

Les formes qui présentent le maximum de déviation embryonnaire sont surtout les Anisocycla et Turbonilla, dans la famille Pyramidellidx : ainsi que l'indiquent les figures 21 (A. fragilis, Desh. de l'Eocène), fig. 22 (T. tenuiplicata, Desh.) ou 23 (Belonidium gracile, Desh. de l'Eocène parisien), l'embryon se compose de plusieurs tours sénestres, - on en compte jusqu'à cinq, — qui s'enroulent autour d'un axe faisant un angle de plus de 45 degrés avec celui de la coquille, du côté $\mathrm{OP}$, c'est-à-dire en s'orientant 
vers l'ouverture de celle-ci : il en résulte que, pour se raccorder à la spire, le dernier tour de l'embryon subit une torsion héliçoïdale qüi déroute absolument l'œil de l'observateur, lorsque celui-ci n'examine que des vues isolées, prises dans des positions opposées comme le sont les figures 21 à 23; mais, si l'on fait patiemment évoluer le sommet de la coquille sous l'objectif du microscope, on remarque que le dernier tour sénestre, au lieu de continuer son enroulement ascendant de droite à gauche, dévie d'abord perpendiculairement à l'axe d'enroulement de l'embryon, puis s'infléchit obliquement dans une direction opposée à la direction initiale, et se raccorde enfin au commencement de la spire normale, sans que le passage d'une surface héliçoìdale à l'autre soit indiqué par aucun pli : il y a une continuité parfaite, aucun arrêt subit de la croissance, et même, quand la spire est ornée, les ornements ne commencent guère avant qu'il y ait au moins un quart ou une moitié de tour enroulé dans le sens normal.

L'embryon ci-dessus décrit est dit loxogyre; mais il est rare que sa spire soit aussi développée : elle est déjà moins allongée dans les Turbonilla (fig. 22) que dans les Anisocyla (fig. 21), el elle est à peine saillante dans les Odontostomia, dont le nucléus forme une sorte d'oreiller reposant sur la spire, de sorte que l'embryon peut être dit pulviné (Ex. O. hordeola, Lamk. de l'Eocène, fig. 24).

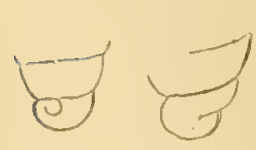

Fig. 24 .

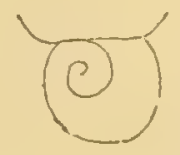

FIG. 23.
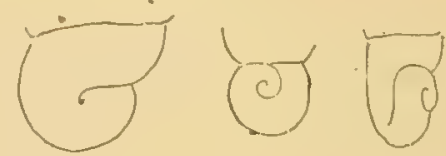

Fif. 26.

Quand il est paucispiré, l'embryon hétérostrophe n'est pas toujours adhérent à la spire : il se détache souvent en forme de crosse, dans un plan passant par l'are vertical de la coquille (Ex. Mathildin Baylei, de Boury, de l'Eocène inférieur, fig. 25, ou Actaon Gmelini, Bayan, de l'Eocène moyen, fig. 26, ou encore 
Tuba striata, Lea, de Claiborne, fig. 27). Mais, à mesure qu'il devient papilleux, le nucléus tend à se renverser complètement (Ex. Actæon subinflatus, d'Orb. de l'Eocène moyen, fig. 28, et Nucleopsis subvaricatus, Conrad, de Claiborne, fig. 29); il y a des

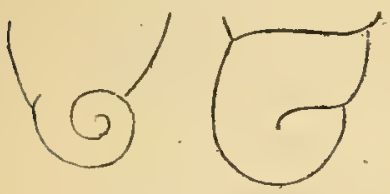

FIG. 27.

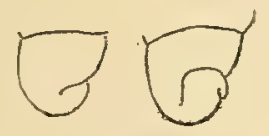

Fig. 28 .

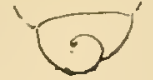

FIG. 29.

coquilles où il est complètement empâté dans la spire (Ex. Acrocoelum Bouryi, Cossm. de Cuise, fig. 30, ou Solarium canaliculatum, Lamk. Parnes, fig. 31, ou encore, du côté de l'ombilic. Discohelix Dixoni, Vasseur, de l'Eocène de Bretagne, fig. 32); dans ces conditions, l'embryon in volvé ne montre pas le nucléus, qui est complètement caché du côté opposé, etl'on pourrait croire,

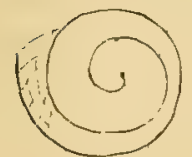

Fig. 30 .

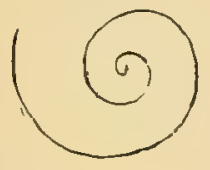

FIG. 31 .

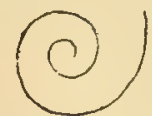

FIG. 32.

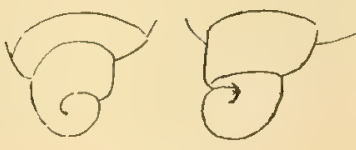

Fig. 33.

au premier abord, que cet embryon n'est pas sénestre; ce'st seulement en vérifiant si le côté qu'on aperçoit comporte un nucléus. ou s'il est ombiliqué, qu'on peut se former une opinion sur le sens réel de la gyration, et, comme il s'agit d'un corpuscule microscopique, cette vérification rencontre parfois de telles difficultés, qu'on s'explique l'incertitude qui règne encore sur la véritable disposition de l'embryon de certaines coquilles, c'est-à-dire sur leur classement définitif dans telle ou telle famille.

Pour terminer, on peut encore citer, comme exemple d'une forme tout à fait anormale d'embryon sénestre, dit tordu, Douvilleia arenaria, Mell. du gisement de Jonchery (fig. 33), dont 
le nucléus subit deux torsions successives avant de s'emboîter sur le premier tour caréné de la spire.

D'après ce qui précède, on voit qu'il n'est pas aisé de décomposer géométriquement le phénomène en vertu duquel l'animal embryonnaire rejette ses viscères l'un côté a l'autre, en changeant le sens d'enroulement de sa coquille; aucun des malacologistes qui ont étudié la question ne paraît avoir cherché à fournir même une hypothèse expliquant les motifs de ce changement d'allure dans la croissance du mollusque. Je ne puis davantage donner d'explication plausible à ce phénomène, mais l'étude de la coquille me permet, du moins, d'affirmer que la transition ne se fait que graduellement et qu'il n'y a pas, dans ce fait, de mouvement brusque, comparable à celui d'un portefaix qui rejetterait son fardeau d'une épaule sur l'autre; d'ailleurs, on ne concevrait pas qu'il se produisit un rirement subit sans un point d'appui qui ferait précisément défaut au mollusque, s'il n'est pas, à ce moment, fixé contre un corps immobile, d'une masse supérieure à la sienne, et plus résistant que le fluide dans lequel il nage comme le font la plupart des mollusques de haute mer qui ont l'embryon sénestre.

\section{COLUMELIE}

Ainsi que je l'ai indiqué en examinant le mode d'enroulement de la coquille, l'axe autour duquel se fait cet enroulement est tantôt idéal, au milieu d'une cavité en entonnoir, tantôt entouré de la matière dont se composent les parois des tours resserrés en contact; dans le premier cas, il n'y a pas, à proprement parler, de columelle, mais une série de parois columellaires superposées, dont la coupe transversale ferme une calotte en forme de cône plus ou moins évasé; dans le second cas, la section transversale montre un véritable pilier axial, contre lequel viemnent se souder les parois columellaires des tours de spire.

En général, la section transversale de chaque tour reproduit 
assez exactement l'ouverture de la coquille, au moins dans sa forme générale, abstraction faite des caractères accessoires que peuvent présenter les bords ou l'extrémité antérieure de cette ouverture. Par conséquent, eu égard à la difficulté qu'on éprouve à se procurer de bonnes sections transversales des coquilles, c'est sur la partie visible de l'intérieur de l'ouverture qu'on étudie les caractères de la paroi columellaire ou de la columelle, tout en tenant compte des modifications que peut subir cette columelle, à mesure que la coquille grandit.

En principe, la paroi columellaire se compose d'une surface héliçoïdale plus ou moins excavée qui se raccorde, par une courbe ou par un angle arrondi avec le plancher et avec le plafond du tour de spire. Très creuse quand l'enroulement des tours est lent, la paroi columellaire est presque droite quand l'accroissement est rapide, et alors elle représente bien réellement l'axe de la coquille. Sa surface, dite simple quand elle est unie, porte souvent des plis spiraux dont le nombre, la nature, la saillie et la persistance sont très variables.

Le but de l'existence de ces plis.est, je le crois, absolument inconnu, et cependant on doit a priori supposer qu'ils jouent un rôle essentiel dans les mouvements que l'animal doit faire pour sortir de sa coquille ou pour y rentrer, ou plutôt pour porter sa coquille dans un sens ou dans l'autre, quand il nage ou lorsqu'il rampe, attendu que c'est à la paroi columellaire que s'attachent les muscles adducteurs des Gastropodes ${ }^{1}$.

Les plis columellaires s'enroulent en spirale contre la paroi sur laquelle ils font saillie, soit comme un simple ienflement arrondi, soit comme un gradin taillé carrément, soit comme une lamelle tranchante qui encombre parfois la section libre du tour de spire; il en est qui sont divisés en deux ou bifides, ce sont alors des rainures spirales qui entaillent la paroi et séparent de larges rubans plus ou moins aplatis. Ils ne sont pas toujours

I Voir, à ce sujet, dans la note insérée à la fin de l'annexe de cette livraison, l'explication proposée par M. Dall. 
persistants, certaines coquilles à columelle plissée quand les individus sont encore jeunes, ont la columelle à peine renflée ou même tout à fait simple à l'ouverture, quand l'animal a atteint sa taille adulte; l'inverse se produit également.

L'obliquité souvent très grande de ces plis donne à la columelle la même apparence que si elle était tordue une ou plusieurs fois sur elle-même; je conserverai cette expression, qui est souvent utilisée dans les diagnoses, quoiquelle soit impropre, attendu que, si l'on concoit qu'une barre malléable (en verre ou en fer fondu) puisse subir dans toute sa longueur un effet de torsion qui la plisse en spirale, on ne se rend pas bien compte de l'effort qu'il faudrait exercer sur une série de parois columellaires superposées pour y produire simultanément des rides qui se correspondraient d'un tour à l'autre; la vérité, c'est qu'il n'y a pas de torsion et que le renflement dont se compose chaque pli est produit, au fur et à mesure de l'accroissement, par la sécrétion du manteau.

La disposition des plis, leur importance relative quand il y. en a plusieurs superposés, varient peu ; il est rare qu'ils soient égaux entre eux, mais, quand ils sont inégaux, c'est avec régularité, c'est-à-dire qu'ils sont croissants ou décroissants, en complant d'avant en arrière, l'ouverture étant orientée en haut, le sommet en bas.

La terminaison de la cólumelle, à la base de la coquille, est un caractère essentiel au point de vue de la distinction des genres, et intimement lié d'ailleurs à l'existence ou à l'absence d'un canal pour le passage du siphon : c'est donc en même temps que la disposition de l'ouverture que doit être étudié le mode de raccordement de l'extrémité de la columelle, de sorte que j'y reviendrai plus loin, en traitant de l'ouverture.

Le bord columellaire se compose d'une couche, souvent très calleuse, de matière vernissée qui recouvre la paroi de la columelle, et dont la présence ne peut se constater qu'à l'ouverlure, sur la base de la coquille où il prend quelquefois un grand dévéloppement. 
Ce qui précède s'applique aus coquilles munies d'une columelle pleine, ou même perforée par un ombilic, qui est le résultat du défaut d'adhérence des parois columellaires entre elles; mais il y a plusieurs familles (Haliotidr, Calyptræidæ, Scaphandridix, etc...) dans lesquelles non seulement il n'y a pas de columelle, ainsi que je l'indiquais au début, l'axe d'enroulement étant idéal, mais encore dont la paroi columellaire est supprimée, ou plutôt n'est visible que sur sa face opposée, l'enroulement se faisant absolument comme pour la confection d'un cornet en papier ; la coquille se réduit à un tube creux ou à un cône vide. Dans ce cas, comme l'a très heureusement exprimé Fischer, en donnant, dans son Manuel, la coupe de Velainella columnaris, Vasseur, la paroi columellaire se confond avec le test externe auquel elle adhère, suture contre suture, de sorte que l'animal habilait, en réalité, ce qui serait l'ombilic dans une coquille d'une autre famille.

\section{OUVERTURE}

L'ouverture d'un Gastropode, improprement appelée bouche par quelques auteurs, est l'orifice par lequel sortent de la coquille ou y rentrent, tous les organes nécessaires au mouvement, à la nutrition et à la respiration de l'animal; c'est également par cet orifice que ses sens peuvent s'exercer, ainsi que ses moyens de défense, quand il en possède : il en résulte que la forme de l'ouverture doit probablement être en rapport avec la biologie du mollusque.

Les coquilles patelliformes ou capuliformes sont presque entièrement en ouverture, dont le contour, ou péritrême, forme généralement la base sur laquelle on les pose pour les examiner. Celles de la famille des Fissurellidæ ont une autre ouverture ou plutôt une perforation opposée, correspondant à l'anus. Mais le cas le plus général est celui d'une ouverture située à la base des circonvolutions de la spire et présentant, lorsque l'animal est 
adulte, des caractères distinctifs à défaut desquels tout classement est à peu près impossible.

Les Gastropodes ont été longtemps subdivisés en deux groupes, selon que l'ouverture est ou n'est pas entière, c'est-à-dire que le contour antérieur ne comporte pas, ou comporte, au contraire, un sinus, une échancrure, ou même un canal plus ou moins prolongé: on dénommait holostomes les coquilles à ouverture entière, et siphonostomes celles dont l'ouverture est interrompue au point de jonction du contour supérieur avec l'extrémité de la columelle, pour le passage d'un siphon.

On a renoncé à cette classification, d'abord parce qu'elle avait l'inconvénient d'écarter les unes des autres des familles dont l'animal a une organisation identique, et en outre parce qu'il y a des genres pour lesquels il est à peu près impossible d'affirmer que l'ouverture est réellement échancrée, tant est faible la sinuosité de leur contour, de sorte que les uns les considèrent comme holostomes, les autres comme siphonostomes. Cependant, à ne considérer que les Pectinibranchiata, - qui forment le groupe de beaucoup le plus important des Gastropodes à coquille, - la subdivision en question se fait, à peu d'exceptions près, vers le milieu de la série rangée d'après la formule de la radule (c'està-dire d'après les plaques linguales étudiées au microscope sur le mollusque vivant), de sorte que, tout en adoptant cette dernière classification, on peut encore conserver une certaine homogénéité dans l'arrangement des groupes, d'après la forme de l'ouverture, et employer utilement les mots Siphonostomes et Holostomes.

Lorsqu'on examine de face l'ouverture d'un Gastropode enroulé, le sommet de la coquille dirigé vers le bas ${ }^{1}$, la partie du con-

1 La position quion doit donner à la coquille, quand on veut la figurer et la décrire, a été l'objet de controverses; c,est un tort, à mon avis, que de chercher à la rendre conforme à celle qu'occupe l'animal, quand il rampe ou qu'il nage, car, lorsqu'on veut étudier les détails d"horlogerie d'une montre, on ne la regarde pas du côté du cadran. En définitive, la partie la plus importante de la coquille étant l'ouverture, il faut l'examiner de face ou de profil, et comme les dessinateurs ont l'habitude d'admettre que le rayon lumineux tombe à 45 degrés, venant de l'angle supérieur de gauche de la feuille de papier, il faut placer la coquille de manière que l'ouverture et la base soient le mieux éclairées possible, c'est-à-dire orienter l'ouverture vers le haut. 
tour de l'ouverture qu'on voit à gauche s'appelle labre, ou bord externe, celle qui est à droite est le bord interne, ou bord columellaire. Quand la coquille est holostome, le labre se raccorde, en haut ou en avant, au bord interne par un contour. ininterrompu qui forme le bord supérieur ou antérieur de l'ouverture ; enfin, lorsque le labre, au lieu d'aboutir simplement à l'avant-dernier tour, soit sous un certain angle, soit tangentiellement, se relie en arrière, c'est-à-dire à la partie inférieure ou du côté postérieur de l'ouverture, à un prolongement de la callosité du bord columellaire, reposant en contact plus ou moins parfait sur la base du dernier tour, le péristome est dit continu. Dans ce cas, il arrive généralement que la jonction se fait sous un angle aigu, de sorte qu'il existe, en ce point, une sorte de gouttière, souvent prolongée par une callosité qui descend sur la spire, soit jusqu'à la suture de l'avant-dernier tour, soit même jusqu'au sommet de la coquille (Rimella).

Que le péristome soit continu ou discontinu, l'ensemble du contour circonscrit soit par les bords libres de l'ouverture, soit par la base du dernier tour, a une forme rarement circulaire ou ovale, plus généralement piriforme ou palmée (la pointe orientée vers le bas), ou fusoïde, surtout quand il existe un canal antérieur, ou rhomboïdale quand la partie supérieure du labre prend une direction oblique, à peu près parallèle au contour de la partie du bord columellaire reposant sur la base du dernier tour; l'ouverture a encore quelquefois la forme d'un secteur, quand la columelle fait un angle plus ou moins ouvert au point où elle s'implante sur cette base, et lorsqu'en même temps le bord externe est développé en quart de cercỉe à peu près régulier.

Il faut aussi examiner l'ouverture de profil, vue du côté du labre : il est rare que l'ensemble du contour soit contenu dans un même plan passant par l'axe vertical de la coquille, ou obliquement incliné par rapport à cet axe, l'inclinaison étant mesurée à gauche ou à droite de l'axe, du côté antérieur. Le cas le plus général est celui où les bords ne sont pas dans un même plan, de 
sorte que le labre ne masque pas, dans la vue de profil, toutes les autres parties du contour qui se raccordent entre elles par des courbes d'une rare élégance, servant de limite à une surface gauche (pour employer le terme géométrique). Il y a aussi des exemples d'ouvertures complètement déviées (Dieretostoma, Strophostoma), c'est-à-dire qu'au lieu de continuer son accroissement normal, le dernier tour se rejette latéralement, ou se projette en avant, de sorte que l'ouverture se détache dans une direction divergente.

Outre l'obliquité qu'il peut prendre par rapport à l'axe, ainsi que je viens de l'indiquer pour le plan de l'ouverture, le labre vu de profil est droit ou curviligne, mais le plus souvent sinueux. La direction que prend son contour, aux abords du point où il rejoint la suture du dernier tour, a une très grande importance au point de vue du classement générique des coquilles : à peu d'exceptions près, dans toutes les coquilles d'un même genre, je dirai presque d'une même famille, - le labre présente la même disposition; la jonction est normale, quand son contour tombe perpendiculairement a la suture; si elle se fait obliquement elle est antécurrente, lorsque le contour s'incline davantage avant de se raccorder, en s'éloignant de plus en plus de l'axe vers l'ouverture, rétrocurrente, au contraire fet c'ést le cas le plus fréquent), si le contour rebrousse vers l'axe en s'écartant de l'ouverture, et en faisant un crochet qui se termine brusquement contre la suture (Nerinxidx, Ceritella), ou qui revient ensuite en sens inverse, après avoir formé un sinus plus ou moins profond (Surcula, Conus). Dans quelques genres, cette échancrure n'est pas immédiatement voisine de la suture (Pleurotoma, Murchisonia), et, dans les Pleurotomarïdx, elle se transforme même en une fissure, souvent aussi profonde que la moitié du dernier tour et correspondant à une organisation tonte particulière du manteau de l'animal; quand la fissure se ferme, et qu'il ne reste plus que des perforations isolées du test (Ditremaria, Schismope, Haliotis), le labre en conserve encore la trace par l'existence d'un faible sinus. 
Le raccordement du labre avec le bord supérieur se fait par une courbe orientée à droite de l'axe vertical, quand le bord supérieur est proéminent, à gauche de cet axe quand le bord est éch ancré; pour observer cette sailliẹ ou cette échancrure du contour antérieur de l'ouverture, fort importante au point de vue générique, on doit regarder la coquille en plan, la pointe enfoncée dans un bain de sable. Quant au raccordement du bord supérieur avec l'extrémité de la columelle ou avec le bord columellaire, il est extrêmement variable, selon que la coquille est holostome ou siphonostome.

Dans les ouvertures entières, dénuées d'échancrure, le contour antérieur n'est pas toujours arrondi et la jonction ne se fait pas toujours, comme dans les Delplinula et les Ampullina, par un prolongement curviligne du bord columellaire: tantôt il y a un angle net; la columelle se terminant en pointe dans cet angle et le bord columellaire s'infléchissant à peine pour adoucir la brisure de la jonction; tantôt il y a un évasement du bord columellaire, et l'ouverture est alors dite versante en avant (Diastoma, Sandbergeria, Actronella); si cet évasement se rétrécit, la sinuosité du contour se transforme en une sorte de bec (Pseudotaphrus, Ceritella), ou en une échancrure subcanaliculée (Stoszichia), qu'on distingue encore plus neltement quand on regarde la coquille en plan. A ce bec ou à cette échancrure correspond assez souvent un bourrelet (Lacuna, Aplustridx) qui s'enroule sur la base de la coquille, et dont la convexité a exactement la même amplitude que le sinus formé par ce bec, de sorte que l'on peut en conclure que le rôle de ce bec ne doit pas être le même que celui du canal siphonal, et que, par conséquent, la coquille est encore holostome, malgré son apparence siphonostome.

L'ouverture des coquilles siphonostomes se termine en avant par un canal plus ou moins développé, quelquefois droit dans le prolongement de l'axe (Fusus), ou bien tordu et infléchi dans sa longueur (Streptochetus, Triton), rarement fermé par une soudure de ses bords opposés (Murex, Triforis), parfois renversé en arrière (Cerithium, Vertagus, Morio), dans d'autres cas 
tronqué presque à sa naissance (Tritonidea, Potamides), ou même réduit à une échancrure très profonde (Cassis, Cypræa) entaillée sur la base et bordée, de sorte qu elle n'a rien de commun avec la forme du bec dont il a été question ci-dessus.

Lorsque le canal est droit, ou simplement tordu, mais allongé (Rostellaria, Terebellum), la columelle finit généralement en pointe sur le bord de ce canal dont elle suit les inflexions (Latimus); mais, quand le canal est court, quand il est lordu, et surtout quand il est profondément échancré, ou hien la columelle est subitement tronquée (Truncaria) un peu plus bas que le contour supérieur, ou elle est repliće et rejetée vers la droite, en formant une carène (Nassa) qui limite le canal, mais qu'il ne faut pas confondre avec un véritable pli columellaire.

Quant au bord columellaire, il forme généralement un bourrelet qui contourne la sinuosité basale ou l'échancrure et se raccorde ensuite avec le bord supérieur.

Après avoir étudié la forme générale du péristome, il est utile de dire quelques mots de son épaisseur: il est rare qu'il soit mince dans les coquilles arrivées à l'âge adulte. Cependant le labre, qui en forme la partie principale, est quelquefois très mince, même dans les individus qui ont atteint leur taille définitive; on s'en apercoit à l'état de conservation de certains fossiles dont on ne trouve presque jamais le bord intact (Turitella, Mesalia, Melanopsis); mais généralement le labre est taillé en biseau à l'intérieur, quand il n'est pas, en outre, réfléchi à l'extérieur, comme l'embouchure d'une trompette (Teliostoma), ou bien bordé par un bourrelet quelquefois très large et très épais (Ringicula, Marginella), qui peut aussi êlre dédoublé (Dissostoma), digité par des ramifications divergentes (Alaria, Pterocera), ou échancré par un sinus antérieur (Strombus), ou encore développé en une aile tout à fait détachée (Gladius), de sorte que l'ouverture, dont l'espace libre a simplement une forme ovale dans le fond, prend, au péristome, un développement qui échappe à toute définition. 1)ans certains cas, le labre est festonné ou lacinié par 
de petites découpures qui correspondent aux ornements de la surface.

En ce qui concerne le fond de l'ouverture, indépendamment de sa forme générale, il comporte souvent des modifications accessoires, dues à l'existence de plis ou de dents, de rides ou de tubercules, soit sur la columelle, soit à l'intérieur du labre, soit encore sur la partie du bord columellaire reposant sur la base de l'avant-dernier tour; lorsque l'ouverture est ainsi encombrée par des saillies internes qui en changent totalement la forme, elle est dite grimaçante (Ringiculidæ, Persona).

A l'intérieur du labre, ce sont généralement des crénelures ou des dents isolées, dites palatales, qui ne se prolongent presque jamais dans la cavité de l'ouverture, et qui sont situées sur une côte ou un renflement interne, un peu au delà du biseau formant le bord externe, parallèlement à ce bord (Ranella, Siphonatia). Souvent ces tubercules correspondent à un bourrelet de la surface extérieure, c'est-à-dire à une varice qui ne coïncide pas avec le péristome, de sorte qu'on les aperçoit-seulement au fond de l'ouverture, tandis que le bord en est dénué (Terebralia). Dans quelques cas, il n'existe qu'une seule dent postérieure (Marginella), et c'est plutôt la cessation subite du renflement interne du labre, servant de limite à une entaille juxtaposée à la suture; ailleurs, cette dent est simplement implantée au milieu du labre (Mitreola).

Quant aux plis columellaires, j'ajouterai seulement quelques mots à ce qui en a été dit à propos de la columelle : ils se terminent généralement sans atteindre le contour extérieur du bord columellaire (Voluta), il y en a même qui atteignent à peine la partie visible de la columelle, et qu'on ne distingue que quand l'ouverture est incomplète (Borsonia). Dans d'autres genres, au contraire, quelques-uns de ces plis s'enroulent sur le dos du canal et rejoignent même le contour supérieur (Fusimitra, Actron).

Il ne faut pas confondre avec de véritables plis les rides que 
porte quelquefois le bord columellaire (Tritonidea) et qui ne se prolongent pas sur la columelle, à l'intérieur de l'ouverture. Je mentionnerai aussi, pour mémoire, les côtes accessoires ou les dents qui s'intercalent entre les plis, à l'entrée de l'ouverture (Traliopsis, Clausilia); ce sont là des exceptions dont la description trouvera sa place, çà et là, dans quelques diagnoses isolées.

Dans le but de faciliter les diagnoses et de leur donner plus de clarté, on établit souvent une distinction entre les plis enroulés sur la columelle proprement dite, dans la partie comprise entre le point où elle s'implante sur la bàse et son extrémité antérieure, et les plis situés sur la partie du bord columellaire appliquée sur cette base, c'est-à-dire sur le plancher de l'ouverture; ces derniers se nomment plis pariétaux (Stroplia). De même que sur la columelle, ce sont parfois des dents ou des tubercules qui n'existent qu'à l'entrée de l'ouverture (Pisania, Ringicula) quand la coquille est adulte. L'eremple le plus frappant qu'on puisse citer de cette disposition est le genre Cassis, dont le bord columellaire, largement étalé, se couvre d'une multitude de rides irrégulières qui le rendent complètement rugueux.

\section{ORNEMENTATION}

La surface extérieure d'un Gastropode est tantôt lisse, tantôt chargée de saillies ou d'entailles régulières auxquelles on donne le nom d'ornements, parce qu'elles contribuent, en effet, à lui donner un aspect agréablement varié, très utile, en tous cas, pour la distinction des espèces entre elles, et même des genres entre eux.

Même quand la surface est lisse, on y remarque généralement des lignes ou stries d'accroissement, dirigées dans le sens axial, s'il s'agit d'un Gastropode enroulé, concentrique sur les coquilles patelliformes; elles représentent les stades successifs du 
développement des tours de spire; pour qu'elles soient invisibles, il faut que la surface soit recouverte d'un vernis émaillé absolument brillant (Eulima, Marginella). Lorsque ce développement subit un arrêt, principalement dans les genres dont l'ouverture est bordée, la trace en est indiquée par un renflement plus ou moins saillant, par des côteś nommées varices, quelquefois régulièrement disséminées sur la surface, ou se succédant d'un tour à l'autre (Pteronotus); souvent la dernière varice correspond au côté opposé à l'ouverture (Triton, Ranella); parfois le galbe général de la coquille est rendu gibbeux par suite de la présence de ces renflements (Persona, Cerithium).

L'orientation des accroissements reproduit presque exactement l'obliquité ou la sinuosité du labre : à ce point de vue, pour la détermination des genres, surtout dans les fossiles secondaires dont l'ouverture est rarement entière, l'étude des accroissements sur le test est d'un secours précieux et permet quelquefois de classer dans des familles tout à fait différentes, des formes dont l'aspect extérieur paraît être le même au premier abord.

Les ornements sont en relief ou en creux : les premiers sont de simples filets étroits et peu saillants, ou des rubans aplatis, plus larges que les intervalles qui les séparent, ou des côtes (costules el cordons) généralement arrondies, ou des carènes tranchantes, ou même des lamelles saillantes, quelquefois voûtées à l'intérieur; les seconds sont des stries, souvent d'une finesse telle qu'on ne les voit qu'à la loupe, tantôt parallèles, tantôt réunies deux à deux, c'est-à-dire anastomosées, des ponctuations régulièrement alignées, ou des sillons un peu plus larges et plus creux que de simples stries, ou de véritables rainures canaliculées, dont la largeur est telle qu'il vaut mieux pour la clarté de la définition, mentionner comme ornements les rubans saillants qui les séparent.

L'ornementation d'un Gastropode enroulé peut être, soit axiale, c'est-à-dire dans le sens des accroissements, soit spirale, c'est-àdire parallèle aux sutures; pour les coquilles déroulées (Verme- 
tus, Tenagodes, Dentalium), on peut à la rigueur conserver les anciennes dénominations, transverse et longitudinal, qui n'exigent aucun effort d'esprit pour reconstituer l'enroulement; de même pour les coquilles patelliformes (Patella, Emarginula, Capulus, Hipponyx, Siphonaria), il est plus naturel d'adopter les mots concentrique et radial ou rayonnant qui se comprennent sans définition.

Il y a une extrême variété dans les combinaisons de ces deux séries d'ornements: des pages entières ne suffiraient pas pour définir péniblement tous les cas qui peuvent se présenter, aussi j'indiquerai seulement un nombre limité de termes usuels qui expriment à peu près l'importance relative d'une des séries par ropport à l'autre.

Quand l'une de ces séries est prédominante et qu'il s'agit d'ornements en relief, on dit que la coquille est costulée dans le sens axial, cerclée dans le sens spiral, et, s'il s'agit d'ornements en creux, elle est striée ou sillonnée, quel que soit le sens: elle est réticulée, lorsque les ornements en relief ou en creux ont à peu près la même importance dans le sens axial que dans. le sens spiral, cancellée quand les costules l'emportent, sur les sillons ou filets spiraux, décussée sice sont, au contraire, des cordons spiraux traversés par de fines stries ou des lamelles d'accroissement plus serrées.

L'ornementation en creux n'engendre pas une grande variété dans l'aspect de la surface: les accroissements produisent généralement des ponctuations sur les sillons spiraux (Actron), ou bien des traits dans les interstices des rubans (Actronidea); quelquefois ces rubans sont séparés par des stries dont la disposition est telle que les rubans semblent se recouvrir partiellement et sortir les uns de dessous les autres, la surface est alors imbriquée (Paryphostoma); lorsque les stries forment entre elles un treillis oblique, elle est dite guillochée.

Les ornements en relief sont en majorité dans la série des Gastropodes siphonostomes: outre les combinaisons déjà très variées 
dont il vient d'être question, ils présentent les différences les plus nombreuses qu'on puisse imaginer, à cause des saillies accessoires dont ils sont chargés et qui s'alignent soit dans le sens axial, soit dans le sens spiral.

Tantôt ce sont des granulations ou des perles, isolées ou reliées par des cordonnets, tantôt de véritables tubercules ou des nodosités produites au point d'entrecroisement des deux systèmes de côtes, comme dans les mailles d'un filet, tantôt des pointes quelquefois épineuses (Trigonostoma), ou même des tubulures quand ces épines sont creuses. (Typhis, Pereirza); si les lamelles d'accroissements sont finement ondulées et relevées par des filets spiraux on dit que l'ornementation est crépue (Murex, Trichotropis); si de petites granulations rugueuses et très serrées sont répandues sur toute la surface, indépendamment des côtes principales, on dit qu'elle est chagrinée (Auricula), elc... Je n'insiste pas davantage: un coup d'œil jeté sur la figure qui doit accompagner toute diagnose, suppléera aux lacunes de celte énumération.

On se rend compte de la raison d'être des ornements axiaux, qui représentent la succession des accroissements de la coquille et qui participent, par conséquent, à la biographie de l'animal qu'abritait cette coquille; et encore il est permis de se demander pourquoi le mantęau secrète plus abondamment dans certains cas que dans d'autres, la matière dont est formé le test. Mais il n'existe, à ma connaissance, aucune explication sur le but des ornements spiraux, et d'une manière plus général, sur les motifs pour lesquels une coquille est lisse ou ornée; cependant il paraît évident que cette ornementation n'est pas seulement faite pour permettre aux conchyliologues de distinguer les genres ou les espèces les uns des autres; la meilleure preuve c'est la constance de ces ornements dans une même espèce, ce qui nous autorise à conclure qu'ils jouent un rôle dans les mœurs particulières à cette espèce; même les changements qui se produisent dans le ornements du test, qui s'effacent parfois dans les coquilles tout à 
fait adultes (Campanile), prouveraient que ces ornements étaient plus ou moins utiles à charque étape du développement de l'animal. Il est vrai, d'autre part, qu'il existe des groupes où la variation de l'ornementation, dans une seule espèce, est telle qu'elle déconcerte les tentatives de détermination; mais, comme ce fait se produit pour quelques formes limitées, on serait autorisé à penser que c'est précisément parce qu'elles ont un genre de vie approprié, c'est-à-dire un habitat pour lequel l'ornementation est jusqu'à un certain point indifférente. (Voir A. LoGard, Études sur les Variations malacologiques, 1881.)

Avant de terminer ce qui est relatif à l'aspect extérieur de la coquille des Gastropodes, il me reste à dire quelques mots de la base du dernier tour, dont l'ornementation présente rarement la mème disposition que sur le reste des tours, ainsi que les modificalious qui peuvent résulter de l'existence d'un ombilic sur celte base.

Dans un grand nombre de cas, la base est séparée du dernier tour par un angle plus ou moins émoussé constituant la périphérie de la base; quelquefois c'est une carène saillante (Adeorbis, Solarium), ou un cordon isolant un disque basal (Scalaria), ou bien encore une strie, la dernière de celle qui ornent concentriquement la base (Dialopxis), le dernier tour étant, au contraire, lisse. Quant aux ornements produits par les accroissements, on les désigne habituellement sous le nom de rayons, quoiqu'à la vérité ces rayons ne partent réellement d'un centre que si la base est largement ombiliquée (Solarium); dans les siphonostomes imperforés, ces rayons se ramifient sur la partie dorsale du canal opposée à l'ouverture, sur le cou, pour employer l'expression proposée par M. de Gregorio, et ils y produisent souvent des lamelles emboîtées (Muricidx, Cassididæx).

L'ombilic qu'on observe sur la base d'un grand nombre de Gastropodes, est un caractère précieux au point de vue de la distinction des genres entre eux, car il est rare qu'il y ait, dans un même genre, des coquilles ombiliquées et d'autres absolument imperforées; dans ces dernières, le bord columellaire recouvre 
plus ou moins hermétiquement la fente ombilicale; quelquefois il s'y dépose une énorme callosité qui envahit une partie de la base (Neverita, Cepatia, Rotella, Tinostoma, Rotellorbis). Même lorsqu'il est réduit à une simple fente, l'ombilic peut être bordé par un bourrelet lisse (Lacuna) ou sillonné (Sulcoactæonina); ce bourrelet, dont l'enroulement spiral se perd sous le bord columellaire, aboutit en avant au contour supérieur de l'ouverture et y produit ce bec dont j'ai déjà signalé l'existence, en étudiant la forme de l'ouverture. Au lieu d'un bourrelet circa-ombilical, on observe, dans quelques genres (Ampullina), un limbe, c'est-àdire une carène qui s'enfonce en spirale dans l'ombilic, qui se raccorde en avant presque tangentiellement avec le contour supérieur et qui limite une couche vernissée tapissant la paroi interne de l'ombilic: ce limbe se distingue même dans certaines coquilles à base imperforée (Diastoma, Sandbergeria), il double en quelque sorte le bord columellaire et y produit un renflement pariétal, en s'enfonçant sous ce bord dans l'intérieur de l'ouverture. Enfin, lorsque le bourrelet, souvent crénelé ou perlé par les accroissements, sort de l'ombilic, soit en faisant un large circuit (Liotia, Collonia), soit en adhérant à la paroi interne de l'ombilic (Natica), il prend le nom de funicule : dans ce cas, il se produit généralement, au point où il aboutit, une petite expansion du bord columellaire, qui représente à peu près la section transversale du funicule, et que certains auteurs désignent par le terme glosse, ou lèvre.

Quand le bord columellaire dégage complètement l'ombilic, et que ce dernier, quoique étroit, forme un entonnoir qui laisserait apercevoir l'intérieur de la spire jusqu'au sommet, s'il était éclairé, la coquille est dite perforée (Niso, Trypanaxis, Cryptoplocus, Itieria). Enfin, dans les formes discoïdales à ombilic largement ouvert, la base se réduit à une bande circulaire plus ou moins étroite (Planorbis, Straparollus, Homalaxis), séparée par un angle quelquefois caréné de l'entonnoir en gradins formé par la cavité ombilicale. 


\section{STRUCTURE DU TEST}

Fischer, dans son Mamel de Conchyliologie, le professeur Zittel, dans son Manuel de Paléontologie, ont consacré d'excellentes pages à la structure et au mode de formation du test des coquilles: il me suffira de rappeler brièvement les principales définitions adoptées par ces auteurs, et de tirer de leurs considérations quelques conclusions sommaires relatives à l'usage qu'on peut faire de ces éléments pour la détermination des genres fossiles.

La plupart des Gastropodes ont une structure porcellanée, la partie calcaire de leur test est formée de trois couches superposées, qui peuvent se dédoubler et se détacher successivement, quand leur ciment organique disparait par la fossilisation; la couche externe et la couche interne se composent de plaques empilées de la même manière, longitudinalement ou transversalement, tandis que dans la couche médiane, qui est générale. ment la plus épaisse, les plaques prismatiques s'agglomèrent dans une direction perpendiculaire ou oblique à celle des deux autres couches.

Ce n'est guère que dans les sables tertiaires que les Gastropodes se présentent avec la frâicheur intacte de leur test: dans les terrains secondaires et, à plus forte raison, dans les terrains paléozoïques, la couche externe a généralement disparu; toutefois l'ornementation reste encore imprimée sur la couche médiane, ou elle n'y subit que des modifications qui n'en altèrent pas toujours les caractères distinctifs. Cependant Koken cite des Porcellia qui, lorsqu'elles ont la couche externe de leur test, présentent sur la quille dorsale une série de perforations tubulées, tandis que, quand il ne reste que la couche médiane, l'observateur ne dis tingue, à la place de cette ligne de perforations, qu'une double rainure pui pourrait qui faire confondre la coquille avec un $\mathrm{Bel}$ - 
lerophon; si, enfin, la couche médiane disparaît à son tour, il n'y a plus, à la place de la rainure, qu'un bombement plus ou moins saillant, ne portant aucune trace des tubulures caractéristiques $\mathrm{du}$ genre Porcellia.

Ainsi la fossilisation, et surtout l'influence de l'ancienneté des sédiments, agissent dans le sens d'une atténuation ou d'une oblitération complète des caractères extérieurs du test, même pour les fossiles qui ne sont pas à l'état de moules indéterminables: c'est une difficulté de plus à ajouter à la liste de celles que rencontre déjà le Paléontologiste, dans ses essais de classification.

Dans certains genres (Conus, Terebellum), le test se résorbe sur les premiers tours, c'est-à-dire que la couche médiane commience par disparaître, ainsi qu'il résulte des coupes en travers reproduites par les auteurs (Fischer, Zittel), et que même la couche externe et la couche interne s'amincissent tellement que, si la coquille est libre dans le sable, lorsqu'on la vide, les fragments des premiers tours tombent avec le sable. Ce caractère a permis à d'Orbigny de démontrer que certaines Actæonina, semblables à des Conus par leur aspect extérieur, doivent être classées dans les Actronidæ, parce que la coupe faite dans l'axe de la coquille pétrifiée indique la persistance des cloisons à tout âge. Je ne crois pas qu'on ait jamais étudié les causes de cette résorption interne : en tous cas, elle n'est pas accidentelle.

De l'épiderme, soyeux, fibreux ou piléeux, qui recouvre souvent le test des coquilles vivantes, il ne reste rien dans les fossiles; d'ailleurs, il disparaît même sur les espèces actuelles, pour peu qu'elles aient été quelque temps roulées dans la mer. Il résulte de là qu'on ne peut guère faire entrer les vestiges de coloration du test en ligne de compte dans la détermination des genres fossiles: łes traces qu'on en observe exceptionnellement sur quelques rares échantillons, consistent en bandes ou fascioles brunes, rarement en ponctuations (points jaunes dans $N$. millepunctata du Plaisancien). Dans les Neritidæ cependant là fossilisation a très souvent respecté les couleurs foncées qui 
ornaient le test de l'animal en vie; mais on ne peut même pas utiliser ces vestiges pour séparer les espèces de cette famille, altendu que précisément, dans un grand nombre d'entre elles, la coloration varie d'un individu à l'autre.

Je ne parle que pour mémoire des rangées de perforations microscopiques qu'on observe sur certaines coquilles (.Megatylotus crassatinus, Ampullina abscondita) et qu'il ne faut pas confondre avec l'ornementation du test: cette disposition quasi-spongieuse, mais plus régulière cependant, est rare dans les Gastropodes et doit jouer un rôle dans les fonctions de l'épiderme.

En ce qui concerne la nacre que présente le test de certaines familles (Trochidx, Haliotidx), c'est une mince couche interne dont l'irisation miroite à l'entrée de l'ouverture; elle résiste à la fossilisation dans les terrains sableux ou argileux, mais elle disparait completement dans les terrains calcaires ou terreux. Cependant, quandle test n’est pas trop altéré, on peut encore vérifier si la coquille était nacrée en détachant une mince couche de ce test, sans atteindre tontefois la gangue interne du moule remplaçant l'animal; la couche nacrée apparaît alors quand elle existe.

\section{PIICES ICCESSOIIES}

Indépendamment de la coquille, les mollusques de la classe des Gastropodes ont souvent des pièces accessoires, telles que les plaques du gésier (Scaphander), l'opercule, le clausilium, etc.

Il est presque superflu de mentionner les plaques du gésier qui sont toujours détruites par la fossilisation.

L'opercule, fixé à la partie postérieure du pied des Gastropodes, sert à fermer leur ouverture, lorsqu'ils se retirent en se contractant (Fischer); par conséquent, ce n'est que dans les couches dont le dépôt s'est effectué dans un milieu parfaitement calme, comme au sein des lacs par exemple, qu'on peut trouver des coquilles encore 
munies de leur opercule en place. Dans les genres où cette pièce est cornée, elle n'a pas résisté à la décomposition; il ne s'agit donc que d'opercules calcaires, et, la plupart du temps, on les recueille isolés : c'est done seulement par leur affinité avec ceux des genres vivant actuellement, qu'on peut reconnaître à quelles coquilles ils doivent être appliqués. Pour les opercules des genres éteints, on en est réduit aux conjectures; aussi me dispenserai-je d'insister sur ce sujet, d'ailleurs traité d'une manière très complète dans le Manuel de Fischer (p. 444).

Enfin, le clausilium est aussi une pièce accessoire, que l'on n'a signalée qu'à l'intérieur de l'ouverture des Clausiliidæx; il est bien rare qu'on le trouve en place dans les fossiles, et d'ailleurs c'est une organisation toute spéciale dont l'étude sort du chapitre des généralités. 


\section{DIVISION DU SUJET}

La présente livraison est consacrée à la revue des Opisthobranchiata : cet ordre a été placé par les conchyliologues, tantôt au début, tantôt à la fin de la classification des mollusques, mais loujours dans le voisinage des Pulmonata. Si j'en entreprends l'étude avant celle des Prosobranchiata, c'est qu'ils forment un groupe homogène, bien limité, se prêtant tout à fait, par son étendue restreinte, à l'essai que je tente en publiant cette première livraison.

J'y joins d'ailleurs les Nucleobranchiata et, parmi les Pulmonata, le sous-ordre des Thalassophila, qui sont à peine représentés dans la faune fossile. Quant aux autres Pulmonata, je compte ne les passer en revue qu'après toute la série des Gastropodes marins.

En tête de chaque famille, après l'indication sommaire des caractìres distinctifs de la famille, je place un tableau récapitulatif des genres, des sous-genres et des sections qu'elle comporte, et je divise ce tableau en troıs parties: la première, relative aux formes signalées à l'état fossile, résume seulement les noms des coupes que j'admets, soit comme genres, soit seulement comme sous-genres, soit enfin comme simples sections; dans la seconde, je me borne à citer les noms des formes qu'on n'a pas signalées à l'état fossile, et qui, par conséquent, n'intéressent pas mon étude, exclusivement paléontologique; enfin, dans la troisième, j'indique les genres qui me paraissent devoir ètre éliminés de la famille, pour des motifs que je rappelle brièvement. 
Ce tableau des matières a surtout pour but de bien fixer la valeur relative des divisions génériques que j'ai admises : je sais que beaucoup de mes confrères n'admettent ni les sections, ni même les sous-genres, et qu'ils mettent radicalement sur le même rang toutes les coupures qu'ils font dans une famille. Cette opinion ne me semble pas conforme aux principes de subdivision qu'on retrouve à tous les degrés dans la Création; elle exclue l'idée d'une évolution graduelle des êtres qui, pour passer du simple au composé, de l'unité initiale à la multiplicité actuelle, doit nécessairement procéder par voie d'embranchements successifs. Pour prendre une comparaison frappante dans un tout autre ordre d'idées que dans la nature, je dirai, par exemple, qu'un général ne commande pas directement à tous ses soldats: or, la hiérarchie d'une armée existe aussi en histoire naturelle, et elle satisfait mieux l'esprit qu'une méthode consistant à attribuer' autant d'importance à des caractères 'principaux qu'à des caractères secondaires. On objecte, il est vrai, qu'en admettant les sous-genres et les sections on s'expose à contrevenir à la règle de nomenclature binominale: d'abord ce prétexte est spécieux, car rien n'oblige celui qui veut désigner une espèce, à lui donner plus de deux noms, qu'il prenne pour le premier le nom du genre, du sous-genre ou de la section; en second lieu, quand même il devrait en résulter, dans certains cas, l'énonciation de trois noms, dont un (celui du sous-genre ou de la section) entre parenthèses, je ne vois pas où serait l'inconvénient s'il doit en résulter plus de clarté pour le lecteur, surtout quand cela se réduit au fond à une pure question de typographie.

C'est pourquoi je n'ai pas hésité à adopter la division en genres, sous-genres et sections, chaque fois qu'il y a lieu, sans m'y croire cependant contraint par les lois de la symétrie.

Chaque genre, chaque sous-genre et chaque section est ensuite l'objet d'une diagnose établie sur un modèle uniforme, d'après l'espèce type, et amendée, s'il y a lieu, d'après le plésiotype fossile: il ne m'a pas toujours été possible de me procurer des échantillons des espèces typiques pour les faire photographier, 
surtout quand il s'agit de formes exotiques, précieusement conservées dans des Musées de l'étranger (British Museum, Université d'Adélaïde en Australie, Smithsonian Institute); dans ce cas, j'ai calqué et fait reproduire la figure donnée par l'auteur, de sorte que je suis arrivé, à peu d'exceptions près, à donner l'iconographie de tous les genres d'Opisthobranchiala signalés à l'état fossile. Les photographies ont été faites d'après les échantillons des collections que je cite, par deux collaborateurs dévoués, MM. Ridel et Boursault, dont le zèle et l'habileté ont réussi à obtenir d'excellents clichés, ne nécessitant qu'un petit nombre de retouches pour la photolypie, confiée à MM. Sohier et Campy.

Contrairement à l'opinion de quelques-uns de nos confrères, qui pensent qu'une description de deux lignes, accompagnée d'une bonne figure, suffit amplement pour caractériser une coquille, je n'ai pas hésité à développer largement les observations relatives aux rapports et aux ditférences à l'aide desquels on justifie la séparation des genres fossiles soit entre eux, soit en les comparant aux formes vivantes: il m'a toujours semblé qu'en matière d'histoire naturelle/une affirmation doit être étayée par des preuves basées sur l'observation; d'ailleurs, les diagnoses sont souvent presque identiques, à quelques mots près, de sorte qu'il faut bien appeler l'attention du lecteur sur ces différences, en apparence légères, et expliquer pour quel motif on leur attribue une importance capable de justifier la séparation proposée. Si beaucoup d'auteurs avaient procédé de cette manière, on ne serait pas aujourd'hui dans l'hésitation au sujet de la valeur des noms qu'ils ont donnẻs.

L'histoire du genre se termine par un tableau indiquant à quels niveaux stratigraphiques son existence a été, jusqu'à présent, authentiquement constatée : à cet effet, dans chaque terrain, je cite une ou plusieurs espèces, vérifiées autant que possible par moi-même, et le nom de la collection à laquelle appartiennent les échantillons qui m'ont permis de faire cette vérification; à défaut, j’indique l'auteur dont l'ouvrage contient les figures 
permettant de signaler ces témoins biologiques. Quant aux terrains dont les noms sont placés en regard, j’ai adopté la classification proposée dans le Bulletin de la Société géologique de France, par MM. Munier-Chalmas et de Lapparent $\left(3^{e}\right.$ série, t. XXI, $n^{\circ} 6,1893$ ), et paraissant admise pour la légende de la feuille d'assemblage des cartes à l'échelle de $1 / 320000^{\circ}$. Toutefois, comme la multiplicité des subdivisions stratigraphiques serait sans intérêt au point de vue spécial de la descendance des Gastropodes dans les temps géologiques, j’ai emprunté à cette classification : pour le groupe paléozoïque, les noms des systèmes, pour le groupe mésozoïque, ceux des étages, et seulement ceux de séries dans le groupe néozoïque. Enfin, l'énoncé de cette répartition stratigraphique se termine, s'il y a lieu, par une ligne ou deux, correspondant à l'époque actuelle.

Ces tableaux de répartilion stratigraphique m'ont permis de reconstituer, à la fin de la livraison, un résumé graphique de l'enchaînement ancestral des Opisthobranchiata, tel qu'il résulte de l'état actuel de nos connaissances paléontologiques : à cet effet, je ne me suis pas borné à tracer, comme l'ont fait d'Orbigny, Zittel et tout récemment White, une table à double entrée représentant par des traits plus ou moins allongés la longévité d'une famille, d'un ordre ou d'une classe; mais j'ai cherché à. me rapprocher du système en éventail auquel je faisais allusion, au début de la préface de cette livraison. Il est bien évident que le résultat auquel j'arrive ne se présente pas avec la régularité de bifurcations successives, également épanouies de chaque côté du. centre; néanmoins il paraît confirmer, jusqu'à un cerlain point, la théorie d'après laquelle les types actuels seraient issus d'une origine commune, qui serait, pour les Opisthobranchiata, le genre Actxonina, ou plutôt l'un de ses sous-genres Cylindrobullina. Quelque imparfaite que soit encore cette conclusion, elle tend du moins à démontrer l'utilité des recherches dans le sens de celles que j'ai entreprises. 


\section{OPISTHOBRANCHIATA}

Le sous-ordre I, Nudibranchiata, ne comprenant que des animaux sans coquille, n'a pas laissé de traces de son existence dans les temps géologiques.

Le sous-ordre II; Tectibranchiata, le seul dont la coquille souvent rudimentaire, ait pu se conserver à l'état fossile, est divisé par P. Fischer en trois groupes, Cephalaspidea, Anaspidea et Notaspidea, selon qu'ils possèdent un disque céphalique, un bouclier dorsal, ou qu'ils n'en ont pas.

Le groupe A, le plus important au point de vue du nombre des familles, est lui-même subdivisé selon qu'il y a un opercule ou qu'il n'y en a pas, et dans ce dernier cas, selon que la coquille est extérieure (Ectoconcha) ou recouverte par le manteau $($ Entoconcha).

Si l'on admet ce classement, voici comment se répartissent les familles, en y ajoutant celles que je vais proposer :

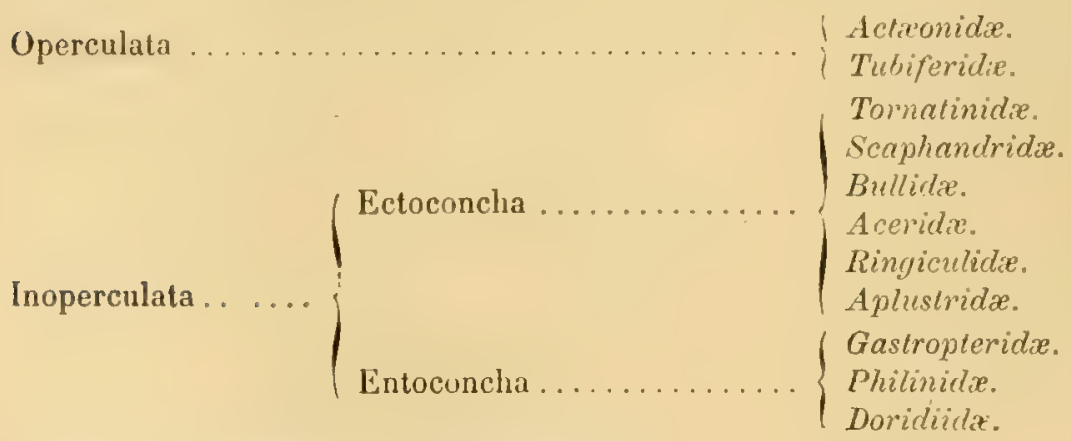

Le groupe B, Anaspidea, se f Entoconcha ........ A plysiidid. subdivise en........ Ectoconcha........ Oxynoeidx.

Enfin le groupe C, Notaspidea, ne comprend que trois Pleurobranchidx. familles ........................ Runcinidx.

Toutes les cuquilles du groupe A ont l'embryon hétérostrophe plus ou moins saillant. 


\section{AC'T EONID}

Coquille ovale, lisse ou ornée de sillons spiraux souvent ponctués; spire généralement courte, à embryon hétérostrophe, à tours embrassants; labre peu incliné, à peine sinueux; ouverture relativement grande, allongée, arrondie, entière et parfois versante en avant, rétrécie en arrière par la convexité de la base qui vient en contact avec le plan du labre; columelle plissée ou tordue, quelquefois à peine infléchie, ou même simple à l'âge adulte.

Tableau des genres, sous-genres et sections

\section{ACTEON}

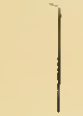

TORNATELLAA<smiles>C1=CCCC1</smiles>

ACT EONIDEA<smiles>C=C</smiles>

ADELACT FON

$$
\begin{aligned}
& \text { Acteon } \\
& \text { Solidula } \\
& \text { Semiacteon }
\end{aligned}
$$

\section{LIOCARENUS}

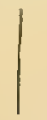

ACT EONINA

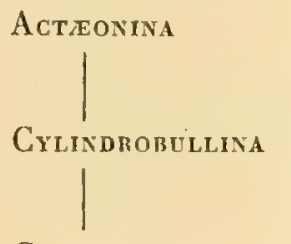

Goniocylindrites
Tornatellea

Triploca

ACténidea

Crenilabium

Riclaxis

Liocarenus

Bulimacteon

Nucleopsis

Sous-famille

Nucleopsinæ.
Sous-famille

Tornatellinæ.

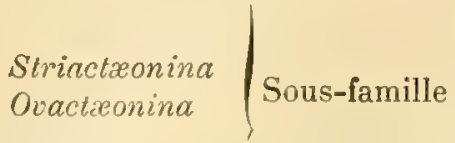

\begin{tabular}{l|l} 
Conactron & Actæoninæ.
\end{tabular} 


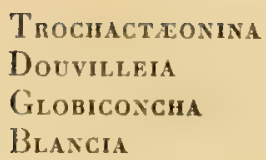

Sous-famille

Globicoxcha

Blaxcia

Globactronina.

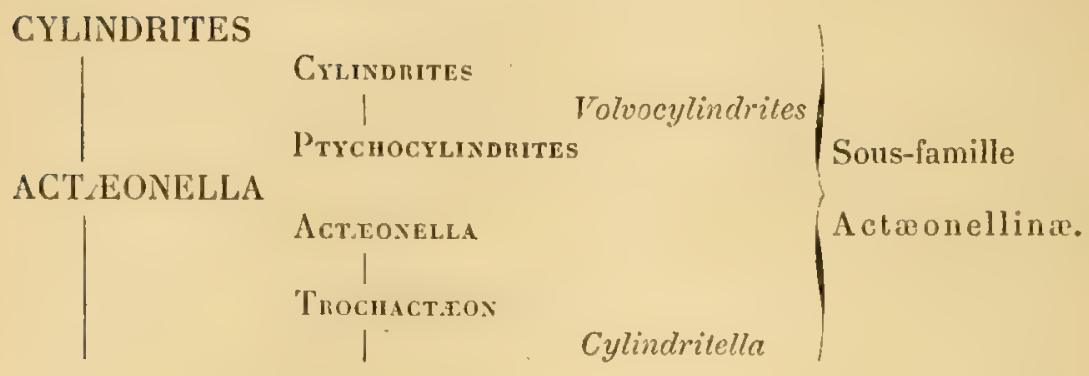

Genres et sous-genres non signalés à l'état fossile

Ovuracraox. Dall. 1889. (Type: O. Mecki, Dall. la Ilavane.) Ouverture d'Actrenella sans plis, sommet perforé comme celui d'une Bulla.

\section{Genres et sous-genres à éliminer des 0pisthobranchiata}

Levcotixa, A. Ad., 1860. Ouverture et embryon de Pyramidellidx; coquille identique à Raulinia. Mayer, 1865̆, d'après la vérification que j’ai faite sur deux espèces (L. lirala, Carp. et L. digitale, $\mathbf{\Lambda}$. Ad.) étiquetées de la main d'Adams, et obligeamment communiquées par M. Crosse.

Kuesnella, A. Ad., 1860. Grâce à l'obligeance de M. Newton, du Britislı Museum, j’ai constalé que ce genre, dont le type n'a

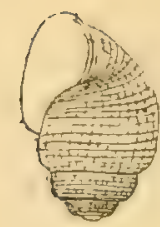

Fifi, 34.

Kleinella cancellaris, Ad. jamais été figuré, a la spire obtuse au sommet, la columelle dénuée de pli, et le labre se raccordant normalement à l'avant-dernier tour, au lieu d'être dans un plan tangentiel à la base; ces caractères, qui s'écartent complètement de ceux des Actronidx, rapprochent les Lleinella des Menestho. A l'appui de cette assertion, j'ai fait reproduire (fig. 34) un dessin fait par M. Smith, d'après le type $K$. cancellaris, A. Ad. du British Museum. (Voir Ann. mag. nat. hist., vol. V, sér. 3, p. 302.)

Volvaria, Lamk. 1801. Embryon homœostrophe, en goutte de suif, d'après la vérification que j'en ai faite sur un individu de V. Lamarcki, Desh. Dans ces conditions, ce genre n'appartient évidemment pas aux Actreonidx, ni aux Bullidx, où on l'a successivement classé, mais il se rapproche plutôt des Volutidx. 
Cylindritopsis, Gemm. 1889. Suivant l'opinion de M. Koken, on ne peut admettre dans les Actæonidæ, ni même dans les Opisthobranchiata, le genre permo-carboniférien Cylindritopsis, caractérisé par sa forme de Strobeus, avec un pli columellaire et un bec antéricur échancré. La raison principale qui justifie cette élimination est, à mon avis, la forme du labre obliquement incliné à gauche de l'axe, du côté antérieur; l'origine marine des calcaires à Fusulina, de la vallée du fleuve Sosio, en Sicile, où ont été recueillis les Cylindritopsis, ne permet guère de supposer que ce soient des Auriculidx; je crois plus naturel de les rapprocher des Macrochilidx, comme le propose Koken, et par conséquent de les classer dans les Pyramidellidie, où nous les retrouverons ultérieurement.

ACT EON, Montf. 1810.

(= Tomatella, Lamk. 1812; = Speo, Risso 1826; sec. Fischer) (= Kanilla, Silvertrop 1838; = Myosota, Gray 1847; sec. Zittel)

Un ou plusieurs plis columellaires, ouverture régulièrement arrondie en avant; sillons spiraux ponctués.

Actæen, sensu stricto:

Type: Voluta tomatilis, Lin. Viv.

Forme ovale; embryon peu saillant, dévié, hétérostrophe; spire généralement plus courte que le dernier tour, à sutures bien marquées; surface totalement ou partiellement sillonnée dans le sens spiral, avec de fines lamelles d'accroissement qui ponctuent seulement le creux des sillons; ouverture allongée; arrondie et entière en avant, rétrécie en arrière; labre arqué, un peu sinueux en arrière, épaissi à l'intérieur; columelle épaisse, non tronquée, traversée par un fort pli spiral et peu oblique, dont le prolongement contourne l'ouverture et se relie par une courbe régulière au bord supérieur. 
Diagnose prise sur une coquille typique de la Méditerranée, ma coll. Plésiotype fossile de l'Eocène, A. subinfatus, d'Orb. (Pl. I, fig. 1) ma coll.

Observ.-A côté du groupe typique, qui est largement représenté dans les terrains tertiaires, on pourrait admettre un second groupe pour A. Gmelini, Bayan (Pl. 1, fig. 2), dont le pli columellaire est moins arrondi, plus large, sillonné par une dépression qui lui donne l'aspect bifide; dont l'embryon est plus saillant et forme une crosse déviée avec un tour et demi enroulé autour d'un axe perpendiculaire à celui de la cocquille, et montrant un nucléus apical distinct, tandis que, dans les Actæon typiques, ce nucléus est souvent noyé dans un empâtement à demi recouvert par le premier tour dextre qui succède à l'embryon. Toutefois, ces différences légères ne justifient pas la çéation d'une section distincte. L'opercule cormé des Actron ne s'est pas conservé à l'état fossile.

Répart. stratigr.

Tunoviex....... Plusieurs espèces dans le Crétacé supérieur de l'Inde

et ( 1 clxon curculio, Forbes et junceus, Stol.) munies d'un seul pli columellaire, d'après la figure et le texte Sexoxiex... ... de Stoliczka ; aucune espèce certaine en Europe.

Paleocene..... Nombrenses espèces typiques dans le bassin de Paris (Acticon Gilberli, Cossm. Deshayesi, Mun. Ch. Loustaux, Desh. etc.), ou dans l'Alabama (A. punctalus, Lea et linealus, Lea) ma coll. Mayence ou de l'Allemagne du Nord ( 1 . punctatosulcatus, Phil.) ma coll.

Mrocexe...... Plusieurs espèces bien caractérisées, dans le Bordelais (A. semistriatus et punctulatus, Fér.) ma coll.; une espèce du Tertiaire de la Jamaïque (Torn. textilis, Guppy), d'après la figure de l'auteur.

Pltocene....... Le type existe fossile à Ficarazzi, ma coll. (dedit M. de Monterosato; signalé à Anvers, dans le Crag, d'après la figure de Nyst.

Epoque actuelle. Environ 20 à 30 espèces vivant dans toutes les mers, d'après $P$. Fischer.

Solidula, Fisch.v. W., 1807. Type: Voluta solidula, Lin. Viv. (=Buccinulus, Ad. 1850; = Dactylus; Schum, 1817; sec. P. Fischer).

Forme, embryon, spire et ornementation d'Actæon; ouverture allongée, arrondie et un peu versante en avant, rélrécie en arrière; 
Actreon

labre arqué, un peu sinueux en arrière, non épaissi à l'intérieur ; columelle épaisse, portant en avant un large pli. bifide, dont le prolongement contourne l'ouverture et se relie par une sinuosité au bord supérieur; bord columellaire portant en arrière un second pli simple et plus mince que l'autre, enfoncé en spirale à l'intérieur de l'ouverture et peu visible quand celle-ci est intacte.

Diagnose prise sur une coquille typique de la Nouvelle-Calédonie, ma coll. Plésiotype fossile du calcaire grossier, Actron Bevaleti, Baudon (PI. I, fig. 3-4), coll. Pezant.

Observ. - Se distingue des Aclæon typiques par sa plication columellaire et par la forme un peu versante du contour supérieur de l'ouverture; si ces différences ne justifient pas la séparation d'un genre distinct, elles permettent du moins de séparer les Solidula des Actæon et de ne pas substituer au nom Actæon un vocable antérieur, il est vrai, mais très incorrectement formé, puisque c'est un simple adjectif et précisément le nom spécifique du type.

Répart. stratigr.

Eocene....... Une espèce dans le bassin de Paris (A. Bevaleti, Baudon), coll. Pezant, Bourdot, ete.

Mrocene ....... Une espèce dans le Bordelais, dont le pli supérieur est à peine bifide (A. strialellus, Grat.) ma coll.

Epoque actuelle. Vivant dans la Mer Rouge et aux Philippines, d'après P. Fischer.

Semiactæon, Cossm. 1889. Type: Torn. sphoricula, Desh. Eoc.

Forme et spire d'Actxoon; embryon à nucléus hétérostrophe, presque totalement involvé el sans saillie; ornementation cancellée; ouverture courte, ovale, atténuée à ses deux extrémités; labre arqué, sinueux en arrière, souvent épaissi par un bourrelet externe très obsolète; columelle droite, portant au milieu un pli tordu à peine saillant; bord columellaire ne recouvrant pas la fente ombilicale, non raccordé à sa jonction avec le contour supérieur. 
Diagnose prise d'après un individu typique du calcaire grossier des environs de Paris (pl. I, fig. 7-8), coll. Pezant.

Observ. - Se distingue des Actron typiques par son embryon non saillant, par la faible proéminence du pli columellaire, par sa columelle droite, ne se courbant pas pour se raccorder au bord supérieur, par son ombilic étroitement perforé, enfin par son ornementation plutôt treillissée que spirale et ponctuée; se distingue des Leucotina ou Raulinia (Pyramidellidæ), malgré une grande analogie de forme et d'ornementation, par la courbure et l'épaississement du labre qui n'est pas incliné à gauche de l'axe au côté antérieur, par la forme moins courte de l'ouverture qui est plus rétrécie en arrière; enfin, par la plication obsolète de sa columelle.

Répart. stratigr.

Eocene....... Une espèce dans le bassin de Paris, A: sphrericulus, Desh, ma coll., coll. Pezant.

Mrogexe ....... Une espèce dans le Bordelais, A. cancellalus, Grat., d'après Benoist.

TORNATELLEA, Conrad, 1860.

Plusieurs plis columellaires; ouverture échancrée par une sinuosité antérieure.

Tornatell жa, sensu stricto. Type: T. bella, Conr. Eoc.

Forme, embryon, spire et ornementation d'Actæon; ouverture assez large, subéchancrée ou sinueuse en avant, peu rétrécie en arrière; labre arqué, non sinueux en arrière, épaissi et crénelé ou sillonné à l'intérieur; columelle peu courbée, recouverte d'une levre mince qui porte deux plis obliques et lamelleux, et qui se termine en pointe dans l'angle de droite de l'échancrure du contour supérieur.

Diagnose faite d'après T. simulala, Sol. de Barton (pl. I, fig. ǒ-6), ma coll., espèce du même genre que le type (sec. Fischer).

Observ. - A été confondu, notamment par Tryon, avec Solidula; s'en distingue par la disposition de ses plis columellaires, par l'épaississement 
Tornatellaea

interne et souvent crénelé du labre, surtout par l'échancrure du contour antérieur, bien visible lorsqu'on regarde la coquille en plan : ces caractères justifient la sépàration d'un genre distinct des Actron, bien plus ancien dans la série géologique.

Répart. stratigr.

Sinemurien..... Une espèce douteuse à la base du Lias (Tubifer Heberti, Piette), coll. de l'Ecole des Mines.

Charmouthien... Une espèce à peu près certaine dans l'Est de la France (Orthostoma fontis, Dum.), coll. du Musée de Dijon.

Toarcien...... La même espèce, à Champigneulles, coll. de la Sorbonne.

Bajocien....... Trois espèces certaines, soit à Sully, "soit à Nancy (Tornatella pulchella, Desh., etc.), coll. Deslongchamps, Pellat, Brasil, de la Sorbonne, etc.

Bathonien ...... Deux espèces typiques, dans l'Est et dans le Boulonnais (Tornatella cingillata, Terq. et multistriata, Rig. et Sauv.) coll. de l'Ecole des Mines, coll. Rigaux.

Callovien...... Une espèce probable dans les couches de MontreuilBellay (Tornatella Lorierei, Héb. et Desl.), d'après la figure donnée parles auteurs.

Oxfordien ...... Une espèce inédite dans les environs d'Elatma, en Russie; coll. de l'Université de Moscou.

Rauracien ..... Une espèce certaine, à Saint-Mihiel (Tornatella myosotis, Buv.) coll. Moreau.

Sequanien ..... Plusieurs espèces certaines et inédites, dans le Boulonnais et la Charente; seront décrites dans la Revision de la Paléontologie française.

Portlanden.... Une espèce probable dans la Meuse et dans l'Yonne (Tornalella secalina, Buv.) d'après la figure donnée par l'auteur et par de Loriol et Cotteau.

Neocomen..... Une espèce certaine dans l'Est de la France (Acræon marullensis, d'Orb.) coll. Moreau.

Barremien ..... Une espèce nouvelle, des couches rouges de Vassy (T. Lapparenti, nob.). Voir l'annexe et la pl. II, fig. 21-22, coll. de la Faculté catholique de Paris.

Albien........ Une espèce bien caractérisée dans le Gault de Cosne, ( $T$. cosnensis, de Lor.) d'après la figure donnée par l'auteur.

Cenomanien.... Une espèce certaine dans la Meule de Bracquegnies (Act. affinis, Sow.) coll. Bourdot; autre espèce du Mans ( $A$. cenomanensis, Guér.); d'après la photographie faite par l'auteur.

Tunoniex....... Une espèce probable dans l'Est de la France (Torna- 
tella lacrymoides, Barr. et de Guerne) d'après la figure donnée par les auteurs.

Senoniev....... Deux espèces certaines, à Aix-la-Chapelle (Actronina doliohum, Mull. et Mulleri, Bosq.), d'après les figures de M. Holzapfel; existe aussi dans le Crétacé de l'inde.

Paleocene ...... Une espèce bien caractérisée dans le bassin de Paris (Tornatella parisiensis, Desh.) ma coll.

Eocene ........ Une espèce dans les couches de Barton et de Wemmel (Torn. simulata, Sol.) ma coll.; le type dans l'Alabama $(T$. bella $=$ lala, Conr.), d'après lia figure de l'auteur (Amer. journ. of Conch.).

Oligocene..... Le plésiotype ( $T$. simulata, Sol.) dans le bassin de Mayence, ma coll.

Mrocene........ Même espèce dans les faluns du Bordelais, d'après Benoist.

Triploca, Tate, 1893.

Type: T. ligata, Tate. Eoc.

Forme et embryon d'Actæon; spire un peu allongée, ornée de sillons finement ponctués, à sutures bordées d'un sillon plus profond; ouverture de Tornatellæa; labre épaissi, non crénelé; columelle munie de trois plis tranchants et parallèles, les deux antérieurs très rapprochés; bord columellaire rétléchi sur la région ombilicale, et se reliant par une sinuosité subéchancrée avec le contour supérieur.

D'après des échantillons typiques; reproduction de la figure de l'auteur (Pl. VII, fig. 19).

Observ. — La différence capitale entre ce sous-genre et le genre Tornatellæa consiste dans l'existence de trois plis columellaires, au lieu de deux; il se distingue des Ringinella, dont il a complètement l'aspect, par son labre non bordé et par ses plis columellaires qui n'ont pas tout à fait la disposition de ceux des Ringinella. Dans ces conditions, je conserve le sous-genre Triploca dans les Actxonidx que je rattache aux Tornatellxa.

Répart. stratigr.

Eocene........ Une espèce, type du sous-genre, dans le Tertiaire d'Australie, ma coll. (plusieurs échantillons donnés par M. Tate). 
AGT\&ONIDEA, Gabb. 1873.

Columelle tronquée en avant, munie d'un seul pli médian, non enroulé à la base.

Acteonidea, sensu stricto. Type: A. oryza, Gabb. Tert.

Forme étroite; embryon peu saillant, hétérostrophe et dévié; spire plus courte que le dernier tour, à sutures marquées; surface finement décussée, à lạmelles d'accroissement un peu crépues; ouverture allongée, à peine élargie en avant, très étroite en arrière; labre peu épais, asse\% arqué, un peu incliné par rappòrt à l'axe et à droite du côté antérieur; bord columellaire peu excavé, largement étalé en arrière, aminci et tordu en avant, se terminant par une troncature contre le bord supérieur, qui fait une sinuosité subéchancrée, souvent laciniée; pli columellaire placé plus haut que le tiers de la hauteur, saillant, épais et brusquement interrompu à la limite du bord columellaire qui recouvre complètement l'ombilic.

\section{Diagnose prise d'après $A$. Munieri, Desh. d'Acy en Multien}

(Pl. I, fig. 20-21) ma coll.

Observ. - Les Actæonidea doivent être génériquement séparés des Actæon, à cause de leur forme étroite, de leur plication columellaire, de leur columelle tronquée, et de leur échancrure sinueuse formant presque un bec à l'extrémité antérieure de l'ouverture; cependant leur embryon, la forme de leur labre et même l'ornementation, bien qu'un peu différente, les rapprochent encore des Actæon. Je n'ai pas eu à ma disposition d'échantilion de l'espèce typique, $A$. oryza ; mais la figure qu'en a donnée Tryon (Struct. and. syst. Conch.) me paraît presque identique à notre A. Munieri, sauf quelques différences spécifiques, de sorte que j'ai pris, sans hésitation, ce dernier comme plésiotype pour la diagnose qui précède.

Répart. stratigr.

Eocene....... Deux espèces dans le bassin de Paris (A. Munieri et dactylinus, Desh.) ma coll. 


\section{Actaeonidea}

Ougocene...... Une espèce dans le Tongrien de l'Allemagne du Nord (Torn. alata, von Konen), d'ap. la figure de l'auteur. Mrocene....... Outre le type dansle Tertiaire d'A mérique, une espèce dans les faluns du Bordelais (A. pinguis, d'Orb.) ma coll.

Rictaxis, Dall. 1891. Type: Act. punctato-colatus, Garp. Viv.

Forme ovale; embryon peu saillant, hétérostrophe et dévié; spire courte, à sutures linéaires : ornementation d'Actzon; ouverlure fusoïde, atténuée en avant; labre peu épais, presque vertical, à peine curviligne, faiblement échancré en arrière; bord columellaire aminci du côté postérieur, calleux et fortement excavé dans sa moitié supérieure, se terminant par une troncature obliquement infléchie, contre le bord antérieur qui est à peine échancré par une faible sinuosité; gros pli columellaire épais, se prolongeant jusqu'à l'arête qui limite la callosité du bord interne.

Diagnose prise d'après l'espèce typique (Pl. I, fig. 10) ma coll.

Observ. - Cette forme est voisine d'Actronidea, dont la rapprochent sa columelle tronquée et son embryon peu saillant; mais le pli columellaire, quoique n'étant pas davantage enroulé sur la base, est beaucoup plus gros, placé plus haut, sur une excavation plus profonde du bord columellaire, qui s'étend moins en arrière et qui est plus obliquement courbé du côté antérieur, de sorte que l'ouverture présente plus l'apparence d'un bec rudimentaire, que dans le genre Actronidea. Enfin la forme et l'ornementation des Riclaxis sont différentes et se rapprochent plus de celles des Acticon: il est done légitime de séparer ces deux coupes, mais en ne considérant l'une que comme une subdivision sectionnelle de l'autre; si l'on ne tient compte que des dates, il serait plus correct de prendre pour genre Rictaxis, qui est de deux années antérieur à Acleonidea, tandis que ce dernier est géologiquement l'ancêtre de l'autre.

Répart. stratigr.

Eocene....... Deux espèces (Act.punclalus, Lea et annectens, Meyer) dans l'Alabama, ma coll.; la première surtout, identique au type vivant.

Epoque actuelle. Une espèce vivant sur les côtes de Californie, type de la section. 
Cremilabium, Cossm. 1889. Type: Act.aciculatus, Cossm. Eoc. (= Lissactæon, Monts, 1890. Natur. Sicil., p. 28).

Forme étroite; embryon saillant, hétérostrophe et dévié perpendiculairement à l'axe; spire au moins égale à l'ouverture, à sutures linéaires; surface presque lisse, ou très finement striée dans le sens spiral, stries plus visibles à la base; ouverture courte, étroite, ovale en avant; labre mince, presque vertical; bord columellaire très étroit, muni d'un pli mince qui s'enfonce très obliquement en arrière dans l'ouverture, portant en avant de fines crénelures, et se terminant en pointe effilée contre le bord supérieur qui fait une sinuosité subéchancrée.

\section{Diagnose faite d'après le type de Cuise (Pl. I, fig. 9) ma coll.}

Observ. - Ce sous-genre se rattache aux Actæonidea par la troncature de la columelle et par la disposition de l'embryon, mais il s'en écarte par toūs ses autres caractères, principalement par ses.crénelures columellaires; les Crenilabium ressemblent aussi à quelques Actron lisses ou très étroits, mais leur échancrure et leurs crénelures les en distinguent facilement. J'ai, non sans difficulté, avec un très puissant grossissement, constaté l'existence de stries spirales et de très faibles crénelures columellaires sur l'espèce choisie par M. de Monterosato comme type de son genre Lissactron (Act.exilis, Jeffr.) : il y a donc identité complète entre ce nom et notre sous-genre antérieur Crenilabium. En ce qui concerne Act. exilis, il y a d'ailleurs lieu de remarquer que le nom exilis ne pourrait être conservé, comme faisant double emploi avec Etheridgei, Bell, qui non seulement est antérieur, mais encore qui a été décrit et figuré, tandis que l'autre est un nom de liste, s'appliquant à un individu très usé, comme le constate Wood (Crag. moll.), de sorte qu'il ne pourrait correctement servir de type à une nouvelle coupe générique.

Répart. stratigr.

Senonien....... Une espèce probable à Aix-la-Chapelle (Actæonina lineolala, Reuss), d'après le type communiqué par M. Holzapfel.

Paleocene..... Une espèce à Copenhague (Aclæonina elata, v. Kon.) d'après la figure.

Eocene....... Deux espèces, outre le type, dans le bassin angloparisien (Act. crenalus, elongatus, Sow.) ma coll. 
Actreonidea

Ouıgocene...... Deux espèces certaines, l'une dans l'Allemagne du Nord (C. lenue, v. Kon.) d'après l'auteuir ; l'autre dans l'étage stampien (Act. Bouryi, Cossm. et Lamb.), ma coll.

Mrocene........ Une espèce dans les faluns du Bordelais (Act. Basteroti, Ben.) ma coll.

Pliocene....... Une espèce certaine dans le Crag et en Sicile (Act. Etheridgei, Bell.) coll. du Musée de Dijon.

Epopuracturle. Une espèce vivant dans l'Atlantique (A. Etheridgei $=A$. exilis, Jeffr.) d'après la figure de l'ouvrage de 11. Dautzenberg sur les mollusques des $A$ çores.

ADELAGT EON. nom. mut.

$$
\text { (= Myonia, A. Ad. 1860, non Dana, 1847). }
$$

Adelact eon, sensu stricto. Type: Act. papyraceus, Bast. Mioc.

Forme allongée; embryon sans saillie, à peine dévié, à nucléus hétérostrophe, empâté dans les tours suivants; spire égale ou supérieure au dernier tour, à sutures enfoncées ou canaliculées; surface totalement décussée par des rainures et des stries ou fines lamelles d'accroissement; ouverture courte, ovale, à péristome mince; labre rectiligne, obliquement incliné par rapport à l'axe, vers la gauche du côté antérieur; columelle peu excavée, avec un faible pli postérieur, bord columellaire peu épais, recouvrant imparfaitement la fente ombilicale et se raccordant sans sinuosité au contour supérieur.

Diagnose prise d'après le type fossile de Saucats, Acl.papyraceus, Bast. (pl. 1, fig. 15), ma coll.

Observ. - Ce genre ressemble aux Actzon par l'ensemble de ses caractères, il s'en écarte par son embryon non saillant, paraissant homœostrophe au premier abord, mais dont le nucléus n'est pas apparent, de sorte qu'on en conclut qu'il a subi une déviation telle que la face opposée, où se trouve le nucléus, est adhérente au reste de la spire, comme l'indique le grossissement ci-contre (fig. 35). Dans ces conditions, 
Adelactreon.

comme l'ornementation de la spire a beaucoup d'analogie avec celle des Actron, quoique le pli columellaire soit placé plus bas et le labre incliné dans le sens opposé, comme d'autre part l'embryon se rapproche plus de celui de quelques-uns des membres de la famille Actronidx, que des Pyramidellidæet principalement des Odontostomia, il semble que la question très controversée du classement de ce genre est désormais tranchée. Les formes fossiles que je rapporte à ce genre diffèrent un peu de Myonia concinna, Ad., que je possède d'Australie, par leur pli placé encore plus en arrière, à peine visible, et par leur fente ombilicale: ces caractères distinctifs ne justifieraient pas la séparation d'un sous-genre, ni même d'une section; cependant il doit être entendu que la diagnose qui précède étant faite d'après le plésiotype fọssile, c'est à ce dernier que devra, en tous cas, s'appliquer le nom Adelactæon, de sorte que si l'on en sépare ultérieurement les Myonia vivantes, il y aura lieu de leur donner un autre: nom, attendu que le genre Myonia doit changer de nom pour corriger un

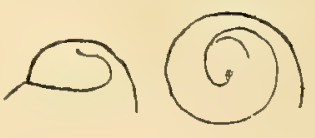

Fig. 35.

Embryon d'Adelactæon. double emploi qui a échappé à Adams; la nouvelle dénomination que je propose rappelle l'incertitude ( $\alpha \delta \eta_{\lambda} \lambda \sigma_{\text {, }}$ douteux) que j'ai éprouvée pour le classement de ce genre dans les Actæonidx.

Répart. stratigr.

Mrocene........ Plusieurs espèces dans les faluns du Bordelais (Act. papyraceus, Bast et scalariformis, Ben.) ma coll.; autre espèce voisine dans l'Allemagne du Nord (Torn. elcita, von Ǩænen) d'après la figure.

Epoque Actuelle. Une espèce type du genre, vivant au Japon, non figurée, d'après les auteurs; autre espèce des mers australiennes, envoyée sous le nom $\boldsymbol{M}$. concinna, Ad. (par M. Tate), ma coll.

LIOCARENUS, Harris et Burrows, 1891.

(=Fortisia, Bayan, 1870, non Rondani, 1861).

Columelle épaisse, faiblement coudée, labre épais, obliquement incliné.

Liocarenus, s. str. Type: Auricula conovuliformis, Desh. Eoc.

Forme ovale et globuleuse; embryon hétérostrophe, dévié en travers, à nucléus empâté dans la spire; spire très courte, co- 
nique, à sutures marginées; ornementation formée de stries spirales obsolètes, plus visibles sur de jeunes individus: ouverture arquée, étroite, peu élargie, arrondie et presque versante en avant; labre très épais intérieurement, taillé en biseau sur le bord, non sinueux, obliquement incliné sur l'axe, vers la gauche du côté antérieur; columelle courte, calleuse, excavée, épaissie au milieu par un renflement qui, sur de jeunes individus, ressemble à un pli rudimentaire, et qui s'oblitère à mesure que la coquille vieillit; bord columellaire vernissé, se raccordant par une courbe régulière au contour antérieur de l'ouverturc qui n'est presque pas sinueux.

\section{Diagnose prise d'après un individu typique de Vaudancourt} (Pl. I, fig. 16-17) ma coll.

Observ. - Se distingue des Actæon par l'épaississement et l'obliquité du labre, par absence d'un véritable pli columellaire, même à tout âge, ainsi qu'il résulte d'une section faite suivant l'axe par M. Berthelin; par son ornementation, enfin par son embryon qui forme un crochet perpendiculaire à l'enroulement, mais qui est peu saillant et dont on n'aperçoit pas le nucléus apical caché par la spire.

Répart. stratigr.

Turonien?..... Un seul fragment dans les grès d'Uchaux, le péristome seul conservé, coll. Chaper.

Eocene........ Deux espèces, l'une type du genre, dans le bassin parisien, l'autre dans le Vicentin (Fort. Hilarionis, Bayan), d'après la figure.

Nucleopsis; Conrad, 1865. Type: N. subvaricatus, Conr. Eoc.

Forme de Liocarenus; embryon hétérostrophe, peu saillant; spire et sutures de Liocarenus; ornementation formée de sillons spiraux dont les intervalles portent des filets peu saillants, surtout sur les individus adultes et près des sutures, tandis que, sur la base, les sillons sont ponctués par les stries d'accroissement; ouverture et columelle de Liocaremus; labre subvariqueux à l'extérieur, ses accroissements successifs produisent, sur la spire 
et sur le dernier tour, des varices obsolètes et peu régulières; bord columellaire très mince en arrière, un peu épaissi en avant, se raccordant au contour supérieur comme dans le genre Liocarenus.

Diagnose prise d'après un individu typique de Claiborne

(PI. I, fig. 18-19) ma coll.

Observ. - Forme très voisine de-Liocarenus, s'en distingue seulement par son ornementation en demi relief, par ses varices peu apparètes, par son renflement columellaire qui est un peu plus saillant à tout âge, enfin par le peu d'épaisseur du bord columellaire. Le nom Nucleopsis a été proposé par Conrad (Catal. Eoc. olig.) en 1860, et cependant dans le "Check list ", p. $9(\mathbf{1 8 6 6})$, il cite la même espèce sous le nom d'Actæon; d'après ce qui précède, on voit que sa première idée était plus exacte, attenđu que $N$. subvaricalus diffère beaucoup des véritables Actæon.

Répart. stratigr.

Eockse........ Une seule espèce type, dans l'Alabama, ma coll.

Bulimact 艮on, Gossm. 1892. Type: Act. Bernayi, Gossm. Eoc.

Forme ovale, étroite; embryon inconnu; spire un peu allongée, à galbe conoïde, à sutures profondes; ornementation formée de stries spirales, irrégulières et obsolètes, assez écartées sur le dernier tour ; ouverture courte, ovale, un peu versante et arrondie du côté antérieur, rétrécie en arrière; labre épaissi à l'intérieur, faiblement sinueux, obliquement incliné sur l'axe, vers la gauche du côté antérieur; columelle assez épaisse, munie d'un renflement médian, qui ressemble à un pli faiblement tordu; bord columellaire étroit, peu calleux, se raccordant avec une légère sinuosité au contour supérieur de l'ouverture.

Diagnose refaite d'après le type de Valmondois (Pl. I, fig. 11-12), coll. Bernay.

Observ. - Se distingue de Liocarenus, par la forme générale de la coquille, par ses sutures non marginées, par son ornementation, par son 
Liocarenus

ouverture plus courte et plus ovale, par son péristome moins épais; mais les autres caractères génériques, obliquité du labre, indice de pli columellaire, ouverture presque versante à la base, sont semblables à ceux du genre Liocarenus et justifient le rapprochement proposé à titre de sousgenre. Se distingue, en outre, de Nucleopsis par sa forme plus allongée, par son ornementation bien différente, par l'absence de varices, par son labre plus sinueux et son ouverture plus versante en avant. Quoique les Bulimactxon aient à peu près la forme des Actæon, ils appartiennent à un groupe tout à fait différent à cause de l'inclinaison du labre.

Répart. stratigT.

Eocene....... Un seul individu type, dans le bassin de Paris. (coll. Bernay).

AGT AONINA, d'Orb. 1847.

(= Orthostoma, Desl. 1842, non Ehrenberg, non Andonius, 1834, non Gonrad, 1838).

Ouverture longue, généralement arrondie et versante en avant; spire étagée en gradins; columelle calleuse, non plissée; labre sinueux en arrière.

Aстеоnina, sensu stricto. Type: A. acuta, d'Orb. Coral.

Grande taille; forme étroite et allongée; embryon ? spire longue, à galbe un peu conoïde, à sutures étagrées par une rampe étroite et carénéc; surface lisse, stries d'aceroissement presque droites, peu visibles; ouverture allongée très étroite, presque linéaire en arrière, médiocrement élargie au milieu, atténuée, quoique entière, à son extrémité antérieure; labre simple aigu, à peine curviligne, presque sans inclinaison ; columelle courte, épaisse, lisse, faisant un angle de 150 degrés à sa jonction avec la base du dernier tour, amincie en avant et infléchie, se terminant en pointe contre le bord supérieur; bord columellaire calleux, largement étalé, se raccordant sans sinuosité, mais avec un angle arrondi, au contour antérieur de l'ouverture. 
Diagnose complétée d'après un individu de l'espèce type, de Valfin (Pl. II, fig. 4) coll. Favre, au Musée de Genève.

Observ. - Se distingue des Actæon par sa columelle non plissée, par sa surface lisse, par sa spire en gradins; des Liocarenus par l'inclinaison et le peu d'épaisseur du labre, par sa columelle moins excavée, dénuée de renflement, par son ouverture plus étroite, surtout en avant. A défaut d'indications de la part de d'Orbigny qui a créé le genre Actæonina dans le Prodrome (I, p. 118), les auteurs donnent généralement comme type A. durmoisiana, d'Orb., qui est synonyme d'A. acuta, d'Orb., de sorte que c'est plutôt ce dernier nom d'espèce qu'il y a lieu de citer comme type du genre. La restauration de l'extrémité antérieure de l'ouverture est manifestement inexacte: on lui attribue généralement une forme arrondie qui est contraire à la réalité, car l'ouverture se rétrécit au point que certains échantillons paraissent subcanaliculés, ou munis d'un bec à l'instar des Ceritella. Il est vrai que l'on ne rencontre que bien rarement des exemplaires complets, l'extrémité antérieure est presque toujours mutilée; mais, en suivant les stries d'accroissement, on peut la reconstituer et s'asșurer qu'elle n'était ni sinueuse, ni échancrée, seulement atténuée par l'inflexion de la columelle vers le côté du labre.

Répart. stratigr.

Bathonien...... Plusieurs espèces, l'une typique en Normandie ( $A$. Deslonchampsi, d'Orb.) coll. Deslonchamps; l'autre dont la rampe s'atténue avec l'âge $(A$. mitræformis, Cossm.) coll. Rigaux, Legay.

Rauracien....... Une espèce type, dans l'Est de la France, très variable dans ses proportions, toutes les coll.

Sbquanien...... Variété de la même espèce, même région (Orthost. Moreana, Buv.) coll. Moreau.

Portlandiex..... Une espèce non encore décrite, dans la Seine-Inférieure, coll. Boutillier.

Striacteonina, nov. sect. Type : Orthost. avena, Terq. Lias.

Forme ovoïdo-cylindrique; spire assez courte, à galbe conique, étagée en gradins par une rampe carénée; au-dessus de la carène est invariablement un profond sillon spiral; surface ornée de stries spirales, quelquefois apparentes sur le milieu du dernier tour et toujours sur sa base; ouverture et labre d'Actæonina; 
columelle arquée, se raccordant par une $S$ régulière avec la base de l'avant-dernier tour; bord columellaire d'Actxonina.

\section{Diagnose prise d'après le type d'Hettange (Pl. I, fig. 22) coll. de} l'École des Mines.

Observ. - Cette section se distingue des Actxonina typiques par sa taille moindre, par ses stries à la base, par son sillon spiral au-dessus de la carène, par sa columelle plus haute, plus régulièrement arquée. Néanmoins, je ne crois pas que les caractères différentiels justifient la séparation d'un genre, ni même d'un sous-genre distinct: le faciès général de ces coquilles est celui d'Actxonina en réduction de grandeur; les autres différences, qui portent sur les caractères secondaires, ont seulement une valeur sectionnelle, suffisamment constante pour qu'on ne puisse jamais confondre, avec les Actronina proprement dites, les Striactæonina qui ont précédé leur apparition dans la série jurassique.

Répart. stratigr.

Hettangien.... Presque exclusivement localisée à la base du lias, ef représentée par de nombreuses espèces (Orth. aveet

Sinemurien...... na, Tq. Buvigneri, Tq. Sinemuriensis, Mart. decorata, Mart.), coll. de l'Ecole des Mines, du Musée

Bathonien ..... Une espèce douteuse (Actæonina sartharcensis, d'Orb. d'après la figure de la Paléontologie française.

Ovacteonina, nov.ect. Type: Act. sparsisulcata, d'Orb. Lias.

Forme ovale, peu ventrue; embryon obliquement coudé et dévié; spire longue, à galbe conoïde, à tours convexes, non carénés, à sutures bordées d'une rampe arrondie; surface très finement striée dans le sens spiral, à sillons plus écartés sur la base du dernier et sur la rampe suturale; ouverture courte, rétrécie en arrière, ovale, atténuée et un peu versante en avant; labre arqué, rétrocurrent près de la suture; columelle assez longue, excavée, infléchie à gauche du côté antérieur ; bord columellaire calleux, détaché de la base, et dont la carène extérieure se prolonge en contournant la sinuositẻ versante du bord supérieur. 
Diagnose prise d'après deux individus typiques de Fontaine Etoupefour (Pl. I, fig. 23-24), coll. Deslongchamps.

Observ. - Cette section se distingue des Actxonina typiques par son ouverture courte, par son labre arqué, par sa columelle plus allongée et plus excavée, enfin par ses stries basales; des Striactronina par ses tours non étagés, dénués de sillon spiral au-dessus de la rampe suturale, par son ouverture plus versante, et par sa forme générale plus ovale. Cependant je ne crois pas qu'on puisse élever cette nouvelle coupe au rang de sous-genre distinct ; les caractères que je viens d'énumérer n'ont, comme ceux des striactæonina, qu'une importance secondaire, aussi je me borne à la proposer comme section démembrée du groupe principal. J'ai observé l'embryon sur un individu type dont le sommet esten excel-

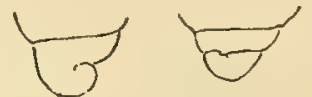

FIG. 36 .

lent état (fig. 36), coll. Deslongchamps: c'est une crosse un peu saillante dont le nucléus est enroulé autour d'un axe à plus de 90 degrés avec celui de la coquille, et est un peu empâté dans la spire.

Répart. stratigr.

Sinemurien..... Une espèce inédite à Drevain, coll. Pellat ; sera décrite dans la Revision de la Paléont. française.

Chamouthien... Plusieurs espèces parmi lesquelles le type, coll. Deslonchamps.

Bajocien....... Une espèce inédite à Nancy, coll. Gaiffe ; sera décrite dans la Revision de la Paléont. française.

Bathonien...... Plusieurs espèces (Act. cequipartila), Cossm; loriereana, d'Orb. coll. Rigaux) Legay.

Oxfordien...... Une espèce probable (Act. Sabaudiana d'Orb.) d'après la figure de la Paléont. franç.

Sequanien...... Une espèce caractéristique (Act. Pilleti, de Lor.) coll. Pellat, Rigaux.

Portlandien.... Une espèce certaine (Ov. hypermeces, Cossm. = Act. exilis, de Lor. non Jeffr.) coll. Pellat, Rigaux.

Neocomen...... Une espèce probable ( 4 ct. dupiniana, d'Orb., d'après la figure de la Paléont.

Barremien..... Une espèce nouvelle des calcaires d'Orgon, 0 . urgonensis, nob. (Pl. VI, fig. 25̈) coll. Boutillier.

Albien........ Une espèce très probable dans le Gault de Cosne (Act. unisulcata, de Lor.), d'après la figure donnée par l'auteur.

Cenomanien.... Deux espèces probables à Blackdown et à Bracquegnies (Phasianella Sowerbyi, d'Orb., et formosa, Sow.) d'après les figures de Briart. 
Turonien....... Deux espèces dans le Crétacé de l'Inde (Act. obesa el et

Senonien...... columnaris, Stol.) indiquées par Stoliczka comme dénuées de plis columellaires.

Cylindrobullina, v. Ammon, 1878.

Type : Actromina fragilis, Dunker, Lias.

Forme ovale; embryon hétérostrophe, obliquement dévié, à nucléus aplati; spire courte, à galbe conique, à sutures étagées par une rampe plus ou moins aplatie; surface lisse, stries d'accroissement curvilignes, peu visibles; ouverture d'Actrenina; labre mince, curviligne, à peine incliné en arrière du côté antérieur, avec une sinuosité rétrocurrente près de la suture, correspondant à la rampe spirale, quand celle-ci existe; columelle peu arquée, calleuse, portant un imperceptible renflement qui s'atténue en avant, dans l'évasement versant de l'ouverture; bord columellaire très mince en arrière, un peu détaché en avant, limité du côté de la base par une carène qui contourne la sinuosité du bord supérieur.

Diagnose refaite d'après un individu typique d'Halberstadt

(Pl. II, fig. 1) coll. de l'Ecole des Mines.

Observ. - Ce sous-genre se distingue des Actronina proprement dites par sa forme généralement moins allongée, par son labre dont le contour est convexe au milieu et sinueux postérieurement, par sa columelle plus faiblement excavée, par son ouverture plus arrondie en avant. Sa surface toujours lisse ne permet pas de le confondre avec les Striaclæonina ni avec les Ovactáonina, malgré l'analogie de leur forme extérieure. Quant à l'embryon, aucun des individus que j'ai examinés ne m'a permis d'en étudier la forme, mais Koken en donne une excellente figure (Entwickelung der Gastrop., p. 400, fig. 19) pour Acheonina scalaris, qu'il rapporte au genre Cylindrobullina, actuellement le plus ancien des Opisthobranchiata.

Répart. stratigr.

Carboniferien... Deux espèces, l'une de Visé, ressemblant à un Conactron, mais plus ovale (Scalites carbonarius, de Kon). coll. Destinez, l'autre de Tournai (Scalites fusiformis, de Kon.) coll. du Musée de Lille. 
Actaeonina

Trnoliex ....... Une espèce à St. Cassian (Act. scalaris, Munst. $=A$. abbreviata et alpina, Klipst.) d'après les figures, embryons grossis par Koken et par Kittl.

Rhetien ....... Une espèce dans la dolomie du Tyrol et les couches bitumineuses d'Angleterre (Act. elongata, Moore), d'après la figure donnée par von Ammon.

Simimumen...... L'espèce type, à la base du Lias (Act. fragilis, Dun ker), coll. de l'Ecole des Mines.

Charmouthien... Deux espèces citées dans les couches de Ratisbonneet de Bayreuth, von Ammon.

Bajocien....... Une espèce inédite, à Nancy, coll. de la Sorbonne; sera décrite dans la Rev. de la Pal. française.

Bathonien...... Plusieurs espèces caractéristiques(Act. scarburgensis, M. L., Beaugrandi, R. S. etc.), coll. Rigaux et Legay.

Oxfondien...... Une espèce de Neuvizi, coll. Péron; sera décrite darıs la Rev. de la Paléont. française.

Ravracier...... Une espèce certaine dans l'Oolite corallienne (Orihost. Humbertina, Buv.) coll. Moreau.

Krmeridgien.... Une espèce douteuse (Orthost. Marioe, Buv. = Act. cincta ou nuda, Cont.) coll. du Musée de Montbéliard.

Pontlandien .... Plusieurs espèces certaines dans le Boulonnais ( $\mathrm{Act}$. cylindracea, Cornuel, et Cyl.portlandica, Cossm. = Act. Buvignieri, de Lor. non Terquem) coll. Pellat, Rigaux, Legay.

Gonacteon, Meek, 1863. Type : Conus cadomensis, Desl. Lias.

Forme conique; embryon? spire de Cylindrobullina, à tours étagés par une rampe limitée par une carène crénelée; surface lisse, seulement plissée par quelques accroissements irréguliers ; ouverture très étroite, à bords parallèles; labre un peu arqué, faiblement échancré sur la rampe suturale; columelle de Cylindrobullina.

Diagnose refaite d'après des échantillons typiques de FontaineEtoupefour (Pl. II, fig. 5๊-6), coll. Deslongchamps.

Observ: - Cette section se distingue surtout par sa forme régulièrement conique et son ouverture très étroite; sa spire est plus étagée que celle 
Actreonina

des Cylindrobullina proprement dites, et la rampe de la suture correspond à une échancrure moins sinneuse du labre; mais, comme presque tous les autres caractères sont voisins, je ne puis l'admettre que comme section du sous-genre Cylinarobullina. D'Orbigny a démontré que les tours des Conactron ne se résorbent pas à l'intérieur comme ceux des Conus. Quant à Conus tuberculatus, Duj. de la Craie de Touraine, indiqué par P. Fischer comme pouvant être rapproché des Conactæon, ne fût-ce qu'à cause de son ornementation, je ne suis pas d'avis d'admettre ce rapprochement.

Répart. stratigr.

Cranmovtuex... Une espèce, type de la section, avec plusieurs variétés, coll. Deslongchamps.

Euconact aon, Meek, 1863. Type: Conus concavus, Desl. Lias.

Forme conique ou extra-conique; embryon à nucléus un peu saillant; spire plane, ou même excavée, à tours embrassants, à sutures peu profondes et bordées par un sillon spiral; dernier tour formant toute la hauteur de la coquille, à surface lisse ou sillomnée dans le sens spiral; ouverture très étroite, ì bords parallèles; labre peu arqué, échancré en arrière; columelle de Cylindrobullina; bord columellaire assez large, non détaché.

Diagnose refaite d'après des individus typiques de Fontaine-

Etoupefour (Pl. II, fig. 7-8) coll. Deslongchamps.

Observ. - Cette section ne se distingue des Conactzon que par la forme de la spire. On se demande si une aussi faible différence mérite la création d'une coupe distincte; cependant je n'ai pas supprimé le nom Euconactron, parce que je n'ai remarqué aucune tendance au passage graduel de l'une de ces formes à l'autre, et qu'il est impossible de les con fondre ensemble, à cause de leur aspect extérieur.

Répart. stratigr.

Srnemuriex..... Une espèce dans l'Est de la France (Orthostama maubertense, Terq.) d'après la figure donnée par l'auteur.

Charmouthien... Trois espèces dans les mêmes gisements de Normandie (Conus concavus, abbreviatus et Caumonti, Desl.) coll. Deslongchamps. 
Goniocylindrites, Meek, 1863.

Type : Cylindrites brevis, Morr. et Lyc. Bath.

Forme courte, subcylindrique; embryon peu saillant; spire plane, à sutures profondes; dernier tour formant toute la hauteur de la coquille, tronqué et caréné à la périphérie du plan de la spire; surface lisse, stries d'accroissement presque verticales, crénelant souvent la carène inférieure, traçant sur les tours de spire un crochet antécurrent; ouverture étroite en arrière, ovale et arrondie en avant; labre mince à peine curviligne, échancré entre la carène et la suture; columelle peu arquée, sans aucune apparence de pli, ni de renflement; bord columellaire peu calleux en arrière, se détachant en avant et découvrant une petite fente ombilicale, puis se raccordant, par une courbe régulière, avec le contour supérieur de l'ouverture.

\section{Diagnose prise sur un individu typique du Boulonnais}

(Pl. II, fig. 2-3), coll. Rigaux.

Observ. - C'est à tort que les Goniocylindrites ont été rapprochés des Cylindrites: l'absence de pli columellaire, la forme de l'extrémité antérieure de leur ouverture, l'inclinaison de leur labre ne permettent pas de les classer dans le même groupe d'Actæonidæ; ils se distinguent des Actæonina, non seulement par leur forme tronquée, mais encore par leur ouverture plus arrondie en avant, par leur fente ombilicale et par leur labre antécurrent près de la suture; des Cylindrobullina, par leur columelle dénuée de renflement, par leur fente ombilicale, par leur labre plus rectiligne au milieu, antécurrent près de la suture; des Euconactæon par les mêmes caractères et, en outre, par leur forme beaucoup moins conique, par l'absence de sillon spiral près de la suture; des Trochactæonina, qui ont presque la mème forme, par leur columelle sans pli et par leur spire plane, sans-saillie. Dans ces conditions, il paraît légitime d'admettre Goniocylindrites comme sous-genre d'Actzonina.

Répart. stratigr.

Bathoniex..... Une espèce type du sous-genre, en France et en Angleterre; coll. Rigaux et Legay.

Rauracien ..... Une espéce bien caractérisée, dans la Meuse (Orihost. conulus, Buv.), coll. Moreau. 


\section{Aetreonina}

Kimeridgiey .... Une espèce certaine dans le Boulonnais (Act. Morini, de Lor.), coll. Pellat.

Pontlandien.... Une espèce de la Meuse décrite comme Bulla truncatula, Buv., d'après la figure.

Trochact eonina, Meek, 1863. Type: A. ventricosa, d'Orb. Kim.

Forme ventrue, ovoïdo-conique; embryon? spire très courte, à galbe extra-conique, à sutures bordées d'une rampe un peu excavée; dernier tour lisse, formant presque toute la coquille, élargi et arrondi en arrière, alténué à la base; ouverture peu étroite du côté postérieur, peu dilatée, arrondie et versante en avant; labre presque vertical, non sinueux en arrière, se raccordant à peu près normalement à l'avant-dernier tour ; columelle à peine excavée, munie, plus haut que le milieu, d'un renflement pliciforme dont le prolongement se confond avec la limite extérieure du bord columellaire et se joint ensuite au contour du bord supérieur.

Diagnose prise d'après un plésiotype du Corallien de Cordebugles, Tr. Bigoti, nob. (Pl. VI, fig. 17) coll. Boutillier.

Observ. - Le type de ce sous-genre est une coquille du Kiméridgien, que d'Orbigny ne connaissait qu'à l'état de moule et qu'il n'a figurée que du côté du dos; c'est une témérité, de la part de Meek, d'avoir altribué un nom générique à un tel modèle; cependant cet auteur a été merveilleusement guidé par son instinct, car avec de meilleurs matériaux j'arrive à la conclusion que cette coupe Trochactronina est nécessaire et doit être conservée. Outre $A c t$. ventricosa, dont je connais un seul échantillon en médiocre état, provenant du Boulonnais (coll. Pellat) et assimilé au type par M. de Loriol, j'ai étudié de petits individus du Corallien de Normandie, que je n'hésite pas à considérer comme des plésiotypes certains de ce sous-genre; ils en ont exactement le galbe, mais leur ouverture, anssi intacte que celle d'une coquille tertiaire, porte un pli qui s'atténue peut-être avec l'âge, et qui a beaucoup d'analogie avec celui des Donvilleia, quoiqu'il soit placé plus en avant; le labre peu incliné n'est pas plus sinueux que celui des Douvilleia, le bord columellaire est également bien caréné, de sorte qu'à part la disposition de la spire un peu différente, on peut admettre que les Trochactæonina sont les ancêtres des 
Douvilleia, ce qui les écarte sensiblement des Actronina et des Cylindrobullina, dont on les rapprochait jusqu'à présent.

Répart. stratigr.

Bathonien..... Une espèce de grande taille, dans l'Aisne (Cassis esparcyensis, d'Arch.), coll. Piette, et une petite coquille de la Sarthe, rapportée à tort au Bajocien (Act. Davoustana, d'Orb.), d'après la figure de la Paléont: française.

Rauracien ..... Plusieurs espèces inédites de petite taille (Trochactæonina Bigoti), etc., seront décrites dans la Revis. de la Paléont. française.

Sequaxien ..... Une espèce à peu près certaine, dans la Meuse (Tornat. virdunensis, Buv.) d'après la figure donnée par l'auteur.

Kimeridgien..... Une espèce type, de grande taille, dans l'argile de Villerville, d'après la Paléont. française.

Portlandien.... La même espèce, ou assimilée, quoique à un niveau plus élevé, dans le Boulonnais, coll. Pellat.

Douvilleia, Bayle, 1883. Type: Buccin. arenarium, Mell. Eoc.

Forme ovale; embryon hétérostrophe, à nucléus très saillant et fortement tordu; spire de Cylindrobullina, assez courte; surface lisse, à stries d'accroissement presque droites, souvent saillantes et presque costulées vers la carène inférieure des jeunes individus; ouverture de Cylindrobullina, versante du côté antérieur; labre mince, à peu près vertical, à peine sinueux sur la rampe suturale; columelle épaisse, peu arquée, portant, quand la coquille est jeune, un pli transverse et saillant, qui s'oblitère à mesure que vieillit la coquille et se transforme enfin en un renflement obsolète, bord columellaire de Goniocylindrites, recouvrant imparfaitement la fente ombilicale dans les jeunes individus, la base porte autour de cette fente un bourrelet rudimentaire qui n'est limilé par aucun sillon. 
Diagnose refaite d'après des individus typiques de Jonchery: l'un jeune, montrant le pli columellaire (PI. III, fig. 1), ma coll.; l'autre adulte, avec la columelle seulement renflée (Pl. II, fig. 10), coll. Bourdot.

Observ. - Ce sous-genre se distingue des Actronina par sa forme et par sa columelle; des Cylindrobullina par son pli columellaire mieux indiqué, par son labre dont le contour n'est pas arrondi au milieu, ni échancré au-dessus de la suture; des Goniocylindriles par les mêmes caractères, et en outre par sa spire non tronquée, par sa columelle plus excavée; des Trochactioonina par la forme générale et par la fente ombilicale de la base, surtout sur les jeunes individus. On voit, d'après ce qui précède, que la séparation de ce sous-genre est justifiée; cependant, si l'on constatait que la columelle des Trochactronina'subit, selon l'âge des individus, les mêmes transformations que celle des Douvilleia, il est évident que les seules différences de forme extérieure ne mériteraient pas qu'on plaçât ces deux coupes sur le même rang, et, dans ces conditions, Douvilleia ne devrait être alors qu'une simple section de Trochactaonina.

Répart. stratigr.

Palmocene..... Une seule espèce à la base du Tertiaire parisien.

Globiconcha, d'Orb., 1842. Type: G. rotundata, d'Orb, Cénom.

Forme presque sphérique; embryon? spire courte, ou même involvée? sutures subcanaliculées; demier tour embrassant, à surface lisse; ouverture arquée, étroite en arrière, peu dilatée, arrondie et versante en avant; columelle lisse, très courte, à bord mince se prolongeant par une carène qui circonscrit l'évasement de l'ouverture.

Diagnose prise d'après l'espèce typique (PI. II, fig. 9) coll. de l'Ecole des Mines.

Observ. - Ce sous-genre se distingue de ceux du même groupe par sa forme plus arrondie et par son ouverture arquée; la columelle paraît dénuée de pli ou de renflement, autant qu'on peut en juger dans l'état de conservation des individus étudiés jusqu"à présent. Stoliczka propose d'éliminer cette coupe, par le motif que d'Orbigny y a classé les formes les plus hétérogènes; comme le type (G. rotundata) est une coquille qu'il est 
impossible de rapporter à aucun autre sous-genre d'Actæonidæ, je ne vois pas de raison pour ne pas admettre Globiconcha.

Répart. stratigr.

Cenomaxiex ..... Une espèce type dans l'Ouest de la France.

Senonikx....... Une espèce très incertaine, à spire involvée (G. marrotiana, d'Orb.) d'après la figure de la Paléont. française; mais M. Arnaud (in litt.) pense que c'est un Strombus dont le canal a disparu et qui est fréquent dans la Craie des Charentes.

Blancia, Bourg. 1875. Type: B. maceana, Bourg. Tur.

Forme ovoïdo-conique; spire involvée; dernier tour acuminé en arrière, ovale et arrondi à la base; surface à peu près lisse, striée par les accroissements ; ouverture étroite, à bords presque parallèles, faiblement dilatée et un peu versante à la base ; labre mince, à peu près droit, si l'on en juge par les stries d'accroissement; columelle lisse, très courte, excavée; bord columellaire calleux, peu étalé, se prolongeant à la base par une carène qui se raccorde au contour supérieur.

Diagnose refaite d'après les figures du t. V. des Mém. de la Soc. des Sc: nat. de Cannes, 1875 ; reproduction de ces figures (Pl. VII, fig. 7-8) d'après un dessin fourni par M. de Loriol.

Observ. - Ce sous-genre a tout à fait la forme générale d'une Actæonella; mais l'auteur affirmant qu'il n'y a pas de trace de plis à la columelle, à moins de supposer qu'il ait fait une restauration complètement inexacte de l'ouverture, je suis obligé de rapprocher Blancia de Globiconcha, malgré la difiérence apparente de la forme générale de la coquille, et en me fondant surtout sur la ressemblance de la partie antérieure de l'ouverture. Quant au labre que la figure indique comme incurvé en spirale rétrocurrente, du côté postérieur, cette disposition est évidemment due à une mutilation de l'ouverture; les stries que portent les fragments de test, encore adhérents au dernier tour, indiquent au contraire un labre presque vertical, comme celui des Globiconcha.

Répart. stratigr.

Turonien..... Une espèce, dans la Craie chloritée de Vence. 
CYLINDPITES, Morr. et Lyc. 1848.

(=Cylindrites, J. Sow. 1824, non d'Argenv. 1757).

Coquille subcylindrique, columelle infléchie en avant; bord columellaire calleux, avec un et quelquefois deux plis médians. Cylindrites, sensu stricto. Type Actron acutus, Sow. Bath.

Forme ovale, subcylindrique, allongée; embryon? spire très courte, tantôt saillante, à galbe extra-conique et à sutures étagées par une rampe étroite, tantôt excavée avec un bouton mammillé au sommet; dernier tour embrassant, très grand, formant quelquefois toute la coquille, à surface lisse, à stries d'accroissement obliques et sinueuses en arrière; ouverture très étroite, presciue linéaire, à peine un peu plus large en avant, paraissant canaliculée quand elle est incomplète, mais néanmoins entière, arrondie et un peu versante à la base; labre très mince, très obliquement incliné sur l'axe, à droite du côté antérieur, à contour curviligne, échancré vers la suture par une sinuosité rétrocurrente qui correspond à la rampe spirale; bande columellaire calleuse, s'enroulant à la moitié ou au tiers supérieur de l'ouverture, portant à tout âge un pli médian, peu saillant, souvent obsolète, dont le prolongement se joint au contour caréné de cette bande columellaire; columelle obliquement coudée en avant, terminée en pointe amincie à sa jonction avec le bord antérieur, dont le contour légèrement sinueux est circonscrit par l'extrémité de l'arête limitant le bord columellaire.

Diagnose refaite d'après un individu typique (Pl. II, fig. 17) coll. Legay, el pour l'ouverture, d'après un individu complet de $C$. cylindricus (PI. II, fig. 15-16) coll. Rigaux.

Observ. - Ce genre se distingue des Actronina par sa bande columellaire munie d'un pli médian, par le contour échancré de son ouverture, 
par son labre oblique et sinueux près de la suture, enfin par sa columelle infléchie dans une direction opposée. Je n'ai pas cru devoir diviser les Cylindrites proprement dits en deux groupes, selon que la spire est saillante ou excavée, parce que l'on observe tous les passages d'une forme à l'autre. En ce qui concerne İa dénomination Cylindrites, elle a été mentionnée dès 1824, par Sow. (Min. Conch., pl. 4อ̆ŏ, fig. 1), mais il n’a pas cru devoir l'adopter ; enfin le nom de d'Argenville, emprunté à Luidius, doit être rejeté comme antérieur à la nomenclature linnéenne.

Répart. stratigr.

Charmouthiex... Une espèce douteuse, en Angleterre (C. Wilsoni, nob. $=C$. xqualis, Wilson, non Terq.) d'après la figure donnée par Wilson.

Bajocien....... Plusieurs espèces en Angleterre ( $C$. mamillaris, tabulatus, turriculatus, Lye.), d'après les figures.

Bathoniex...... Nombreuses espèces (C. acutus et cuspidatus, Sow. allus, Morr et Lye. gradatus et conopsis, Cossm. æqualis, Terq., etc.) coll. Legay, higaux, del'Eccole des Mines, ma coll., etc...

Rauracien ..... Une espèce douteuse à Valfin (C. Elalloni, de Lor.); une autre certaine dans le Jura bernois ( $C$. mitis, de Lor.) d'après les figures des Mém. de la Soc. paléont. Suisse.

VoLVOcylindRITES, nov. sect.

Type: Volvula marcousana, Guir. et Ogér. Séq.

Forme cylindrique, étroite; spire complètement involvée, dernier tour formant toute la coquille; surface lisse, stries d'accroissement peu visibles, droites; ouverture de Cylindrites; labre mince, à peu près vertical ; columelle très courte; bande columellaire et pli de Cylindrites.

Diagnose faite d'après un individu typique de Valfin (Pl. II, fig. 18-19) coll. du Musée de Genève.

Observ. - Cette section se distingue des Cylindrites proprement dits par sa spire involvée, par son labre rectiligne et vertical: ces caractères ne justifieraient pas la création d'un sous-genre. Il ne paraît pas admissible de rattacher cette forme aux Volvulella tertiaires, qui ont aussi leur 
Cylindrites

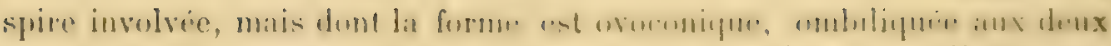
extrémités, qui ont la surface striéc, la columelle mince, non plisséc, cle.

Répart. stratigr.

Seqvaxiex...... Une seule espece, type de la section, dans la plupart et

Kisundogux....

Nécomis..... des gisements de l'list de la lirance et de la Suisse; tris repandue dans les collections.

Une espece paraissant dinuée des plis columellaires des Acticonella, mais encore peu certaine, les types ayant l'ouverture incompletement dégagée (Yolvula dactylus, l’ict. cl Camp.) coll. du Muséo de Genève.

Ptychocilixdmites, nov. subgen.

Type: Bulla Condati, Guir. et Ogér. Iím.

Forme de Cylindrites; embryon? spire excavéc, avec un bou-

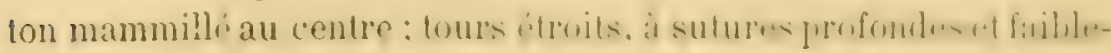

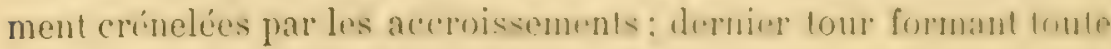
la hauteur, à surface lisser, à stries d'arecroiscenurnt droites, mon

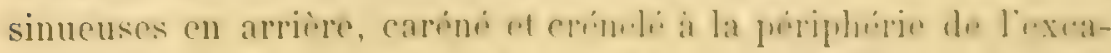
vation de la spire; onverture itroite. a burds parallides a columelle

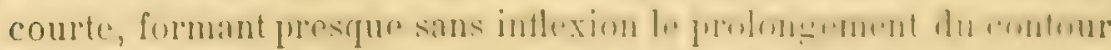

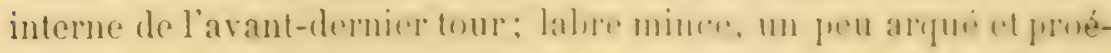

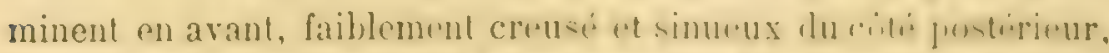
aboulissant normalement a la suture: furd columellitim mince,

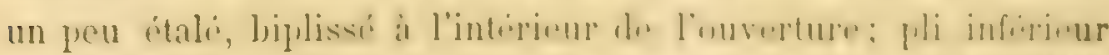

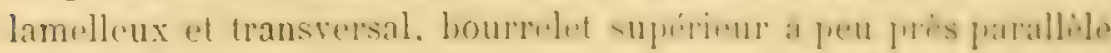
à ce pli et contournant l'échancrure antérieure de l'ouverture.

Diagnose faite d'après des individus typiques d'Oyomax (']. III, fig. A-5)

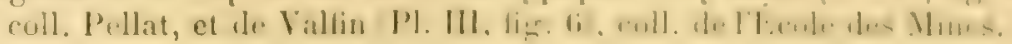

Observ. - Ce sous-genre se distingue des Cylindrites par sa columelle biplissée (quoique la lamelle inférieure ne soit pas visible lorsfiue l'ou. verture est intacte), par ses stries d'accroissement moins arquées, excavées méme en arrière, dénuées de sinuosité rétrocurrente au-delin des crénelures orthogonales qu'elles produisent sur la carìne inférieure. II ctablit 
une transition entre les Cylindrites et les Actronella, mais il se rapproche plus des premiers que de celles-ci, qui ont l'ouverture beaucoup plus versante, le bord columellaire plus calleux, triplissé. Rien de commun d'ailleurs avec les Bullidi.

Répart. stratigT.

Kineridgien..... Une seule espèce, type du sous-genre, dans l'Est de la France et en Suisse, la plupart des collections.

AC'Æ※NELLA, d'Orb. 1842.

Ouverture versante, labré échancrée en arrière, columelle à trois plis.

Actaonella, sensu stricto. Type: Actæonella lævis, d'Orb. Tur.

$$
\text { (=Voloulina, Stol. } 1868=\text { Proteobulla, de Greg. 1882) }
$$

Forme ovoconique, ou subcylindrique, plus étroite en arrière qu'en avant; spire complètement involvée; dernier tour formant toute la coquille, lisse ; ouverture à bords parallèles, à peine dilatée et étroitement échancrée par une sinuosité versante du côté antérieur; labre mince, presque droit sur toute sa longueur, un peu renversé à gauche de l'axe vers le contour supérieur; columelle courte, peu arquée, munie de trois plis presque horizontaux, décroissant d'arrière en avant; bord columellaire se prolongeant autour de l'échancrure sinueuse du contour supérieur de l'ouverture, par un bourrelet peu saillant.

Diagnose refaite d'après un individu typique d'Uchaux (PI. II, fig. 14) coll. du Musée de Dijon; autre individu de la Craie des Charentes (Pl. II, fig. 13) coll. Arnaud.

Observ. - D'Orbigny n'a pas indiqué quelle espèce il prenait pour type de ce genre, mais Meek a désigné, en 1863, A. lavis comme type et a proposé pour la première espèce décrite par d'Orbigny, qui a la spire saillante, le nom Trochaction malheureusement trop voisin de Trochac- 
tronina. Plus tard, en 1868, Stoliczka (Sitz. Acad. Wien, LII), ignorant cette désignation, a proposé Voloulina pour A. lavis; mais il a retiré, en 1868 (Pal. cret. Ind.), cette dénomination qui eût été bien préférable. Les lois de la priorité nous obligent à suivre cet exemple, tout en regrettant qu'il faille en revenir aux noms de Mleek. Toutefois le type de ce genre est la coquille d'Uchaux, dénommée $A$. lievis, par d'Orbigny, et non celle de Gosau, que Zekelia identifiée à tort avec l'espèce française, exemple qui paraîl avoir été imité par tous les auteurs qui ont suivi ; or la coquille de Gosau est tout à fait différente de la nôtre : quoique l'une et l'autre soient assez variables dans leurs proportions, on ne peut admettre que ce soit la même espèce; aussi je propose pour celle de Gosau un nom nouveau A. terebellum, nob. (Pl. II, fig. 20) coll. du Musée de Dijon. - Voir l'annexe.

Quant au genre Froteobulla (P. prima, de Greg. Foss. de Pachino) il a été proposé pour un simple moule interne de Volvulina: la figure donnée par l'auteur est identique aux moules d'A. Tavis de la Craie des Charentes que j'ai sous les yeux; ce nom doit donc être rayé de la nomenclature.

Répart. stratigr.

Tunonien..... Plusieurs espèces, soit à Uchamx (A. levis, d'Orb.), soit à Gosau (A. lerebellum, nob.); ma coll., coll. Arnaud, etc...

Senoniex ...... Plusieurs espèces différentes du type, dans la Craie des Charentes ( $A$. crassa, d'Orb.; 1 . involula, Coq.) coll. Arnaud.

Trochacteon, Meek, 1863. Type : Act.renauxiana, d'Orb. Tur. (= Spiraction, Meek, 1863).

Forme ovale, plus ou moins allongée: embryon? Spire à tours nombreux, étroits, embrassants, à galbe généralement exiraconique; sutures peu profondes, boidées par une étroite rampe spirale; dernier tour bien plus grand que la spire, lisse, coniquement atténué du côté antérieur, labre, mince, généralement mutilé, dont le contour, indiqué par les stries d'accroissement, est faiblement arqué au milieu, très échancré en arrière vers la rampe suturale; columelle courte, peu arquée, s'implantant presque sans intlexion sur la base du dernier tour; bord columellaire mince et étalé en arrière, épais et calleux en avant, traversé transversalement par une bande qui porte trois gros plis enroulés presque 
horizontalement, décroissant d'arrière en avant; le pli inférieur, d'abord distinct du contour caréné de la bande, se confond ensuite avec elle, contoúrne l'évasement très ouvert dv bord supérieur.

Diagnose complétée d'après les figures de Zekeli, et d'après une espèce nouvelle de la Craie des Charentes, Aclæonella Arnaudi, Cossm. (PI. III, fig. 2-3) coll. Arnaud. - Voir l'annexe.

Observ. - Ayant admis, d'après l'interprétation de Meek, que le type du genre Actæonella est $A$. lavis, c'est-à-dire une coquille à spire complètement involvée, il est légitime d'en séparer, comme sous-genre distinct, les formes à spire apparente, qui ont d'ailleurs l'ouverture plus largement évasée en avant, et le labre profondément échancré près de la suture: les autres caractères sont presque identiques. Quant à la section Spiractæon, proposée par Mcek pour les formes à spire plus allongée et plus conique que celle d'A. renauxiana, elle ne me paraît pas utile à conserver : il y a, particulièrement dans le gisement de Gosau, une série d'espèces qui relient graduellement $A$. renawxiana (type de Trochactæon) à $A$. conica (type de Spiraclæon) et qui ont I'ouverture identique; ce serait donc excessif d'attribuer à ce seul caractère de l'allongement de la spire, suffisant pour distinguer les espèces entre elles, la valeur même d'une section.

\section{Répart. stratigr.}

Barremien...... Une espèce nouvelle et bien caractérisée à Orgon (A. Boutillieri, nob. Pl. VI, f. 18-19) coll. Boutillier. - Voir l'annexe.

Cenomaniex..... Une espèce dans la meule de Bracquegnies ( $A$. belgica, nob. $=A$. conica, Br. et Corn. non Zekeli) changée de nom pour double emploi; coll. Bourdot et du Musée de Lille.

Tunonien ....... Outre le type d'Uchaux, ma coll., nombreuses espèces dans le gisement de Gosau (A. conica, voluta, elliptica, Zekeli, etc...), d'après les figures données par l'auteur.

Senonien....... Plusieurs espèces, soit au Beausset (A. gigantea), coll. Michalet, soit dans les Charentes (A. Arnaudi, Cossm.) coll. Arnaud, soit à Gosau (A. obtusa), d'après les figures de Zekeli. 
? Gylindritella, White, 1887. Type: G. truncata, White. Crét.

Forme subcylindrique;'spire courte, à tours embrassanls, peu convexes, à sutures peu visibles; dernier tour formant la plus grande partie de la hauteur de la coquille, probablement lisse; ouverture d'Actxonella; labre à contour inconnu; columelle arquée vers la gauche en avant et munie d'une série de trois ou quatre plis anguleux, décroissant d'avant en arrière, le premier en haut plus ohlique, formant presque un canal avec le bord opposé, le dernier en bas presque transversal; bord columellaire épais et même calleux en arrière, à sa jonction avec la suture du dernier tour, se terminant en avant?

Diagnose d'après White (Contr. pal. Brazil); reproduction de la figure (Pl. VII, fig. 16).

Observ. - Cette section douteuse se distingue des tclxonella à spire saillante (Trochaction) par sa forme presque cylindrique et par ses plis non parallèles, décroissants; des Cylindriles par ses plis columellaires. II est très difficile de se faire une opinion certaine sur la légitimité de cette séparation, qui a été faite d'après des moules internes ou des contreempreintes; la disposition toute particulière des plis columellaires aurait une importance sullisante pour justifier la création d'une nouvelle section, si toutefois White n'a pas dénommé comme quatrième pli l'empreinte de la torsion antérieure de la columelle, ce qui arrive par exemple avec les moules internes de Cylindrites auxquels on pourrait être tenté d'attribuer deux plis, lorsqu'il n'y en a réellement qu'un seul au milieu de la bande columellaire; s'il en était ainsi, il n'y aurait plus de motif pour séparer les Cylindritella des Trochactieon, dont quelques-uns ont une forme étroite, à spire courte (Ex. Acl. belyica, Cossm.) qui est très voisine de celle de la plupart des espèces classées par White dans son nouveau genre. La décroissance des plis, leur obliquité, observées sur des empreintes, peuvent être mises en doute, c'est seulement la certitude de leur nombre qui pourrait faire trancher la question: or White indique lui-même que la columelle porte trois ou quatre plis, ce qui me porte à croire que le quatrième est très hypothétique. 
Senonien....... Plusieurs espèces au niveau de Rio Pabas, province de Para (Brésil), d'après les figures de l'ouvrage de Ch. White.

TUBIFERID $\mathrm{E}$, nov. fam.

Coquille turriculée, lisse ou ornée de plis ou de costules d'accroissement presque droites, obliques, avec une sinuosité rétrocurrente près de la suture; embryon dévié, hétérostrophe; spire plus ou moins allongée, à tours embrassants, généralement étagés; labre un peu incliné à droite de l'axe du côté antérieur, entaillé en arrière; ouverture courte, subcanaliculée en avant, quoique non échancré; columelle droite, sans plis, faisant un angle à son point d'implantation sur la base de l'avant-dernier tour.

Observ. - Bien que le rapprochement de cette nouvelle famille avec les Actronidæ paraissent, au premier abord, un bouleversement inattendu, je ferai remarquer qu'il était déjà prévu par les auteurs qui ont créé les genres que je propose de placer dans les Tubiferidre, car ces auteurs s'accordent à leur attribuer l'aspect actéoniforme, et même plusieurs espèces ont été décrites comme Actronina ou Orthostoma, notamment par Buvignier et de Loriol. Les caractères qui justifient, en définitive ce rapprochement naturel, sont les suivants :

$1^{\circ}$ Forme de l'embryon qui, ainsi que j'ai pu l'étudier avec un fort grossissement sur une espèce du corallien (Ceritella carinella, Buv. Orthostoma), forme une petite crosse déviée ayant bien la disposition des nucléus hétérostrophes;

$2^{\circ}$ Direction des stries ou des côtes d'accroissement qui, tout en étant moins curvilignes que celles des Cylindrobullina, sont obliques et échancrées à la suture comme celles des Cylindrites;

$3^{\circ}$ Enroulement des tours qui sont embrassants, de sorte que, comme cela a lieu dans tous les Actzonidx, l'ouverture est rétrécie en arrière par le contact presque tangentiel du plan du labre avec la convexité de l'avant-dernier tour.

A côté de ces rapports, il y a lieu cependant de faire ressortir les différences qui motivent la création d'une famille distincte des Actronidx:

$\mathbf{1}^{\circ}$ La forme de la columelle, qui est droite, ni plissée, ni tordue, paraissant implantée comme une arête verticale sur la convexité de la base; 
2. L'existence d'un canal plus ou moins obturé qui termine l'ouverture, de sorte que le contour supérieur comporte une sorte de bec, ou au moins un angle dont on ne trotive guère l'indice que dans les Actroniclea;

$3^{\circ}$ La longueur de la spire qui, dans les Tubiferidie, est bien supérieure à celle des Actronicle les plus allongés, et qui même est parfois turriculée comme celle des Cerithidie.

J'ai choisi pour cette famille un nom qui rappelle celui de l'un des genres tombant en synonymie de Cerilella, c'est-a-dire du grenre typique : d'abord, il ent été peu rationnel d'admettre une famille Ceritellidxe dans Ies Opisthobranchiata, il est déjà regreltable que la dénomination Ceritella doive y rester égarée, de par les lois de la priorité; ensuite, c'est un dédommagement à l'adresse de M. Piette, dont le genre Tubifer était bien plus correctement et plus heureusement formé que celui de Morris et Lycett, quoique plus récent.

Cette famille ne comprenant, jusqu'à présent, que le genre Ceritella et sa section Fibula, il ne paraît pas nécessaire d'en faire l'objet d'un tableau, comme je l'ai fait pour d'autres familles plus nombreuses.

CERITELLA, Morr. et Lyc. 1850.

(=Tubifer, Piette, 1856 et 1857, non Lamk. Pol. 1816).

Ceritella, sensu stricto. Type: C. acula, Mor. et Lyc. Bath.

Forme en général turriculée, rarement courte; embryon saillant, dévié, hétérostrophe; spire égale ou supérieure au dernier tour, à sutures étagées; dernier tour court, embrassanı, à base ovale; surface presque toujours striée ou costulée par les accroissements; ouverture peu allongée, subcanaliculée en avant, rétrécie en arrière; labre oblique, échancré près de la suture; columelle droite, faisant un angle de 135 à $150^{\circ}$ avec la base de l'avantdernier tour, et un angle d'environ $90^{\circ}$ avec le contour supérieur.

Diagnose complétée d'après une espèce voisine du type, $C$. Sowerbyi, Morr. et Lyc., du Boulonnais, coll. Legay; reproduction du type, d'après la figure de Morr. et Lyc. (PI. VII, fig. 10); autre espèce costulée, C. conica, M. et L. (P'l. VI, fig. 4-ã) de Ilidrequent, coll. Legay.

Observ. - En admettant même que le type du genre Tubifer ne soit pas 
Ceritella

identique à celuidu genre Ceritella, le nom proposé par M. Piette n'aurait pu être conservé, comme faisant double emploi avec une dénomination de Lamarck.

Observ. - Ainsi que je l'ai fait remarquer à propos du classement de la famille Tubiferidæ, la forme de l'embryon supprime toute hésitation sur le rapprochement à faire entre les Ceritella et les Actæonidx; j'ai pu observer cet embryon sur un individu bien conservé de $C$. carinella, Buv. (fig. 37).

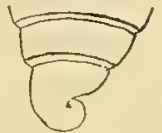

FIG. 37

Répart. stratigr.

Sinemurien..... Une espèce douteuse à Semur (Orthostoma exile, Mart.) d'après un fragment du Musée de Dijon.

Bajociex....... Une espèce en Angletérre (C. Lindonensis, Hudl.), d'après Hudleston et Wilson.

Batroniex...... Nombreuses espèces, outre le type dans le Boulonnais, dans l'Aisne, en Angleterre Cerithium Petri, d'Arch. Actronina Francqana, d'Orb.) ma coll. C. conica et Sowerbyi, M. et L.) coll. Legay et Rigaux.

Rauracien.... . Nombreuses espèces dans l'Est et l'Ouest de la France (Actronina pupoides, d'Orb.) coll. du Musée de la Rochelle; (Orthostoma rissuides, Buv.) coll. Horeau; (Actronina plicata, Zitt. et Goub.) coll. Boutillier.

Szquanien....... Plusieurs espèces dans l'Est ou le Boulonnais Orthostoma virdunense, Buv.) d'après la figure.

Kmeridgren.... Une espèce dans le Boulonnais (Actronina Micheiati, de Lor.) d'après la figure. Plusieur's espèces à Valfin, colı. du Nuséum de Lyon.

Portlandren.... Plusieurs espèces dans le Boulonnais (Actxonina dolium, de Lor.) coll. Legay (Cerithium Lorleti, de Lor.) coll. Pellat.

Fibula, Piette, 1857. Type : F. undulosa, Piette, Bath.

Forme turriculée; embryon dévié; spire longue, conique, à sutures bordées d'une rampe très étroite; dernier tour; embrassant, à base très convexe; surface ornée de plis ou de stries d'accroissement obliques, avec une sinuosité échancrée et rétrocurrente sur la rampe suturale; ouverture très courte, large, subcanaliculée en avant et en arrière; labre dilaté, dont le contour supérieur, développé en arc de cercle, fait un angle de 60 à $90^{\circ}$ arec le bord opposé; columelle droite, sans inflexion, faisant un 
angle de 110 à $140^{\circ}$ avec la base de l'avant-dernier tour, se terminant en pointe légirement recourbée contre l'angle du contour supérieur, mais le bec ainsi formé se ferme et s'oblitère à mesure que la coquille vieillit; bord columellaire calleux, détaché, recouvrant imparfaitement la fente ombilicale.

Diagnose prise d'après la description et la figure de l'espèce type, reproduite (Pl. VII, f. 12) sur un calque de la figure donnée dans le Bull. de la Soc. géol. de France.

Observ. - J'ai autrefois considéré Fibula comme synonyme de Ceritella (Contrib. gastr. Bath., 188\%, p. 108), en me fondant sur ce que le principal caractère cité par Piette, celui de l'obturation du canal, peut varier d'un individu à l'autre, selon l'âge. $A$ près un nouvel examen de la question, je crois cependant que l'on peut admettre Fibula, sinon comme un genre tout à fait distinct, ainsi que l'a fait M. Hudleston dans son mémoire sur les Gastropodes de l'oolithe inférieur, du moins comme une section de Ceritella, où l'on classerait les formes turriculées qui n'ont guère l'aspect des Actxomina: dans ces conditions, les. Fibula se distingueraient par leur base plus arrondie, étroitement perforée, par leur bord columellaire plus détaché, par leur canal plus ou moins fermé, enfin par l'angle moins ouvert que fait leur columelle avec la base de l'avant-dernier tour.

Répart. stratigr.

BajocıEx....... Deux espèces, dont l'une au moins est certaine, en Angleterre ( $F$. angustivoluta, Ifudl.) d'après la figure de Palæontograph. Society.

Bathoniex ..... Plusieurs espèces, outre le type, dans l'Lisne ( $F$. nudi. formis, Piette) et en Angleterre (Cer. phasianoides, Morr et Lyc.), d'après les figures.

\section{TORNA'TINII)}

Goquille cylindrique ou fusiforme, à spire saillante et courte, rétuse ou concave, ou même involvée; ouverlure très étroite, arrondie et versante ou sinueuse à la base; columelle souvent plissée; labre très échancré à la suture. 
Tableau des genres, sous-genres et sections

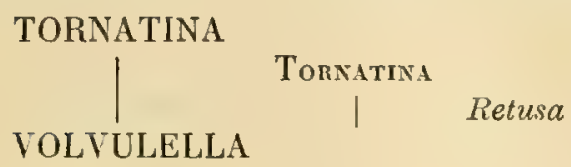

TORNATINA, A. Adams, 1850.

Forme cylindrique, spire non involvée, labre échancré. Tornatina, sensu stricto. Type: T. voluta, Quoy et G. Viv.

Forme cylindrique, un peu ovale; embryon hétérostrophe, formant une pointe mucronée; spire très courte, plus ou moins étagée, à sutures fortement canaliculées; surface lisse ou très finement sillonnée dans le sens spiral; ouverture très étroite en arrière, parfois contractée au milieu par le labre, versante et obliquement tronquée à la base; labre arqué au milieu, rétrocurrent vers la suture, sur le canal de laquelle il est profondément échancré; bord columellaire calleux, portant un fort pli spiral qui contourne la sinuosité versante du bord supérieur.

Diagnose prise d'après un plésiotype fossile T. lajonkaireana, Bast., de Saint-Avit.(Pl. III, fig. 26-27) ma coll.

Répart. stratigr.

Rauraciex...... Une espèce inédite, à Glos, coll. Boutillier; sera décrite dans la Rev. de la Pal. française.

Portlandex.... Une espèce typique dans le Boulonnais (T. Oppeli, de Lor.) Coll. Pellat.

Eocexe........ Une espèce typique du calcaire grossier parisien (Bullina grignonensis, Desh.) coll. Bezançon; autre espèce douteuse dans l'Alabama ( $T$. Wetherelli, Lea) d'après la figure.

Oligocene...... Deux espèces caractérisées, l'une à Étampes (Bullina exerta, Desh.) ma coll., l'autre dans le Vicksburgien des États-Unis ( $T$. crassiplica, Conr.) ma coll. 


\section{Tornatina}

Mrocene....... Une espèce plésiotype ci-dessus, très commune dans le Bordelais; autres espèces de Floride ( $T$. canaliculata, Say) citées par Dall.

Plrocent...... Une espèce certaine de Vaucluse ( $T$. hemipleura, Font.) d'après la figure.

Epoque actuelle. Environ 40 espèces dans les mers chaudes, d'après le catalogue de Pretel.

Retusa, Brown, 1827. Type : Bulla truncatula, Brug. Viv.

$1=$ Utriculus, Brown, 1827, non Schum. = Coleophysis, Fischer, 1883, même type.)

Forme cylindrique; spire tronquée, souvent concave, carénée à la périphérie, mucronée au sommet jar le nucléus embryomaire; surface lisse ou sillonnée à la base du dernier tour, quelquefois plissée en arrière par les accroissements; ouverture très étroite, dilatée et échancrée en avant; labre peu sinueux, infléchi au milieu; columelle courte, un peu excavée, tronquée en avant, portant en arrière un simulacre de pli, souvent alssent.

Diagnose prise d'après l'espèce type, fossile à Cannes (PI. III, fig. 24-25) ma coll.

Observ. - Conformément à la correction faite par Bucquoy, Dautzenberg et $G$. Dollfus, il y a lieu de rétablir pour cette section le nom créé par Brown pour le type auquel Adams a attribué la dénomination Utriculus déjà employée par Schumacher, tandis que P. Fischer a proposé de lui donner un nom nouveau. Cette section ne se distingue des Tornalina proprement dites que par sa spire rétuse, par son galbe plus cylindrique, par son labre à peine arqué, et par sa columelle très faiblement plissée. Néanmoins je ne crois pas que Retusa ait même la valeur d'un sousgenre, non seulement à cause du peu d'importance de ces caractères différentiels, dont la plupart ont plutôt une valeur spécifique que générique, mais surtout pour le motif suivant : si le genre Tornatina est complètement séparé de Relusa, sa descendance dans les temps géologiques présente une lacune importante et peu explicable entre le Portlandien et l'Eocène, tandis qu'en n'admettant les Relusa que comme une section qui supplée à la forme principale, dont l'apparition est même plus ancienne. cette lacune se trouve comblée et l'histoire de l'ensemble des Tornalina 
Tornatina

continue presque sans interruption, depuis le Bathonien jusqu'à l'époque actuelle.

Répart. stratigr.

Bathonien..... Une espèce du Boulonnais inédite et certaine, coll. Rigaux; sera décrite dans la Rev. de la Paléont. française.

Sbquaniex ...... Deux espèces typiques : l'une dans le Boulonnais et le Hanovre (Tornatina Sauvagei, de Lor.), coll. Rigaux, Pellat; l'autre à Tonnerre (T'. Munieri, de Lor.) coll. de la Sorbonne.

Portlandien .... Une espèce dans la Meuse et dans I'Yonne (Bulla cylindrella, Buv.) ma coll.

Néocomien..... Une espèce à peu près certaine en Suisse (Bulla Jaccardi, Pict. et Camp.) d'après les figures.

Barrémien ...... Une espèce de la couche rouge de Vassy (Bulla tenuistriata, Cotteau) coll. de l'Institut catholique; autre espèce caractéristique en Suisse et à Orgon (Bulla urgonensis, Pict. et Camp.) d'après un exemplaire de la coll. Boutillier, conforme aux figures.

Albrex........ Une espèce certaine et inédite, dans l'Aube ( $R$. Berthelini, nob.) coll. Berthelin. - Voir l'annexe.

Turoniex...... Deux espèces probables dans l'Inde (Bullina alternata et cretacea, d'Orb.) d'après Stoliczka.

Senovien ...... Une espèce probable à Aix-la-Chapelle (Cylichna gradata, Holz.) d'après la figure.

Paleocene..... Une espèce bien caractérisée à Copenhague (Tornatella plicatella, von Køen.) d'après la figure.

Mrocexe...... Une espèce probable à Pontlevoy (Bulla pseudotornatina, Dollf. Dautz' d'après la liste préliminaire; autre espèce de Floride (Bulla sulcala, d'Orb.). d'après Dall.

Pliocene....... L'espèce type dans l'Astien de Cannes, ma coll. Deux autres espèces dans le Plaisantin et la Calabre, citées par Foresti et Seguenza.

Epoque actuelle. Environ 30 espèces, outre le type de la Méditerranée, dans toutes les mers, d'après le catalogue de Pætel. 
VOLVULELLA, R. B. Newton, 1891.

$(=$ Volvula, Ad. 1850, non Volvulus, Oken 1815; = Rhizorus, Montf. 1810, méconnaissable d'après Dautz. et Dollf.)

Spire involvée, à sommet rostré; ouverture échancrée, columelle faiblement plissée.

Volvulella, sensu stricto. Type: Bulla acuminata, Brug. Viv.

Forme ovoïdo-conique, atténuée à ses deux extrémités; spire invisible, involvée et recouverte par le rostre plus ou moins acuminé, parfois perforé, que forme l'enroulement de l'extrémité inférieure du test; surface du dernier tour lisse, ou ornée de sillons visibles aux deux extrémités; ouverture étroite, linéaire, occupant toute la longueur de la coquille, à peine dilatée du côté antérieur et échancrée à la base; labre mince, peu arqué, presque vertical, souvent contracté au milieu; columelle courte, tordue et tronquée à la base, portant quelquefois un fort pli transversal, placé assez bas; bord columellaire très étroit, recouvrant incomplètement une fente ombilicale, quelquefois épaissi au point de rendre moins visible la sinuosité du contour supérieur auquel il se raccorde.

Diagnose prise sur l'espèce typique de la Méditerranée; plésiotype de l'Eocène, V. Dekayi, Lea (1'l. IV, fig. 1-2) Claiborne, ma coll.

Observ. - Les espèces tertiaires, que j’assimile à la forme vivante, en diffèrent par plusieurs caractères, qui fixent l'attention au premier abord, mais qui ne présentent pas, dans les différentes espèces que j'ai examinées, une fixité suffisante pour qu'on puisse les prendre comme base de la séparation même d'une simple section : en effet, le pli columellaire de V. lanceolata, Sow, de Barton est extrêmement saillant, le bord est épais et l'échancrure antérieure, à peine indiquée; le sommet est à peine perforé, mais il l'est beaucoup plus dans V. Dekayi, Lea de l'Alabama; dans ces deux espèces, il sort de cette perforation une sorte de columelle apicale et calleuse qui se termine au rostre du sommiet; enfin, la surface, lisse 
dans V. acuminata vivant, est entièrement et fortement sillonnée dans l'espèce de Barton, et elle est incomplètement striée aux deux extrémités dans la plupart des autres formes de l'Eocène.

Répart. stratigr.

Eocene....... PIusieurs espèces dans le bassin anglo-parisien et l'Alabama ( $V$. radius, Desh. oxyacrum, Cossm. lanceolata, Sow. Dekayi, Lea, etc...) ma coll.

Oligocene ..... Deux espèces dans l'Allemagne du Nord ( $V$. apicina, Phil. inlumescens, V. Kœn.) d'après les figures.

Mrocene....... Une espèce du Bordelais (V. Bruguierei, Benoist) ma coll.

Pliocene....... L'espèce type dans l'Astien de Cannes, ma coll.; à Monte-Mario, coll. du Musée de Dijon; citée dans le Crag par Wood.

Epoque actuelle. Une quinzaine d'espèces dans les mers d'Europe, l'Océan indien, les mers de Chine, d'après P. Fischer.

\section{SGAPHANDRIDA}

Coquille externe, involvée, à spire toujours cachée, généralement imperforée au sommet ; ouverture dilatée, laissant apercevoir l'enroulement interne de la coquille; pas de columelle; bord columellaire un peu calleux, se raccordant par une courbe régulière au contour supérieur.

Tableau des genres, sous-genres et sections

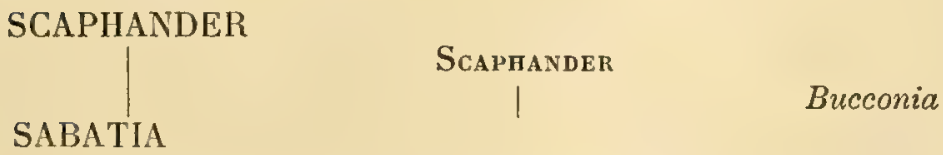

Genres et sous-genres non signalés à l'état fossile

Smaragdinella, A. Ad., Nona, H. et A. Ad. (Classée dans les Philinidx, par Tryon). 


\section{Genres à éliminer des Scaphandridæ}

Raincountia, Fischer, 1884. Malgré son apparente analogie avec les Smaragdinella, cette coquille me paraîtrait beaucoup plus à sa place dans les Calyptrxidx, dont elle se rapproche par la double inflexion du bord libre de sa lame columellaire, formant à sa naissance un pilier calleux enroulé sur lui-même et creusé à l'extérieur, comme on n'en voit pas d'exemple dans les Scaphandridx; l'inflexion coudée du bord columellaire n'a aucun rapport avec le pli tuberculeux des Sabatia. Je propose done d'éliminer ce genre des Opisthobranchiata. Type : $R$. incilis, Fischer (Pl. VI, fig. 14) de Gourbesville, coll. de l'Ecole des Mines.

SGAPHANDER, Montfort, 1810.

$$
\text { [= Assula, Schum. 1817, d'après P. Fischer }]
$$

Scaphander, sensu stricto. Type : Bulla lignaria, L. Viv.

Forme ovale, conoïde, rétrécie en arrière, dilatée en avant; enroulement autour d'un axe iléal, les lours n'étant pas en contact les uns avec les autres; surface ordinairement striée dans le sens spiral ; sommet excavé, imperforé, recouvert d'une callosité produite par un épaississement du bord externe ; labre arqué, profondément échancré à son point d'attache avec le sommet de la coquille; ouverture largement dilatée en avant, un peu versante et échancrée à la base, de sorte qu'on peut apercevoir l'intérieur de la coquille jusqu'au sommet; bord columellaire mince et large en arrière, calleux et étroit en avant, parfois caréné à l'extérieur.

Diagnose prise d'après un individu typique de la Méditerranée; plésiotype fossile du bassin de Paris, $S$. conicus, Desh. (Pl. IV, fig. $3-\check{\text { }}$ ) coll. Bernay.

Observ, - Le plésiotype fossile ne diffère du type vivant que par sa spire perforée au sommet et par son bord colimellaire caréné à l'extérieur; en outre, plusieurs espèces fossiles possèdent un renflement interne 
Scaphander

très obsolète, qui part transversalement du bord du labre, vers le tiers inférieur, et qui s'enroule à l'intérieur de la paroi de la coquille; il existe un léger indice de ce renflement sur l'individu vivant de $S$. lignarius que j'ai décrit ci-dessus, et on en voil également la trace sur les moules internes qu'on recueille dans le Miocène du Portugal. Dans ces conditions, il ne paraît pas qu'il y ait lieu de séparer les Scaphander fossiles de ceux de l'époque actuelle, même pour en faire une section du genre principal.

Répart. stratigr.

Eocene....... Plusieurs espèces dans le bassin anglo-bel ge-parisien (S. parisiensis, d'Orb. conicus, Desh. Cauveti, de Rainc. altavillensis, Desh. Brongniarti, Desh. etc...) ma coll.; dans le Vicentin ( $S$. Fortisi, Brongn.) d'après les figures.

Oligocene..... Une espèce dans l'Allemagne du Nord ( $S$. dilatatus Phil.), d'après les figures de l'ouvrage de von Konen.

Mrocene....... Trois espèces distinctes du type vivant, dans le Bordelais (S. Grateloupi, aquitanicus, Ben. sublignarius, d'Orb.) ma coll. ; une autre probablement différente de $S$. lignarius, dans le Portugal, ma coll.

Pliocene ....... L'espèce type, dans le Crag et à Anvers, ma coll.; signalée aussi en Italie et à Rhodes, d'après Dollfus et Dautzenberg.

Epoque actuelle. Le type vivant dans toutes les mers de l'hémisphère boréal, d'après $\mathrm{P}$. Fischer ; quelques autres espèces dans l'Australie et l'Atlantique, d'après Pætel.

Bucconia, Dall. 1890. Type: Scaphander nobilis, Verrill. Viv.

Forme ovale, globuleuse, également atténuée à ses deux extrémités; enroulement et ornementation de Scaphander; sommet étroitement perforé, non calleux; labre arqué, prolongé en arrière par un bec saillant qui dépasse le sommet de la coquille, et entaillé par une petite échancrure rétrocurrente, avant son insertion dans la perforation apicale; ouverture peu rétrécie du côté postérieur, largement dilatée et ovale en avant ; bord columellaire excavé en $S$, très étroit, se terminant en pointe à droite du contour supérieur. 
Diagnose prise "d'après la figure du type, in Dall (Moll. South. Eastern Coast of U. S, $\mathbf{1 8 8 9}$, pl. LXIV, fig. 106) ; reproduite sur un calque (fig. 38).

Observ. - Cette section s'écarte des Scaphander typiques par sa forme moins conoïde, plus bulloïde, par son sommet moins calleux et perforé, par le bec postérieur de son labre, enfin par son bord columellaire plus étroit et moins calleux ; $\boldsymbol{M}$. Dall ajoute, en y assimilant un fossile de l'Eocène d'Amérique, que le bord columellaire porte une étroite gonttière, qui ne

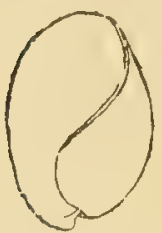

Fra. 38.

Bucconianobilis, Verr. paraît pas exister sur le type vivant; peut-être n'est-ce que l'impression en creux, sur le moule, de la callosité de ce bord. En tous cas, la séparation des Bucconia ne me semble admissible que comme une section des Scaphander, les caractères différentiels qui précèdent, n'ayant qu'une importance tout à fait secondaire; si toutefois la gouttière dont il vient d'être question, existe bien sur le plésiotype fossile, comme ce serait une différence beaucoup plus importante, c'est à ce plésiotype qu'il conviendrait d'appliquer un nom nouveau et peut-être un classement dans une autre famille que celle des Scaphandridie.

Répart. stratigr.

EockNe....... Une espèce peu certaine dans l'Amérique du Nord (Haminea grandis, Aldrich), d'après la figure donnée par Dall.

Epoque actuelle. Le type vivant sur les côtes des États-Unis, d'après la figure donnée par Dall.

\section{SABATIA, Bellardi, 1877.}

SABATIA, sensu stricto.

Type: S.. Isseli, Bell. Plioc.

Forme et enroulement de Scaphander; spire excavée, à perforation en grande partie recouverte par une callosité ; surface ornée de stries spirales que traversent de fins plis lamelleux; labre de Scaphander; bord columellaire calleux dans toute sa hauteur, séparé de la base par un sillon superficiel, caréné et aminci en pointe en avant, portant en arrière un pli transversal épais, taillé en biseau, et, au-dessous de ce pli, quelques rides granuleuses. 
Diagnose refaite d'après un échantillon de l'espèce type (Pl. II, fig. 11-12), communiqué par MI. Sacco, musée de Turin.

Observ. - Il ne paraît pas douteux que ce genre doit être classé dans la famille Scaphandridæ, caractérisée par l'absence de columelle : les coupes longitudinale et transversale qu'en donne Bellardi (fig. 7 et 8) prouvent que l'enroulement se fait autour d'un axe idéal, sans contact des tours entre eux; mais l'existence d'un pli columellaire sur tous les individus qu'on a recueillis, écarte complètement les Sabatia des S'caphander et justifie la séparation d'un genre distinct.

Répart. stratigr.

Pliocene....... Une seule espèce type, localisée aux environs de Turin. Epoque actuelle. Une espèce des côtes de Floride iS. bathymophila, Dall.), d'après la figure donnée par l'auteur.

\section{BULLID E}

Coquille externe, globuleuse ou cylindrique, à spire peu ou point visible, perforée au sommet; ouverture entière et dilatée en avant; labre peu arqué, presque vertical, non échancré à son point d'insertion et dépassant le sommet; columelle courte, excavée, quelquefois plissée ou subtronquée à la base; bord columellaire calleux, un peu versant.

Tableau des genres, sous-genres et sections

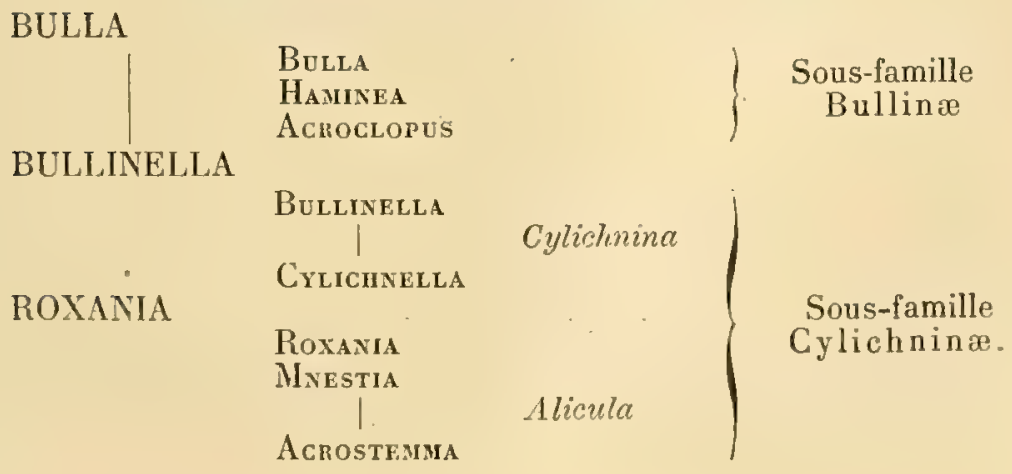




\section{Genres ot sous-genres non signalés à l'état fossile}

Atys, Montf. 1810 (non Leach. Crust. 1815); Dinia, H. et A. Ad. 1858 (non Stal. Ilem. 1874); SAo, II. et A. Ad. ; Pнysema, H. et A. Ad. 18508; WeinkaufFia, A. Ad., 1858.

Clistaxis, nom. mut. [ = Cryplaxis, Jeffr. 1883, non Lowe 18ä4, nec Reuss. 1863 ]. J'appelle l'attention sur cette derniere rectification d'un double emploi qui a échappé à Jeffreys, pour un genre que lui attribue M. de Monterosato (Nomencl., p. 144, 1884) Type : Cylichna parvula, Jeffr. des côtes de Crète.

\section{BULLA, Linné 1759 (Klein 1753).}

Bulla, sensu stricto.

Type: $B$. ampulla, L. Viv.

Test solide; forme globuleuse, enroulée; spire étroitement perforée au sommet; surface lisse ou spiralement striée à ses extrémités; ouverture rétrécie en arrière, très dilatée et entière en avant; labre peu arqué, légèrement incliné at gauche de l'axe du côté antérieur, dépassant le sommet et dénué d'échancrure à son point d'insertion; columelle courte, excavée, sans trace de pli; bord columellaire mince en arrière, épais et large sur la base, versant et un peu caréné à l'extérieur, recouvrant la fente ombilicale, se raccordant par une courbe régulière au contour supérieur, où il n'aboutit pas tout à fait tangentiellement.

Diagnose faite d'après un individu de l'espece type; plésiotype pleistocène de Biot, B. striata, Brug. (Pl. IV, tig. 6-7) ma coll.

Observ. - Les espèces jurassiques et crétacées, que je rapporte au genre Bulla, s'en rapprochent par leur forme, par leur ouverture et par leur sommet perforé, mais s'en écartent par la minceur de leur test (peut-être due à la fossilation) et par leur bord columellaire moins calleux, quoique l'état de conservation des individus étudiés ne permette pas d'être complètement affirmatif à l'égard de ce dernier caractère. Dans ces conditions, il serait téméraire de proposer la création d'un sous-genre ou méme d'une 
section pour ces premiers représentants du genre Bulla, qui pourraient d'ailleurs être aussi des Haminea.

Répart. stratigr.

Charmodthien... Une espèce en Normandie (B. liasina, Eug. Desl.). coll. DesI.

Bathonien ...... Une espèce probable en Normandie (B. globulosa, Desl.), coll. Desl.

Callovirn...... Une espèce très globuleuse dans la Sarthe et la Côted'Or (B. Lorierei, d'Orb.), coll. de l'Ecole des Mines.

Sequaxien...... Une espèce certaine dans la Haute-Marne et la Charente ( $B$. matronensis, de Lor .), coll. du Musée de la Rochelle.

Portlandiex.... Une espèce certaine dans l'Yonne et dans le Boulonnais ( $B$. Letteroni, Cott.), coll. Rigaux.

Neoconien..... Deux espèces certaines, l'une en Suisse (B. avellana, Pict. et Camp.), d'après les figures; l'autre de l'Aube, nouvelle $B$. marullensis, nob. (Pl. VI, fig. 15-16), coll. de l'École des Mines. - Voir l'annexe.

Aptren........ Fragments peu déterminables, cités par Pictet et Campiche (Crétacé de Sainte-Croix).

Cenomanien..... Une espèce probable, dans la meule de Bracquegnies (B. Ryckholti, B. et Corn.), d'après les figures.

Senoniex....... Deux espèces probables dans le Missouri supérieur (Haminea minor, Meek et Cylichna volvaria, Meek), d'après les figures données par l'auteur.

Eocrne........ Une espèce de petite taille et lisse, dans le bassin parisien (B. globulus, Desh.), ma coll.

Origocene ...... Une espèce bien caractérisée dans le Tertiaire de la Jamaïque (B. Vendryesiana, Guppy), d'après les figures.

Pleistocene..... L'espèce plésiotype du gisement de Biot, ma coll.

Epoque actuelle. Plusieurs espèces dans les mers chaudes et tempérées, d'après P. Fischer; environ 50, d'après Pætel.

Haminea, Leach, in Gray, 1847. Type: Bulla hydatis, L. Viv.

Test mince; forme de Bulla; spire invisible, à sommet ombiliqué, non perforé; surface finement striée à la loupe ; ourerture de Bulla; bord columellaire mince, peu étalé, faisant un angle avec le contour supérieur, au point où il se raccorde avec lui. 


\section{Bulla}

Diagnose faite d'après un individu de l'espèce type; plésiotype fossile des faluns de Bossée, II. navicula, da Costa = cornea, Lamk. (PI. IV, fig. 98-29) ma coll.

Observ. - S'il est aisé de distinguer les Haminea vivantes des Bulla par la minceur de leur test peu coloré, par leur sommet imperforé et surtout par les caractères anatomiques de l'animal, cette distinction est à peu près impossible, quand il s'agit de formes fossiles, surtout en médiocre état de conservation: c'est pourquoi j'ai conservé dans le genre Bulla proprement dit les coquilles secondaires dont le test est absent ou aminci, et qui ressemblent, à ce point de vue, à des Haminea, sans qu'on puisse affirmer qu'elles en sont.

Répart. stratigr.

Mrocene ....... Une espèce plésiotype en Touraine, signalée ci-dessus; autre espèce de Floride, identique à $H$. virescens, Sow. d'après. Dall.; autre espèce du Bordelais (H. saucatsensis, Ben. mss.) ma coll.

Pluocene....... Deux espèces dans l'Astien de la Calabre et des $A l p e s-$ Maritimes (B. hydatis et navicula) d'après Dollfus et Dautzenberg; autre espèce dans le Plaisantin et les Pyrénées-Orientales ( $H$. Weinkauffi, Mayer) d'après les figures de l'ouvrage de Fontannes.

Epoque actuelle. Dispersée dans toutes les mers, d'après P. Fischer; environ ö0 espèces, d'après l'æetel.

Acrocolpus, nov. sub.gen. Type: Bulla plicata, Desh. Eoc.

Taille petite; forme trapue, cylindracée, spire à sutures canaliculées, visible au fond d'une large perforation apicale ; surface plissée par les accroissements; les plis, droits dans toute la hauteur du dernier tour, s'anastomosent à la partie inférieure, de manière à former, autour de la perforation du sommet, une couronne d'arêtes curvilignes et rétrocurrentes. Ouverture étroite, peu dilatée en avant où elle est versante et légèrement chanclée; labre presque vertical au milieu, incliné à gauche de l'are du còté antérieur, rétrocurrent el profondément ćchancré à son point d'insertion avec le canal sutural ; columelle courte, obliquement coudée avec la base, peu excavée, dénuée de plis; bord columel- 
laire épais, se raccordant par un contour régulier avec le bord supérieur qui est un peu sinueux.

\section{Diagnose prise d'après le type ducalcaire grossier, $B$. plicalá de Chaussy (Pl. IV, fig. 11-13) ma coll.}

Observ. - Cette forme doit être séparée des Bulla, non seulement à cause de ses plis axiaux au sommet, mais surtout pour son labre échancré en arrière, pour sa spire visible dans la perforation apicale; enfin sa columelle coudée et son contour supérieur subéchancré s'écartent un peu de la columelle arrondie et du contour rectiligne de $B$. ampulla. Néanmoins, quoique ces différences aient une réelle importance, je ne crois pas que $B$. plicata appartienne à un genre complètement distinct des Bulla, et qu'elle ait été habitée par un animal dont l'anatomie soit tout à fait différente, comme cela a lieu pour les genres suivants; c'est pourquoi je propose de rattacher Acrocolpus comme sous-genre de Bulla.

Répart. stratigT.

Eocene ....... Une seule espèce type du sous-genre, dañs le bassin de Paris, la plupart des collections.

BULLINELLA, Newton, 1891.

[= Cylichna, Loven 1846, non Burmeister 1844].

Forme cylindracée ; ouverture étroite, entière ; columelle plissée.

Bullinelia, sensu str. Type: Bulla cylindracea, Penn.Viv.

Forme cylindrique; spire profondément perforée au sommet par un ombilic assez large, au fond duquel on apercoit l'enroulement des tours; dernier tour embrassant toute la coquille, tronqué et souvent un peu plus atténué du côté du sommet; surface en général ornée de stries spirales, plus visibles à la basé du dernier tour, reparaissant quelquefois autour de la troncature apicale. Ouverture très étroite sur la plus grande partie de sa hauteur, dilatée, arrondie et entière en avant, où son contour supérieur 
Hullinella

fait une sinuosité échancrée, qui dérouvre plus ou moins l'enroulement interne; labre à peu près vertical, dépassant toujours la troncature de la spire; columelle courle, se reliant en arrière, sans inflexion, à la base de l'avant-dernier tour, munie en avant d'un renflement pliciforme, plus ou moins saillant; bord columellaire assez épais, caréné à l'extérieur, se raccordant par une courbe régulière avec le contour supérieur.

\section{Diagnose prise d'après un plésiotype fossile du calcaire grossier parisien, Bulla Verneuili, Desh. (Pl. IV, fig. 8-10) ma coll.}

Observ. - Ce genre se distingue des Bulla, non seulement par la forme plus cylindrique de la coquille, mais encore par le pli tordu plus ou moins apparent, que porte la columelle, enfin par l'échancrure du contour supérieur de l'ouverture, qui n'existe pas dans les Bulla proprement dites et qui est à peine indiqué dans les Acrocolpus. P. Fischer classe les Cylichna dans la famille Scaphandridx, quoique la coquille de ces derniers n'ait pas de columelle; Tryon en fait le type de la famille Cylichnidx, déjà proposée par Meek, en 1876, et il y classe aussi les Volvula, les Utriculus et les Diaphana, qui appartiennent à des groupes tout à fait différents au point de vue anatomique, de sorte que cette famille est un assemblage hybride; il me paraît plus rationnel de rapprocher les Bullinella des Bulla, dont elles ne s'écartent pas par des caractères fondamentaux et qui ont deux points communs avec elles: coquille complètement externe, columelle formée. Toutefois, comme ce dernier point me laissait-quelques doutes, M. Berthelin a eu l'habileté et la patience de trancher deux sections dans l'axe d'individus de $B$. Bmuguierei du calcaire grossier; quoique les cloisons internes soient, sinon résorbées, du moins si minces que ces deux coupes ne permettent pas d'examiner comment est fait le nucléus embryonnaire, elles montrent du moins un pilier columellairo perforé par une étroite cavité spirale qui correspond à la fente ombilicale, à peu près recouverte sur la base par le bord culumellaire; or il serait impossible de faire une section similaire sur un Scaphander, il ne resterait que le vide au centre: il y a done là une différence capitale qui justifie la séparation de deux familles distinctes.

Un second groupe de Bullinella pourrait ètre admis pour quelques coquilles de l'Eocène, dont le sommet est tronqué, anguleux à la périphérie du dernier tour, el dont le labre échancré en arrière ne dẹpasse pas la troncature; l'entonnoir de la spire est tantôt complètement recouvert par une callosité (B. acrotoma, Cossm. de l'Alabama), tantôt excavé par une rampe conique qui porte la trace des accroissements de l'échancrure sinueuse du labre (B. goniophora, Desh. anomala, Edw. du bassin anglo- 
Bullinella

parisien). Comme il existe un passage graduel des formes dont le sommet est imperforé à celles qui ont un entonnoir plissé, il me paraîtrait excessif de proposer une nouvelle coupe pour ces coquilles qui se rattachent aux Bullinella typiques, à spire visible.

Répart. stratigr.

Sexoniex....... Plusieurs espèces très probables dans la Craie d'Aixla-Chapelle (Cyl. Bosqueti, Mulleri, Holz.), d'après les figures de l'auteur; une espèce probable dans la Craie de l'Inde (C. inermis, Stol.), d'après la figure. Quant aux espèces indiquées par Meek, elles n'appartiennent vraisemblablement pas au genre Bullinella.

Paleocene..... Une espèce des sables de Bracheux (B. angystoma, Desh.) ma coll.

Eockne....... Plusieurs espèces dans le bassin de Paris (B. Verneuili, Bruguierei, Desh., etc.) et dans l'Alabama (B. Saint-Hilairei, Lea), ma coll.

Oligocene ...... Quelques espèces dans le bassin de Paris et de Mayence (B. minuta, Desh., etc., ma coll.) et dans l'Allemagne du Nord (B. multistriata, secalina, von Kœnen)d'après les figures.

Mrocene....... Quelques espèces dans le Bordelais et dans le bassin de l'Adour. (B. convoluta, $\mathrm{Br}$.) ma coll.

Plrocene....... Plusieurs espèces, parmi lesquelles le type vivant, dans le Crag et en Italie, ma coll.

Epoque actuelle. Nombreuses espèces dispersées dans toutes les mers, d'après P. Fischer et d'après Pætel qui y comprend celles de la section suivante.

Crutchnina, Monts. 1884. Type: Bulla umbilicata, Mtg. Viv.

$$
[=\text { Acrotrema, Cossm. |1889. Catal. Eoc. IV, p. 317.] }
$$

Forme cylindracée, souvent conoïdale et rétrécie en arrière; spire invisible, étroitement perforée au sommet; dernier tour ovoïdo-cylindrique, non tronqué en arrière; ornementation et ouverture de Bullinella. 
Diagnose prise d'après le plésiotype fossile du bassin de Paris, B. cylindroides, de Parnes (Pl. IV, fig. 17-19) ma coll.

Observ. - Les différences entre cette section et les Bullinella proprement dites sont légères, et ne consistent que dans la forme quelquefois conique du dernier tour des Cylichnina, surtout dans l'absence de troncature au sommet, perforé d'un ombilic extrêmement étroit au fond duquel il est impossible d'apercevoir l'enroulement de la spire; aussi y a-t-il des espèces dont le classement est embarrassant, par exemple B. Saint-Hilairei, Lea et galba. Conr., que certains auteurs considèrent comme synonymes, et dont il faut attentivement examiner le sommet, à l'âge adulte, pour être en état de les séparer.

Le nom Acrotrema, que j'ai récemment proposé pour celte section (type: B. cylindroides), me paraît synonyme de Cylichnina, Monteros., quoique la description de cet auteur se réduise aux quatre mots " sommet atténué et ombiliqué ": la première espèce qu'il cite, sans indiquer si c'est le type, est $C$. levisculpta, Tiberi, que je ne connais pas; mais il a eu l'obligeance de m'envoyer $C$. umbilicata, Montg. et nitidula, Lovèn, deux autres espèces méditerranéennes rapportées par lui au même genre et dont la ressemblance avec les formes que j'ai classées dans le genre Acrotrema, est incontestable. Il y a done synonymie entre ces deux dénominations, le nom Cylichnina antérieur doit seul être conservé et j'indique comme type C. umbilicata.

Répart. stratigr.

Paleocene ..... Une espèce à peu près certaine à Copenhague $(C$. discifer $a$, von Kin.), d'après la ligure.

EOCENE....... Nombreuses espèces, soit dans le bassin de Paris (Bulla cylindroides, ambigena, consor's, strialissima, conulus, Caillati, Desh. etc.) ma coll. ; soit en Angleterre (B. elliptica, Sow.) ma coll.; soit dans l'Alabama (B. galla, Conr.) ma coll.

Oligocene ...... Plusieurs espèces, soit dans le bassin d'tampes et de Mayence (Bulla conoidea et colalct, Desh.) ma coll.; soit dans l'Allemagne du Nord (C. labiosa, interstincla, von Kœn. Bulla Lau'enti, Bosq. et minima, Sanab.), d'après les figures.

Mrocene....... Plusieurs espèces dans les faluns du Sud-Ouest (Bulla tarbelliana, Grat. subangysioma, d'Orb.) ma coll.

Pliocene....... Le type vivant existe à l'élat fossile en Sicile, communiqué par M. de Monterosato; signalé aussi dans le Crag d'Anvers par Nyst.

Epoque acturle. Vivant dans la Méditerranée, l'Adriatique el l'Atlantique, d'après Dollfus et Dautzenberg. 
Cylíchnella, Gabb. 1873. Type: Bulla bidentata, d'Orb. Viv.

Forme ovoïde, subglobuleuse; spire invisible, très étroitement perforée au sommet; dernier tour embrassant, atténué à ses extrémités, lisse ou faiblement sillonné dans le sens spiral ; ouverture très étroite en arrière, dilatée, arrondie et un peu versante en avant; labre peu arqué, quelquefois contracté au milieu, dépassant à peine le sommet; columelle courte, munie de deux plis inégaux el écartés, l'antérieur peu saillant, se réduisant quelquefois à un court renflement, l'inférieur' étroit, lamelleux, transversalement enfoncé dans l'intérieur, rejoignant extérieurement le contour caréné du bord columellaire qui est calleux, bien appliqué sur la base, relié par une courbe régulière au contour supérieur.

Diagnose prise d'après la figure donnée par Tryon, complétée d'après le plésiotype fossile du Bordelais, C. vasatensis, Ben. mss. (Pl. IV, fig. 14-16) ma coll.

Observ. - Ce sous-genre se distingue des Bullinella et particulièrement des Cylichnina, par ses deux plis columellaires, par la forme arrondie et épaisse du bord antérieur de l'ouverture, qui ne présente pas le bec subéchancré des Roxania.

Répart. stratigr.

Eocene ....... Une espèce douteuse dans le Miocène inférienr de l'île de la Trinité, Eocène d'après Dall ( $C$. ovum-lacerti, Gruppy), d'après la figure très médiocre de l'auteur, n'indiquant pas le pli antérieur. Autre espèce inédite, mais bien caractérisée, dans les sables du BoisGouët, coll. Bourdot.

Mrocene....... Plésiotype du Bordelais, ci-dessus signalé; le type vivant existerait fossile à Ilaïti, d'après Guppy.

Plrocene....... Une espèce de Floride très voisine du type vivant; mais rapportée par Dall. à C. ovum-lacerti, Guppy; non figurée.

Epoque acturle. Le type dans la mer des Antilles, d'après Dall et Tryon. 
ROXANIA, Leach, 1847.

[=Atysanct.,non Atys Montf. 1S10; Roxrmiella, Monts, 1884].

Forme de Bulla; spire perforée, base ombiliquée, ouverture échancrée du côté antérieur; columelle tronquée à son extrémité supérieure.

Roxania, sensu stricto.

Type: R. Cranchi, Leach (= Bulla utriculus Br.) Viv.

Forme globuleuse, enroulée; spire invisible, étroitement perforée au sommet; surface couverte de sillons spiraux et ponctués; base munie d'une fente ombilicale; ouverture un peu rétrécie en arrière, à peine dilatée en avant, subéchancrée sur son contour supérieur; labre presque vertical, non sinueux en arrière ; columelle excavée, tordue en avant et se terminant par un coude tronqué contre l'échancrure du bord supérieur; bord columellaire mince en arrière, calleux en avant, détaché de la base et s'arrêtant à la troncature de la columelle.

Diagnose prise d'après des individus typiques de la Méditerranée; plésio-type fossile du calcaire grossier de Grignon, Bulla avulata, Lamk. (Pl. IV, fig. ont-2y ma coll.; antre exemple d'un groupe

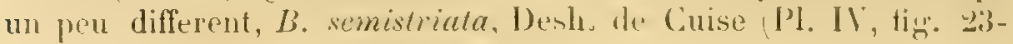
24) ma coll.

Observ. - M. de Monterosato (Nomencl. 188k) a séparé avec raison ce genre des $A t y s$, dont il diffère par la forme de sa columelle à peine tordue et par son labre qui ne se prolonge pas par un bec au-dela du sommet. Les Roxania se distinguent des Bulla par leur ouverture moins entière en avant, par leur columelle torlue et tronquée, par leur fente ombilicale; des Bullinella par leur forme plus ventrue, par leur ornementation, par leur columelle moins plissée, mais tronquée; enfin des Cylichnella, qui ont presque la même forme, par l'absence de deux plis columellaires, par la disposition de leur ouverture échancrée à la base, et par leur columelle qui ne se raccorde pas par une courbe régulière au contour supérieur.

M. de Monterosato en a séparé (Nomencl. 1884 une scction Roxanirlla 
Roxania

(type B. Jeffreysi, Weink) qui ne se distingue guère que par la minceur du test, la coquille est presque diaphane; les autres caractères me paraissent identiques, en tout cas je ne crois pas qu'on puisse, en Paléoconchologie, distinguer les Roxaniella fossiles des Roxunia: si l'on devait faire une séparation, je l'admettrais plutôt pour le groupe de coquilles qui ont le sommet plus largement perforé, la forme plus cylindracée, quoique ventrue, les sillons inégalement groupés en deux faisceaux en avant et en arrière, peu ou point ponctués, avec une ouverture semblable à celle des Roxania proprement dites; mais je ne crois pas utile de dénommer ce groupe, dont les caractères n'ont ni une importance, ni une fixité suffisantes pour mériter même úne section.

Répart stratigr.

Senoniex....... Plusieurs espèces probables dans la Craie supérieure du Missouri (Haminea occidentalis, subcylindrica, minor, Meek) d'après les figures, et conformément à l'auteur qui les rapproche d'ailleurs des Roxania.

Paleocrne..... Deux espèces certaines, dans les sables de Jonchery (Bulla glaphyra et cincta, Desh.) ma coll.; autre espèce probableà Copenhague (B. clausa, v. Køen.) d'après la figure.

Eoceve....... Plusieurs espèces bien caractérisées, dans le bassin Anglo-parisien (Bulla ovulata, Lamk, biumbilicata, sulcatina, Lamarcki, semistriala, Desh.') ma coll.

Oligocene ..... Une espèce du Tongrieu inférieur de Belgique ( $B$. utriculoides, Bosq.) ma coll.; deux espèces dans l'Allemagne du Nord, l'une typique (Atys clara, v. Koen.), l'autre du second groupe (Cylichna adjecta, v. Koen.), d'après les tigures données par l'auteur.

Mrocene....... Une espèce typique dans le Bordelais (B. sututriculus, d’Orb.) ma coll.; autre espèce des mêmes gisements et du second groupe (B. burdigalensis, d'Orb.) ma coll.

Pliocene...... Une espèce très commune dans l'Astien et le Plaisancien des Alpes-Maritimes et d'Italie (Bulla uiriculus, Br. synonyme de $B$. Cranchi, d'après Monteros.) ma coll.

Epoque Actuelle. Le type vivant dans la Méditerranée, l'Adriatique et le Nord de l'Atlantique, d'après Monterosato.

Mnestia, H el A. Ad. 1854 Type: M. marmorata, A. Ad. Viv.

Forme ovale, ventrue; spire invisible, imperforée; dernier tour embrassant toute la coquille, atténué à ses deux extrémités, 
Ioxania.

perforé par une fente ombilicale à la base, et muni en arrière d'une dépression qui circonscrit un bourrelet circa-apical ; surface ornéc de stries spirales, fines au milieu, plus profondes et plus écartées sur la base, ainsi que sur le bourrelet postéricur; ouverture étroite en arrière, peu dilatée et échancrée en avant; labre assez épais, prolongé du côté postérieur par un bec qui dépasse beaucoup le sommet, avec une entaille assez profonde dans la callosité fermant l'entonnoir de la spire; columelle très courte, excavér; subitement coudée en avant, où elle se termine en pointe contre l'échancrure du bord supérieur; bord columellaire étroit, détaché de la fente ombilicale, terminé à la troncatune de la columelle.

Diagnose prise d'après un plésiotype fossile de l'Oligocène de Pierrefitte, Bulla turgidula, Desh. (Pl. V, fig. 1-3) ma coll.

Observ. - Ce sous-genre s'écarte des Roxania par sa forme, par sa spire imperforée, entourée d'un bourrelet apical, et par le bec, correspondant à ce bourrelet, que forme le labre avant d'aboutir à son point d'insertion. Je ne connais le type vivant des Mnestia que par la figure qu'en donne Tryon, dans son Structural Manuel, mais jai été frappé de l'identité de celte forme et de notre Bulla turgidula; il y a aussi quelque analogie avec les Alicula, Eichw; mais on verra ci-après les différences.

Répart. stratigr.

Origocene..... Une espèce dans le bassin d'Etampes et de Mayence (B. turgidula, Desh), ma coll.

Mrocene....... Une espèce bien caractérisée dans l'Allemagne du Nord (Bulla Weissi, v. Koen.) d'après les figures données par l'auteur.

Epoque actuelle. Deux espèces dans les mers de la Chine, d'après l'otel.

Alicula, Eichw. 1830.

Type: Bulla cylindrica, Gm.

[= Alicula, Ehr. 1831, idem typus].

Forme et ouverture de Mnestia; sommet subperforé, dépourvu de bourrelet; surface ornée d'un faisceau drstries spirales ir chaquo 
extrémité, lisse au milieu du dernier tour; labre ne dépassant pas le sommet; columelle munie d'un pli tordu et tronquée à la base; bord columellaire de Mnestia.

Diagnose prise d'après un plésiotype fossile des plages de la mer Rouge, A. Ehrenbergi, Issel; reproduction de la figure (fig. 39).

Observ. - Cette section me parait peu différente du sous-genre Mnestia; elle s'en écarte toutefois par l'absence d'un bourrelet apical et d'un bec postérieur, par son pli columellaire plus apparent. Elle ressemble aussi beaucoup aux Roxania proprement dites; cependant, outre que la forme de la coquille est plus fusoïde, plus atténuée aux deux extrémités, la columelle porte un véritable pli qui fait défaut dans les Roxania.

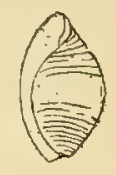

FIG. 39.

Alicula Ehrenbergi, lssel.

Répart. stratigr.

Preistocene.... Plusieurs espèces, parmi lesquelles le type et le plésiotype, dans les plages soulevées de la mer Rouge, à l'époque quaternaire; d'après les figures de Issel. Epoque actelele. Environ trois espèces dans la mer Rouge/A. bacillus, succisa, Ehr.) d'après Issel, Malac. mar. rosso.

Acrostemia, Cossm. 1889. Type: Bulla coronata, Lamk. Eoc.

Forme conique, ou ovoïdo-conique, rétrécie en arrière; spire étroitement perforée, à tours visibles, circonscrite par un angle très arrondi; surface du dernier tour ornée de sillons spiraux à la base, et de petits plis d'accroissement très serrés, plus saillants sur le bourrelet circa-apical, où ils sont réticulés par quelques filets spiraux; ouverture très étroite en arrière, dilatée et échancrée à la base; labre presque droit, profondément entaillé à la suture, vis-à-vis d'un canal spiral qui s'enfonce dans la perforation de la spire; columelle plus ou moins excavée, à peine plissée et quelquefois subtronquée en avant. 
Diagnose prise d'après l'espèce typique du bassin de Paris (Pl. III, fig. 21-23), échantillon du calcaire grossier de Mouchy, ma coll.

Observ. - Ce sous-genre doit être séparé des Bullinella, non seulement à cause de la forme conique, quelquefois ovale, du dernier tour, mais surtout parce que la spire est couronnée par un bourrelet réticulé dont la saillie est limitée par une petite dépression de la partie postérieure du dernier tour; enfin parce que le labre porte une échancrure profonde au point où il s'attache à la spire; quant à la columelle, elle présente des caractères variables: dans les individus typiques du calcaire grossier, elle est à peine excavée, sans aucune trace de pli, et ne parait pas véritablement tronquée à la base; les individus de l'Éocène inférieur portent, au contraire, un faible pli tordu, et enfin les autres espèces de l'Eocène supérieur du bassin de Paris, appartenant indubitablement à la même section, ont la columelle tout à fait tronquée près de l'échancrure basale de l'ouverture, de sorte qu'on peut les rapprocher des Roxania et des Mnestia; mais les Acrostemma se distinguent des premières par leur bourrelet et leur échancrure suturale, des secondes par leur forme, par l'ornementation bien différente de leur bourrelet, par leur labre dépassant à peine le sommet.

Répart. stratigr.

Palbocene..... Le type commence à apparaitre dans les sables de Bracheux, ma coll.

Eocene ........ Plusieurs espèces, outre le type, dans le bassin angloparisien (Bulla Bezançoni, Morlet et elacate, Bayan) ma coll.

Mrocene....... Une espèce certaine dans les faluns du Bordelais (Atys Toumoueri, Ben. mss) ma coll.

Pliocene....... Une espèce typique à Altavilla (Cylichna condita, Monts.) d'après les échantillons envoyés par l'auteur.

Epopue actuelle. Une espèce vivant dans la Méditerranée (Bulla siriatula, Forbes) d'après Monterosato.

ICERIDI, nov. fam.

Coquille externe, pouvant contenir l'animal, à test mince el hyalin; spire visible, non perforée; ouverture dilatée et découverte en avant; enroulement autour d'un axe idéal, columelle 
absente; bord columellaire très mince et très étroit, recouvrant hermétiquement la fente ombilicale.

Observ. - La plupart des auteurs ont classé les genres pour lesquels je propose cette nouvelle famille, soit dans les Scaphandridæ ou les Bullidæ, soit dans les Aplustridæ, soit même dans les Lophocercidæ (Tryon). Ces arrangements me semblent hybrides : le test mince de ces coquilles, leur spire visible, les écartent des Scaphandridx; si l'animal peut rentrer complètement dans le test, comme cela a lieu pour les Bullidx, l'enroulement dénué de columelle les distingue des Bulla et Bullinella qui ont une columelle bien formée; quant aux Aplustridæe et aux Lophocercidæx, il convient de n'y classer que des formes habitées par des animaux ne rentrant pas complètement à l'intérieur de la coquille, et d'en exclure les genres à coquille, entièrement externe, quoique la minceur de leur test rapproche les Aceridæ des Aplustrum et des Hydatina. En résumé, je crois que la meilleure solution consiste à adopter cette famille nouvelle, qui comprendra une série assez homogène.

Tableau des genres, sous-genres et sections ACERA.
AMPHISPHYRA.

Genres et sous-genres non signalés à l'état fossile

Cruindrobulla, P. Fischer. 18007 ; Volvatella, Pease, 1860.

AGERA, Müller, 1776.

$$
\text { [E Eucampe, Leach, 1847, sec. P. Fischer]. }
$$

Forme globuleuse ou subcylindrique; spire tronquée, à tours canaliculés; labre profondément échancré près de la suture; ouverture très sinueuse en avant.

Ackra, sensu stricto.

Type: A. bullata, Mull. Viv.

Forme ovale, ventrue, quelquefois cylindracée; embryon lisse, hétérostrophe, à nucléus dévié dans un plan orthogonal; spire 
tronquée ou à peine saillante, composée d'un petit nombre de tours croissant rapidement et séparés par des sutures profondément canaliculées: dernier tour embrassant toute la coquille, orné de stries spirales très fines. Ouverture étroite en arrière, subitement évasée, entièrement découverte en avant par une large sinuosité du contour supérieur; labre très mince, renversé à gauche de l'axe du côté antérieur, arqué au milieu, profondément entaillé sur la carène postérieure qui limite la rampe canaliculée des tours de spire; enroulement autour d'un axe idéal, columelle absente; bord columellaire mince, très étroit, se raccordant par une courbe régulière à la sinuosité du bord supérieur.

Diagnose prise sur A. soluta Cliemn.; plésiotype de l'Eocène

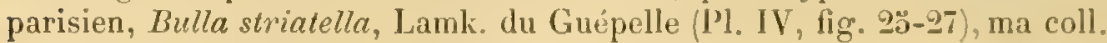

Observ. - S'il n'y a aucune hésitation possible dans le classement des Acera tertiaires et à la rigueur, des espèces crétacées, il y a quelque incer titude en ce qui concerne les formes jurassiques qui, pour la plupart, n'ont pas la spire saillante et sont plus ovales, plus allongées que les Acera typiques; cependant, comme elles ont l'échancrure caractéristique du labre et les tours plus ou moins canaliculés, il me paraitrait excessif de proposer un démembrement subgénérique qui ne serait fondé que sur une différence de forme, surtout quand la plupart des échantillons à comparer sont dénués de leur test.

Répart. stratigr.

Batmonien..... Une espèce peu cerlaine, à l'état de moule (Bulla miinceva, Desl.) coll. Desl.

Calloviex...... Une espèce inédite, de la Sarthe, coll. de l'Ĺcole des Mines : sera décrite dans la Rev. de la Paléont. française.

Rauraciex...... Une espèce douteuse de l'Mllemagne du Nord (Bulla subquadrala, Romer) d'après la figure défectueuse de l'auteur.

Kimendogren.... Deux espèces du sous-étage ptérocérien, dans la Ilaute-Marne et le Boulonnais (1. blaisiaca et Beaugrandi, de Lor.) d'après les figures et les échantillons, coll. Pellat.

Neocomex..... Une espèce nouvelle et bien caractérisée, du gisement de Marolles, A. neocomiensis, nol. (P'l. VI, fign. 23-24) coll. de l'Ecole des Mines. - Voir l'annexe. 
Cenomaniex.... Une espèce à sutures canaliculées, dans la meule de Bracquegnies (Tornatina ovala, Br. et Corn.) d'après les figures de ces auteurs.

Senovien....... Une espèce à peu près certaine, dans le Crétacé du Brésil (A. Brovoni, White) d'après la figure; autre espèce de la craie supérieure de Syrie (A. siliciosa, Whitfield) d'après la figure.

Eocene ....... Une espèce bien caractérisée, dans le bassin de Paris (A. strialella, Lamk.) ma coll.

Oligocane ..... Une espèce plissée par les accroissements, dans l'Allemagne du Nord (Bulla plicata, Phil., à changer en $A$. Koeneni, nob. non B. plicata, Desh.) d'après la figure donnée par M. von Kœnen; autre espèce dans le Vicentin. ma coll.

Mrocene........ Une espèce à peu près certaine dans l'Allemagne du Nord (Bulla Bellardii, von Konen) d'après la figure de l'auteur.

Pliogene....... Une espèce probable dans le Crag (Bulla nana, IVood) d'après la figure de l'auteur.

Epoque actuelle. Vivant dans toutes les mers, d'après P. Fischer.

AMPHISPHYRA, Lovèn, 1846.

[= Diaphana, Brown 1827 et 1833, non Diaphania, Hübn. 1816 , Lepid.].

Forme de Scaphander, spire visible, non saillante; labre à peine échancré, ouverture peu sinueuse en avant.

AMPHISPHYRA, sensu stricto.

Ex. Bulla hyalina, Turton = Volvaria pellucida Brown. Viv.

Forme ventrue, très dilatée; nucléus embryonnaire saillant; spire un peu concave, non ombiliquée, à tours peu nombreux, croissant rapidement; dernier tour conoildal, formant toute la hauteur de la coquille, atténué en arrière, élargi en avant, orné de fines stries spirales. Ouverture étroite en arrière, rapidement dilatée, entière et arrondie en avant, dont le contour supérieur, 
quoique peu sinueux, découvre largement l'intérieur de la coquille, qu'on peut apercevoir jusqu'au sommet; labre très mince, presque droit sur la plus grande partie de sa hauteur, se raccordant en arrière à la paroi opposée, en formant une sorte de godet subcanaliculé, sans échancrure; enroulement autour d'un axe idéal, columelle absente ; bord columellaire mince, très étroit, non détaché, se raccordant par une courbe régulière au contour supérieur.

Diagnose faite d'après un plésiotype fossile des sables de Cuise, Bulla assula, Desh. (Pl. V, fig. 11 et 22-23) ma coll.

Observ. - Ce genre, dont le test est aussi mince que celui des Acera, s'en distingue par sa furme plus conoïde, moins cylindrique, par sa spire sans saillie, et surtout par son labre non échancré en arrière, par son ouverture beaucoup moins découverte à la base; il s'écarte des Scaphander par le peu d'épaisseur du test, par son labre non échancré et par sa spire visible. Il n'est pas possible de conserver Diaphana, Brown, comme l'a fait Tryon, car cette dénomination est synonyme de Diaphania déjà employé; la correction faite par Lovèn a l'avantage de faire disparaître un nom de genre formé d'un adjectif et, par conséquent, peu correct.

Répart. stratigr.

Bajocien....... Une espèce nouvelle, coll. Gaiffe; sera décrite dans la Revis. de la Paléont. française.

Cenomarien .... Une espèce probable dans le Colorado (Haminea truncata, Stanton) d'après la figure de l'auteur.

Eocene....... Deux espèces typiques dans le bassin de Paris (Bulla assula et pulchella, Desh.) ma coll.

Oligocene..... Une espèce bien caractérisée dans le bassin d'Étampes (Scaph. stampinensis, Cossm.) ma coll.

Miocene....... Une espèce incertaine dans l'Allemagne du Nord (Philine undulata, von Kœn.) d'après la figure de l'auteur; antre espèce inédite des faluns de Bordeaux, coll. Degrange-Touzin.

Pliocene...... Le type vivant, dans les marnes de Théziers, d'après la liste de M. Vignier (Bull. Soc. géol. de Fr., 1836).

Epoque actuele. Vivant dans les mers du Nord et de l'Amérique, d'après P. Fischer; neuf espèces, d'après P’etel en y comprenant les Diaphana qu'il laisse séparées des Amphisphyra, quoique le type soit le même. 


\section{APLUSTRID}

Coquille en partie externe, à test mince, globuleuse, à spire visible, ou même saillante et parfois conoïdale ; ouverture dilatée, munie d'un bec antérieur plus ou moins échancré, qui correspond à l'extrémité d'un bourrelet basal; columelle généralement tronquée au bord du bec ; labre non échancré en arrière.

Observ. - Les Aplustrum, qui sont le type de cette famille, sont bien différents des Acera, surtout par leur columelle tordue en spirale et presque droite, ainsi que par le bec antérieur auquel elle aboutit; mais les différences d'aspect extérieur sont beaucoup moins tranchées entre les $H y d a-$ tina, classées dans la même famille, lorsqu'on les compare aux formes fossiles d'Aceridæ, et particulièrement aux Amphisphyra. Cependant les coquilles tertiaires que j'ai classées dans ce dernier genre ne présentent pas la trace de l'échancrure rudimentaire que l'on constate, plus ou moins indiquée, sur toutes les Hydatina vivantes; en outre, leur ouverture est bien plus découverte en avant et leur enroulement spiral se fait autour d'un axe fictif, tandis que les Aplustridæ paraissent avoir la columelle formée; enfin, les Aceridæ ont une coquille externe, au lieu que celle des Aplustridæ ne peut pas contenir entièrement l'animal : il est vrai que ce dernier caractère ne peut être d'aucune utilité pour la distinction des formes fossiles.

Tableau des genres, sous-genres et sections

SULCOACTEON

HYDATINA

BULLOPSIS

Genres et sous-genres non signalés à l'état fossile

Aplustrum, Schum. 1817 (non Aplustre Swains. 1810, nec Amplustrum Gray 1847).

Bullinula Beck 1840 (=Bullina, Ad.non Fér.1821). Les espèces crétacées indiquées par Stoliczka ou par Ilolzapfel, comme appartenañt à ce 
genre, me paraissent des Cinulia non adultes ou des fragments indéterminables (B. obtusiuscula, Stol.). Quant au rapprochement proposé par Zittel entre Aclxonina strialosulcata du Corallien et ce genre Bullinula, il est plus près de la vérité, mais ce n'est pas absolument le même genre, ainsi qu'on va le voir ci-après. Par conséquent, dans l'état actuel, je ne connais pas de Bullinula fossiles.

\section{SULCOACTEON, nov. gen.}

$$
\text { [= Bullinula, in Zittel, non Beck]. }
$$

SulcoAGtAEN, sensu stricto.

Type: Act. striatosulcata, Zitt. et Goub. Jur.

Forme ovale, semblable à celle de Tornatellæa; spire saillante, courte, à galbe presque conique, à sutures enfoncées, sans gradins. Surface tantôt à demi lisse, tantôt entièrement sillonnée; base du dernier tour perforée, toujours ornée de sillons spiraux, dont le dernier limite un bourrelet entourant la fente ombilicale. Ouverture ovale, peu allongée, se terminant par un bec un peu échancré qui correspond à l'extrémité du bourrelet basal ; labre arqué, rétrocurrent près de la suture; columelle courte, peu excavée, se terminant en pointe contre le bec antérieur; bord columellaire plus ou moins calleux, détaché, ne recouvrant pas complètement la fente ombilicale qui le sépare du bourrelet basal.

Diagnose prise d'après un individu typique de Glos (Pl. I, fig. 13-14) coll. de la Sorbonne.

Observ. - J'avais d'abord classé ce genre dans les Actixonidie; mais, après un examen plus approndi des caractères de l'espèce type, je me rallic à l'opinion de Stoliezka et de Zittel, qui rapprochent A. striatosulcala des Bullinula, par conséquent dans les Aplustridie. Toutefois il y a de réelles différences entre cette espèce jurassique et $B$. lineata, Word, figurée dans le Struct. Manuel de Tryon: d'abord le bourrelet basal, dont il n'est même pas fait mention dans la diagnose du grenre Bullinula, et qui a beaucoup d'analogie avec celui des Aplustrum; en outre, le bord columel- 
laire est plus épais que celui des Bullinula, le labre n'est pas crénelé; d'antre part l'existence d'un ombilic sur la base, la saillie de la spire, la columelle lisse et un peu excavée, distinguent les Sulcoactron des Aplustrum: c'est donc un genre nécessaire et intermédiaire entre Bullinula et Aplustrum.

Répart. stratigT.

Bajocien....... Une espèce du Calvados, confondue avec Torn.pulchella; sera décrite dans la Revision de la Paléontol. française.

Bathonien ...... Une espèce du Boulonnais confondue avec Act. Lorierei; sera décrite dans la Revision dé la Paléontol. française.

Oxfordiex...... Une espèce certaine, en Russie(Actzon Perovskianus, d'Orb.) coll. de l'Université de Mloscou.

Rauraciex ...... Outre le type cité ci-dessus, une espèce certaine dans la Meuse et le Calvados (Tomatella hordeola, Buv.) coll. Moreau et Boutillier.

Sequaniex...... Deux espèces nouvelles dans le Boulonnais, coll. Legay; seront décrites dans la Revis, de la Paléont. française.

Portlatdien..... Une espèce certaine du Boulonnais (Tornatella Leblanci, de Lor.) coll. Pellat, Rigaux, Legay.

Neoconien...... Plusieurs espèces certaines de l'Yonne et de Suisse (Actzon marginatus, d'Orb.) coll. du Muséum de Paris (Act. Nerei, Pict. et Camp. Act. icaunensis, Cotteau) coll. du Musée de Genève.

Urgoniex ...... Une espèce nouvelle des calcaires d'Orgon, Sulconct. ovoideus, nob. (PI. VI, fig. 28-29) coll. Boutillier et Curet; autre espèce incertaine d'Escragnolles ( $A c t$. astierianus, d'Orb.) d'après les figures de la Paléont. française.

HYDATINA, Schum. 1817.

Forme de Bulla ; spire apparente, peu excavée, à sutures non canaliculées; embryon hétérostrophe, globuleux et dévié ; dernier tour globuleux, à surface lisse; ouverture dilatée, légèrement échancrée sur le bord supérieur; bourrelet basal à peine indiqué aboutissant à la sinuosité du contour; labre arrué, à peine sinueux en arrière, se repliant tangentiellement au bord opposé. 
Diagnose prise d'après un individu de l'espèce type, Bulla physis, Lin. de l'île Maurice, ma coll.

Paldirydatina, nov. sect. 'Type: Bulla undulata, Rean. Bath. Forme ovale, parfois subcylindrique; spire étroitement excavée ; ouverture élargie en avant, peu ou point sinueuse sur son contour supérieur; labre un peu échancré en arrière; columelle courte excavée.

Diagnose prise d'après un individu de l'espèce type, à llidrequent (Pl. V, fig. 4-6) coll. Legay.

Observ. - Je n'ai pu me décider à identifier aux Hydatina actuelles les coquilles secondaires dénommées Bulla, qui ont la spire découverte, étroitement ombiliquée; leur état de conservation, généralement dénué de test, ne permet pas d'étudier les caractères de l'ouverture, de sorte qu'il est à peu près impossible de vérifier si le contour supérieur est sinueux ou régulièrement continu, sans l'échancrure de $H$. physsis, qui est d'ailleurs à peine indiquée sur une autre espèce vivante de l'Océan indien $(H$. velum); il ne faudrait donc pas attacher trop d'importance à ce dernier caractère qui, lorsqu'il existe, justifie le classement des Hydatina dans les Aplustridx. La plupart des espèces jurassiques ont une forme moins globuleuse que $H$. physis; leur labre décrit, en urrière, une sinuosité plus rétrocurrente, sans que ce soit une entaille comparable à celle des Acera; d'ailleurs, les tours ne sont pas canaliculés et l'ouverture n'est pas découverte en avant: il est done facile de séparer les Hydalina jurassiques des decra. Enfin il y a un point dont il y a lieu de tenir compte, c'est qu'aucune $I y d a$ tina n'a encore été signalée dans les terrains tertiaires, pour relier les formes secondaires, à celle des mers actuelles, et même celles du terrain crétacé sont très hypothétiques. Dans ces conditions, toutes les probabilités semblent établir que ce ne sont pas des IIydatina proprement dites, mais au moins une section ancestrale a laquelle je propose d'appliquer le nom Palxohydatina.

Répart. stratigr.

Sinemurien..... Une espèce à peu près certaine (Bulla Flouesii, Eug. Desl.) d'après un moulage de la coll. du Musée de Genève.

Bajociex....... Une espèce inédite des environs de Nancy, coll. Gaiffe et Bleicher; sera décrite dans la levision de la Paléont. française. 
Batrontex...... Le type de la section existe à l'état fossile dans le Boulonnais et en Angleterre.

Sequiniex ...... Une espèce très répandue dans l'Allemagne du Nord, le Jura et le Boulonnais (Bulla suprajurensis, Rom.) d'après des échantillons de diverses provenances.

Krmeridgiex..... Une espèce probable dans la Meuse (Bulla Dyonisea, Buv.) d'après la figure.

Cenomanien ..... Une espèce très douteuse, à l'état de moule dans les grès du Mans (Bulla Orbignyi, Guér.) d'après la figure de l'album paléontologique de la Sarthe.

Senoniex ...... Une espèce dont l'ouverture est inconnue (H.parvula Whiteaves) crétacé du Canada; compàrée par. l'auteur à une Bullopsis, mais sans pouvoir affirmer qu'il y ait des plis columellaires.

\section{BULLOPSIS, Conrad, 1858}

BULlopsis, sensu stricto.

Type : B. cretacea, Gonr. Crét.

Forme d'Hydatina, atténuée en avant, tronquée en arrière; spire déprimée; dernier tour rentlé; ouverture pyriforme dilatée et ovale à la base; bord columellaire muni de deux plis proéminents placés très haut, limité du côté de la base, par une carène qui se raccorde au contour supérieur.

Diagnose prise d'après la description donnée par Conrad (Journ. of the Acad. Sc. nat. Phil., III, 1858); reproduction d'une copie de la figure (fig. 40), donnée en 1860 dans le t. IV.

Observ. - D'après ce qui précède, ce genre ne différerait des Hydatina proprement dites que par la présence de deux plis à la columelle; cette plication ne semble guère se concilier avec les caractères des Aplustridx, et demanderait une plus ample vérification; malheureusement la figure que Conrad a donnée deux ans après sa diagnose, laisse beaucoup à désirer: les plis sont placés à peu près à l'emplacement de ceux des Actronella, mais la dilatation de l'ouverture du côté antérieur et la troncature postérieure de la coquille ne ressemble guère à la forme des Trochactron;

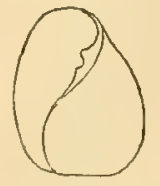

FIG. 40 .

Bullopsis cretacea. Conr.

pour faire ce rapprochement, il faudrait done admettre que Conrad a pris pour la forme normale de la spire une troncature accidentelle. Dans ces conditions, il faut nécessairement attendre qu'on ait de meilleurs maté- 
riaux, avant de se former une opinion définitive sur le classement de cette coupe générique.

Répart. statigr. Sexonien?......

Une espèce de Mississipi, type du genre, trouvée avec כ̋ autres espèces dans Tippalı Country, sans indication exacte du niveau.

\section{RINGICULIDA}

Coquille ventrue, spire courte, à nucléus hétérostrophe ; surface généralement sillonnée dans le sens spiral, quelquefois réticulée ou ponctuée par les accroissements: ouverture étroite, à péristome calleux, plus ou moins échancrée à la base, rétrécie par des plis à la columelle et même par des dents pariétales, ou à l'intérieur du labre qui est invariablement bordé d'un bourrelet variqueux.

Observ. - Le classement de cette famille dans les Opisthobranchiata parait définitivement fixé, non seulement par les caràctères anatomiques de l'animal, mais aussi par l'embryon qui, dans les Ringicula, a la plus grande analogie avec le nucléus apical des Aclxon. D'antre part, le disque céphalique de l'animal des Ringicula ressemble à celui des Actæon, l'animal peut rentrer dans sa coquille; enfin il y a des Tornatellea crétacécs que l'on distingue difficilement des Ringinella, quand celles-ci n'ont pas leur bourrelet labial. C'est pour ces motifs que Zittel a rapproché les Ringiculide des Actronide, au lieu de les placer immédiatement après les Aplustridx, comme l'a fait P. Fischer, qui se basait exclusivement sur la radule.

Tableau des genres, sous-genres et sections

RINGICULA

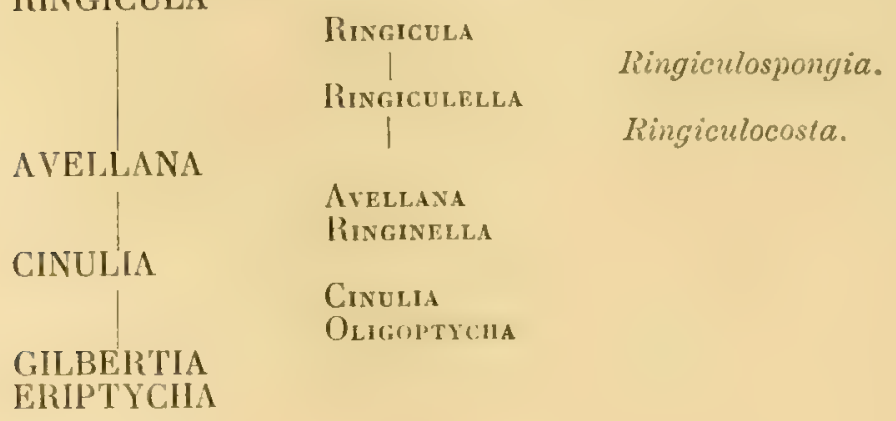




\section{Genres et sous-genres à éliminer de la famille}

Triptycha, Muller. Autant qu'on peut en juger par la figure, Triptycha. limnxiformis doit être classé dans les Auriculidæe et ne peut être considéré comme une coquille d'Opisthobranchiata.

RINGIGULA, Desh. 1838.

[ = Aptycha, Meek 1863, non Aptychus, Meyer, 1829.]

Spire saillante; labre épais, lisse ou crénelé à l'intérieur ; columelle courte, munie de deux gros plis transverses; bord columellaire calleux, portant en arrière une dent pliciforme.

Ringiculd, sensu stricto. Type: Auricula ringens, Lamk. Eoc.

Taille petite; forme ovale, ventrue ; embryon dévié, à nucléus empâté ; spire assez courte, à sutures canaliculées; surface entièrement ou partiellement sillonnée par des stries spirales, rarement lisse ; ouverture petite, peu dilatée, canaliculée en arrière, échancrée en avant ; labre curviligne, incliné à droite de l'axe du côté antérieur, épais, denticulé à l'intérieur, extérieurement bordé par un large bourrelet dénué de stries spirales; le maximum de l'épaisseur du labre est au milieu; il s'amincit en avant et en arrière comme le bord d'une oreille humaine. Columelle courte, arquée, munie de deux plis, l'anlérieur épais contourne l'échancrure supérieure de l'ouverture et rejoint le bourrelet du labre, l'inférieur plus lamelleux et plus transverse s'atténue sur la callosité basale ; bord columellaire largement calleux, formant en arrière une gouttière, à sa jonction avec le labre, portant une dent pariétale très allongée, qui bifurque souvent du côté extérieur ; en avant, cetle callosité columellaire se termine vis-à-vis de l'échancrure du contour supérieur. 
Diagnose prise d'après un individu de l'espèce type, de Grignon (P1. III, fig. 12-14), ma coll.

Observ. - C'est à tort que quelques auteurs attribuent une onverture canaliculée aux Ringicula, qui sont bien holostomes, mais dont le contour supérieur est seulement échancré dans l'épaisseur de la callosité du labre. $\mathrm{Si}$, comme l'affirme Stoliczka, et comme parait l'indiquer la figure, lringicula labiosa, Forbes (Tomalella) a bien les caractères des Ringicula, le nom Aptycha proposé par Meek pour cetle espèce de l'Inde est synonyme et doit disparaitre; il aurait d'ailleurs fait un double emploi avec $A$ plychus.

Répart. stratigr.

Cenomanien.... Une espèce très douteuse, au Mans (R. Deshryesi, Guér.) d'après Morlet.

Turosiex...... Une espèce nouvelle d'Uchaux (R. urorensis, Cossm.), d'après trois échantillons de ma coll. (P). VI, fig. 26-27). - Voir l'annexe. Autre espèce des Bains de Rennes ( $R$. Temenili d'Arch.), coll. de Grossouvre : j'ai vérifié que le labre porte bien, à l'intérieur, les denticulations caractéristiques.

Sexonita....... Une espèce certaine dans le Crúlacé de l'Inde (R. acuta, liorbes), d'après la figure donnće par Stoliczka; autre espèce typique à Aix-la-Chapelle (K. IIagenowi, Mull.), d'après les figures de l'ouvrage de llolzapfel.

P'aleocexe..... Une espèce bien caractérisée dans les sables d'Abbecourt et de Jonchery ( $R$. Cossmanni, Morlet), ma collection.

Eocene ........ Outre le type précité, nombreuses espèces dans le bassin anglo-parisien ( $\boldsymbol{R}$. minor, Desh. Lanrglassei, Besanconi, Rainconti, Norlet), ma coll.: daus l'Alabama ( $R$. biplicala, Lea), ma coll.; dans les Pyrénées ( $R$. vasea, T'ourn.), d'après la figure de l'auteur.

Ohrocexe..... Une espèce typique dans l'Allemagne dı Nord (R. gracilis, Sandb), d'apres von Koenen.

Mrocene....... Une espèce typirue dans le Tortonien des Iandes (R. Crossei, Morlet), d'après la figure.

Epoque acturle. Plusieurs espèces vivant dans les mers actuelles (R. encarpoferens, denticulata, Caron), d'apris Morlet, dans sa Monographie. 
Ringiculospongta, Sacco, 1892. Type: R. Bonellii, Desh. Mioc.

Forme de Ringicula ; spire très courte; surface ornée de sillons spiraus, obliquement guillochés par de fines stries en zigzag; ouverture allongée et très étroite ; labre denticulé à l'intérieur: bordé à l'extérieur d'un gros bourrelet qui envahit la spire et qui, comme le reste du péristomé, est poncliculé par de petites perforations d'un aspect spongieux; columelle munie de deux plis assez épais; dent pariétale presque confondue avec la callosité columellaire.

Diagnose prise d'après des individus typiques des environs de Turin, donnés par M. Sacco (Pl. VI, fig. 11-12), ma coll.

Observ. - L'ornementation de cette coquille, la contexture spongieuse de son péristome, la forme de sa dent pariétale, justifient la séparation qu'a proposée M. Sacco; mais je ne crois pas qu'on puisse, pour des différences aussi secondaires, admettre Ringiculospongia comme cous-genre, c'est seulement une section à démembrer des Ringicula proprement dites.

Répart. stratigr.

Mrocexe...... Une seule espèce type, avec plusieurs variétés, dans le Piémont (R. pseudoringens, ovuloidea, perinflata, Sacco), d'après les figures.

Ringigulella, Sacco, 1892. Type: $R$. auriculata, Mén. Plioc. [ERingiculina, Monts., 1884, insuffis. caract.].

Forme, spire et ornementation de Ringicula; ouverture très étroite en arrière, un peu plus dilatée et faiblement échancrée en avant ; péristome très épais, non spongieux; labre incliné, non denticulé à l'intérieur, bordé à l'extérieur par un très large bourrelet; columelle à deux plis, l'antérieur très épais, ne se confondant pas exactement avec le contour supérieur; bord columellaire très largement calleux, portant en arrière un contrefort 


\section{Ringicula}

longiludinal, plus ou moins saillant, auquel aboutit perpendiculairement la dent pariétale qui souvent se dédouble, de sorle que la coquille semble quadriplissée.

Diagnose prise d'après un individu de l'espèce type du P'laisancién de Bologne $R$. auriculata, var. quadriplicala, Morlet (Pl. IH, fig. 7-9), ma coll.

Observ. - L'absence de denticulation au labre n'est pas le seul caractère qui justifie la séparation du sous-genre Ringiculella: le péristome n'n pas tout à fait la même disposition que dans les Ringicula proprement dites, le pli pariétal surtout est bien plus compliqué et forme une sorte de $\rightarrow$ dont la branche horizontale se dédouble quelquefois. Morlet avait. établi, d'après ce dernier caractère, un très grand nombre d'espèces qu'il y a lieu de réduire dans une large mesure ainsi que l'a fait $\mathbf{M}$. Sacco dans sa Monographie des fossiles du P'iémont, attendu que ce sont des variations individuelles qui n'ont aucune constance.

Dans cette Monographie, M. Sacco n'a pas signalé et discuté le sousgenre Ringiculina, proposé dès 188t, c'est-à-dire huit ans plus tôt, pour R. leptochila, Brugn., sans aucune diagnose à l'appui. Comme cette espèce est, d'après M. Sacco, une forme non adulte de $R$. auriculala, var. major, Grat., il parait incorrect de remplacer la dénomination kingiculella qui a été bien caractérisée, par Ringiculina qui, quoique antérieure, ne correspond même pas à une véritaljle espèce complètement formée, et dont les caractères n'ont pas été précisés par son auteur. Toutefois, avant de trancher définitivement cette question de priorité, j'ai consulté la figure et la description de $R$. leptochila (Miscell. malac., 1873) : or j'ai constaté que, malgré l'assertion de Brugnone, qui affirme que son espèce est bien distincte de $R$. auriculata et qu'il n'en existe pas de plus adulte dans le même gisement, ce n'est qu'un jeune individu qui ne parait porter que deux plis, parce que la troisième dent n'est pas complètement formée et que la callosité columellaire est encore rudimentaire, comme cela a lieu souvent par de jeunes $R$. ringens qui ont le labre mince et édenté. Il n'y a donc pas de doute possible.

Répart. stratigr.

Eocene....... Une espèce tris rare dans le calcaire grossier parisien (R. Dugasti, Morlet), ma coll.

Oligocene..... Plusieurs espèces typiques dans l'Allemagne du Nord (R. coarclata, aperta, seminuda, von Konen), d'après les figures de l'auteur.

Mrocene....... Nombreuses espèces ou variétés du type, soit en Italie (R. gigantula, Dod., etc.), d'après les figures don- 
nées par M. Sacco; soit dans le Bordelais (R. Baylei, Douvillei, Morlet, etc.), ma coll.

P'ziocene....... Le type et ses variétés dans le Plaisancien et l'Astien d'Italie ou des Alpes-Maritimes ( $R$. buccinea, Br. africana, Depontaillieri, Morlet, etc.), ma coll.

Epoque actuelle. Une trentaine d'espèces dans toutes les mers chaudes et tempérées, d'après P'. Fischer.

Ringiculocosta, Sacco, 1892. Type: $R$. costata, Eichw. Mioc.

Taille très petite ; forme et ouverture de Ringiculella ; spire étagée à la suture; surface cancellée par des cordonnets spiraux très fins et par des costules d'accroissement un peu plus écartées comme dans les Alvania ; dent pariétale simple et peu développée; callosité colúmellaire à peine étalée en arrière ; labre muni d'un tubercule interne.

Diagnose prise d'après les échantillons types d'Eichwald, reproduction de la figure dessinée (Pl. VII; fig. 11), d'après ces échantillons communiqués par M. Sokolov.

Oberv. - Si cette coupe ne se distinguait des Ringiculella que par l'existence de costules axiales, et de cordonnets, au lieu de stries spirales, je ne l'aurais pas admise, même comme section de ce sous-genre; mais il y a d'autres caractères qui, quoique d'une importance secondaire, s'ajoutent à cette différence d'ornementation, notamment la disposition scalaroïde des tours de spire, le resserrement du callus dans l'angle inférieur de l'ouverture, la dent pariétale qui est simple et transverse, le tubercule du labre, etc.

Répart. stratigr.

Oligocene......

Mrocene.......

Plocene........
Une espèce dans les sables d'Étampes (R. minutissima, Desh.), d'après la figure de l'auteur.

Le type en Volhynie et dans le Tortonien de MonteGibbio, d'après M. Sacco.

Une variété du type, dans l'Astien du Piémont ( $R$. astensis, Sacco), d'après l'auteur. 
AVELLANA, d'Orb. 1842.

Ouverture sinueuse el subéchancrée, sur le contour supérieur; deux plis antérieurs à la columelle; labre bordé à l'extérieur, souvent denticulé à l'intérieur.

Avellana, sensu str. Type: Auricula incrassata, Sow. Cénom.

Forme globuleuse; spire courte, à galbe conoïde; surface ornée de côtes spirales, dont les intervalles sont décussés ou ponctués par de fines lamelles axiales; ouverture longue, étroite en arrière, peu dilatée en avant, avec une sinuosité subéchancrée sur son contour supérieur ; labre rectiligne, à peu près vertical, épaissi et souvent rétléchi, denticulé ou quelquefois fortement denté à l'intérieur, bordé à l'extérieur par un large bourrelet aplati dont la surface ne porte que quelques sillons d'accroissement régulièrement écartés. Columelle courte, excavée, munie de deux gros plis lamelleux et distants; bord columellaire calleux, recouvrant presque entièrement la fente ombilicale, muni en arrière d'une dent pliciforme ou même d'un renflement peu saillant, contournant en avant l'échancrure supérieure, pour faire sa jonction avec le bourrelet du labre.

Diagnose prise d'après l'espèce type, complétée d'après un individu d'une espèce voisine, A. dubia, Br. et Corn. de la meule de Bracquegnies (Pl. III, fig. 1כ̆-17), ma coll.

Observ.-Contrairement àl'opinion de Meek (Cret. Upper Missouri 1876), je ne crois pas qu'on doive classer Lvellana comme sous-genre de Cimulia, dont le nom est antérieur, mais dont les caractères sont bien diflérents, comme on le verra plus loin. La séparation, d'ailleurs motivée, de ces deux genres permet de conserver la dénomination de d'Orbigny, qui tomberail en synonymie dans l'hypothèse de Meck.

Les Avellana se distinguent des Ringicula par leur ouverture moins profondément échancrée, par leur ornementation décussée, par la disposition du pli antérieur qui s'arrête subitement à la limite du bord columcllaire, 
tandis que, dans les Ringicula, le pli est dans le prolongement du bourrelet qui contourne l'échancrure et rejoint le labre; au contraire, le bord columellaire qui, dans les Ringicula, se termine à l'échancrure sous le prolongement du pli, est chez les Avellana, le prolongement du bourrelet du contour supérieur : la disposition est donc exactement inverse dans ces deux genres.

Répart. stratigr.

Albiex......... Plusieurs espèces, outre le type, dans le Gault d'Angleterre, de France ou de Suisse (A. subincrassala, dupiniana, hugardiana, d'Orb.), d'après les figures de la Paléont. française.

Cenomaniex.... Nombreuses espèces, outre le type, en France et en Angleterre'(A. cassis, mailleana, d'Orb, ete.); en Belgique soit dans la Meule ( $\lambda^{\prime}$. dubia), ma coll., soit dans la Tourtia (A. Prevosti d'Arch.), coll. du Musée de Dijon.

Ringinella, d'Orb. 1842. Type: R. clementina, d'Orb. Gault.

[= Stomatodon, Seeley 1861, insuffis. caract. $]$

Forme ovoïdo-conique ; spire allongée, pointue, à galbe conique; surface ornée de sillons écartés et finement ponclués ; ouverture courte, anguleuse en arrière, dilatée en avant, avec une sinuosité subéchancrée sur le contour supérieur ; labre épaissi par un très large bourrelet aplati, non dentelé à l'intérieur ; columelle peu excavée, munie de deux plis lamelleux, l'antérieur bifide, le postérieur assez écarté de l'aulre, tous deux se terminant à la limite du bord columellaire, qui est dans le prolongement du contour supérieur.

Diagnose prise d'après des individus typiques de Saint-Florentin (Pl. III, fig. 28-30), coll. de l'École des Mines).

Observ. - Ce sous-genre se distingue des Avellana par sa spire pointue et plus allongée, par son ornementation, par son pli antérieur bifide, par l'absence de callosité et de pli pariétal dans l'angle inférieur de l'ouverture; des Triploca qui ont trois plis bien distincts, par ses deux plis qui ne paruissent ètre au nombre de trois que quand l'antérieur est bien divisé 


\section{Avellana}

en deux, et par son large bourrelet au labre. C'est dans ce sous-genre qu'il me semble prudent de classer le moule à peu près indéterminable du grès vert de Cambridge, auquel Seeley a donné le nom Slomalodon, avec cette seule différence que les deux plis columellaires sont placés plus au milieu; quant à l'ouverture de cette coquille, si elle a paru holostome à l'auteur, c'est que, comme le fait remarquer Stoliczka, tous les moules internes d'Avellana ont le même aspect.

Répart. stratigr.

Neocomiex..... Plusieurs espèces en France (Aclaxon albensis, d'Orb., etc.), d'après les figures de la Paléont. francaise.

Aptien........ Une espèce du gisement de Sainte-Croix (Avellana aptiensis Pict. et Camp.), d'après les figures de ces auteurs et d'après un échantillon médiocre de la coll. du Musée de Genève.

Atbien........ Plusieurs espèces, outre le type, en lirance, en Angleterre et en Suisse (Tornatella lacryma, Mich., inflata, Fitton), coll. de l'Ecole des Mines et du Musée de Dijon (Avellana alpina, Pict. et Roux), coll. du Musée de Genève.

CINULIA, Gray, 1840.

Ouverture faiblement sinueuse à la base; un seul pli columellaire; labre bordé d'un bourrelet étroit, lisse à l'intérieur.

Ginulis, sensu stricto. 'Type: Auricula globulosa, Desh. Néoc.

Forme globuleuse; spire courte, subitement effilée en pointe au sommet, à galbe extra-conique; dernier tour subanguleux en arrière, ovale à la base, orné de stries spirales et ponctuées; ouverture étroite et arquée, à peine sinueuse sur son contour supérieur; labre épais, bordé à l'extérieur d'un étroit bourrelet, lisse à l'intérieur; columelle très courte, avec un pli très oblique dont le prolongement se raccorde avec le péristome, sur le bord antéricur de l'ouverture, bord columellaire peu calleux en arrière: dénué de dent pariétale. 
Diagnose prise d'après la figure du type, dans la Paléont. française, reproduite (Pl. VII, fig. 17).

Observ. - Il y a d'importantes différences entre ce genre et les Avetlana: d'abord le nombre des plis, puis la disparition à peu près complète de l'échancrure antérieure, enfin le labre moins largement bordé. Dans les Cinulia proprement dites, le pli se raccorde au péristome, et le bord columellaire est peu calleux et ne porte pas de dent pariétale; quant aux Ringinella qui ont ce dernier caractère commun avec les Cinulia, le pli supérieur, d'ailleurs bifide, ne se confond pas avec le contour; enfin, la forme pointue de la spire écarte complètement les Cinulia des deux autres coupes.

Répart. stratigr.

Neocomien..... Une espèce, type du genre, d'après la Paléontologie crétacée.

Cenonanien.... Une espèce douteuse, à Cassis (Actæon ovum, Duj.), d'après la Paléont. française.

Oligoptycha, Meek, 1876.

Type: Actæon concinmus, Hall et Meek. Grét.

Forme globuleuse; spire courte, déprimée, obtuse; surface ornée de stries spirales, fines et ponctuées; ouverture auriforme, à peine sinueuse à la base; labre bordé d'un étroit bourrelet à l'extérieur, lisse à l'intérieur; columelle très courte, excavée, avec un seul pli transverse, très saillant, limité au contour du bord columellaire, qui est calleux et s'étend dans l'angle inférieur de l'ouverture.

Diagnose prise d'après la figure de l'ouvrage Meek et Hayden, reproduite (Pl. VII, fig. I气̃).

Observ. - Par sa forme générale, ce sous-genre se rapproche des AvelIana; mais son bourrelet étroit et lisse à l'intérieur, son unique pli columellaire, la disparition de l'échancrure basale, me paraissent justifier le classement des Oligoptycha près du genre Cinulia; ils s'en distinguent toutefois par la disposition du pli qui est presque horizontal (si la figure est bien exacte), beaucoup plus saillant, et qui ne se raccorde pas avec le 
Cinulia.

contour supérieur, par la callosité columellaire plus développée, enfin par la forme de la spire, qui n'est pas pointue.

Répart. stratigr.

Senonien .......

Une espice type, provenant des couches crétacées supéricures du Missouri, c'est-à-dire à peu près l'équivalent de la Craie de Maëstricht.

GILBER'TIA, Morlet em. 1888.

[non Gilbertima, dedic. Gilbert nec Gilbertin.]

Ouverture non sinueuse à la base, mais latéralement versante; labre muni de deux tubercules: callosité columellaire très développée, avec deux plis antérieurs transverses et une côte pariétale longitudinale.

Gilbertia, sensu stricto: Type: G. imopinata, Morl. Paléoc.

Forme globuleuse; embryon à peine dévié, à nucléus probablement hétérostrophe, mais empâté dans une minuscule excavation; spire très courte; surface ornée de stries spirales fines et écartées; ouverture auriforme, sans échancrure ni sinuosilé sur son contour supérieur; labre épais, presque vertical, renversé à gauche de l'axe, du côté antérieur, muni d'un large bourrelet extérieur qui porte quelques stries irrégulières d'accroissement et deux tubercules dentiformes à l'intérieur. Columelle courte, excavée, avec deux plis spiraux el lamelleux, très rapprochés; bord columellaire fortement calleux, s'étendant sur une partie de la base qui est déprimée, creusé par une dépression latérale et versante vis-à-vis des plis columellaires, rejoignant cn avant le bourrelet du contour supérieur de l'ouveriure, muni en arrière d'une longue côte pariétale parallèle à son contour et faisant un angle très aigu avec le pli columellaire inférieur. 
Diagnose prise d'après des individus typiques de Jonchery (Pl. III, fig. 18-20) ma coll.

Observ. - Après un nouvel examen de cette singulière coquille, je n'hésite pas à reconnaître que j’ai fait erreur en proposant (Catal. Eoc. IV, p. 3د̆1) de la rapprocher des Pedipes, et en soutenant cette opinion (Bull. Soc. malac. Belg., XXVI, 3 oct. 1891), contre M. E. Vincent, qui la classait au contraire dans les Ringiculidæ. C'est, en effet, dans cette dernière famille qu'est sa véritable place, auprès des Avellana, ou plutôt des Eriplycha: la disposition de l'embryon que j'ai enfin pu observer intact, l'enroulement des plis columellaires, qui ne sont pas de simples dents, contrairement à ce que j'avais cru observer, la côte pariétale qui ne ressemble pas à la dent des Pedipes, enfin la dépression versante de l'ouverture à la base, remplaçant l'échancrure des Ringicula ou la sinuosité des Avellana, justifient cette conclusion. Toutefois le genre Gilbertia mérite d'être distingué des Avellana, à cause de ses tubercules labiaux, de son ouverture non sinueuse en avant et de sa côte pariétale; ainsi que des Cinulia, à cause de ses plis columellaires, de sa côte pariétale, de sa callosité basale, de son labre plus largement bordé et intérieurement tuberculeux, de sa spire non mucronée.

Répart. stratigr.

Paleocene....... Outre le type de la Marne une espèce bien caractérisée à Copenhague (Cinulia ultima, v. Kœen.) d'après la figure de l'auteur, et une espèce probablement différente du type (Avellana teriaria, Vinc.) d'après la citation de l'auteur.

ERIPTYCHA, Meek, 1876.

[Euptycha, Meek 1863, non Hübner 1816.]

Ouverture très étroite, subcanaliculée à la base; labre bordé d'un étroit bourrelet, intérieurement tuberculeux; un pli columellaire parfois bifide et une dent pariétale très variable.

ERIPtycha, sensu str. Type: Auricula decurlata, Sow. Turon.

Forme globuleuse, subsphérique; spire courte; ornementation d'Avellana; ouverture arquée très étroite, grimaçante quand la 


\section{Eriptycha}

coquille est adulte, non sinueuse sur son contour supérieur, mais étroitement subcanaliculée par une étroite échancrure cntaillée aux dépens de l'épaisseur du péristome; labre épais, presque vertical, un peu incliné à gauche de l'axe, du côté antérieur', bordé à l'extérịeur par un bourrelet assez étroit, surtout en arrière, portant à l'intérieur plusieurs tubercules dentiformes en avant et de fines crénelures du côté postérieur. Columelle très courte, excavéc, munie d'un gros pli lanelleux, presque toujours bifide, qui se prolonge et se tord sur le contour supérieur de l'ouverture, dont il est séparé par l'échancrure superficielle déjà mentionnée: bord columellaire large et calleux, avec une dent pariétale à peine indiquée sur les jeunes individus, lamelleuse et saillante, quelquefois échancrée en deux protubérances, dans les individus adultes.

Diagnose prise d'après des individus typiques des Bains de Rennes (Pl. VI, fig. 1-3) coll. de Grossouvre; autre forme voisine, E. Humboldli, Mull., individu non adulte de Vaels (Pl. III, fig. 10-11) coll. de l'École des Mincs.

Observ. - Il n'y a pas lieu d'attacher une imporlance capitale aux variations de la dent pariétale, car on risquerait decréer des sections distinctes selon l'âge de l'individı qu'on étudie; l'échancrure basale et l'alssence d'une véritable costule pariétale distinguent ce genre des Gilbertia qui s'en rapprochent le plus; les Eriptycha s'écartent, d'autre part, des Cinulia et des Avellana par leur plication, par leur labre tuberculeux et par leur contour supérieur non sinueux. L'échantillon de Vaels que j'ai fait photographier (Pl. III) ne ressemble guère au type (Pl. VI); cependant, si l'on se reporte aux excellentes figures données par M. Holzapfel (Aachener Kireide, Pl. VI, fig. 19.22), et qui représentent quatre individus tous différents, on constate qu'il faut admettre une très grande variabilité dans la plication columellaire des espèces de ce genre, 'selon l'âge, ct souvent sur la même espèce.

Répart. stratigr.

Neocomen..... Une espèce probable dans l'Aube ( $\mathrm{Acl}$. ringens, d'Orb.) d'aprés la Paléont. française.

Tunoniex...... Le type à Gosau (Tyrol), d'après les figures de Zekeli; individus bien conformes des Bains de Rennes, coll. de Grossourve. 
Sex̃oniex . .... Trois espèces bien caractérisées, dans le Crétacé supérieur de l'Inde (E. globata, larvata, Stol, oviformis, Forbes) d'après les figures de l'ouvrage de Stoliczka; probablement aussi Avellana scuptilis, Stol.; une espèce dans les grès d'Aix-la-Chapelle Cinulia Humbold $i$, Muller) d'après les figures de l'ouvrage de Ilolzapfel, et d'après un individu non adulte de la coll. de l'École des Mines.

\section{PIILINID A}

Goquille mince, complètement interne; ouverture très découverte, spire incomplètement enroulée autour d'un axe fictif.

Tableau des genres, sous-genres et sections

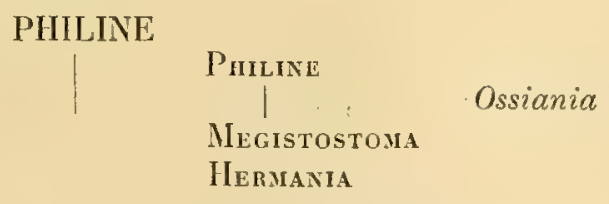

\section{Genres et sous-genres non signalés à l'état fossile}

Chelinodura, Ad. 18 ö0; Phanerophtaludus, Ad. 18000 ; Cryptophtalmús, Ehr. 1831 ; Johania, Monts. 1884; Philnopsis, Pease 1860.

PHILINE, Ascanius, 1772.

[=Bullea, Lamk. 1801; = Lobaria, Mull. 1776; = Utriculopsis, Sars 1870; = Laona, Ad. 1865 ; sec. P. Fischer.]

Philine, sensu slricto. Type: Bulla aperta, Lin. Viv.

Forme d'un Scaphander déroulé; spire formée d'un cornet faisant une seule révolution, imperforée au sommet; surface dorsale lisse, striée en spirale, ou plissée par les accroissements; ouver- 
I'hiline.

ture formant toute la coquille, laissant apercevoir l'enroulement rudimentaire de la spire; labre arrondi, dépassant a peine le sommet, se raccordant par une sinuosité avec le callus de l'extrémité inférieure du bord columellaire qui est très mince et peu étalé sur la base.

Diagnose prise d'après un individu de l'espèce type de la Méditerranée (Pl. VI, fig. 13) ma coll.

Répart. stratigr.

P'hocexe...... Une espèce dans le $\operatorname{Crag}(B$. calena, Mont, sub. nom. B. sculpta., Wood) d'après les figures de l'ouvrage de Wood; la même dans la Calabre, d'après Séguenza.

Epoque actuelle. Vivant dans toutes les mers, d'après P. Fischer el Dall.

Ossiania, Mont 1884. Type: Bulliea quadrata, Wood. Plioc.

Forme quadrangulaire; dernier tour coudé au milieu; surface finement ornée en spirale; ouverture presque rectangulaire, à coins arrondis; labre un peu déprimé, dépassant à peine le sommet; bord columellaire mince et étroit, très excavé au milieu.

Diagnose prise d'après les figures de l'ouvrage de Wood, reproduites (IPI. VII, fig. 3 ).

Observ. - Cette section ne me paraît différer des Philine que par sa forme extérieure; mais je ne puis la supprimer, n'ayant pas l'espèce type sous les yeux.

Répart. stratigr.

Plocene...... Une espèce type dans le Crag d'Angleterre, d'après les figures de Wood.

Epoque actuelle. Une espèce de la Méditerranée (Philine Monlerosaloi, Jefir.) d'apris Monterosato. 
Megistostona, Gabb. 1864. Type: M. striatum, Gabb. Paléoc.

Forme et spire de Philine; bord columellaire calleux; labre prolongé en arrière et formant une digitation parfois aiguë, avant de se raccorder au sommet.

Diagnose prise d'après un plésiotype possible du bassin de Paris, Bullza expansa, Desh. (PI: V, fig. 7-8), du Fayel, ma coll.

Observ. - Ce sous-genre ne se distingue des Philine que par deux caractères constants, qui ont une importance secondaire, la digitation du labre et l'épaississement du bord columellaire; dans ces conditions, comme Megistostoma n'est pas un genre distinct de Philine, le type $M$. striatum doit changer de nom spécifique, pour éviter le double emploi avec $P$. striala, Desh. du calcaire grossier parisien : je propose $M$. Gabbi, nob. Les couches dans lesquelles a été recueillie cette espèce n'appartiennent pas à la Craie, mais à la base de l'Eocène, d'après White.

Répart. stratigr.

Senoniex....... Une espèce très douteuse dans la Craie de Syrie (M. patulum, Whitf.); la figure n'indique ni digitation labiale, ni épaisșissement columellaire.

Paleocene..... L'espèce type en Californie, d'après P. Fischer qui y assimile les fossiles parisiens.

Eocene........ Plusieurs espèces bien caractérisées dans le bassin de Pāris (Bulliea striata, excavata, expansa, Vaudini, Desh., Philine corrugata, Cossm.) ma coll.; dans le Viceniin (Bullxa Meneghinï, Bayan.) coll. de l'École des Mines.

Mrocene...... Une espèce dans l'Allemagne du Nord ( $P$. complanata, v. Kœn.) d'après les figures de l'auteur.

Pltocese ...... Une espèce certaine dans le Plaisantin (Bullea rostrata, Desh.) coll. de J'École des Mines.

Hermania, Monteros. 1884. Type: Bullea scabra, Mull. Viv. [non Hermannia, Nic. Arachn. 1855.]

Forme étroite et allongée; spire incomplètement enroulée, apparente, obtuse et excavée au sommet; dernier tour cylindro-conique, 


\section{Philine}

élégamment guilloché par des chaînettes allernant arec des stries, qui prennent en avant une direction divergente, parallèle au bord columellaire. Ouverture étroite en arrière, très dilatée en avant, laissant apercevoir l'impression musculaire à l'intéricur du labre qui est échancré près de la suture; bord columellaire très mince, peu distinct.

Diagnose prise d'après la description et la figure de l'ouvrage de Wood, reproduite (PI. VII, fig. 1-2).

Observ. - Cette coquille ressemble plus à un Scaphander qu'à une Philine, dont elle s'écarte par sa forme moins déroulée, par son ornementation et par sa spire apparente: elle s'y rattache cependant par la minceur du test et par les caractères de l'animal. Je n'ai pu étudier l'espèce type.

Répart. Stratigr.

Mrocene........

Deux espèces probables dans l'Allemagne du Nord (Philine intermedia el rotundata, v. Kon.) d'après les figures de l'auteur.

Phocexe....... Le type dans le Cragd'Angleterre, d'après les figures.

Epoque actuelle. La même espèce vivant sur les côtes d'Ecosse, dans la Méditerranée et l'Adriatique, d'après Monterosato.

\section{APLYSIII}

Coquille interne, mince, plus ou moins translucide, ayant la forme d'une lamelle à peine courbée; le côtẻ du sommet et l'enroulement de la spire représenté par un épaississement plus ou moins calleux du bord.

Tableau des genres, sous-genres et sections

DOLABELLA. 


\section{Genres et sous-genres non signalés à l'état fossile}

Aplysia. Juin. Les individus qui ont été cités par Philippi (A.grandis et deperdita) dans le Pliocène de la Sicile, ne sont que la couche interne de certains Pectunculus ou Lucina très abondants, et se dédoublant quelquefois, d'après la note publiée par Depontaillier (Journ. Conch.).

Aplysiella, Fischer 1872; Siphovotus, Ad. 1850; (non Brandt, nom changé en Syphonota H. et A. Adams, qui grammaticalement est identique); Dolabrifer, Gray 1847; Notalchus, Cuvier; Acresia, Rang 1828; Stylochilus, Gould 1892; Pnyllaplysia, Fisch. 1872, coquille inconnue?

DOLABELLA, Lamk, 1801.

Dolabella, sensu stricto. Type: D. Rhumphï, Guvier. Viv.

Forme de Megistostoma encore plus déroulée et entièrement ouverte, représentant à peu près une doloire gauchie; spire tout à fait encrontée par l'épaississement du bord columellaire ; labre un peu courbé, muni en arrière d'une sáillie subdigitée, au-delà de laquelle le contour inférieur est profondément entaillé et porte un petit rebord très étroit.

Diagnose prise d'après un individu de l'espèce typa, de la Nouvelle-

Calédonie (PI. V, fig. 12-13) ma coll.

Répart. stratigr.

Mrocene...... Une espèce peu certaine dans le Tertiaire de la Floride (D. Aldrichi, Dall), d'après un simple fragment plus enroulé en spirale et moins aplati que le type vivant; reproduction de la figure donnée par l'auteur (PI. VII, fig. 14).

Epoque actuelez. Vivant dans la Mer Rouge, l'Océan indien, l'Océan Pacifique, d'après P. Fischer, une dizaine d'espèces, d'après le catalogue de Pæetel. 


\section{OXYNOEID/E}

Corfuille cartilagineuse, non susceptible de se conserver à l'état fossile; dans ces conditions, bien qu'il existe une certaine analogie de forme entre les Oxynoe el les $A \operatorname{cer}^{2} a$, il ne paraît pas qu'il $\mathrm{y}$ ait lieu d'y rapporter aucune forme paléontologique.

\section{PLEUROBRANGIID.E, RUNCINIDA}

Coquille membraneuse ou absente, non susceptible de fossilisalion.

\section{UMIBRELLIDA}

Coquille patclliforme, ovale, à sommet subcentral, à nucléus sénestre; impression musculaire continue.

Tableau des genres, sous-genres et sections

UMBRELLA.

TYLODINA.

Genre non signalé à l'état fossile

JoAnnisia Monteros. 1884 (Type: Tylodina cilrina, Joannis = Umbrella patelloides, Cantr.). 
UMBRELLA, Chemn, 1788.

$$
\begin{gathered}
\text { [- Acardo Lamk., 1801, non Brug., 1791. = Umbraculum, } \\
\text { Schum., 1817. = Gastroplax, Blainv., } 1819 . \\
=\text { Umbrella, Lamk., 1819.] }
\end{gathered}
$$

UMBrella, sensu stricto. Type : $U$. chinensis, Chemn. Viv.

Forme aplatie, plus ou moins régulière; embryon capuliforme, placé presque au milieu; surface extérieure lisse, sillonnée par des accroissements irréguliers, mal nivelée; surface interne rayonnée au centre; impression musculaire formant un ruban concentrique assez large, plus écartée du bord aux extrémités que sur les côtés latéraux.

Diagnose prise d'après un plésiotype fossile des sables d'Aizy, U. laudunensis, Desh. (Pl. V, fig. 9-10) ma coll.

Observ. - Ainsi que l'a fait observer M. Dall, (Explor. gulf Mexique, p. 60), la dénomination Umbrella n'a été régulièrement adoptée par Lamarck qu'en 1819. Dans son cours, en 1809, il s'est borné à employer le nom " l'Ombrelle " qui n'est ni latinisé, ni accompagné d'une diagnose; dans lintervalle Schumacher ayant publié la deseription de son genre Umbraculum qui s'applique aux mêmes coquilles, cette dénomination devrait prévaloir, d'après M. Dall. Mais le nom Umbrella était adopté antérieurement même au cours de Lamarck: on le trouve déjà dans Chemnitz, en 1788, appliqué à la même espèce comme type (Patella umbellala, Gm.); il n'est donc pas possible de reprendre le nom Umbraculum qui se trouve, en fait, postérieur à Umbrella, non Lamk. sed Chemnitz.

Répart. stratigr.

Eocene ........ Le plésiotype ci-dessus signalé dans le bassin de Paris. Oligocene ...... Une espèce très douteuse, dont la surface interne n'a pu être étudiée, dans l'Allemagne du Nord (U.plicatula, von Kœn.) d'après la figure donnée par l'auteur.

Phrocene....... Une espèce dans la Haute Italie ( $U$. elongata, Mich.) d'après Zittel; dans le Plaisantin et en Sicile $(U$. mediterranea, Lamk.) d'après Philippi et Monterosato. 
Epoque actublze. Deux espèces vivant dans la Méditerranée et l'Océan indien, aux Canaries, d'après P. Fischer; dans la mer des Antilles, d'après Dall.

TYLODINA, Rafinesque, 1814.

Trcodiva, sensustricto. Type: T. punctulata, Rafinesque. Viv.

Coquille conique, déprimée, ovale ; sommet subcentral; impression musculaire continue ; bords feuilletés, fendillés, membraneux.

Diagnose reproduite d'après P. Fischer, reproduction de la figure donnée par Tryon (Pl. VII, fig. 13).

Répart. stratigr.

Pleistocent.... Une espèce citée par Philippi en Sicile (T. Rafinesquei, Phil.).

Epoque actuelle. Quatre espèces vivant dans la Méditerranée, sur les côtes de Norvège et de Californie, d'après P. Fischer, et d'après le Catalogue de Pretel.

NUCLEOBRANCHIAT'A

\section{P'TERothachatd}

CARINARIA, Lamk. 1801.

Garinaria, sensi stricto. Type : C. vitrea, Lamk. Viv.

Coquille vitreuse et fragile, cupuliforme; nucléus dextrogyre, héliçoìdal, multispiré, carène dorsale dentelée; accroissements régulièrement costulés; ouverture grande, à bord simple. 
Diagnose reproduite d'après P. Fisclıer; plésiotype fossile du Piémont, C. Hugardi, Bell. reproduction de la figure (Pl. VII, fig. 9).

Répart. stratigr.

Mrocene...... Deux espèces dans les environs de Turin (C. Hugardi Bell. et Pareti, Mayer) d'après Bellardi et Zittel.

Puocene....... Une espèce à Trapani (C. peloritana, Seguenza).

Epoque actuelle. Huit espèces vivant dans la Mléditerranée, l'Atlantique, l'Océan indien, les mers de Chine, d'après P. Fischer.

\section{Genres et sous-genres non signalés à l'état fossile}

Pтеrotrachea, Forskal, 178ä (= Firola, Brug. 1792) pas de coquille. Firoloida, Lesuéur, 1817 (= Firolella, Troschel, 18ås) pas de coquille. Cardapoda, d'Orb.1839 (=Carinaroida, Souleyet 18ə2) coquille microsc. Ceropleura, d'Orb. 1841, d'après P. Fischer...... pas de coquille.

\section{ATLANTID A}

Coquille mince, spirale, discoïde, operculée; embryon saillant.

ATLANTA, Lesueur, 1817.

[E Steira, Eschboltz, 1825, d'après P. Fischer, non Steira, IVestw., 1837.]

Atlanta, sensu stricto. Type: A. Peroni, Lesueur. Viv.

Forme comprimée; sommet dextre, formant un petit nucléus du côté droit; tours en contact ; carène dorsale très saillante ; ouverture ovale, étroite, profondément échancrée au-dessus de la carène, à bord simple et tranchant; opercule spiral, portant un petit nucléus spiral, à spire dextre. 
Diagnose reproduite d'après le Manuel de P'. Fischer.

Répart. stratigr.

Mrocrne...... Une espèce dans le Tertiaire de Saint-Domingue (A. cordiformis, Gabb.), le type au Musée de Philadelphie, n'a pas été figurée (Dall. in litt.); autre espèce très douteuse, non nommée, à PolnischOstrau, d'après Kittl.

Epopue actuelle. Environ 40 espèces vivant dans les parties chaudes de l'Atlantique, la Méditerranée, l’Océan Pacifique, d'après P. Fischer.

\section{EOATLAN'TA, Cossm., 1889.}

Test translucide ; tours déroulés, à section circulaire, dépourvus de carène.

Eoatlanta, sensu stricto.

Type: Cyclostoma spiruloides, Lamk. Eoc.

Forme d'une corne d'abondance ; nucléus embryonnaire légèrement saillant; tours arrondis, détachés, ornés de fines stries annulaires et marqués, de place en place, par des accroissements assez réguliers.

Diagnose faite d'après un échantillon typique de Grignon

(l). VI, fig. 6-7) ma coll.

Observ. - Par la minceur de son test et par la disposition de son sommet dextrogyre, cette singulière coquille parait appartenir à la famille Allantidx, quoiqu'elle n'ait pas la carène dorsale des Atlanta, ni l'échancrure de l'ouverture; elle ressemble aussi aux Spirula, mais elle est dénuée de cloisons internes.

Répart. stratigr.

Eocene ........ Une seule espèce connue et très rare, dans le calcair e grossier parisien. 
Genre non signalé à l'état fossile

Oxygyrus, Bensar, 1837. (= Ladas, Cantr. $1841=$ Helicophlegma, d'Orb. 1839 = Browonia, d'Orb. 1841, d'après Pætel).

\section{PULMONATA \\ (Thalassophila)}

\section{SIPIIONAIRIIDA}

Coquille patelliforme, dissymétrique ; impression de l'adducteur de la coquille interrompue par un sinus latéral correspondant à l'orifice pulmonaire et situé du côté antérieur.

Tableau des genres, sous-genres et sections SIPHONARIA

$\mid \begin{array}{ll}\text { Siphonaria } \\ \text { Williamia }\end{array}$

Sous-genre non signalé à l'état fossile

Lirioua, Dall, 1870; coquille très mince.

SIPHONARIA, Sow. 1824.

[=Liria, Gray, 1824; - Trimusculus, Schmidt.]

Siphonaria, sensu stricto. Type : S. sipho, Sow. Viv.

Test solide; forme ovale ou arrondie; sommet obtus, placé au centre ou un peu en arrière; surface ornée de côtes rayonnantes 
Siphouarta

qui produisent le plus souvent des festons ou même des digitations, sur les bords de l'ouverture; impression musculaire en fer à cheval, dont les deux extrémités antérieures sont réunies par un sillon superficiel qui correspond à la ligne d'attache du manteau de la coquille; la branche de gauche (quand on regarde l'intérieur, le côté antérieur orienté vers le haut) est interrompue par une gouttière plus ou moins profonde, qui part du centre et aboutit au bord en y produisant une faible saillie du contour : au-dessous de cette gouttière, la branche gauche, plus courte que l'autre, est terminée en massue ; au-dessus de la gouttière est un lobe isolé, relié par le sillon horizontal avec la branche droite, dont l'extrémité antérieure ne s'élargit pas.

Diagnose d'après un plésiotype fossile du bassin de Paris,

S. spectabilis, Desh. de Valmandois (Pl. V, fig. 17-19) coll. Bernay.

Répart. stratigr.

Paleocene..... Une espèce bien caractérisée, à Chenay (Marne) dans les sables de Bracheux ( $S$. Laubrierei, Cossm.) ma collection.

Eocene....... Une espèce dans Ie Suessonien (S. liancurtensis, Cossm.) coll. Chevalier; quatre espèces dans le Bartonien (S. spectabilis, costaria, crassicosia, Desh.) ma coll. (S. glabrata, de Rainc.). coll. de l'Ecole des Mines; aucune espèce signalée au niveau intermédiaire du calcaire grossier.

Mrocene...... Une espèce inédite dans le Bordelais, coll. DegrangeTouzin et S. subcostaria, d'Orb. citée par Benoist; autre espèce signalée par Dollfus et Dautzenberg dans leur liste des faluns de Touraine (Siph. Tournoueri, D. D.); autre espèce dans les couches de Sibérie (S. penginie, Dall).

Epoque actuelle. Nombreuses espèces vivant dans les mers australes et une au sud de l'Europe, d'après I'. Fischer. 
Williamia, Monteros.

Type : Patella Gussoni, Costa. Viv.

[= Scutulum, Monts. non Tournouer, $1869 ;=$ Allerya, Mörch, 1877, non Bourg., 1876 ; = Parascutum, Cossm., 1892.]

Test mince; forme irrégulière; sommet subcentral, un peu recourbé et même spiral sur les jeunes individus ; surface extérieure souvent rayonnée; impression musculaire interrompue, à branches très inégales, non reliées : celle de droite est étroite et se prolonge plus que celle de gauche qui, plus élargie, ne s'élève qu'à la moitié de la hauteur; lobe très obsolète ou indistinct; sillon pulmonaire à peine indiqué.

Diagnose prise d'après le plésiotype fossile du calcaire grossier de Chaumont (Umbrella Raincourti, Cossm. (Pl. V, fig. 20-21), coll. Bourdot.

Observ. - Ce sous-genre se distingue des Siphonaria proprement dites, non seulement par la consistance du test qui est beaucoup plus mince, mais surtout à cause de la forme de l'impression musculaire, dont les branches asymétriques ne sont reliées par aucune ligne de jonction; le lobe est invisible ou confondu avec la branche de gauche, et le sillon pulmonaire est beaucoup moins perceptible entre ce lohe et la branche gauche. Si la figure donnée par MM. Dollfus et Dautzenberg, dans les Mollusques du Roussillon, pour W' Gussoni, est exacte, l'interruption de l'impression musculaire est à droite, quand on regarde l'intérieur de lit coquille, c'està-dire que cette interruption est juste à l'opposé de la position qu'occupe le sillon pulmonaire dans les Siphonaria; mais cette différence n'a pas l'importance qu'on pourrait lui attribuer aú premier abord, attendu que, pour la désignation de côté droit ou côté gauche, tout dépend de l'orientation qu'on donne au sommet : or ces auteurs ont placé le sommet du côté antérieur; en retournant au contraire la coquille, de manière que le côté postérieur soit le plus court, le sillon pulmonaire reprend la place qu'il occupe normalement dans les Siphonariidx, c'est-à-dire le côté gauche, et dans ces conditions, l'individu de l'Eocène que j'ai rapporté au même sousgenre, présente la même disposition.

Si cependant l'on constatait ultérieurement quelques différences, soit dans la structure de l'impression musculaire, soit dans la position du sommet, il y aurait lieu d'appliquer à $U$. Raincourti le nom Parascutumi que j'avais proposé pour corriger le double emploi de $S$ cululum, sans me douter que cette correction avait déjà été faite par M. de Monterosato. 
Répart. stratigr.

Eocene ........ Une espèce, plésiotype ci-dessus signalée.

Oligocenk..... Une espèce, à impression discontinue, dans l'Allemagne du Nord (Umbrella rugulosa, v. Knn.) d'après la figure de l'auteur.

Epoque actuelle. L'espèce type vivant dans la Méditerranée, l'Adriatique, et l'Atlantique, d'après Monterosato.

ANISOMYON, Meek et Hayden, 1876.

Anisomyon, sensu stricto.

Type : Helcion patelliformis, M. et H. Crét.

Test mince; forme patelloïde, obliquement conique; base ovale ou circulaire, à bords simples; surface extérieure à peı près lisse, quelquefois marquée de lignes d'accroissement et de faibles stries rayonnantes ou d'une arête postérieure ; sommet élevé, recourbé, non spiral, presque central ou placé à la moitié de la distance entre le milieu et le bord antérieur. Impression musculaire en fer à cheval très élargi, interrompue du côté antérieur, où ses deux branches très inégales sont reliées par une ligne passant à peu près sous le sommet; la branche de droite (située à gauche quand on regarde le moule interne de l'espèce type) est la plus allongée, et se termine par un crochet ovale; celle de gauche est interrompue assez en arrière, de sorte que le lobe isolé, s'il existe, devait être étroit et allongé ; sillon pulmonaire indistinct, rayonnant du côté postérieur, en admettant qu'il élait tracé entre ce lobe et la branche de gauche.

Diagnose refaite d'après les figures de l'ouvrage de Meek sur la Craie du Missouri; reproduction de la vue, en plan, du moule de l'espèce type (Pl. VII, fig. 18).

Observ. - L'étude de l'impression musculaire et du sommet de ces coquilles ne permet pas de les classer dans les Patellidx, et c'est avee raison que Meek les rapproche des Siphonamiidie. Il y a toutefois, entre elles et les Siphonaria, des différences assez profondes pour motiver la 
Anisomyon

création d'un genre distinct: surtout la direction du sillon pulmonaire qui devait probablement rayonner du côté le plus court, en s'écartant de l'interruption antérieure des branches de l'impression musculaire. La plupart des auteurs hésitent à séparer Anisomyon de Williamia; cependant, dans ce dernier genre, le lobe isolé est placé plus en avant, quand il est visible, et n'a pas l'allongement anormal que paraît présenter celui des Anisomyon, si toutefois les figures données par Meek sont fidèles; quant à la position du sillon pulmonaire, je viens d'indiquer à propos du genre Williamia, qu'elle est bien du côté gauche dans Patella Gussoni, à la condition qu'on oriente le côté le plus court vers le bas; tandis que dans les Anisomyon, si on les oriente de manière que le moule présente le sillon du côté droit, c'est à-dire de manière que la coquille présente cesillon du côté gauche comme les Siphonaria, c'est vers le haut qu'est dirigé le côté le plus court, du moins pour la plupart des espèces que Meek a classées dans ce genre. Il y a done là un motif de plus pour admettre la séparation d'un genre complètement distinct des Siphonaria.

Répart. stratigr.

Senonien....... Plusieurs espèces dans la Craie des États-Unis ( $A$. patelliformis, borealis, alveolus, Shumardi, subovatus; sexsulcalus, Meek et Haydenj d'après les figures donnẻes par ces auteurs.

\section{ACRORIID A}

Coquille irrégulière, àssez élevée; sinus pulmonaire plus ou moins creux, marqué extérieurement par une arête longitudinale plus ou moins saillante, vers laquelle s'incline le sommet; impression musculaire plurilobée?

Observ. - Cette famille, que j’ai proposée dans l'appendice $n^{\circ} 1$ de mon Catalogue de l'Eocène (1892), ne devait comprendre que le genre Acroria, le seul dont l'impression musculaire ait.été étudiée ; mais, indépendamment des caractères anormaux de cette impression, il y a lieu de remarquer que $A$. Baylei, type de ce genre, a le sommet incliné précisément du côté du sinus qui, d'après l'anatomie de l'animal, correspond généralement à l'extrémité antérieure; or, en examinant, d'une part, les Hercynella siluriennes, d'autre part certaines coquilles jurassiques que l'on confond avec les Scur-. ria, j'ai constaté que l'arête externe plus ou moins émoussée qui est probablement l'indice de l'existence d'un sillon pulmonaire, est orientée 
dans la même direction que le sommet de la coquille. Il est donc admissible, au moins à titre provisoire, de rapprocher ces deux formes des Acraria et de les placer dans la mème famille jusqu'à ce qu'on ait pu en étudier aussi l'impression musculaire, pour vérifier si elle est analogue à celle de notre Acroria Baylei.

Tableau des genres, sous-genres et sections

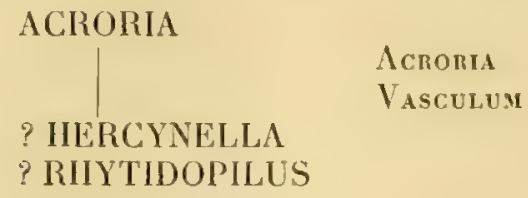

AGRORIA, Cossm. 1885.

Acroria, sensu stricto. Type: Nacella Bayler, Cossm. Eoc.

Test assez mince; forme d'une montagne étroitement comprimée ; sommet subcentral; pointu, faiblement incliné ; surface lisse, munie d'une arête émoussée, qui n'est pas exactement dans l'axe longtiudinal de la coquille, mais qui correspond à la partie excavée de la région dorsale, vers laquelle s'incline le sommet; impression musculaire étroite, en fer à cheval, à branches inégales, se terminant par deux lobes plus larges et subquadrangulaires; de chaque côté de la gouttière du sinus, il existe, en outre, à gauche, un lobe isolé et écarté de l'extrémité de la branche gauche de l'adducteur, à droite une cicatricule rayonnante terminée en massue un peu plus bas que l'extrémité de la branche droite de l'adducteur et que l'autre lobe isolé.

Diagnose prise d'après un individu typique d'llérouval

(Pl. V, fig. 14-16), coll. Bernay.

Observ. - Je n'ai constaté, d'une manière à peu près précise, la disposition plurilobée de cette impression musculaire que sur un seul individu, et d'une manière plus douteuse sur ua autre échantillon; la plupart de ces 
coquilles ont la surface interne vernissée et l'adducteur ne paraît y avoir laissé aucune trace en creux, quelque soin qu'on prenne de faire miroiter l'intérieur du test. Dans ces conditions, il faut encore être très réservé sur les hypothèses relatives à l'anatomie de l'animal qui habitait les Acroria; il est bien évident qu'ils possédaient un orifice pulmonaire, de sorte qu'on peut, presque à coup sûr, les placer dans les Thalassophila; mais je n'ai pas essayé d'expliquer le rôle que pouvait jouer la cicatricule rayonnante, comprise entre les deux branches de l'adducteur et ne coïncidant pas avec la grouttière de cet orifice, ni la raison pour laquelle il existe un autre lobe isolé, du même côté que la branche gauche, par rapport à la gouttière du sinus: autant la présence de ce lobe s'explique de l'autre côté, pour mieux agrafer le manteau de part et d'autre de l'orifice respiratoire, autant elle est peu explicable du même côté, quand il suffirait que la branche gauche s'allongeât un peu davantage. Il est non moins remarquable que le sommet soit incurvé dans la direction de l'arête qui correspond.au sinus pulmonaire, ce qui dénoterait pour l'embryon, une position inverse de celle qu'il occupe dans les Siphonariidx.

Répart. stratigr.

EOCEXE

? Mocese...... Une espèce dans les faluns de la Touraine (A. irregularis, Dollf, et Dautz.); l'échantillon que les auteurs m'ont communiqué, est trop roulé pour qu'on puisse distinguer l'impression musculaire, et sa surface extérieure, marquée de costules obliques comme les corps étrangers en impriment sur les Anomia, ne paraît pas porter l'arête caractéristique des Acroria, de sorte que cette citation me semble très douteuse.

Vasculum, Gh. White, 1889.

Type: V. obliquum, Ch. White. Paléoc.

Forme conique, asymétrique, élevée; sommet presque central, à nucléus obliquement enroulé ; surface lisse, munie d'une arête émoussée, curviligne et déviée à gauche de l'are longitudinal de la cóquille, du côté où la région dorsale est excavée et vers lequel s'incline le sommet; cette arête est limitée d'un côté par une strie rayonnante, et, de l'autre, par une dépression peu profonde ; péritrìme basal presque régulièrement ovale ; impression musculaire? 
Diagnose prise d'après le texte et les figures 19-21 de la Pl. IV du Bull. of Geol. Surv. U. S.; reproduction des figures (1).VII, fig. 4-6).

Observ. - Cette coquille est classée par l'auteur dans les Fissurellida, mais il en signale lui-même l'alfinité avec les Siphonariidxe et Gadiniidx; elle me parait être tout au plus un sous-genre d'Acroria; sa forme lissymétrique, sa rainure déviée de l'axe, précisément du côté où s'incline le sommet, l'écartent absolument des Fissurellidx; au contraire, lisse comme une Acroria, muni d'une arête dorsale à peu près identique, le sous-genre Vasculum ne se distingue de notre genre que par son péritrème plus ovale (et encore il n'est pas sûr que cette coquille ne possède pas un bec rostré du côté où le test a été mutilé et où le contour a été approximativement restauré), par son sommet enroulé, tandis qu'il est obtus (peut-être par suite de l'usure) dans les Acroria; pour décider si V'asculum est simplement synonyme postérieur, il faudrait qu'on pût en étudier l'impression musculaire.

Répart. stratigr.

P'aleocene..... L'espèce type dans le groupe de Laramie, en Californie, d'après $\mathrm{Ch}$. White.

HERGYNELLA, Kayser, 1878.

[= Pilidium, Barr. mss., non Mull., 1847, nec Forbes et Hanley, 1849, nec Midd., 1851].

Hercynella, sensu stricto. 'Type: H. Beyrichi, Kayser. Silur.

Grande taille; forme patelloïde, arrondie, dissymétrique ; sommet un peu latéral, faiblement incliné vers une arête rayonnante, bien limitée, un peu déviée en courbe, et dont l'extrémité produit une saillie sur le bord de la coquille; surface ornée de stries radiales très fines et de lignes d'accroissement irrégulières; à l'inlérieur, une gouttière correspond au pli externe ; impression musculaire? 
Diagnose d'après le Manuel de Paléontologie de Zittel, reproduction de la figure (PI. VII, fig. 20) gisement de Lochkow.

Observ. - Si l'on suppose que cette coquille soit comprimée latéralement, on obtient à peu près la forme d'une Acroria, l'arête est déviée à gauche de l'axe longitudinal, le côté antérieur étant orienté vers le haut; je n'ai malheureusement aucune autre certitude au sujet du classement de ce genre que Zittel place dans les Siphonariidæe et que Fischer rapproche des Capulidx, et qui me paraît plutôt appartenir aux $A$ croriidæx.

Répart. stratigr.

Silunien ....... Une espèce dans les couches siluriennes supérieures de Bohềme, d'après Kayser.

RHYTIDOPILUS, nov. gen.

[- Scurria, Patella auct.].

Ruytidopilus, sensustr. Type: Patella humbertina, Buv. Séq.

Test mince; forme conique, ovale, plus ou moins irrégulière; sommet subcentral, obtus, faiblement incurvé ; région dorsale un peu excavée en avant du sommet, légèrement bombée en arrière; surface ornée de rides d'accroissement peu régulières, souvent entremêlées de stries d'accroissement plus fines; arête obtuse partant du sommet et se dirigeant vers le bord antérieur, en se déviant un peu en courbe par rapport à l'axe longitudinal ; impression musculaire?

Diagnose prise d'après un échantillon typique du Mont des Boucards (Pl. VI, fig, 8-10) coll. Pellat.

Observ. - Le genre que je propose de classer provisoirement dans la famille des Acroriidæx, à côté du genre Hercynella, a pour type un corps que M. de Loriol, sur l'avis textuellement cité de Deshayes, n'a pas liésité 


\section{Rhytidopilus}

á rejeter de la Conchyliologie, en l'attribuant ả une empreinte de vertèbre. Après un examen très attentif de ce type, je crois, malgré l'opinion de ces savants, pouvoir affirmer que cette explication n'est pas soutenable et qu'il s'agit bien effectivement d'une coquille: outre que les échantillons en question n'ont pas la symétrie de contour et de cavité qu'exigerait le moulage de la partie concave d'une vertèbre, leurs rides concentriques, et surtout l'arête courbe et déviée qu'ils présentent invariablement du côté antérieur, ne permettent pas de leur attribuer une telle origine ; au contraire, ils présentent une analogie incontestable avec les Hercynella, quoique leur arête soit plus émoussée et orientée un peu différemment; si, comme je l'ai déjà fait remarquer à propos des Hercynella, on les suppose comprimé latéralement, on obtient assez exactement une Acroria ridée. Quoique l'impression musculaire ne soit pas visible dans les Rhytidopitus étudiés jusqu'à présent, cela n'autorise pas à affirmer, comme l'a écrit Deshayes, qu'elles n'existe pas, d'autant plus que le test était si mince que le moule n'est pas susceptible de porter la trace de cette impression.

Répart: stratigr.

Bathoniex ..... Une espèce en Normandie el à Conlie (Scurria? Douvillei, Cossm.) coll. Desl.

Sequaxien ...... L'espèce type dans la Meuse et le Boulonnais.

himeridiex .... Une espèce à peu près certaine dans l'argile de Villerville (Patella castellanea, Thurm.) coll. Desl.

P'ontlaxdiex .... Une espèce probable dans le Barrois (Palclla suprajurensis, Buv.) d'après la figure donnée par l'auteur.

? Albiex....... Une espèce peu certaine, dans le gault de Cosne (Scurria conica, d'Orb.), d'après la figure de M. de Loriol, qui indique un pli rayonnant, déviẻ en courbe.

\section{GADINIII) A}

Coquille patelliforme, à sillon pulmonaire, extérieurement ornée: sommet excentré du côté postérieur.

Observ. - Pour distinguer cette famille des Siphonariidx, il faut se fonder surtont sur l'anatomie de l'animal, qui n'a ni màchoire, ni branchies : comme la coquille présente des caractères presque identiques dans les deux familles, il n'y a pas de certitude de l'existence de Gadiniidx fossiles: le seul indice qu'on ait, consiste dans l'ornementation un peu différente de la surface et dans la position du sommet. 
GADINIA, Gray, 1824.

\section{[EClypeus, Scacchi, 1834; = Mouretia, Sow., 1835 ;}

= Rowellia, Gooper, 1865.]

GadinIA, sensu stricto.

Type: G. afra, Gm. Viv.

Forme d'un bonnet phrygien; sommet postérieur usé et obtus ; surface externe ornée de cordons rayonnants plus ou moins serrés, traversés par des accroissements peu réguliers qui y découpent de fines granulations; péritrème circulaire ou largement elliptique; impression musculaire en fer à cheval un peu dissymétrique, dont les branches se terminent par de larges expansions en forme de massue; orifice pulmonaire indiqué par un sillon très obsolète, rayonnant du côté gauche (quand on regarde l'intérieur, le côté le plus court orienté en bas); petite impression musculaire distincte, placée en avant de l'extrémité antérieure de l'adducteur, comme dans les Siphonaria (d'après P. Fischer, ni Tryon ni Dollfus et T)autzenberg ne la mentionnent).

Diagnose prise d'après $G$. Garnoli, Payr. et un plésiotype fossile de P'ontlevoy, G. sulcata, Borson (Pl. VI, fig. 20-22) coll. Dollfus.

Observ. - Je n'ai pu contrôler l'existence de l'impression musculaire détachée dont Fischer fait seul mention dans sa diagnose: l'absence de ce lobe isolé aurait une grande importance, et elle permettrait de distinguer sûrement les Gadinia des Siphonaria qui possédent toujours ce lobe. Malheureusement les espèces fossiles qu'on rapporte aux Gadiniidx sont, jusqu'à présent dans un état de conservation qui augmente encore la difficulté de séparer ces deux formes: c'est donc sous toutes réserves qu'il faut accepter les citations qui suivent.

Répart. stratigr.

Paleocene.....

Mrocene ...... Une espèce des faluns de Touraine, très voisine des Hipponyx, mais dont l'impression ne parait pas symétrique ( $G$. sulcata. Borson) coll. Dollfus.

Proceve ...... L'espèce de la Méditerranée, fossile à Melazzo (G. Garnoti) d'après Philippi.

Epoque Actuelle. Plusieurs espèces dans la Méditerranée, sur les côtes d'Afrique et d'Australie, d'après P'. Fischer. 


\section{ANNEXE \\ DESCRIPTION DES ESPÈCES INÉdTES CITÉES DANS CETTE PREMIIÈRE LIVRAISON}

L'examen de la répartition stratigraphique des genres qui précèdent m’a amené à étudier plusieurs formes, soit entièrement nouvelles, soit déjà connues, mais inédites. Pour me conformer aux règles de la nomenclature, j’ai annexé ci-après les descriptions sommaires de ces espèces, leur iconographie, ainsi que l'indication des rapports et des différences qu'elles présentent avec les formes voisines, déjà connues dans d'autres terrains. Ce sont surtout les terrains crétacés qui forment le contingent de celte courte annexe; quant aux espèces nouvelles des terrains jurassiques, j'espérais que la première livraison de la Revision que j'ai entreprise de la Paléontologie francaise paraîtrait en temps utile pour me permettre d'en citer les noms dans ces Essais. Mais la publication de ce second travail ayant subi quelques retards inclépendants de ma volonté, je me suis borné dans les tableaux de répartition stratigraphique, à signaler, sans les nommer, les espèces jurassiques en question, à indiquer la collection dans laquelle elles se trouvent, et à ajouter qu'elles seraient prochainement décrites. 
Tornatellaea Lapparenti, nov. sp.

Pl. II, fig. 21-21.

Forme ovoïdo-conique; spire pointue, assez allongée, à galbe conique; six tours un peu convexes, dont la hauteur dépasse la moitié de la largeur, à sutures canaliculées; dernier tour ovale, arrondi à la base; surface ornée de huit à dix stries spirales sur chaque tour, et d'un grand nombre de sillons ponctués, équidistants et serrés, sur le dernier tour et sur la base. Ouverture courte, large, anguleuse en arrière, arrondie et échancrée en avant; labre à peine courbé, presque vertical, non bordé; columelle courte, droite, faisant un angle de $120^{\circ}$ avec la base de l'avant-dernier tour, munie de deur plis obliques et tordus.

Dis. Longueur, 9 mill. Diamètre, 5 mill. Dernier tour de face, $61 / 2$ mill. Ouverture de profil, $41 / 2$ mill.

Rapp. Diff. Se distingue par ses stries fines et nombreuses, par son ouverture plus courte que celle de T. multistriata, Rig. et Sauv. du Bathonien, qui a d'ailleurs moins de sillons spiraux. Cornuel l'a signalée sous le nom Actron albensis : or cette dernière espèce, qui est de l'étage néocomien inférieur de Marolles, a trois plis et le labre bordé comme les Ringinella; il y a lieu d'en séparer celle-ci, qui devrait plutôt être comparée à T. marullensis du Néocomien; mais elle s'en distingue par sa forme moins allongée, par son dernier tour plus arrondi, par ses sillons plus serrés, plus nombreux, moins grossièrement ponctués.

Grs. Urgonien, dans la couche rouge de l'Aube.

Loc. Vassy, deux individus (Pl. II, fig. 21-22) coll. de l'Institut catholique, à Paris.

Ovactaeonina urgonensis, nor. $s p$.

Pl. VI, fig. 25.

Taille petite; forme étroite, fusoïde; spire allongée, étagée, à galbe un peu conoïde; huit tours plans, dont la hauteur atteint les trois cinquièmes de la largeur, séparés par des sutures que borde une étroite rampe spirale; dernier tour assez court, cylindracé en arrière, ovale à la base ; surface lisse? ouverture étroite, arrondie en avant? columelle un peu excavée.

Dr. Longueur, 4 1/2 mill. Diamètre, $13 / 4$ mill. Dernier tour de face, 3 mill. Ouverture de profil, $21 / 4$ mill. 
Rapp. Diff. Jolie petite coquille, qui a l'aspect d'une minuscule Actronina dormoisiana. Cependant je ne l'ai pas rapportée au genre Aclronina, non seulement parce que ce sont des coquilles de grande taille, qui ne paraissent pas avoir franchi les limites des terrains jurassiques, mais encore parce que l'ouverture me parait plus arrondie à la base, quoiqu'elle soit mutilée sur l'uniqque individu décrit, et quoique l'état d'usure du test ne permette pas d'allirmer qu'il y a des stries basales, comme en portent toutes les Ovactionina.

Gis. Urgonien, dans les calcaires blanes, intercalés entre la couche à Requienia et les calcaires marneux à Spatangues du Néocomien (d'après M. Curet).

Loc. Orgon, unique (PI. VI, fig. 25) coll. Boutillier.

Aclaconella terebellum, nom. mut. Pl. II, fig. 20.

1852. - Actronella lievis, Zekeli. Gastrop. Gosaugeb., p. 11 Pl. VII, fig. 11 (non d'Orb.)

Forme très étroite comme un Terebellum, pointue au sommet, subcylindrique au milieu; spire involvée; dernier tour formant toute la coquille, à peine alténué à la base; ouverture presque linéaire, un peu élargie en avant ; labre mince, peu arqué, obliquemont renversé à gauche de l'axe, du côté antérieur; bord columellaire muni de trois plis peu saillants, presque invisibles quand l'ouverture n'est pas mutilée.

Dn. Longueur, 35 mill. Diamètre, 10 mill.

Rapr. Diff. Il n'est pas possible de confondre cette coquille avec Act. laxis, du Turonien de france, qui n'a jamais une forme aussi ćlroite et qui est toujours renflée au milieu : pour une longueur igale a celle de l'échantillon d'A. terebellum que j'ai figuré, Act. levis aurait au moins tou ä millimètres de diamètre en plus. Zekeli avait d'ailleurs signalé celle différence, et comme elle est constante, la séparation s impose.

Gis. 'Turonien supérieur.

Loc. Gosau, fréquente (Pl. II, fig. 20) coll. du Musée de Dijon; ma coll.

'rochacticon Mnnadi, nov. sp. Pl. III, fig. 2-3.

Forme ovale, olivoïle, étroite, allongée; spire, assez courte, à galbe probablement conique, quand la pointe n'est pas usée; tours 
à peine convexes, dont la hauteur égale environ le tiers de la largeur, séparés par des sutures faiblement étagées qu'accompagne une strie spirale; dernier tour grand, ovoïdo-cylindrique, régulièrement atténué du côté antérieur; surface entièrement lisse Ouverture très étroite en arrière, à peine dilatée en avant, où elle se termine par une sorte d'échancrure versante et subcanaliculée; labre mince et toujours mutilé, échancré en arrière, entre la strie et la suture; columelle oblique, peu excavée, presque dans le prolongement de la base de l'avant-dernier tour ; bord columellaire mince et étalé en arrière, calleux en avant, portant trois gros plis parallèles, épais et égaux aux intervalles qui les séparent; callosité du bord antérieur, bien limité du côté de la région ombilicale, aboutissant un peu au-dessus de l'échancrure indécise du contour supérieur.

Dıм. Longueur, 5̋ mill. Diamètre, 20 mill. Dernier tour de face, 43 mill. Ouverture de profil, 39 mill.

Rapp. Diff. Cette espèce ne peut se confondre avec T. conicus, Zek. du Turonien de Gosau, car elle a la spire beaucoup plus courte et la forme moins ventrue; quant à $T$. volula, Zek. qui a la spire longue et étagée par une rampe canaliculée, c'est une espèce encore plus différente. Comme il est rare de rencontrer en France des Gastropodes crétaciques encore munis de leur test, il m'a paru intéressant de signaler cette espèce nouvelle et de la dédier au géologue érudit, chercheur infatigable qui l'a recueillie.

Grs. Provencien inférieur, couche II, d'après M. Arnaud.

Loc. Charente: Châteauneuf, type (Pl. III, fig. 2-3); Charmant, autre individu identique; coll. Arnaud.

Trochacteon Boutillieri, nov. sp. $\quad$ Pl. VI, fig. 18-19.

Taille petite; forme étroite, cylindrique; spire très courte, obtuse au sommet, à galbe extraconique; trois ou quatre tours très étroits, séparés par des sutures indécises; dernier tour lisse, formant presque toute la coquille, cylindracé au milieu, arrondi en arrière, faiblement atténué à base. Ouverture très étroite, à peine dilatée du côté antérieur"; labre mince, presque droit; bord 
columellaire calleux, munis de deux plis bien visibles et d'un léger rentlement postérieur qui correspond probablement à un troisicme pli columellaire, quard l'ouverture est mutilée.

Drs. Longueur, 7 mill. Diamètre, 3 mill. Ouverture de profil, $61 / 4$ mill.

Rapp. Diff. Cette petite coquille est le premier représentant du genre Actronella dans les terrains crétaciques, et elle établit une liaison entre ce genre et son ancêtre Cylindriles des terrains jurassiques, avec lequel elle a plus de ressemblance qu'avec les Actronella globuleuses ou involvées. La columelle des deux échantillons que j'ai examinés, n'est malheureusement pas assez dégagée pour qu'on puisse aflirmer avec certitude qu'il y a trois plis columellaires; mais il y en a au moins deux, plus saillants que ne le sont ordinairement le renflement médian et la torsion antérieure des Cylindrites; j’en conclus que c'est une forme intermédiaire qui marquerait précisément la transition atavique d'un genre à l'autre. Il est vrai que M. Curet m'a aussi communiqué du même gisement plusieurs échantillons d"un Trochaction globuleux, à spire courte et a nucléus proboscidiforme, qui est évidemment nouveau et qui est beaucoup plus voisin des formes ventrues du Turonien.

Grs. Urgonien, dans les calcaires blancs.

Loc. Orgon, unique (Pl. VI, fig. 18-19) coll. Boutillier; autre individu, coll. Curet.

Ringicula turonensis, nov. sp.

Pl. VI, fig. 26-27.

Forme ovale, peu ventrue; spire subulée, à galbe à peu près conique; quatre à cinq tours à peine convexes, séparés par des sutures linéaires; dernier tour ovale, arrondi à la base; columelle munie de deux plis assez tranchants, avec une côte pariétale en arrière ; bord columellaire? labre?

Drм. Longueur, วั $1 / 2$ mill. Diamètre, $21 / 2$ mill.

Rapp. DifF. L'état de conservation des trois individus que je possède ne me permet pas de vérifier si la surface du test de cette espèce est réellement lisse, ou si cette apparence est due à l'usure : toutefois le classement de cette espèce dans le genre Ringicula ne me parait pas douteux, à cause de sa plication columellaire qui est bien indiquée sur deux de ces échantillons, et qui ne ressemble pas à celle des Ringinella. En tous cas, l'espèce est bien nouvelle et se distingue de ses congénères par sa forme plus globuleuse et par sa forme conique.

Gis. Turonien, dans les grès rouges.

Loc. Uchaux, Irois individus (Pl. VI, fig. 26-27) ma coll. 
Retusa Berthelini, nov. $s p$.

Forme cylindrique, courte et trapue; spire tronquée, presque plane, avec un petit nucléus saillant; dernier tour un peu atténué à la base, orné vers la troncature postérieure, de fins plis d'accroissement. Ouverture étroite en arrière, ovale à la base qui est subombiliquée; labre presque vertical; columelle courte, excavée, dénuée de pli?

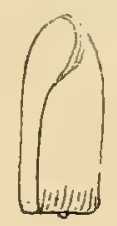

FIG. 41.

Retusa Bertheli$n i, \operatorname{Cossm}$.

Dru. Longueur, 1,75ั mill. Diamètre, 0,75 mill.

Rapp. Diff. Se distingue par sa forme courte, par son dernier tour non atténué en arrière; les autres espèces néocomiennes et urgoniennes sont beaucoup plus étroites et moins rectangulairement tronquées au sommet. Je n'ai pu, même avec un fort grossissement, apercevoir de stries spirales sur la surface, tandis que les plis axiaux, voisins de la carène postérieure, sont bien visibles à la loupe. Cette espèce a un grand intérêt, parce qu'elle comble une lacune entre les formes du Crétacé inférieur et celles du Crétacé supérieur.

Gis. Albien, dans le gault moyen.

Loc. Le Gâti (Aube), deux échantillons (fig. 41) coll. Berthelin.

Retusa tenuistriata [Cotteau]: Pl. VI, fig. 30 . 1854. Bulla tenuistriata, Cott. Prod. moll. Yonne, p. 47.

Forme cylindracée, faiblement ovale à ses extrémités; spire tronquée, formant une cuvette dont le diamètre est environ les deux tiers de celui du dernier tour, qui embrasse toute la coquille; surface très finement ornée, à la base, de stries spirales qui s'effacent sur le milieu du dernier tour. Ouverture longue et étroite, élargie et arrondie du côté antérieur ; columelle courte, excavée, ne présentant aucune trace de pli.

Drs. Longueur, 16 mill. Diamètre $61 / 2$ mill.

Rapp. Diff. Très voisine de R. cylindrella, Buv,, elle paraît cependant devoir en être séparée, non seulement à cause de ses fines stries, dont la disparition sur l'autre espèce lisse, est probablement le résultat de l'usure, mais à cause de sa forme moins cylindrique, plus atténuée vers 
l'excavation de la spire qui occupe une moins grande largeur. On ne peut. confondre cette espèce avec $R$. urgonensis, Pict. et Camp. du Jura sulisse, qui a le dernier tour plissé autour de l'excavation de la spire, et qui est d'ailleurs plus étroit. Quant à $R$. Jaccardi, Pict. et Camp. du Néocomien suisse, il a presque le même galbe que $R$. tenuistriala, mais il s'en distingue aussi par ses plis d'aceroissement curvilignes, tris sallants i la partie postérieure du dernier tour. Calteau a très brièvement décrit cette espèce dans son Prodrome de l'Yonne, mais je ne puis hésiter à y reconnaître l'échantillon de la Ilaute-Marnè dont je viens de donner la diagnose.

Gis. Urgonien, dans la couche rouge, et Néocomien inférieur, d'après Cotteau.

Loc. Vassy unique (Pl. VI, fig. 30), coll. de l'Institut catholique. Fiontenoy, Saint-Sauveur, Auxerre (fide Cotteau).

Bulla marullensis, nov. sp.

Pl. VI, fig. 15-16.

Forme globuleuse, ovale, plus atténuée en avant qu'en arrière; spire étroitement perforé au sommet; surface lisse; ouverture très étroite du côté postérieur, dilatée et arrondie à la base; labre dépassant à peine le sommet; columelle peu excavée, assez haute.

Diм. Longueur, 14 mill. Diamètre, 10 mill.

Rapp. Dirf. Se distingue de B. avellana, Pict. et Camp. du Néocomien de la Suisse, par son ouverture plus subitement dilatée en avant, par sa columelle plus haute; quoique l'échantillon figuré par ces auteurs soit dans $u$ itat de conservation assez fruste, a litat de mule incomplet, il ne me paraît néanmoins pas possible de le rapporter à la même espèce que le notre.

Gis. Néocomien inférieur.

Loc. Marolles (Aube), unique (Pl. VI, fig. 1ö-16) coll. de I'École des. Mines.

Cylichnella vasatensis, Benoist in lill. I'l. IV. tigr. I1-lti.

Forme ovale, ventrue, courte; spire invisible, étroitement perforée ; dernier tour embrassant toute la coquille, complèlement lisse, inégalement atténué à ses deux extrémités, un peu plus rentié vers la base que vers le sommet. Ouverture étroite en arrière, peu dila- 
tée du côté antérieur, légèrement versante et șinue use à la base ; labre épais, peu arqué, dépassant à peine le sommet, se raccordant presque sans inflexion avec la sinuosité du bord supérieur; columelle excavée, munie en avant d'un pli très oblique, et en arrière, d'une lamelle transversale; bord columellaire un peu calleux du côté postérieur, limité à la base par le prolongement du pli lamelleux, qui forme une carène contournant la sinuosité versante de l'ouverture.

Drm. Longueur, 3 1/2 mill. Diamètre, $21 / 2$ mill.

Observ. - Se distingue, par sa plication, des autres Bullide des faluns: elle appartient indubitablement au genre Cylichnella, Gabb et ressemble à la figure de $C$. bidentala, Gabb qui est l'espèce type de ce genre ; cependant elle est plus globuleuse que l'espèce des Antilles et dénuée de sillons spiraux. Mon ami, MI. Benoist, ayant pris la peine de la trier parmi des échantillons mélangés que je lui avais soumis, je me fais un devoir et un plaisir de conserver à l'espèce le nom manuscrit qu'il lui avait attribué, car je ne crois pas que cette coquille ait été connue de Grateloup ou de Basterot.

Grs. Langhien inférieur et moyen des environs de Bordeaux.

Loc. Mérignac, peu rare (Pl. IV, fig. 14-16) ma coll.; Saucats (Moulin de l'église), unique, ma coll.

\section{Acera neocomiensis, nov. $s p$.}

Pl. VI, fig. 23-24.

Forme ovale, subcylindrique; nucléus apical saillant; spire à peine proéminente, un peu excavée au sommet, découverte par l'enroulement du dernier tour, à galbe arrondi; quatre tours croissant rapidement, convexes, séparés par des sutures profondément canaliculées: dernier tour formant presque toute la coquille, ovale dans son ensemble, faiblement cylindracé au milieu, atténué à la base; surface lisse, autant qu'on peut en juger par quelques fragments de test. Ouverture très étroite en arrière, dilatée et découverte en avant; labre mince, curviligne, échancré à la suture par une entaille très profonde; bord columellaire étroit, excavé, se raccordant par une courbe régulière à la sinuosité antérieure du contour de l'ouverture. 
Drs. Longueur, 16 mill. Ouverture de profil, 14 mill.

Rapr. Difr. Cette espèce est la seule qui ait été signalée à la base des terrains crétaciques, et par sa forme elle se rapproche plus des espèces tertiaires que de celles du Jurassique; elle se distingue toutefois d'A. striatella par sa spire à peine proéminente et par son galbe ovale; sì on la compare au contraire à $A$. Beaugrandi, du Kiméridgien, qui est géologiquement assez voisin, on remarque qu'elle est plus courte, que son ouverture est beaucoup plus découverte en avant et que sa spire n'est pas excavée.

Gis. Néocomien inférieur.

Loc. Marolles, neuf individus (P. VI, fig. 23-24) coll. de l'École des Mines.

Sulcoaclaeon ovoideus, nov. sp.

Pl. VI, fig. 28-29.

Taille petite; forme ovoïdo-globuleuse; spire courte, obtuse au sommet, à galbe conoïdal et subulé; quatre tours convexes, séparés par de profondes sutures, croissant rapidement, dont la hauteur dépasse la moitié de la largeur, surtout à l'avant-dernier tour; dernier tour ovale, ventru, arrondi à la base; surface ornée de sillons réguliers, équidistants. Ouverture, assez large, subéchancrée en avant; labre arqué; bord columellaire paraissant dénué de plis, séparé de la base par une petite fente ombilicale; bourrelet basal à peine indiqué.

Dıм. Longueur, $51 / 2$ mill. Diamètre, $31 / 4$ mill. Dern. tour de face, $41 / 2$ mill. Ouverture de profil, 3 mill.

Rapp. Diff. J'ai comparé cette espèce à une forme (Act. astieriana, d'Orb.) déjà décrite dans la Paléontologie française et provenant du même étage, à Escragnolles, dans le Var; mais, si la figure et la description de d'Orbigny sont exactes, A. astieriana serait beaucoup plus allongé et aurait la spire conique et pointue, avec un angle spiral de $43^{\circ}$; d'ailleurs, quoique d'Orbigny n'ait pas mentionné l'existence de plis columellaires, il n'est pas absolument certain que la coquille d'Escragnolles soit bien un Sulcoactron, tandis que notre espèce en est certainement une et représente la dernière forme de ce genre qui a commencé à apparaitre à la base de l'oolithe jurassique.

Gis. Urgonien, dans les calcaires blancs.

Loc. Orgon, trois individus (Pl. VI, fig. 28-29) coll. Boutillier; deux individus, coll. Curet. 


\section{ADDENDA}

Page 80, section Fibula, ajouter:

Srn. Pseudonerinæa, de Lor. 1880. Il n'y a pas de différences génériques entre ces deux formes; je m'en suis aperçu à la dernière heure, mais j’y reviendrai avec un peu plus de détails dans la Revision de la Paléontologie française.

\section{Note ajoutée pendant l'impression.}

J'ai reçu, trop tardivement pour pouvoir en faire mention dans l'introduction, un numéro de The american naturalist (nov. 1894, p. 909), contenant une note de $\mathbf{M}$. Dall, qui répond à la question que j'ai posée sur la corrélation qui doit exister entre les plis de la columelle de la coquille d'un Gastropode et les mours de l'animal qui habite cette coquille. Cette note est intitule "The mecanical cause of folds in the aperture of the shell of Gasteropoda ", et je vais en donner ici une courte analyse.

Comme point de départ de son explication, l'auteur prend une observation qu'il a faite au sujet de la position du point d'attache du muscle adducteur sur la columelle : il a remarqué, en effet, que dans les formes munies de plis, ce muscle s'attache à une distance plus grande de l'ouverture, que dans les coquilles non plissées. Comme ce muscle forme un point d'arrêt fixe pour le mouvement d'entrée ou de sortie, par l'ouverture, des parties mobiles de l'animal, qui se développent à l'intérieur du manteau, tapissant la paroi interne de la coquille, il en résulte que la cavité libre dans laquelle s'effectue ce mouvement, forme un étui contre lequel le manteau est continuellement serré par le corps élastique qu'il recouvre.

Si cet étui se resserre assez rapidement - et c'est ce qui arrive précisément quand le muscle est placé très profondément, par exemple un tour entier en arrière de l'ouverture, - le manteau, en se déplaçant, doit se contracter pour entrer dans la partie plus étroite; cette contraction d'une surlace membraneuse trop étendue produit des rides, et les rides constamment pressées contre la paroi enduite d'un mucus, dont la sécrétion par le manteau forme la matière de la coquille, y dessinent des rainures ou des sillons dont les interstices sont des plis ou des côtes saillantes qui se logent entre les rides du manteau. C'est surtout contre la columelle, qui est l'axe héliçoîdal de ce mouvement, que le manteau doit se trouver plissé dès qu'il pénètre dans la cavité de l'ouverture; d'où il résulte que les plis columellaires sont en général plus importants que ceux du labre oủ l'expansion de la surface du manteau se fait d'une manière plus graduelle; c'est aussi ce qui explique pourquoi, dans les Siphonostomes, le premier pli est dans le voisinage du canal. 
M. Dall indique, en outre, plusieurs faits qui confirment son explication, c'est que dans les Volutidie, par exemple, qui sont fortement plissées, le manteau est relativement bien plus étendu que dans les Buccinida, et que c'est un motif pour qu'il se ride davantage en se contractant pour rentrer dans la coquille; de même dans les Cypricidie, dont le manteau recouvre presque toute la surface de la coquille, les deux bords de l'ouverture sont encombrés de plis qui doivent correspondre aux nombreuses rides qu'il doit faire pour pénétrer dans cette étroite fente. Si, au contraire, le manteau, tout en étant très étendu, ne rentre pas complètement ì l'intéricur de la coquille, comme cela arrive pour certains Opisthobranchiata, pour les Sigaretus et les Harpa, il n'y a de plis ni à la columelle ni au labre, tandis que les espèces de Cypricidie qui sont dénuées de plis, sont précisément celles dont l'ouverture est plus grande à l'état adulte.

Il est incontestable que l'explication que donne notre confrère est extrêmement ingénieuse :à défaut d'observations faites sur le mollusque lui-mème, M. Dall indique une expérience qu'il est facile de répéter, et qui consisterait à faire rentrer un mouchoir dans un entonnoir dt manière qu'il enveloppe un bouchon, et l'on voit alors les rides se former sur la toile, avec plus ou moins de régularité. Le manteau des Gastropodes se comporte-til exactement comme ce mouchoir? C'est ce qu'il resterait à démontrer, s'il était possible de saisir sur le vif l'animal pendant qu'il sort de sa coquille ou qu'il y rentre.

Observations sur le tableau phylogénétique

Le tableau graphique que j'ai fait intercaler ci-conlre résume lhistoire des opisthobranchiata, dans les temps géologiques, et est fondé sur ce principe que tous les types dérivent l'une origine commune. Les tracés, en traits pleins, indiquent la présence certaine d'un genre ou d'un sous-genre a un etage; les traits interrompus reprisentent, au contraire, les hypothèses relatives it la filiation ancestrale de ces formes.

Il résulte de cet arrangement, qui n’a rien d'absulu, que les formes primitives ne se seraient pas perpétuées jusqu'à l'époque actuelle et y seraient renjplacées par des formes dérivées, dont l'afflucnce s'est surtuut produile it la base du lias, il l'éporque néncomienne et pendant l'Eocéne. I la fin des systèmes crétacique et jurassique correspond, d'autre part, l'extinction d'un certain nombre de formes mésozoïques.

Ilitons-nous d'ajouter que ces conclusions générales pourront ètre, dès demain, infirmées par la dicouverte de nouveanx maleriaux; car le nombre des giscments oi l'on a jusqu'a présent recueilli des Gastropodes mésozoinques en bon 'tat de conservalion, ne représente gu'un point infime en regard de l'étendue et de la puissance des couches à explorer.

Le lecteur excusera l'imperfection graphique de ce tablean qui n'est que la reproduction du crorquis tracé de la main de l'auteur. 
NÉTIQUE DES OPISTHOBRANCHIATA

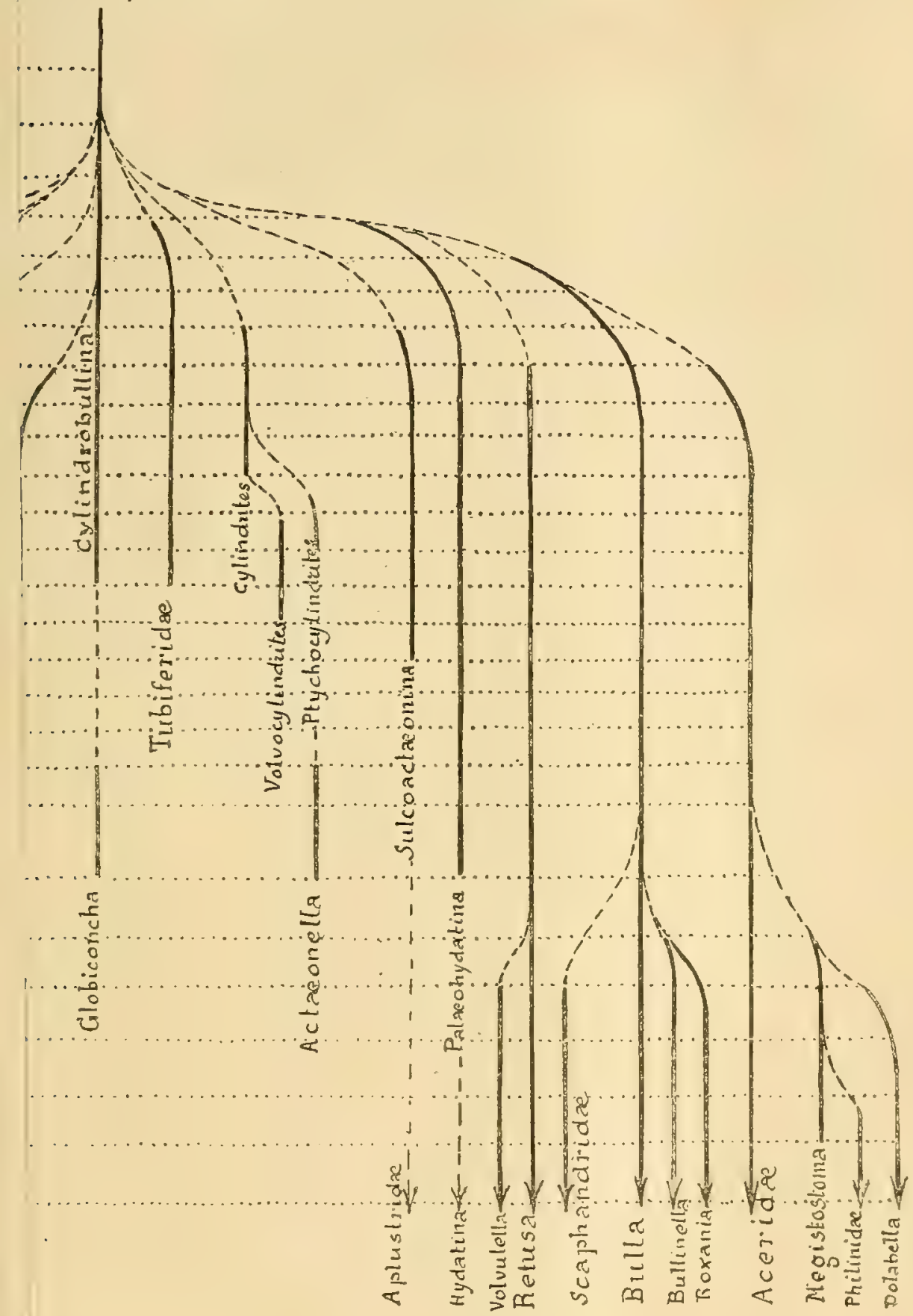



TABLEAU PHYLOGÉNÉTIQUE DES OPISTHOBRANCHIATA

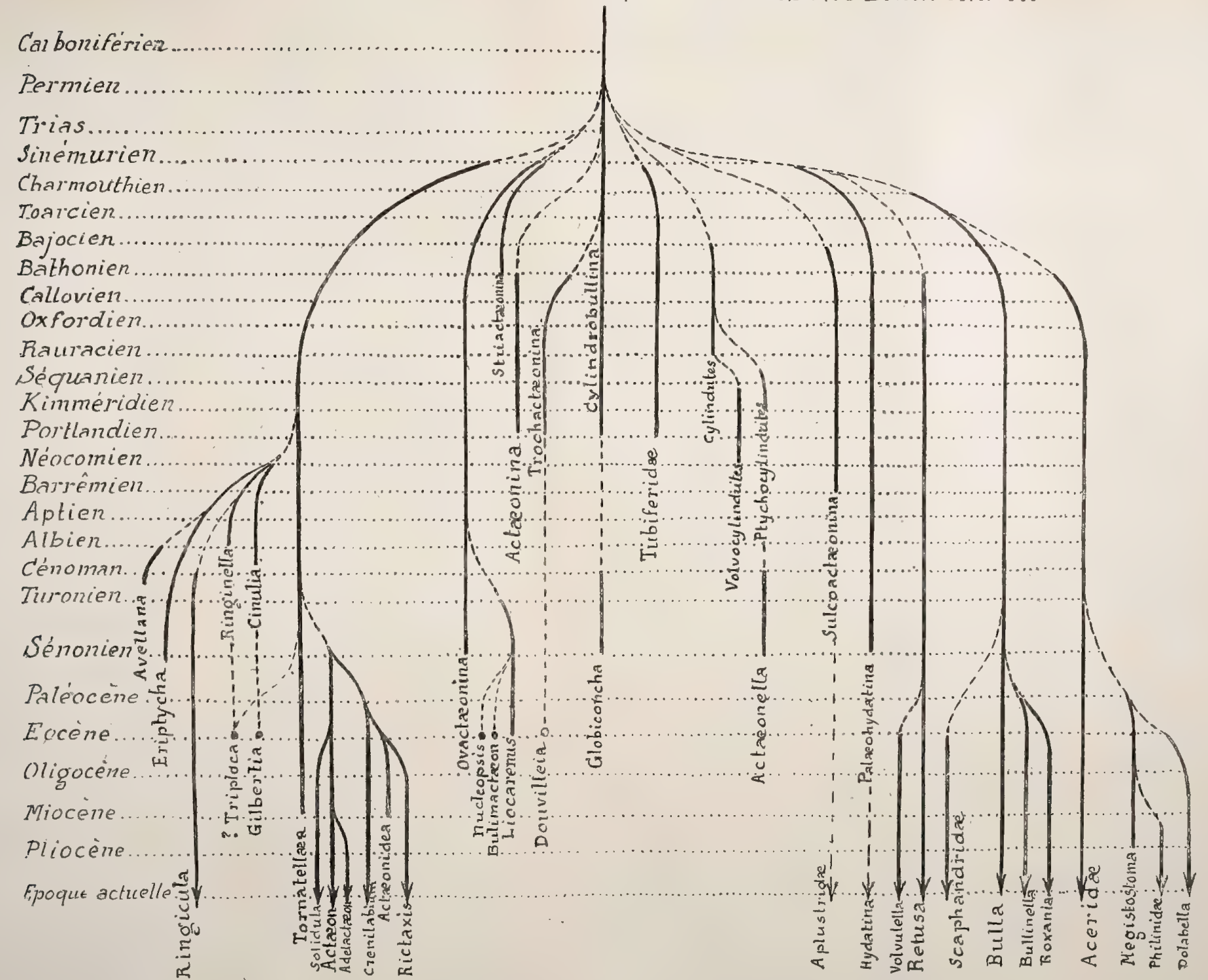





\section{TABLE ALPHABÉTIQUE}

DES

FAMILLES, GENRES, SOUS-GENRES, ETG.

Les noms en italiques sont ceux des synonymes.

\begin{tabular}{|c|c|c|c|}
\hline & Papec & & Pares \\
\hline$\ldots \ldots \ldots \ldots \ldots \ldots \ldots$ & 131 & 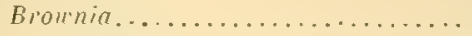 & 13.3 \\
\hline A.era $\ldots \ldots \ldots \ldots \ldots \ldots \ldots \ldots$. & L11:3 & 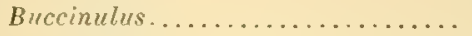 & 46 \\
\hline dithinfil $\ldots \ldots \ldots \ldots \ldots \ldots \ldots$ & 10:2 & Bucconia.................... & 87 \\
\hline$d \cdot 1+s i n \ldots \ldots \ldots \ldots \ldots \ldots$ & 129 & Iinlimatimen. . . . & $\because 7$ \\
\hline 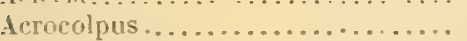 & $4 \cdot 2$ & Bn${ }_{1}{ }_{1} \ldots \ldots \ldots \ldots \ldots \ldots \ldots \ldots \ldots \ldots$ & 90 \\
\hline 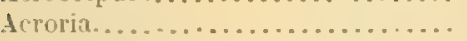 & $1 ; 0$ & Bullisa................. & $12 ;$ \\
\hline 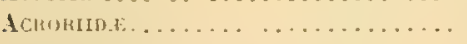 & 139 & 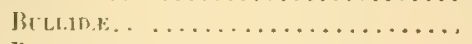 & \$9 \\
\hline derustrmivil. . . . . . . . . . . . . & 1111 & 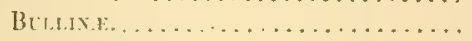 & 89 \\
\hline 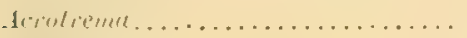 & $! ;$ & $\operatorname{limu} \ldots \ldots \ldots \ldots \ldots \ldots \ldots \ldots$ & 107 \\
\hline $1 \ldots \ldots \ldots \ldots \ldots \ldots \ldots \ldots \ldots$ & $\therefore: i$ & $1 \cdot l_{11} \ldots \ldots \ldots \ldots \ldots \ldots \ldots$ & $9:$ \\
\hline\|\|$_{1} \ldots \ldots \ldots \ldots \ldots \ldots$ & 73 & mula $\ldots \ldots \ldots \ldots \ldots \ldots \ldots$ & 107 \\
\hline$[: 1.1, \ldots \ldots \ldots \ldots \ldots \ldots \ldots$ & i i & Bullupsis..................... & 111 \\
\hline$\ldots \ldots \ldots \ldots \ldots \ldots$ & 拄 & & \\
\hline |ил. $\ldots \ldots \ldots \ldots \ldots \ldots$ & ;il & Cardiapoda ............... & 133 \\
\hline$n_{1}$ & is & Garinaria. . . . . . . . . . & $1: 3: 2$ \\
\hline${ }_{1}, \ldots \ldots \ldots \ldots \ldots \ldots, \ldots$ & $\because:$ & 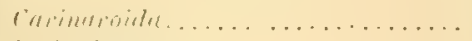 & 1333 \\
\hline 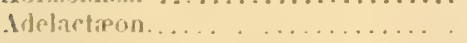 & $\because \mathrm{i}$ & $H_{1} \ldots \ldots \ldots \ldots \ldots \ldots \ldots \ldots$ & is \\
\hline la $\ldots \ldots \ldots \ldots \ldots$ & 1011 & 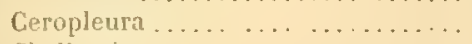 & $1: 33$ \\
\hline$\ldots \ldots \ldots \ldots \ldots$ & $13 i$ & odura................ & 120 \\
\hline 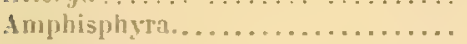 & $111: i$ & Cimulia $\ldots \ldots \ldots \ldots \ldots \ldots \ldots \ldots$ & $1: 211$ \\
\hline 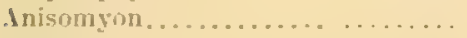 & 138 & $i \ldots \ldots \ldots \ldots \ldots \ldots \ldots$ & !n \\
\hline b................... & 107 & $\ldots \ldots \ldots \ldots \ldots \ldots \ldots \ldots$ & li: \\
\hline & 107 & hysis . ............. & $i:-$ \\
\hline & $1-19$ & tron...$\ldots \ldots \ldots \ldots \ldots \ldots$ & bii \\
\hline$\ldots \ldots \ldots$ & $12 ! 1$ & ahium,................. & $\therefore 3$ \\
\hline$\bullet$ & 1] & aris .................. & $! 11$ \\
\hline & $11: 3$ & phlatmus. ............. & $13: 3$ \\
\hline & Sli & $\ldots \ldots \ldots \ldots \ldots \ldots \ldots \ldots$ & 13 \\
\hline||$l:|a|: 1$ & $1: 3: 3$ & 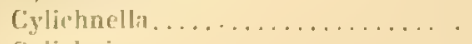 & $1 \%$ \\
\hline IIt.unin. & $1: 3: ;$ & $n a 1 \ldots \ldots \ldots \ldots \ldots$ & 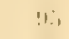 \\
\hline $11 \%$ & !n & $1, \ldots \ldots \ldots \ldots \ldots \ldots \ldots$ & $x ! !$ \\
\hline & 18 & 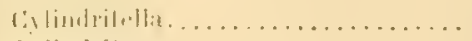 & iti \\
\hline I1 $11: 11: 1 \ldots$ & 11 is & 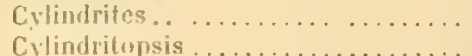 & ill \\
\hline & & Cylindrubulla $\ldots \ldots \ldots \ldots \ldots \ldots \ldots$ & [11:) \\
\hline
\end{tabular}


Cylindrobullina.

Dactylus. .

Dinia.

Dolabella.

Dolabrifer.

Douvilleia.

Eortlanta.

Eriptyclia.

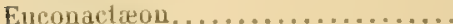

Euptyche.

Filuulit.

Firola.

Firolella.

Firoloida.

Finliviu r.

Gadinia $\ldots . . . . . . . . . . . .145$

Gadinidoe....................... 144

Gastioplux,................ 181

Gilhertia......................

Gilbertmill...................

Globicteonint.................

Globiconcha....................

Goniocylindrites...............

Ilaminea.......................

Helicophlegma...................

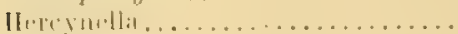

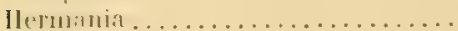

Hermtum!iz..................

IIvdationa.

Joannisia.

Juhnuik, ...................

Kenilla.

Luelas.

Laone..........................

Lencotina.....................

Livcartuus....................

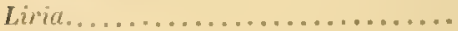

Liriola ........................

Lissuclicun ....................

Lobaria ......................

Megistostoma...................

Mnestia.........................

Mouretia........................

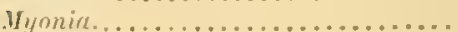

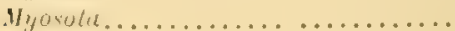

Pages

6:-

46

$10 \%$

90

129

129

67

134

123

103

64

123

7!

132

132

132

12.2

68

91

$13:$

lit

127

137

10!

130

$12: 3$

45

$4:$

$13 j$

123

4

is

13:

13

12:j

127

99

145

S.4

(j)
Ne

Notarchus.................. $\quad 1: 9$

Nícleobraxchitra.............. 13:

NUCLEOPSIYY.

Nucleopsis .................... in

Oligoptycha................. 1 1

Opisthomaxchit..............

Grthostoma.................. is

Ossiania...................... 1:6i

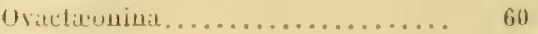

Ovulactwon...................

Oxygyrus.................... 1:3;

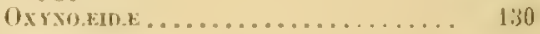

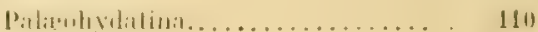

l'arascutum................... 1:3i

Phanerophtalmus .............. 12:;

Philinc.................... $1:$.

Philaido................... 12.;

Philinopsis ................... 12.

Phyllaplysia................ 12!

Physema.........................

Pilidium.................... 1't.

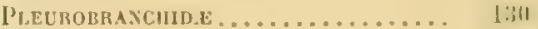

Protedulle.

Pseudoneriusea............... 1:.,

Pterolrachieit ................. 13:2

PTFHOTRACH.EIDE............ 13:2

Ptychocylindrites............ 72

PLLvoxit 1.

Raincourtia................. sti

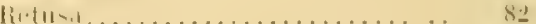

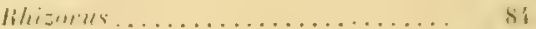

Mhytidupilus................. 1 is

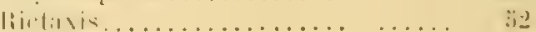

Kingicula.................... 11:3

Minginulella ...................

lim.14t111................ 11:

Ilingiculina.................... 11:

Rintriculvensta. .............. 11 i

lkingiculospongia............. 11:

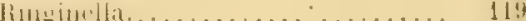

Rowellia.................... 1 1 hi.

lioxania....................... !s

li, rminirlla...............

liuxcridok................ 1;31

Solbatia................... sis

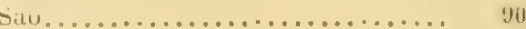

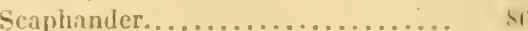

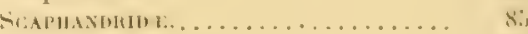

Scutulum....................... $1:$ 19

Semilutieun, ............... 117

Siphonaria.................. $1: 1 \%$

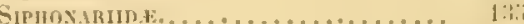

siplunrutus.............. 


\section{DES FAMILLES, , GENRES, SOUS-GENRES, ETG.}

Smaragdinella.

Pages

Solidula....................

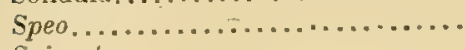

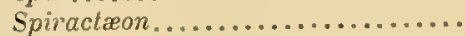

Steira.......................

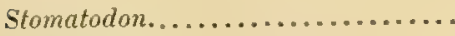

Striactatonina.................

Stylochilus...................

Sulcoactreon.

Thalassophila .................

Tornatella.

Tornatellæa...................

Tornatellin.................

Tornatina...

TORxatinid ..................

Trimusculus.

Pages

Tubifer .................... 78

Tubiferid.................... 77

Tylodina .................. 132

Umbraculum................ 131

Umbrella...................... 131

UMBRELLID................... 130

Utriculopsis ................ 127

Utriculus.................. 82

Vascultum ................... 141

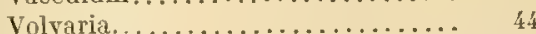

Volvatella................... 103

Volvoc ylindrites................ 71

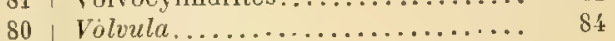

133 Volvulella................... 84

Triploca.....................

Triptycha ....................

Trochaction .................

Trochactæonina.

Weinkauffia.................. 90

66 Williamia................. 137 



\section{EXPLICATION DES PLANCHES}




\section{PLANCHE I}

1. Acteon subinflatus, dorb.

2. Action Guelini, Bayan.

3-4. Solmula Bevaleti, (Baudon).

5̆-6. Toratell.ea simulata, (Sol.).

7-8. Semiact mox aphinicicus, (Desh.).

9. Crenilabium aciculatum, Cossm.

10. Rictaxis puxctatochitatus, (Carp.).

11-12. Bulmactaox Bemxay, Cossm.

13-14. Sulcoact mon staiatoscucates (Zit1, ef Gomb)

15. Anelact con papyaceus, (Bast.).

16-17. Liocarexus coxovuliforis, (1)esh.).

18-19. Nucleopsis suevaricatus, (Conr.).

20-21. Actæonidea Muxrem, (Desh.i.

22. Stricticonisa ivexi, (Terq.)

23-24. Ovict noxina sparsisulcata, (d'orlo.).
Eocène rrossisst 4 fois.

Eocène grossiss' fois.

Encène grossisst ĭ fois.

- Eocene grossiss 3 fois.

Encène grossiss 5 fois.

Eocene grossiss' 8 fois.

Vivante mrossiss 2 fois et 1/2.

Focène grossiss" 3 fois.

Raurac. grossiss' 4 fois.

Miocene grossiss 4 fois.

Eocene grossiss 1 fois et $1 / 2$.

Focène mrossiss' 3 lois.

Eocene grossiss' f fols.

Sinémur. grossiss 2 fois.

Charmonth. mrossisst 2 fois. 

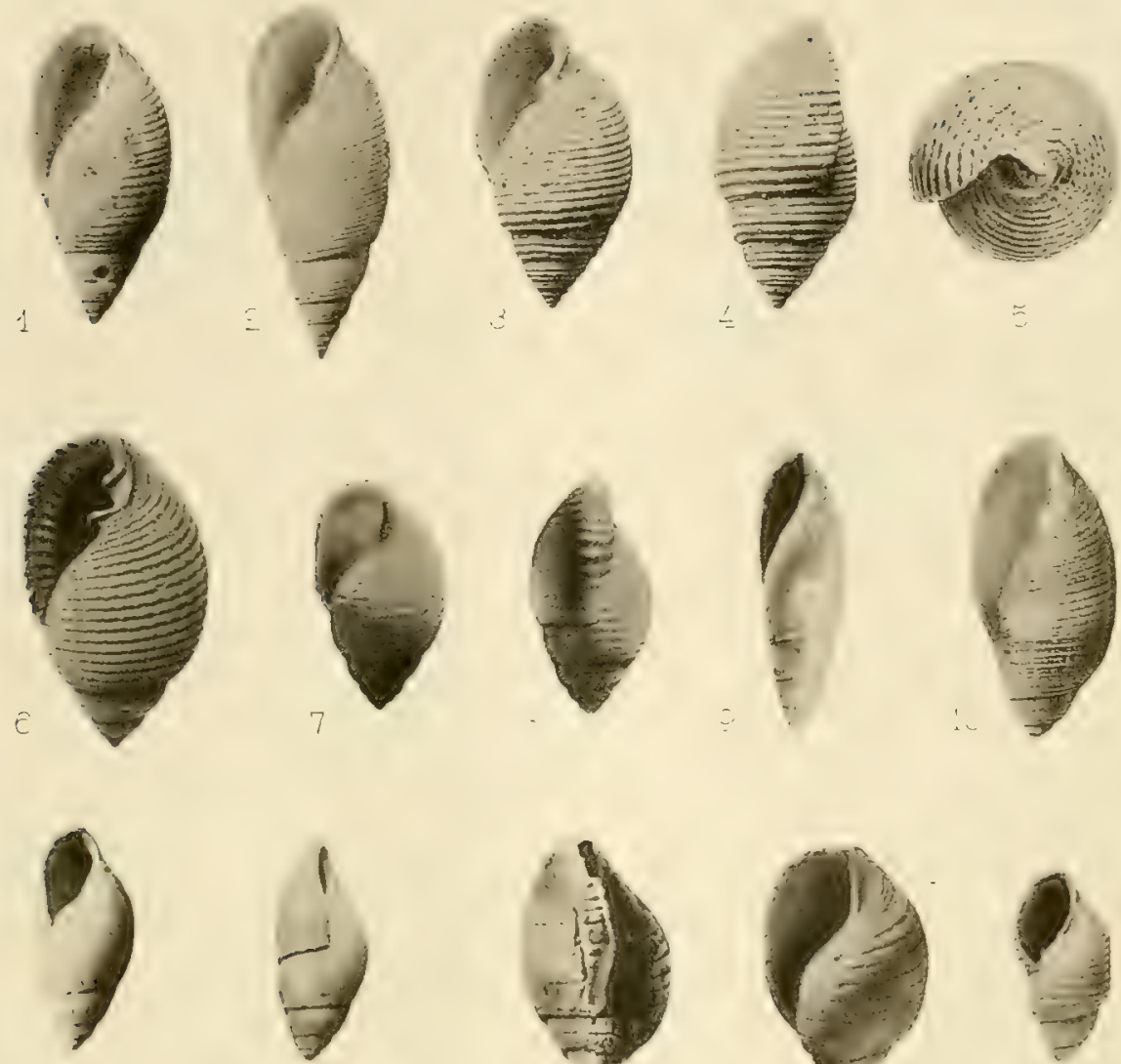

11

$$
12
$$
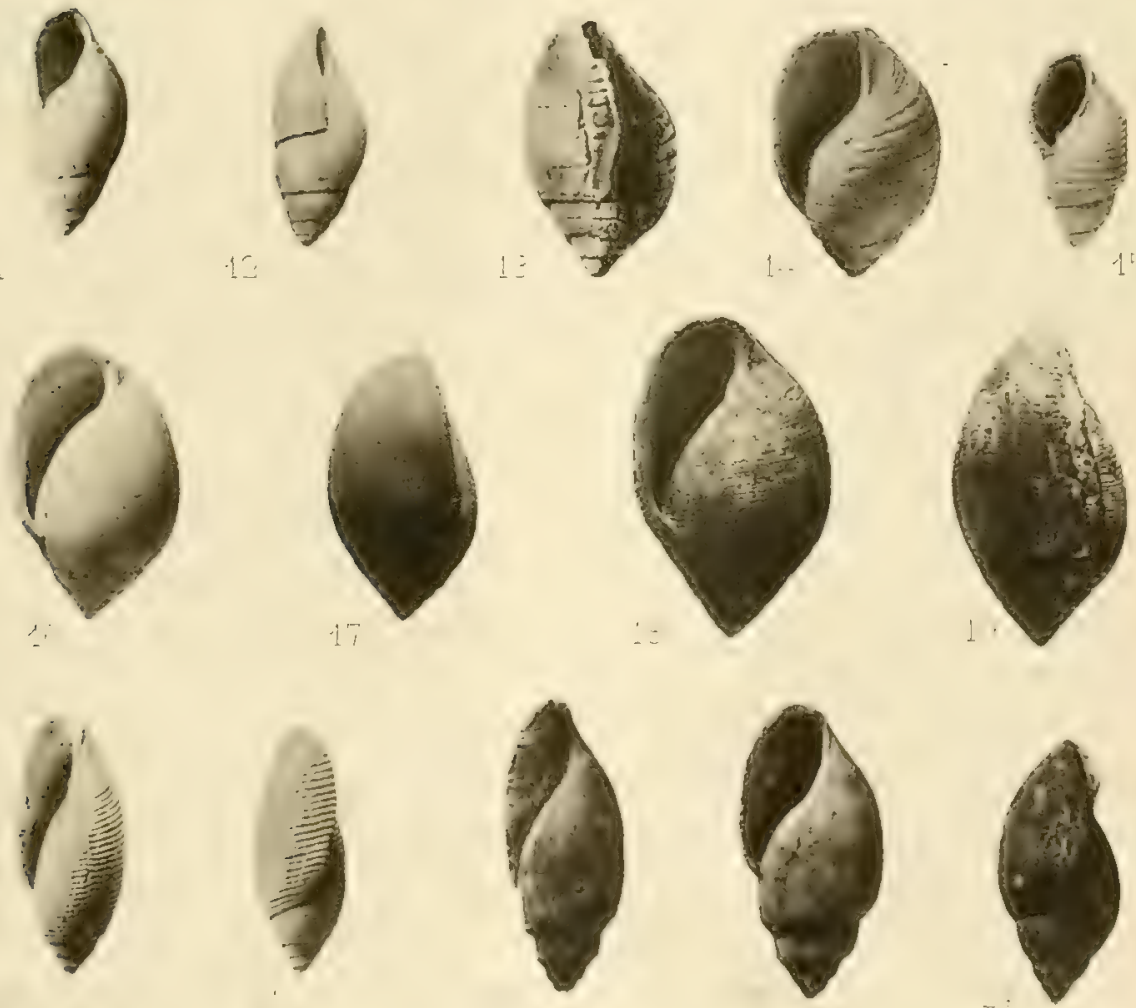




\section{PLANCHE II}

1. Cylixorobullind Fragilis, (Dunker)

2-3. Goxiocylindrites Brevis, (Morr. et Lyc.)

4. Actoonina Acuta, d'Orb.

:i-6. Conact.aox cadouexsis, (Desl.).

7-8. Euconacteox coxcarus, (Desl.).

9. Globiconchi rotuxdata, d'Orb.

10. Douvilleia arexaria, (Meller.).

11-12. Sabatia Isseli, Bellardi.

13-14. ACt wonedia Levis, d'Orb.

1;-16, Crlandates cylixducus, Morr. el Lye.

17. Crumdrites acutus, (Sow:).

18-1\%. Volvocyumdutes yarcousaxus, (Guir. el Og.). Sterfuiu.

20. Acthosella terebelua, Cossm.

21-2.2. Tornatellat Lapparexti, Cossu.
Sinémur. grossisst 3 lois.

Bathon. grandeur naturelle.

Séquan. réduction ì $2 / 3$.

Charmouth, grandeur naturelle.

Charmouth. grandeur naturelle.

Génounan. grandeur naturelle.

Eocène grandeur naturelle.

Pliocène grossisst 1 fois et $1 / 2$.

Turon. grandeur naturelle.

Bathon. grandeur naturelle.

Batlion. grossiss 1 fois et $1 / 2$.

Turon. grandeur naturelle.

Urgon. grossiss 3 fris. 

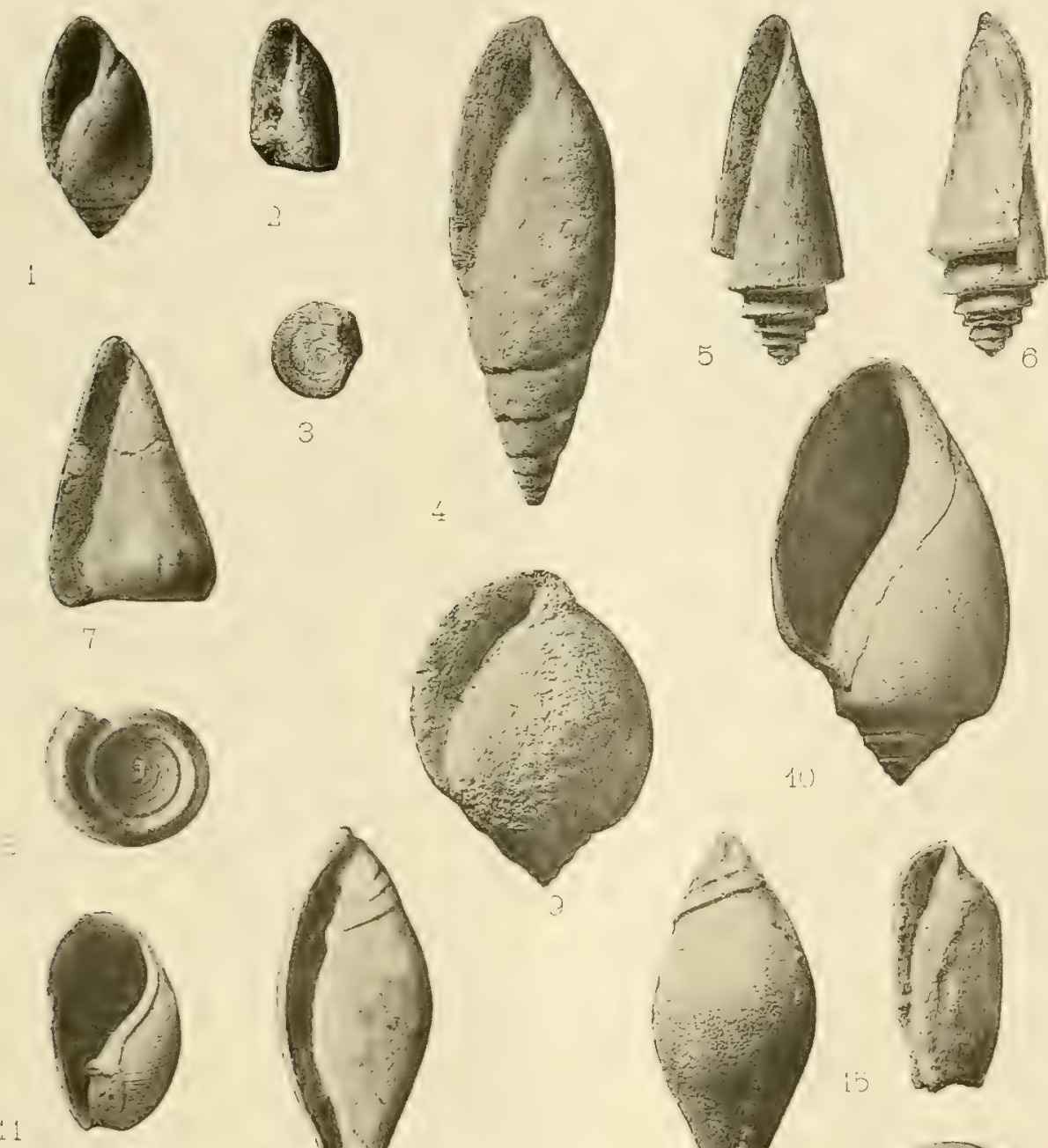

3

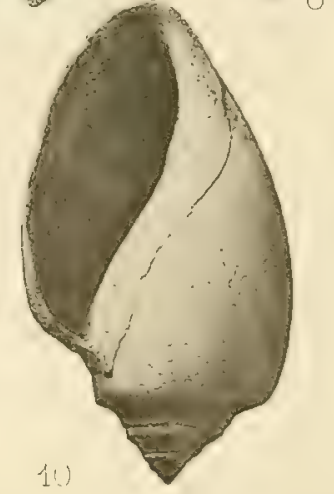

$+1$
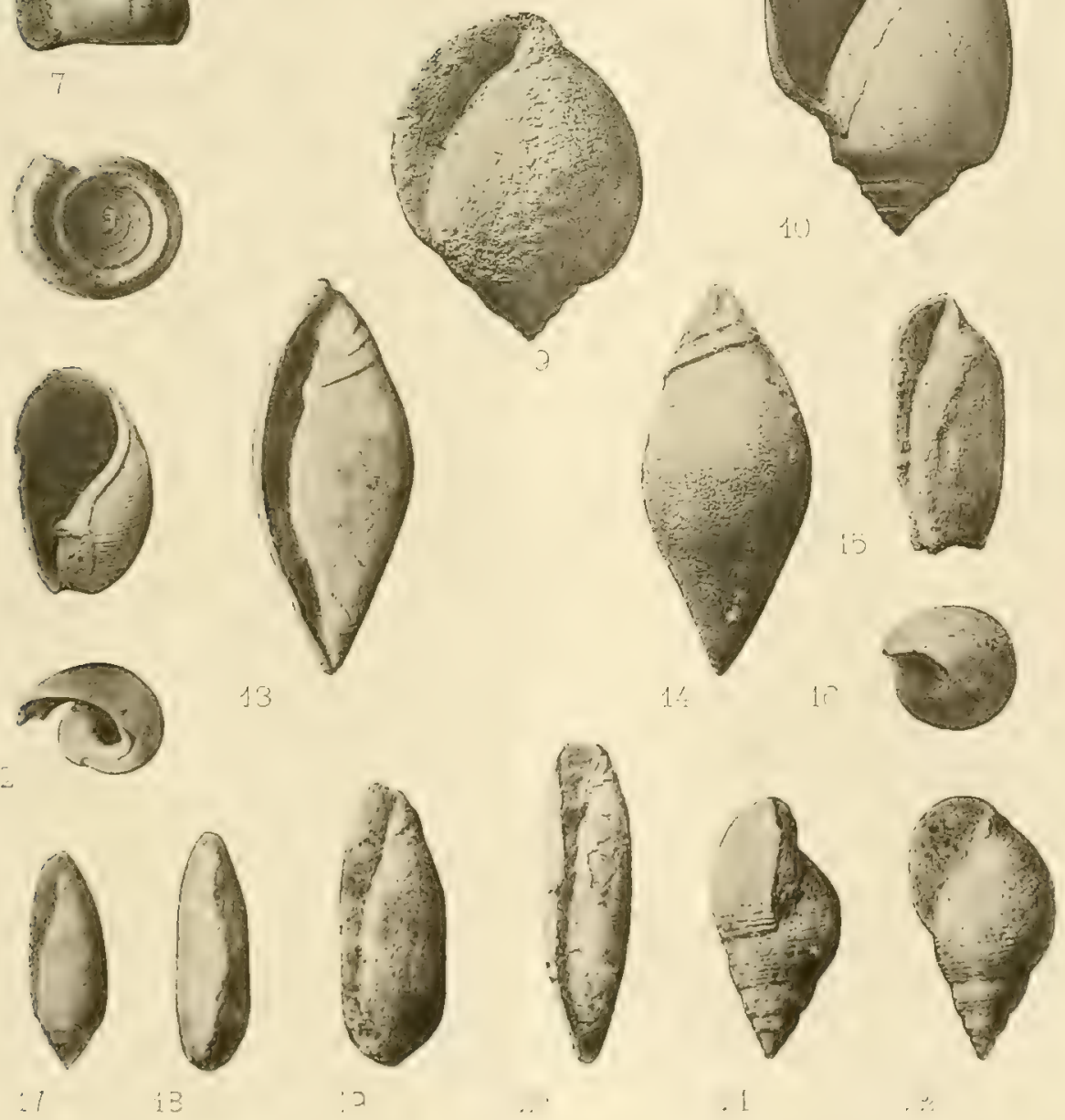

3 



\section{PLANGHE III}

\begin{tabular}{|c|c|c|}
\hline 1. Douvilleis areviria, (Mellev.). & Eocène & Erossisst 2 fois. \\
\hline 2-3. Thochacteon Arnaud, Cossu. & Turon. & grandeur nafurelle. \\
\hline 4-6. Ptychogrlixdhtes Condat. (Guir. et Og.). & Séquan. & granleur naturelle. \\
\hline 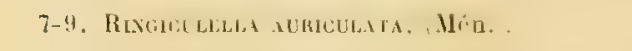 & Minènt & Erossisst Z firis el 1/2. \\
\hline 10-11. Eriptrcha llumboliti, (Mull.). & Sénon. & frossiss' 2 fois. \\
\hline 12-14. Rrygicula Ringens, (Lamk.). & Eocène & grossiss' 4 fois. \\
\hline 15-17. Avellaxa bubia, Br. et Corn. & Ginomen. & grossissi 2 fois. \\
\hline 18-20. Gilbertia ixoplyata, Morlet. & Eocéne & grossiss ${ }^{t} 5$ fois. \\
\hline 21-23. Acrostemia coronatum, (Lamk.). & Eocène & grossiss' 2 fois. \\
\hline 24-25. Retusa truxgatula, (Brug.). & Pliocène & grossisst 7 fois. \\
\hline 26-27. Tornatina Lajoxkairiana, (Bast.). & Miocéne & grossiss 4 fois. \\
\hline 28-30. Ringivella clementixa, d'Orb. & Albien & grossiss 2 fois. \\
\hline
\end{tabular}



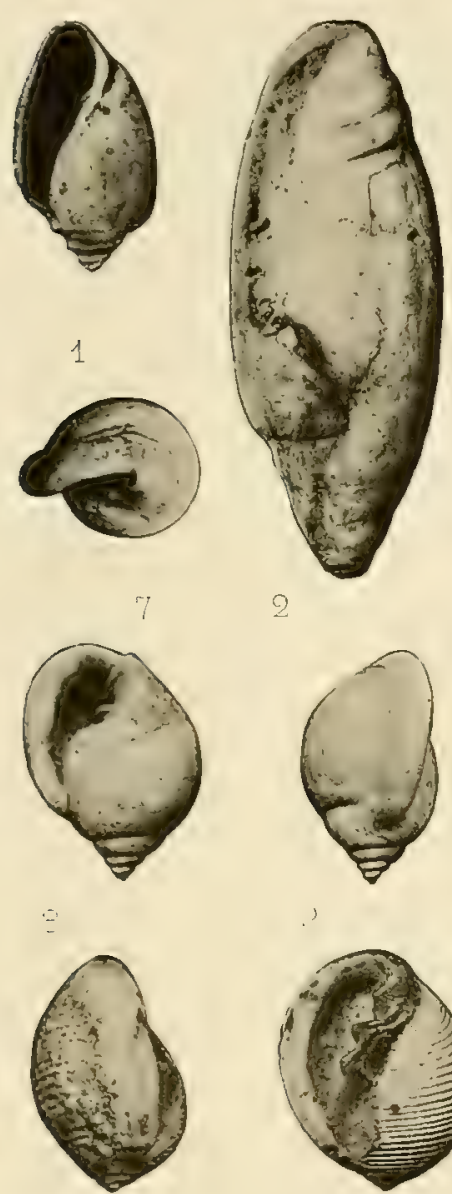

$1=$

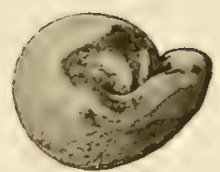

17

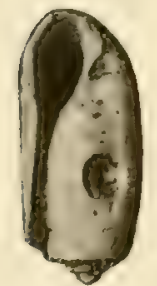

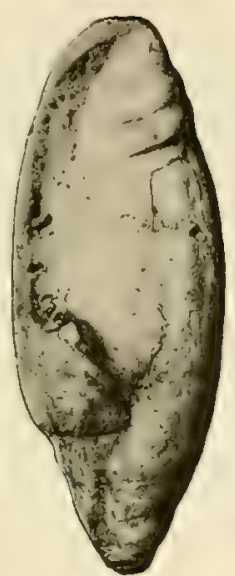
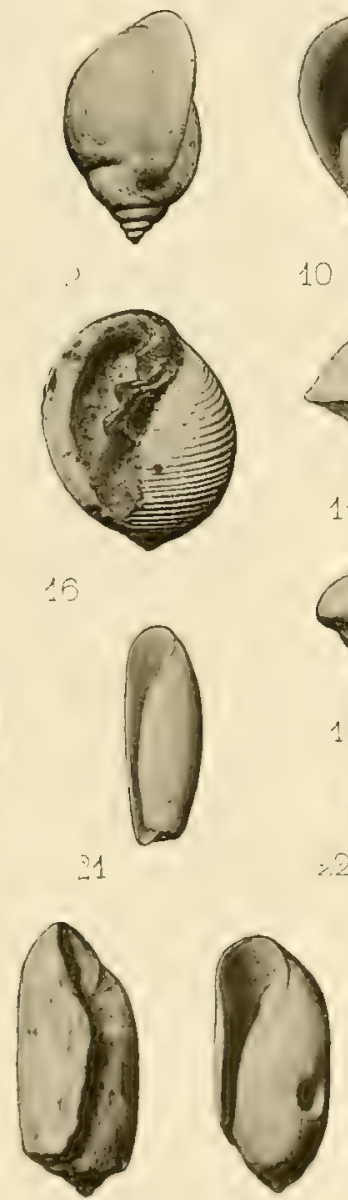

2) E

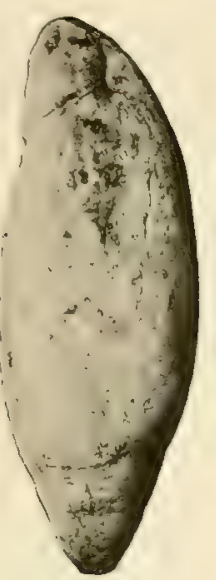

3

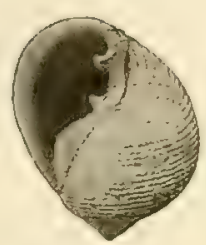

10

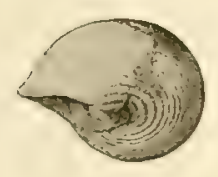

11

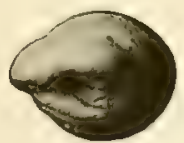

(1)

$\therefore 2$
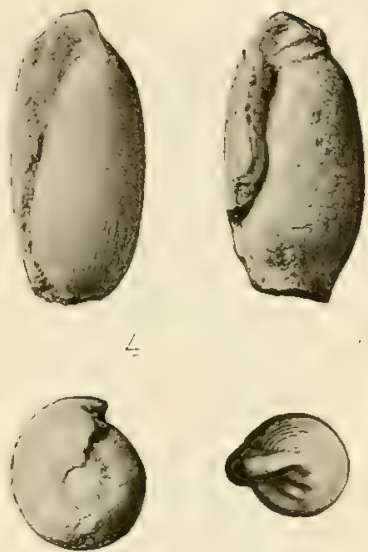

12
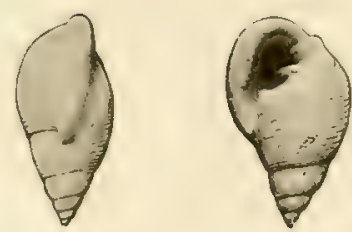

$1 L$
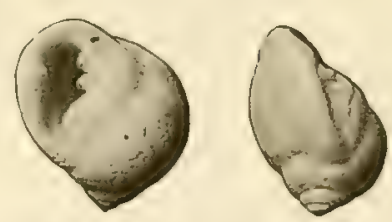

20
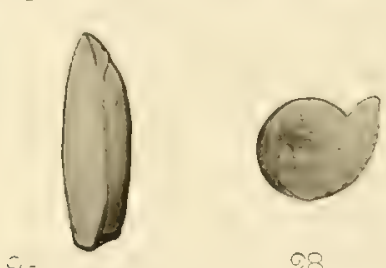

98
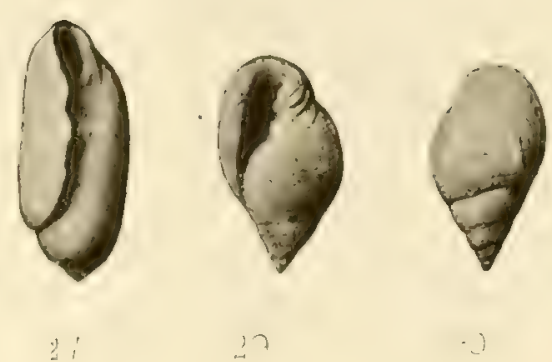




\section{PLANCHE IV}

\author{
1-2. Volvulella Dekayi, (Lea). \\ 3-5: Scapuaxder coxicus, Desh. \\ 6-7. Bulla striata, Brug. \\ 8-10. Bullixella Verveuili, (Desh.). \\ 11-13. Acrocolpus plicatus, (Desh.). \\ 14-16. Cylichnella vasatensis, Benoist. \\ 17-19. Cylichinima cylindroides, (Desh.). \\ 20-22, Roxania ovllata, (Lamk.). \\ 23-24. Roxania semistriata, (Desh.). \\ 25-27. Acera striatblla, (Lamk.). \\ 28-29. Haminea Corvea, (Lamk).
}

$\begin{array}{ll}\text { Eocène } & \text { grossiss } 4 \text { fois. } \\ \text { Eocène } & \text { grandeur naturelle. } \\ \text { Pleistoc. } & \text { grossiss } 1 \text { fois et } 1 / 2 . \\ \text { Eocène } & \text { grossiss } 1 \text { fois et } 1 / 2 . \\ \text { Eocène } & \text { grossiss } 4 \text { fois. } \\ \text { Mlocène } & \text { grossiss } 7 \text { fois. } \\ \text { Eocène } & \text { grossiss } 2 \text { fois. } \\ \text { Eocène } & \text { grossiss } 2 \text { fois. } \\ \text { Eocène } & \text { grossiss } 2 \text { fois. } \\ \text { Eocène } & \text { grossiss } 2 \text { fois. } \\ \text { Miocène } & \text { grossiss } 2 \text { fois et } 1 / 2 .\end{array}$



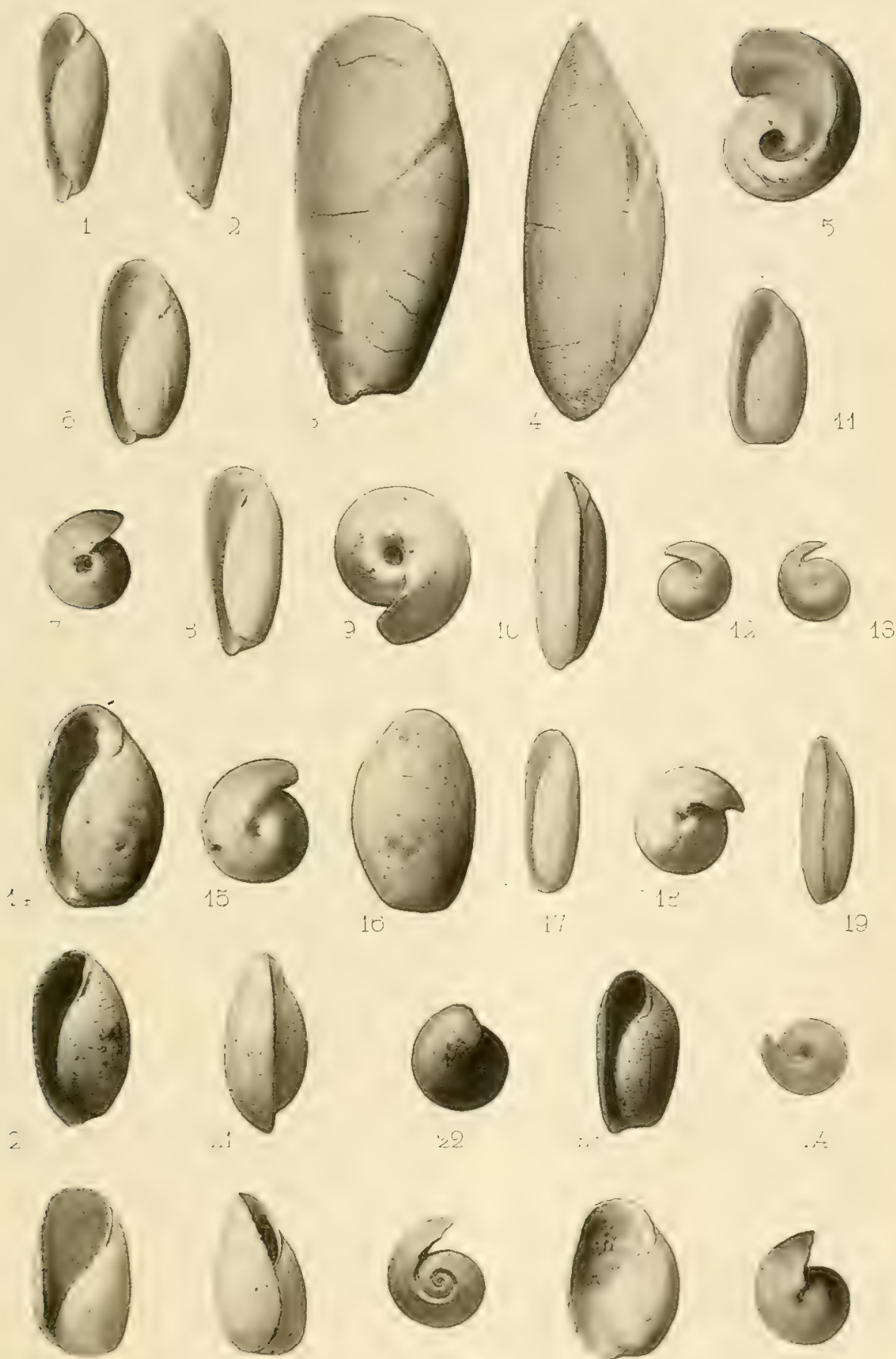

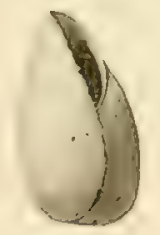

는

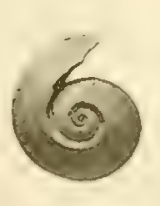

2

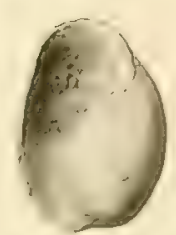

3

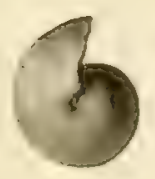

2) 



\section{PLANCIIE V}

1-3. Mnestia turgidula, (Desh.)

4-6. Paldomyditina undulata, (Beau.)

7-8. Megistostoma exparisu, (Desh.)

9-10. Unbrellat ladouxexsis, (Desh.)

11. Ampiisphya assula, (Desh.)

12-13. Dolabela Ruumpun, Cuvier.

14-16. Acroria Baylei, (Cossm.)

17-19. Sipionaria spectabilis, Desh.

20-21. Willianda Raincourti, (Cossm.)

22-23. Ampuisphya assuld, (Desh.)
Oligocẻne grossiss 4 fois.

Bathon. grandeur naturelle.

Eocene grossiss 2 Cois.

Eocène grossiss' 2 fois.

Eocène grossiss' 10 fois.

Vivante grandeur naturelle.

Eocene grossiss 2 fois.

Eocene grossis' 2 fois.

Eocène grandeur naturelle.

Eocène grossiss' 5 fois. 

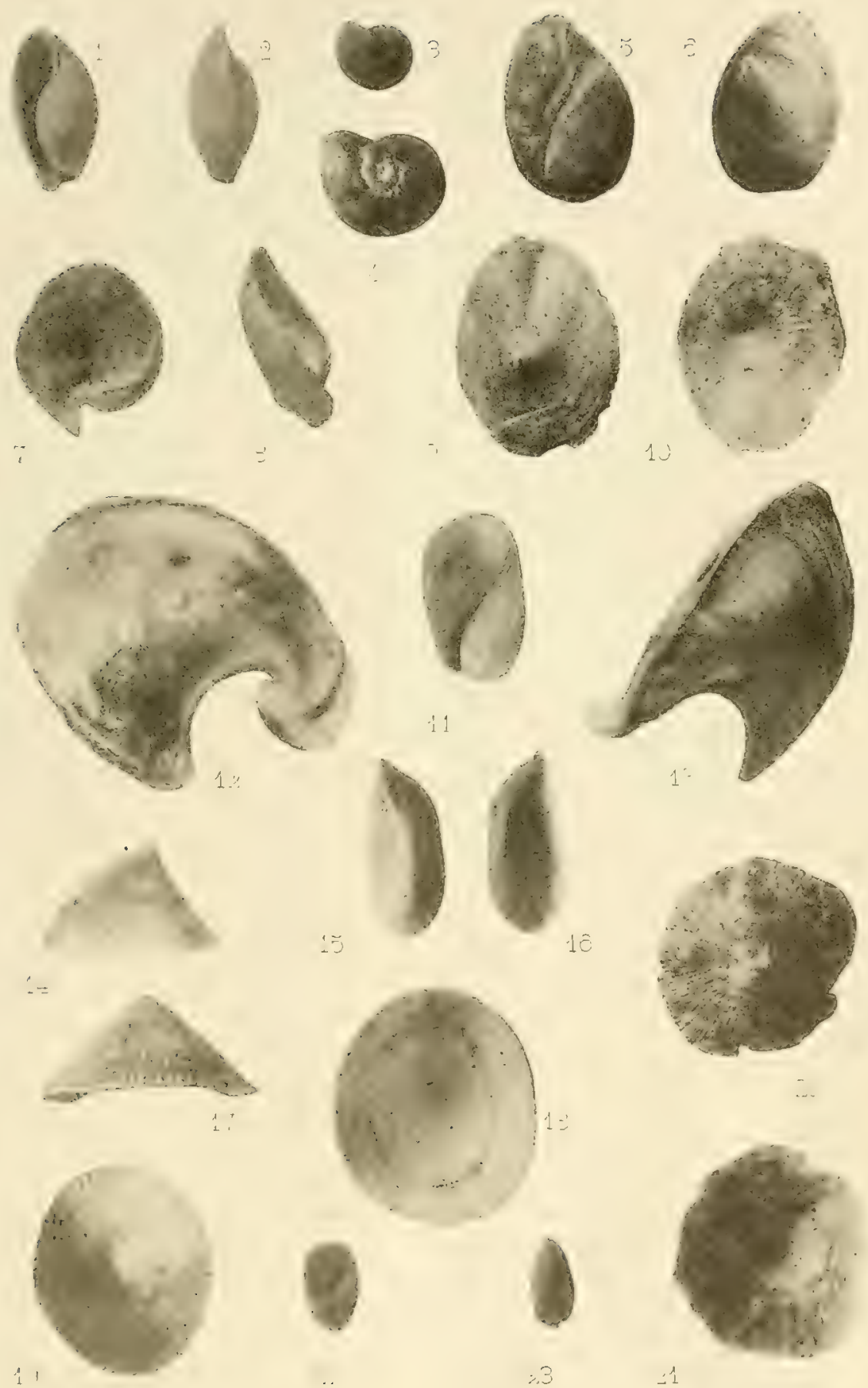




\section{PLANCHE VI}

1-3. ERaptycil inecuitata, (Sow.)

i-5. Ceritela cosica, (Mor, el Lyc.)

(i-7. Eoatrayta spincloides, (Lamk.)

\$-10. Rivtunopuls II Mberti, (Buv.)

11-12. Rixgiculospoxgia Boxelui, (Wesh.)

13.) P'Hutise APERT, (Lin.)

14. Ruxcourtil mcius, Fischer.

13-16, Bella yarullexsis, Cossm,

17. 'Trochicteronisa Bigoti, Gossm.

1N-19. ACtkonela Bortuliteri, Cossm.

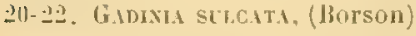

23-2'́, Acera neocomiensis, Cossu.

2:. Ovacteonisi undonexsis, Cossm. 2li-2t. Rixgicelat turonexsis, Cossm.

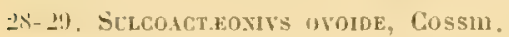

30. Metcsi texuistriat., (Cotteau).
Turon. grossiss' 3 fois.

Bathon. grossisst 2 lois.

Focene grossiss's fois.

Séquan. grossiss 2 fois et 1/2.

lliocene grossisst 2 fois et $1 / 2$.

Vivante grossiss 1 fois el $1 / 2$.

Pliocene srossiss 10 fois.

Néocom. prossiss 1 fois et $1 / 2$.

llawrac. grossiss 6 fois.

Dinrint. rrossiss' 3 fois.

Viocine grossiss 3 fois.

Vimeont grossiss 1 fois et $1 / 2$.

Barréu, ugrossiss' 6 fois.

Turon. grossisst $\ddot{z}$ fois

Barrèm, grossiss 3 fois.

Barrênı, grandeur naturelle. 

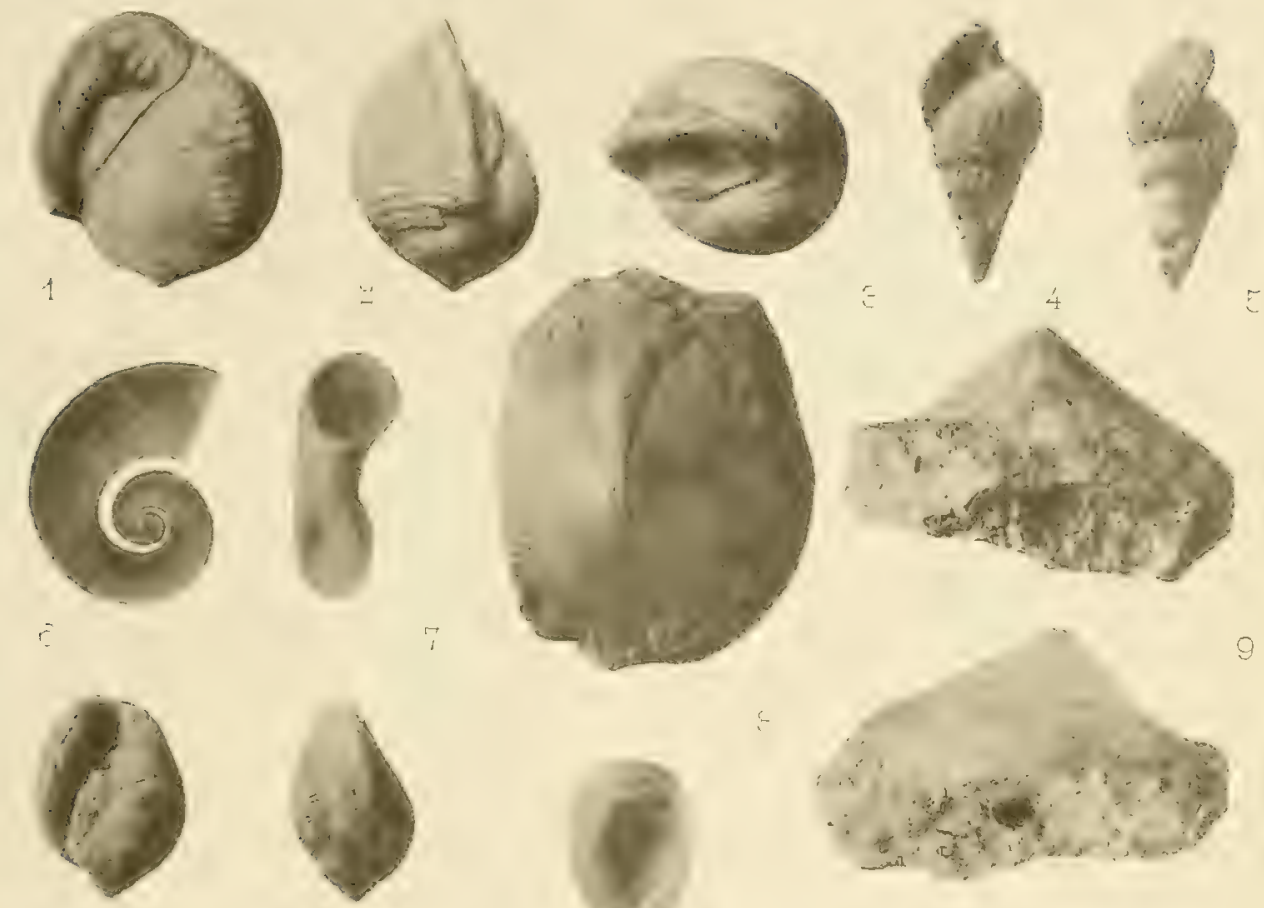

$\therefore$
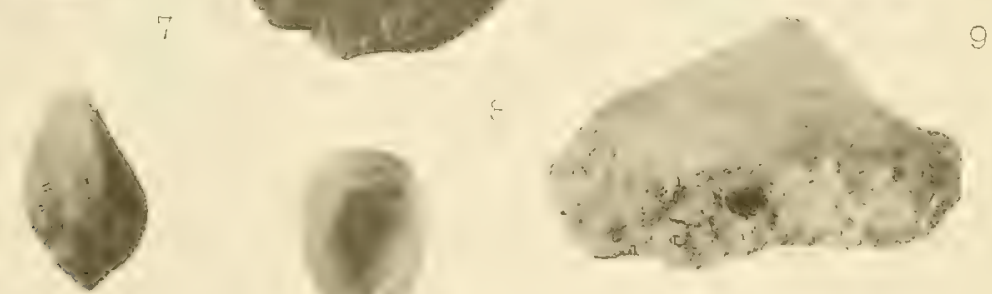
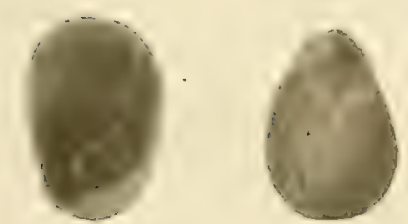

$1=$

$\therefore:$

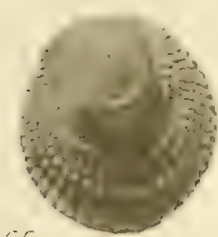

50

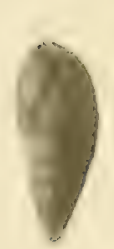

25

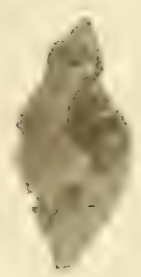

26
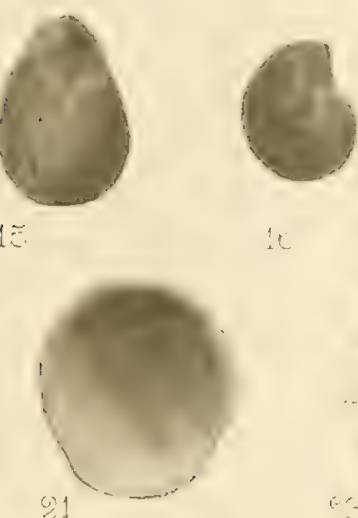

is
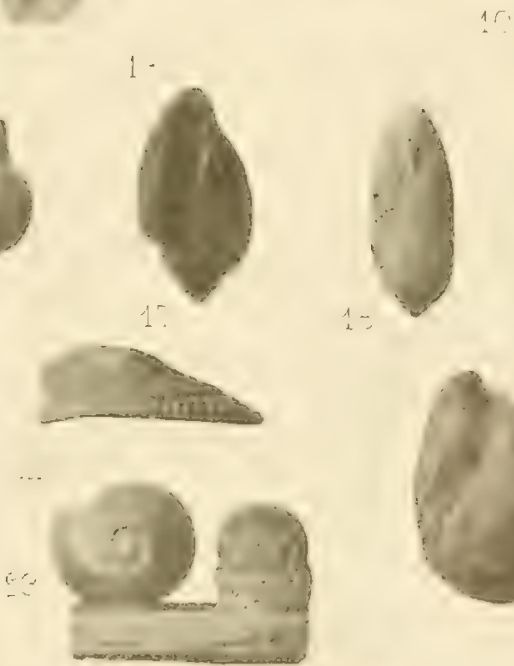

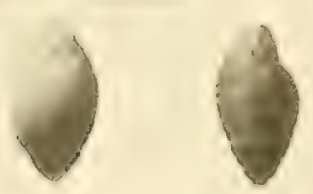

28

8

29

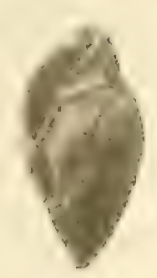

27

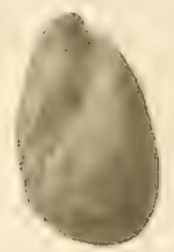






\section{PLANCHE VII}

1-2. Hermania scabra, (Müll.)

3. Ossinia guadrata, (Wood)

4-6. Vasculum obloum, Ch. White

7-8. Blaxcia maceana, Bonig.

๖. Ciminaria IIugand, Bellardi

10. Cempella icura, Morr. et Iyc.

11. Rinilculocosta costata, (Eichw.)

12. Fibula uxnulosa, Piette

13. Tylodixa puxctulata, Rafin.

14. Dolabella ilomichi, Dall.

15. Oligoptycha coxcinxa, (Hall et Meek).

16. Cylindriteld truxcata, Ch. White.

17. Cixulia globulosa, (Desb.)

18. Ansomyoy patellifonms, Meek et Hayden

1. Triploca linita, Tate.

- Iercyiella Beyrichi, kayser.
Pliocène d'après Wood.

Pliocène d'après Wood.

Paléncène d'après White.

Turon. d'aprés Bourguignat.

Miocéne d'aprẻs Bellardi.

Bathon. d'aprés Morrisetlycelt.

Miocène d'après nature.

Bathon. d'après Piette.

Vivante d'après Tryon.

Mincène d'après Wall.

Sénon. d'après Meek.

sénon. d'après White,

Néocom. d'après d'Orbigny.

Sẻnon. d'après Neek.

Eocéne d'après Tate.

Silur. d'après Ziltel. 
Essais de Paléoconchologie

PI. VII

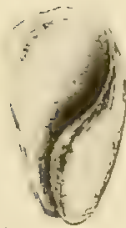

Gis

( $)$
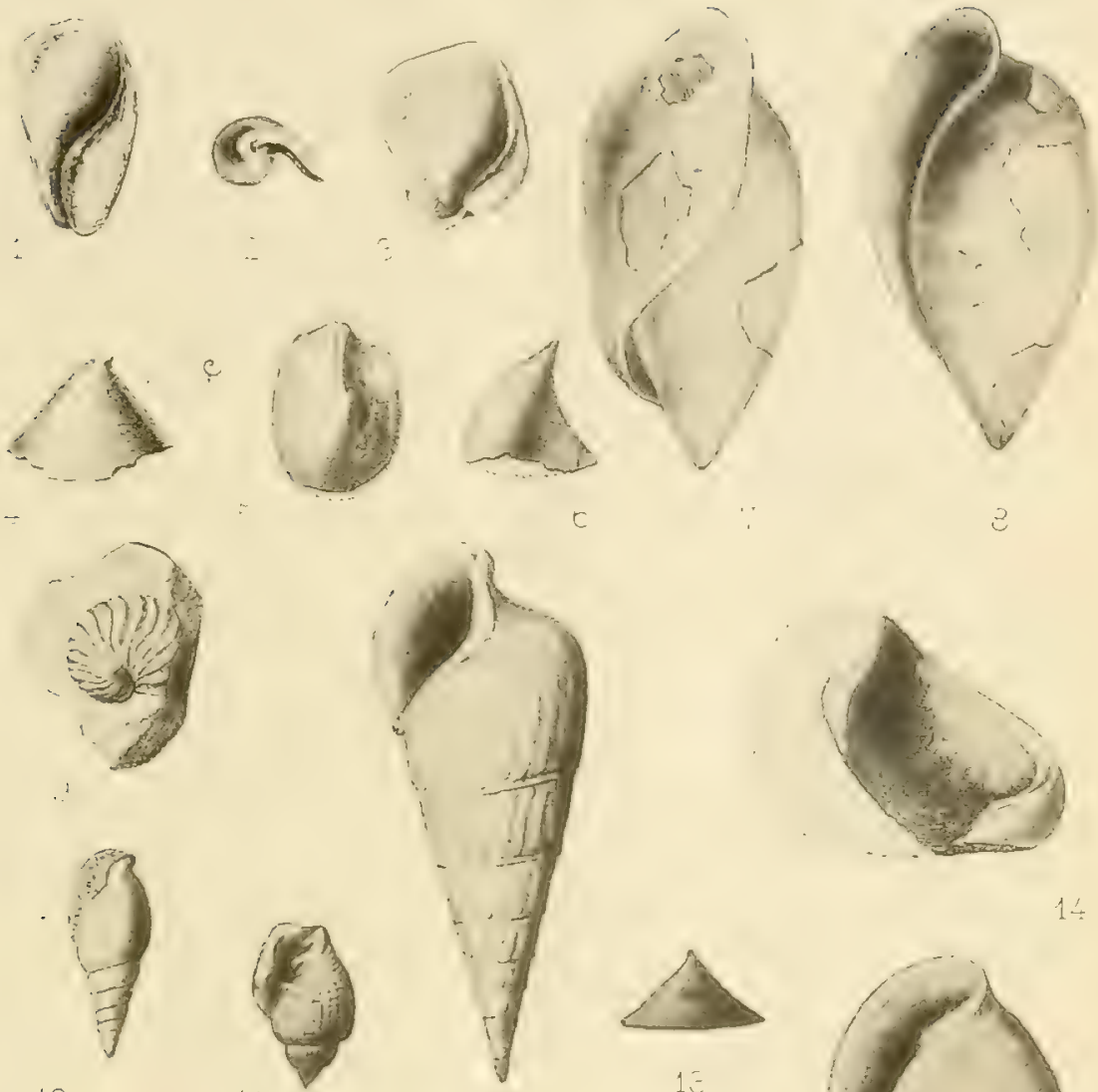

$$
\pm
$$

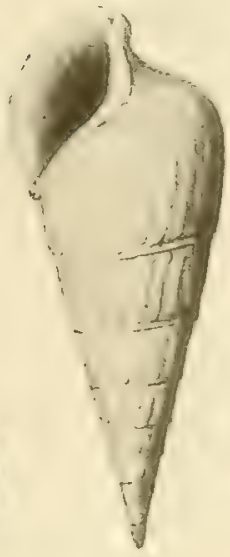

1

(3)
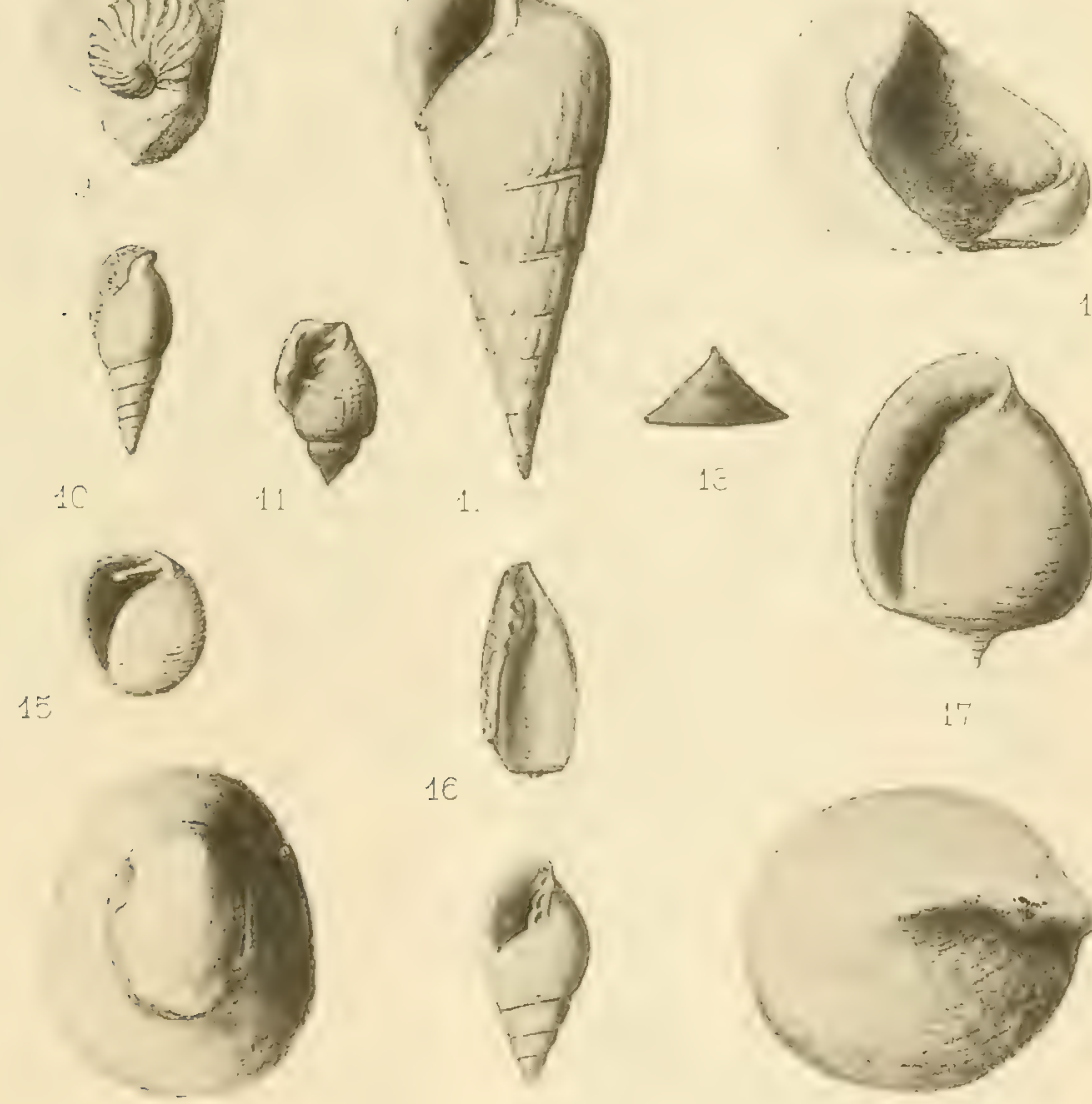

16
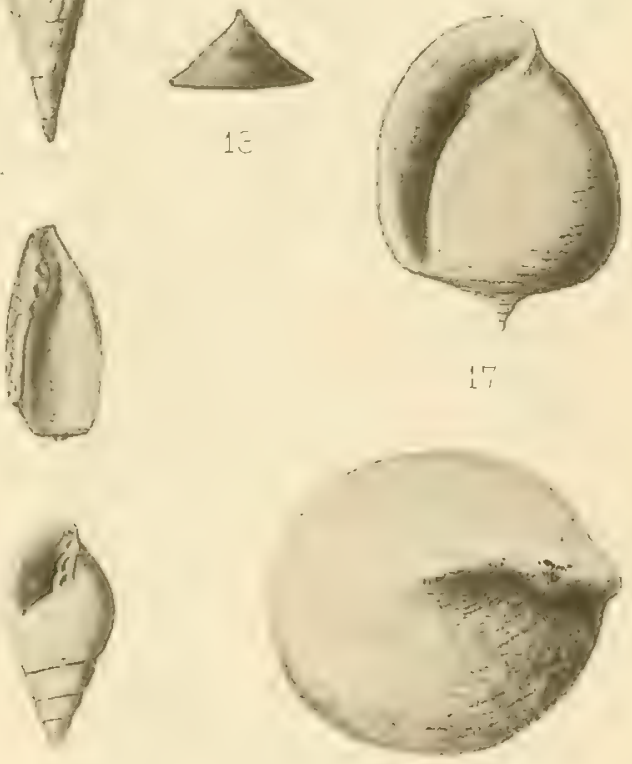

$1 \cdot$ 



\section{ESSAIS}

DE

\section{PALÉOCONCIIOLOGIE COMIPARÉE}


OUVRAGES DU MÊME AUTEUR

Catalogue illustré des coquilles fossiles de l'Eocène des environs de Paris (1886-1896). Cinq vol. in-8, avec 46 planches lithographiées, y compris les appendices. Prix : $111 \mathrm{fr}$.

Revision sommaire de la faune du terrain oligocène marin aux environs d'Etampes (1891-189:3). Trois fuscicules in-8, avec 3 planches lithographiées. Prix : 12 fr. 50.

Notes complémentaires sur la faune éocénique de l'Alabama 189:3). 1 vol. in-4, avec 2 planches phototypées. Prix : $8 \mathrm{fr}$.

Sur quelques formes nouvelles des faluns du Bordelais 1891-189:; Denx brochures avec 3 planches phototypées. Prix : 6 fr.

Essais de paléoconchologie comparée, $18910 \%-18961$. D(1x liviaisuns. avec 15 planches phototypées. Prix : $33 \mathrm{fr}$.

Mollusques éocéniques de la Loire-Inférieure 189"-1896 . Delı fascicules, avec 9 planches photolypées. Prix: $18 \mathrm{fr}$.

Revue bibliographique de paléozoologie. Comple rendu trimestrit des ouvrages récents, à dater de Janvier 1897.

Prix: $\left\{\begin{array}{l}\text { Union postale, } 6 \mathrm{fr} \text {. } \\ \text { Hors de l'union postale, } 7 \mathrm{fr} \text {. } \\ \text { Par numéro isolé, } 2 \mathrm{fr} \text {. }\end{array}\right.$

S"adresser à l'Auleur, 95, rue de Maubeurje.

(Envoi franco contie mandat postal.) 


\section{ESSAIS}

DE

\section{PALEOCONCHOLOGIE}

\section{GOMPARÉE}

par M. COSSMANN.

\section{DEUXIĖME LIVRAISON}

(Dẻcembre 1896)

Recid Dec. 23.

\section{PARIS}

CHEZ L'AUTEUR

9 , HUE MAUHEUGE, 9Ј
COMPTOIR GÉOLOGIQUE

ธ̋, RUE MONSIEUR LE PIINCE, 53 

Paris, Novembre 1896.

La préface qui sert d'introduction à la première livraison de ces "Essais ", s'appliquant à l'ensemble de l'ouvrage, me dispense d'en écrire une spéciale à la seconde livraison : je me borne donc ici, avant d'entrer en matière, à indiquer certaines améliorations apportées au texte, sur le conseil de quelques amis.

Les tableaux de classification, par famille, des genres, sousgenres et sections ne devaient être, dans ma pensée, qu'un sommaire résumant, sous une forme synoptique, l'arrangement que j’adopterais pour ces divisions génériques, à l'exclusion des rapports et différences qu'elles présentent entre elles, et dont l'indication détaillée est mentionnée dans le texte relatif à chaque genre, sous-genre ou section.

Toutefois un de nos confrères m'a fait remarquer qu'il suffirait de compléter très brièvement ces tableaux par l'indication des caractères les plus saillants, pour leur donner immédiatement la raleur de tableaux dichotomiques, justifiant d'un seul coup d'œil les bases de l'arrangement proposé. Cette amélioration ne laisse pas que de présenter, dans l'exécution, de réelles difficullés, tant au point de vue lypographique, pour ne pas nuire à la clarté du classement, qu'en ce qui concerne l'impossibilité malérielle où l'on se trouve souvent d'exprimer, en très peu de mols, des caractères complexes, plus ou moins importants, et cependant capables de motiver les distinctions faites entre les subdivisions d'une même famille.

Xianmoins j'ai essayé, dans la mesure de ce qu'il m'a été possible, de donner satisfaction à ce desideralum, en ajoutant, entre 
crochets el en pelit caractères, quatre ou cinq mots au plus, pour caractériser ces subdivisions par le critérium le plus frappant, el avec autant de symétrie qu'en comporte l'histoire naturelle des êtres organisés.

Plusieurs de nos lecteurs ont demandé quelques explications au sujet de l'emploi des mols néo-type ${ }^{1}$ et plésiolype dont-il est fait usage dans cet ouvrage. Il est d'autant plus utile d'en donner une définition, que le sens à attribuer à ces deux mots doit varier suivant qu'il s'agit des genres ou des espèces :

$1^{\circ}$ Pour les genres, le type est représenté par une espèce bien définie, quand l'auteur du genre a désigné l'espèce à laquelle s'applique exactement la dénomination générique qu'il propose. Lorsqu'il n'a pas eu cette précaution essentielle (c'est le cas de beaucoup d'ouvrages anciens), il est d'usage de prendre comme type la première des espèces décrites par l'auteur du genre, à moins qu'elle n'ait été elle-même choisie comme type d'un genre ou sous-genre, ultérieurement formé aux dépens du genre primitif, et détinitivement accepté; à défaut de la première, on se rejetle sur la seconde, et ainsi de suite. Or il arrive souvent que, d'élimination en elimination, il ne reste plus aucune esperce primordiale pour servir de type au genre ainsi démembré. Dans ce cas, il est bien évident qu'il faut conserver au moins une forme pour représenter le grenre qui a le droit de priorité, et alors l'espèce choisie à cet effet, avec de sérieux motifs à l'appui, peut être qualifiée néo-type.

Ainsi le néo-type d'un genre est l'espèce qui, à défaut de type, doit être désormais considérée comme typique: il ne peut y en avoir qu'une seule et le préfixe " néo " a simplement pour but de rappeler que le choix de ce type est postérieur à la création du genre. Il résulte encore de là que, si le type a une fixité absolue,

1 J'arais d'abord adopté post-type, mais on m'a fait remarquer l'étymologic hyluride de ce mot, moitié latine, moitié grecque; $\hat{j}^{\prime} y$ ai done définitivement subslitué néo-type. 
le néo-type qui peut être contesté, quant au choix de l'espèce proposée, n'est pas nécessairement invariable.

Au contraire, le plésio ty pe est une espèce voisine de l'espèce type, mais différente, appartenant vraisemblablement au même genre, au même sous-genre, à la même section, et qui le représente, soit à une époque gẻologique, soit dans une région géographique, différente de celle qui a été désignée comme " habitat " de l'espèce type. Il résulte de là qu'il peut y avoir plusieurs plésiotypes pour un même genre, et que néanmoins chacun d'eux peut être définitivement admis et classé comme plésiotype.

$2^{\circ}$ En ce qui concerne les espèces, la définition et l'emploi de ces deux mots sont nécessairement un peu différents : comme le type d'une espèce est un échantillon unique, qui a servi de modèle à la description et à la figure de cette espèce; il ne peut y avoir d'utilité à le remplacer par un néo-type, que si cet original a été détruit ou a disparu pour une raison quelconque; mais encore faut-il, pour qu'on puisse admettre cette substitution, qu'il soit bien démontré que le nouvel échantillon représente absolument la forme typique que l'auteur avait en vue quand il a créé l'espèce, quelque défectueuse ou insuffisanle que soit la figure qu'il en a donnée: on n'a guère cette garantie que si ce nouvel échantillon provient de la même localité, exactement au même niveau, surtout s'il fait partie de la même récolte, quelquefois si c'est un échantillon meilleur, montrant mieux les caractères spécifiques, par suite de son état de conservation.

En dehors de ce cas, qui se présente d'ailleurs bien rarement, l'échantillon, soit de la même localité, soit d'un autre gisement, qu'on assimile à une espèce, après une comparaison avec le type ou avec les figures originales, et dont on donne une nouvelle description et une nouvelle figure, n'est, à proprement parler, que le plésiotype de cette espèce.

Il résulte de là que le néo-type d'une espèce peut, dans certains cas, être contestéet descendre au rang de plésiotype ; qu'en outre il peut y avoir autant de plésiotypes que l'on juge utile d'en pro- 
poser pour la même espèce ; qu'enfin ces plésiotypes n'ont qu'une fixité relative, puisqu'il peut toujours arriver qu'on leur attribue ultérieurement la valeur d'une variété, d'une espèce distincte.

Je n'ai pas joint à cette livraison, comme je l'avais fait pour la première, de tableau phylogénétique, indiquantla filiation présumée des genres, dans les temps géologiques. J'ai en effet, pour m'en abstenir, plusieurs molifs: d'abord les familles étudiées ci-après ne forment qu'un fragment infime de la masse considérable des Gastropodes prosobranches, de sorte que l'on ne pourra bien se rendre compte de leur enchaînement qu'après un exposé de l'ensemble des familles qui composent ce sous-ordre, saulbien entendu pour ce qui concerne les Nérinées qui, comme on le verra ciaprès, paraissent intermédiaires entre les Opisthobranches et les Prosobranches. Ensuite la disposition de mon tableau phylogénétique a donné lieu à certaines critiques qui nécessiteraient l'arloption d'une autre forme graphique, sur laquelle mon choix n'est pas définitivement arrêté.

J'y reviendrai donc ultérieurement, et il est probable que ce ne sera guère avant d'avoir terminé au moins la série des Siphonostomes. 
ENTOMOTENIATA, nov. subordo.

Familles.... $\left\{\begin{array}{l}\text { TUBIFERID } A, \text { Cossm. 189.. } \\ \text { ITIERIID } A, \text { nov. fam. } \\ \text { NERINEIDA, Zittel, } 1873 .\end{array}\right.$

Aninal inconnu. - Coquille caractérisée par l'existence d'une échancrure profonde et très étroite, à la jonction du labre avec l'avant-dernier tour; les accroissements de cette échancrure forment, contre la suture, une bande presque linéaire, tantôt en saillie, tantôt en retrait sur une rampe déclive qui a exactement la même largeur que la bande.

Embryon hétérostrophe, dévié en forme de crosse courte et oblique.

Ouverture holostome, terminée en avant par un bec ou une sinuosité subcanaliculée, non échancrée, dans l'angle formé par l'intersection du contour supérieur et de la columelle; bord columellaire ne se raccordant pas au bord basal par une courbe régulièrement arrondie.

Labre presque vertical, à peine incliné à droite de l'axe du côté antérieur, arqué du côté postérieur où il est profondément entaillé avant de se raccorder avec la suture, souvent muni à l'intérieur d'une lamelle spirale.

Columelle parfois perforée, lisse ou plissée, toujours infléchie à droite à sa jonction avec le contour supérieur, près du bec basal; paroi inférieure de l'ouverture quelquefois munie d'une lamelle spirale dite pariétaje.

Observ. - J'entrerai dans quelques développements pour justifier: d'une part la création d'un nouveau sous-ordre; d'autre part l'assemblage des familles exclusivement fossiles avec lesquelles je propose de le constituer ; enfin la position systématique qu'il y a lieu de lui attribuer dans la classification générale des Gastropodes. 
I. - insi que l’indique la diagnose ci-dessus, le principal caractere des Entomolicniata, celui qui motive leur dénomination, est l'existence d'une bande sufurale, rappelant celle des Pleurotomarizda, à cette différence près qu'elle n'occupe pas la mêne position sur les lours de spire. L'échnnerure correspondante du manteau de l'animal devait évidemment avoir un but analogue, sinon identique, au point de rue de son organisation ou de ses mœurs. Une échancrure semblable existe chez quelques Opisthobranches, par exemple les Aceridx qui y laissent passer un filament palléal.

Un second caractère, non moins important, mais dont on n'a malhertreusement pu vérifier la constance que dans l'une des trois familles de c' nouveau sous-ordre, celle des Tubiferidx, c'est la disposition de l'embryon qui, chez Cerilella el Pseudonerinea, est hétérostrophe et dévié en forme de crosse, exactement comme dans les Actronidx, et n'est pas pulvini comme celui des Odontostomia, ni enroulé autour d'un axe diflérent de celui de la coquille, comme cela a lieu chez Turbonilla.

En troisième lieu, quoique l'ouverture soit holostome, et que l'animal qui labitait la coquille n'ait certainement pas été siphoné, cette ouverture est invariablement anguleuse ou sinueuse à la base, avec me tendaner à la formation d'un bee subcanaliculé, qui est produit par une inflexion de la columelle, avant qu'elle se joigne au confour supérieur: ce bec, excessivement court, n'est jamais échancré, ses accroissements produisent sur la base, lorsqu'elle est ombiliquée, un bourrelet ou une carène qui circonscrit l'ombilic. On observe une disposition semblable àce bee chez la plupart il's Mathildia, chez quelques Rissoidx, chez.les Cerithioderma, c'est-it-dire dans des genres que l'on considere habituellement comme holostomes: l'ombilic caréné, par suite de la présence d'un angle à la base de l'ouverture, existe également chez Niso.

Tels sont les trois caractères fondamentaux qui, par leur association et par leur constance, me paraissent justifier le groupenent a part des trois lamilles en question. Les autres caractères ne se présentent pas avec la même constance dans ces trois familles, ils ont seulement un intérêt particulier et doivent nous servir de base pour exclure certaines hypothèses au sujet du classement des Entomotceniata. Ces caracteres, variables sclon la famille, sont les suivanis:

L'existence, sauf dans la famille Tubiferidie, d'une lamelle spirale i l'intérieur du labre (quelquefois même plusieurs), caractère que l'on u'a encore signalé chez aucun autre Gastropode que ceux des familles Ilieriidx et Nerineidx; je ne parle pas, bien entendu, des plis accidentels, non spiraux, qui garnissent, de place en place, l'intérieur du labre d'un grand nombre de formes marines, saumâtres ou pulmonées, car ce ne sont pas, à proprement parler, des lamelles continues comparables à celles des Nerinea. A cette particularité, dont le but anatomique m'échappe absolument, correspond généralement sur la surface des tours de spire une tendance à l'évidement: on remarque même, sans que ce soil toute- 
fois une règle absolue, que plus les tours ont extérieurement l'aspect évidé, plus la plication du labre est saillante et encombre l'espace libre de la cavité interne où se logeait l'animal ; en outre, le point le plus profond, ou le sommet de l'angle du profil de l'évidement, sur le galbe extérieur, correspond précisément à la hauteur de la lamelle intérieure du labre. Aucune forme de Cerithiidæ ne présente un évidement pareil sur la spire, au contraire les plis qu'on observe de place en place à l'intérieur du labre sont situés juste au droit de varices saillantes sur la surface externe; quant aux Pulmonés, tels que les Auriculidæe et Cluusiliidie, si leur ouverture est parfois grimaçante au point de laminer étroitement le passage de l'animal, c'est par suite de l'existence de dents qui ne persistent pas en spirale à l'intérieur du labre, et auxquelles correspond quelquefois une cicatrice en creux isolée sur la surface externe.

Il y a une autre particularité, qui n'existe toutefois que chez quelques Nerineidx, c'est que cette lamelle spirale, ainsi d'ailleurs que celles dont la columelle est munie, se dilate parfois et se subdivise en moulures accessoires, à son extrémité libre opposée à la base, de sorte que, si l'on fait la coupe axiale de la coquille, on obtient, depuis le sommet jusqu'à la base, une figure multilobée représentant la cavité interne habitée par l'animal entre toutes ces saillies spirales et compliquées. C'est encore là un caractère tout à fait spécial à certaines formes de Nerineidæ ou d'Itieriidæ.

Je ne cite que pour mémoire les plis columellaires et pariétaux, qui existent aussi chez les Pyramidellidæx et Cerithïdæx, puisque c'est même en partie le motif pour lequel les auteurs ont rapproché les Nerineidæ de l'une ou de l'autre de ces deux familles, selon que les plis sont columellaires ou pariétaux. Cependant, ici encore il y a lieu de remarquer, à titre de particularité, qu'on ne trouve jamais de Pyramidella qui possède un aussi grand nombre de plis que Ptygmatis par exemple.

L'existence d'un large ombilic chez certains genres d'Itieriidæe et de Nerineidær ne peut pas davantage être invoqué comme un caractère spécial, attendu qu'on remarque des entonnoirs semblables dans les genres Niso (Pyramidellidx) et Trypanaxis (Cerithiidx). Cependant c'est bien à tort que quelques auteurs ont comparé les Cryptoplocus largement ombiliqués aux Niso qui ont aussi un bec à la base de l'ouverture, ou bien qu'ils ont rapproché des Nerinxa le genre Halloysia, Briart et Cornet, qui est seulement une sorte de Trypanaxis à plis columellaires.

Quant à la forme de la coquille des Entomotæniata, sa variabilité est précisément ce qui m'a le plus embarrassé : les tours sont tantôt embrassants (Tubiferidæx et Itieriidx), tantôt superposés sans aucun recouvrement (Nerineidæ); la spire est soit conique, très courte, rétuse ou même excavée au sommet, soit plus allongée et plus cylindrique que dans aucun autre groupe de Gastropodes: ainsi, à côté d'Itieria bulliformes, surtout lorsqu'elles sont jeunes, on trouve, dans ce même sous-ordre, des Nerinella baculiformes, dont on n’a jamais le sommet, parce qu'il est à peu 
près impossible quiun corps si allongé se conserve inlact, même dans les meillenres conditions de sédimentation. Il est vrai que cette variabilité, qui nuit en apparence à l'homogénéité des formes comprises dans notre nouveau sous-ordre, plaide d'autre part, comme on le verra ci-appès, en faveur du classement que je propose de lui attribuer: car il confine, par quelques-unes de ses formes, aux Opisthobranches, et ressemble par quelques autres aux Terebra, qui commencent la série des Prosobranches.

11 me reste a faire encore quelques observations au sujet de l'ornemenlation: bien que ce ne soit pas un caractère sur lequel on puisse baser un système de classification, il est incontestable qu'elle joue un rôle imporlant, tout au moins pour guider le Conchyliologiste. Or, elle présente précisément assez de constance dans nos Entomolixniala, qui sont lisses ou faiblement ornées et qui ne portent jamais de rarices, ce qui s'explique d'ailleurs par la faible épaissenr du labre, qui est en général très mince, sauf vis-à-vis du point où il est intérieurement consolidé par une lamelle spirale; on y remarque seulement des plis d'accroissement, obliques et sinueux chez quelques Tubiferidx, parfois divisés en tubercules obsoletes par des dépressions spirales; ou bien des cordons spiraux peu saillants chez les Nerineidx, avec de petites granulations perlées, quelquefois même des nodosités obsolètes. Les formes très allongées sont généralement dimorphes, c'est-à-dire que les premiers tours ne ressemblent guère, par leur ornementation, aux demiers qui deviennent lisses, les ornements s'effaçant avec une banalité rui déroute le paléontologiste dans la séparation des espèces.

II. - Ainsi que j’ai déjà eu l'occasion de l'indiquer ci-dessus, le sousordre Entomotieniata se compose de trois fanilles qui ont pour caractères comnuns ceux dont jai, en mème temps, signalé la constance: la bande suturale, témoin invariable d'une échancrure à la partie inféricure du labre; le bec subcanaliculé à la base de l'ouverture; et probablement l'enbryon, quoique je ñaie pu vérifier ce caractère, jusqu ä présent, que sur line des trois familles.

Les Tubiferidie ont déjà été examinées dans la première livraison de ces "Essais"; pendant le conrs de l'impression de cette livraison, je me suis aperçu qu'il $y$ avait lieu de classer dans cette famille le genre I'seudonerinea de Lor., qui est si voisin de Fibula, Pielte, que je l'avais cru identique même et que j’avais considéré ces deux dénominations conme synonymes. Ainsi constituée, cette famille est très homogène, mais ses rapports avec les véritables Nérinées ne paraissent pas se dégagrer au premier abord, d'autant moins que les Tubiferidx ont encore les tours embrassants comme les Opisthobrunches, el qu'elles ne possedent jamais de plis, ni au labre, ni meme à la columelle.

Mais, dès que l'on examine la nombreuse série des coquilles désignées sous le nom Nerinea, on s'aperçoit que tantôt clles ont des plis nombreux et très compliqués, tantôt un seul pli simple, tantôt entiu absence complète 
de plication; d'autre part, on est bientôt amené à les diviser en deux groupes, l'un comprenant les formes telles que Itieria, à tours embrassants, avec ou sans plis à la columelle et au labre, l'autre restreint aux Nérinées proprement dites, dont les tours sont toujours superposés, avec ou sans plis à la columelle et au labre; de sorte que les différences résultant du nombre ou de l'absence des plis ne paraissent avoir qu'une valeur accessoire au point de vue de la séparation des familles, et justifient tout au plus la séparation des genres et des sous-genres dans chaque famille.

En résumé donc, on passe des Tubiferidx, par l'intermédiaire de Pseudonerinea, dont les tours sont peu embrassants, aux Nérinées sans plis qui ont les tours un peu plus superposés, de même que quelques Ceritella trapues confinent de près aux Itruvia qui n'ont qu'une plication rudimentaire. Si l'on ajoute à ces motifs la ressemblance que présentent extérieurement quelques jeunes 1tieria complètement involvées, avec des Actæonella ou même avec les Bullidær, tandis que les Ceritella peuvent être prises pour des Actron à bec antérieur, on conclut que, si les trois familles dont il vient d'être question forment un groupe bien homogène, ce groupe a beaucoup d'affinités avec les Tectibranches.

III. - C'est, en effet, près des Tectibranches, et peut-être même avec les Tectibranches, que je propose de classer mon nouveau sous-ordre, en rompant complètement avec la tradition qui consiste à placer les Nérinées près des Cérithes à cause de leur canal rudimentaire, ou près des Pyramidellidx, à cause de leur forme turriculée et de leur plication.

Sur les trois caractères fondamentaux des Entomotæniata, il en est déjà un qui est identique à celui des Tectibranches, c'est l'embryon en forme de crosse hétérostrophe. Quant aux deux autres, on trouve l'indice de l'échancrure suturale et du bec de l'ouverture dans quelques familles de Tectibranches: presque tous les Actaanidæ ont le labre rétrocurrent près de la suture, celte entaille est même déjà très visible chez Cylindrites, et les Aceridæ en possèdent une aussi profonde que celle des Nérinées; en ce qui concerne le bec, s'il n'est pas complètement formé dans les véritables Actronina, il a une tendance à apparaitre chez les Striactronina, les Actronidea, et surtout chez les Cylindriles, dont la columelle s'infléchit en avant exactement comme celle de Ceritella, et dont le contour basal est aussi sinueux que celui de Pséudonerinea.

Enfin l'encliainement ininterrompu qui existe, ainsi qu'on vient de le prouver, entre les Actronidæe et les Nerineidæ, est un argument que je crois décisif, quoiqu'en réalité ce soit une preuve par l'absurde: car, si on écarte les Nerineidx des Tectibranches pour les reporter, comme on l'a fait jusqu'à présent, prẻs d'autres lamilles à spire allongée et à canal rudimentaire, on ne peut en faire autant avec les Tubiferidæ qui leur sont intimement liées, ni surtout avec les Ilieriidæ qui s'accommoderaient mal d'un pareil classement. Il faut done nécessairement laisser ce sous-ordre tout entier près des coquilles avec lesquelles quelques-uns de ses membres 
ont le plus d'aflinité, sous peine de le disloquer d'une manière beaucoup moins rationnelle encore.

J'aurais vivement désiré appuyer ce classement sur une hypothèse tirée de l'organisation probable des animaux qui habitaient les coquilles d'Entomolaniata, c'est-í-dire fáre de la synthèse au lieu d'une analyse par voie d'élimination; j'aurais voulu déduire des caractères de ces coquilles la preuve d'une diflérence dans la disposition des branchies par exemple, puisque c'est sur cet organe que repose la division actuclle des Gastropodes en ordres et sous-ordres. Mahtheurensement j'ai été obligé d'y renoneer, eu égard à l'état actuel de nos connaissances, bien que je sois persuadé, sans pouvoir le démontrer, que leur organisation devait être, en quelque sorte, intermédiaire entre celle des Opisthobranches et celle des Prosobranches, avec un peu plus d'affinité pour les premiers.

A ce point de vue, l'échancrure suturale a principalement appelé non attention a cause de sa constance : j'espérais y trouver la preuve que les Entomotieniata devaient être munis d'un lobe palléal, comme les Tectibranches et les Pulmonés.

Mais notre savant confrère de l'École normale de Gand, M. Paul Pelseneer, que j'ai consulté sur ce point, m'a fait remarquer que, chez Acera par exemple, qui a une échancrure, "le lobe palléal ne fait pas saillit " par là, il sort latéralement; l'échancrure laisse seulement passer le: " filament palléal bien connu de ce genre... Si done nous voulons recons" tituer l'animal de Nerinea, nous ne pouvons pas conclure qu'il possé" dait un lobe palléal parce que la coquille a une échanerure suturale, " mais simplement que le manteau avait, dorsalement, une échancrure " correspondante... L'échancrure du labre est tout à fait sans influence " sur la branchie : celle-ci est la même chez Aceraque chez Scaphander ". "Beaucoup de Gastropodes possèdent une semblable échancrure, el " Acera seul, à ma connaissance, présente un filament palléal qui y passe: "le rôle de ce filament est certainement peu prépondérant; bien que je " n'aie janais observé Acera vivant, je présume que cet appendice est " une sorte de gardien de l'ouverture palléale (un organe tactile, par con"séquent)."

"Je suis donc porté à croire que chez Nerinea, conme chez les Pleu"rotomariidie, Emarginula, Siliquaria, etc... il ne passait rien par celte "échancrure de la coquille, et que celle-ci marque seulement l'existence d'une échancrure correspondante du manteau... Dans Pleurctomaria,

"Scissurella, Emarginula (j'ai pu m'en assurer chez ces deux derniers)

"l'échancrure se trouve juste au-dessus de l'anus et sert it l'expulsion des

"fèces et de l'eau respiratoire; chez Ccmoria, Haliolis, cette échancrure

"s'est en partie fermée et le ou les orifices restants ont la même position "relative et le même rôle.

"Dans Scissurella et Haliotis, dé petits tubercules palléaux (issus du " bord même, done différents de celui d'Acera) passent par la fente ou les "orifices de la coquille. L'échancrure de Plemotoma et Siliquaria se 
" trouve aussi dans la même position relative que dans Scissirella, et, bien " que je n'aie pu m'assurer de la chose, je crois qu'on peut par analogie " lui attribuer le même rôle. "

"Chez Pleurotomaria, Haliotis, Emarginula, Fissurella, l'anus est assez " loin du bord extérieur du manteau : aussi comprend-on facilement "l'existence de cette échancrure qui permet une issue plus rapide des « excréments hors de la cavité palléale... Je pense que, sans crainte de se " tromper, on peut affirmer que l'échancrure coquillière de Nerinea à la " même signification."

Il résulte des observations très intéressantes qui précèdent que ce ne serait pas dans l'échancrure suturale des Entomotæniata qu'il faudrait chercher l'explication de leur organisation particulière, ni la preuve de l'exactitude de la place que je leur attribue dans la classification systématique, puisque cette dernière est principalement basée par les auteurs modernes sur la disposition des branchies respiratoires.

Cependant j'ai nommé ce sous-ordre Entomotæniata, parce que la bandelette suturale, produite par les accroissements de cette échancrure, est tout à fait caractéristique et n'existe chez aucun autre Gastropode à ouverture échancrée : aucun des genres mentionnés par notre confrère n'a l'échancrure placée près de la suture, on pourrait presque dire dans la suture; si donc, - hypothèse très admissible, - l'échancrure des Entomotæniata sert aussi d'exutoire anal, e'est que l'anus est relégué à un emplacement tout à fait différent de celui des Pleurotomaria par exemple, encore plus bas que celui des Surcula dont le labre fait un crechet antécurrent avant de se raceorder avec la suture. Non seulementil doit en résulter une différence corrélative dans le mode d'expulsion des matières fécales ou des eaux ayant servi à la respiration, mais encore il est très admissible que ce déplacement de l'anus, que la modification de la dynamique musculaire nécessaire pour produire l'effort d'expulsion, que l'éloignement du point d'évacuation des eaux respiratoires, correspondent précisément à une modification inconnue de la disposition des branchies. Bien que ce ne soit qu'une supposition, elle est assez vraisemblable pour justifier l'importance que j’ai attribuée à la bandelette suturale et la nécessité de grouper dans un sous-ordre distinct les formes qui présentent ce caractère.

En attendant qu'on puisse démontrer que ce sous-ordre se rapproche, par la nature de ses organes respiratoires, des Tectibranches auprès desquels je propose de le classer, on peut du moins se guider d'après les raisons que j'ai données ci-dessus, c'est-à-dire par l'impossibilité où l'on st' trouve d'arriver à une solution rationnelle, si on assigne une autre place aux Entomotreniata.

Enfin, on remarquera qu'il s'agit de formes mésozoïques dérivant probablement des Tectibranches qui sont beaucoup plus anciens, puisqu'ils remontent à l'époque carboniférienne, tandis que les premières Cerilella et Nerinea n'apparaissent que dans l'étage hettangien. Comme les Eniomolseniata se sont subitement éteints à la fin de la période crétacique, ils 
représenteraient un rameau tronqué, qui se serait greffé sur la souche des Tectibranches et qui n'aurait trouvé que pendant l'époque secondaire les conditions particulieres de son genre de vie.

Je me suis longuement appesanti sur les considérations qui précèdent, parce qu'il m'a semblé que la création d'une division fondamentale mérite plus d'explications justificatives que lorsqu'il s'agit seulement de proposer l'adoption d'une espèce nouvelle; le déplacement que je préconise heurtera certainement l'opinion de beancoup de nos confrères, car on n'est pas lıabitué au voisinage des Nérinées et des Bulles. Néanmoins j'ai la conviction que ce classement sera ultérieurement confirmé par la découverte de matériaux plus probants que ceux dont j'ai pu disposer, el que l'on pourra alors imposer à ce groupe de coquilles une dénomination qui soit plus en harmonie avec celles dont on fait usage pour la classification dans les Manuels de Conchyliologie.

\section{TUBIFLIRIDA}

Observ. - Je n’ai rien à ajouter à la diagnose de cette famille, que jai proposée (Essais de Pal. comp. I, p. 77, 1893̈) pour un certain nombre de corpuilles jurassiques, confondues jusqu'à présent soil avec les dclxanidx, soit avec les Cerithiidx. La revision de ces espèces a fait l'objet d'un Mémoire (Etudes sur les Gastr. jurass. I. - Mém. pal. Soc. géol de lir. T. V. el VI, 189ð-96), dans lequel j’ai déjà indiqué ce que je viens de développer plus complètement à propos des Entomolxniata, c'est-à-dire que cette famille devrait etre rapprochée des Nerineidie et qu'il y aurait lieu dy comprendre le genre Pseudonevinea, de Loriol. La création du sous-ordre nouveau Entomolixniala, qui comprend les Tubiferidx, m'oblige ì revenir sur cette famille et sur les genres quil y a lieu d'y admettre.

Tout d'abord, il est entendu qu'elle doit être éliminée des T'ectibranches, malgré les aflinités qu'elle présente avec eux, el qu'elle forme tout au plus la transition entre ceux-ci et les Nérinées qui paraissent s'en écarter do prime abord. Mais, comme cette transition se fait précisément par l'intermédiaire de Pseudonerinea que j'avais d'abord (loc. cit., p. 15ä) considéréc comme synonyme de Fibula, j’ai dû rectifier ma première opinion el séparer ces deux formes. Le tableau ci-dessous tient compte de ces rectilications, et du remaniement qui en résulte dans la classification des Tubiferidæ. 
Tableau des genres, sous-genres et sections.

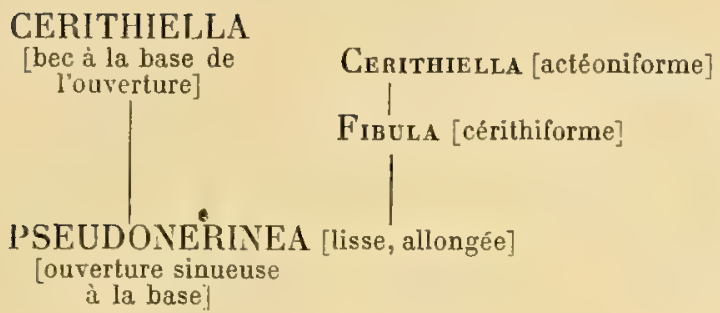

Fibula [tours plissés]

Sequania [spire dimorphe]

\section{CERITHIELLA, Morr. et Lyc. em.}

Observ. - Je ne reviendrai ni sur la diagnose, ni sur la répartition stratigraphique de ce genre, car je n'ai aucun fait nouveau à signaler à ce sujet. Mais je crois nécessaire de rectifier l'orthographe du nom qui, étant un diminutif latin de Cerithium, ne peut être écrit Ceritella, puisque ce serait le diminutif de la traduction française Cérite; il me paraît d'autant plus nécessaire de faire cette petite correction de nomenclature, malgré l'habitude qu'on a d'employer l'orthographe de Morris et Lycett, que cela fera disparaítre toute incertitude au sujet de la synonymie de Cerithiella, Verrill 1882, que plusieurs auteurs persistent à conserver, sous le prétexte que cette dénomination n'est pas littéralement identique à l'autre.

Fibula, Piette, 1857. Type: F. undulosa, Piette, Bath.

Observ. - N'ayant pu, dans la première livraison de mes « Essais », que reproduire une copie de la figure originale du type de ce genre, je crois intéressant de donner une figure (PI. I, fig. 9) d'une espèce plésiotype $F$.nudiformis, Piette, d'après un échantillon du Bathonien de Maisoncelle, dans les Ardennes, coll. de l'Institut catholique.

Sequania, Cossm, 1895. Type: Cerithinm Cotteaui, de Lor. (= Sequania Lorioli, Cossm!) Seq.

Taille grande ; forme trapue; spire dimorphe, faiblement étagée près de la suture; tours un peu convexes, les premiers ornés de costules axiales légèrement obliques, tuberculeuses, arrêtées en-deçà de la bande suturale, se transformant en plis 


\section{Cerithiella}

d'accroissement plus serrés et assez obsolètes sur les derniers tours; base arrondie, séparée par une dépression du cou très court, sur lequel s'enroule un bourrelet. Ouverture en secteur de cercle, terminée à la base par un bec large, entaillé et échancré dans l'épaisseur de la columelle, non rejeté au dehors; labre curviligne en avant, oblique en arrière, fortement échancré sur la suture; columelle courte droite, faisant un angle de $120^{\circ}$ avec la base del'avant-dernier tour, dénuée de plication.

Diagnose faite d'après les types de Tonnerre (Pl. III, fig. 1-4), coll.

Cotteau, communiqués par M. Péron.

Observ. - J'ai proposé cette section dans l'Annuaire géologique universel ( Vol. X, 1893, édité en 1893̈) à l'occasion de l'analyse de l'ouvrage de M. de Loriol sur les mollusques séquaniens de Tonnerre; le type de cette section, Cerithium Colleaui, de Loriol, ne peut conserver le nom déjà enployé par Cossmann et Lambert en 1883, pour une espèce de l'Oligocène des environs d'Étampes: en conséquence, j'ai remplacé cette dénomination. par Sequania Lorioli, nob., et je n'ai fait la correction de nomenclature spécifique qu'après le changement de gen re, de sorte qu'on ne puisse alléguer qu'il y a double emploi avec un Ceriltizum portant déjà le nom Lorioli.

Rapp. et diff. - Si l'on ne possédait que les derniers tours de cette coquille, il n'y aurait aucun motif pour la séparer de Fibula; mais M. de Loriol a précisément fait remarquer que les premiers tours de spire de son espèce, jusquau douzième au moins, portent une ornementation qui n'existe jamais dans les véritables Fibula, dont la surface est seulement plissée, et qui sont d'ailleurs plus courtes et plus ventrues que Sequania: ces ornements tuberculeux, qui rappellent ceux de quelques Cerithiella, s'effacent quand la coquille atteint la taille adulte, de sorte qu'il n'y a aucune ressemblance entre deux fragments de la même espèce et qu'on risquerait de les rapporter, l'un aux Cerithinm, l'autre aux Fibula. Ce dimorphisme dénote une organisation particulière de l'animal, et tout au moins assez différente pour quon puisse admettre Sequania comme section de Fibula.

Répart. Stratigr.

Sequanex ..... Une seule espece lype de la section, dans les environs de Tonnerre. 
PSEUDONERINEA, de Loriol 1890.

(三Fibula, Cossm. 1895, Essais, I, p. 1əั5, non Piette).

Pseudonerinea, sensu str. Type: P. blauenensis, de Lor. Raur.

Forme conique, allongée, turriculée; spire aiguë, subulée ; embryon de Cerithiella : tours plans, lisses, étagés près de la suture par une rampe étroite, sur laquelle se forme la bande du sinus; dernier tour assez élevé à la base, ovale, imperforé. Ouverture étroite, en secteur elliptique, terminée en avant par une sinuosité assez large, qui ressemble à un bec quand le contour supérieur n'est pas absolument intact ; labre peu incurvé, dénué de pli à l'intérieur ; columelle lisse, cylindracée, faisant un angle de $150^{\circ}$ environ avec la base de l'avant-dernier tour; bord columellaire calleux, bordé à l'extérieur par une carène qui se raccorde avec le contour sinueux de la base de l'ouverture.

Diagnose refaite: d'après un échantillon de l'espèce type, provenant de Blauen (PI. I, fig. 5), ma coll.; d'après un plésiotype, Chemnitzia Clio, d'Orb. du Ptérocérien d'Oyonnax (Pl. I, fig. 7-8) coll. de l'Institut catholique; et d'après un autre plésiotype, Nerinea Clytia, d'Orb. du Rauracien de l'Yonne (Pl. I, fig. 6), coll. de l'Ecole des Mines.

Rapp. et diff. - Ce genre est évidemment très voisin de Fibula: je l'y ai même réuni, dans la première livraison de ces Essais (p. 15ั5̃), n'ayant pu, pendant l'impression, me procurer les matériaux de comparaison qui me décident actuellement à conserver Pseudonerinea et même à le considérer comme un genre absolument distinct. Les caractères différentiels sur lesquels repose cette séparation sont les suivants: forme toujours plus allongée de la spire, absence complète d'ornementation sur les tours, courbure plus ovale de la base du dernier tour qui se raccorde en avant sans aucune inflexion, tours presque superposés, le dernier étant beaucoup moins embrassant que chez les autres Tubiferidix; enfin la différence la plus importante, seulement visible sur des échantillons parfaitement conservés, consiste dans la forme de l'ouverture qui est largement sinueuse à la base (voir fig. 8) et n'est pas réellement canaliculée par un bec, lorsqu'elle n'est pas mutilée La forme de l'embryon a élé indiquée et figurée par M. Bigot dans le T. XXIV du Bulletin de la Soc. géol, de France (1896, p. 29). 
Répart. Stratigr.

P'seudonerinea

Barocren ...... (Une espèce dans les calcaires gris de la Vénétie, niveau

ou supérieur à Durga crassa (Chemnitzia Canona,

Bathonien..... Bohm), d'après la figure donnée par l'auteur.

Rauracies...... Outre l'espèce type en Suisse, une autre espèce plus étroite, dans le même gisement de Blauen $(P$. gracilis, de Lor.); autre espèce, commune dans l'Yonne et dans les gisements sableux des environs de Lisieux (Ner. Clylia, d'Orb.), Coll. de l'École des Mines, coll. Bigot, ma coll.

Sequanien...... Une espèce assez répandue dans le Boulonnais (Cer. Pellati, de L.or.), coll. Legay, Bigaux.

Kimmenidien.... Une espèce typique dans le sous-étage Ptérocérien du Jura (Chemnitzia Clio, d'Orb., coll. de l'Institut catholique.

Pontlandien.... Une espèce pupoïde dans le Bolonien (Cerith. Micheloti, de Lor.), coll. Rigaux.

Ungonien...... Une espèce à peu près certaine de l'Urgaptien d'Espagne (Cerith. Verneuili, Vilan.) d'après les figures de l'Atlas de Mallada.

ITIEIIID L, nov. fam.

Forme ovale ou conoïde; spire courte, tantôt irrégulière et rétuse au sommet, tantôt régulièrement élagée; lours embrassants, parfois même enveloppant complètement la spire, ou se recouvrant irrégulièrement, séparés par une étroite rampe sur la suture, lisses ou portant simplement des nodosités variqueuses, plus ou moins régulières. Dernier tour très grand, à base ovale, étroitement ombiliquée et munie, autour de l'entonnoir ombilical, d'un bourrelet qui correspond au bec antérieur.

Ouverture étroite, allongée, toujours anguleuse et même quelquefois linéaire en arrière, peu dilatée en avant, et terminéc à la base par un bec aigu : labre mince, oblique, rétrocurrent vers la suture dans laquelle se dissimulent les accroissements de l'échancrure; columelle courte, faisant un angle ouvert el très arrondi avec la base de l'avant-dernier tour, à peine infléchie contre le bec antérieur. 
Plication composée d'une forte lamelle an térieure à̃la columelle, généralement d'un pli spiral à l'intérieur du labre, un peu plus bas que le pli columellaire, et quelquefois d'un pli pariétal, très écarté du pli columellaire.

Rapp. et diff. - Le caractère principal des coquilles que je propose de classer dans cette nouvelle famille est d'avoir les tours embrassants, ce qui n'a jamais lieu dans les Nerineidx, dont les tours se superposent au lieu de se recouvrir; il en résulte que les sutures sont étagées et que la bande du sinus est précisément située sur la rampe suturale, tandis que la plupart des Nérinées proprement dites ont une suture superficielle et une bande légèrement saillante. Par le recouvrement de leurs tours, les Itieriid se rapprochent davantage des Tubiferidæ et de certaines Actronella; mais elles s'en écartent par leur plication, par leurs nodosités, par la profondeur de l'échancrure suturale qui, même chez Pseudonerinea, n'atteint pas la longueur de la fente des Itieria; enfin par leur axe toujours ombiliqué.

\section{Tableau des genres, sous-genres et sections.}

\section{ITIERIA}

[spire enveloppée sétuse au sommet]

ITRUVIA [plis $1-0$, spire non rétuse, ombilic étroit]

ItIERIA ${ }^{1}$ [plis $2-1$, spire irréguliẻre, ombilic étroit]<smiles>[CH]1[CH]C=C1</smiles>

Campichia [plis 1 ou $2-0$, spire tronquée, pas d'ombilic] ।

PHANE:ROPTYXIS lplis 2 ou $3-1$ ou 2, ombilic caréné].

ITIERIA, Nath. 1842.

Forme ventrue; spire enveloppée, rétuse ou tronquée au sommet; surface lisse, quelquefois irrégulièrement bossuée ; ouverture linéaire, peu élargie en avant; columelle fortement plissée à la base ; labre simple ou denté.

Itieria, sensustricto. Type: Actron cabanetianus, d'Orb. Kim.

Spire d'abord excavée, avec un nucléus mucroné au centre de l'entonnoir, puis changeant de galbe et devenant conoïdale, à

1 Dans tout ce qui va suivre, le premier chiffre représente le nombre des plis colimellaires et pariétaux, le second représente le nombre des plis du labre. 
mesure que la coquille vieillit ; tours croissant d'abord tres lentement, puis irrégulierement, d’inégale largeur, séparés par des sutures bordées d'une étroite rampe, portant ça et là des nodositús formées par des arrêts de l'accroissement du lest; dernier tour ovale, arrondi à la base, qui est un peu déprimée aux abords de la carine circa-ombilicale : ombilic étroit, muni à l'intéricur l'un pli spiral (ficle Mathéron) ou plutôt d'une saillie forméc par le retrait des tours de spire.

Ouverture arquée, très étroite même en avant, munie d'un bec peu saillant, à l'extrémité antérieure, au point où aboutit la carène basale; labre presque vertical, peu incliné, fortement rétrocurrent en arc de cercle du côté postérieur, un peu sinueux à la base, avant de se raccorder à la carène, muni d'un pli situé assez haut; columelle très courte, portant un gros pli lamelleux : second pli pariétal, écarté du pli columellaire.

Diagnose refaite d'après un individu jeune de Valfin (PI. I, fig. 1-2) el d'après un individu adulte d'Oyonnax (Pl. I, fig. 3-4), coll. de l'École des Mines.

Observ. - J'ai restreint le genre Itieria aux limites que lui a primitivement assignées Mathéron : c'est à tort, selon moi, que Pictet, Stoliczka, Zittel, de Loriol, rattachent aux Itieria des formes qui appartiennent sans doute à la même famille, mais qui s'écartent du type ci-dessus décrit par des caractères tellement variés, qu'en cherchant à les comprendre dans un même genre on arrive à en dénaturer la diagnose, à la rendre absolument vague, et à la confondre presque avec celle des Nérinées, comme la a fait d'Orbigny, quoiqu'il y ait de profondes démarcations entre Itieria et Nerinea. On verra ci-après, au fur et à mesure, quels sont les caractères distinctifs de ces nourelles coupes d'Itieriedie, et on constatera que, dans beaucoup de cas, elles sont précisément en harmonie avec leur habitat stratigraphique.

Répart. Stratigr.

Rauraciex..... liespèce type dans l'Yonne, ¿̀ Châtel-Censoir (fide d'Orbigny).

Sequaniex...... L'espèce type dans les couches tithoniques de Stramberg (fide 'Littel) et de Sicile (fide Gemmellaro); 
autre espèce, avec la précédente, dans le Frioul (I. obesa, Pir.) d'après la Monogr. de Pirona.

Kimmeridiex.... L'espèce type dans le Jura et dans l'Ain, au sous-étage Ptérocérien, coll. de l'École des Mines et du Musée de Dijon.

Campichia nov. sub. gen.

Type: Itieria truncata, Pict. et Camp. Urg. (=Itieria, Pict. et Camp. =Itruvia, Stol. ex parte).

Taille petite; forme cylindro-conique, tronquée, de sorte que la coquille peut se tenir debout quand on la pose sur son sommet; spire excavée, avec un bouton mamillé au centre; tours étroits, complètement enveloppés par le dernier, dont le galbe est ovoïdocylindrique, atténué à la base, dénué de perforation ombilicale. Ouverture très étroite, un peu plus large au milieu qu'à ses extrémités, terminée en avant par un bec subcanaliculé ; labre vertical, ne portant aucun pli lamelleux à l'intérieur; columelle. assez courte, munie de deux plis saillants, très rapprochés, quelquefois d'un seul au milieu de la hauteur; traces de plis pariétaux très obsolètes, au nombre de trois sur l'espèce type.

Diagnose faite d'après les types de Châtillon de Michaille dans l'Ain (Pl. I, fig. 12-13), coll. Pictet au Musée de Genève.

Rapp.et diff. - Pictet et Campiche ont décrit deux espèces urgoniennes, qu'ils classent dans le genre Itieria, tandis que Stoliczka les rattache à son genre Itruvia. En réalité, il ne me paraît pas possible de confondre avec Itieria (sens. slr.) des coquilles complètement tronquées à tout âge, dont la spire n'est jamais développée, dénuées d'ombilic et de pli au labre, enfin souvent munies de plis pariétaux multiples; le moins qu'on puisse faire est de les placer dans un sous-genre d'Itieria, en conséquence je propose la création de cette nouvelle coupe qui porterait le nom d'un des deux auteurs de la description des fossiles du Crétacé de Sainte-Croix.. Cette subdivision concorde d'ailleurs avec les données de la stratigraphie, puisque les veeritables Itieria ne dépassent pas l'étage Kimméridien, tandis que Campichia semble, jusqu'à présent, localisée dans l'Urgonien : aucune forme analogue, qui puisse établir une filiation, n'a encore été signalée dans le Portlemdien, ni dans le Néocomien. 
Itieria

Répart. Stratigr.

Ungonex...... Deux especes qui diffèrent par leur galbe et par leurs plis columellaires, dans les calcaires blanes de Bellegarde (I. truncala et umbonata, I'ict. Camp.), d'après les types de la coll. du Nusée de Genève.

ITRUVIA, Stol. 1867 , ex parle

(=Itieria, Fisch. Man. Conchyl. 1884).

Itruvia, sensu str. Type: Pyramidella canaliculata, d'Orb. Tur.

Forme conoïde, turriculée; spire assez longue, à tours étroits et à sutures profondément canaliculées; dernier tour plus petit que la moitié de la hauteur totale, embrassant et recouvrant parliellement l'avant-dernier tour, arrondi à la base qui paraît perfor'ée d'un étroit ombilic. Ouverture courte, peu large, avec un bec antérieur; columelle concave, portant un pli spiral tout à fait en avant; labre seulement muni d'un renflement interne, qui laisse sur le moule une trace spirale très obsolète.

Diagnose refaite d'après un individu de l'espèce type, à l'élat de moule, provenant d'Uzès (PI. I, fig. 11), coll. de l'Institut catholique; et d'après des individus du gisement d'Uchaux $\langle$ Pl. I, fig. 10〉, coll. Cossmann.

Observ. - En instituant ce genre distinct d'Itieria (Cret. Gastr. of South India, 1867, p. 177), Stoliczka y a classé cinq espèces, dont les deux premieres et la cinquième à la rigueur ont entre elles une certaine analogie (Pyr. canaliculata, d'Orb. et carinala, Reuss; Itrusia globoides, Stol.); tandis que les deux autres (Itieria truncala et umbonala, P. el C.) ont, ainsi qu'on l'a vu ci-dessus, un faciès bien différent, et n'ont aucune alfinité avec les trois premières. Il ressort de là que Stoliczka a eu raison de distinguer le genre Itruvia, mais qu'il ne l'a pas formé d'une manière liomogène; en retirant de ce genre les deux espèces que jai rapportées au nouveau genre Campichia, j'ai done usé du droil qui consiste à admettre pour type d'un genre la première des espèces que l'auteur y cite, quand mème celle-ci n’aurait qu une partie des caractères hybrides que contient la diagnose du grenre.

Rapp. et diff. - Les Itruvia se distinguent des Campichia, non seulement par leur spire turriculée qui, contrairement à ce qu'avance Stoliczká 
par analogie avec les Actronella, ne passe pas graduellement de la forme rétuse à la forme saillante; mais encore par le renflement spiral que porte le labre et que n'a pas signalé Stolizcka, parce qu'il n'avait pas à sa disposition d'échantillons de l'espèce que je considère comme le type de ce sous-genre; l'espèce de l'Inde (I. globoides) qu'il rapporte à ce mème genre Itruvia parait, il est vrai, avoir un bec antérieur disposé comme celui de Campichia, tandis que les moules internes de Pyramidella cancaliculata ne permettent pas d'en soupçonner l'existence; mais, en examinant attentivement les échantillons munis de leur test, quoique l'ouverture en soit malheureusement très mutilée, on en distingue l'indice du moins sur l'un des deux individus que je possède d'Uchaux, la columelle me semble munie d'un pli spiral servant de limite à ce bec, et perforée par un ombilic étroit dont on aperçoit la trace sur l'autre fragment qui ne comporte que les premiers tours.

Enfin, lorsqu'on restreint Itruvia comme je viens de le faire, le genre Ilieria ne présente plus la même anomalie au point de vue de la répartition stratigraphique, attendu que les Campichia forment exactement le lien intermédiaire entre les véritables Itieria et les Itruvia et coupent à peu près par la moitié la période géologique qui sépare l'extinction des premières et l'apparition des secondes.

Repart. Stratigr.

Cexomaniex.... Une espèce probable au niveau d'Ostrea pseudoafricana; dans le Portugal (Itieria bellasensis, Choffat), d'après la Monographie de Choffat; autre espèce dans la Tunisie (Pyr. Gaudryi, Thomas et Péron), d'après l'atlas de l'Explor. scient.; autre éspèce inédite dans les couches à Caprotina costata de la- Charente-Inférieure, coll. Chaper.

L'espèce type dans le Gard et à Uchaux, ma coll.; autre Tunoxiex..... espèce dans le calcaire à Hippurites de Bohême et $(P y)^{2}$. carinata, Reuss), d'après Pictet et Stoliczka; troisième espèce dans l'Inde, groupe d'Arrialoor (I. globoides), d'après Stoliczka.

PHANEROPTYXIS 1, nov. gen.

(= Itieria, ex parte in Zittel)

Phaneroptyxis, sensustr. Type: Nerinea Moreana, d'Orb. Raur.

Forme ovoïdo-conique; spire peu allongée, obtuse au sommet, à galbe conoïde; tours embrassants, assez étroits, croissant

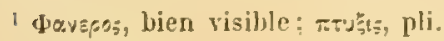


Phanevoptyxis

irrégulièrement, lisses ou simplement ornés, soit de costules tuberculeuses, soit d'une rangée de nodosités arrondies; dernier tour au moins égal à la moitié de la longueur totale, subcylindrique, ovalement atténué à la base, qui porte un bourrelel très étroit el très saillant autour de l'entonnoir de l'ombilic.

Ouverlure fusiforme, subcanaliculée à ses deux extrémilés; labre presque droit, portant invariablement un pli spiral vers le tiers antéricur, et quelquefois un second rentlement pliciforme situé un peu plus bas; columelle ayant à peu près la moitié de la hauteur de l'ouverture, faisant un angle arrondi de $150^{\circ}$ au moins avec la base de l'avant-dernier tour, munie d'un pli antérieur et lamelleux, à peu près à la hauteur du bourielet circa-ombilical; au-dessous de ce pli se montre un rentlement qui se transforme parfois en une seconde lamelle spirale, moins saillante que la première; enfin un pli pariétal, mince el saillant, existe toujours à la partie postérieure de l'ouverture; bord columellaire mince, délaché de la fente ombilicale, et se raccordant avec le bec antérieur.

Diagnose faite d'après un individu typique de Merry-sur-Yonne (Pl. II, fig. I), coll. de l'École des Mines.

Rapp. et diff. - Le sous-genre Itruvia a été si mal caractérisé, et le genre Ilieria a été appliqué à des formes si hétérogènes, que j’ai, en les restreignant, renoncé à y rattacher $N$. Moreana qui représente une coupe tout à fait différente, ayant certainement la valeur d'un genre bien distinet, caractérisé par sa plication et par son ombilic. La plupart des auteurs ont confondu cette espèce et ses congénères arec Ilieria à cause de leurs plis; cependant la spire est bien differente, elle niest jamais rétuse et son accroissement n'est pas irrégulier; d'ailleurs la columelle porte un seeond renflement pliciforme qui n'est visible sur aucun échantillon d'Itieria cabanetiana. L'ombilic se rétrécit parfois au point de disparaitre completencut sous le bord columellaire: mais on le retrouve généralement en mutilau la columelle.

Répart. Stratigr.

Ravmaciza..... I. espèce type dans la Meuse el lans l'Youne, coll. Gaiffe, coll. de l'École des Mines et du Muserce ce 
Phaneroptyxis

Dijon; autre espèce dans l'Yonne (N. fusiformis, dOrb.), coll. du Musée de Dijon; autre espèce dans le Jura suisse ( $N$. Clymene, d'Orb.), d'après Thurmann, et à Saint-Hihiel, d'après Buvignier.

Sequarier...... L'espèce type à Tonnerre, d'après de Loriol ; plusieurs espèces dans l'Europe centrale, soit en Suisse (Ner. Tschani et simmenensis, Ooster), d'après les figures du Corallien de Wimmis par Ooster; soit dans les couches de Stramberg(Itieria Slaszycii, Zeuschner, I. austriaca, rugifera et melanioides, Zittel, I. Renevieri, de Lor., I. mullicoronala, Zittel), d'après les figures de l'atlas de Zittel et de la monographie de Peters; autres espèces dans le Frioul el en Sicile (I. decipiens, Pir. Catulloi, Gem:, d'après la Monogr. de Pirona.

Kimmentoiex..... Espèce voisine du type, mais distincte, à Oyonnax et dans la Charente, coll. de l'École des Mines, coll. Boreau; sera décrite dans les Contributions à la Pal. fr. des terr. jur.

Portlandiex.... Une espèce nouvelle dans la Haute-Saône, coll. du Musée de Dijon; sera décrite dans les Contrib. à la $\mathrm{Pal}$. fr. des terr. jur.

Urgoínen...... Une espèce probable dans le Portugal (Xieria Neumayri, Choffat) d'après les figures de la Monographie crétacique par M. Choffat.

NERINEIDA, Zittel 1873.

Forme très variable, tantôt conique ou même conoïde, tantôt subcylindrique ou bacillaire; spire généralement allongée; tours superposés, ne se recouvrant jamais; sulures ordinairement situées en saillie; surface lantôt lisse ou simplement marquée, dans le sens axial, de nodosités assez obtuses, tantôt ornée de cordonnets spiraux quelquefois perlés; axe d'enroulement tantòt plein, tantòt perforé, ou même très largement ombiliqué.

Ouverture rhomboïdale, même quadrangulaire, terminée à la base par un bec subcanaliculé qui n'est jamais recourbé; labre toujours inclinè à droite de l'axe du côté antérieur, invariablement rétrocurrent près de la suture, contre larquelle il est échancré par une entaille extrêmement profonde ; accroissements de l'échan- 
crure formant, au-dessus de la sulure, une bande très étroite, souvent linéaire, toujours visible et ordinairement saillante; columelle droite, faisant un angle de 100 à $150^{\circ}$ avec la base de l'avant-dernier tour, à peine infléchie contre le bec antérieur.

Plication très variable, selon les genres, sous-genres et sections, mais grénéralement constante depuis le premier tour jusqu'au dernier; le nombre des plis spiraux, qui se réduit parfois à 0 , peut atteindre 10 et encombrer totalement la cavité interne de la coquille; ce nombre est généralement impair, parce qu'il y a presque toujours un pli de moins au labre que sur les parois opposées.

Observ. - Les caractères de cette famille paraissent, au premier abord, peu précis à cause de leur variabilité; cependant, tout en adoptant l'ordre habituel de mes diagnoses, j'ai groupé ces caractères en trois alinéas dont le second contient précisément ceux dont la constance justifie précisément la création de cette famille; si l'on y ajoute cette particularité que les tours des véritables Nerineidx ne sont jamais embrassants, on admettra l'élimination que j'ai faite des Itieriide dont l'introduction, dans cette famille, contribuait à en rendre la diagnose encore plus vague.

\section{Tableau des genres, sous-genres et sections.}

\section{NERINEA}

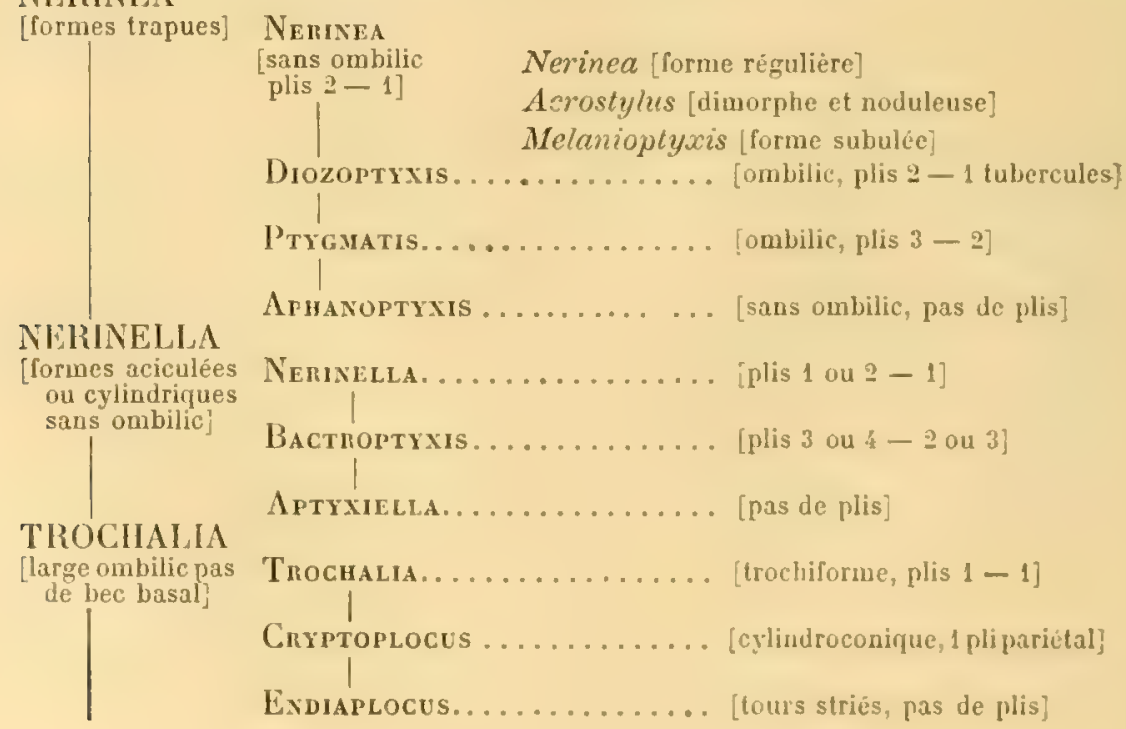




\section{Genre à éliminer de la famille.}

Halzoysia, Briart et Cornet, 1878. Type : H. biplicata, B. et C. du Paléocène de Mons, petite espèce perforée de la base au sommel, comme les Trochalia, et munie de deux plis columellaires, de sorte que Fischer l'a rapprochée des Nerineide; mais, en examinant la direction des stries d'accroissement sur la figure, on constate qu'elles sont antécurrentes vers la suture, et que par conséquent le labre ne devait pas porter d'entaille rétrocurrente comme celui de Nerinea. Dans ces conditions, la coquille du calcaire grossier de Mons me paraît devoir être plutôt placée auprès de Trypanaxis, dont elle ne se distingue que par sa plication columellaire, ou peut-être est-ce même une Alocaxis, voisine d'A. cylindracea, Desh. qui est précisément à peu près contemporaine d' $H$. biplicata, dans les sables inférieurs de Châlons-sur-Vesle, en France.

NERINEA 1, Defr. 1825.

Forme turriculée; tours superposés, généralement excavés ou au moins presque plans, à sutures saillantes et bordées en-dessus par une bande très étroite, souvent ornés de cordons tuberculeux ou perlés; dernier tour peu élevé, à base déclive ou même un peu creuse. Ouverture subquadrangulaire ou rhomboïdale, terminée en avant par un bec subcanaliculé, ou au moins par un angle aigu, plication très variable, parfois nulle, pouvant atteindre le nombre de 7 plis, soit à l'intérieur du labre, soit sur la columelle, soit enfin sur la région pariétale; plis tantôt lamelleux, tantôt composés, c'est-à-dire étroits à leur base, épanouis ou bifurqués à leur extrémité libre : il y en a ordinairement un de plus à la columelle et sur la base que sur le labre, de sorte qu'à de rares exceptions près le nombre total en est impair.

Nerinea, sensu stricto. Type : N. tuberculosa, Defr. Raur.

Forme un peu trapue; spire à galbe conique parfois assez allongée; tours excavés, dont la hauteur n'atteint pas ou ne dé-

1 Lorthographe exacte est Nerinea et non pas Nerinae (étymologie Närvn) : c'est d'ailleurs bien ainsi que l'a écrit Defrance. 
Nerinea

passe guère les deux tiers de la largeur; dernier lour alleignant parfois le quart de la longueur totale, à base déclive, non ombiliquée; un pli à la columelle, un pli pariétal, un pli au Jabre, tous trois lamelleux et simples, divisant la coupe de l'ouverture en quatre lobes à peu près égaux; bec bien formé à l'extrémité antérieure de l'ouverture, et correspondant à un canal spiral compris entre le pli columellaire et le plafond de l'ouverture.

Diagnose faite d'apres un individu typique de Coulanges-sur-Yonne, (Pl. Il, fig. 2), coll. de I'École des Mines; autre individu de P'uiseux, dans les Ardennes (PI. III, fig. 8), coll. du Musée de Lille; coupe d'une espèce plésiotype, N. Salinensis, d'Orb., du Portlandien de Noiron, dans la Ilante-Saône (PI. 1, fig. 16), coll. du Musée de Dijon.

Observ. - Le lype du genre de Defrance a élé perdu de vue par la pluparl des auteurs, de sorte que, non seulement on a interpréte le genre Nerinea d'une manière tout à fait différente, mais encore on a identifié l'espéce lype avec $N$. Defrancei, Desh. de la Morée: il y a lieu de restituer it l'espèce si répandue dans les couches coralliennes du Rauracien et du Séquanien le nom tuberculosa, Defr. et de la considérer comme le vérilable type du genre Nerinea s. s. Par un hasard singulier, l'espèce a laquelle Rinmer a donné le même nom tuberculosa (Nordd. Ool. 1836, p. 141, pl. XI, fig. 99) me parait identique à la figure donnée par Defrance dans le Dictiomaire des Sciences naturelles (1825, pl. XXXIV, fig. 3), de sorte qu'il ne semble pas nécessaire de donner un autre nom a l'espéce du Hlanovre.

La diagnose de Defrance, les figures de son atlas, indiquent, il est vrai, l'existence de trois plis columellaires (y compris le pli pariétal), tandis que, sur tous les exemplaires de $N$. huberculosa (ainsi que sur toutes les espèces voisines), on ne constate, en réalité, que l'existence d'un pli à la columelle et d'un pli pariétal: il est probable que Defrance, abusé pa. l'état défectueux de conservation de son échantillon, aura confondu un renflement de la columelle avec un vrai pli. Pour éclaircir ce point douteux, il aurait fallu comparer cet échantillon type de la collection Defrance ; malleureusement, il résulte des recherches qu'a bien voulu entreprendre II. Bigot, et de la communication quil ma faite des 15 exemplaires de Nerinea que contient actuellement cette collection, léguée a feu Deslongchamps, que le type représentant l'extrémité apicale de Norinea tuberculosa a été égaré : il n'y a, parmi ces exemplaires, fu'un seul échantillon, bien conserve d'ailleurs, d'une couleur rougeatre, parassant identique à 
Nerinea

la figure de $N$. tuberculosa, Rømer, et dont l'étiquette porte « Cérite d'Allemagne. Cerith germanicum, Defr. - Knorr, tab. CVI, sect.II de Neustadt près de Hanovre. Il est bien possible que Defrance ait fait connaitre aux savants allemands que la coquille du Hanovre, dont il possédait un exemplaire, était bien identique à son type de $N$. lieberculosa et que ce soit là l'origine de la coïncidence d'emploi du nom tuberculosa par Romer.

Quoi qu'il en soit, la désignation du type ne paraît pas douteuse, si l'on s'en rapporte à la figure de l'atlas du Dictionnaire des Sciences naturelles.

Répart. Stratigr.

Bajocien....... Plusieurs espèces lisses et allongées comme des Nerinella dans l'Oolite inférieure d'Angleterre $(N$. oolilica, Witchell, expansa Hudl., reeldensis, IIudl.), d'après les figures de la Monogr. Brit. jur. gastr. de M. Hudleston.

Bathoniex...... Plusieurs espèces lisses, striées ou subtuberculeuses, dans la grande oolite du Boulonnais, de l'Orne et de l'Aisne (N. bathonica, Rig. et Sauv., mullistriala, Piette, esparcyensis, Piette, olinensis et prxpeciosa, Cossm. etc...) coll. Rigaux, Legay, Cossmann, Piette, Deslongchamps; en Angleterre (N. Eudesi, Morr. et Lyc.), d'après M. Hudleston.

Oxfordiex...... Une espèce lisse, à Neuvizi dans les $\operatorname{Ardennes~}(N$. Acreon, d'Orb.), coll. de l'École des Mines.

Rauracien...... Outre le type du genre, plusieurs autres espèces dans l'Yonne et dans la Meuse ou dans les Ardennes, dans l'Allemagne du Nord (N. Caslor, d'Orb., $N$. pseudospeciosa, sequana, Thirria, N. Creilia, d'Orb., Cynthia, d'Orb., etc...), d'après les figures de la Paléont. franç. ou les échantillons des Musées de Lille et de Dijon; en Angleterre (N.pseudovisurgis, Hudl. et Goodhalli, Sow.), d'après les figures de M. Hudleston dans Geol. Mlag.

Sequaxiex...... Nombreuses espèces dans le Boulonnais, à Tonnerre, dans le Jura bernois, en Autriche, en Suisse et en Sicile ( $N$. elegans, Thurm., posthuma, Zittel, Kobyi, de Lor., Gagnebini, de Lor., Quehenensis, de Lor., ursicina, Thurm., suprajurensis, Voltz, Hoheneggeri, Peters, Wimmisensis, Ooster, Oppeli, Gem.), d'après les figures des Monographies de Thurmann, de Loriol, Zittel, Peters, Ooster, Gemmellaro et les échantillons des coll. Rigaux, Legay, Musée de Dijon. 
Kimmenties.... Plusieurs espèces dans le Plérocérien de Valfin on dOyonnax (N. Thumanni, Etallon, Calliope, d'Orb., urbatrix, de Lor., incisa, Etallon, sculpia, Etallon, binodosa, Etallon, canaliculala, d'Orb., etc...), d'après les figures de la Monogr. et d'après la coll. de M. de Loriol.

Pontlandiex.... De Deux espéces, soit dans le Jura, soit dans les Charentes $(N$. salinensis et scntonensis, d'Orb.), d'après la Paléont. franc. el la coll. du Musée de Dijon.

Neocomira..... Plusieurs espeecs dans le Valangien du Jura ( $V$. marcausana, d'Orb., valdensis, Pict., el Camp., Meriani, Etalloni, Pict. et Camp.), d'après les figures de la Paléont. franç. et de la Monographie de SainteCroix.

Urgonien ...... Plusieurs espèces, soit à Orgon (N. renauxiana, d'Orb.), coll. de l'École des Mines et de l'Institut cathol.; soit en Algérie, soit dans le Jura suisse (N. coquandiana, d'Orb., vogliana, Mortillet, crozetensis, Pict. et Camp. etc...), d'après la P’aléont. franç. el la Monographie de Sainte-Croix; dans le Gard el le Portugal(N.gigantea, d Hombre-lirmas), d'après d'Orbigny et Sharpe ; en Espagne ( $N$. Archimedis, d'Orb.), d'après le Synopsis de Mallada, etc...

Artir........ Une espèce bien caractérisée à Sainte Croix (N. apliensis, Pict. et Camp.) d'après la Monographie susdite; autre espece en Espagne ( $N$. Chloris, Coq.), d'après le Synopsis de Mallada.

Albiex........ Une espèce dans le Gault de la Perte du Rhône ( $\mathbf{N}$. gaullina, Pict. et Camp.), d'après la Monographic de Sainte-Croix.

Cexomaxiex..... Une espèce certaine à l'Ile d'Aix (N. amisiana, d'Orb.), d'après la Paléont. franç. et les échantillons des coll. Chaper et Arnaud; deux espéces en $\mathrm{Mlgérie}$ et en Tunisie ( $N$. bicalenala et gemifera, Coq.), d'après l'Explor. scient. de la Tunisie par M. P'éron.

Turosiex....... Une espèce bien caractérisée dans les marbres blancs de Syrie $(\boldsymbol{N}$. berylensis), d'apres l'ouvrage de Blanclienhorn; plusieurs espices dans les couches de Gosau ( $N$. incarula, Bronn, /lexuosa, Sow.), d'après les figures de la Monogr. de Zekeli.

Seroxiex....... Une espèce dans les Charentes el le Var ( $N$. bisulcala, d'Arch.), d'après la Paléont. franç. el les échantillons de ma coll. ; autre espece dans lilude $(N$. 
Nerinea

blanfordiana, Stol.), d'après la Paléont, de l'Inde méridionale, par Stoliczka ; autre espèce au Mexique (N. Schotti, Conr.), d'après les figures du geol. Report de Conrad.

Acrostruus ${ }^{1}$, nov. sect. Type : Ner. trinodosa, Voltz. Portl.

Forme pupoïde; spire dimorphe, d'abord styliforme au sommet, puis extraconique, et enfin à galbe conoïdal sur les cinq ou six derniers tours ; tours nombreux, les premiers étroits et excavés sur la partie effilée de la spire, les suivants partiellement convexes, séparés par des sutures linéaires et superficielles, au-dessus desquelles est une bande assez large que limite une strie imperceptible; avant-dernier tour, dont la hauteur atteint les trois quarts de la largeur, orné de trois rangs inégaux denodosités obsolètes, celles du haut plus saillantes et séparées des autres rangs par une rainure assez profonde. Dernier tour imperforé à la base; ouverture rhomboïdale; pli du labre très saillant, formant sur le moule interne une large et profonde rainure aux trois cinquièmes de la hauteur; plis columellaire et pariétal saillants et écartés, le premier plus épais.

Diagnose faite d'après un échantillon typique de Lods dans le Jura (Pl. III, fig. 7), coll. de la Faculté des sciences à Besançon; autre échantillon, dont une coupe, de Noiron dans la Haute-Saône (Pl. III fig. ̊-6), coll. du Mlusée de Dijon.

Rapp. et diff. - Le dimorphisme de cette coquille, très imparfaitement indiqué sur la figure de la Paléontologie française, est un caractère bien spécial, qui me décide à proposer pour elle une nouvelle section, bien qu'il n'y en ait, jusqu'à présent, aucun autre représentant connue dans la série des terrains secondaires: l'extrémité de la spire présente, en effet, un aspect proboscidiforme, tout à fait inattendu dans le genre Nerinea; si l'on y ajoute l'ornementation particulière des tours de spire, la largeur anormale de la bande suturale, on admettra que l'animal qui habitait cette coquille présentait probablement, comparativement aux véritables Nerinea,

1 Axpos, sommet; $\sigma \tau \nu \lambda .05$, colonue. 


\section{Nerinea}

quelques différences qui justifient la séparation de la nouvelle section que je viens de proposer. Acrostylus trinodosus est, d'ailleurs, une coquille dont on ne trouve, pour ainsi dire, jamais d'individu bien complet, muni de son test: sur plus de trente échantillons que j’ai eus sous les yeux, pour composer la diagnose ci-dessus, il n'y en a que trois qui aient des fragments plus ou moins longs de leur appendice styliforme, et cet appendice manque précisément sur l'individu un peu plus frais que j'ai photographié pour les caractères de la surface, tandis que celui que je reproduis pour sa colonne longue de près de 1 centimètre a la surface dans un état pitoyable; une coupe assez nette fait voir la plication interne.

Répart. Stratigr.

Portlandiex.... L'espèce type assez fréquente dans le Jura ct la IlauteSaône.

Melanioptyxis, nov. sect. Type: Ner. Altararis, Cossm. Bath.

Taille moyenne; forme conique; spireallongée, un peu étagée; tours généralement lisses, parfois ornés de fines stries spirales, séparés par une étroite rampe coïncidant avec la bande suturale; dernier tour arrondi ou à peine angruleux à la périphérie de la base, qui est ovale et convexe. Ouverture en secteur elliptique, subcanaliculée en avant; labre droit, presque vertical, à peine arqué en arrière, portant un fort pli spiral vers le quart antérieur de sa hauteur; columelle droite, à peine infléchie en avant, faisant en arrière un angle de 130 à $140^{\circ}$ avec la base de l'avantlernier tour, munie d'un pli antérieur très oblique el peu saillant; le pli pariétal est bien rarement visible et devient trìs obsolète près de l'ouverture des individus adultes.

Diagnose faite d'après un individu typique de Montarlol, dans la Haute-Saône (Pl. IV, fig. 10), coll. du Musée de Dijon.

Rapp. et diff. - Cette forme s'écarte tellement du type des Nerinea, guilil me paraît nécessaire de l'en distinguer, au moins à titre de section: ses lours lisses ou à peine striés, non excavés, mais un peu étagés, sa bande suturale confondue avec la rampe, sa base ovale, son ouverture en secteur, non rhomboïdale, lui doment un peu l'aspect des I'sendomelania; mais, outre qu'elle possède un bec subcanaliculé comme les Nerineidx, clle porte un pli très saillant au labre, et deux autres plis qui, quoique peu 
Nerinea

apparents près de l'ouverture, sont manifestement visibles sur les coupes transversales des premiers tours.

Répart. Stratigr.

BAJOCIEN........

Deux espèces probables en Angleterre ( $N$. expansa el subglabra,IIudl.), d'après la Monogr. Brit. jur. Gastr. de M. Hudleston.

Bathonien...... Plusieurs espèces, outre le type, dans les Ardennes, dans l'Orne et en Angleterre ( $N$. Archiaci, d'Orb., N. quincuncialis, Cossm., N. Sharmanni (Rig. et Sauv.) Musées de Lille et de Dijon, Coll. Cossmann, Deslongchamps, Piette, Rigaux, etc.

Diozoptyxis ${ }^{1}$, nov. subgen. Type: Ner monilifera, d’Orb. Cénom.

Forme trapue, conique ; spire turriculée; tours nombreux, très étroits, en gradins, dont la hauteur ne dépasse guère le quart de la largeur, ornés de deux rangs de tubercules arrondis, la rangée du bas plus saillante, étageant les sulures; dernier tour peu élevé, arrondi à la périphérie de la base, qui est à peine convexe, déclive à $90^{\circ}$ avec le profil de la spire, et perforée au centre d'un étroit entonnoir ombilical. Ouverture quadrangulaire, bien plus large que haute, subcanaliculée à la base; un pli spiral très saillant à l'intérieur du labre, entre les deux rangs de tubercules de la surface externe; deux plis columellaires, pas de pli pariétal.

Diagnose faite d'après un échantillon typique du Mans (Pl. II, fig. 5), coll. du Musée de Nantes.

Rapp. et diff. - Les espèces de ce groupe ont été, jusqu'à présent, confondues avec les véritables Nerinea: elles s'en distinguent cependant par la forme tout à fait déprimée de leurs tours de spire et de leur ouverture, par leurs rangées de nodosités serrées, par la position de leurs plis columellaires très rapprochés, enfin surtout par leur perforation ombilicale qui ressemble un peu à celle de Ptygmalis, dont les écarte cependant leur plication et leur ornementation. Il paraît done nécessaire d'intercaler un nouveau sous-genre entre Nerinea et Ptygmalis, et impossible d'admeltre le classement proposé par Pictet qui place $N$. monitifera dans son genre Cryploplocus.

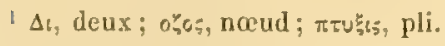


Répart. Stratigr.

Cenomaxies....

TuRONIEN......

Sexonien....... Uneespèce probable dans la Charente ( $N$. marroliana, d'Orb.), d'après les figures de la Paléont. franç. qui n'indiquent pas d'ombilic?

Ptyamatis, Sharpe 1849 (ex parle).

Type: $N$. bruntrutana, Thurm. Séq.

Forme tantôt conique et trapue, tantôt étroite et cylindracée ; spire relativement courte, à galbe quelquefois conoïdal ; tours plans ou faiblement excavés, souvent étaçés sur la suture, el dont la hauteur atteint à peine la moitié de la largeur, lisses dans la plupart des espèces, ou ornés de quelques cordons spiraux, et rarement de tubercules obsolètes ; dernier tour peu élevé, anguleux ou caréné à la périphérie de la base qui est toujours ombiliquée; ombilic assez étroit, circonscrit par un angle aigu, sans bourrelet. Ouverture subquadrangulaire, à bec antérieur plus ou moins marqué ; labre presque droit, muni d'un pli saillant sous la carène basale, et d'un renflement tris obsolète à peu de distance de l'échancrure suturale; columelle portant deux lamelles transversales, l'antérieure plus saillante; un troisième pli pariétal, plus écarté, sur la base; ces plis tendent à s'élargir et à se bifurquer à leur extrémilé libre, de sorte que les six lobes principaux qui représentent la coupe transversale de la cavilé de la coquille se subdivisent souvent, et qu'on peut en compter 7, 8 ou 9.

Diagnose refaite d'après un échantillon de l'espèce type provenant de I'Oxfordien des Ardennes(PI. II, fig. 3), coll. de l'licole des Hines; et d'après un plésiotype de l'élage Plérocérien du Jura, N. carpathica, Zeuschner (PI. II, fig. 4), coll. de l'École des Mines.

Rapp. et diff. - Si l'on restreint le sous-genre Ptygmalis aux formes du mème groupe que $V$. Umentrutana, c'est-it-dire l'espèce que Sharpe 
Ner'inea

avait en vue quand il l'a proposé, si l'on en exclut les formes étroites, non ombiliquées, qui n'ont d'autre affinité avec cette espèce que léurs plis compliqués, on trouve que ce sous-genre très homogène se distingue facilement des véritables Nerinea, non seulement par l'existence d'un ombilic, et par le nombre des plis au bord columellaire et au labre, mais encore par l'accroissement plus lent de la spire et par les proportions plus courtes du dernier tour : il y a là un ensemble de caractères qui justifient amplement l'admission de Plygmotis. Quant à l'application de ce nom au second B des deux groupes indiqués par Sharpe, dans son étude sur les Nérinées du Portugal (p. 108), et dont le premier A contient des espèces imperforées et étroites, appartenant à une tout autre section, je ne crois pas qu'il puisse y avoir de doute: attendu que Sharpe a luimême pris le soin de donner préalablement (p. 181, fig. 4) la coupe de $\mathrm{N}$. bruntrutana comme type de Plygmatis.

Répart. Statigr.

Bathoxiex....... Une espèce probable dans le Calvados, quoique les auteurs ne lui attribuent que trois plis $(N$. Voltzi, Desl.); mais l'ouverture du type unique est très mutilée, coll. Deslongchamps.

Oxfondiex....... L'espèce type à Wagnon (Ardennes), coll. de l'École des Mines.

Rauracien...... Outre le type dans le Jura bernois et dans la Meuse, plusieursautres espèces, soit dans le Jura $(P$. crassa, Etallon, mirabilis, de Lor.), d'après la Monogr. de Loriol; soit dans l'Yonne (Ner gradala et dilalala, d'Orb.), d'après la Paléont. franç.

Sequanien...... Outre le type, à Tonnerre, plusieurs espècesvoisines, soit à Tonnerre, soit dans la Haute-Marne, soit en Autriche et dans le Frioul ou en Sicile ( $P$. curmontensis, de Lor. carpathica, Zeuschner, salomoniana Cotteau, pseudobruntrulana, Gemmell.), d'après les Monogr. de MM. de Loriol, Gemmellaro, Pirona et Zittel (Ner Haueriet planenensis, Peters), d'après la Monogr. de Peters.

Krmmenidiex..... Plusieurs espèces à Valfin, dans le sous-étage Ptérocérien ( $P$. carpathica, Zeuschner, Nogreti, Guir. el Ogér.), d'après la Monogr. de M. de Loriol; dans le Hanovre (P. Mandelshohi, Bronn), d'après Ziltel.

Pontlandien..... Une espèce près de Salins, confondue par d'Orbigny avec le type $(P$.erronea, Zittel $1873=P$. orlignyana, Thurm. in Contejean 1839 '), d'après la Paléont. franc.

: La correction faite par Contejean, en $\mathbf{1 8 5 9}$, bien avant celle de Zittel, ne peut ûlre 


\begin{abstract}
Nerinea
Neocomex...... Une espèce douteuse dans le sous-élage Valangien du Jura (Ner. cyathus, Pict. Camp.) désignée comme Plygmatis, par Pictet, qui indique cependant queles fours se recouvrent sur la moitié de leur hauteur: s'il en élait ainsi, cette espèce appartiendrait plutôt au sous-genre Phaneroptyxis.

Cexomasiex..... Une espèce subeylindrique el subombiliquée, à tours étroils, dans la Charente-Inférieure (Ner Fleuriausa, d'Orb.), coll. Arnaud; cette espèce existerait aussi en Syrie dans les sables à liudistes, d'après Blanckenhorn; autre espèce probable dans le Quadersanstein des environs de Dresde (N. Geinitzi. Goldf.), d'après la figure de Geinitz.
\end{abstract}

Turoniex....... Une espèce bien caractérisée, sauf que l'ombilic est à peu près clos (N. Requieniana, d'Orb.), dansl'Aude, les Bouches-du-Rhône, d'après la Paléont. franç., et dans la Charente (Pl.IV, fig. 2), coll. Arnaud; autre espèce voisine dans le Provincien de la Charente ( $\mathbf{P}$. carentonensis, Cossm., fig. 3), deux espèces faiblement ombiliquées dans les couches de Gosau (N. turrilellaris, Munst., Buchi, Zek.), d'apres la Monogr. de Zekeli et les échantillons de ma coll. ; autre espèce de grande taille, cylindracée el peu ombiliquée, à Gosau (N. nobilis, Munst.), d'aprés la Monogr. de Zekeli.

Sexomien....... Une espèce probable, mais peu ou point ombiliquée dans la Craie supérieure de Syrie ( $\mathrm{V}$. abundans Blanck.)

Il résulte de ce qui précède que le faciès des Plygmatis tend à se modifier à la fin de la période crétacique, ou que tout au moins une subdivision apparaît dans le Cénomanien, caractérisée par sa forme cylindracée et par le rétrécisscment de l'ombilic.

Aphanoptyxis 1, nov. subgen.

Type: Cerithium Defrancei, Desl. Bath

Forme trapue, conique, turriculée; tours concaves, dont lis hauteur atteint les deux tiers de la largeur, à sutures saillantes,

admise, attendu qu'il existait, dès $185 \%$, une $\mathrm{V}$. orbignyana, Piette : mais elle met en lumière un autre double emploi, successivement commis par Zeuschner et Gemmellaro qui ont donné le nom Orbignyana a deux autres especes; celle de Zeuschner devra porter le nom mutala, nobis; quant à l'aulre, Gemmellaro a lui-méme proposí de remplacer sa dénomination par pulica.

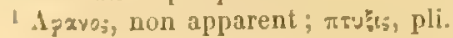


Nerinea

ornés de filets spiraux ; dernier tour caréné à la périphérie de la base, dont la perforation ombilicale est entièrement recouverte par le bord columellaire. Ouverture à peu près carrée, terminée par un bec court ; labre peu incliné, dénué de pli ; bord columellaire calleux, sans lamelle ni pli pariétal.

Diagnose établie d'après le type d'Hidrequent (Pl. II, fig. 6), ma coll.

Rapp. et diff. - L'absence complète de plis ou de lamelles spirales ne me permet pas de rapporter cette coquille aux véritables Nerinea, dont elle a un peu la forme; d'autre part, quoique la perforation ombilicale soit indiquée sous le bord columellaire, elle est toujours lermétiquement close par.lui et n'a pas l'aspect du large entonnoir des Cryptoplocus, dont l'ouverture est d'ailleurs dénuée du bec qui existe chez Cerith. Defrancei, et est munie d'un pli pariétal absent dans notre sous-genre Aphanoptyxis. L'existence d'une bande suturale bien visible, et en outre l'ornementation des tours de spire, ne permettent pas davantage de le rapprocher des Cerithium, ni des Pseudonerinea qui ont du reste l'ouverture entière à la base.

C'est pourquoi j'ai proposé ce nouveau sous-genre, qui occupe, par rapport à Nerinea (s. s.), la même situation que Aplyxiella par rapport à liverinella. L'espèce type a été décrite comme Cerithium par Deslongehamps, dans les Mlém. de la Soc. linn. de Normandie (1842) et placée ensuite par d'Orbigny dans son genre Chemnilzia qui contient une quantité de formes hétérogènes, et enfin par moi, en 1880̃, dans le genre Cryptoplocus.

Répart Statigr.

Bathonien ..... Une espèce, type du sous-genre, dans le Boulonnais, l'Aisne, la Normandie, coll. Cossmann, Piette, Deslongchamps.

Rauracien..... Une espèce probable dans la Meuse (N. substriala, d'Orb.), d'après la Paléont. française.

NERINELLA, Sharpe 1849 (extens).

Forme généralement étroite, subcylindrique; spire très longue, tours dont la hauteur égale ou dépasse même la largeur, généralement excavés, séparés par des sutures plus ou moins oblirques et toujours saillantes, lisses ou ornés de bandelettes spirales parfois perlées: dernier tour anguleux à la périphérie de la base 
qui est excavée et imperforée. Ouverture quadrangulaire, terminée en avant par un bec long et un peu incurvé, à plication très variable.

Nerinella, sensu striclo. Type: $N$. Dupiniana, d'Orb. Néoc.

Forme aciculée; spire pointue, presque toujours dimorphe, les premiers tours étant plus excavés, moins élevés et même plus étagés que les derniers qui ont une tendance à devenir plans; ornementation habituellement formée de cordonnets spiraux, tantôt lisses, tantôt finement granuleux, particulierement celui qui est siluć au milieu de chaque tour; sutures placées sur une arète saillante qui fait ressortir l'évidement des tours; dernier tour assez élevé, à base obliquement déclive, limitée par un bourrelet subanguleux ou par une carène aigü̈.

Ouverture plus ou moins étroite, toujours rhomboïdale; labre obliquement incliné à gauche de l'axe, du côlé antérieur, sinueux et rétrocurrent vers la suture, invariablement muni d'un pli interne situé un peu au-dessous de l’angle périphérique de la base; columelle droite, munie d'une lamelle pariétale généralement bien visible, et d'un pli antérieur souvent plus obsolète ou confondu avec le coude que fait la columelle, au bord du bec subcanaliculé qui termine l'ouverture à la base: au total, trois plis paraissant quelquefois se réduire à deux ou même à un seul, par suite d'une saillie insuffisante de l'un ou de deux d'entre eux.

Diagnose refaite d'après un plésiotype de l'élage Ilettangien de la Vendée, N. Grossouvrei, nob. (Pl. II, fig. 9-11). Coll. Chartron; autre plésiotype du Rauracien, $N$. tornatella, Voltz, de Chattel-Censoir (PL. IlI, fig. 11-12), coll. Péron.

Observ. - La plupart des auteurs ont considéré Verinella soit comme symonyme de Nerinea, soit comme une coupe mal définie; je l'ai moimême inexactement interprété dans une précédente étude sur l'étago Bathonien (1885); M. Iludleston s'est davantage rapproché de la réalité, un désignant (1890) sous ce nom la plupart des Nerinea de l'Oolite infé- 
Nerinella

rieure qui nont qu'un petit nombre de plis. Je crois être actuellement arrivé à une délimitation plus rationnelle en étendant un peu l'acception primitive de Sharpe, le créateur de cette coupe; le type que cet auteur avait en vue est indiqué à la page 103, où il donne (fig. 2) la coupe d'une $N$. Dupiniana privée de son pli columellaire antérieur, plutôt qu'à la page 107, oủ il admet 3 subdivisions de Nerinella; A - columelle simple, B - columelle avec un pli, C - structure interne imparfaitement connue. D'ailleurs, en 1849, à l'époque où il a fait paraitre son mémoire sur les Nérinées du Portugal, Sharpe n'avait à sa disposition que la Paléontologie française des terrains crétacés, et fort peu de documents sur les Nerinea jurassiques, dont la découverte plus récente confirme précisément l'interprétation que je propose d'admettre pour son genre.

Rapp. et diff. - Les Nerinella se distinguent des Nerinea principalement par leur aspect baculiforme ou aciculé, parleurs tours plus nombreux et surtout plus élevés, par leur bec plus canaliculé à la base de l'ouverture, par le système d'ornementation bien différent de leurs tours de spire. Je ne fais pas entrer en comparaison le nombre des plis qui est le même et dont la position est à peu près identique dans Nerinea et Nerinella d'une part, chez Plygmatis et Bactroptyxis d'autre part, ni leur absence complète qui caractérise aussi bien Aphanoptyxis que Aptyxiella; cette plication variant dans les deux genres d'une manière parallèle, il en résulte qu'on ne peut y attacher que la valeur d'un caractère de sous-genre, tandis que c'est par l'ensemble des autres caractères distinctifs que peut se justifier la séparation bien nette à faire entre les deux genres en question.

Répart. Stratigr.

Hettaxgiex..... Le plésiolype ci-dessus, en Vendée, coll. Chartron, autre espèce dans les calc. gris des Alpes méridionales (Aptyxiella norigliensis, Tausch), d'après la figure donnée par l'auteur.

Charmouthex... Une espèce nouvelle, dans les Deux-Sèvres, coll. Janet; sera ultérienrement décrite dans "Contrib. it la Pal. fr. terr. jur. II. "

Bajociex....... Plusieurs espèces à plicalion variable en apparence, dans l'Oolite inférieure d'Angleterre $(N$. gracilis, Isyc., dericta, Hudl., alliooluta, Witchell, cingenda, Phill. etc...), d'après la Mon. de M. Hudleston.

Bationiex..... Nombreuses espèces dans la grande Oolite du Pasde-Calais, de la Normandie, des Ardennes, de la Còte-d'Or el de la Ilaute-Saône, ainsi qu'en Angleterre (N. scalaris, d'Orb., acicula, d'Arch., funiculiferaPiette, pseudocylindrica, d'Orb., pseudopunctala, Cossm., Burignieri, Pielte, pectinala, Piette, eleganlula, d'Orb., Cerith. Dufrenoyi, d'Arch. etc...), d'après 
la Paléont. franç, ella Monogr. de M. Cossmann, coll. Cossmann, Deslongchamps, Pielle, ligaux, Muséce (le Dijon, elc...

Oxfondex ..... Une espèce a Trouville (N. Allica, d'Orb.), d'après la Paléont. franę.

Rauracier..... Nombreuses espèces dans la Meuso et dans l'Yonne $(N$. sulcylindrica, d'Orb), canaliculata, Jollyana, collaldina, turriculata, subtricincta, ornata, d'Orb.. ele...), d'après la Paleont. frang. coll. de I'École des Mines, du Musée de Dijou, ete.

Sequanien ..... Nombreuses espèces dans les Chatrentes, la HauteMarne, YYomne et Io Jura (N. elatior, altenensis, Marix, d'Orb.), d'aprés la l'aléont. franç., coll. Beltrémieux, Janet, ma coll. Musée de Dijon ( $\boldsymbol{N}$. pseudospeciosa, de Lor., elegans, Thurm., scalata, Voltz, Greppini, de (Lor.), d'aprés la Monogr. de M. de Joriol sur le Jura bernois: en $\Lambda$ utriche $(N$. Hoheneggeri, Peters, cochleoides Ziltel), llaprès les Monogr. de Peters el Zittel sur les couches de Stramberga plusieurs espèces dans le Boulonnais (N. salagea, Cyane, banniensis, de Lor.), d'après la Monogr. de MM. de Loriol et P'ellat: autre espèere dans le Frioul (N. Taramelli, Pir.), diapris la Monogr. de P'irona.

Kimmeriden.... Plusieurs espèces dans le sous-élage Pérocérien do Valfin et d'Oyonnax (N. Bernardiana, Calliope, d'Orb., Chantrei, de Lor., turritella, Voltz), d'après Ia Monogr. de M. de Loriol: dans la Meuse el le Jura $N$. contorta, Buv.), d'après l'Atlas de Buvignier "t d'après de Loriol; plusieurs espèces dans le Virgulien du Doubs ( $N$. styloidea, Mustomi, Contejean), d'après la Monogr. des environs de Montbéliard par Contejean.

P'ortuandiex.... D Deux espèces dans le Jura el la Ilaule-Saône (N. Eralo, d'Orb., cylindica, Vollz), d'après la Paléont. franç.: autro espèce dans la Meuse ( $N$. bacillaris, Buv.), d'après l'Atlas de Buvignier; une espece dans l'Yonne ( $N$. vallonia), d'apris la Monogr. de MM. de Loriol of Cotteau.

Neocosiex..... Plusieurs espèces dans la llaute-Marne, l'Yonne el le Jura (N. Royeriana, Dupiniana, matronensis, d'Orb.), d'aprés la Paléont. franç.; dans le Valangien de la Suisse ( $N$. lobala, d'Orb., funifera, Piel. et Camp.), d'après la Monogr. de Sainte-Croix. 
Nerinella

Ungoniex ...... Une espèce dans le Jura suisse $(N$. orbensis, Pict, et Camp.), d'après la Monogr. de Sainte-Croix; autre espece dans l'Urg-aptien d'Utrillas, en Espagne (N. subflexuosa, nob. non flexuosa, Sow.), d'après le Synopsis de Mallada.

Aptiex......... Une espèce à peu près certaine dans les sables ligniteux d'Utrillas, en Espagne ( $N$. Utrillasi, Vern. et de Lor.), d'après le Synopsis de Mallada.

Cenomaxiex..... Une espèce dans les couches superposées au banc de Trigonies, en Syrie ( $N$. Shicki, Fraas), d'après la figure de Blanckenhorn.

Turosiex...... Une espèce dans la Charente (N. subæqualis, d'Orb.), d'après la Paléont. franç.; individu avec test du Provencien de Châteauneuf (Pl. IV, fig. 1), coll. Arnaud; trois espèces dans les couches de Gosau (N. flexuosa, Sow., granulata, Munst., gracilis, Zek.). d'après la Monogr. de Zekeli.

Senoxiex....... Une espèce douteuse dont la plication n'est pas indiquée ( $N$. subpulchella, d'Orb.), d'après la Paléont. franç.

Il résulte de ce qui précède que les Nerinella sont beaucoup plus rares dans le Crétacé supérieur que les véritables Nerinea, mais qu'elles apparaissent bien auparavant, dès la base du Lias : e'est encore un motif de plus pour distinguer les deux genres.

Bactroptyxis ${ }^{1}$, nov. subgen. Type: Ner. implicata, d'Orb. Bath. (= Ptygmatis auct. ex parte)

Forme d'une baguette cylindrique; spire tellement allongée qu'on n'en recueille jamais que des fragments; tours dont la hauteur dépasse la largeur, évidés ou aplatis, séparés par une suture située sur une fine arête saillante, lisses ou simplement ornés de stries spirales; dernier tour peu élevé, caréné à la périphérie de la base. Ouverture étroite, rhomboïdale ; labre droit, muni à l'intérieur de deux ou trois plis, celui du milieu presque toujours subdivisé, celui du bas parfois très obsolète ; columelle un peu concave, munie de trois plis, auxquels il faut généralement ajouter un faible pli pariétal; le pli antérieur est le

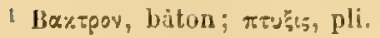


Nerinella

plus ccmpliqué et le plus saillant, il contribue à limiter le canal antérieur de l'ouverture; la coupe transversale de celle-ci présente 7 ou 9 lobes, selon que les plis sonl simples ou composés.

Diagnose établic d'après un individu de l'espèce type dllidrequent (PI. III, fig. 13), coll. Rigan; autre individu du mème gisement (fig. 14), ma coll.

Rapp. et diff. - Malgrẻ la similitude du nombre et de la disposition de leurs plis, il nest pas possible de classer dans le méme genre Plygmatis et Bactroplyxis, à cause de leur faciès absolument différent: les premieres ont un ombilic el des tours étroits, un bec trés court à la base de l'ouverture, tandis que les coquilles baculiformes que je propose de séparer de Plygmatis s. s. ont la base imperforée, les tours à peu près carrés, un canal bien formé, ce qui permet de les distinguer même des Plygmatis moins trapues el subcylindriques quion trouve dans le Crétacé supérieur. Enfin les plis eux-mèmes ne sont jamais aussi nombremx ni aussi compliqués chez Plygmalis que dans la plupart des Bactroplyxis, de sorte que le nombre des lobes de la coupe transrersale est toujours moindre.

Répart. Stratigr.

Bajociex....... Denx espèces dans la Meurthe-et-Moselle (Ver. Lebruniana, d'Orb., Jonesi, Lyc.), coll. Gailfe et Bleicher; plusieurs espèces on viriétés dans loolite inférieure d'Angletere ( $N$. Guisei, Witchell, campana, Hudl., pisolihica, Witchell, xena, Hudl, Jonesi, Lye'., producta, Witchell, oppetensis, Lie., ete.), dapres la Monogr. de Brit. jur. gastr., par MI. Hudleston.

Bathoкiex ...... Plusieurs espees, outre le Iype, dans le Bonlomais, le Calvalos, l'Aisne, la IIaute-Saine (N. bacilles, dUrb., trachea, Desl., fuiculosa, Desl., aromensis, d'Orb.), d'après la Paléont. frame., coll. liganux, ma coll. musée de Dijon, coll. Deslongchamps; autre espice dans la grande Oolite d'Angleterder ( $N$. complicala, Witch.), dapres le catalogue de Itudleston ef Wilson.

Raubaciex...... Une espere dius la Meuse el l'Tome (N. Clio, d'Orb.), d'après la Paléont. franç:; antre espèce dans le Jura bernois, conlondue arec $N$. contorla, par II. Greppin; unc espece it Nattheim, en Allemagne (N. leres, Goldf.), diprès Zillel.

Sequanen ...... Liespice rauracienne dans le Jura bernois ( $N$. Clio), 
Nerinella

d'après M. Greppin; autre espèce dans les couches de Stramberg ( $N$. crebriplicala, Zittel), d'après la Monogr. de Zittel, plusieurs espèces, dont une sénestre, en Sicile et dans le Frioul ( $N$. Beneckei, Petersi, sinistrorsa, Gem.), d'après les Monogr. de de Gemmellaro et de Pirona.

Kimmeridiex.... Une espèce dans le sous-étage Ptérocérien du Jura et de l'Ain ( $N$. Cassiope, d'Orb.), d'après la Paléont. franç.; l'espèce rauracienne $(N$. Clio), d'après la Monogr. de M. de Loriol, sauf vérification.

Il résulte de ce qui précède que les Bactroptyxis ont une extension géographique et surtout stratigraphique bien moindre que les véritables Plygmatis.

Aptyxiella, Fischer 1885.

Ner. sexcostata d'Orb. Séq.

(=Aptyxis, Zittel 1873, non Troschel 1868; = Pachystylus, Gemm, 1878, non Pachystyla, Mörch 185̌, nec Pachystylus, Woll. Col. 1873).

Forme d'une alêne; spire très allongée, aiguë, à tours carrés ou plus hauts que larges, ornés de filets spiraux, séparés par des carènes saillantes, sur lesquelles est la bande suturale el sous lesquelles est la suture un peu en retrait; base imperforée, très excavée. Ouverture quadrangulaire; labre vertical, rétrocurrent sur la carène postérieure; columelle droite, faisant un angle de 120 à $130^{\circ}$ avec la base de l'avant-dernier tour, se terminant en pointe effilée contre le bec antérieur, dénuée de plis ainsi que la base; les moules internes montrent, sur les premiers tours, une rainure obsolète qui semblerait indiquer l'existence d'une légère saillie spirale à l'intérieur du labre : mais celte rainure s'efface sur les derniers tours, dont le moule présente au contraire des traces de cordonnets saillants ( 2 ou 3 ) qui indiqueraient que la paroi interne du labre est faiblement sillonnée. 
Diagnose refaite: d'apres une contre-empreinte d'un échantillon de l'espèce lype (Pl. III, fig. 7), provenant des Minimes, it la Rochelle, coll. Beltrémieux; et d'après le moule interne d'une espèce plésiotype $N$. mpellensis, dOrb. de la Rochelle (PI. III, fig. 10), coll. Beltrémieux.

Rapp. et diff. - Daprès la diagnose primitive, ce sous-genre ne différerait des véritables Nerinella que par l'absence de plis, tant à la columelle. qu'au labre, et par son ornementation non perlée, exactement comme A phanoplyxis par rapport ì Nerinea; en effet, même quand l'un des plis lles Nerinella, celui du labre, n'est pas visible it l'ouverture, le pli columellaire et le pli pariétal sont généralement bien apparents, et en tous cas le moule interne de la coquille en porte la trace. Chez Aptyxiella, au contraire, ces deux derniers plis manquent absolument, ainsi que j'ai pu le constater; mais le labre n'en est pas démuni à tout âge, car il me parait bien établi qu'il existe toujours un faible pli spiral sur la paroi interne des premiers tours, et que ce pli s'efface avec l'age, soit completement (A. sexcostata), soit pour être remplacé par des rainures obsolètes dont lintervalle serait formé précisément par l'aplatissement progressil du pli (A. rupellensis) : ce caractère n’avait pas échappé ì d'Orbigny qui l'a indiqué sur la figure 3 de la Pl. 271, dans la Paléontologie française.

Répart. Stratigr.

linvaciex ..... Plusieurs espèces probables dans la Meuse, l'Youne, ou a Nattheim en Allemagne ( $N$. substriala, d'Orb., planala, Quenst., subcochlearis Munst.), d'après Ziltel dans sa Monogr. Gastr. Stramberger Schichten.

Sequaniex ...... Deux espèces certaines dans la Charente-Inférieure (N. sexcostata, d'Orb. et rupellensis, d'Orb.), coll. Beltrémieux.

Kimmeridex .... Plusienrs espèces typiques dans le sous-étage l'térocérien de Valfin et d'Oyonnax (A.valfinensis, de Lor., N. retrogressa, Etall., A. Etalloni, de Lor.), d'apris la Monogr. de M. de Loriol.

Pontlandex.... Une espèce douteuse dans le Boulomiais (Turrilella Simanni, de Lor.), d'après Zittel, yuoique la tigure de la Monogr. de M. de Loriol nindique pas si les stries d'aceroissement font un sims rétrocurrent près de la suture.

Nzocomen..... Une espèce probable dans le sous-étage infravalanginien du Portugal (A. infravalanginiensis, Choffat), d'après la Monogr. crélacique de M. Choftat. 


\section{TROGHALIA, Sharpe 1849.}

Forme conique, largement ombiliquée; spire à galbe plus ou moins extraconique, à tours étroits, parfois sillonnés; base du dernier tour un peu convexe; non carénée à la périphérie de l'ombilic; ouverture quadrangulaire, dénuée de bec à l'angle supérieur de droite.

Trochalid, sensu str.

Type : Ner. annulata, Sharpe. Grét.

Forme trochoïde; tours lisses, souvent un peu évidés; labre épaissi à l'intérieur, ou même portant un pli aux deux tiers de sa hauteur; bord columellaire lisse, ou muni d'un pli situé assez bas, non pariétal cependant.

Diagnose refaite d'après des échantillons imparfaits d'une espèce plésiotype, Ner. patella, Piette, du Bathonien de Rumigny (Pl. II, fig. 7-8), coll. Piette.

Observ. - Malgré l'opinion exprimée par M. de Loriol (Boulonnais, 1874, P. 62), je ne puis considérer Trochalia comme absolument synonyme de Cryploplocus: il est exact que le genre Trochalia de Sharpe comprend un amalgame de coquilles ombiliquées qui n'appartiennent évidemment pas à la même coupe sous-générique; mais Pictet ayant nettement indiqué que son genre Cryploplocus est caractérisé par l'existence d'un pli pariétal seulement, il faut relenir la dénomination Trochatia pour les espèces qui ont invariablement un pli saillant ou tout au moins un renflement à l'intérieur du labre, et qui ont quelquefois un pli columellaire comme $T$. annulata; cette espèce est d'ailleurs la première des deux que Sharpe a figurées, tandis quil se borne à citer dans le texte, comme appartenant peul-être au même genre, Ner. subpyramidalis et depressa, c'est-ít-dire de véritables Cryptoplocus à pli pariélal. Il n'y a done aucun doute sur l'interprétation it faire du genre de Sharpe, qui est distinct de celui de Pictet, quoirqu'il paraisse le compléter au point de vue de l'enchâ̂nement stratigraphique.

Répart. Stratigr.

Batномis. ..... Une espèce caractérisant tout un niveau du Bathonien supérieur des Ardennes (Ner. patella, Pielte), coll. Pielte, Musée de Lille. 
Trochalia

Neocomen..... L'espèce type dans le Porlugal, d'après la figure de Sliarpe.

Cryptoplocus, l'ict. el Camp. 1861.

Type :Ner. depressa, Voltz. Sér.

Forme conique, plus ou moins évasée; spire à galbe extraconique; tours étroits, lisses, un peu convexes, parfois étagés à la suture; dernier tour peu élevé, avec un angle arrondi à la périphérie de la base qui est convese et munie d'un large entonnoil ombilical, laissant apercevoir l'enroulement interne de la spire. Ouverture quadrangulaire, terminéc en avant par un angle droit, avec un indice de bec auquel aboutit l'angle circa-ombilical; labre simple, mince, très profondément échancré près de la suture; bord columellaire un peu calleux, arrondi, dénué de lamelle spirale; un seul pli pariétal, parfois effacé près de l'ouverture.

Diagnose faite d'après un individu de l'espece lype, dle Valfin (PI. II. fig. 13-14); coupe d'un autre individu de la Haute-Saòne (I'I. II, fig. 12), coll. du Musée de Dijon.

Rapp. et diff. - Il n'y a pas de Irès grandes différences entre Cryploplocus et Trochalia : dans les deux sous-cgenres, on tronve des espèces it forme trochoide et à lours légerement convexes; le principal caractere distinctif consiste dans la position et le nombre des plis, qui se réduisent chez les Cryptoplocus à une lamelle pariétale, landis que les Trochalia ont un pli columellaire et un pli plus ou moins bien formé sur le labre, Dans ces conditions, pour les motifs que j'ai indiqués ci-dessus, à propos de Trochatia, je suis d'avis de conserver la coupe proposée par Pictet et Campiche, mais à titre de sous-genre senlement.

Répart. Stratigr.

Rauracien ..... Le type apparait déjả dans loolite blanche de SaintMihiel, daprès la Paléontologie française; antre espèce dans le Corallien de Nattheim $(N$. terehra, Liet.), d'après Zittel; autre espèce dans le calcaire it Diceras de Kelheim et en Sicile (N. subpyramidalis, Munst.), diaprès \%iltel. 


\section{Trochalia}

Sequanien ..... Lespèce type dans la Charente-Inférieure, le Boulonnais, à Tonnerre, dans la Haute-Marne et le Jura bernois, en Sicile et dans le Frioul, d'après la Paléont. franç. et les Monogr. de M. de Loriol, de Gemmellaro et de Pirona; autre espèce dans le Tithonique inférieur d'Allemagne et de Sicile (N. pyramidalis Munst.), d'après Zittel, Gemmellaro et Peters; plusieurs espèces voisines du type dans les couches de Stramberg et dans le Frioul (C. succedens, consobrinus, angulatus, Zittel), d'après les Monogr. de Zittel et de Pirona.

Kinmeridiex .... L'espèce type dans le sous-étage Ptérocérien, à Valfin et à Oyonnax, coll. du Musée de Dijon, coll. de Loriol, etc.

Pontlandiex .... Une espèce dans le Jura (Ner. macrogonia, Thurm. = subpyramidalis, d'Orb.non M.), d'après la Paléont. franc., correction signalée par Zittel.

Ungoniex...... Une espèce dans les couches à Caprotines de SainteCroix (C. Sanctz-Crucis, Pict. et Camp.), d'après la Monogr, de ce gisement.

Endiaplocus 1, nov. subgen.

Type : Turritella Roissyi, d'Arch. Bath.

Forme conique ou extraconique; spire pointue, turriculée; tours plus ou moins étroits, légèrement évidés, à sutures saillantes, ornés de sillons spiraux et réguliers ; dernier tour anguleux à la périphérie de la base qui est lisse, déclive, peu convexe et perforée d'un entonnoir médiocrement évasé. Ouverture quadrangulaire, entièrement dénuée de plis à tout âg'e, non canaliculée à la base.

Diagnose établie d'après un individu d'une espèce plésiotype, Cryptoplocus Munieri, Rig. et Sauv., provenant d'IIidrequent (Pl. I, fig. 14-1气̃), coll. Legay.

Rapp. et diff. - Sur aucun des échantillons entiers ou mutilés, quie je connais des deux espèces de ce groupe, je n'ai constaté la Irace, ni l'appa-

1 Evô:เ $\alpha$, manque de, $\pi$ hoxos, pli. 
Trochalia

rence d'un pli, soit au labre, soit à la columelle, soit sur le bord pariétal; en outre, les tours sont striés, leur's sutures sont sur une arète saillante et bitide, enfin la base est carénée a la périphérie: pour tous ces motifs, il me paraît rationnel de séparer ces espèces des Trochalia et des Cryploplocus, dans la même situation relative que Aphanoptyxis vis-i-vis de Verinea, et que A plyxiella vis-i-vis de Nerinella. Il est d'ailleurs indubitable que ce sont des Nerineidar; car les stries d'accroissement forment un crochet rétrocurrent près de la suture inférieure, le long de laquelle on distingue une bande linéaire, formée par les accroissements de ce simus, et n'ayant par conséquent aucun rapport avec les genres Viso ou Turritella.

Répart. Stratigr.

Bathonien..... Deux espèces typiques dans le Boulonnais et dans l'Aisne (Turr. Roissyi, d'Arch. et Crypt. Munieri, R. et S.), coll. Rigaux, Legay, Piette, ma coll.

\title{
ORdRE DES PROSOBRANCHIATA.
}

\author{
Sous-ordre : PECTINIBRANCHIATA.
}

Division A : TæNIOGLOSSA.

\section{TEIR EIBII I A}

Forme étroite, pointue comme une tarière ou une alêne; cmbryon conoïdal à nucléus un peu dévié, homéostrophe; tours nombrux, lisses ou ornés, à sutures souvent bordées. Ouverture canaliculée et échancrée à la base ; accroissements de l'échancrure toujours limités par un bourrelet ou une carène qui s'enroule sur le cou.

Observ. - Comme l'indique le tablean ci-après, je comprends dans la famille Terebride le genre Pusionella, qui a été successivement placé près 
des genres Fusus, Buccinum, Terebra, Clavalula, c'est-à-dire dans quatre lamilles bien diflérentes, à cause de ses caractères ambigus. Fischer el Tryon le classent dans les Clavatulinx à cause de la forme de la coquille et de son opercule; mais le labre n'a pas l'entaille caractéristique des Clavalula, il ne présente qu'une très légère sinuosité, tandis que le canai, quoique un peu plus long que celui des Terebra, est échancré, peu profondément il est vrai, toutefois suftisamment pour qu'un bourrelet caractéristique chez les Terebridx, toujours absent dans les Pleuralomidx, s'enroule sur le cou du canal. C'est donc, selon moi, une sous-famille de Terebrida (Gray a mème proposé, en 180̄7, une famille Pusionellidæ), et on la distingue des formes typiques par la brièveté de la spire, par l'excavation de la base du dernier tour, par la longueur du canal et le peu de profondeur de son échancrure, enfin, par la position des yeux de l'animal (fide Tryon).

\section{Tableau des genres, sous-genres et sections.}

\section{TEREBRA}

[spire longue]

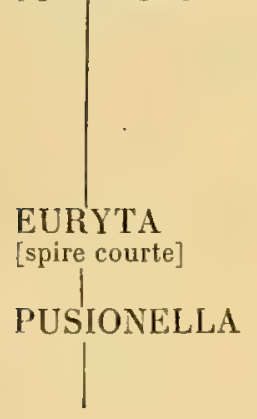

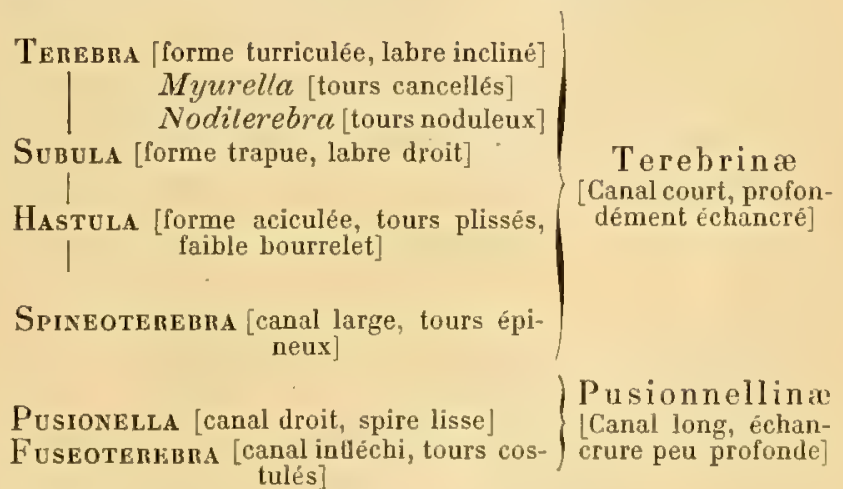

\section{Genres et sous-genres non signalés à l'état fossile.}

Inpages, Smith, 1873. - T. cærulescens, Lamk. N'a pas été caractérisé nettement par l'auteur; mais, en examinant le type, qui est intermédiaire entre Subula et Hastula, lisse comme les premières, étroil comme les secondes, on remarque que le canal est profondément échancré, que le labre est rétrocurrent à la suture, et que les tours sont embrassants comme ceux des Euryta.

Euryta (sensu stricto) H. et A. Adams, 1803: Type: $T$. aciculata, Lamk. Cette coupe doit ètre génériquement séparée des Terebra, non seulement à cause de la forme courte de la spire et de l'aspect bucciniforme de l'ouverture, mais encore à cause de l'ornementation épineuse des tours de spire, et de l'embryon qui est obtus, court et dévié. La forme typique n'existe pas à l'étal fossile : mais on peut y rattacher le sous-genre Spineolerebra. 
TEREBRA, Adanson 1757 (Lamk. 1797, non 1801). $(=$ Terebrum, Montfort 1810).

Forme étroite, subulée, conique ; embryon lisse, conoïdal, à nucléus dévié; spire très longue, pointue, à tours nombreux, étroits, généralement munis d'une bande suturale qui ne correspond pas à une échancrure labiale. Ouverture courte, largement canaliculée et profondément échancrée à la base; labre mince, peu sinueux, ordinairement incliné à gauche de l'axe du côté antérieur; columelle non plissée, infléchie en avant, se terminant en pointe et munie d'un rebord saillant le long du canal; bord columellaire mince, non calleux, sous lequel sort une côte étroite qui s'enroule sur le cou du canal, limite les plis d'accroissement de l'échancrure et aboutit à l'extrémité anguleuse du labre.

Terebra, sensu stricto. Type : Buccinum subulatum, Lin. Viv.

Forme aciculée ; embryon paucispiré ; tours très nombreux, brillants, à peu près lisses; bande suturale saillante sur les premiers tours, tendant à s'effacer sur les derniers; dernier tour très court, un peu excavé à la base, autour du cou du canal. Ouverture subrhomboïlale; labre très incliné; columelle verticale, peu renflée, formant un angle arrondi de $100^{\circ}$ avec la base de l'avant-dernier tour.

Diagnose faite d’après un individu typique des íles Plilippines; plésiotype fossile, T. acuminata, Borson (PI. IV, fig. 11), échantilIon astien de Vezza d'Alba, ma coll. (don de M. Sacco).

Observ. - Le genre Terebra, créé par Adanson, a élé appliqué en 1797 par Lamarck(Soc. hist. nat. de Paris) à Bucc. subulaum, Lin ; puis en 1801, sans aucun motif, Lamarck a, dans son cours, indiqué un autre type tout à fait différent, Bucc. maculatum Lin., de sorte que Schumacher, jugeant que ce nouveau type ressemble plus à une alêne qu'à une tarière, a changé le nom Terebra en Subula. Cette modification n'eût pas cite admissible 
s'était agi du même type: mais, en tenant compte du choix primitif de Lamarck, qui vise bien une espèce térébriforme, il paraît correct de reprendre Terebra pour T. subulata, et de conserver Subula pour $T$. maculata. Quant à Terebrum, c'est un simple changement de désinence, proposé par Montfort, et tombant en synonymie avec le genre d'Adanson.

Il est extrêmement rare de trouver des Terebra dont la pointe est intacte; c'est pourquoi les auteurs ont généralement omis d'indiquer quelle est la forme de l'embryon. Il m'a paru utile de combler cette lacune, après une étude minutieuse des tours embryonnaires de plusieurs échantillons fossiles dont l'extrémité

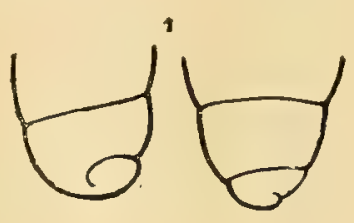

FIG. 1. était bien conservée : le résultat de cet examen est que l'embryon des Terebridse se compose d'un nucléus homéostrophe et obtus, auquel succèdent plusieurs tours lisses, ayant un galbe conoïde.

Répart. Stratigr.

Eocene....... Une espèce à embryon en goutte de suif (Fig. 1), dans l'Eocène d'Australie ( $T$. platyspira, Tate), ma coll.

Mrocene....... Le plésiotype ('T. acuminata, Bors.), dans l'étage Tortonien (fide Sacco).

Plrocene....... Le même plésiotype dans le Plaisancien et l'Astien, à Cannes, coll. Cossmann.

Epoque actuelle. Le type (T. subulala, L.) coll. Cossmann; nombreuses espèces dans toutes les mers, d'après Tryon.

Myurella, Hinds, 1844.

mbluidy ariw. Type: T.affinis, Gray. Viv. (= Strioterebrum, Sacco 1891. - Type: T. Basteroti, Nyst).

Forme de Terebra; tours ornés d'une bande suturale étroite et crénelée, séparée par un sillon qui persiste jusqu'au dernier tour; an-dessus de ce sillon, filets spiraux croisant des costules axiales et courbes. Ouverture contournée, largement échancrée à la base; columelle renflée au milieu par la trace que laisse, sous le bord columellaire, la carène limitant, sur le cou du canal, les accroissements de l'échancrure. 
Diagnose faite d'après un plésiotype fossile, T. pliocenica, Font., de l'Astien de Canne (Pl. IV, fig. 13), ma coll.

Observ. - M. Sacco ayant lui-même indiqué, parmi les formes vivantes assimilables a son sous-genre Striolerebrum (Imoll. dei terr. terz. del Piemonte) le type $T$. affinis du sous-genre Myurella, il n'est pas possible de conserver cette dénomination qui fait un double emploi évident, d'autant moins que la distinction à faire entre Myurella et Terebra s. s. est ellemême peu tranchée, attendu qu'il y a des passages graduels d'une forme a l'autre: aussi c'est seulement à titre de section que j'ai admis le genre de Hinds.

Rapp. et diff. - Celte section se distingue surlout par son ornementation: la présence, sur les tours, de sillons spiraux qui séparent des filets plus ou moins serrés, la persistance du sillon postérieur qui isole la bande. suturale, les crénelures souvent très saillantes dont celle-ci est ornée, permettent de distinguer facilement les Myurella des véritables Terebra. Si l'on ajoute à ces caraclères, parfois fugitifs chez certaines espèces, que la columelle a l'aspect biplissé, parce qu'elle est bombée au milieu et fortement carénée à sa limite antérieure, on peut à la rigueur justifier la création de cette section.

Répart. Stratigr.

Senoniex...... Une espèce très donteuse dans le Santonien supérieur des Corbières et à Gosau (Fusus cingulatus, Sow.): l'ouverture est incomplete, aussi bien sur les figures de Zekeli et de d'Archiae que sur l'échantillon de la coll. de Grossouvre, mais l'ornementation est identique à celle de certaines Myurella.

Eocene....... Une espèce typique dans les sables de Claiborne ( $T$. andrega, de Greg.), ma coll.

Oligocene ...... Une espèce très voisine de celle de l'Eocène dans le Vicksburgien du Mississipi ( $T$. divisura, Conrad), d'après Dall, qui l'assimile même à l'espèce vivante $T$. dislocala.

Mocene....... L'espece type du sous-genre Striaterebrum (T. Basteroti) en Italie et dins le Bordelais, ma coll. Embryon d'un individu de l'Ilelvétien de Salles (Fig. 2), ma coll.

Plocene..... Plusicurs espèces oul variétés dans le bassin du Rhône et le Piémont (T. pliocenica, Font.), ma coll. (T. relicularis, Pecch.), d'après la Monogr. de M. Sacco.

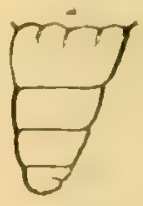

Fig. 2. 
Terelin

Epoque actuelle. Nombreuses espèces dans toutes les mers ( $T$. affinis, variegala, armillala, dislocala, nebulosa) etc.... groupe B d'après Tryon.

Noditerebra, nov. sect.

Type : T.geniculata, Tate. Mioc.

Forme cérithiale, relativement courte; embryon conoïde; paucispiré ; spire aiguë, à galbe conique; tours convexes en avant, déprimés au-dessus du bourrelet sutural, ornés d'une doable rang'ée. de nodosités, les unes sur le bourrelet sutural, les autres sur la convexité antérieure où elles s'allongent davantage, et de stries spirales très obsolètes. Ouverture ovoïde, peu allongée, rétrécie et anguleuse en arrière, terminée à la óase par un canal large, oblique et échancré ; labre saillant en avant, subéchancré vis-à-visde la première rangée de nodosités, antécurrent vers la suture vis-à-vis du bourrelet; columelle en $S$, non bombée au milieu, élroitement bordée le long du canal ; carène saillante limitant sur. le cou du canal les accroissements de l'échancrure.

Diagnose établie d'après le type fossile du Tertiaire d'Australie, individu de Muddy Creek (Pl. IV, fig. 21), ma coll. (don de M. Tate).

Rapp. et diff. - La séparation de Myurella, comme section distincte de Terebra, rend nécessaire la création d'une autre section pour les formes plus courtes et moins subulées que ces deux groupes : cest surtout par l'ornementation de la spire et par le profil du labre que sedistingue Noditercbra. Mais, de même qu'il existe des espèces intermédiaires entre Terebra et Myurella, de même il y a des formes qui relient graduellement certaines Myurella aux Noditerebra bien caractérisées; l'échancrure, d'ailleurs peu profonde du labre, n'est elle-même que la conséquence de la saillie des nodosités antérieures, qui sont produites par la courbure des costules axiales interrompues sur la dépression postérieure de chaque tour. Quoi qu'il en soit, malgré l'existence de ces passages de transition, on peut à la rigueur admettre Noditerebra comme une section composée d'espèces qu'il est facile de séparer à première vue.

Répart. Stratigr. Mrockí........ L'espèce type en Australie, ma coll.

Epoque actulle.. Plusieursespèces (T. varicosa, Iinds, lessellala, Gray, coneava, Siay), dans les îles Marquisesel les mers de l'Amérique centrale, d'après le Manuel de Tryon. 
Subula, Schum. 1817. Type: Bucc. maculatum, Lin. Viv. (= Terebra, Lamk. 1801, non 179f; Acus, Humphrey, 1797, in Gray 1847, non Johnston, 1650); = Abretia, H. et A. Adams, 1853)

Forme conique, un peu trapue, mais allongée; embryon multispiré; tours embrassants, à sutures linéaires, souvent plissés par les accroissements, rarement ornés de stries spirales, généralement marqués d'un sillon spiral qui disparaît sur les individus adultes; dernier tour assez grand, à base ovale, non excavée. Ouverture très étroite en arrière, munie d'une gouttière suturale, à peine atténuée en avant, largement et profondément échancrée à la base; labre peu incliné, à peine rétrocurrent à la suture; columelle un peu convexe au milieu, faisant un angle très ouvert avec la base de l'avant-derniel tour.

Diagnose refaite d'après un individu typique de Taïti; plésiotype fossile du Miocène inféricur de Saucats, T. fuscata, Br. (PI. IV, fig. 7), coll. Cossmann; autre individu vu de profil (Pl. IV, fig. 8), de l'llelvétien de Manthelan, ma coll.

Observ. - Sans répéter l'explication donnée ci-dessus, à propos du genre Terebra s. $s$, j’ajoute que le genre Acus, non publié en 1797 par Humphrey, révélé seulement en 1840 par Swainson qui ne l'a pas adopté, et accepté en 18.17 par Gray qui a pris pour type $T$. maculala, ne peut être admis pour deux raisons: d'abord parce qu'il s'applique au mêne type que Subula qui a été caractérisé 30 ans plus tôt, ensuite parce que le nom Acus avait déjà été employé au xvir siècle en Ichthyologie.

Rapp. et diff. - La diflérence signalée par Schumacher, qui existe entre la forme extérieure de $T$. subulata et celle de $T$. maculala, mérite d'être prise en considération: comme elle coincide avec d'autres caractères, tels que l'inclinaison du labre, la disposition de la columelle, le recouvrement des tours, la forme de l'embryon, j'estime qu'on peul admettre Subula comme un sous-genre différent de Terebras. s. Mais je ne crois pas qu'on en puisse séparer Abretia, dont le type (T. cerithina) ne diffère de T. maculala que par sa forme un peu plus étroite, avec uı sillon spiral plus persistant sur les derniers tours : c'est a cette forme que se rattaclıe notre plésiotype fossile, $T$. fuscala, plutôt qu'i la forme typique 
de Subula. Comme d'ailleurs tous les autres caractères de l'ouverture, de la columelle subplissée, de l'inclinaison du labre, etc..., sont identiques, je ne crois pas qu'on puisse même admettre Abretia comme une section de Subula.

Répart. Stratigr.

Mrocene........ Le plésiolype apparail dans l'Aquitanien et le Langhien de la Gironde, continue dans l'Helvétien de la Touraine, puis dans le Tortonien de Salles et de Monte Gibbio ( $T$. fuscala, Br.), ma coll.

Pliocese....... La même espèce dans le Plaisancien de Bologne et dans l'Astien de Cannes, ma coll.

Epoque actuelle. Plusieurs espèces, outre le type (T. chlorala, Lamk., albida, Gray) dans la Polynésie, à Malacca, aux Seychelles, en Australie.

Hastula, H. el A. Adams, 1853. Type: T. strigillata, Lamk. Viv.

Forme pointue, à galbe régulier; embryon conoïdal, multispiré ; tours non embrassants, assez élevés, subulés, souvent plissés par les accroissements, dépourvus de sillon spiral; base du dernier tour obliquement déclive. Ouverture rhomboïdale, atténuée en avant, peu échancrée à la base du canal ; labre presque vertical; columelle droite, faisant un angle de plus de $130^{\circ}$ avec la base de l'avant-dernier tour, à peine infléchie et très étroitement carénée sur le bord du canal; bourrelet très obsolète, limilant les accroissements de l'échancrure sur le cou du canal.

Diagnose établie d'après un plésiotype fossile, T. plicatula, Lamk. de l'Eocène de Villiers-Neauphle (Pl. IV, fig. 1ä-16), ma coll.; vue grossie de l'embryon d'un autre individu (Fig. 3), ma coll.

Rapp. et diff. - L'espèce que j'admets comme plésiotype a beaucoup d'analogie avec les lormes vivantes qui dérivent de T. strigillala, T. albula, Menke, T. hastata, Gm. : elles sont caractérisées par l'angle très ouvert que fait la columelle avec la base de l'avant-dernicr tour, par la faible profondeur de l'échancrure, par la disparition presque complète du bourrelet sur le cou du canal. Leur forme subulée les rapproche, il est vrai, de Subula, mais, outre qu'elles n'ont jamais de sillon spiral. même sur les premiers tours, ceux-ci ne sont pas

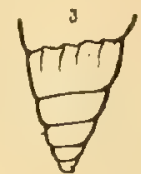

FIG. 3. 
Terebra

embrassants comme ceux de $T$. maculala, de sorte que louserture ne comporte pas de goullière suturale.

Répart. Stratigr.

EOcene........

Le plésiolype ci-dessus indiqué existe dans les trois sous-étages du bassin de l'aris et daus la LoircInférieure; denx especes typiques dans l'Australie du Sud (T. angulosa el crassa, Tate), d'apres les figures données par l'auteur.

Oligocene...... Une espèce dans le Tongrien inférieur de l'Allemagne du Nord $T$.plicosa, v. Konen) d'après les figures données par l'auteur; autre espèce dans les conches supérieures du bassin de Cassel ( T. Beynichi, Semper) ma coll.

Mrocene....... Une espèce typique dans le sous-étage Langhien du Bordelais (T. striata, Bast.), ma coll. ; antre espece dans l'llelvétien d'Italie ( $T$, subcinerea), d'aprés la Monogr. de M. Sacco.

Plrocene...... Une espèce typique dans le Plaisancien de Bologne ( $\mathbf{T}$. costulata, Bors.), ma coll. ; autre espèce dans le hassin du Rhône et en Italie (T. Farinesi, Font.), d'après les ligures données par l'auteur et d'aprés la Monogr. de M. Sacco.

Epopqe actuelle. Plusieurs espèces, outre le type ( $T$. cinerca, Born. ar $i-$ culina, Reeve, hastata, Gm., nilida, Hinds, etc...), dans la Polynésie, les mers du Japon, les Indes oceidentales, les côtes Ouest d'A frique, elc..., d'après le Manuel de Tryon.

EURYTA, H. et A. Adams, 1853.

Forme fusoïde ou buccinoïde, peu allongée; embryon composé de deux tours lisses, à nucléus obtus et dévié ; lours embrassauss, élevés, ornés de côtes binoduleuses ou subépineuses; dernicr tour grand, à base parfois sillonnée. Ouverture étroite, avec unc gouttière postérieure et un canal antérieur ; labre à peu près verlical, légèrement sinueux vis-à-vis de la rangée supérieure de nodosités; columelle héliçoïdale, se raccordant par un arc trìs ouvert avec la base de l'avant-dernier tour, intléchie près de l'échancrure basale qui est très large. 
Diagnose refaite d'après un individu dı type vivant aux Antilles, $T$. aciculata, Lamk. var. nodosoplicala, Dunk. (Pl. IV, fig. 12), ma coll.

Spineoterebra, Sacco, 1891. Type: T. spinulosa, Doderl. Mioc.

Forme assez courte, pupoïde; spire à galbe conoïdal ; tours ornés de costules subépineuses en arrière, un peu étagés à la suture. Ouverture étroite, peu profondément échancrée à la base du canal qui est à peu près aussi large qu'elle et très court; bord columellaire épais et calleux, limité par une dépression; bourrelet de l'échancrure très écarté, s'enroulant peu obliquement sur le cou du canal.

Diagnose établie d'après un individu typique du Tortonien de Stazzano (Pl. IV, fig. 20), ma coll. (don de M. Sacco).

Rapp. et diff. - J'ai indiqué, à la suite du tableau de classification des Terebridæ, les motifs qui justifient la séparation du genre Euryta qui ne parait pas avoir été rencontré jusqu'à présent à l'état fossile. Néanmoins j'en ai donné ci-dessus une figure, pour mieux faire saisir les caractères qui rattachent à ce genre, plutôt qu'aux Terehra, le sous-genre Spineoterebra: la forme générale est analogue, et l'ornemєntation est à peu près semblable; toutelois il existe, chez les Euryta vivantes, des stries basales qui persistent sur le cou du canal et qu'on n'aperçoit pas chez T. spinulosa, dont la base est entièrement lisse; en outre, les nodules épineux forment la rangée inférieure sur les tours de cette dernière espèce, tandis que c'est au contraire la rangée supérieure qui est la plus saillante dans le type vivant. Il y a aussi d'autres caractères qui distinguent Spinecterebra, quoiqu'ils n'aient qu'une importance secondaire : ce sont la largeur et la brièveté du canal, le peu de profondeur de l'échancrure, la callosité columellaire. En résumé, au point de vue du classement, c'est exactement un sous-genre d'Euryla.

Répart. Stratigr.

Mrocenf....... Le type ( $T$. spinulosa) avec plusieurs variétés (T. Doderleiniana, For.). dans le Tortonien d'Italie d'après Sacco et Foresti; autre espèce Irès voisine du type, a Cacella en Portugal ( $T$. Algarbiorum, da Costa, d'après les figures données par l'auteur; plusieur's espèces dans les couches supérieures de Muddy 


\begin{abstract}
Euryta
Creck en Australie ( $T$. subspectabilis et convexiuscula, Tate) d'après les figures données par l'auteur.

Epoeueactuelee. Outre le type vivant d'Euryla, à Mazatlan et à Panama, plusieurs autres espèces, en Californie ( $T$.fulgurala, Phil.) et dans la Mer Rouge (T. nassoides, Hinds), d'après le Manuel de Tryon. Il faut en exclure T. Cosentini, Phil, qui n'est autre que T. aciculata, Lamk. indiquée par erreur dans la Méditerranée.
\end{abstract}

PUSIONELLA, Gray, 1847.

(=Netrum, Phil. 1850)

Pusionelia, sensu stricto.

Type: $P$. nifat, Adanson. Viv.

Forme clavatulée, fusoïde, un peu ventrue; embryon paucipiré, subglobuleux, à nucléus obtus; spire aigruë, médiocrement allongée, à tours lisses.s. embrassants et généralement étagés audessus de la suture; dernier tour au moins égal à la moitié de la longueur totale, à base plus ou moins excavée et subanguleuse à la périphérie, ornée de filets spiraux qui s'enroulent sur le cou canal. Ouverture rhomboïdale, à bords parallèles, munie d'une gouttière dans l'angle postérieur et d'un canal allongé, étroit et presque droit, peu échancré à la base; labre mince, curviligne, à peine échancré, ou plutôt sinueux vers le tiers inférieur de sa hauteur; columelle arquée à sa jonction avec la base de l'avantdernier tour, à peine infléchie le long du canal; bord columellaire peu calleux; bourrelet de l'échancrure peu saillant.

Diagnose refaile d'après le type vivant, ma coll.; et d'après le plésiotype de l'Helvétien d'Italie, P. tauronifal, Sacco (Pl.IV, tign.9) de Colli Torinesi, coll. du Musée géol, de l'Université de Turin.

Observ. - J'ai indiqué, à propos de la famille Terebriclie, les molifs qui me décident à classer ce genre dans ladite famille, au lieu que la plupart des auteurs le considèrent à présent comme un membre de la famille P'leurolomidx, principalement parce que la forme extérieure de la coquille a de l'analogie avec quelques Clavatula : mais le labre est trop peu sinueux 
Pusionella

pour que l'on puisse rapprocher Pusionella de Clavalula dont le canal n'est pas du tout échancré. D'ailleurs l'existence d'un autre groupe de coquilles, qui participent à la fois aux caractères de Terebra et de Pusionella, et pour lesquelles $M . S a c c o$ a proposé le genre $F$ usoterebra, démontre l'enchainement évident de ces formes entre elles; je suis persuadé que cette opinion se confirmera quand on connaîtra mieux l'animal de Pusionella.

Répart. Stratigr.

Mrocene....... Trois espèces, une dans l'étage Langhien du Bordelais (Pleurot. saucatsensis, Mayer) d'après M. Sacco; deux dans l'Helvétien d'Italie ( $P$. pedemmatana et tauronifat, Sacco), types communiqués par M. Sacco.

Epoqueactuelle. Outre le type (ma coll.), cinq espèces presque exclusivement sur les côtes occidentales d'Afrique, d'après le Manuel de Tryon et ma coll. (don de M. Dautzenb).

Fusoterebra, Sacco, 1891. Type: Fusus terebrinus, Bon. Mioc.

Forme étroite, assez longue; spire pointue; tours nombreux, ornés de plis étroits, subnoduleux près de la suture inférieure et au milieu de la hauteur de chaque tour; dernier tour égal au quart de la largeur totale, atténué à la base sur laquelle se prolongent les plis axiaux. Ouverture étroite, fusoïde, terminée en avant par un canal assez long, étroit et contourné, peu profondément échancré à la base; labre vertical, épaissi à l'intérieur; columelle infléchie en $S$ très allongée, obtusément anguleuse le long du canal, recouverte d'un bord mince et assez large ; carène très saillante, limitant les accroissements de l'échancrure sur le cou du canal.

Diagnose refaite d'après des individus de Tortonien de San-Agata

(Pl. IV, fig. 14), coll. Cossmann (don de M. Sacco).

Rapp. et diff. - Quoique Fusus lerebrinus ait une ornementation qui rappelle un peu celle de quelques Furyta, la séparation qu'a proposée M. Sacco me paraît molivée, non seulement parce que les plis se prolongent sur la base du dernier tour, qui ne porte aucune trace de stries spirales, mais surtout à cause de la forme contournée du canal qui ressemble à celui de Latirulus; entin, sur le cou du canal est un bourrelet 


\section{Pusionell:}

heaucoup plus saillant, les tours sont moins embrassants, lo dernier est moins élevé, elc...; comparée à Pusionella s.s., Fusolerebra s'en dislingue par sa spire plus allongée, par son ornementation et par sou canal légèrement tordu.

Répart. Stratigr.

Mrocene....... Le type el plusieurs variétés dans le Tortonien d'Italie, d'après la Monogrr. de M. Sacco.

\section{IPLEULO' TOMIOL}

Forme généralement fusoilde; embryon homoeostrophe; labre muni, du côté postérieur, d'une sinuosité ou d'une entaille plus ou moins profonde, placée plus ou moins près de la sulure; columelle lisse en général, parfois plissée ou ridée. Opercule corné, ovale, ànucléus latéral ou apical, beaucoup plus petit que l'ouverture, absent chez toute une sous-famille.

Observ. - La séparation en deux familles distinctes, des Pleurotomidae et des Conidx, est de date relativement récente el est justifiéc par les différences yu'on observe dans l'analomie de l'animal de Conus et de Pleurotoma. La transition d'une famille à l'autre se fait par l'intermidiaire des Borsonia, Bathyloma el Genatia, les deux premières élant des Peurolomidie, landis que le troisième de ees genres cost plutot voisin de Comus, quoique les fours ne soient pas résorbés à l'intérieur de la coquille adulte.

Les Pleurotomidx sont divisés par la plupart des auteurs en quatre sous-familles, selon l'existence ou l'absence et selon la forme de l'opercule: ce dernier, élant de nature cornce, n'est pas conservé à l'état fossile, de sorte que cette classification ne peut être suivie par les paliontologistes qu'à la condition de la corroborer par des observalions concordantes, lirées des autres caracteres de la corpuille. Nous y ajoutons une cinquieme sous-famille, exclusivement représentée dans les terains crétaciques. Mais, à part cette sous-famille, composie de genrias dont la position systimatique a élé très contestée, les Pleurotomidit ne commencent à apparaûtre qu’à partir des terrains tertiaires, saul deux ou trois formes de la fin de la période crólacique, dont l'itat de conservation laisse d'aillours beaucoup à désirer, et sur lesquelles je ne puis me former une opinion définitive, nayant à ma disposition ipue les figures des ouvrages dans lesquels elles sont décrites, et aussi parce que le niveau exact de certaines couches d'Amérique, d'ou proviennent ces coquilles, exige une confirmation certaine : jusqu'ì pré. 
sent, on peut seulement dire qu'elles sont attribuées à la période crúlarique, mais qu'elles confinent au terrain tertiaire.

Un certain nombre de genres n'étant encore connus, qu'à l'état vivant j'ai, par une innovation qui s'écarte un peu de l'ordonnance adoptée dans la première livraison de cet ouvrage, introduit dans le tableau général de classification des genres de Pleurotomidæx ceux d'entre eux qui ne sont pas encore cités à l'état fossile; une lettre de renvoi entre parenthèses permet au lecteur de se reporter à la liste sommaire des genres et sousgenres appartenant exclusivement à l'époque actuelle. Quoique celte addilion sorte du cadre paléontologique de notre entreprise et qu'elle risque ultérieurement d'attribuer la prédominance à la conchyliologie de l'époque actuelle, je compte m'y conformer désormais, dans tous les cas où il y aura un mélange équilibré des deux faunes : il en résultera une plus grande facilité pour la comparaison systématique des formes entre elles.

Rapp. et diff. - Les Pleurotomidæ étant des coquilles manifestement siphonostomes, je n'ai pas à les comparer aux Nerineidæ, qui n'ont pas un véritable canal, mais simplement un bec à l'extrémité antérieure de l'ouverture. D'ailleurs l'échancrure du labre n'occupe pas la même position chez les Pleurotomidæ que chez les Entomotæniata, et surtout la disposition en est bien différente : au lieu d'une entaille profonde et étroite, coïncidant avec la suture et au-delà de laquelle le contour du labre se raccorde immédiatement à la suture, le sinus pleurotomique est un demi-cercle ou un triangle, voire même un arc de cercle très ouvert, tantôt écarté de la suture, tantôt situé sur une rampe en gouttière contiguë à la suture, mais dont le contour est toujours antécurrent vers louverture, de sorte que le raccordement se fait soit obliquement, soit avec un quart de cercle.

Si l'on rapproche les Pleurotomidæ des Terebridie, qui nont pas de sinus et qui ont un canal court, profondément échancré, on remarque que la transition d'une famille à l'autre peut se faire insensiblement par l'intermédiaire des Pusionellinx, que quelques auteurs rapprochent de Clavalula, quoique leur labre soit, pour ainsi dire, dépourvu de sinuosité, tandis que les autres (et j'ai suivi cet exemple) classent Pusionella dans les Terebridæe. Il parait donc établi qu'il y a beaucoup d'affinités entre ces deux familles; la distinction peut principalement se faire par l'opercule et par des caraclères tirés de l'anatomie de l'animal, c'est-à-dire qui échappent aux investigations des Paléontologistes obligés d'admettre une coupure un peu arbilraire. 
Tableau des genres, sous-genres et sections.

\section{CLAVATULA}

I sinus écarté d la suture]

SURCULA

sinus sur la rampe suturale]

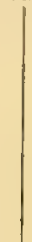

PLEUROTOMA

[sinus sur la carène]

\section{DRILLIA}

[sinus sur la rampe, canal court et échancré]

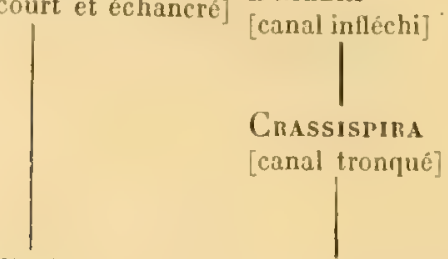

SPIROTROPIS [sinus bordé contigu à la suture

Drillia [spire turriculée]

Brachytoma (G) [strombiforue] Conopleura (D) [coniforme]

Crassispira [costules interrompues]

Cymalosyminx [costules ininterrompues

\section{BELA}

[canal court, sinus presque nul]

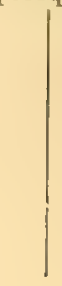

Bela

Galliotectum (E)

Bela [forme turriculée, cítes arquées]

Buchoria forme ovale cûtes druites.

Hedropleura [labre bordé]

Daphnobela [canal large, Ironqué]
Typhlomangilia (F)

Belomitra (G) 
ROUAULTIA

[sinus sur la carène] BORSONIA

[sinus voisin de la Borsonid [un pli saillant, canal long] suture]

\section{BATHYTOMA}

Cordieria [deux plis ou plus, canal court]

Mitromorpha [deux plis, labre denticulé]

[columelle subplissée, Bathytoma [embryon conoïde, columelle subplissée] sinus écarté de la suture]

Epalxis [embryon proboscidiforme, columelle ả peine tordue]

\section{ASTHENOTOMA}

[columelle plissée, ca-Asthenotoma

nal court]

[un seul pli]

$\left.\right|_{\text {Aphanitona }}$

[deux plis, sinus presque nul]

Scobinella

[rides columellaires,

canal très court]

Trypanotoma

[columelle non plis- Trypanotoma [forme dextre] sée, sinus peupro- Sinistrella [forme sénestre] [ond]

\section{Asthenotoma [sinus large]}

Endiatoma [sinus presque nul]

\section{TEREBRITOMA}

[sinus sutural canal très court

PHOLIDOTOMA

\section{BEISSELIA}

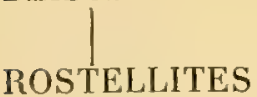

\section{ROSTELLITES}

\section{GOSAVIA}

MANGILIA

[labre épais]

$$
\mid
$$

[columelle à peu près lisse, canal étroit et droit]

[columelle lisse, forme courte, canal large et recourbé]

[columelle tordue, canal large et long]

[columelle fortement plissée, forme conique, canal court]

\section{Mangilia}

[labre et columelle Mangitia [sinus bien entaillé] lisses]

\section{Eucituara}

[labre et columelle Eucithara [canal court] plissés] Githaropsis (H) jcanal un peu long]

\section{Clathunella}

[labre plissé, colu- Clathurella [canal court] melle ridée, dent Glyphosloma [canal un peu long] pariétale]
Mangiliella [sinus à peine indiqué] 


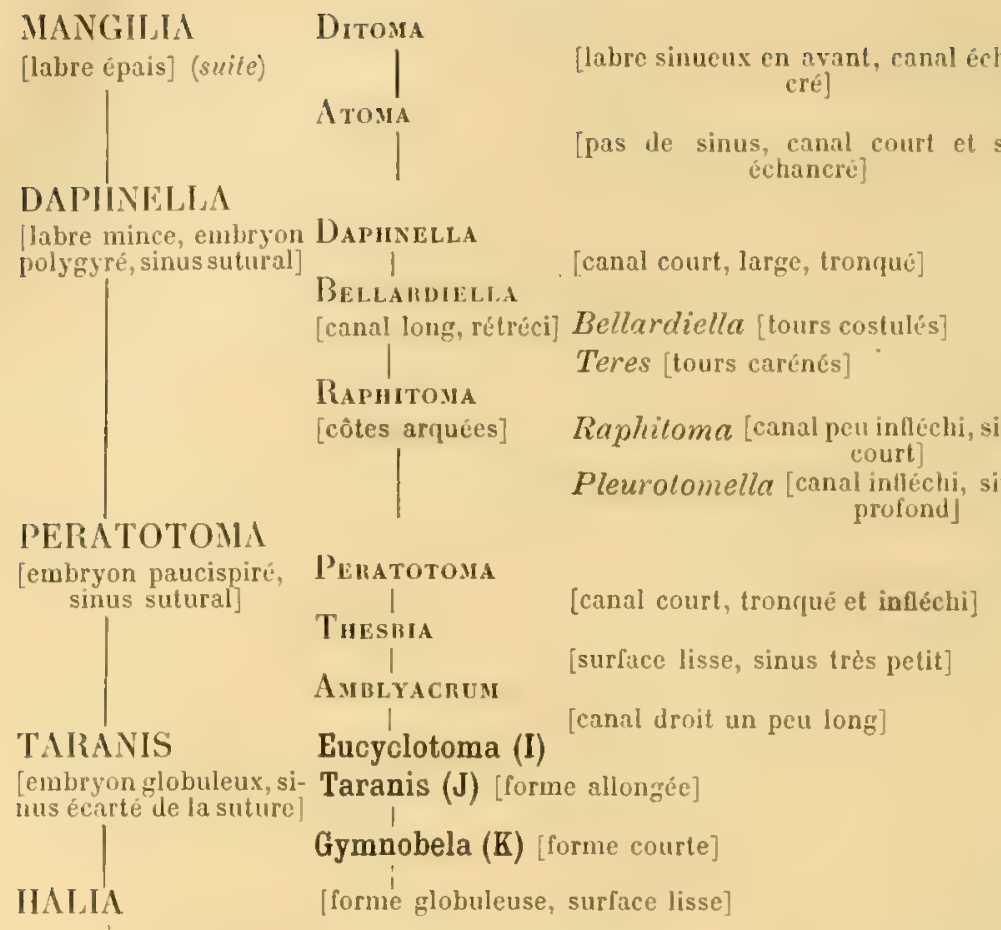

Zafra (L), Aforia (M), Eubela (N) - Incerta sedis.

\section{Genres et sous-grenres non signalés à l'état fossile.}

(A). Clionella, Gray, 18\%̄. - Type : Buccinum sinuatum, Born. (Pl. buccinoires, Lamk). Canal extrêmement courl, profondément échancré; ornementation de Drillia, opercule de Clavalula. Ce sous-genre n'est pas thuviatile, comme on l'arait d'abord supposé; Tryon en cite et en figur. sept espèces, localisées sur les côtes de l'A frique méridionale.

(B). Gemula, Weinkauff, 1876. - Type: P. gemmala, Hinds. Daprès le Manuel de Tryon, celte section ne se distinguerait de Pleurotoma s.s. que par sa carène perlée ou nodulense, et par son embryon dont les deux premiers tours sont lisses, landis que les autres sont costulés dans le sens axial; Tryon en cite et en figure une demi-douzaine d'especes dans les mers de Chine et de P'olynésie.

(G). Brachytoma, Swainson, 1840 (non Brachystoma sec. Tryon). Type: $P l$. strombiformis, Sow. Canal allongé et présentant un sinus antérieur, comme dans les Strombus; l'échancrure du labre est obliquement et profondément entaillée sous une varice à contour finement pecliné, dont est muni le labre à sa partie inférieure; la spire est à peu près 
égale au dernier tour. II n'y a pas lieu de classer dans celte section toutes les espèces qu'y indique Tryon, mais seulement celles qui ont l'aspect strombiforme.

(D).Coxorleura, Hinds, 1844. - Une seule espèce, type de la section: C. striata, Hinds. C'est une Drillia, à spire courte et coniforme, à ourerture très étroite et sinueuse, à canal relativement long el infléchi, à columelle calleuse et à sinus profond.

(E). Callotectum, Dall, 1889. - Type: C.vernicosum, Dall. Coquille ayant la forme d'une Bela: l'animal est aveugle, n'a ni dent, ni glande venimeuse; l'opercule a un nucléus apical, il est épais et étroitement courbé.

(F). Typhlonangilia, Sars, 1878. - Type: T. nivalis, Lovén. L'animal est aveugle et ressemble à celui de Bela; mais la coquille présente une réelle ressemblance avec celle de nos Eopleurotoma, toutefois l'embryon est obtus et le sinus voisin de la suture, comme dans le genre Drillia, de sorte qu'il n'y a pas lieu d'attacher une grande importance à cette analogie d'ornementation, d'autant moins que Typhlomangilia est une forme des mers froides, tandis qu'Eopleuroloma habitait des mers tempérées.

(G.) Belonitra, Fischer, 1882. - Se rapproche de Bela par son sommet mamelonné, par son sinus à peine indiqué, par son canal court; mais le bord columellaire porte plusieurs petits plis profonds qui rattachent cette forme à Borsonia.

(H). Crthamopsis, A. Adams, 1865 (non Cilharopsis, Pease, 1868). Type: C. cancellata. A. Ad. Coquille non figurée, qui ne parait se distinguer de Eucilhara que par son canal un peu moins court et par son ornementation treillissée.

(I). Eucyclotona, Bœttg. 1895. - Type: Clathurella bicarinata, Reeve. D'après l'auteur, celte section doit comprendre des espèces à ouverture édentée, dont le sinus entaillé sur la gouttière suturale est tout à fait circulaire et forme des accroissements ponctués.

De mème, Pseudodaphnella, Bottg. 189د (type: Cl. Philippinensis, Reeve) se distinguerait par son canal court, large et échancré.

(J). Taranis, Jeffreys, 1870. - Type: T. Mörchi, Malm. Forme de Peratoloma; tours cancellés; sinus triangulaire, écarté de la suture: l'embryon, que j’ai examiné sur un échantillon de la coll. de l'École des Mines, est tout à fait globuleux, composé d'un tour et demi, à nucléus dévié el infléchi vers l'intérieur. On peut donc, à la rigueur, admettre Taranis comme genre distinct.

(K). Grumobe La, Verrill, 188ə. - Type: G. engonia, Verrill. D'après les figures de l'ouvrage de Dall sur les dragages du Blake, ce genre rappelle Taranis par son ornementation et par la position du sinus à peine indiqué; mais la forme de la coquille est courte et presque globuleuse, le canal est Irès court.

(L). Zafra, A. Adams, 1872. - Type: T. pupoidea, Ad. Coquille décrite dans les Columbellidx, et rapprochée de Thesbia par Tryon et par Fischer: sinus à peu près nul, côtes axiales presque droiles, canal très court et 
échancré, bord columellaire calleux et limité. Le fossile que j'avais rapporté à ce groupe (Catal. Eoc. IV) n'est, en réalité, qu'une Buchozia : il n'a pas le canal échancré.

(M). Aforia, Dall, 1889. - Type: Pl. circinata, Dall. D'après l'auteur, ce groupe ressemble aux Pleurotoma typiques, mais l'animal n'a pas d'opercule; les tours de spire sont carénés et le sinus coïncide avec la carène.

(N). Eubera, Dall, 1889. - Type: Pl. limacina, Dall. Classée d'abord par l'auteur dans le genre Bela; cette coquille a été ensuite ramenée par lui dans les Daphnellex, à titre de section: elle paraît caractérisée par sa spire conique el subulée, munie d'un rang de granulations contre la suture, par son canal court et son sinus peu profond, coincidant avec ces granules.

\section{Genres et sous-genres à éliminer des Pleurotomidæ.}

Columbarium, von Martens, 1881. - Type: C. spinicincta, v. Mart. J'ai constaté, sur des plésiotypes fossiles de l'Australie du Sud, qque les coquilles de ce groupe ont un embryon de Fusus bien caractérisé. F'ischer. place le genre Cohumbarium dans les Pleurolomidx, à cause de l'aflinité de sa radule; mais il ny a pas de sinus labial et les épines de la périphérie ont un aspect muricoïde : on retrouvera ce genre près des Fusus.

Mesocinlotoma, Seeley, 1861. - Type nonfiguré : $M$. striala, Sow de la Craie d'Angleterre. Taille petite; forme régulièrement spirale; spire turriculée, très allongée; tours convexes, déprimés à la sulure; canal court? labre avec un sinus qui forme une rainure arrondie au milien du tour, comme celle de Pleurotomaria. Ces caractères hybrides ne permettent pas, à défaut d'une figure, de se faire une opinion sur le classement de cette coquille : comme d'ailleurs elle ne parait pas avoir été retrouvée, il semble que cette dénomination doit être définitivement abandonnée.

Heteroterma, Gabb, 1869. - Type: H. trochoidea, Gabb, de la Craie supérieure de Californie. C'est une coquille épaisse, à spire très courte el tectiforme, à canal long et droit, à labre un peu sinueux, près de la suture d'après le texte, vis-à-vis de l'angle noduleux du dernier tour d'après la figure; l'échantillon figuré est d'ailleurs incomplet. Dans cette incertitude, il esíplus prudent d'attendre de meilleurs matériaux avant de fixer définitivement le classement de ce genre, en admettant quil ne se confonde pas avec l'une des nombreuses coupes déjà proposées dans la famille Fusidx. 
GLA VATULA, Lamk. 1801.

Spire longue, à embryon obtus; canal assez court, presque droit, subéchancré à son extrémité; sinus écarté de la suture.

Glavatula, sensu stricto. Type: C. muricata, Lamk. Viv. (=Clavicantha, Swains. 1840).

$\mathrm{T}$ est épais ; forme conique ; spire étagée, aiguë; embryon lisse, conoïde, à nucléus obtus et déprimé, tours plans ou un peu excavés, généralement armés d'une rangée inférieure d'épines ou de tubercules pointus, quelquefois ornés d'une rangée supérieure de costules courtes, croisées par des cordonnets spiraux; base du dernier tour un peu excavée, s'atténuant rapidement en un canal relativement court et presque droit, sur le cou duquel s'enroule un bourrelet obsolète qui limite les accroissements de l'échancrure de ce canal.

Ouverture piriforme, assez large en arrière, subitement rétrécie en avant, terminée par une troncature à peine sinueuse ou échancrée, à la base du canal siphonal ; labre rectiligne en avant, fortement arqué au milieu, entaillé par un sinus large et triangulaire, à sommet arrondi et écarté de la suture, au-delà duquel le contour du labre aboutit à peu près perpendiculairement à la suture; bord columellaire lisse, arqué en arrière, rectiligne en avant; dans l'angle inférieur de l'ouverture, une callosité pariétale limite une goultière souvent assez profonde.

\footnotetext{
Diagnose faite d'après des plésiotypes fossiles: $P$ l. spinosa, Grat., de Peloua (Pl. IV, fig. 19), et $\mathrm{Pl}$. romana, Defr., de Toscane (Pl. V, fig. 2), ma coll.
}

Observ. - La pluparl des auteurs citent comme exemple du genre Clavalula : C. imperialis, Lamk. : cependant, en 1801, Lamarck a lui-même désigné $C$. muzieato ; il est vrai que c'est une espèce tellement variable que l'on pourrait à la rigueur y réunir l'autre. Quoi qu'il en soit, si l'on s'en réfère au type officiel du genre $C$. muricala, l'une de ses variétés 


\section{Clavatula}

C. bimarginata, Lamk.) est absolument voisine des formes tertiaires que Bellardi a rapportées au genre Clavalula : la diagnose ci-dessus, qui est faite d'après le plésiotype fossile, s'applique, presque sans y changer un mot, à $C$. bimarginata ; il n'y a donc aucun doute sur cette assimilation, d'autant moins que l'ornementation elle-même, qui est très variable che\% C. muricala, s'y présente avec toutes les formes qu'on constate dans les différents groupes de Clavalula tertiaires, épines, granulations, costules tuberculeuses, etc... groupes que Hornes et Auinger ont classés au nombr de six, mais qui ne paraissent pas mériter le nom de sectionś, attendu qu'il y a de fréquents passages de l'un à l'autre.

La dénomination Clavicantha a été proposée en 1840 par Swainsor pour Pleurot. imperialis Lamk, avec celle diagnose "Coquille épaisse, subfusiforme, surface rugueuse, tours subcouronnés, canal court, labre pourvu d'un sinus court et large " ; plusieurs auteurs ont appliqué cette diagnose et le nom Clavicaulha à des furmes qui sont du genre Drillia et qui n'ont aucun rapport avec $P$. imperialis. In réalité, Clavicantha doit être pris comme synonyme de Clavatula, attendu que le type ne se distingue guère, au point de vue spécifique, de $C$. muricata.

Rapp. et diff. - Il y a de réelles affinités entre Clavahula et Pusionella, ci-dessus décrite dans la fumille Terebrilla, non seulement par la forme générule, mais par l'opercule et par l'embryon; cependant l'absence com. plète de sinus chez Pusionella, l'échancrure à peine indiquée à l'extrémité du canal de Clavalula, justifient la séparation de ces deux genres et leur classement dans deux familles différentes. L'opinion de lischer, qui consilère Pusionella comme une forme intermédiaire entre les familles Terebridie et Pleurolomidx, parait done bien fondée: c'est par l'intermédiaire de Clavatula que s'effectue cet enchainement naturel.

Répart. Stratigr.

Mrocene....... Nombreuses espèces dans les faluns du Bordelais af de la molasse de la Provence et de la Corse, en Italic, dans le bassin de Vienne, etc. ( $\mathrm{Cl}$. asperulala, Lamk, calcarala, Grat., heros el gothica, Mayer. Defrancei, Bell., styriaca, Clarx, Hœrn. el Auing., ete.), ma coll. et d'après les Monographies de Bellardi et de Ilornes et Auinger, d'apres Depéret ol Lociarl.

Plocker...... Quelques espèces dans le bassin du Rhône, dans les

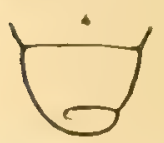

Fig. 4 .

Époque actuelle. Alpes-Maritimes et en Italie (Cl.Depereti, Font., ruslica, Br., inflexa, Bell., rumana, Defr., intervupta, Br., geniculala Bell.), ma coll. et d'après la Monogr. de Bellardi. Embryon d'un individu du Messinien d'Orciano (Fig. 4), ma coll.

Outre le type et ses variétés, ciny ou six especers sur les côtes de l'Afrique occidentale. 
Clavatula

Trachelochetus, Cossm. 1889. Type: Pleur. desmia, Edw. Eoc.

Forme conique; spire longue; embryon obtus et mamillé ; tours ornés de bourrelets granuleux, profondément excavés audessus du bourrelet sutural; dernier tour atténué à la base, terminé par un canal presque droit, peu allongé, qui a le cou gonflé. Ouverture piriforme ; labre plissé à l'intérieur, entaillé sur la rampe excavée, par une échancrure largement arrondie en demicercle, aboutissant normalement à la suture; bord columellaire mince, peu étalé et déprimé en arrière, légèrement gonflé au milieu, obliquement infléchi vers l'embouchure du canal.

\section{Diagnose refaite d’après un échantillon typique de Barton}

(Pl. IV, fig. 17-18), ma coll.

Rapp. et diff. - Quand j'ai décril cette section (Catal. Eoc. IV, p. 20̈4), j’ai signalé les différences qu'elle présente avec les véritables Pleuroloma; mais j'ai omis d'indiquer ses rapports avec Clavatula, à laquelle elle ressemble tellement qu on ne peut la distinguer comme genre: c'est tout an plus une section, caractérisée par son ornementation non épineuse, par son cou gonflé et par son labre intérieurement plissé. Ce rapprochement q un réel intérêt, parce qu'il prouve que Clavatula commence à apparaître plus tôt qu'on ne le pensait jusqu'à présent, dès la fin de la période éocénique, où sa présence n'avait pas encore été signalée.

Répart. Stratigr.

Eocexe....... L'espèce type dans les couches bartoniennes du bassin anglo-parisien, ma coll.

Oligocene..... Une espèce voisine du type, dans le Tongrien de l'Allemagne du Nord ( $\mathrm{Pl}$. humilis, Beyr.), d'après la Monographie de M. von Kœenen.

Mrocene....... Une espèce douteuse dans le Langhien d'Italie ( $\mathrm{Cl}$. apenninica, Bell.), d'après la Mlonographie de Bellardi, qui n'indique pas les caractères de l'ouverture el n'a figuré que la vue dorsale de la coquille; autre espèce probable dans le Langhien el l'Aquitanien de Saucats, près Bordeaux ( $P$. evolula, Mayer), d'après la figure du Journal de Conchyliologie, 1891. 


\section{Clavatula}

Perrona, Schum. 1817. Type: P.tritonium, Schum. Viv. (=Tomella, Swains. 1840; =? Cochlespira, Conr. 1865, fide Greg.).

Forme variable, tantôt irrégulière et trapue, tantôt conique et subulée; spire élagcé, lisse, aiguë au sommel; embryon oblus et dévié ; tours plans, dénués d'épines, en gradins, parfois carénés au-dessus de la suture; base et ouverture de Clacalulu, arec un canal généralement allongé et infléchi en avant; sinus labial assez large, plutôt arrondi que triangulaire.

Diagnose faite d'après un plésiotype fossile, (Cl. Jouannati, Desm. var., descendens, Hilber, du Tortonien de Lapugy (Pl. V, fig. 1). ma coll. ; et d'après un autre plésiotype subulé, $C l$. semimarginala, Lamk. de l'élage Langhien de Saucats (Pl. V, fig. 13), ma coll.

Observ. - Daprès M. de Gregorio (Mlab., p. 37), le genre Cochlespira, Conr., qui a pour type Pleur. engonata, ne diffère pas de $P$. spirala, et par conséquent fait double emploi avec la section Perrona: je n'ai pas les matériaux nécessaires pour contrôler cette assertion, la reproduction de

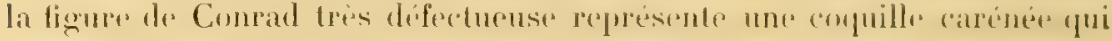
a plutôt l'aspect d'une Rouaultia (voir ce genre).

Rapp. et diff. - II n'y a que de faibles différences entre Perrona et Clavatula: l'embryon est un peu plus dévié, le canal est plus long, plus coudé, et la spire est généralement lisse, quoique la carẻne de certains individus ait quelquefois la trace de tubercules obsolètes, qui seraient comme le premier indice des épines des véritables Clavatula. Cependant, si l'on compare à Clav. imperialis Tomella lineala, Lamk,; que Tryon prunit a Perrona, on trouve qu'il y a de grandes differences, de sorte que 'ce n’est qu'en passant par toute la série des formes intermédiaires qu'on r'aconnait que Perrona n'est tout au plus qu'une section de Clavalula. Dans les formes fossiles, l'écart est beaucoup moindre que chez les types ('xtrêmes que je viens de citer: $\mathrm{Cl}$. Jouanneti, qui est l'analogue de Perrona obesa, Reeve, est extrêmement voisin de certaines variétés de C\%.gothica, Mayer, espèce qui se relie d'autre part à $\mathrm{Cl}$. asperulata, l.amk. Je n’ai d’ailleurs pas constaté l'existence de Perrona fossiles ayant li constriction caractéristique de la spire ni la callosité pariétale de Tomella lineata, qui est une forme exceptionnelle, que Fischer a indiquée comme distincte de Perrona : il en résulte que je n'ai pas à discuter celle question au point de vue paléontologique. 
Répart. Stratigr.

Eocene ...... Deux espèces de Cochlespira aux États-Unis ( $P$. engonala et hella, Conr.), d'après M. de Gregorio; mais, airsi que je l'ai indiqué ci-clessus, je crois que ces coquilles ont plus d'alfinités avec le genre Rouaultia qu'avec Periona.

Mroceve ....... Plusieurs espèces typiques dans les faluns du Bordelais, dans la molasse de la Provence, en Italie et dans le bassin de Vienne (C. Jouanneti, Desm. carinifera, Grat.semimarginata, Lamk. spirala, Math. vindobonensis, Partsch), ma coll. et d'après $\mathbf{M}$. Depéret.

Epoque actuelle. Environ six espèces sur les côtes de l'Afrique occidentale, du Cap et de l'Australie, d'après le Manuel de Tryon.

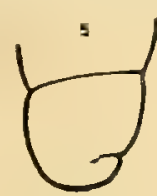

Fig. :5.

Embryon de Tomella lineata (Fig. 5), ma coll.

SURGULA, H. et A. Adams, 1855.

(=Turricula, Schum. 1817, non Klein 1753, nec Hermann 1783).

Canal long; échancrure sur la rampe contiguë à la suture; opercule de Clavatula.

Surcula, sensu stricto.

Type: Pl. Javana, Lin (= nodifera, Lamk), Viv. (三Pleurofusia, de Greg. 1890 ; = Surculites, Conr. 1865).

Forme allongée, fusoïde ou biconique; spire turriculée; embryon lisse, conoïde, à nucléus pointu; tours convexes en avant, excavés en arrière, souvent costulés sur la partie convexe, parfois anguleux ou subcarénés au-dessus de la rampe postérieure; sutures bordées d'un bourrelet toujours lisse. Ouverture piriforme, terminée par un canal tantôt un peu infléchi en avant et dilaté à son extrémité, tantôt presque droit et également étroit dans toute sa longueur ; labre mince, lisse à l'intérieur, arqué au milieu, entaillé par une échancrure prolonde, qui est situéesur la rampe excavée, à peu de distance de la suture; bord columel- 
laire mince en général, rarement calleux, toujour's étroit, terminé en pointe effilée contre l'embouchure du canal.

Diagnose refaite d'après le type vivant, et d'après un plésiotype fossile de l'Eocène de Villiers, dans les environs de Paris, Pleur. Iransversaria, Lamk. (P). V, fig. 3-4), ma coll.

Observ. - On pourrait, à la rigueur, distinguer deux sections parmi les Surcula, l'une représentée par le type vivant, ayant le canal intlechi en avant, avec un bourrelet obsolète sur le cou et des tours nodulenx; l'autre ayant pour type $S$. australis, Roissy, avec le canal presque rectiligne, sans bourrelet, la spire simplement ornée de filets spiraux; cest à colte dernière forme que siappliquerait la dénominalion Turricula, Schum. (Type: T. flammea, Sch.), si elle ne tombait pas en synonymie. Mais, même dans les espèces vivantes, il $y$ a de nombreux passages d'une forme à l'autre, et celte transition graduelle est encore plus visible chez les espèces fossiles, dont le canal est quelquelois infléchi $(P l$. intermerlia, Bronn), ou bien parfaitement droit (Pl. Lamarcki, Bell.), dont la spire commence avec des côtes et dont le dernier tour est lisse (S. consobrina, Bell.). C'est pour cette raison que j'ai éliminé ou rejeté dans la synonymir de Surcula, au lieu de les admettre comme sections, Pleurofusia, de Greg. et Surculites, Conrad: le premier de ces genres a pour type Pl. longirostropsis, de Greg. et pour plésiotypes $P l$. Lamarcki et anomala qui sont des Surcula à canal droit, ornées de côles; lautre genre Surculiles, proposé par Conrad dans Amer. Journ. Conch. I, p. 219, comme sous-genre de Surcula, ne diffère S. iransversaria que par l'angle subcaréné qui sépare la convexité antérieure, sur chaque lour, de la rampe inférieure el excavée: le type $S$. annosus Conr. ost d'ailleurs dans un élat de conservation assez délectueux.

Rapp. et diff. - Ce genre se distingue de Clavalula par la position de l'échancrure, par la forme de la base el par la longuenr du canal; mais li forme de son opercule le place dans la même sous-lánille.

Répart. Stratigr. Sexovien.........

Plusieurs espèces dans la Craie superieure du Missouri (Turris minor, Evans el Schum. contortus et Hilzi, Meek), d'après la Monographie de Meek el Hayden; quatre espèces dans la Craic de Californic (S. preallenuala, sinuala et inconspicua, Gabb Turris claylonensis, Gabb (d'après la Monograplie de Gabb et Whitney; autre espece douteuse dans les marnes vertes de New-Jersey (S. strigosa, Gabb), l'après la Monographie de Whitfield; une espece douleuse dans la Craie du Brésil (Pleur. Harpya, White), d'apres la Monographie de White. 
Paleocerr..... Une espèce dans les sables de Bracheux, $P l$, antiqua Desh), ma coll. ; autre espèce à Copenhague (Pl. Johnstrupi, v. Kœnen), d'après les figures données par l'auteur.

Eocene....... Nombreuses "espèces dans le bassin anglo-parisien (Pl. transversaria. Lamk. subelegans, d'Orb. teretrium, Edw. rostrata, Sol. Vaudini, Desh. dentala, Lamk. inarata, Sow. etc.), ma coll.; plusieurs espèces dans le Claibornien des Etats-Unis $(P l$. Tuomeyi, Aldr'. Surc.altenuala, Conr. P. longirostropsis, de Greg.), d'après les figures données par Aldrich el par M. de Gregorio.

Oligocene ..... Plusieurs espèces aux environs de Paris, en Belgique et en Allemagne ( $P$. belgica, Goldf. Selysi et regularis, de Kon. Zimmermanni, Phil. perdita, Semp. Beyrichi; Phil. rostralina, v. Konen), ma coll. et d'après la Monographie de M. von Kœnen; autre espèce typique dans le Vicksburgien de Red Bluff, Mississipi

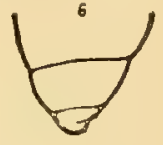

FIG. 6. (Pl. longiformis, Aldr.), ma coll.

Embryon de S. belgica (Fig. 6), ma coll.

Mrocene....... Nombreuses espèces dans le Bordelais, en Italie, en Autriche (S. strialulata, Lamk. perlonga, Bell. Sismondx, Bell. et Mich. diademata, Bell. Laurx, et Ottilix, Hœrn. et Auing.), ma coll. et d'après les Monographies de Bellardi et de Hornes et Auinger.

Pliocene....... Nombreuses espèces dans le bassin du Rhône, dans les Alpes-Maritimes, en Italie ( $S$. mimula, Font. dimidiala, Br. intermedia, Bronn. Coquandi, Bell. recicosla, Bell. ete.) ma coll. et d'après les Monographies de Fontannes et de Bellardi; plusieurs espèces dans les couches récentes de Java $(P l$. Smithi, Dijki etgembacana, Mart.), d'après les études de Martin sur les terrains tertiaires de Java.

Epoque actuelle, Une vingtaine d'espèce dans les mers tropicales, d'après le Manuel de Tryon.

Arcistrosyrinx, Dall. 1881. Type : A. elegans, Dall. Viv. (= Candelabrum, Dall. 1878, non Blainv. 1830).

Forme étroile, en tarière; spire étagée, à galbe conique; embryon petit, paucispiré, à nucléus granuleux ; tours en gradins, 
Sureula

munis en arripe d'une carine pertinée ou denticulée, sous lapuelie est une gouttière excavée, séparée de la suture par une autre carène ou par un bourrelet perlé; ornementalion composée de filets spiraux finement granulenx. Ouverture triangulaire et squalène en arrière, termince en avant par un canal très long, lout à fait droit, un peu rétréci au milieu, plus dilaté à son extrémité antérieure; labre obtusément plissé à l'intérieur, peu arqué au milieu, profondément enlaillé en demi-cercle sur la goullière posléricure, entre la crête et la carène suturale, puis antécurrent tangentiellement à la suture; bord columellaire mince et étroit.

Diagnose refaite d'après un plésiotype fossile du calcaire grossier de Parnes, Pl. terebralis, Lamk. (PI. V, fig. 5-(i), coll. Pezant; vue de l'embryon d'un individu de Cuise (Fig. 7), ma coll.

Rapp. et diff. - Celle section se distingue des Surcula typiques, non seulement à cause de la crête pectinée qui orne ses tours de spire, mais encore à cause de son embryon un peu différent, moins conoïde et plus petit, enfin parce que le labre des individus adultes est intérieurement plissé. M. Dall a fait remarquer l'analogie exterieure de cette nouvelle coupe el du genre Columbarium, von Martens, que beaucoup d'auteurs placent à tort dans la famille Pleurolomidx: ainsi que je l'ai indiqué ci-dessus, outre que Columbarium n'a pas de sinus véritablement échaneré, son em-

bryon bulbiforme el très gros le rapproche de Fasciolariidx.

Répart. Stratigr.

Paleocene..... Une espèce douteuse dans les couches de Copenhague: (Pl. aff. Volgeri, Phil.), d'après la figure donnée par M. von Konen; un fragment très douteux dans le calcaire de Mons'Pl. ampla, Br. et Corı.), d'apres la Monographie de Briart et Cornet.

Eocere....... Le plésiolype ci-dessus désigné, dans le bassin de Paris, aux niveaux des subles de Cuise et du calcaire grossier, ma coll, ; et dans le Londinien d'Anglelerre, d'après Edwards. Autre espece dans le Claibornien de Jackson, Mississipi ( 1. columbaria, Mldr.), d'après la tigure donnce par l'auteur, el d'après la détermination de M. Dall. 
Surcula

Oligocene ...... Une espèce à peu près certaine dans le Tongrien de l'Allemagne du Nord ( $P l$. perspirala, von Køn.), d'après la Monographie de M. von Kœnen; autre espèce dans le Vicksburgien du Mississipi $(P l$. cristata, Conr.), ma coll.

Mrocene ....... Une espèce trapue dans l'Allemagne du Nord ( $P$ l. circumfossa, von Kœn.), d'après les figures de l'auteur; autre espèce dans les couches tortoniennes d'Ostrau-Karwin (Pl.serrata, M. Horn.), d'après la figure donnée par M. Kittl.

Pliocene... .... Une espèce dans le Mlessinien d'Edeghem, près Anvers $(P l$. Corneti, v. Kon. = sublerebralis, Nyst var. $)$, d'après les figures de l'ouvrage de $\mathbf{M}$. von Konen sur le Miocène de l'Allemagne du Nord.

Epoque actuelle. Deux espèces dans le golfe du Mexique $(A$. elegans el radiata, Dall), d'après les figures données par l'auteur et la communication qu'il m'a faite d'un échantillon de la seconde espèce.

Apiotoma, Cossm. 1889. Type : Pleurot.pirulata, Desh. Eoc.

$=$ Strombina, de Greg. 1890, ex parte, non Bronn. 1849, nec Mörch. 1859

Forme étroite, piroïde ; spire courte et étagée, à galbe ovoüdoconique; embryon conoïdal, à bouton mamillé; tours carénés ou anguleux, avec une rampe suturale, principalement ornés de filets spiraux; dernier tour ovale, élancé, à base à peine atténuée, se terminant par un canal extrêmement long, presque entièrement droit ou à peine infléchi vers son extrémité antérieure. Ouverture très étroite, subpiriforme; labre mince, peu arqué, entaillé par un sinus tout à fait contigu à la suture; bord columellaire mince, peu distinct.

Diagnose refaite d'après un individu élancé de l'espèce type, provenant de Cuise (Pl. V, fig., 7-8), ma coll.

Observ. - Le sous-genre Strombina, de Greg., dans lequel cet auteur place $P l$. stromboides, Lamk. Pl. cymxa, Edw. nupera et gemmata, Conr., se compose soit de véritables Surcula, soil d'Eopleurotoma comme on le 
verra plus loin, soil d'Apioloma comme j'ai pu le vérifier sur des échantillons de Claiborne: dans ces conditions, ce sous-genre tombe nécessairement en synonymie avec des dénominations antérieures, et il doit par conséquent être rayé de la nomenclature. D'ailleurs il n'aurait pu être admis, le nom Strombina ayant déjà été précédemment employé par Bronn, puis par Mörch.

Rapp. et diff. - Je conserve cetle section de Surcula, non seulement parce que la forme piroïle de la coquille est tout à fail caractéristique, mais encore parce que l'embryon, au lieu d'avoir un nucléus régulièrement. pointu, se termine par un bouton mamillé qui lui donne un aspect un peu diflérent; enfin l'échancrure du labre est moins profonde el placée encore plus près de la suture, avec laquelle le labre se raccorde obliquement, sur un bourrelet tout à fait contign.

Répart. Stratigr. Eocene.........

Lespéce type, avee plusieurs variétés, dans le Suessonien et le calcaire grossier des environs de Paris, ma coll. ; et à Clarendon Ilill, d'après Edwards, aver: I'. cymzea. Autre espèce dans le Claibornicn dw l'Alibama ( $P$. gemmala, Conr.), ma coll. : quant it $P$. nupera, Conr., ce n'est probablement qu'un individu de gemmala, dont le canal mutilé parait plus colrt.

Glinura, Bell. 1875.

Type: C. Calliope, Bell. Mioc.

Forme conique, assez ventrue; spire courte, imbriquée; tours fortement carénés en avant, largement excavés en arrière, finement ornés au-dessous de la carène qui est dentelée; dernier tour très grand, à base excavée, terminé en avant par un canal médiocrement allongé, assez étroit, obliquement infléchi à droite de l'axe. Oaverture subtriangulaire, rétrécie du côté antéricur; labre peu arqué, formant une saillie proéminente vis-à-vis de la carène, entaillé sur la rampe postérieure par un sinus largement arrondi en quart de cercle incomplètement lermé, et aboutissant presque perpendiculairement à la suture; columelle un peu sinueuse, faisant en arrière un angle arrondi avec la base de l'avant-dernier tour; bord columellaire mince et peu calleux, lisse. 
Surcula

Diagnose faite d'après un échantillon typique du Messinien de Sienne

(Pl. V, fig. 19), ma coll.

Rapp. et diff. - Quand Bellardi a créé ce sous-genre, il l'a placé dans la sous-famille Pseudotominæ; l'opinion de Fischer, qui le rapproche au contraire de Surcula, me parait mieux fondée, attendu que Clinura a un canal plus allongé et une entaille mieux échancrée que Pseudotoma. Cependant cette entaille n'a pas la profondeur de celle d'Ancistrosyrinx, qui y ressemble par sa crête dentelée, mais qui s'en écarte par son canal long et droit. En résumé, la forme toute particulière de cette coquille justifie la séparation d'un sous-genre distinct de Surcuía s.s.

Répart. Stratigr.

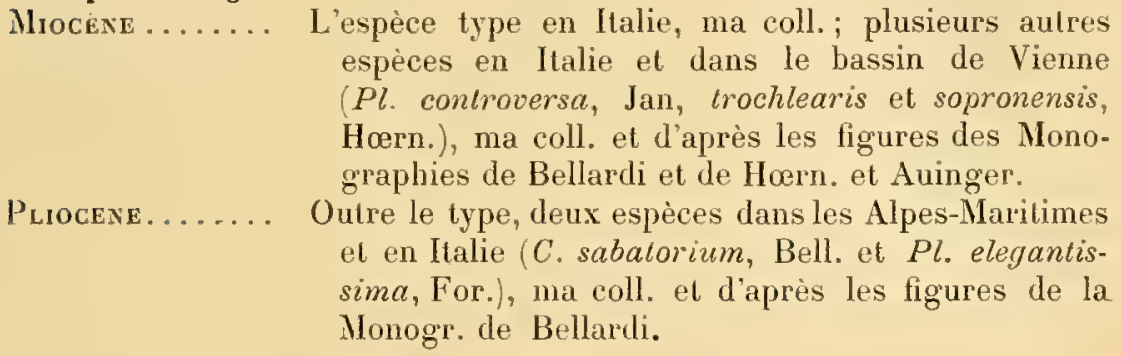

PLEUROTOMA, Lamk. 1798.

(= Turris, Bolten 1798, non Humphrey 1797 ;

$=-$ Leucosyrinx, Dall 1889).

Sinus sur la carène, écarté de la suture inférieure ; bord columellaire non calleux.

Pleurotom, sens. str. Type: Murex babylonius, L. Viv.

Forme turriculée, fusoïde; spire longue, aiguë; embryon conoìde, à nucléus obtus; tours anguleux, généralement crénelés sur l'angle, ou cerclés par des cordonnets spiraux. Ouverture piriforme, terminée par un canal long, ouvert, tantôt presque droit, tantôt présentant une double inflexion, non échancré à son extrémité antérieure qui est à peu près dans l'axe de la coquille ; labre mince, très arqué au milieu, muni en arrière d'une entaille 
Pleurotomi

étroite, profonde, éloignée de la suture et coincidant avec la rangée de crénelures ou de plis qui marquent les arrêts de l'accrois. sement du sinus; à partir de ce sinus, le contour du labre est obliquement antécurrent vers la suture; bord columellaire lisse, assèz large et velnissé en arrière, aminci vers l'extrémité du canal.

Diagnose faite d'après un plésiotype de l'Astien de Cannes, $P$. rotala, Br. (PI. V, fig. 14-10̃) el du Plaisancien de Biot (lig. 16; pour l'enlaille, autre espèce du Plaisancien de Biot, $P l$. turricula, Br. (Pl. V, fig. 11-12), ma coll.

Observ. - Lorsque Bolten a proposé, avant la création du genre Pleuroloma, par Lamarck, la dénomination Turris, pour Murex babylonius, ce nom avait déjà été employé par Humphrey pour un groupe de Turrilella; il est vrai que, déjà en 1705 , Rhumphius a désigné M. babylonius, sous le nom de Turris babylonica; mais celte dénomination, qui n'a été appuyce par aucune règle de nomenclature binominale, est rejetée par la plupart des auteurs qui conservent Pleuroloma.

Dans sa magistrale ctude sur les Pleurolomidx, Bellardi a exposé les difficultés qu'on rencontre, lorsqu'on cherche à établir une classification naturelle des Pleurotoma proprement dits, c'est-à-dire des coquilles qui ont le sinus situé sux la caréne médiane, et le canal plus ou moins long: il est à peu près impossible de trouver des caractères tranchés qui aient assez de constance pour motiver la séparation de sous-genres ou de seclions. Cependant, en ce yui concerne particulièrement la longueur du canal, il y a une réelle incompatibilité dans le rapprochement à faire entre les formes vivantes dérivant de type, telles que $P$. grandis, Gray, variegata, Kiener, dont le canal allongé est à peu près droit, ou $P$. tigrina Lamk., dont le canal est encore très long, mais doublement intléchi, et $P$. cingulifera, Lamk, par exemple, dont le canal coupé presque à sa naissance rappellerait complètement les Drillia, si la position du sinus ne démontrait pas quil s'agit bien d'un Pleuroloma.

Aussi les auteurs (qui, soit en conchyliologie vivante (Tryon), soit en Paléontologie (Bellardi), ont étudié de longues séries de Pleurotoma, ontils presque toujours divisé leur énumération des espècès en deux groupes au moins: espèces à canal allongé - c'est la forme typique, - el espèces à canal court, pour lesquelles aucun nom n'avait été proposé jusqu'en 1889 , à l'époque où j'ai élab)li trois nouvelles sections (IIemipleurotoma, Eopleurotoma et Oxyacrum), pour des formes ćocéniques qui ne se raltachent pas exactement autype.

Dans ces conditions, la dénomination Pleurotoma serait restreinte aux formes à canal long, plus ou moins droit, dont l'entaille latérale est placée 
Pleurotoma

sur une bande saillante, située environ vers la moitié de la hauteur de chaque tour, quelquefois plus en avant encore, et souvent ornée de crénelures qui marquent les arrêts de l'accroissement du sinus, tandis que le reste de la surface est simplement orné de cordonnets plus ou moins serrés, plus ou moins saillants.

Rapp. et diff. - Outre la différence de l'opercule, caractère dont les paléontologistes ne peuvent faire usage, Pleurotoma se distingue de Surcula par la position de l'échancrure qui n'est jamais placée entre la carène et la suture, mais qui coïncide toujours avec cette carène; en outre, le nucléus embryonnaire est moins pointu, et ressemblerait plutôt à celui de Clavatula: toutefois ce dernier genre se distingue par sa large échancrure, par sa base excavée. J'ai cité dans la synonymie le sous-genre Leucosyrinx, Dall, qui ne paraît se distinguer du type que par son canal un peu moins long par son test mince et blanchâtre, par son sinus peu profond.

Répart. Stratigr.

Eocene....... Pas de forme européenne connue, mais une espèce aberrante, dans l'Australie du Sud, à embryon paucispiré dont le nucléus est obtus et dévié, ayant le canal court et large, un peu infléchi, les tours cerclés de cordonnets, ete... ( $P$. perarata, Tate), ma coll.

Oligocexe...... Une espèce certaine aux environs de Paris, en Belgique, dans le bassin de Nayence et dans la Haute Italie (Pl.Sandbergeri, Desh.), ma coll.; plusieurs espèces dans le Tongrien inférieur de l'Allemagne du Nord ( $P$. plana, Gieb. explanata, v. Kœn.), d'après la Monogr. de M. von Konen.

Mrocene...... Nombreuses espèces en Italie, dans le bassin de Vienne, dans les faluns de Bordeaux et la molasse de Provence $(P$. rolala, Br.trifasciata, Horn. Carolinx, Hoern. et Auing. spiralis, M. de Serres, cuneata, Dod. vermicularis, Grat. coronala, Munst. etc.), ma coll. et d'après la Monogr. de Bellardi.

Pliocene....... Plusieurs espèces en Italie el dans le Crag. ( $P$. monilis, $\mathrm{Br}$. turricula, $\mathrm{Br}$. non Montg., rotata, $\mathrm{Br}$, lurrifera, Nyst), ma coll. el d'après les Monographies de Bellardi et Wood; plusieurs espèces dans le Tertiaire supérieur de Java $(P$. Woodroardi, gendiganensis et grissensis, Mart.), d'après la Monogr. de Martin. Embryon de $P$. rolata, de Biot. (Fig. 8), ma coll. 
Epoque actuele. Une vinglaine d'espèces dans les mers chaudes, d'après le Manuel de Tryon.

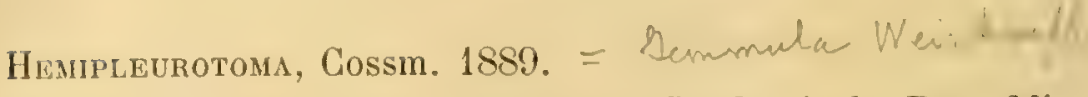

Néotype : $P l$. denticula, Bast. Mioc. (= Coronia, de Greg. 1890, ex parte).

Forme turriculée, clavatulée; spire longue, à galbe conique ; embryon de Pleurotoma; tours généralement crénelés, excavés en arrière, et munis contre la suture d'un bourrelet ou d'une carène lisse; dernier tour à base sinueuse, terminé par un canal peu allongé, presque droit. Ouverture piriforme, subitement rétrécic à la naissance du canal ; labre très arqué avec un sinus presque reclangulaire, vis-à-vis la rangée de crénelures, généralement au-dessous du milieu de la hauteur des tours; bord columellaire mince et peu calleux.

Diagnose refaite d'après le nouveau néotype, échantillon du Langhien de Léognan (Pl. V, fig. 9-10), ma coll. Autre espèce plésiotype Pl. Giebeli, Bell. du Tortonien de Salles (Pl. V, fig. 20-21), macoll.

Observ. - En 1889, j'ai choisi comme type de celle section P. Archimedis, Bell., c'est-à-dire la première des espèces décrite par Bellardi dans la seconde section de ses Pleurotomes; malheureusement c'est une espèce rare, dont le type figuré a le canal très mutilé et qui ne peut servirutilement à résumer les caractères essentiels de notre groupe. C'est pourquoi je n'hésite pas à suppléer à cette indication par celle d'un néotype, appar. tenant évidemment à la même section, mais plus répandu et d'ailleurs plus ancien au point de vue stratigraphique.

La dénomination Hemipleuroloma, qui indique bien qu'il s'agit de demi. Pleurotomes, est antérieure d'une année à Coronia, de Greg. et peut être considérée comme absolument synonyme, attendu que notre confrère sicilien a pris comme type de son sous-genre Pl. aculirostra, Conr. de Claiborne, qui est une espèce très voisine de $P l$ denticula, el qu'en outre il comprend parmi les espèces caractéristiques de son sous-genre Coronia, Pl. Archimedis el denticula, qui sont le type et le néolype de IIemipleurotoma: il est vrai quil y classe également $[$ '. terebralis, qui est un 
Pleurotoma

Ancistrosyrinx, et $P$. rotalu qui est un Pleurotoma typique, mais ce serail une raison de plus pour abandonner la dénomination Coronia.

Rapp. et diff. - Ainsi que je l'ai indiqué à propos de Pleurotoma s. s., il n'est pas aisé de fixer exaclement la limite de cette section: la brièveté du canal, la position de l'échancrure moins écartée de la suture, quoique placée sur une carène saillante êt crénelée, l'existence d'un bourrelet non perlé près de la suture inférieure, sont des caractères un peu fugitifs, de sorte que l'hésitation est permise quand il s'agit de classer dans un groupe ou dans l'autre certaines espèces intermédiaires. Ainsi, par exemple, j'avoue que, pour quelques variétés de $P$. coronata, Munst. et subcoronala, Bell. des échantillons pourraient, à la rigueur, être classés dans les Pleurotoma typiques, et d'autres dans les Hemipleurotoma. Il semblerait en résulter que cette durnière section est arbitraire et qu'il est prélérable de la supprimer radicalement. Néanmoins, comme il est inadmissible de réunir des formes -extrêmes, telles que, parmi les coquilles vivantes, $P$. grandis d'une part et $P$. cingulifera d'autre part, qui sont les deux extrêmes opposés, en ce qui concerne la longueur du canal,je préfère conserver Hemipleurotoma, qui répond à une subdivision déjà pressentie par Bellardi, et sacrifier le classement des espèces douteuses qui établissent graduellement la transition entre cette section et la forme typique.

Répart. Stratigr.

Paleocene...... Une espèce certaine dans les sables de Bracheux (P. Laubrierei, Cossm.), ma coll. ; autre espèce dans le Landénien de Belgique ( $P$. sub-Duchasteli, Vinc.) d'après la figure publiée par l'auteur; une espèce probable dans le calcaire de Mons ( $P$. Pauli, Br. et Corn.), d'après la Monogr. de Briart et Cornet.

Eockne........ Plusieurs espèces dans le bassin anglo-parisien (P. Nilssoni, Desh., Prestucichi, Edw.. melableta, Cossm. cancellata, Wateleti, uniserialis, Desh. plebeia, Sow.), ma coll.; dans le Claibornien des Etats-Unis ( $P$. acutirostra, Conr. Desnoyersi el Beaumoni, Lea, etc.), ma coll.; dans l'Australie du Sud ( $P$. Samueli et murndeliana, T. Woods), ma coll.).

Ourgocene...... Plusieurs espèces dans le bassin de Paris, en Belgique et en Allemagne (P. Parkinsoni, Desh., Duchasteli, Nyst., laticlavia, Beyr., difficilis, Gieb., undatella, Phil., lunulifere et odontophora, V. Kœn, undiclavia, Beyr., loeviuscula, Sow. elc.), ma coll. et d'après la Monogr. de M. von Kœenen.

Mrocene....... Outre le néo-type, nombreuses espèces dans le Bordelais, en Itahe et dans le bassin de Vienne $(P$, Gie- 
Pleurotoma

beli, Galvanii, coronifera, desita et stricta, Bell. contigua, Br., decorala el multistriata, Bell., aquensis, Grat., Annx et Mathildx, Hoern. et Auing.), ma coll. et d'après les Monogr. de Bellardi et de Hornes et Auinger.

Purocene....... Plusieurs espèces dans le Crag. d'Angleterre et de Belgique ( $P$. porrecta, Wood, semicolon, Sow., Icenorum, Wood. Udekemi, Nyst.), ma coll. et d'après la Monogr. de Wood; dans le Tertiaire superieur de Java ( $P$. Sondeiana, adengensis, karangensis, Mart.), d'après la Monogr. des fossiles de Java.

Epoque actuele. Nombreuses espèces dans la mer Rouge, l'Océan indien, les mers du Japon et de la Polynésie. ( $P$. cingulifera, Lamk., emythrsa, Jickeli, violacea, Hinds), d'après le Manuel de Tryon; aux Açores, à une profondeur de 1,5ă7 mètres, dragages du prince de Monaco, coll. Dautzenberg, l'échantillon a son opercule avec nucléus apical.

Eoplecrotom. Cossm. 1889. Type: P. mullirostata 1)esh. Eoc.

(= Strombina, de Greg. 1890, ex parte, non Mörch 1859, nec Bronn 1849).

Forme turriculée; spire allongée, à galbe conique; embryon paucispiré, à nucléus obtus ou papilleux; costules obliquement arquées, subnoduleuses au tiers de la hauteur de chaque tour, interrompues ou atténuées sur une dépression postérieure, reparaissant près de la suture inférieure, le long de laquelle elles forment un bourrelet perlé; dernier tour peu atténué, à base rétulièrement déclive, terminé par un canal court, toujours tordu. Ouverture étroite et piriforme; labre arqué, entaillé par une échancrure peu profonde, peu écartée de la suture, et coïncidant avec les nodosités qui accentuent généralement l'angle des costules arquées; columelle coudée au milieu de sa hauleur, infléchie en avant; bord columellaire étroit et calleux. 
Pleurotoma

Diagnose refaite d'après le type, et d'après un plésiotype de l'Eocène de Villiers, $P l$. curvicosta, Lamk. (PI. VI, fig. 1-2), ma coll. Vue de l'embryon (Fig. 9).

Observ. - Le sous-genre Strombina, que M. de Gregorio a proposé, dans sa Monograplie de l'Alabama, pour $P$. nupera, Conr., est partiellement synonyme de notresection Eopleurotoma, car cette espèce est absolument du même groupe que $P$. curvicssla; il est vrai que l'auteur classe dans le même sous-genre : $P l$. gemmata, Conr. qui est un Apiotoma, $\mathrm{Pl}$. heros et Seguini, Mayer, qui sont des Clavalula absolument caractéristiques, et $P$. cymæa, Edw. qui est une Surcula du même groupe que $S$. dentata, Lamk.; mais c'est un motif de plus pour ne pas conserver une

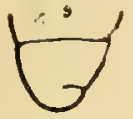

FIG. 9 coupe formée d'une manière aussi hybride; enfin la dénomination s'trombina avait déjà été employée deux fois avant 1890.

Rapp. et diff. - Il est beaucoup plus aisé de séparer Eopleuratoma de Pleurotoma, que Hemipleurotoma; outreque l'ornementation a un faciès particulier, le canal un peu coudé, la columelle calleuse, l'embryon obtus, l'échancrure peu profonde et voisine de la suture, sont des caractères distinctifs dont on ne peut méconnaître l'importance. D'ailleurs, je ne connais pas d'espèce intermédiaire entre Eopleurotoma et Hemipleuratoma, la séparation est bien tranchée et le classement des coquilles dans l'une ou l'autre de ces sections offre d'autant moins de difficultés que les Eopleurotoma paraissent exclusivement cantonnés à la partie inférieure des terrains tertiaires.

Répart. Stratigr.

Paleociane...... Plusieurs espèces probables dans le calcaire de Mons (P. Hannonix, Malaisei et Duponti. Br. et Corn.) d'après la Monogr. de Briart et Cornet; une espèce dans le bassin de Paris ( $P$. infraeocænica, Cossm.), ma coll. ; deux espèces dans les couches de Copenhague ( $P$. Seelandica et Torelli, v. Kœn.), d'après les figures de l'auteur.

Eocene....... Outre le type, nombreuses espèces dans le bassin anglo-parisien et dans le Claibornien des ÉtatsUnis ( $P$. undala, bicalenx, Lamk. Lajonkairei expedita, propinqua, fucluosa, rudiuscula, plicaria, tenuistriala, Desh., oligocolpa, Cossm., nupera, Conr., Honinghausi, Sayi, Lea, depygis, Conr., elc.).

Oligocene...... Une espèce certaine dans les environs d'Étampes ( $P$. Leunisi, Phil.), ma coll.; autre espèce dans le Tongrien inférieur de l'Allemagne du Nord $(P$. edentala, v. Kon.), d'après la Mon. de M. Konen. 
Oxyacrum, Cossm. 1889. Type: Pl. obliterala, Desh. Eoc.

Forme biconique; spire peu allongée; embryon lisse, conoïde, polygyré, à nucléus pointu; tours ornés de costules arquées, interrompues par une dépression inframédiane; base du derniel" tour obliquement déclive; canal très court, peu courbé, à peine rétréci, largement tronqué sans échancrure à son extrémité antérieure. Ouverture étroite, à peine plus large en arrière que sur la hauteur du canal; labre mince, fortement arqué, entaillé un peu au-dessous de l'argle des côtes, vis-à-vis la dépression spirale du dernier tour; columelle un peu calleuse, bombée au milieu.

Diagnose refaite d'après un échantillon de l'espèce type, provenant du calcaire grossier de Mouchy (Pl. V, fig. 17-18), ma coll. Vue de l'embryon (Fig. 10).

Rapp. et diff. - Par son ornementation, cette section

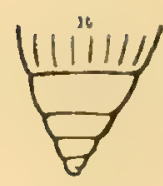

F's. 10. se rapproche beaucoup d'Ëopleuroloma; mais, outre que le canal est encore plus court et plus droit, que la forme est plus biconique, l'échancrure est un peu au-dessous de la rangée de crénelures et ne coïncide pas avec elle; entin l'embryon est bien différent et sa pointe est tout à faitcaractéristique. C'est un pelit groupe fort intéressant, qui me paraît localisé, jusqu"à présent du moins, dans le bassin anglo-parisien.

Répart. Stratigr.

Eocrne....... Outre le type, plusieurs especes dans le Parisien et le Bartonien ( $P$. inflexa, Lamk, constricta, lepta, Edw. contabulata, Desh.), ma coll.

DRILLIA, Gray, 1838.

Canal court; labre subvariqueux; sinus voisin de la suture.

DRILLIA, sens str.

'Type : P. umbilicata, Gray. Viv. (- Monitiopsis, Conr. 1865).

Forme étroite, fusoïde; spire turriculée, longue; embryon lisse, polygyré, conoïde, à nucléus obtus; tours convexes en avaut, 
où ils sont ornés soit de costules, soit de nodosités obliques, séparées en arrière, par une dépression spirale, d'un bourrelet plus ou moins saillant qui accompagne la sulure; dernier tour plus pelit que le reste de la spire, à base arrondie, terminé en avant par un canal court, large, oblique et un peu infléchi à gauche à son extrémité, qui est légèrement échancrée : sur le cou du canal s'enroule un bourrelet obsolète qui correspond à cette. échancrure. Ouverture assez étroite, pirifor'me, peu rétrécie du côté antérieur, munie d'une gouttière dans l'angle postérieur; labre peu arqué, épaissi ou même variqueux sur la parie de son contour qui correspond aux côtes, entaillé sur la dépression spirale par une échancrure peu profonde, puis antécurrent obliquement vers la suture; bord columellaire étroit, calleux, souvent muni d'une petite gibbosité vis-à-vis de la gouttière postérieure.

Diagnose faite daprès un plésiotype fossile du Plaisancien de Biol, D. Allionii, Bell. (Pl. V, fig. 3-ŏ), ma coll. Vue de l'embryon (Fig. I1).

Observ. - L'interprétation du genre Drillia a peu varié : la plupart des auteurs admettent $D$. ragayanensis comme type de ce genre, quoique la première espèce de Gray soit $P$. umbilicala; l'une et l'autre sont d'ailleurs moins élancées que notre plésiotype; cependant Tryon classe dans la section Brachytoma la plupart des Drillia typiques et en conserve d'autres dans la section Drillia s. s.; il y a évidemment absence d'homogénéité dans son groupement, qui serait à réviser. Aussi, en ce qui concerne les espèces fossiles, le rapprochement proposé par Bellardi, qui classe $D$. Allionii comme la première des espèces typiques de Drillia, me parait beaucoup plus conforme à l'interprétation correcte

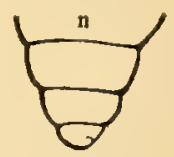

FIG. 11. du genre de Gray, c'est-àdire à celle qui résulte de l'élimination successive des types des sections postérieurement créées aux dépens de ce genre par les autres auteurs.

Quant au genre Monitionsis, Conr., qui a pour type Pl. elaborata. Conr., je n'y vois d'autres différences avec les Drillia que celles qui résultent de l'ornementation : de profonds sillons spiraux découpent des rubans sur des plis axiaux, au lieu que les Drillia ont habituellement des costules subnoduleuses et des filets spiraux : ce n'est pas un motif sulfisant pour justifier même la séparation d'une section.

Rapp. et diff. - Drillia se distingue de Surcula el Pleuroloma par la 
brièvelé et par la largeur du canal, qui est en outre échancré à son extrémité antéricure, et muni d'un bourrelet sur le cou. Cependant quelques Drillia ressemblent beaucoup à Eopleurotoma qui a aussi le canal assez court, mais on les en distingue de suite par la position de l'échancrure qui ressemble à celle de Surcula; d'autre part, l'épaississement du labre est un caractère particulier aux Drillia, et quion ne trouve ni chez Pleurotoma, ni chez Surcula; je n'en rapproche que pour mémoire Trachelochetus qui a le canal droit, le cou gonllé, le labre plissé, l'échancrure située plus haut, ete.

Répart. Stratigr.

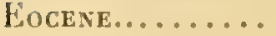

Oligocene...... Plusieurs espèces dans le bassin de l'Adour, en Belginue, en Allemagne ( $P$. crassinoda, Desm., aculicoslata, Nyst, D. Semperi, acaulis, truncalula, aberrans, v. Kion ete.), ma coll. el d'aprés la Monogr. de 11 . von Koenen; trois ou quatre especes probables dans le Vicentin ( $P$. inaspecta, Gnalce, ambigua, Fuchs), d'après la Monogr. de Fuchs.

Mrocene...... Plusieurs espèces en Touraine, dans le Bordelais, en Italie, dans le bassin de Vienne et de l'Allemagne du Nord (D. Euphrosinx, Mayer, Bellardii, Desm., Scillie, Bell., Pareli, Mayer, crebricosta, Mayer, multinoda, Grat. Suessi, Horn., Auingeri, R., Ilorn. Victurix, II. et A., spinescens, Partsch, Hosiusi. von Knen.). ma coll. et d'après les Monogr. de Bellardi, de Hornes et Auinger, et de von Konen.

Pliocene....... Plusieurs espèces dans les Alpes-Maritimes, le bassin du Rhône, en Italie, à Java (D. Allionii Bell. oblusangula, Br.,pinensis, Bell., hypoglypta, Font., intermupta, echinata, Lamk. Ermelingi, inexspectata, balaviana, Mart., Marlini, Cossm. = nodosa, Mart. non Bell.), ma coll. el d'après les Monogr. de Bellardi, de Fontannes et de Martin.

Eroque actuelle. Très nombreuses espèces dans toutes les mers, presque toutes celles de la section Brachytoma dans le Manuel de Tryon, à l'exception de quelques formes stromboïdes qui appartiennent effectivement à celle section. 
Crassispira, Sirainson, 1840.

Type: P. Boltæ, Val. (= incrassata, Sow. non Defr.). Viv. (= Tripia, de Greg, 1890 ; = Crassopleura, Monts. 1884).

Forme étroite, turriculée; spire à galbe conique ou conoïde ; embryon paucispiré tout à fait obtus; tours ornés de côtes tuberculeuses ou granuleuses, cessant subitement au-dessus de la dépression spirale qui les sépare de la suture; dernier tour peu convexe, à base obliquement déclive, terminé par un canal très brièvement tronqué et assez profondément échancré, sur le cou duquel est un gonflement, plutôt qu'un bourrelet, correspondant aux accroissements de cette échancrure. Ouverture étroite, à bords à peu près parallèles; labre arqué, mince à son contour, généralement variqueux en arrière de ce contour, prolondément entaillé sur la dépression postérieure, par une échancrure étroite et parallèle à la suture; bord columellaire oblique, calleux, assez large, recouvrant plus ou moins hermétiquement la fente ombilicale qui le sépare du bourrelet sur le cou du canal.

Diagnose faite d'après des plésiotypes fossiles : l'un, D. Brocchii, Bon. de l'Astien de Cannes (Pl. VI, fig. 6-7), ma coll. ; l'autre, D. angulosa, Desh. de l'Eocène moyen de Villiers (Pl. V, fig. 2y-23), ma coll. Vue de l'embryon (Fig. 12).

0bserv. - J'inscris comme synonyme de Crassispira le sous-genre Tripia, de Greg., qui a pour type $P$. anteatripla, espèce tout à fait voisine de notre $P$. angulosa du bassin de Paris: c'est tout un groupe de petites espèces moins grossièrement costulées que le type d. Crassispira, ou même uniquement carénées; mais je ne crois pas que celle différence de l'ornementation, d'ailleurs très variable, justifie la séparation d'une section. Je réunis également å ce sous-genre le groupe Crassopleura, Monte-

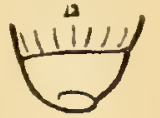

FIG. 12. rosato, dont le type $P$. Maravigna ne paraît se distinguer que par sa columelle plus calleuse.

Rapp. et diff. - C'est principalement par la brièveté et par la largeur du canal qu'on distingne assez facilement Crassispira de Driltia s. s.; en outre, ce canal ést plus ćchancré, l'entaille du sinus est plus profonde; 
Jrillia

enfin lembryon est paucispiré el bien plus oblus. Quant à l'ornementation. elle est moins luberculense et elle se reduit parlois it des filets spiriux, sur lesquels les granulations des premiers tours ne persistent pas jusqu'au dernier.

Rẻpart. Stratigr.

Focexe........ Nombreuses especes de petite taille dans le bassin anglo-parisien el dans le Claibornien des ElitsUnis ( P. angulosa, Desh. Iurrella el granulata, Limm. filifera, Mell. üachia. Edw. Danjouxi, Baudon, subgranulosn, d'Orb. Mausseneli al liypermeces, Cossm. Lonsdalei, Lea, anteatripla de Greg. abundans, Conr.), ma coll. et d'après la Mlonogre. de M. de Gregorio sur l'Eocene de l'Nlabama.

Obrgocene...... Plusieurs espèces dans le Tongrien do l'Allemagno du Nord (P. bicingulata, D. Iruncalula. v. Kon.), d'après la Monogi. de M. von Koenen.

Mocene...... Nombreuses espèces dans le Bordelais, en Touraine, en Italie, dans le bassin de Vienne et l'llelvétien des $\Lambda$ çores, dans la Virginie et la Floride (P. falla.x, Grat. Gestini, Desm. pustulata, Br. Lerelra, Bast.fratercu? a, Bell., raricosta, Bon. yilberosa, Bell. Athenais Mayer, bifilosa Bell. strombillus, Duj. obeliscus, Desm. latesulata, Bell. distinguenda, Mayer, granaria, Duj. Herminx, H. et A. perlurvila, Bronn, ebenina, Dall, ostrearum, Stearus) ma coll. et daprès les Monogr. de Bellardi, de Ilornes el Auinger, de Dall, de Mayer.

Plocene....... Plusieurs espèces en Italie, dans le bassin du Rhôn. à Java, dans la Floride (D. Brocchii, Bon. crispata, Jan, Calurii, de Stef. Iyponglyptr, Font. Djocdjocarlit, Martin, Buffoni el Torcapeli, Mayer, podagrina, piscalor, acurugata, Dall), ma coll. el il'apres hes Monogr. de Bellardi, de Fontannes, Martin, Dall, ele.

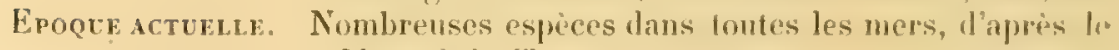
Manuel do Tryon.

Cymatosyrinx, Dall, 1889. Type: P. lunata, Lea. Mioc.

(= Clavus. Montf. 1810, non Clava, Gm. .1789, nec Humphrey, 1797).

Forme en général trapue; spire souvent très courle; lours tuberculeux, ou ornés de costules noduleuses sur l’angle médian, 
gónéralement dénués de filets spiraux, ou faiblement striés; base un queu convexe, portant souvent une chainetle antérieure de granulations, se terminant par un canal très court, très large, dont le cou porte quelques sillons enroulés en spirale. Ouverture subrhomboïdale, à peine rétrécie en arant ; labre arqué, entaillé contre la suture par une échancrure plus profonde que la sinuosité des côtes; bord columellaire large et calleux.

Diagnose faite d'après une espèce vivante, typique du genre Clavus, $P$. auriculifera, Lamk. ma coll. ; et d'après un plésiotype fossile du calcaire grossier de Villiers, $P$. simplex, Desl. (Pl. V, fig. 24-20̈), ma coll., ce dernier se rapprochant davantage de la forme Cymatosyrinx.

Observ. - Le nom Clavus Montf. est un double emploi évident avec Clava, dont il né diffère que par la désinence, et qui a été bien antérieurement employé par Gmelin, pour un genre de Polypiers, par Martynn, pour une espèce de Vertagus (d'après Dall) et par Humphrey pour un genre de Mollusques. C'est pourquoi j'y substitue Cymatosyrinx, dont le type est un Clavus parfaitement caractérisé et qui s'applique mieux aux formes fossiles dénuées des épines dont est parfois orné $P$. auriculifera: Quant à la dénomination Clavicantha, Swainson, elle a été considérée par la plupart des auteurs comme exactement synonyme de Clavus : mais il n'es! pas possible de la reprendre pour corriger le double emploi qui a échappé à Montfort; ainsi que je l'ai signalé plus haut, Clavicantha a été proposé pour Pleurot imperialis, Lamk., qui est un Clavalula, et ne peut convenir, à aucun titre, aux espèces du groupe de Clavalula scabra, Lamk., qui est le type du genre Clavus, Montf. En résumé, en admeltant mème que l'on veuille conserver une dénomination distincte à créer pou' $P$. auriculifera, et quelques autres formes vivantes tout à fait épineuses, cela n'empêcherait pas d'admettre également Cymatosyrinx, pour les espèces fossiles simplement noduleuses et pour la plupart des autres Clavus, de l'époque acluelle.

Rapp. et diff. - La diagnose de cette section, qui comprend des formes très variées, est nécessairement empreinte d'indécision : néanmoins, on peutdire que Cymalosyrinx, qui a le même embryon que Drillia s.s., s'en écarte par son ornementation et par la brièveté de son canal; comparée à Crassispira, qui a le canal aussi court, elle sen distingue par ses costules noduleuses, par son embryon moins obtus, par son sinus contigu à la suture : quand l'ouverture n'est pas complètement formée, on pourrait croire que le sinus a la même courbure que les côtes arquées qui bordent 


\section{Drillia}

la suture; mais, sur le bord du labre des individus adultes et bien intacts, on constate que l'échancrure est assez étroite et profonde comme celle de Crassispira, quoique moins écartée de la sulure.

Répart. Stratigr.

Eocexe ....... Une espèce typique dans le bassin de Paris $\left(P^{\prime}\right.$. simplex, Desh.) ma coll. ; autre espèce peu certaine dans le Claibornien des États-Unis ( $P$. fita, de Gregr), d'après la Monogr. de l'Eocène de l'Nlabama.

Oligocene...... Deux espèces probables dans le Tongrien de l'Allemagne du Nord (D. nassoides et densistria, v. Kon.). d'après la Monogr. de M. von Koeneu.

Mocene....... Plusieurs espèces dans la Touraine, le Bordelais, l'ltalie, le bassin de Vienne, l'Allemagne du Nord, la Floride (P. incrassala, Duj. soror, Bell, Suessi, Hlorn. lunata, Lea, Neumanni, Dall. eburnea, Conr. Selenkx, v. Koen.), ma coll. el d'après les Monogr. de Bellardi, de Hoemes et Auinger, et Dall et de: von Kwenen.

Plocene...... Plusieurs espèces en Italie, dans le bassin du Rhône, la Floride (P. sigmoidea, Bronn, rhodanica, Font. acila, Dall, pagodula, Dall.), ma coll. et d'apres les Monogr. de Bellardi, de Fontannes et de Dall.

Epoque actuelle. Nombreuses especes dans loutes les mers, d'après le Manuel de Tryon.

SPIROTROPIS, SArs, 1878.

Sinus toul à fait contigu à la suture el extérieurement évasé ; embryon globuleux; canal non échancré.

Spirotropis, sens. str. Type: P. carinata, Biv. Viv.

Forme turriculée ; spire assez longue, élagée ; embryon pancispiré, globuleux, à nucléus obtus ; tours lisses, carénés au milieu, excavés sous la carène; dernier tour à base convexe, terminé par un canal court, large, non échancré à son extrémité antérieure. Ouverture piriforme, peu rétrécie en avant; labre arqué, mince, entaillé contre la suture par un sinus assez large et profond, dont le bord extérieur est évasé et se raccorde tangen- 
tiellement avec la suture; bord columellaire mince el étroit, non sinueux.

Diagnose faite d'après un échantillon de l'espèce type, du Finmark. (PI. V. fig. 26-27), coll. de l'École des Mlines.

Rapp. et diff. - Fischer classe Spirolropis comme sous-genre de Dritlia, Tryon en fait un genre distinet : cette dernière opinion me parait plus proche de la vérité, à cause des différences que présente l'animal, dans la disposition de ses tentacules, de ses yeux el de sa dentition. En ce qui concerne la coquille, le sinus est tout à fait contigu à la suture, et son contour est réfléchi à l'extérieur; d'autre part, l'embryon est tout à fait globuleux, et par conséquent bien différent de celui des Drillia typiques, ou même des Crassispira; enfin l'absence d'ornementation sur la spire est un caractère particulier à Spirotropis.

Répart. Stratigr.

Mrocexe....... Une espèce souvent confondue avec le type, dans le Piémont et le bassin de Vienne ( $P$. modiola, Jan), ma coll.

Pliocene...... La même espèce, ou une variété se rattachant à la forme vivante, dans le Crag d'Angleterre, dans les Alpes-Maritimes, en Italie et dans le post pliocène de Sicile ( $P$. carinala, Biv.), na coll. el d'après les Monogr. de Wood et de Philippi, sec., Monterosato. Embryon d'un individu de Canues (Fig. 13), ma coll.

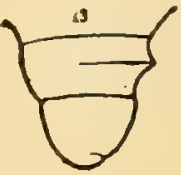

FIG. 13.

Epoque actuelle. Le type, unique espèce connue, sur les côtes de Norvège et aux Açores, à la profondeur de 4024 mèlrès, coll. Dautzenberg.

BELA, Leach in Gray, $181 \%$.

Forme trapue ; embryon globuleux et obtus; canal court; droit, atténué et sans échancrure à son extrémité antérieure; sinus à peu près nul.

BeLA, sens. str.

Néotype : B. turricula, Montg. Viv.

Forme fusoïle ou buccinoide; spire plus ou moins courle, souvent étagée au-dessus de la suture; embryon paucispiré, à 
nucléus lout à fail arrondi; tours convexes ou subanguleux, olnés de costules arquées et de filets spiraux. Ouverture étroite, ovale ou subpiriforme, terminée par un canal à peine rétréci, très court, à peu près droit, dont l'extrémité est atténuée, arrondie, sans aucune échancrure; labre peu épais, sinueux, très peu entaillé en arrière, vis-à-vis la courbure des côtes, antécurrent et tangent à la suture; bord columellaire lisse, calleux, assez large, aminci et subcaréné à l'embouchure du canal.

Diagnose refaite d'après le type vivant et d'apres un plésiotype de l'Eocene d'Australie, B. pulchra, Tate (Pl. VI, fig. 10-11), ma coll. Embryon grossi (Fig. 14).

Observ. - Si l'on s'en rapportait aux indications de Gray, le type du genre Bela serait $M$. nebula, Mlgu (Murex, ) qui serait aussi le type de Raphiloma, d'après Bell, 1846. Néanmoins j'ai adopté l'opinion de la plu-

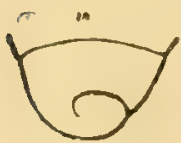

Fia. 14. part des auteurs qui ont atmis comme exemple mieux caractérisé Bela turricula, qui devient ainsi le néolyp du genre, quoique $B$. nebula soit anssi une Bela. Les Bela, ayant un opercule identique i celui de Pleurotoma, sont classés par la plupart des auteurs (Fischer, Tryon) dans la même famille ; cependant Bellardi a proposé, en 1874, une sous-fanille Belinx, à cause de l'exiguité du sinns, de la brièveté du canal el de l'embryon globuleux de ces coquilles: je ne vois pas bien l'utilité de cette création, altendu que ce sont seulement des différences génériques.

Les Bela n'ont commencé à apparaitre que dans les terrains tertiaires : $B$. clathrala, décrit par Gabb (Paleont. Calif.) comme provenant de la Craie, me parait, d'après la figure, très voisine de Surcula mrallemula, du même auteur.

Répart. Stratigr.

Locene....... Outre le plésiotype d'Australie ci-dessus indique, un espèce dans le bassin de P’aris (B. lamellicostala, Cossm.), ma coll.

P'locene...... Une espèce à côtes arquées, dans les faluns helveiliens de la Touraine (P. amona, Duj.), ma coll.

Mrocexe....... Outre l'espéce type, plusieur's formes voisines dans l' Crag d'Angleterre (Clavat. Trevellyana, Turlonis, Wood, Bela rufa et nebula, Montg.), d'itpres lir Monogr. de S. Wood; une espece dans les couches 
récentes de Java ( $P$. fragilissima, Mart.) d'après la Monogr. de Martin.

Epoque acturle. Nombreuses especes, exclusivement dans les mers froides, daprès le Manuel de Tryon.

Buchoza, Bayan, 1873. Type : Auricula citharella, Lamk. Eoc.

$$
\begin{gathered}
(=\text { Etallonia, Desh. 1862, non Oppel 1861; } \\
=\text { Zafra, Cossm. 1892, non Ad.). }
\end{gathered}
$$

Forme ovale; spire très courte ; embryon subglobuleus et obtus; tours subulés, ornés de côtes droites et de filets spiraux; ouverture étroite, à bords à peu près parallèles, atténuée en avant et presque complètement dénuée de canal; labre peu épais, à contour vertical, à peine curviligne, légèrement sinueux en arrière; bord columellaire calleux, infléchi en avant.

Diagnose faite d'après un individu de l'espèce type, provenant de Réquiécourt (Pl. VI, fig.12-13!, coll. Pezant.

Observ. - Le rapprochement proposé par Fischer, qui classe Buchozia près de Bela, est tout à fait justifié : Deshayes plaçait à lort son gienre Elallonia entre Actæon et Ringicula, ne remarquant pas que cette corpuille a un canal rudimentaire, un léger sinus, surtout un embryon identique a celui de Bela, et n'ayant rien de commun avec celui des Tectibranches. En corrigeant le double emploi de nomenclature qui a échappé à Deshayes, Bayan n’a d'ailleurs pas rectifié le classement de Buchozia.

Rapp. et diff. - Cette section est très voisine de Bela; toutelois le canal -est encore moins formé et le sinus du labre encore moins arrondi, les côtes sont plus droites, le galbe de la spire est plus subulé, les tours ne sont pas convexes et étagés : on peut done admettre la séparation Buchozia, el y classer le fossile parisien que j'ai à tort rapporté au genre-Zafra (Z. decussata, Cossm.), et qui n'a pas le canal échanerí, la forme colombelloïde du type de ce genre.

Répart. Stratigr.

Paleocene..... Une espéce dans les sables de Bracheux (E $\ell$. prisca. Desh.), ma coll.

Eocene........ Outre le type, plusieur's espèces dans le bassin de Paris, dans le Cotentin et dans la Loire-Inférieur. (B. crassicostala el $Z$. decussala, Cossm. El. Gervit- 
lei, Desh.), ma coll. el coll. Bourdot; autre espèce dans IAustralie du Sud (Pusionella hemiothone, Tate), ma coll. [Pl. VI, fig. 8-9]

Miocene ........ Une espèce certaine dans l'Ilelvétien de la Touraine (B. cancellata, Lollf. Dautz.), ma coll, ; autre espèce nouvelle (B. dormitor, Dollf. Dautz.), d'après l'Litude préliminaire des faluns de la Touraine.

\section{Hedropleura, Monts. mss, in Bucq. Dollf. Dautz. 1882. Type: Murex septangularis, Montg. Viv.}

Forme ovoïdo-conique; spire courte ; embryon paucispiré, subglobuleux, à nucléus déprimé ; tours lisses, subulés, à sutures ondulées, ornés de côtes droites et épaisses, qui se succèdent; Jase du dernier tour obliquement déclive. Ouverture étroite, en lorme de pépin, terminée par un canal de Buchozia; labre épais, extérieurement bordé, à peine sinueux près de la suture; bord columellaire de Buchozia.

Diagnose refaite d'après un échantillon de l'espèce type, fossile pliocénique des environs de Turin (PI. VI, fiğ 14-10ั), coll, du Muscie de Turin, communiqué par M. Sacco.

Rapp. et diff. - La création de cetle section est tout à fait justifiée, yuand on en compare le type à Bela turricula; mais les différences sont leaucoup moins profondes, quand on la rapproche de Buchoria: ce n'est guère que par ses larges cótes polygonales, par sa surface lisse, par son rmbryon moins globuleux, à nueléus plus déprimé, qu'on peut distinguer Iredropleura, et ce sont là des caractères plutôt spécifiques. Si l'on réunissait ces deux formes, on aurait un enchainement ininterrompu pendant loute la période tertiaire, jusqu'à l'époque actuelle: on peut du moins admettre que celle-ci descend de l'autre et la conserver comme section distincte.

Répart. Stratigr:

Mocene....... L'espèce type dans le Tortonien des environs de Turin, d'après Bellardi; autre espece dans l'llelvétien de Touraine (II. cf. Contii, Bell.), d'après l'élude préliminaire des faluns de Touraine, par Dollfus et Dautzenberg; mais l'échantillon un peu usé que je possede de Mandhelan me parait identique au type vivant. 
Pliocrne ...... Outre l'espèce type en Italie et dans le Crag d'Angleterre, deux formes voisines dans les environs de Turin (B. Conlii et bucciniformis, Bell.), d'après les Monogr. de Bellardi et de S. Wood.

Epoque actuelle. L'espèce type et plusieurs variétés, nommées par Monterosato, dans la Méditerranée et aux Açores.

DAPHNOBELA, nov. sect.

Type: Bucc. junceum, Sow. Eoc.

Forme étroite, allongée; spire parfois très courte, à galbe fusiforme et subconoïdal ; embryon composé d'un seul tour, à nucléus en goutte de suif; tours un peu convexes, sillonnés spiralement, bordés au-dessus des sutures qui sont parfois très profondes; dernier tour grand, ovale, atténué à la base qui se termine par un canal large, court et tronqué. Ouverture à borcls à peu près parallèles, non rétrécie à la hauteur du canal ; labre uı peu épaissi, parfois plissé à l'intérieur, à peine arqué et presque pas sinueux en arrière; columelle droite, faisant un angle très ouvert avec la base de l'avant-dernier tour; bord columellaire un peu calleux.

Diagnose faite d'après un échantillon typique de Barton

(Pl. V, fig. 30-3I), ma coll.

Rapp. et diff. - J'avais d'abord placé Bucc. junceum dans les Bela typiques: mais, en comparant de nouveau la forme du canal de cette coquille à celle de $B$. turricula, j'ai constaté qu'elle s'en écarte tellemen! qu'il faut au moins admettre une section distincte. J'ai, d'ailleurs, été confirmé dans cette opinion, par le rapprochement à établir entre cette espèce et une forme de l'Eocène d'Australie, qui n'est pas tout à fait semblable, mais qui a le même canal, et qu'on doit évidemment classer dans le même groupe: l'espèce australienne a le labre à peu près droit, sans sinus, non plissé à l'intérieur, la spire plus courte, le bord columellaire plus mince, etc. Toutes deux se distinguent en outre de Bela par le caractère de leur ornementation et par leurs profondes sutures. Si on les compare à Daphnella, dont elles se rapprochent par leur canal, on remarque immédiatement qu'elles ont un embryon absolument différent, qui ne ressemble pas davantage à celui de Peratotoma; d'ailleurs, l'absence presque complète de sinus s'oppose également à ce rapprochement. 


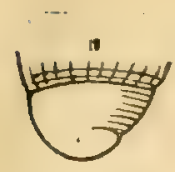

Fia. 15 .
Répart. Stratigr.

Eocene....... Outre le lype dans le Bartonien d'Anglelerre, l'espece un peu aberrante d'lustralie (Daphnella gracillima, Tate), ma coll. Embryon grossi (Fig. 13).

DONOVANIA, Bucq. Dolle. Dautz. 1882.

$1=$ Lachesis, Risso 1826, non Daudin 1804, nec Savigny: = Nesæa, Risso 1826, non Lamk. 1812, nec Leach. 1818; = Chanvetia, Monts. 1881; = Folinea, Monts. 1884).

Donovania, sens. str. Type: Bucc. minimum, Montg. Viv.

Forme buccinoüde; spire courte; embryon obtus, mamelonné; tours treillissés; base du dernier tour convexe, se terminant subitement par un canal extrêmement court, tronqué transversalement, non échancré. Ouverture large, ovale, rétrécie à la troncature du canal ; labre épaissi par un bourrelet obtus à l'extérieur, et muni de plis obsolètes à l'intérieur, à coniour à peu près vertical, à peine sinueux en arrière; columelle arquée, obliquement infléchie à l'extrémité antérieure; bord columellaire mince, étroit, peu distinct.

Diagnose refaite d'après un échantillon typique du Post-pliocène de Palerme (Pl. V, fig. $98-29$ ), ma coll. Embryon grossi (Fig. 16).

Observ. - La synonymic de ce grenre est assez confuse non seulement it cause du double emploi de Risso, mais encore à cause de la nécessité de réunir les deux formes que cet auteur eroyait distinctes: Nescea n'est autre que Lachesis, et, par conséquent, la dénomination Chauvetia, proposée par Monterosato pour corriger re deuxième double emploi, doit elle-mème être éliminée. Entin le nom Folinxe, proposé par Ilonterosato pour Buccinum Lefebvrei. Marav., que beancoup d'auteur's considèrent comme une simple variélé de Lachesis minima, ne peut

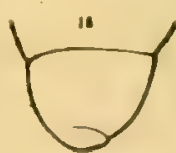

Fin. 16. réllement pas être admis, mème ì titre de section du genre Donovania.

Rapp. et diff. - Cette petite coquille ressemble plus it un Buccinidx quià un Pleurotomidx; néanmoins, elle est actuellement rapprochée dẹ 
Donovania

Bela par la plupart des auteurs qui ont pu étudier l'animal en vie: son opercule est, parait-il, identique à celui de Pleurotoma, son embryon est globuleux comme celui de Bela, son sinus y ressemble également, le labre est bordé comme celui d'Hxdropleura; seul, le canal s'écarte-tout à fait, par sa troncature rétrécie, de la plupart des formes de la famille Pleurotomidx. Il est donc rationnel de conserver Donovania comme genre distinct.

Répart. Stratigr.

Pliocexe ...... L'espèce type en Italie, sous le nom Lach. brunnea, Donov, d'après Bellardi.

Post-plocene... L'espèce type dans les terrains tout à fait récents de Sicile, ma coll.

Epoque Actuelte. Huit espèces, soit dans la Méditerranée, soit au Japon, soit aux Indes Occidentales, soit à l'île Saint-Paul, d'après le Manuel de Tryon.

ROUAULTIA, Bellardi, 1877.

(=Borsonia, Bell. 1838, ex parte ; = Cochlespira, Conr. 1875).

Rouaultia, sens. str. Type: $R$. subterebralis, Bell. Mioc.

Forme fusoïde ; spire turriculée, étagée, à galbe conique ; tours divisés au milieu par une carène saillante et crénelée, excavés de part et d'autre de cette carène ; base du dernier tour convexe, rapidement atténuée, terminée en avant par un canal allongé, presque droit, dont l'extrémité n'est pas échancrée. Ouverture étroite, subtrigone ; labre assez mince, plissé à l'intérieur, entaillé sur la carène par un sinus étroit et profond, obliquement antécurrent sur la rampe postérieure; columelle munie, au quart de sa hauteur, d'un renflement pliciforme très oblique et à peine saillant, obliquement infléchie et rectiligne au-dessus de ce pli; bord columellaire mince, limité par une strie, se terminant en pointe bien en-deçà de l'éxtrémité du canal. 
Diagnose refaite d'après deux échantillons typiques de Telti Borelli (Pl. VI, fig. 16-17), coll. du Musée de Turin.

Observ. - Fischer, dans son Manuel, ne cite même pas le genre Rouaultia, Tryon en fait un synonyme douteux de Genotia, Zittel le conserve avec raison auprès de Borsonia, dans le groupe des formes a colu-

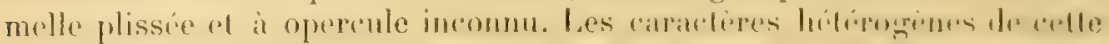

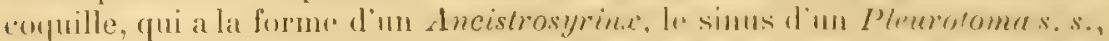
la columelle d'une Borsonia, sont certes embarrassants: cependant, si l'on admet qu'il y a, entre la forme de l'opercule el la disposition de la columelle, une corrélation intime, il y a lieu de classer Rouaultia dans la sous-famille Borsoninx, dont l'opercule est inconnu il est vrai, puisqu'elle se compose presque exclusivement de formes fossiles, mais dont les coquilles devaient être habitées par des animaux à peu prés semblables, à opercule identique. Quant ì la synonymie de Cochlespira, ainsi que je l'ai fait remarquer à propos de Perrona, je ne suis pas assez sûr du classement de la coquille figurée par Conrad, pour proposer de remplacer par celle dénomination antéricure la création parfaitement définie par Bellardi.

Répart. Stratigr.

Mrocene....... Trois espèces en Italie el dans le Bassin de Vienne (R. sublerebralis, Bell. lapugyensis, Hayer el bicoronala, Bell.), d'après la Monogr. de Bellarli; autre espèce des couches de la Molasse, à Cabrières dans le Vaucluse $(R$. candellensis, Font.), d'apris les Etudes de Fontannes sur le bassin du Rhône.

BORSONIA, Bellardi, 1838.

Sinus large et peu profond près de la sulure; columelle munie d'un ou de plusieurs plis.

Borsonia, sens. str.

'Iype: B. prima, Bell. Mioc.

(= Cordieria, Rouault, ex parte, 1819).

Forme fusoïde; spire allongée; à galbe conique; embryon paucispiré, à nucléus obtus et dévié : tours anguleux et noduleux sur l'angle médian, avec des cordons grossiers sur la partie antérieure, et des filets plus fins ou totalement effacés sur la rampe postérieure; base du dernier tour convexe, régulièrement 
Borsonia

atténuée, terminée par un canal assez long et légèrement intléchi. Ouverture étroite, subpiriforme ; labre mince, arqué, entaillé sur la rampe postérieure par une échancrure large en arc de cercle peu profond, et aboutissant obliquement à la suture; columelle en général munie d'un pli saillant placé très bas, et au-dessus de lui, d'un renflement à peine sensible, au point médian où elle fait un coude pour s'intléchir à droite; parfois il ne reste, comme chez Rouaultia, que ce rentlement médian; bord columellaire un peu calleux, rétréci en avant.

Diagnose refaite d'après des échantillons typiques de l'Helvétien des environs de Turin (Pl. VI, fig. 18 et 20), collection du Musée de Turin.

Observ. - Dans son Mémoire sur l'Éocène des environs de Pau, en créant le genre Cordieria, Rouault ne s'est pas dissimulé qu'une partie de ses espèces tombaient en synonymie avec Borsonia: toutefois la distinction qu'il a faite entre le nombre des plis columellaires est due à une interprétation inexacte de la diagnose de Bellardi, attendu qu'en réalité il y a deux plis à la columelle de Borsonia prima, si l'on compte comme un pli le renflement antérieur. Seulement, comme on le verra plus loin, Cordieria se distingue par d'autres caractères, de sorte que, contrairement à l'avis de la plupart des auteurs qui ont adopté, sans le vérifier, l'avis de Rouault, ces deux dénominations doivent être conservées et appliquées à des formes bien séparées. Quant à l'allongement du canal de Borsonia, il n'est pas le résultat, comme le pense M. von Koenen (Norddeulsch. Unterolig. II, p. 460), de ce que les individus sont moins mutilés que d'autres; car les individus de $B$. prima que j'ai étudiés et qui sont en bon état de conservation ont réellement le canal long et étroit.

Rapp. et diff. - Il est facile de justifier la séparation de Rouaultia et de Borsonia, à cause de leur forme extérieure qui est tout à fait différente, et parce que le sinus n'est pas du tout situé au même point; j'ai indiqué, à propos de Rouaultia, les motifs qui m'ont décidé à rapprocher ces deux genres l'ungle l'autre: en particulier la disposition du canal est la mème, et Borsonia prima a en plus un pli columellaire inférieur; mais ce pli n'existe pas chez toutes les espèces, notamment dans une forme nouvelle de la Loirc-Inférieure, dont la columelle a absolument l'aspect de celle de Rouaultia, quoique la forme extérieure et la position du sinus soient bien celles des véritables Borsonia. Ce fait confirme l'opinion qui résulte de l'examen d'un grand nombre d'espèces de Borsoninx, c'est que dans cette sous-famille le nombre et la saillie des plis à la columelle n'ont pas l'importance qu'on serait tenté de leur attribuer. 
Répart. Stratigr.

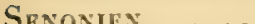

Paleocene....

Focexe.........

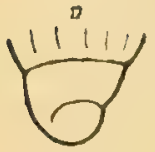

FIG, 17.

Ohigocene.....

Mrocene......

Pliocene.......

Epopue actuelle. Une espèce inédite provenant des dragages de l'lliron-

delle, aux $\Lambda$ çores (profondeur de 1300 mètres),
coll. Dautzenberg; autre espèce aux iles Philip-
pines (B. armata, Bottg.), daprès une diagnose
non accompagnée de tigure, note de $M$. Boetlger
en $189 \%$.

delle, aux $\Lambda$ çores (profondeur de 1300 mètres),
coll. Dautzenberg; autre espèce aux iles Philip-
pines (B. armata, Bottg.), daprès une diagnose
non accompagnée de tigure, note de $M$. Boetlger
en $189 \%$.

delle, aux $\Lambda$ çores (profondeur de 1300 mètres),
coll. Dautzenberg; autre espèce aux iles Philip-
pines (B. armata, Bottg.), daprès une diagnose
non accompagnée de tigure, note de $M$. Boetlger
en $189 \%$.

delle, aux $\Lambda$ çores (profondeur de 1300 mètres),
coll. Dautzenberg; autre espèce aux iles Philip-
pines (B. armata, Bottg.), daprès une diagnose
non accompagnée de tigure, note de $M$. Boetlger
en $189 \%$.

delle, aux $\Lambda$ çores (profondeur de 1300 mètres),
coll. Dautzenberg; autre espèce aux iles Philip-
pines (B. armata, Bottg.), daprès une diagnose
non accompagnée de tigure, note de $M$. Boetlger
en $189 \%$.

Une espèce douteuse dans la Craie supéricure de Californie (Cortieria mitreformis, Gabb), d'après la Monogr. de Gabb. et Whitney.

Une espèce dans le calcaire de Mons (B. Comansi, Br. et C.), d'après la Monogr. de Briart et Comel.

Deux espèces dans les environs de l'au, à Bos d'Arros (C. pyrenaica et biarritzensis, Rouault), d'après un échantillon de la coll. de l'École des Mines ot d'après les figures de l'auteur ; autre espece i Selsey, en Angleterre ( $C$. biplicala, Sow.) ma coll.; une espèce nouvelle, à columelle non plissée dans le bassin de Campbon, Loire-Inférieure (B. brilanna, Cossm.), coll. Dumas et Berthelin; deux espèces dans l'Australie du Sud (B. olouyensis, Tate et $P$. Clare, Ten. Woods), ma coll. Embryon. de B. olwayensis (Fig. 17).

Deux espèces probables dans le Vicentin (B. lugensis et pungens, Fuchs), d'après la Monographic de San Gonini par Fuchs.

Outre le lype, une autre espèce dans l'Helvétien des environs de Turin (B. Rouaulti, Bell.) d'après la Monogr. de Bellardi; autre espèce dans le Langhien des environs de Bordeaux (B. Uurdigalina, Ben.), d'après le Catal. des testacés de Saucats.

Une espèce dans les couches d'Lideghem a la limite supérieure du Miocène, près d'Anvers (B. uniplicala. Nyst, ma coll.

Cordieria, Rouault 1849. Néotype: $C$. iberica, Rouault. Eoc.

(= Phlyctania, Cossm. 1889, non IIübner 1816; = Phlyctis, Harris et Burrows 1881).

Forme généralement ventrue; spire médiocrement allongée; embryon paucispiré, à nucléus obtus et subglobuleux; tours 
Borsonia

orné de côtes pustuleuses, interrompues sur la dépression inférieure située au-dessus du bourrelet qui borde la suture; base du dernier tour invariablement ornée d'une chaînette spirale plus ou moins obsolète, avec de petites granulations tuberculeuses ou des crénelures deux fois plus nombreuses que les côtes du dernier tour. Ouverture assez large, à peine atténuée en avant, terminée par un canal très court, non échancré et légèrement infléchi à son extrémité antérieure ; labre mince, rarement entier, souvent plissé à l'intérieur, très arqué au milieu, entaillé près de la suture par un sinus en général peu profond; columelle sinueuse, portant presque au milieu deux plis souvent peu saillants ou enfoncés à l'intérieur de l'ouverture, généralement égaux et peu obliques, quelquefois un troisième renflement antérieur; bord columellaire calleux, un peu détaché en avant et décourrant quelquefois une étroite fente ombilicale.

Diagnose refaite d'après un plésiotype du calcaire grossier de Chaussy, B. calvimontensis, Desh. (PI. VI, fig. 21-22), ma coll.

Observ. - Rouault n'ayant pas indiqué de type pour le genre Cordieria, el les deux premières espèces qu'il a décrites étant de véritables Borsonia, c'est la troisième espèce qu'il faut prendre comme néo-type: or, cette espèce est identique aux formes parisiennes pour lesquelles j'avais proposé le nom Phlyctænia, antérieurement employé par Hübner, de sorte que cela rend inutile la correction Phlyctis proposée par MM. Harris el Burrows.

Rapp. et diff. - Si l'on se reporte à ce que j'ai indiqué ci-dessus, à propos du genre Borsonia, au sujet de la longueur du canal qui n'est pas le résultat d'une mutilation de la coquille, on reconnaitra qu'il n'est pas possible de comprendre dans le même groupe les Cordieria, qui n'ont, pour ainsi dire, pas de canal; en outre, les plis sont au moins au nombre de deux, les côtes sont pustuleuses et la base porte une chainette perlée qui est tout à fait spéciale : ce sont là des caraclères importants qui ne permettent pas de confondre Cordieria avec Borsonia. Quant au sinus, il n'est pas possible d'en tirer un motif de séparation des deux groupes, attendu que, chez quelques Cordieria, par exemple celle que j’ai figurée comme plésiotype, ce sinus est presque aussi prolond que celui de B. prima, quoique plus voisin de la suture, tandis que d'autres espèces (B. acutala et nodularis, Desh., etc.) n'ont presque pas de sinus. 
Répart. Stratigr.

EOcene.........

Mrocene........

Pliocene.......

Ougocene..... Nombreuses espèces soit dans le bassin de Mayence ( $B$.

Outre le type de Bos d'Arros, nombreuses espèces dans les environs de Paris (13. Chevallieri, Cossn., Bellardii, brevicula, lurbinelloides, obesula, Desh., cresnensis, de Rainc. nodularis, marginala, minor, incerla, Desh. etc.), ma coll, ; une espece nou. velle dans la Loire-Inférieure au BoisGouët (C. Dumasi, Cossm.), coll. Dumas; deux espèces das le gise-

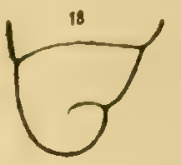

Jig. 18. ment de Barton (B. sulcata et semicostata, Edw.), d'après la Monogr. d'Edwards. Vue de l'embryon. de C. brevicula (Fig. 18), ma coll. gracilis, Sandb.), ma coll.; soit dans l'Allemagne du Nord et en Belgique (B. Ineluci, Nyst, plicala, Beyr., turris, Giebel, cosiulata, coarctala, oblusa, splendens, v. Koen.), ma coll. el d'après la Monogr. de M. von Konen.

Une espèce douteuse dans l'Allemagne du Nord, confondue avec $B$. uniplicata, mais paraissant avoir le canal plus court, d'après les figures de la Monogr. de $\mathbf{M}$. von Krenen, gisement de Dingden.

Une espece un peu aberrante dans le Messinien d. l'Italie centrale (Turtinella Iargioniana, d'Anc.), ma coll.

Mitromorpha, A. Adams.

Type: 11. lirata, $\Lambda$ d. Viv.

Forme de Conomitra; spire courte, subulée ; embryon paucispiré, obtus; tours subulés, cancellés ou sillonnés; dernier tour supérieur à la moitié de la longueur totale, ovoïdo-conique, obliquement atténué à la base. Ouverture étroite, à bords presque parallèles, terminée par un canal peu distinct, court et tronqué ; labre à peu près rectiligne, à peine sinueux vers la suture, intérieurement muni de denticules: columelle droite, munie sur le bord de deux forts plis obliques qui ne se prolongent pas à l'intérieur; bord columellaire très mince. 
Borsonia

Diagnose faite d'après une espèce plésiolype inédite, du pliocène de Gourbesville (MIanche), M. subulata, nob. (PI. VIII, fig. 21). [Voir la description dans l'annexe.]

Rapp. et diff. - Le classement du genre Mitromorpha est très incertain : il se compose d'espèces vivantes très rares ou qui n'ont pas été figurées, dont les caractères n'ont pas été tous étudiés, de sorte que le fossile que je propose de placerdans cesous-genre n'en fait peut-être pas partie. Mais, si cette assimilation est exacte, la place de Mitromorpha serait auprès de Borsonia ou plutôt de Cordieria, dont elle se distinguerait seulement par son aspect mitriforme et par les denticules internes du labre, par l'absence presque complète du canal qui se confond avec le prolongement déclive de la base. Si on compare ce genre à Milrolumna, Bucq. Dollf. Daulz., on trouve qu'il s'en distingue par ses deux plis columellaires au lieu de trois, non prolongés sur toute l'étendue de la columelle à l'intérieur de la coquille, tandis que c'est le contraire dans le genre Mitrolumma qui appartient bien à la famille Mitridæ.

Répart. Stratigr.

Pliocene ........ L'espèce plésiotype dans le Cotentin, ma coll.

Epopue actuelle. Outre le type du Japon, deux ou trois espèces peu homogènes, dont l'une a précisément le labre plissé à l'intérieur.

BATHYTOMA, Harr, et Burr. 1891.

Forme ventrue; canal assez court avec un bourrelet sur le cou; columelle subplissée ou renflée; sinus écarté de la suture.

Bathyтола, sens. str. Type: Murex cataphractus, Br. Plioc.

(= Dolicholomá, Bell. 1875, non Hope, Col. 1839).

Forme ovale, trapue, spire conoidale, turriculée; embryon lisse et régulièrement conoïdal, à nucléus petit et dévié; tours subanguleux, avec une carène crénelée plus haut que la moitié de leur hauteur, excavés entre cette carène et la suture qui est bordée; dernier tour grand, ovale, atténué à la base, terminé en avant par un canal large, un peu courbé et légèrement échancré, sur le cou duquel s'enroule un gros bourrelet. Ouverture étroite, 
Ballıytoma

subpiriforme, plus anguleuse en arrière qu'à l'extrémité antérieure; labre assez épais, parfois plissé ì l'intérieur, arqué, avec une profonde échancrure vis-à-vis la carène du dernier tour, se raccordant par un quart de cercle perpendiculairement à la suture; columelle sinueuse, tangente à la base de l'avant-dernier tour, munie d'un coude plissé vis-à-vis de l'enronlement du bourrelet sur le cou du canal; bord columellaire mince et large en arrière, plus calleux et plus étroit en avant, contournant le bourrelet qui recourre la fente ombilicale, et se terminant en pointe à l'extrémité du canal.

Diagnose faite d'après un échantillon de l'espèce type, montrant le pli columellaire, du Plaisancien de Biot (PI. VIII, fig. 14), ma coll.; autre individu plus intact, du Tortonien de Saubrigues (P). V, fig. 19 et Pl. VIII, fig. 12), ma coll. Embryon grossi (Fig. 19).

Observ. - Aux termes des règles de nomenclature adoptées par le

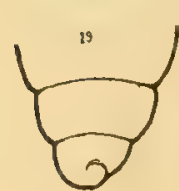

[16. 19. Congrès de Bologne, la dénomination Dolicholoma ayant été employée avant Bellardi en Entomologic, la correction faite par MII. Iarris et Burrows, à l'aide du précieux répertoire de Scudder, doit évidemment être admise: toutefois il eût peut-être été préférable d'oublier ce double emploi qui ne choquait personne et de conserver Dolicholoma qui est un nom universellement connu.

Rapp. et diff. - Cette forme a beaucoup d'analogie avec Borsonia; anssi je ne comprends pas pourquoi Fischer et Tryon, rompant avec la tradition créée par Bellardi qui plaçait ces deux genres dans la même sous-fanille, ont placé Dolichotoma auprès de Genotia, surtout sans en connaitre l'opercule. Aujourd'lıui, d'après le travail de M. Dall sur les dragages de l'Mlbatros, on connat l'animal et l'opercule de Pleurol. Carpenteriana, Gabb, dont la coquille ressemble à celle de Bathytoma: or, cet opercule, dont le mucléus apical est malhenrensement brisé ou usé, est bien plus fort, plus ipais, plus noir que celui des Conidx; d'autre part, la dentition el la glande venimeuse de l'animal ressemblent à celles de Bela; il y a done des molifs sćrieux pour rapprocher Bathyloma des Pleurolomide, et, en raison des analogies de la coquille, de placer ce genre dans la sous-fiumille Borsoninite.

Il y a d'ailleurs des différences importantes entre Borsonia ct Bathytoma, la forme de l'embryon, la position du sinus, le bourrelet du cou du canal, le pli columellaire réluit à un gonflement produit par l'enroulement de ce bourrelet sous la callosité qui recourre la columelle. Si l'on compare 
Bathytoma

Bathytoma à Rouauttia, qui a également la columelle gonflée et le sinus écarté de la suture, on trouve que lous les autres caractères sont différents.

Répart. Stratigr.

Eocexe....... Plusieurs espèces, soit dans le bassin anglo-parisien (Pl. iurbida, Sol.), ma coll. ; soit dans l'Australie du Sud ( $P$. atractoides, Gellibrandi, fontinalis, Tate), ma coll.; soit dans le Clairbornien des États-Unis ( $P$. congesta, Conr.), d'après la Monogr de $\mathbf{M}$. de Gregorio sur l'Alabama.

Oligocenr....... Plusieur's espèces dans le Tongrien inférieur de l'Allemagne du Nord (Dol. anodon, subcylindrica, trachyloma, v. Koen. P. ligata, Edw.), d'après la Monogr. de M. von Kœnen; une espèce certaine dans les argiles de Boom ( $P$. crenala, Nyst), ma coll.

Mrocene....... L'espèce type dans les Landes, en Italie et dans le bassin de Viemne, ma coll.; dans l'Allemagne dı Nord, d'après M. von Kæenen qui l'a confondue avee B. turbida; dans le Portugal, d'après la Monogr. de P. de Costa; autre espèce en Italie (Dol. doliohum, Bell.), d'après la Monogr. de Bellardi.

Pliocene....... L'espèce type dans les Alpes-Maritimes el en Italie, ma coll.; dans le bassin du Rhône, d'après la Monogr. de Fontannes; autre espèce dans les couches d'Edeghem, près d'Anvers confinant au Miocène supérieur ( $P l$. sublurbida, d'Orb.), ma coll.

Epoque acturle. Une espèce sur les côtes de la Californie, d'après Dall ; autre espèce aux Philippines (Genota atractoides, Watson), d'après Boettger, citation en 189.̌, c'est-àdire postérieurement à la publication de $P$. atractoides par Tate.

- Epalis , Cossm. 1889. Type : Pl. crenulata, Lamk. Eoc

Forme biconique; spire ventrue, peu allongée ; embryon proboscidiforme, à nucléus obtus el un peu dévié ; tour's subanguleux et crénelés, non excavés en arrière, munis d'un bourrelet bifide au-dessus de la suture; dernier tour assez long, à base atténuée, terminée par un canal court, à peine infléchi, sur le cou duquel s'enroule un bourrelet obsolète. Ouverture de Bathytoma; labre mince, échancré par un sinus assez profond et éloigné de la 
suture; columelle calleuse, à peine coudée et munie d'un gonflement médian, très peu visible.

Diagnose faite d'après une espece plésiotype, $P$. rentricosa, Lamk, du Guépelle (I'l. VI, fig. 29-26), ma coll. Embryon grrossi (Fig. 20) d'après un individu du calcaire grossier de Villicrs:

Rapp. et diff. - J'ai séparé ce sous-gente de Bathyloma,

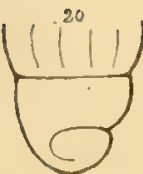

Fiti. 20 . non seulement à cause de la forme générale de la conpille, mais encore à cause de l'embryon quni est plutût proboscidiforme que conoïlal, de la disposition du canal qui est moins coudé, ainsi que de la columelle dont le gontlement pliciforme est beaucoup moins apparent. Ces différences s'atténuent d'ailleurs sur les individus adultes qui ont une analogie incontestable avec Balhylomas. s.

Répart. Stratigr.

Eocexe ....... Trois espèces dans le bassin anglo-parisien el dans la Loire-Inférieure $(P l$. crenulala, rentricosa, Lamk. varians, Liw.), ma coll.

ASTHENOTOMA, Harr. et Burr. 1891.

(=Oligotoma, Bell. 1875, non Westwood, 1836).

Spire longue ; canal court ; columelle plissée ou subplissée ; labre intérieurement denté ; embryon conoïdal.

Astilenotoma, sens. str. Type: Pl. Basteroli, Desm. Mioc.

Taille assez petite ; forme étroite, clavatulée; spire allongée, à galbe conique ; embryon paucispiré, à nucléus obtus; tours généralement ornés de carènes spirales, décussées par des plis d'accroissement sinueux ; base rapidement atténuée, terminée par un canal large, très court et assez profondément échancré, sur le cou duquel s'enroule un bourrelet très obsolète. Ouverture pelite, rhomboïdale, peu rétrécie en avant; labre arqué, mince en son contour, intérieurement épaissi et plissé ou denté, entaillé par une échancrure large et peu profonde, coïncidant à peu près 
Asthenotoma

avec la conrexité médiane des tours; columelle très calleuse, infléchie en $S$, tordue ou plissée au point où se fait l'inflexion antérieure.

Diagnose refaite d'après un échantillon de l'espèce type, du Langhien de Saucats (Pl. VI, fig. 23-24), ma coll. Embryon grossi (Fig. 21).

Observ. - En créant ce genre, dont le nom a dû ètre changé pour corriger un double emploi, Bellardi a indiqué que le pli columellaire se réduit ordinairement à une simple torsion de la partie antérieure de la columelle, mais que la Iongueur de la spire, la brièveté du canal et la forme du sinus écarté de la suture, permettent aisément de distinguer ce groupe des autres Pleurotomidx. A ces caractères, il $\mathrm{y}$ a lieu d'ajouter la plication interne du labre, qu'on constate sur tous les échantillons adultes et intacts, et l'échancrure de l'extrémité antérieure du canal qui, quoique très court, est toujours infléchi à cette extrémité.

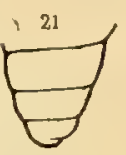

FIG. 21 .

Répart. Stratigr.

Eocexe ....... Plusieurs espèces dans le bassin anglo-parisien, dans le Claibornien des États-Unis, dans l'Australie du Sud (Purpura funiculosa; Desh. Cossmanni, de Rainc. Pl. zonulata, microchila, dissimilis, pupa, brachia, heliçoides, Edw., Olig. Meyeri, Cossm. jacksonensis, Meyer, Pl. consutilis, T. Woods, Asth. Talei, Cossm. (Pl. VI, f. 29), ma coll. [voir l'annexe à la fin de cettelivraison].

Oligocene...... Une espèce probable dans le Tongrien de l'Allemagne du. Nord ( $P l$. bicingulata, Sandb.), ainsi qu'une espèce bartonienne peut-être distincte de celle d'Angleterre (Pl. heliçoides, Edw.), d'après la Monogr. de II. von Konen.

Mrocene....... Plusieurs espèces dans le Bordelais, en Italie, dans le bassin de Vienne (P. Basterati, Desm. pannus, Bast. ornala, Defr. tuberculala, Pusch) ma coll. ( $P$. intersecta, Doderl. mirabitis, Bell. Hecketi, Hœern.), d'après les Monogr. de Bellardi et de Hœrnes et Auinger.

Phocene....... Une espèce dans le Messinien d'Orciano, confondue avec $A$. pannus, Bast., ma coll. 
Endiatoma nov. sect. 'Type: Oligotoma quadricincla, Cossm. Loc. (=Aphanitoma, Cossm. 1883, non Bell. 1875).

Forme très étroite el subulée ; spire longue ; embryon paucispiré, conoïdal; tours ornés comme ceux d'Asthenotoma; base du dernier tour excavée, terminée par un canal peu allongé, non échancré, presque sans bourrelet sur le cou. Ouverture à peine plus étroite en avant qu'en arrière, à bords à peu près parallèles ; labre mince, peu sinueux, curviligne sur toute la hauteur du dernier tour ; columelle coudée au milieu de la hauteur, munie, au point où elle s'infléchit à droite, d'un pli étroit et obsolète; bord columellaire peu calleux, limité par une strie superficielle, se terminant en pointe à l'extrémité antérieure du canal.

Diagnose refaite d'après l'échantillon néo-type d'Aizy, déjả ligguri dans le "Catalogue illustré des Corf. foss. de l'Eoc. " et plus intacl que l'échantillon type de Saint-Gobain (PI. VI, fig. 30), ma coll. Embryon grossi (Fig. 22).

Rapp. et diff. - Après avoir rapporté celte coquille au sous-genre $\perp$ phanitoma, qui s'en distingue par ses deux plis columellaires,

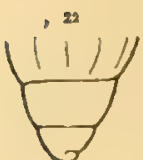

Fig. 22. j'ai proposé de la classer dans le genre Asthenotoma, dont elle est très voisine par son ornementation, mais dont clle s'écarte cependant: par l'absence presque complète de sinus, par son canal un peu plus long et moins tronqué, par son pli columellaire plus saillant, enfin par son embryon moins obtus. Ces caractères différentiels justifient la création d'une nouvelle section Endiatoma.

Répart. Stratigr.

Eocra......... L'espèce type dans le Suessonien du bassin de Paris, ma coll.

Apinanitoma, Bell, 1875. Type : Turbinella labellum, Bon. Mioc.

Forme fusoïde ; spire acuminée, médiocrement allongée ; cmbryon paucispiré, subconoïdal ; tours costulés el treillissés ; der-

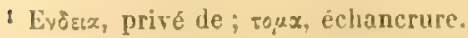


Asthenotoma

nier tour à peu près égal à la moitié de la longueur totale, régulièrement atténué à la base qui se termine par un canal assez court, presque droit, sans échancrure et acuminé à son extrémité antérieure. Ouverture étroite, allongée, à bords presque parallèles ; labre fortement plissé à l'intérieur, sinueux, dépourvu d'échancrure ; columelle presque droite, portant au tiers de sa hauteur deux plis épais, l'inférieur plus large, et quelquefois des rides irrégulières en avant ; bord columellaire calleux, bien limité, se terminant en pointe contre l'extrémité antérieure du canal.

Diagnose refaite d'après des échantillons typiques de Stazzano (Pl. VI, fig. 71), coll. du Musée de Turin.

Rapp. et diff. - Ainsi que le fait remarquer Bellardi, cette forme a beaucoup d'affinité avec Borsonia: on l'en dislingue toutefois par son aspect extérieur, par la position des plis qui sont placés plus bas et sont plus épais, par l'absence d'une échancrure labiale, remplacée par une inflexion curviligne en are de cercle à grand rajon et à petite flèche. Bellardi indique en outre, - mais je n'ai pu le vérifier, - que, dans le jeune âge, les plis columellaires sont presque effacés. Si l'on compare Aphanitoma à Endiatoma qui a également le sinus labial à peine indiqué et l'embryon conoïdal, on remarque que la columelle est munie de deux plis columellaires qui n existent pas chez Endialoma, et qu'elle n'est pas coudée comme celle d'Asthenotoma: ce sont des caractères distinctifs qui justifient la séparation d'un sous-grenre.

Répart. Stratigr.

Mrocexe ...... Outre le type, cinq espèces dans les environs de Turin (A. Pecchiolii, miocrenica, pluriplicala, tumescens el abbreviata, Bell.), d'après la Monogr. de Bellardi. Pliocene......... Une espèce très rare dans le Mlessinien des environs de Savone (A. arclala, Bell.). d'après la Monogr. de Bellardi; autre espèce dans le Messinien d'Orciano (A. hordeola, Doderl.), coll. de l'École des Mines.

Scobinella. Conrad, 1848. Type : S. coelata, Conr. Olig. (=Zelia, de Greg. 1898, non Desv. Dipt. 1830).

Taille petite : forme hordéolée ; spire courte, à galbe conoïde ; embryon mullispiré, d'abord conoidal et lisse, puis comportant 
Asthenotoma

un ou deux tours costulés dans le sens axial; tours de spire munis de carènes spirales, décussées par de fins plis d'accroissement; base rapidement atténuée, terminée par un canal court, échancré à son extrémité, munj d'un bourrelet très obsolète qui s'enroule sur son cou. Ouverture courte, étroite, à peine plus dilatée en arrière que sur la Iongueur du canal; labre épais, portant à l'intérieur quatre ou cinq crénelures allongées, entaillé à quelque distance de la suture par un sinus assez profond; columelle munie de deux plis transverses, éarlés est peu saillants. en avant desquels on dislingue, sur les individus adultes, trois rides parallèles aux plis, et dont l'inférieure est surtout saillante: bord columellaire calleux, bien limité a l'extérieur, se terminant en pointe vers l'extrémité du canal.

Diagnose faite d'apres un plésiotype de lÉ́cene de Jackson, aux Elats-Unis, S.leviplicata, Gabb (PI. VI. fig. 3ö, Ma coll. Embryon grossi (Fig. 23).

Observ. - I a plupart des auleurs (Tryon, Ziltel, Fischer, cle.), n'ayaul eu sous les yenx qutune figure défectueuse et une description incomplite? du type de Conrad, ont confondu Scobinella avec Borsonin;

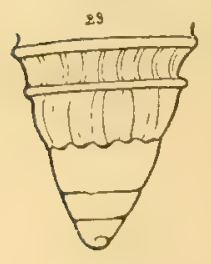

Fio. 23. 11. de Gregorio a suivi cel exemple (Monogr. Loc. Mlai. p. 45), mais il a simultanément proposé un noun nouveau (Zelia) pour me espèce à laquelle il reconnaît lui-méme une grande analogie avec le type de Conrad: en elfir. les caractères de ce genre Zeliz coïncident absolumeni avec ceux de deux espèces qui mont été envoyées sous le: nom Scobinella par M. Meyer el qui m’ont servi it rébablir la véritable diagnose du genre de Conrad. Dans ciss conditions, Zelia doit d'autant plus être rayé de la nomen-

clature des Molluscues, que ce nom avait déja été employé dans une autre branche de l'histoire naturelle.

Rapp. et diff. - Semblable à Asthenoloma par sa lorme génériale, som labre denté, l'échancrure de son canal, la position du sinus et l’ornementalion, ce sous-genre s'en distingue par son embryon, par son canal non comlé. par ses deux plis et ses rides columellaires, yni le rapprochent an contraire d'Aphanitoma; mais il s'écarte de ce dernier par son sinus et far son canal échancré; on remarquera enfin que les costules des toure cmbryonnaires existent aussi chez Asthenotoma Tatei, dont je donne lia description à la fin de lannexe. Ainsi se trouve contirné l'arrangement 
Asthenotoma

que je propose, et d'après lequel Aphanitoma et Scobinella seraient deux sous-genres distincts du genre principal Asthenotoma.

Répart. Stratigr.

Eocene....... Plusieurs espèces : soit en Angleterre ( $P l$. lineata, Edw.) ; soit dans le Claibornien des États-Unis ( $\boldsymbol{S}$. infans, Meyer, sativa, de Greg. leviplicala, Gabb., ma coll.

Oligocene...... L'espèce type dans le Vicksburgien des États-Unis, d'après la Monogr. de M. de Gregorio.

Trypanotona, Cossm. 1893. Type: Pl.terebriformis, Meyer. Eoc.

Forme de Terebra; spire longue, à galbe à peu près conique ; embryon paucispiré, à nucléus en goutte de suif ; tours convexes, ornés de carènes spirales et de crénelures sur la convexité médiane ; dernier tour court, à base arrondie, subitement atténuée en avant, terminée par un canal tronqué et profondément échancré à son extrémité antérieure, avec un bourrelet obsolète s'enroulant sur le cou et limité par une costule un peu plus saillante. Ouverture au plus égale au quart de la longueur totale, presque aussi étroite au milieu qu'en avant ; labre peu épais, plissé à l'intérieur, sinueux, faiblement entaillé sur la convexité du dernier tour par une échancrure très peu profonde; columelle lisse, coudée en $S$ très oblique; bord columellaire étroit, un peu calleux.

Diagnose refaite d'après l'échantillon type de Newton, aux ÉtatsUnis (Pl. VI, fig. 27-28), ma coll. Embryon grossi (Fig. 24), d'après un individu de Claiborne.

Rapp. et diff. - Cette forme n'est évidemment qu'un sousgenre d'Asthenotoma; elle s'en distingue cependant par son canal encore plus court, par son embryon plus obtus, surtout par l'absence complète de pli columellaire, et par son sinus presque aussi faible que celui d'A phanitoma. Il est incontestable que la coquille a un peu l'aspect de Terebra, mais elle sen distingue par son embryon et par son faible sinus

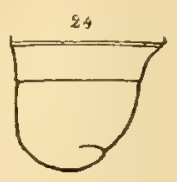

FIG. 24. labial; en outre, l'échancrure du canal est moins profonde et le bourrelet moins bien limité sur le cou. 
Répart. Stratigr.

Eocexe....... Liespece type dans le Claibornien des Élats-Unis, ma collection.

Sinistrella, Meyer, 1887. 'I'ype: Triforis americanus, Aldr. Eoc.

Forme sénestre de Trypanotoma; diagnose identique pour tous les autres caractères.

D'après un échantillon typique du Claibornien de Jackson; aux ÉtatsUnis (Pl. VIl, fig. 22-23), ma coll. Embryon grossi (Fig. 92).

Observ. - La diagnose de Trupanoloma sapplique, sans y changer un mol, à Sinistrella, à cette seule différence que la coquille est sénestre au lieu d'ètre dextre: avec un cliché négatil de l'une des deux formes, on a à peu près l'image exacte de l'autre. Il n'y aurait évidemment pas, dans cette différence d'enroulenent, de raison suffisante pour motiver la création d'une section distincte; mais, comme Sinistrella est antérieur de six années à Trypanoloma, qu'on ne peut pas appliquer celle dénomination à la forme normale qui est dextre, et que d'ailleurs l'auteur n'avail pas du tout cette forme en vue, quand il a proposé Sinzstrella, puisqu'il a décrit d'autre part Pleurotoma terebriformis (type de mon genre Trypanoloma), sans le rapprocher de $S$. americana, je ne conserve Sinistrella que pour désigner la forme sénestre, régulière et non accidentelle, de Trypanotoma. L'espèce

Fic. 23. type présente du reste des différences constantes qui ne permeltent pas de la considérer comme un échantillon sénestre de $T$. terebriformis : j'en possède huit échantillons et je puis affirmer que c'est bien une espèce à distinguer de l'autre.

Répart. Stratigr.

Eocene....... Une seule espèce dans le Claibornicn du Mississipi, ma collection.

TEREBRI'TOMA, Cossm. 1892.

'Terebritoma, sens. str. 'Type: Mangelia? solitaria, Whitf. Crét.

Taille petite; forme étroite; spire turriculée, à galbe conique; tours un peu convexes, ornés de stries spirales écartées, munis 
Terebritoma

d'une rampe déclive au-dessus de la suture; dernier tour très court, arrondi à la périphérie de la base, qui est rapidement atténuée, terminé en avant par un canal tronqué et infléchi à son extrémité. Ouverture subrhomboïdale, peu élevée; labre un peu arqué, entaillé sur la rampe suturale par un sinus assez profond, antécurrent à la sulure; columelle en $\mathbf{N}$, très courte et lisse.

Diagnose faite d'après la figure de "Syrian cretaceous fossils », reproduite (Fig. 26).

Observ. - J'ai proposé cette nouvelle coupe dans l'Annuaire géologique de 1892, en faisant l'analyse du Mémoire de M. Whitfield: la coquille qui en est le type ne ressemble à Mangitia que par sa taille et son sinus, mais elle n'a pas le labre épaissi. Sa forme générale a quelque analogie avec celle de Fibula, toutefois le sinus n'a aucun rapport avec l'entaille suturale des Entomotraniata, et il forme un crochet antécurrent, au lieu d'être profondément rétrocurrent. Néanmoins le classement de ce genre est encore extrêmement douteux : je le place provisoirement près de Trypanotoma, à cause de son

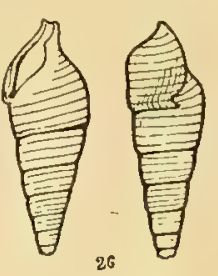

FIG. 26. canal tronqué et très court, et malgré la position tout à fait différente du sinus.

\section{Répart. stratigr.}

Cinétacé........ Une espèce dans les marnes brunes du Mont Gazelle, près d'Abeih, en Syrie, d'après Whitfield.

\section{PHOLIDOTOMA ${ }^{1}$, Cossm. 1896.}

Pноцidotowa, sens.str. Type: Fusus subheptagonus, d'Orb. Sén.

Forme fusoïde, étroite, spire longue, généralement costulée; lours convexes, ornés de cordonnets spiraux, décussés par des lamelles d'accroissement un peu crépues qui se reploient en écailles crochues au-dessus de la suture, contre laquelle elles forment un bourrelet continu ayant à peu près l'aspect d'une râpe; dernier

1 woris, écaille; ยvtoun, entaille. 


\section{Pholidotoma}

tour atténué à la base cui se termine par un canal assez allongé et droit. Ouverture étroite, un peu plus dilatée en arrière que sur la longueur du canal; labre peu arqué, mince, muni contre la suture d'un sinus court qui correspond au bourrelet écailleux; columelle à peu près étroite, faiblement intléchie à son extrémité antérieure, lisse et dénuée de plis ou de torsion; bord columellaire mince.

Diagnose donnẻe au Congrès de l'Association franç. pour l'avancement des Sciences (Session de Carthage, Avril 1896), d'après un échantillon typique de Saint-Cyr, dans le Var (Pl. VIII, fig. 15), coll. Michalet.

Observ. - Je n'ai pu étudier l'embryon qui fait défaut sur les échantillons de cette espèce mis à ma disposition; par conséquent, il m'a été impossible de vérifier si, comme chez Voluloderma (= Rostellites), cet embryon est allongé et multispiré, c'est-à-dire absolument distinet de l'embryon globuleux et paucispiré des Volutidx et des Fusidx. Nóanmoins il ne me paraît pas douteux que, malgré sa columelle lisse, celte nouvelle coupe appartient à la même sous-famille de Pleurolomidix que les genres ci-après énumérés : toutes ces formes sont caractérisées par la présence d'un sinus écailleux contre la suture et par leur ornementation lamelleuse ou crépue, qui donne ì leur surface externe un aspect tout ì fait particulier. Comme ce sont des genres qu'on ne connaît qu'à l'ćlat fossile exclusivement, et même dans les couches crétaciques seulement, l'opercule est nécessairement inconnu, de sorte que la sous-famille Pholidclominx, dans laquelle je propose de les grouper, doit être caractérisée par ce sinus écailleux et cette ornementation crépue, tout en comprenant les coquilles dissemblables par leur forme.

Répart. Stratigr.

Turonien...... Plusieurs espèces dans le Mornasien du Var el dans les couches de Gosau (Fusus heptagonus, Sow non Lamk. Pleurot. fenestrata, Zek.), coll. Michalet et d'après la Monogrr. de Zekeli. 
BEISSELIA, Holzapfel, 1889.

(=Konenia, Holz. 1888, non Beushausen).

Beisselia, sens. str.

Type: Krenenia speciosa, Holz. Sén.

Forme buccinoïde, un peu trapue; spire probablement peu allongée, étagée, à galbe à peu près conique; tours anguleux, costulés en avant, excavés au-dessus de la suture qui est bordée d'une large rangée d'écailles curvilignes, écartées et saillantes; dernier tour à base convexe, rapidement atténuée, terminée par un canal large et probablement infléchi vers la droite de l'axe. Ouverture courte, piriforme, peu rétrécie en avant; labre mince, peu arqué dans la plus grande partie de sa hauteur, entaillé contre la suture par une très profonde échancrure sur le périmètre de laquelle il se retrousse en formant une écaille crochue; puis an delà, il se raccorde avec le bord opposé de l'ouverture; columelle lisse, faisant un angle de $100^{\circ}$ avec la base de l'avant-dernier tour, coudée à droite à la naissance du canal, bord columellaire large, épais, complètement détaché.

Diagnose refaite d'après l'échantillon type de Vaals (PI. VII, fig. 1כّ et 19) coll. Beissel, communiqué par M. Holzapfel.

Rapp. et diff. - Ce genre se distingue de Pholidoloma par son faciès plutôt buccinoïde que fusiforme, par son canal incurvé (quoique la mulilation de l'échantillon type ne permette pas de constater si ce canal est long ou brièvement tronqué à son extrémité), par son sinus plus profond, par son bord columellaire détaché, et par l'angle peu ouvert que fait la columelle avec la base de l'avant-dernier tour ; les écailles suturales sont encore plus saillantes et plus écartées que celles de $P$. subheptagona, el elles se transforment parfois en de véritables tubulures : c'est, à ce point de vue, la forme la plus caractérisée de la sous-famille Pholidotominæ.

Répart. Stratigr.

Sexoxien........ L'espèce type dans les sables verts des environs d'Aixla-Chapelle. 


\section{ROSTELLITES, Conrad, 1855.}

$(=$ Volutoderma, Gabb, 1876).

Rostellites, sens, str.

Type: R. texana, Conr. Grét. sup.

Forme étroile, scaphoïde; spire courte, subulée, à galbe légèrement extraconique; embryon polygyré, aigu (ficle Holzapfel), à nucléus très petit et trochoïde (fide Dall); tours un peu converes, cancellés, ornés de nodosités à l'intersection des mailles, et de fines lamelles d'accroissement, plus saillantes et courbées audessus de la suture; dernier tour très allongé, à base lentement atténuée, se terminant par un canal long, assez large, à peu près rectiligne, vraisemblablement dénué d'échancrure ì son extrémilé antérieure, et par conséquent de bourrelet sur le cou. Ouverture très longue et très étroite, également atténuée à ses deux extrémités; labre presque vertical, à peine arqué, entaillé près de la suture par une échancrure large et peu profonde, correspondant aux petites écailles curvilignes: columelle peu excavée, dans le prolongement de la base de l'avant-dernier tour, munie en arriire de reux ou trois plis épais, généralement obliques, et peu visilıles à l'entrie de l'ouverture, parce qu'ils sont très enfoncés à l'intérieur; bord columellaire mince, non détaché.

Diagnose refaite d’après un échantillon de l'espèce type, provenant de Kaufman, dans le Texas (Pl. VIII, fig. 12), collection du Musée national de Washington, envoyé en communication par le Smilhsonian Institute; plésiotype des environs d'Aix-la-Cliapelle, Pirula fenestrala, Roemer, des sables verts du Sénonien de Vaals (IPI. VII, fig. 16 et 18), coll. du Musée d'Aix-la-Chapelle, envoyé en communication par M. Holzapfel.

Observ. - La synonymie de Rostellites et de Voluloderma n'est pas douteuse, altendu qu'il parait y avoir identité, sinon spécifique, du moins grénérique, entre les espèces types de ces deux genres: Volutoderma navarroensis, Gabb. et Rostellites texuna, Conrad. J'ai sous les yeux, grâce à l'obligeance de nos confrères du musée de Washington, et parliculièrement de M. Stanton, les types de ces deux especes de Californie et du 


\section{Rostellites}

Texas, de sorte que jai pu me convaincre que la réunion de lermes génériques, proposée en 1890 par .1. Dall (Contrib. lert. launa of Florida, p. 71) est tout a fail justifiée; mais je ne partage pas son opinion an sujet de classement de Rostellites.

Se fondant sur l'analogie de la forme extérieure de cette coquille avec certaines Volutidie, sur la présence de plis à la columelle, enfin sur ce que Aurinia dubia et quelques Harpidie possèdent aussi un sinus sulural qui donne passage, non pas comme chez les Pleurolomita a une papille anale pour les déjuctions de lanimal, mais à un prolongrament du mantean qui dépose un vernis sur la partie inférieure de la coquille, M. Dall place. Roslellites auprès de Volutilithes. Pour que ce rapprochement fût admissible, il faudrait que l'embryon de Rostellites fùt, comme celui des Volulidær, paucispiré et très globuleux; car on reconnait immédiatement la spire d'une coquille de l'un des genres de Volutidx par l'embryon qui est tout à fait disproportionné avec les tours suivauts. An contraire, chez Rostellites, l'embryon est, ainsi que Holzappel l'a constaté et figuré, multispiré et pointu ; le nucléus de cet embryon est, ainsi que le reconnaît Dall lui-mème (p. 72), " an acute apex and trochoid, minute nucleus ", c'est-à-dire qu'il $n$ 'a aucun rapport avec celui des Volutidæx, ni même des Fasciolariidie on des Turbinellidx, et qu'il se rapproche plutôt de celui des Pleurolomidx.

Indépendamment de ce molif, qui a un très grand poids, au point de vue du classement par familles, il y a lieu de remarquer qu'il y a une étroite affinité entre tous les genres que j'ai groupés dans la nouvelle sous-famille Pholidolomina, malgré les différences considérables que présente leur forme extérieure qui varie depuis l'aspect fusiforme jusqu'au galbe conique avec une columelle tantôt plissée, tantôt lisse : outre leur sinus écailleux, il y a l'analogie de leur ornementation, l'absence complète d'échancrure à la partie antérieure du canal (tandis que celui-ci est profondément entaillé chez les Volutidx et les Harpidx); il résulte de celte affinité des quatre genres en question qu'on ne pourrait transporter Rostellites dans la famille Volutidx sans y entrainer également Pholidoloma qui a une forme de Fusus, Beisselia qui a une forme de Buccinum, et qui n'ont, ni l'un ni l'autre, de plis columellaires.

En résumé, sans contredire l'assertion de M. Dall, relativement à l'usage probable de l'ćchancrure suturale des Pholidotomina, je maintiens que celte sous-famille ne peut être classée auprès des Volutidx, et je préfère la laisser provisoirement dans les Pleurotomirla, à cause du sinus et del'embryon, jusqu'à ce quion ait la certilude qu'elle doit former une famille dislincte et 'quion ait les éléments nécessaires pour fixer définitivement la place de celle famille.

Rapp. et diff. - La forme générale et les plis columellaires de Rosle'tiles séparent bien nettement ce genre de Pholidotoma et de Beisselia, qui s'en rapprochent par leur sinus écailleux el par leur ornementalion crépue. 
Répart. Stratigr.

Turonicx....... Plusieurs espèces, soil dans les grès de Vaucluse

(Voluta elongata, d'Orb.), ma coll. ; soit à Gosau dans le Tyrol (Pleurol.spinosa, Sow. Voluta prxlonga, Zek.). d'après la Monogr. de Zekeli; soit dans l'Inde, au niveau du groupe de Trinchinopoly (CF. $V$. elongata, d'Orb.), d'après la Monogr. de Stoliczka; soit dans les sables a Pugnellus du Colorado (Rost. ambigua, Dalli et gracilis, Stanton), d'après les figures publiées par l'auteur.

Senomex...... Plusieurs espèces, soit dans la Craie de Californie. du Mexique et du Texas (Rost. texana, Conr. VoluInclerma navarroensis, Gabb, Gabbi, White), coll. du Musée de Washington; soit dans les sables verts de Vaals (Pirula renestrata, Romer, Volutnderma Zilteliana el Gosseleti, Ilolz.), coll. du Musée d'Aixla-Chapelle et d'après la Monogr. d'Holzapfel.

GOSAVIA, Stoliczka, 1865.

Gosavia, sens. str.

Type: Voluta squamosa, Zek. 'Tur.

Forme conique; spire très courte, tectiforme; tours élagés en gradins, ornés de cordons spiraux découpés par des lamelles d'accroissement et munis sur la rampe, près de la suture, d'une rangée d'écailles écartées. Ouverture i bords parallèles, terminée en avant par un canal assez court, large el tronqué; labre presque droit, entaillé à la suture par une profonde échancrure, dont le contour retroussé forme les écailles caractéristiques de la rangée suturale; columelle calleuse, munie de cinq ou six plis, les plis antérieurs plus obliques et plus rapprochés que les plis postérieurs.

Diagnose faite d'après les échantillons types, provenant de Gosau, coll. du K. K. geol. Reichsanstalt, à Vienne, communiqués par M. Bittner ; et d'après des clichés pholographiques, pris sur des échantillons de même gisement, en meilleur état, coll. du Hofmuseum à Vienne (Pl. VII, fig. 26-27), envoyés par M. Kittl.

Rapp. et diff. - Quoique cette forme se rapproche plus de Rostellites que de Pholirotoma, à cause de son canal ample el de ses plis columellaires, 
Rostellites

Gosavia est bien un genre distinct, non seulement à cause de son galbe régulièrement conique et trapu, mais surtout à cause du nombre plus considérable de ces plis; d'ailleurs le canal est moins allongé et la spire est plus étagée. Stoliczka (Eine revision der Gastr. Gosaugeb.) classe ce genre dans les Volutidx, à cause de ses plis columellaires; toutefois, bien que je n'en connaisse pas l'embryon, je n'hésite pas à placer Gosavia dans la sous-famille Pholidotominx à cause du sinus écailleux et caractéristique qui borde la suture.

\section{Répart. Stratigr.}

Turonien ..... Outre le typeà Gosau, dans le Tyrol, une espèce certaine dans l'Inde, groupe de Trinchinopoly (G. indica, Stol.), d'après la Mlonogr. de Stoliczka; autre espèce probable dans la Touraine, quoiqu'on n'y ait pas constaté l'existence de plis columellaires (Conus tuberculatus, Dujard.), d'après les figures dela Paléont. française, et d'après l'avis de Stoliczka.

\section{MANGILIA, Risso emend. 1826.}

Tours costulés ; embryon papilleux, à nucléus légèrement dévié; canal court ; labre variqueux: sinus entaillé plus ou moins profondément dans la varice labiale.

Mangilia, sens. str. Néotype : Pleurot. Vauquelini, Payr. Viv.

(=Clathromangelia, Monts. $1884 ;=$ Cyharella, Monts. 1875, err. typ. pro Cytharella; = Pseudoraphitoma, Boettg. 1895; = Paraclathurella, Boettg. 1895).

Taille petite; forme fusoïde, plus ou moins trapue; spire assez courte, quelquefois étagée; embryon à tours convexes, à nucléus papilleux; tours ornés de costules axiales obliques, généralement repliées vers la suture, parfois cancellées par des filets spiraux; dernier tour égal ou supérieur à la moitié de la longueur totale, à base atténuée, terminé en avant par un canal court, large, tronqué, sans échancrure à son extrémité. Ouverture étroite, à bords à peu près parallèles; labre épaissi par la dernière côte, lisse à 
Man!jilia

l'intérieur, un peu oblique, à peine arqqué, entaillé contre la suture et dans l'épaisseur de la varice, par un sinus crochu et assez profond; columelle presque droite, lisse et arrondie; bord columellaire inince, étroit, à peine distinct.

Diagnose faitr daprès des échantillons typirques des côtes du lioussillon, el d'après nue espèce plésiolype fossile du Plaisancien, M. costala, Donov. provenant de Biot, dans les Alpes-Mtarimes (Pl. VIl, fig. 24-20). ma coll., autre espece representant te groupe Clathomangitia, Pl. quadrillum Dujardin, de l'llolvétien de P'ontlevoy (Pl. VII, fig. 11), ma coll.

Observ. - La création du genre Mangilia (ledié a Mangili, non pas i Mangel) est souvent altribuée à Leach; en réalité, ce genre a été établi, sur son conseil, par Risso, pui y a classé desformes fort hétérogènes, et parmi elles $\mathrm{Pl}$. Vauquelini, puis réformé par Hinds qui y a compris celle espèce, la seule véritable Mangitia qui füt connue de Lisso. arec M. plicatilis: comme cette dernière est synonyme d'Hietropleura seplangularis, Montg., il faut admettre l'autre comme néotype du genre Mangilia.

Si l'on restreint ce genre comme le font actuellement la plupart des auteurs, il est caractérisé par sa columelle et son labre non plissés, par son sinus assez profondément entaillé dans la varice labiale; lomementation est tantôt exclusivement formée de costules axiales à intervalles lisses, lantôt cancellée : c’est au groupe des espèces cancellées que Monterosalu a proposé d'appliquer la dénomination Clathromangilia (Type: $P$ l. granum, Phil, analogue fossile $P$. quadrillum, Duj.). Je ne crois pas qu'il y ail lien d'admettre cette section pour une aussi légère différence d'ornemenlation, d'autant plus qu'il existe des espèces intermédiaires, dans lesquelles apparaissent déjà quelques filets spiraux.

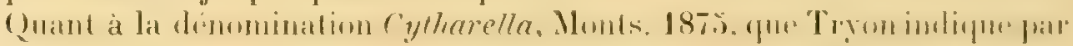
rreur en 1876, et comme synonyme de Cythara, M. de Monterosato ma expliqué que son intention était, dans le cas ou l'on aurait pris comme. néotype de Mangilia, M. Poliana el reliculata, qui sont des Rissoina. d'appliquer une dénomination à ce qui restait de Pleurolomidzedans le genme hybride de Risso. Mais comme celle interprélation ne subsiste plus, des l'instant que to néotype est M. I auquelini, - ce qui a d'ailleurs l'avanlage de ne pas remplacer Rissoina par Manjilia, - l'auteur a Lii-mime renoncé, en 18:, a poursuivre celle reclification complexe, et par conséupuent, Cytharella doit êtro rayé de la nomenclature.

linfin je considere comme synonymes de Mangilia les sections proposires cn 1890 par M. Bollger, daus sa nole sur les mollusques des Plhilippines (Psendoraphitoma ol Paraclathurella): il n'est pas admissible de multiplicr 
Iangilia

à ce point les subdivisions génériques, pour de simples modifications d'habitat.

Répart. Stratigr.

Eocene....... Plusieurs espèces typiques, soit dans le bassin de Paris, soit aux États-Unis $(\boldsymbol{M} . p a-$ risiensis et labratu'a, Cossm., $P l$. acceptata et semicosiulata, Desh., meridionalis, Meyer), ma coll. Embryou grossi (Fig. 27) d'un individu de $\boldsymbol{M}$. parisiensis, provenant du calcaire grossier de Villiers.

Oligocene...... Deux espèces bien caractérisées dans

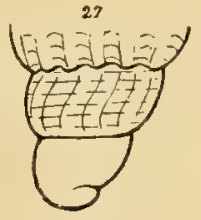

FIG. 27. le Tongrien inférieur de l'Allemagne du Nord et de Belgique (Pl.aculicosta, Nyst., Mang. planistria, v. Koen.), d'après la Monogr. de M. von Koenen, car la figure de l'ouvrage de Nyst est méconnaissable.

Mrocexe....... Plusieurs espèces dans le Langhien des environs de Bordeaux et dans l'Helvétien de la Touraine (Pleur. cheilotoma, Bast., Aglaia, Mayer, quadrillum, Duj., Lemariei,Dollf. Dau(z, labeo, Duj:), macoll. et d'après l'étude préliminaire des faluns de la Touraine, par Dollfus et Dautzenberg; autres espèces en Italie (M. catagrapha, longa, Monterosaloi, Bell.), d'après la Monogr. de Bellardi.

Pliocene....... Nombreuses espèces dans le Piémont, le bassin du Rhône et le Crag. d'Angleterre (M. Biondii, Bell., scabriuscula et ambigua, Brugn., costala, Penn., rugulosa, Phil., milreala, Bon., clalthrata, M. de S., iubulata, Font.. contracta, Bell., Pl. brachysloma, Phil.), d'après les Monogr. de Fontannes, de Bellardi et de Wood; une espèce dans le Tertiaire supérieur de Java (M. ollivia, Mart.), d'après la Monogr. de Martin.

ÉPoque actuelle. Très nombreuses espèces dans toutes les mers, d'après le Manuel de Tryon.

Mangiliella, Bucq. Dollf. Dautz.

Type: Pl. multilineolata. Desh. Viv.

Forme de Mangilia; embryon à nucléus dévié ; tours ornés de -costules axiales serrées et obliques, non repliées vers la suture; 
ouverture et canal de Mangilia; labre épais, un peu arqué, presque sans sinus à la partie inférieure; columelle lisse, un pen incurvée.

Diagnose faite d'après des échantillons de l'espèce type, provenant des côtes du Roussillon (Pl. VII, fig. 13), ma coll.

Rapp. et diff. - La séparation de celte section n'est motivée que par l'absence presque complète de sinus labial; car la forme élancée de la coquille se rencontre également chez beaucoup de Mangilia typiques; quant au degré d'écartement des côtes, que les auteurs de cette section indiquent comme caractéristique, c’est un critérium qui n'a qu'une valeur spécifique.

Répart. Stratigr.

Mrocene....... Une espèce dans l'Helvétien de Touraine, distincle du type vivant ( $\boldsymbol{M}$. turonica, Dollf., Dautz.), diapres l'étudo préliminaire des faluns de la Touraine.

Pliocene....... Une espèce dans le Crag d'Angleterre Clavalula mitrula, Wood), d'après la Monogr. de S. Wood.

Eucithara, Fischer, 1883. Type: Cancell. citharella, Lamk. Viv. (= Cythara, Schum. 1817, non Cithara, Klein 1753 $=$ Otocheilus, Conr. sec. Tryon?

Forme trapue, stromboïde; spire courte, à galbe souvent extraconique; embryon proboscidiforme; tours ornés de costules à jeine obliques et de fines stries spirales; dernier tour tris grand, obliquement atténué à la base qui se termine par un canal court, tronrué et légèrement échancré à son extrémité antérieure. Ouverture étroite, à bords presque parallèles; labre presque droit, épaissi par une varice, plissé à l'intérieur, entaillé en arrière par un sinus à peine visible sur la plupart des espèces: columelle calleuse, à peu près rectiligne, généralement munie de rides transversales. 
Mangilia

Diagnose faite d'après une espèce plésiotype de l'époque actuelle, Mangilia marginelloides, Reeve, provenant des Philippines (PI. VII, fig. 33), coll. de l'École des Mines.

Observ. - Le nom de ce sous-genre a été changé par Fischer pour corriger un double emploi de nomenclature; Tryon et Dall ont, au contraire, conservé Cythara, Schum.; cependant, même si l'on n'admet pas, comme antérieures au système binominal de Linné, les dénominations de l'ouvrage de Klein, il n'est pas possible de conserver un nom employé après Klein et avant Schumacher, dans un sens différent de celui que lui attribue ce dernier auteur. Comme d'ailleurs il y a synonymie complète entre Cithara et Cythara, la correction proposée par Fischer s'impose.

Rapp. et diff. - Ce sous-genre se distingue de Manjitia s. s. par sa forme trapue, par son sinus à peine entaillé, par son labre et sa columelle plissés ou ridés. Il n'a commencé à apparaître que bien après Mangilia, dans les étages supérieurs des terrains tertiaires : les espèces de Cithara décrites par Whitfield, dans son étude sur les marnes vertes de la craie de NewJersey, sont en effet des moules internes peu déterminables qui, par leur grande taille, ainsi que par les traces d'ornementation qu'ils portent, ne peuvent être comparés aux véritables Eucithar . Il en est de même de Cith. cretacea Stoliczha, du Crétacé de l'Inde, malgré le bourrelet labial et la petite sinuosité postérienre qu’indique la figure.

Répart. Stratigr.

Plocexe....... Trois espèces dans les couches tertiaires de Caloosahatchie, en Floride (Mang. balteata, Reeve, psila, Bush., terminula, Dall.), d'après la première partie de l'étude de M. Dall sur le Tertiaire de la Floride.

Epoque actuelle. Nombreuses espèces dans les mers chaudes, d'après le Manuel de Tryon.

Clathurella, Carpenter, $185 \%$.

Type: Clavatula rava, Hinds. Viv.

$1=$ Defrancia, Millet 1826, non Bronn 18t5; = Cirillia, Monts. 1884; = Lienardia, Jouss. 188:\% ; = Corderia,

Monts. 1884, non Rouault; = Philbertia, Monts. 1884; = Leufroyia, Monts. 1884).

Forme buccinoide; spire conique, étagée; embryon paucispiré, papilleux, à nucléus subdévié; tours anguleux, costulés au-des- 
Mangilla sus de l'angle, excavés en dessous, généralement ornés de stries spirales; dernier tour grand, cylindroconique, un peu creusé à la base par une dépression qui sépare le cou du canal. Ouverture rhomboïdale, allongée, terminée en avant par un canal court, large et légèrement échancré; labre presque vertical, à peine curviligne au milieu, entaillé sur la rampe suturale par un sinus ovale et profond, au-delà duquel il est antécurrent vers la suture, aminci à son contour externe, épaissi à l'intérieur où il porte quelques plis allongés et écartés, muni à l'extérieur d'un large bourrelet peu saillant, qui est silué en deçà du contour et qui cesse autour du sinus dont le rebord est plus mince; columelle presque droite, faisant un angle arrondi de $110^{\circ}$ avec la base de l'avant-dernier tour; bord columellaire large et peu calleux, portant un rentlement ou une dent pariétale vis-i-vis du sinus du labre, et quelques crénelures médianes, irrégulières el souvent imperceptibles, se lerminant en pointe à l'extrémité antérieure, contre le canal.

Diagnose faite d'après une espece plésiotype lu Langhien des environs de Bordeaux, C. Milleli, Desm. (Pl. VI, fig. 36-3i) provenant du Péloua, ma coll. Embryon grossi d'une espèce pliociniçue de Biot, C. scaluria, Jan. (Fig. 28).

Observ. - Le type de ce genre a étécréé par Carpenter lans le Catal. Mazatlan, d'après une espèce peu commune des Philippines, de sorte que la plupartdes auteurs y ont substitué comme exemple Murex

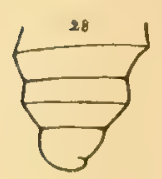
luearis, Mont., qui est micux connu et qui a exactement les mèmes caractères génériques. Quoique les Clathurella soient, en général, peu variables, ce sous-genre a cité l'objet de démembrements excessils, des denominations nouvelles ont mème été proposées pour de simples variétés d'une mèméespèce: d'abord Cirillia (non Cyrilla, Ail.) a pour lype Murea

Fin. 28. linearis, Monter. qui ne differe pas - genciriquement - du type de Clathurella, de sorte que le touble emploi est ivident; Cordieria, qui ne pourrait en tous cas ètre maintemu puisque te nom a déjà été employé par Rouault, a pour lype $P$. reliculala, Ren. qui ne présente aucune difference gémerique ave de véritables Clathurella; Philbertia (1ype: $1 \mathrm{H}$. bicolor, Risso) at Leufrogia (typer: P. Leufroyi, Mich.) sont appliquées it des formes dériviess de Murex purpureus, Montg. qui est une espece de Ciathurella it lours plus arrondis 
Mangilia

et ì surface plus finement réliculée que $C$. linearis: ce sont encore des caractères distinctifs qui suffisent pour séparer des espèces, mais qui ne peuvent motiver la création de sous-genres, ni mème de sections. Enfin Lienardia a été proposé par le docteur Jousseaume, dans le Bulletin de la Soc. zool. de France (1884), pour des coquilles caractérisées " par la présence de dents plus ou moins saillantes sur la partie interne des deux bords de l'ouverture ": or ce sont précisément les caraclères typiques de C. linearis; lorsque M. Jousseaume indique que son sous-genre se distingue des Clathurella "qui ont les bords lisses ", c'est évidemment qu'il le compare à des Mangitia; il n'est donc pas possible de conserver Lienardia qui est complètement synonyme de Clathurella, malgré l'avis de M. Bœttger (Moll. Phil., 1895) qui applique cette section aux Clathurella indopacifiques, et qui en propose même une nouvelle, Hemilienardia (type: $\mathrm{Pl}$. Malleti, Recl.), pour des espèces plus petites, à peu près dénuées de plis columellaires. Cette multiplicité de subdivisions me parait tout à fait excessive et, en tous cas, hors de proportion avee ce que nous avons admis dans les autres genres.

Rapp. et diff.-On distingue aisément Clalhurella de Mangilia parl'exislence de plis ou de rides à l'intérieur du labre et sur la surface médiane du bord columellaire, ainsi que par la dent pariélale et tuberculeuse, ou tout au moins par le renflement calleux, qu'on remarque à la partie postérieure de l'ouverture, vis-à-vis du sinus, lorsque les individus sont adultes. Les rides de la columelle sont quelquefois très effacées, surtout lorsqu'il s'agit de jeunes échantillons, mais les plis internes du labre existent à tout âge sur les individus dont l'ouverture est intacte, landis qu'on n'en constate aucune trace chez Mangilia. Si on compare Clathurella avec Eucithara, on trouve que non seulement la forme générale est tout à fait différente, mais encore que le sinus est beaucoup plus profondément entaillé, tandis que la dent pariétale fait défaut chez Eucilhara.

Répart: Stratigr.

Eocene.........

Mrocene ........

Pliocetie......
Une espèce dans l'Australie du Sud ( $M$. bidentala, Tate), ma coll.

Plusieurs espèces, soil dans le Langhien du Bordelais et l'Helvélien de la Touraine, soit en Italie, soit dans le bassin de Vienne (C. Milleti, Desm. pagoda, hordacea el suturalis, Millet, sublilis, Partsch, subcostellata, d'Orb. scrobiculata, Mich ${ }^{\mathrm{t}}$, effossa, dectivis, Aldrovandii, Bell., elc...), ma coll. et d'après la Monogrr. de Bellardi, d'après l'étude préliminaire des faluns de la Touraine par Dollfus et Dantzenberg. Deux espèces lypirques dans le bassin du Rhône el le Roussillon (C. perpiniana, Fonl. P. consobrina, Mayer), d'après la Monogr. de Fontannes et les 
figures du Journ. de Conchyl. (1891); trois espéces certaines dans le Crag. d'Angleterre el d'Anvers $(P$. linearis, Mont. perpulchra, Wood, et Leuproyi, Mich" $\left.{ }^{t}\right)$, d'après les Monogr.de S. Wood el de Nyst; plusicurs espèces en Italie (C. scalaria, Jan, Luisx, Semp. ringens, Spreafici, albigonensis, Bell. emarginata, Donov.), ma coll. et d'après la Monogr. de Bellardi.

Epoque actuele. Nombreuses especes dans toules les mers, diapris le Manuel de Tryon.

Glyphostom, Gabb, 1872. Type: G. dentifera, Gabb. Mioc.

Forme et ornementation de Clathurella; canal un peu allongé el peu recourbé; ouverture rétrécie; labre très épais, fortement denté à l'intérieur; columelle calleuse, munie d'un grand nombre de plis transversaux qui croissent d'avant en arrière.

Diagnose reproduite d'après la figure de l'espèce type, dius le Manuel de Tryon, dont la copie est ci-contre (Fig. 29).

Rapp. et diff. - Autant que je puis en juger d'après une figure, cette sec29 tion ne diffère de Clathurella que par son canal un peu plus

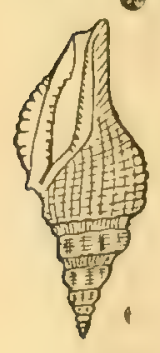
long, presque droit, par ses crénelures columellaires plus saillantes, moins obliques, et par l'absence de dent pariétale. Ces différences sont si peu certaines que M. Dall, - qui d'ailleurs conserve (in lill.) des doutes sur la validité de cette section, - désigne sous le nom de Glyphostoma un certain nombre d'espèces du Miocène de la Floride que je ne distingue pas des Clathurella typiques: il y a du reste des Clatherella européennes ( $C$. scalaria, Jan) qui ont un canal assez long et presque droit. Toutefois il faut attendre, avant

Fis. 29. de supprimer Glyphostoma, qu'on ait pu comparer l'espéce ıype, que je n'ai pu me procurer.

Répart. Stratigr.

Mrocene .......
Liespèce type dans les couches néogènes de Saint-Domingue; quant aux espèces citées par Dall dans la Floride (G. gratula et Watsoni, Dill.), elles ne paraissent pas differer de Clathurella. 
Forme étroite; spire turriculée, à galbe conoïde ; embryon conoïdal, à nucléus un peu dévié et papilleux; tours ornés de costules axiales et de stries spirales très fines dans les intervalles des côtes ; dernier tour grand, à base rapidement atténuée, terminé en avant par un canal court, tronqué et profondément échancré à son extrémité, avec un bourrelet peu saillant et cancellé sur le cou. Ouverture assez étroite, un peu plus dilatée au milieu; labre épaissi par une forte varice, plus mince sur son contour, lisse à l'intérieur, entaillé contre la suture par un sinus très profond, en forme de crochet, portant en avant une sinuosité ou dépression semblable à celle de Strombus; columelle lisse, excavée en arrière, coudée vers la partie antérieure du canal ; bord columellaire assez large, peu épais.

Diagnose refaite d'après un échantillon de l'espèce type, du Plaisancien de Biot (PI. VII, fig. 29-30), ma coll. Embryon grossi (Fig. 30).

Rapp. et diff. - Ce sous-genre se distingue de Mangilia par l'échancrure antérieure de son canal, par le bourrelet qui correspond sur le.cou à cette échancrure, enfin et surtout par la sinuosité caractéristique du contour basal de son labre; à cette dépression correspond une sinuosité des côtes axiales, sur la base du dernier tour. Si on compare $D i$ toma à Clathurella, on l'en distingue, non seulement par ce dernier caractère, mais encore par l'absence de plis à l'intérieur du labre, ainsi que sur la columelle.

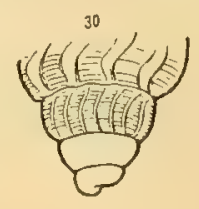

FiG. 30
Répart. Stratigr. Mrocene ......

Pliocene....... L'espèce type dans l'Astien de Cannes et le Plaisancien de Biot, ma coll.; dans le Messinien des envi rons de Savone, d'après la Mlonogr. de Bellardi, et dans le Plaisancien des environs de Bologné, d'après le Catalogue de Foresti. 
Aтoмa, Bellardi, 1875. Type: A. hypothetica, Bell. Mioc.

Forme fusoïde ; spire allongée, à galbe conique; embryon pau('ispiré, subghobuleux et subconoüdal, à nucléus en goutle de suif; tours ornés de costules dioiles et saillantes, décussées par des cordons très obsolètes et écartés; dernier tour assez court, à base rapidement atténuée, terminé en avant par un canal très court, rétréci, un peu infléchi et faiblement échancré à son extrémité, avec un bourrelet très obsolète sur le cou. Ouverture subpiriforme, peu dilatée au milieu, rétrécie à la naissance du canal; labre presque vertical, à peine sinucux, sans échancrure en arrière épaissi par une très forte varice, lisse à l'intérieur; columelle arquée en $S$, dénuée de plis ou de rides; bord columellaire calleux, recouvrant imparfaitement la fente ombilicale qui le sépare du bourrelet du canal.

Diagnose faite d'après des échantillons de l'espèce type de SantaAgata, près Turin (PI. VII, fig. 17), coll. du Musée de Turill.

Rapp. et diff. - Ce sous-genre se rallache à Mangilia par son labre variqueux, mais il s'en écarte par l'absence complète du sinus qui est encore moins apparent que chez Mangiliella et Eucithara: les stries d'aceroissement ne sont pas du tout curvilignes aux abords de la suture, it laquelle clles aboutissent perpendiculairement. Néanmoins, il parait légitime de conserver cette forme dans les Pleurotomidze, à cause de son faciès général et de som embryon qui ne ressemble pas à celui de Siphonalia.

Répart. Stratigr.

Mrocene ....... L'espèce type dans le Tortonien des environs de Turin, d'après la Monogre. de Bellardi; et dans l'Italie centrale d'après Doderlein.

IDAPHNELLA, Hinds, 1814.

Labre mince, non plissé intérieurement; columelle lisse; sinus peu profond, contre la suture, embryon polygyré. 
Daphnella

Daphnelua, sens. str. Type : D. limniformis, Kiener, Viv:

Test mince; taille assez petite; forme ovale, fusoïde ou buccinoïde; spire peu allongée, à galbe conoïde ; embryon lisse, polygyré, régulièrement conique, à nucléus pointu et très pelit; tours convexes, finement cancellés ou réticulés, munis, contre la suture, d'une rampe déclive, parfois un peu excavée; dernier tour très allongé, à base convexe, peu atténuée, terminée par un canal parfois très courl, large, transversalement tronqué, sans aucune échancrure. Ouverture assez étroite, ovale ou plutôt subrhomboïdale; labre simple, à contour arqué, entaillé sur la rampe. suturale par un sinus arrondi et peu profond, généralement dilaté en avant chez les individus adultes et complets; columelle excavée au milieu, faiblement infléchie à son extrémité antérieure; bord columellaire mince, étroit, peu visible.

Diagnose refaite d'après des échantillons typiques des Antilles, et d'après une espèce plésiotype du Mlessinien d'Albenga, sur le golfe de Gênes, D. Romaniz, Lib. (Pl. VII, fig. 31-32), échantillon unique de la collection du Musée de Turin, figuré par Bellardi.

Rapp. et diff. - Ce genre se distingue aisément de Mangilia par son labre mince, de Clathurella par sa columelle lisse, et surtout de toutes les. autres formes de la même sous-famille, par son canal large et tronqué, ainsi que par son labre dilaté avant d'aboutir à la troncature basale, de sorte qu'elle a l'aspect buccinoïde; toutefois le sinus est bien visible, le canal n'est pas échancré à son extrémité antérieure, il n'y a pas de bourrelet sur le cou, mais un simple petit rebord qui est la continuation du bord columellaire, sur les individus complètement adultes.

Répart. Stratigr.

Eocene........ Une espèce nouvelle dans la Loire inférieure (D, eocrenica Cossm.) ma coll.; embryon grossi (Fig. 31).

Mrocene....... Une espèce dans l'Helvétien de Pontlevoy, confondue avec $D$. Salinasi, mais évidemment nouvelle $(D$. ponteleviensis. nob.). Voir la description à l'annexe 31

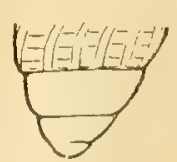
ci-après (Pl. VII, fig. 9-10), ma coll.; Figr. 31. autre espèce dans le Langhien du Bordelais (Homotoma Degrangei, Cossm.), ma coll. 
Pliocene...... Deux espèces dans les Alpes-Maritimes et la Haute Italie (Pl. Romanii, Lib. Salinasi, Bell. Komot.producta, Bell), ma coll. et d'après la Monogre de Bellardi; autre espèce probahle dans le Crag d'Anvers $P l$ similts, Nyst), d'après la Monogr. du Scaldisien de Nyst; une espèce dans le Tertiaire supérieur de Java (D. fragilissima, Mart.), d'après la Monogr. de Martin; une espèce certaine dans les conches de Caloosahatchie, en Filoride (D. cingulata, Dall) d'après la Monogr. de Dall.

Epopve acturcue. Nombreuses espèces dans toutes les mers d'après le Mamuel de Tryon.

Beliardiella, Fischer, 1883.

Type: Murex gracilis, Montg. Viv. $x,+5,1829$

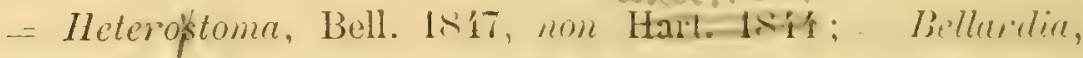
Bucr. Dollf. Dautz. 1882, non Mayer 1870; = Homoloma, Bell. ex max. parte; = Comarmondia, Monts. 1881).

Forme élancée, fusoïde ; spire allongée, à galbe conique; embryon conoïdal composé de deux tours guillochés et d'un nucléus lisse et pointu; tour's converes, costulés et ornés de filets spiraux, munis d'une rampe suturale getnéralement excavé; dernier tour assez court, arrondi à la base qui est rapidement atténuée, terminé par un canal allongé, un peu infléchi, tronqué sans échancrure à son extrémité. Ouverture piriforme, rétrécie en avant, vis-à-vis de l'inflexion du canal: labre très arqqué, mince, entaillé au-dessus de la suture par une échancrure très profonde; columelle en $S$ très oblique, arrondie, lisse; bord columellaire très étroit et très mince.

Diagnose refaite d'après des échantillons de l'espèce type, provenant de ma coll., et d'après une espèce de plésiotype du Plaisancien de Biot, Murex textilis, Br. (P1. VT, fig. 33-34), ma coll. Embryon grossi (Fig. 32).

Observ. - Le genre Bellardin dont le nom a été modifié (par lischer une année avant Monterosato) pour corriger un double emploi, ne comprenait, 
Daphnella

dans la pensée de ses auteurs, qu'une seule espèce vivante, à faciès de Pleuroloma, mais dépourvue d'opercule : toutefois, en examinant les formes très hétérogènes que Bellardi a comprises dans son genre Homotoma, j'ai constaté que beaucoup d'entre elles sont des Bellardiella, à peu près semblables génériquement au type, dont Bellardi fait, au contraire, une Clathurella, quoiqu'il n'ait pas les caractères de ce dernier genre. Il résulte de là que Bellardiella a une extension plus grande qu'on ne le présumait, bien que je n'y aie strictement classé que les formes à embryon polygyré et conoĩde, à labre

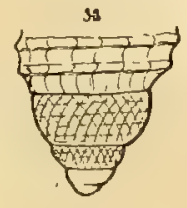

F 1 6. 32. mince et à columelle lisse.

Rapp. et diff. - Au premier abord, il y a, en apparence, de réelles différences entre l'aspect de Daphnella limnxiformis et celui de Bellardiella gracilis; cependant je 'n'admets Bellardiella que comme sous-genre de Daphnella: en effet, quand les individus sont adultes et tout à fait complets, leur canal est moins allongé et moins tordu que le comporte la diagnose de Bucquoy, Dollfus et Dautzenberg, il est méme tronqué exactement comme celui de Daphnella; toutefois l'embryon est un peu différent, la spire est plus allongée et plus conique, le galbe est plus élancé, moins trapu, le labre n'est pas dilaté et, au contraire, il se resserre à la base, vers la naissance du canal, de sorte que l'ouverture est rétrécie. Ce sont là des caractères différentiels suffisants pour motiver la séparation d'un sousgenre, mais pas plus.

Répart. Stratigr.

Mrocexe...... Deux espèces probables dans l'Helvétien des environs de Turin (Kaphit. semicostata et Homol. Soldanii, Bell.); le type dans le Tortonien d'Asti, d'après la Monogr. de Bellardi.

Pliocene....... Plusieurs espèces, outre le type, dans le Plaisancien et l'Astien des Alpes maritimes et de l'Italie (Homol.lextilis, Br. tumens et Raynerali, Bell., Pleur. stria, Calc., ligustica et Desmoulinsi, Bell.), ma coll. et d'après la Monogr. de Bellardi; le type (sous le nom antérieur $P$. emarginala, Donov.), dans le Crag d'Anvers, d'après la Monogr. de Nyst.

Epoque actuelle. Outre le type, plusieurs espèces indiquées comme Daphnella, mais paraissant munies d'un canal long et tordu (D. accincta, Montg. interfossa, Carp. aruginosa el pessulata, Reeve,Jacksonensis, Angas) d'après le Manuel de 'Tryon. 
Teres, Bucq. Dollf. Dautz. 1882.

Type: Pleu".anceps, Eichw. Mioc.(= Pleurolomateres, Forbes)

Forme de tarière un peu allongée; spire turriculée à galbe conique; embryon conique, composé de quatre tours étroits, les deux premiers guillochés, les deux autres lisses, à nucléus pointu. mais subdévié; tours convexes en avant, excavés en arrière, el ornés de carènes spirales; dernier tour convexe à la base qui est rapidement atténuée et se termine par un canal assez court, rétréci et infléchi en avant, tronqué sans échancrure à son extrémité. Ouverture étroite, subpiriforme; labre mince, arqué, entaillé par un sinus assez profond sur la rampe suturale; columelle lisse, un peu calleuse, arrondie, droite au milieu, coudée vers la droite en avant, et s'infléchissant enfin à gauche, vers l'axe, à son extrémilé antéricure.

Diagnose refaite d'après des échantillons de l'espece type, fossiles dans l'Astien de Cannes (PI. VII, fig. 3-4), ma coll. Limbryon grossi (Fig. 33).

Rapp. et diff. - La séparation de cette section parait justifiẻe par la forme

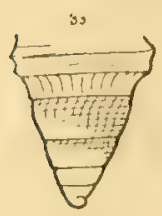

FIG. 33 , tordue que présente, du côté antérieur, le canal moins allongé et plus étroit que celui de Bellardiella; l'échancrure du sinus est placée comme celle de Daphnella, mais l'ornementation a un faciès différent, à cause de la prédominance des carènes spirates; quant à l'embryon, il se rapproche beaucoup de celui de Daphnella et surtout de l'embryon de Bellardiella. Il me semble donc qu'on ne doit pas considérer. Teres comme un sous-genre, mais le rattacher seulement a Bellardiella comme section de ce sous-genre.

Répart. Stratigr. Mrocene.......
L'espèce type dans le bassin de Vienne et dans l'Allemagne du Nord, d'après les Monogr. de Hornes et de von Koonen; existe peut-être aussi dans les environs de Bordeaux, d'après un échantillon de ma coll., mais il est possible que ce soit une espèce distincte et inédite. 
Daphnella

Pliocene....... L'espèce type dans le Crag d'Angleterre, le Plaisancien et l'Astien des Alpes-Maritimes et d'Italie, d'après les Monogr. de S. Wood et de Bellardi, et d'après le catalogue de Foresti; autre espèce voisine, dans le Messinien, le Plaisancien et l'Astien des Alpes-maritimes et d'Italie (Pl. turritelloides, Dall.), ma coll.

Epoque actuelle. Deux espèces; l'une dans la Méditerranée, et l'autre dans les mers boréales, d'après le Manuel de Tryon.

Raphitoma, Bellardi, 1847.

Néotype : Pleur. plicatella, Jan. Plioc.

(=Ginnania, Monts. 1884; = Vielliersia, Monts. 1884;

= Smithia, Monts. 1884, non Edw. et Haime. 1851.)

Forme biconique, assez courte ; spire peu allongée, à galbe conique; embryon polygyré, conoïdal, composé d'un nucléus subdévié, de deux tours lisses et d'un tour costulé.; tours plus ou moins anguleux vers le tiers inférieur de leur hauteur, ornés de costules ployées sur l'angle, et dans leurs intervalles, de stries d'accroissement excessivement ténues, très finement chagrinées, enfin de filets spiraux plus ou moins écartés, parfois alternés, mais toujours plus serrés sur la rampe inférieure que sur la partie antérieure des tours. Dernier tour grand, régulièrement atténué à la base qui se termine par un canal un peu allongé, à peu près droit, arrondi sans échancrure à son extrémité antérieure. Ouverture étroite, peu dilatée au milieu, graduellement rétrécie en avant; labre mince, à contour peu arqué et oblique, avec un sinus peu profond au-dessus de la suture; columelle presque rectiligne, à peine infléchie vers la droite du côté antérieur; bord columellaire lisse, peu calleux, se terminant en pointe effilée à l'extrémité du canal. 
Daphnella

Diagnose refaite d'après un échantillon de l'espèce néotype, provenant du P'laisancien de Biot (Pl. VIII, fig. 17), ma coll. Embryon grossi (fig. 34) d'après un individu de R. plicala, Lamk, du calcaire grossi de Grignon; détail du sinus (Fig. 33̈) d'un autre échantillon.

Observ. - Ce genre, créé par Bellaridi dans sa Monogr. des Pleuro-

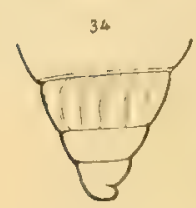

Fici, 34 .

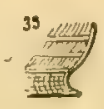

Fro. 35. tomes, a été restreint par lui, en $187 \%$, dans son travail d'ensemble sur les Mollusques du l'iémont, mais il n'en a pas indiqué le type: j'ai choisi comme nóntyp l'une des prenteres uspieces bien caractérisées, qui figuraient dans sa Monogre. de 1847 (section D des Mollusques du P'iémont), attendu que les autres groupes ont, pour la plıpart été érigés en sections distinctes.

Rapp. et diff. - Ce sous-genre se distingue de Daphnella, non seulement par son ornementation, invariablement formée de costules pliées, mais surtout par son canal non tronqué, plus allongé et plus rétréci, par son labre non dilaté, entaillé moins près de la suture; si on le compare it Bellardiella, on remarque que le canal est beancoup plus droit ef que les costules sont, non pas interrompues, mais seulement amincies sur la rampe postérieure de chaque tour. Ces différences justifient amplement la séparation d'un sous-genre, mais elles ne motiveraient pas, a mon avis, l'admission d'un genre distinct; c'est d'ailleurs ce qu'a également proposé Fischer dans son Manuel.

Quant aux sections, proposées en 188 par M. de Mlonterosato, et que je cite dans la synonymie de Raphiloma, elles ont pour type des coquilles qui sont des Raphitoma absolument caractérisées, et ne diffèrent entre elles que par des détails d'ornementation, ayant une valeur spécifique; il serait d'autant moins admissible de former des sections d'après d'aussi faibles différences, que beaucoup d'auteurs ne considèrent quelques-unes de ces coquilles que comme des variétés d'une même espèce. A quelle profusion de nomenclature arriverait-on, si l'on appliquait a toutes les mers du globe ce procédé de sectionnement exagérément minulieux auquel on se laisse entrainer quand on n'étudie qu'une faune locale et surtout peu riche en diversité de formes?

Répart. Stratigr.

Paleocene.....

Une espece probable dans le Landénien de Belgique (Pl. voluleformis, Vine.), d'après une empreinte figurée par l'auteur.

Eocene........ Nombreuses espèces dans le bassin anglo-parisien, dans la Loire-Inférieure, dans le Claibornien des États-Unis (Ploplicala el costellala, Lamk. subal- 
Daphnella

tenuata, d'Orb.quantula, Baudoni, perplexa, Capellinii et cilharella, 1)esh. pachycolpa, leptocolpa, Boutillieri, Plateaui et dictyella, Cossm. campbonensis, Vasseur. venusta, Lea, meridionalis, Meyer), ma coll., coll. Bezançon.

Ougocene...... Plusieurs espèces dans les environs d'Étampes (Pl. costuosa et Prevosti, Desh., Bourdoti, Cossm., et Lamb.), ma coll.; el dans le Tongrien de l'Allemagne du Nord ( $R$. erecta, muricina, et buccinoides, v. Kœen.), d'après la Monogr. de M. von Konen.

Mrocene....... Plusieurs espèces dans le Bordelais, la Touraine, l'Italie, le bassin de Vienne ( $P l$. subcrenulata, d'Orb., affinis, Duj., vulpecula, Br., megastoma, Brugn., alifera et Rissii, Bell., Sandleri, Partsch), ma coll. et d'après la Monogr. de Bellardi; une espèce probable dans l'Allemagne du Nord (Mangelia Kachi, von Kœnen), d'après la figure donnée par l'auteur.

Pliocene....... Nombreuses espèces dans les Alpes maritimes, dans le bassin du Rhône, en Italie, dans le Crag d'Angleterre $(P l$. hispidula et plicatella, Jan, comilatensis, Font., submarginata et sulcatula, Bon., nevropleura et tumidula, Brugn., Libassi, Bell., turgida, Forbes, attenuata, Montg.), ma coll. et d'après les Monogr. de Fontannes, de Bellardi et de S. Wood.

Epoque actuelle. Plusieurs espèces dans la Méditerranée, la mer Égée, l'Australie, sur les côtes de l'Amérique du Nord, d'après le répertoire de Monterosato, et le Manuel de Tryon.

Pleurotomella, Verrill, 1873. Type: Pl. Packardi, Verr. Viv. (- Systenope, Cossm. 1889)

Taille petite; forme fusoïde, un peu trapue; spire assez courte, aiguë; embryon polygyré, avec un nucléus lisse et deux tours très finement cancellés, plus fortement coloré que le reste de la coquille; tours convexes, ornés de costules obliques, généralement crénelées par des filets spiraux, et interrompues, avant qu'elles atteignent la suture inférieure; par une gouttière excavée, sur laquelle il n'existe que de petits plis curvilignes et beaucoup plus serrés; dernier tour grand, à base très convexe, se raccordant 
I)aplunella

par un angle peu ouvert avec le cou du canal qui est droit, tronqué sans échancrure à son extrémité. Ouverture subrhomboïdale, assez lare au milieu, subitement rétrécie à la naissance du canal, labre arqué, mince, sauf quand le bord coïncide avec une côte, parfois lacinié à l'intérieur par des filets spiraux, échancré sur la goutlière postéricure par un profond sinus; columelle droite. faisant un angle de $120^{\circ}$ avec la base de l'avant-dernier tour, obliquement infléchie à droite vers l'extrémité du canal; bord columellaire lisse et très étroit.

Diagnose refaite d'après un échantillon d'une espèce plésiotype, provenant du calcaire grossier de Mouchy, Systenope polycolpa, Cossm. (Pl. VIl, fig. 1-2), ma coll. Embryon grossi (Fig. 36).

Rapp. et diff. - L'espèce type de ma section Systenope ne diffère que par quelques détails d'ornementation de Pl. Packardi, qui

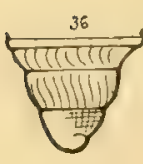

Fi(i, 36 . est le type du genre Pleurolomella: je n'hésite done pas à supprimer le nom que j'avais proposé et à y substituer la dénomination antérieure de Verrill. Plusieurs des espèces de ce groupe ont été confondues soit avec Raphiloma, soit avec Homotoma: elles diffèrent du premier par leur canal subitement rétréci, par leurs côtes interrompues sur la gouttière postérieure, et par leur sinus plus profond; elles se distinguent du second par leur embryon tout à fait différent.

Répart. Stratigr.

Eocene ........ Plusieurs espèces dans le bassin de Paris (Raph. polycolpa, guepellensis, goniocolpa et linophora, Cossm.], ma coll. et coll. Bezançon.

Origocene...... Une espèce dans le Stampien du bassin de Mayence (Pl. Rappardi, v. Koen.), ma coll. ; autre espèce dans le Tongrien de l'Allemagne du Nord (R. Eberti, v. Kon.), d'après la Monogr. de M. von Koenen.

Mrocene....... Quelques espèces probables dans l'Helvétien et le Tortonien d'Italie ( $R$. inxequicosta, Jeffreysi, angulifera et Calandrelli, Bell.), d'après la Monogr. de Bellardi.

P'urocene....... Une espèce à peu près certaine dans l'Astien des environs de Turin ( $P l$. pulchra, Bell.), d'après la Monogr. de Bellardi; autre espèce très incertaine 
dans la Floride, incomplète et à canal droit $(P l$. pistillata, Dall) d'après la figure.

Epoque actuelle. Le type, plusieurs variélés, el quelques espèces à peu près dépourvues de costules sur le dernier tour, habitant les côtes de l'Amérique du Nord, d'après la Monogr. de Dall sur les dragages du "Blake».

PERATOTOMA, Harr. et Burr. 1891.

(= Homotoma, Bell. 1875, non Guérin Mennev. 1829.)

Embryon paucispiré, à nucléus papilleux et dévié.

Peratotoma, sens. str. Néotype: Pl. striarella, Lamk. Eoc.

Taille petite; forme de Pleurotomella; spire peu allongée à galbe à peu près conique; embryon subglobuleux et lisse, composé d'un tour et demi, dont le nucléus forme une papille saillante, presque tordue, d'un aspect tout à fait caractéristique; tours convexes, canaliculés au-dessus de la suture, ornés de filets spiraux et parfois de costules obliques qui ne se prolongent jamais sur la goutlière postérieure, sur laquelle il n'existe que de petits plis curvilignes d'accroissement. Dernier tour assez grand, un peu ventru, convexe à la base qui est rapidement atténuée et qui se termine par un canal court, infléchi et tronqué, sans échancrure à l'extrémité antérieure. Ouverture courte, subrhomboïdale, rétrécie vers le canal; labre mince, lisse, arqué, légèrement sinueux en avant, échancré sur la gouttière suturale; columelle peu calleuse, droite, faisant un angle de $130^{\circ}$ avec la base de l'avantdernier tour, un peu infléchie à droite du côté antérieur.

Diagnose refaite d'après un individu de l'espèce post-type du calcaire grossier de Villiers, près Paris (PI. VIl, fig. 5-6), ma coll. Embryon grossi (Fig. 37), d'après un autre individu du gisement de Mouchy.

Observ. - Le genre Homotoma, changé en Peralotoma par Harris et Burrows pour corriger un double emploi, est composé d'une manière tout 
à fait hétérogène, le Daphnella, de Bellardiella, de Teres et même de Clatherella. Je le restreins aux deux premières espèces de la Monocrr. de Bellardi, et encore je n'ai pu vérifier si elles ont un em-

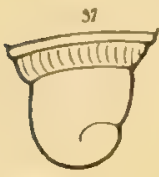

Fig. 37 bryon papilleux; mais elles présentent exactement l'aspect extérieur de l'espéce du bassin de Paris que j'ai choisie comme néotype, précisément à cause de cette incertitule.

Rapp. et diff. - Ce genre ressemble beaucoup, dans son ensemble, à Pleurolomella: on ne peut l'en distinguer d'une manière certaine que par la forme de l'embryonqui est radicalement différent, lisse, paucispiré et papilleux, au lieu qu'il est cancellé, polygyré et conirue dans tout le groupe des formes qui dérivent de Drphnella.

Répart. Stratigr.

Eocexe....... Outre le néotype, quatre espèces certaines dans le bassin de P'aris et dans la Loire inférieure $(P l$ nana et fragilis, Desh. Hom. dimeres et $P$. ozocolpa, Cossm.), ma coll. et coll. Boutillier; trois espèces certaines dans le Claibornien de l'Alabama $\left(I^{2}\right.$, insignifica, IIeilp., Dalli et funiculigera, Cossm.), ma coll.

Ozigocexe..... Deux espèces dans le Tongrien de l'Allemagne du Nord, sous réserve de la rérification de l'embryon (H. alala et hexagona, v. Koen.), d'après la Monogr. de Ml. von. Konenen.

Mocene...... Deux espèces dans l'Ielvétien des environs de Turin (H. Tapparonii et scalarata, Bell.), d'après la Monogr. de Bellardi.

Thesbia, Jeffreys, 1867.

Type: T. nana, Lovèn. Viv.

Taille petite; forme buccinoïde; spire courte, à galbe subconoïdal ; embryon paucispiré, globuleux, à nucléus papilleux; tours convexes, dénués de rampe ou de goutlière à la sulure, à surface lisse; dernier tour relativement très grand, à base convexe, graduellement atténuée, terminé par un canal court et tronqué, dont le cou est à peu près droit. Ouverture ovale, rétrécie à la base, entaillé contre la suture par un sinus excessivement petit; columèlle sinueuse, infléchie à droite vers l'extrémité antérieure du canal; bord columellaire mince, étroit, se terminant en pointe en avant. 
Peratotoma

Diagnose faite d'après une espèce plésiotype de l'Eocène supérieure du Bois de Perthes, aux environs de Paris, T. microloma, Cossm. (Pl. VII, fig. 7-8), coll. Bezançon.

Rapp, et diff. - Ce sous-genre diffère de Peratotoma, par l'absence de gouttière suturale et par la surface lisse de ses tours de spire; en outre, le sinus est beaucoup plus petit et se réduit à une simple entaille bien visible, mais étroite et peu profonde; le labre est moins rétréci en avant, et il se dilate un peu comme chez Daphnella; mais l'embryon globuleux et dévié est tout à fait semblable à celui de Peratotoma.

Répart. Stratigr.

Eocene....... L Lespèce plésiolype dans le bassin de Paris et dans la Loire inférieure, connue par plusieurs échantillons.

Epoque actuelle. Outre le type des mers arctiques, plusieurs espèces non figurées par IVatson, aux îles Kerguélen et Tristan d'Acunha, d'après le Manuel de Tryon.

Amblyacrum, Cossm. 1889. Type: Pl. rugosa, Desh. Eoc.

Taille et forme de Raphitoma; embryon lisse, paucispiré, composé d'un tour et demi, à nucléus obtus, à peine dévié; tours costulés, convexes ou anguleux, ornés ou crénelés par des filets spiraux, plus serrés sur la rampe postérieure que sur la partie antérieure de chaque tour; dernier tour généralement supérieur à la moitié de la longueur totale, à base graduellement atténuée, se terminant par un canal court, à peu près droit, assez large, arrondi sans échancrure à son extrémité. Ouverture étroite et longue, à peine plus dillatée aü milieu que vis-à-vis du canal; labre arqué, mince, entaillé sur la rampe postérieure par une échancrure arrondie, large et peu profonde; columelle presque rectiligne; bord columellaire mince, sous lequel on distingue parfois la trace des filets spiraux enroulés sur la base, et qu'il ne faut pas confondre avec de véritables plis. 
Peratotoma

Diagnose refaite daprès un échantillon typique du calcaire grossier de Mouchy (P. V, fig. 31-32), coll. Pezant. Embryon grossi d'un autre individu (Fig. 38), ma coll.

Rapp. et diff. - Amblyacrum est à Raphiloma, ce que Peraloloma est

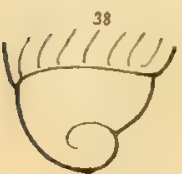

Fig. 38 . à Pleurolomella; sans l'embryon qui est absolument différent et qu'on distingue au premier coup d'œil, il y aurait identité complète au point de vue des caractères génériques. Si on compare ce sous-genre à Peratoloma, on remarque qu'il s'en distingue par l'absence de goultiere suturale, par son canal plus droit, non tronqué, et par oblus et moins dévié.

l'ornementation de sa spire; en outre, l'embryon est plus

Répart. Stratigr.

Eocene...... Trois espèces, outre le type, dans le bassin de Paris, et une espèce certaine dans le Claibornien des ÉtatsUnis (A. Chevallieri, crenuligerum et Bernayi, Cossm. P. tabulata, Conrad), ma coll.

Oligocene..... Une espèce dont jai vérifié l'embryon, à Pierrefitte, près Elampes ( $P$. Dollfusi ', Cossm. el lamb.), ma coll.; autre espèce à embryon paucispiré dans les couches supérieures de Cassel (P. Remeri, Phil.), ma coll.

Mocene...... Une espèce dans le Tortonien des environs de Turin (Murex harpulus, Br.), d'après la Monogr. de Bellardi.

Pliocene...... La même espèce, dont j’ai vérifié l'embryon oblus, a nucléus subdévié, sur des échantillons du Plaisancien de Biot et de Bologne, ma coll.

Époque actuelle. Une espèce au moins, dont j'ai vérifié l'embryon, Daphl nella Vincentina, Crosse, de l'Australie, ma coll., mais il est probable que d'autres Amblyacrum des mers actuelles ont dû être décrits comme Raplittoma, à cause de la ressemblance extérieure.

"Cette dénomination fail double emploi avec l". Dollfusi line qui est un Cryplocanus du Landénien de Belgique : je propose donc, pour l'espéce des environs d'Etampes, 1. Gustavii, prénom de M. G. Dollfus à qui elle était dédiée. 
HALIA, Risso, 1826.

(Priamus, Beck, in Desh. 1838.)

Embryon obtus; sinus nul; columelle tronquée.

Halia sens. str. Type H. Priamus, Meuschen. Viv.

Taille grande; forme d'Agathina; spire courte, obtuse au sommel, à galbe ovale; embryon sans saillie, dont le nucléus elliptique est généralement corrodé; tours peu nombreux, convexes, déprimés vers la suture inférieure, à surface lisse et brillanle; dernier tour très grand; ovale, non atténué à la base. Ouverture large, ovale; labre mince, dilaté et arqué en avant, à peine sinueux en arrière, sans échancrure précise ; columelle très profondément excavée au milieu, infléchie à gauche du côté antérieur et tronquée à son extrémité ; bord columellaire mince, assez étroit, non limité par une strie, quoique bien distinct.

Diagnose faite d'après un échantillon de l'espèce plésiotype $H$. helicoides, Br. fossile dans le Plaisancien d'Italie (Pl. VII, fig. 28), coll. de l'Ecole des Mines.

Rapp. et diff. - Quoique la forme de cette coquille et surtout l'absence de sinus paraissent l'écarter complètement des Pleurotomida, elle se rattache cependant à Daphnella, par la dilatation du labre et la troncature de la base, qui supprime presque entièrement le canal. Au contraire, son embryon n'a rien de commun avec celui de Daphnella, ni même de Peratotoma. Mais, quant à l'animal, il paraît que sa radule est la même que celle de Mangilia, et que son pied a beaucoup d'analogie avec celui des Mangitinæ. Dans ces conditions, je ne partage pas l'avis de M. Sacco, qui propose une famille nouvelle Haliidx, et qui la rapproche des Strombidx; c'est bien dans la famille Pleurotomidx, comme l'ont fait Fischer et Tryon, qu'il y a lieu de placer le genre Hatia.

Répart. Stratigr.

Mrocene...... Une espèce et ses variétés dans l'Helvétien d'Italie (H. pracedens, Pant.), d'après la Monogr. de M. Sacco; autre espèce dans le Tortonien du Portu- 
Inlin

gal, et d'Italie (II. Deshayescana, da Costa), d'après la Monogr. de Pereira da Cosla, toutefois M. Sacen ne la cite aux environs de 'Iurin que comme unt: variété du tỵpe.

Pliocere..... Une seule espèce el ses variélés dans le Plaisancien des Alpes maritimes et d'Italie, souvent conlondue avec l'espèce vivante ì laquelle elle ressemble beancoup (II. helicoides, Br.), ma coll. et d'après la Monogr. de M. Sacco. Vue Fra. 39. du sommet embryonnaire (Fig. 39).

Epocue acturle. Le type sur les côles de l'Atlantique, depuis Cadix jusqu'au Sénégal, d'après Fischer.

\section{CONID/E}

Forme généralement conique; tours presque toujours résorbés à l'intérieur ; spire peu allongée ; dernier tour grand; canal court; ouverture à bords parallèles ou subparallèles; sinus labial peu profond; bord columellaire non plissé; opercule corné, unguiforme et étroit.

Observ. - Les corpuilles de la famille Conidx sont extrêmement nombreuses, surtout daus le tertiaire supérieur et à l'époque actuelle; elles présentent, à peu d'exceptions près, un aspect uniforme qui parait, au premier abord, ètre un motif pour que l'on n'établisse pas un grand nombre de subdivisions dans le genre Conus, c'est-à-dire dans le groupe de coquilles qui ont la spire intérieurement résorbée. Cependant ce genre est un de ceux dont l'étude est le plus difficile pour les paléontologistes, précisément à cause de la multiplicité des sections proposées par dés auteur's qui n'ont envisagé que la malacologie actuelle, et parce que ces sections ne sont guère fondées que sur des différences tout à fait artificielles.

Après Montfort et Swainson, qui avaient déjà créé plusieurs sous-genres, Mörch en a considérablement augmenté le nombre, dans une liste d'espèces, sans en indiquer les caractères. Enfin plus récemment, Weinkaull" a classé les espèces du cabinet Martini-Chemnitz d'une nouvelle manière, qui est peut-être très commode pour le rangement des coquilles vivantes d'une collection, mais qui complique encore davantage la thche de ses successeurs: les sections qu'il a faites sont au nombre de 17 , elles ne s'accordent pas avec celles de Mörch, en ce sens qu'un même sous-genre de ce dernier auteur peut être représenté dans plusieurs sections diffé- 
rentes de Weinkauff; enfin les noms qu'il leur applique sont de simples adjectifs qui ne peuvent évidemment prendre rang dans la nomenclature. Voici d'ailleurs, à titre de renseignement, d'après le Manuel de Tryon qui adopte cette classification, les groupes de Weinkauff :

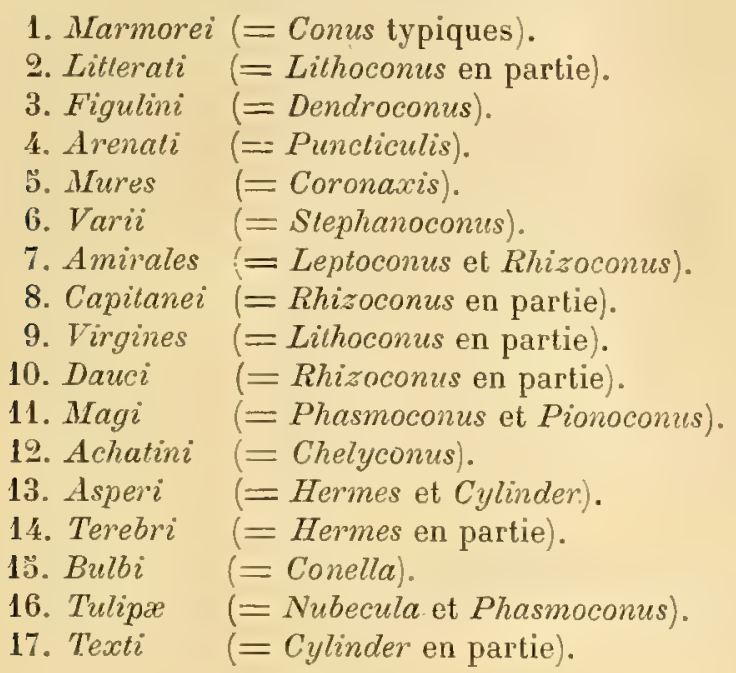

Cette méthode ne peut être admise, non seulement pour les raisons que j'ai indiquées plus haut, mais encore parce que l'on serait dans l'impossibilité d'indiquer des différences sérieuses qui motivent le classement d'une espèce plutôt dans l'un de ces groupes que dans l'autre.

Je préfère done reprendre, comme l'a fait Fischer sans indiquer toutefois les différences qui caractérisent les sections, les dénominations de Mlontfort, de Swainson, de Mörch, ou des autres auteurs, mais en ne les plaçant pas toutes sur le mème rang, car elles sont loin d'avoir une valeur équivalente au point de vue du classement systématique. C'est en partant de ce principe que j'ai dressé le tableau suivant dont la justification se trouve dans les diagnoses de chaque coupe, et qui se rapproche d'ailleurs de la classification d'Adams reproduite par Chenu.

A cette occasion, je crois utile d'appeler l'attention des conchyliologues sur un fait qui me paraît avoir une réelle importance, au point de vue de la classilication des genres de Conidæ : c'est l'existence ou l'absence, dans l'angle inférieur de l'ouverture, d'une rainure ou d'une cicatrice sur le bord opposé au sinus du labre ; je la nomme cicatrice ou rainure pariétale; elle n'a été signalée jusqu'à présent, autant que je le sache, par aucun auteur, quoique beaucoup de figures la reproduisent fidèlement. Je suis d'autant moins à même d'en donner l'explication et d'en signaler le but, que cette rainure existe dans tous les Conus proprement dits, qu'elle se réduit à une cicalrice chez les Conorbis et Cryptoconus, et qu'elle dis- 
paraît complètement des Genolia; peut-être y a-t-il une corrélation avec la propriété de résorption des tours, puisque cette faculté existe, s'alténue ou manque exactement dans les mèmes genres.

\section{Tableau des genres, sous-genres et sections.}

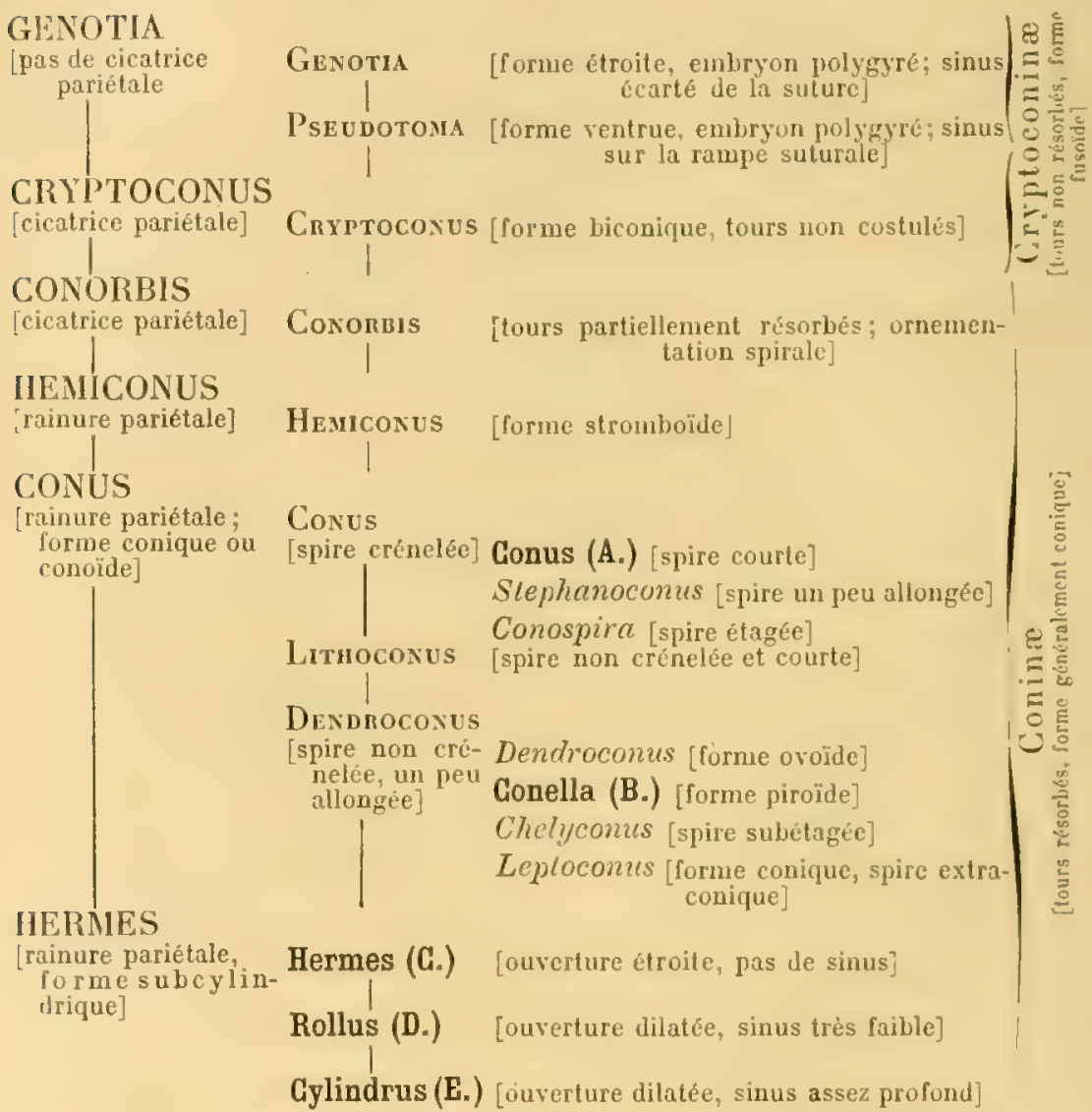

Genres et sous-genres non signalés à l'état fossile.

(A). Conus, Lin. 1758 ( $=$ Rhombus, Montf. 1810; = Coronaxis, Swains. $1840 ;=$ Puncliculis, Swains. $1840 ;=$ Asprella, Schaufuss 1869 ; $=$ Cylindrella, Swains. 1840, non Pfeiffer). Le nombre des subdivisions que Swainson a distinguées dans les Conus typiques, est manifestement exagéré : toutes ces formes it spire couronnée et relativement courte ne diffèrent entre elles que par des caractères spécifiques, la plupart seule- 
ment par leur ornementation ou leur coloration. Beaucoup d'auteurs, même parmi ceux qui s'occupent exclusivement des coquilles actuelles, n'liésitent pas à les réunir (Adams, Weinkauff, Fischer, Tryon) : je suis d'autant plus disposé à suivre cet exemple, que cette question n'a qu'un intérêt secondaire, au point de vue paléoconchologique, puisque le genre Conus s.s. n'existe pas à l'état fossile. Quant à Rhombus, on verra plus loin que cette dénomination doit être éliminée, puisque le type est très voisin de celui de Conus.

(B). Conella, Swains. 1840. - Type: C. plicalus, Sow. et néotype, sec. auct.: C. bulbus, Reeve. Forme très voisine de Dendroconus, un peu plus excavée à la base du dernier tour, ce qui lui donne un galbe piriforme qui peut, à la rigueur, motiver la séparation d'une section : c'est le groupe Bulbi de Weinkauff, le nombre des espèces vivantes de ce groupe ne dépasse pas 11, y compris les variétés du type (Tryon). Je ne connais, parmi les Dendroconus fossiles, aucune forme qui puisse être rapprochée de Conella.

(C). Hermes, Montf. 1810 (= Theliconus, Swains. 1840). - Type : C. nussatella, Lin. Forme étroite, ovoïdo-cylindrique; spire un peu élevée; surface sillonnée; ouverture à bords non parallèles; échancrure du sinus à peu près nulle; rainure pariétale large et profonde.

(D). Roluus, Montf. 1810 (Nubecula, Klein 1703; = Tuliparia, Swains, 1840). - Type : C. geographus, Lin. Forme cylindracée; spire courte, aiguë, à galbe extraconique, couronnée de crénelures oblongues; surface lisse; ouverture dilatée, largement tronquée en avant; labre un peu arqué. presque sans sinus; bord columellaire étroit, cylindrique et tordu; rainure pariétale à peine indiquée.

(E). Cylmonus, Montf. 1810 em. Cylinder (= Textilia, Swains. 1840). Type : C. textilis, Lin. Forme ovoïde, moins cylindrique que celle des deux sous-genres précédents; ouverture dilatée, à bord columellaire tordu vers le tiers de la hauteur du côté antérieur; labre presque rectiligne, avec un sinus assez profond ; rainure pariétale se réduisant à une dépression large et obsolète. M. Sacco indique, dans sa Monographie des mollusques du Piémont, deux espèces du Plaisancien et de l'Astien (C. subtextilis, d'Orb. et planoligusticus, Sacco), comme appartenant peut-être à ce sous-genre : mais, autant que je puis en juger par les figures, ce sont des Chelyconus à spire un peu extraconique, car leur ouverture a les bords parallèles et n'est pas dilatée comme celle des véritables Cylindrus.

En résumé, aucune des formes qui se rattachent au genre Hermes ne paraît avoir existé à l'état fossile.

GENOTIA, H, et A. Adams, em. 1853.

Canal large et échancré à la base, avec un bourrelet enroulé sur le cou; sinus labial assez large, peu proford; bord columel- 
Genotia

laire épais, calleux en avant, séparé du bourrelet par une dépression ombilicale imperforée.

Genotia, sens, str. Type: Bucc. mitriforme, Wood. Viv.

Forme oblongue, fusoïde; spire turriculée, conique; embryon polygyré, composé de deux lours et demi, converes, à galbe conoïdal, à nucléus obtus et déprimé; tours anguleux, généralement tuberculeux sur l'angle et treillissés sur le reste de la surface; dernier tour très grand par rapport à la spire, terminé en avant par un canal un peu sinueux, presque sans étranglement à la base; bourrelet épais, non limité, enroulé sur le cou du canal et aboutissant à son écháncrure antérieure. Ouverture étroite, à bords presque parallèles; labre mince, parfois plissé à l'intérieur, fortement arqué, entaillé par une échancrure arrondie qui coïncide avec l'angle tuberculeux du dernier tour, et au-delit de laquelle le contour du labre se raccorde, par un quart de cercle, perpendiculairement à la suture; columelle légèrement Hexueuse en avant, tangente en arrière à la base de l'avant-dernier tour; bord columellaire presque nul et mince du côté postérieur, plus épais à partir du bourrelet, cylindracé et se terminant en pointe contre l'estrémité antérieure du canal ; pas de cicatrice pariétale.

Diagnose faite d'après une espèce plésiotype du Pliocène inférieur de Sienne, G. Craveri, Bcll. (Pl. VII, fig. 34-35), ma coll. Embryon grossi d'un G. ramosa, de Dax (Fig. 40), ma coll.

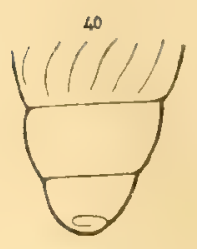

F'1G, 40 .

Observ. - Quoique la forme de cette coquille ne ressemble pas à celle de Conus, et que les tours ne soient pas resorbes it l'intérieur, l'opercule étant, d'itprés Adams, identique à celui de Conus, il y a lieu de classer Genotia (non Genuta) dans la famille Conidx: je propose d'ailleurs de grouper les genres à tours non résorbés dans une sous-famille distincte Cryptoconine, qui est intermédiaire entre Pleurotomidee et Conides s.s.

Répart. Stratigr.

EOCENE.........

Plusieurs espèces à labre plissé, dans le bassin angladarisien et dans les environs de Nantes ( $P$. lyra, 
Genotia

Desh., Schlumbergeri, de Raine., pyrgola et aspera, Edw., conoidea, Sol.), ma coll.

Oligocene ..... Une espèce dans le Tongrien de Belgique ( $P$. bellula, Phil.), ma coll.; antre espèce dans le Tongrien de l'Allemagne du Nord (P. pseudocolon, Gieb.), d'après la Mnnogr. de M. von Koenen; une espèce dans les couches supérieures du Vicentin, $c f$. $G$. ra. mosa, d'après Fuchs, mais probablement différente.

Mrocene........ Plusieurs espèces dans le Langhien, l'Helvétien et le Tortonien des environs de Dax et de Bordeaux, dans l'Helvétien de la Touraine, dans la Molasse de la Provence et de la Corse, en Italie et dans le bassin de Vienne ( $P$.ramosa, Bast., austrogallica, Mayer, G. Craveri, Bell. Eilisæ, H. et A.), ma coll. ; et en Italie ( $G$. proavia et Mayeri, Bell.), d'après la Monogr. de Bellardi.

Pliocene...... Une espèce dans le Messinien de Sienne (G. Craveri, Bell. , ma coll.; autre espèce dans le Plaisancien et l'Astien ( $G$. Bonnani, Bell.), d'après la Monogr. de Bellardi.

Epoque actuelle. Le type et ses variétés sur les côtes occidentales d'Afrique; autre espèce peu certaine au Japon, d'après le Manuel de Tryon.

Pseudotoma, Bell. 187\%.5 Type : P. bevis, Bell. Mioc.

Forme ventrue; spire assez courte, à galbe conoïdal ; embryon lisse, paucispiré, à nucléus obtus en goutte de suif ; tours tantôt lisses, tantôt ornés, excavés au-dessus de la suture; dernier tour grand, arrondi à la base, terminé par un canal presque droit, profondément échancré à son extrémité ; bourrelet arroudi, limité par un étranglement du cou et aboutissant à l'échancrure du canal. Ouverture piriforme, assez large en arrière, à peine plus étroite en avant, à bords non parallèles; labre mince, médiocrement arqué, avec un sinus très peu profond et arrondi au-dessous de la convexité du dernier tour, puis obliquement antécurrent vers la suture; columelle presque verticale, à peine infléchie à droite du côté antérieur, se raccordant par un angle arrondi et très ouvert avec la base de l'avant-dernier tour; bord columellaire do Genotia; pas de cicatricule pariétale. 


\section{Genolliat}

Diagnose refaite d'après une espèce plésiotype de l' $\Lambda$ stien de Cannes, $P$. intorta, Br. (Pl. VIII, fig. 11), ma coll. ; autre espèce à faciès de Climera, dans le Tortonien de Vüslau (Autriche), P. Bonellii, Bell. (= P. Bracteata, Bronn, non Murex bracteatus, Br.) Pl. VII, fig. 1112, ma coll. Embryon grossi (Fig. 41), d'après un individu de Biot.

Rapp. et diff. - D'après Tryon, Pseudotoma serait synonyme de Genotia, tandis que Fischer l'admet au rang de sous-genre distinct; celte dernière opinion me paraît beaucoup plus fondée, si l'on tient comple, non seulement de la forme et de la position du

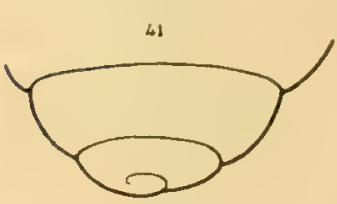

Fig. 41 . sinus qui est moins prolond, plus ouvert et situé plus bas, de la columelle qui est moins fluxueuse, de la forme générale qui est plus trapue, du cou du canal qui est plus obtus, mais surtout de. l'embryon qui est beaucoup plus court et plus obtus; on peut même se demander si ces différences importantes ne justifieraient pas la séparation d'un genre completement distinct. Quant. aux différences d'ornementation, elles n'ont pas la valeur que Bellardi leur a attribuée, attendu que notre plésiotype est a peu près orné comme une Genotia, tout en présentant les autres caractères de $P$. levis, qui est le type d'après Bellardi.

Répart. Stratigr.

Eocene....... Plusieurs espèces dans le bassin de Paris. dans le Claibornien des États-Unis et dans l'Australic du Sud ( $P$. coronata, Lamk. Loustaux et quiela, Desh. colpophora, Cossm. Heilprini, Aldr. Daph. sculptilis et crassilirata, T'ate), ma coll.; une espece dans le London clay d'Angleterre, rapportée à tort a $P$. intorta, et dont le nom a été clangé en. P. Topleyi, par M. von Konen.

Oligocene..... Plusieurs espèces : suit dans le Rupélien de Betgrique (P.Morreni, de Kon.), ma coll.; soit dans le Tongrien de l'Allemagne du Nord (P. coniformis, anyystoma, crassistria, v. Koen.); autre espece dans les cuuclies. de Dego en Italie ( $P$. oligocanica, Bell.) d'après la monogr. de Bellardi.

Miocene....... Nombreuses espèces, outre le type, dans le Langhien des environs de Bordeaux, dans l'Helvétien et le Tortonien d'Italie, et dans le bassin d'Ostrau Karwin en Autriche ( $I^{\prime}$. sliviolala, semirugusa, Genei, Orbignyi, conneclens, prxceders, pirmata, Bonellii el hirsuta, Bell.) d'après le Calal. de Benoist, la Mo- 
nogr. de Bellardi et une note de M. Kittl; autr espèce à Edeghem et dans l'Allemagne du Nord ( $P$. Bodei,v. Kœn.), ma coll., plusieurs autres espèces ou variétés dans le bassin de Vienne ( $P$. Idie, Malvinie, R. Horn. Hoheneggeri et orlaviensis, M. Horn.), d'après la Monogr. de Hœernes el Auinger.

Pliocene....... Une espèce très répandue dans le Plaisancien et l'Astien des Alpes maritimes et d'Italie ( $P$. inlorta, Br.) ma coll.; deux autres espèces déjà citées dans le Miocene, dans le Plaisancien et l'Astien des Alpes marit. (P. Bonellii et brevis, Bell.), ma coll.

Epoque actuelle. Deux espèces encore inédites, provenant des dragages de l'Hirondelle, coll. Dautzenberg.

\section{GRYPTOCONUS, von Kœnen, 1867.}

Forme biconique; embryon paucispiré, obtus ; ouverture à bords. non parallèles; canal non échancré en avant, sinus large et triangulaire; bord columellaire très calleux

Cryptoconus, sens. str. Type: Pl. filosa, Lamk. Eoc.

Forme en général trapue; spire assez allongée, à galbe conique; embryon peu développé, à nucléus à peine saillant et obliquement dévié; tours peu convexes, lisses ou ornés de filets, généralement déprimés au-dessus des sutures qui sont bordées; dernier tourgrand, à base ovale ou déclive, ornée de filets plus serrés qui. s'enroulent sur le cou du canal. Ouverture peu dilatée au milieu, à peine rétrécie sur le canal qui est extrêmement courl, ovale à son extrémité ; labre très arqué, entaillé sur la dépression posté-rieure par une échancrure triangulaire et arrondie au sommet, puis antécurrent obliquement sous un angle de $45^{\circ}$ vers la suture; columelle presque droite, un peu tordue en avant; bord columellaire étroit, très calleux, séparé de la convexité du cou par une: dépression ombilicale presque tonjours imperforée; cicatricule. pariétale à peine visible dans l'angle inférieur de l'ouverture. 
Cryptoconus

Diagnose refaite d'après un individu de l'espèce type du calcaire grossier de Villiers (PI. VII, fig. 20-21), ma coll. Embryon grossi (Fig. 42).

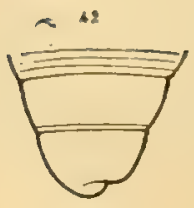

FIG. 42 .

Rapp. et diff. - Ce genre, un des meilleurs qui aient été proposés, se distingue de Pseudotoma, non seulement par la forme extérieure et l'ornementation de la spire, mais par son canal à peu près nul, sans aucune échan. crure ì l'extrémité antérieure, par son bord columellaire plus étroit et plus cylindracé; en outre, le nucléus embryonnaire est moins obtus.

Répart. Stratigr.

Paleocene..... Une espèce à peu près certaine dans le Landénien de Belgique $(P l$. Dollfusi, Vinc. $)$ d'après la figure donnée par l'auteur.

EOcene........ Nombreuses espèces, outre le type, dans le bassin anglo-parisien, dans la Loire inférieure; dans le Vicentin, aux environs de Thun et d'Einsiedeln P. prisca, Sol. clavicularis et ylabrala, Lamk. calophora, subdecussata, evulsa, lineolata, crecta, approximala, bistriata, labiata, elongata, Desh. C. Baudoni et infragradalus, Cossm.), ma coll., et d'après les Monogr. d'Ldwards et de MayerEymar; autre espéce dans le Claibornien des EtatsUnis (C. Comradi, de Greg.), d'après la Monogr. de M. de Gregorio.

Oligocene..... Plusieurs espèces, soit à Gaas ( $P$. subfilosa el emarginata, d'Orb.), soit dans le Vicentin ( $P$. alsiosa, Brongn.), ma coll.; cette espéce dans le Tongrien de l'Allemagne du Nord et de Belgique (C. Dunkeri, von Kon.), d'après la Monographie de M.von Konen; deux espèces dans les couches de Dego, au P'icmont ( $C$. degensis, Mayer et exacutus, Bell.), d'apris la Monogr. de M. Sacco.

CONORBIS, Swainson, 1810.

Tours partiellement résorbés sur le plancher et vers le sommel (fide IKœnen); columelle rectiligne. 
Conorbis, sensu extenso, von Kiøn. 1867.

Type: Conus dormitor, Sow. Eoc.

Forme biconique, trapue; spire peu allongée, toujours plus courte que l'ouverture, à galbe régulièrement conique; embryon composé de deux tours et demi, à nucléus arrondi et un peu dévié; lours cerclés par des cordons spiraux ou par des rubans aplatis que séparent des rainures plus étroites, et finement plissés par les accroissements; dernier tour très grand, ovale en arrière, coniquement atténué à la base qui est largement tronquée, avec une faible échancrure à l'extrémité du canal. Ouverture étroite, longue, à bords tout à fait parallèles; labre mince, lisse à l'intérieur, largement développé en arc de cercle, échancré au-dessus de la suture par un sinus arrondi; columelle rectiligne dans la plus grande partie de sa longueur, torulue sur elle-même à la base, le pli de torsion presque vertical; bord columellaire, très étroit et très court, un peu calleux vis-à-vis de la torsion columellaire, séparé par une rainure d'un bourrelet obsolète qui correspond, sur le cou du canal, à l'échancrure basale; cicatricule pariétale très effacée, dans l'angle inférieur de l'ouverture.

Diagnose refaite d'après des individus de l'espèce type, provenant de Barton (Pl. VIII, fig. 16. et 18), ma coll. Embryon grossi (Fig. 43), d'après un individu de $C$. marginalus, Lamk., provenant du calcaire grossier de Mouchy.

Rapp. et diff. - Dans une thèse demeurée classique, M. le docteur von Konen a démontré, avec des coupes à l'appui, que le genre de Swainson, qui ne comprenait primitivement que l'espèce type, doit être appliqué à toutes celles dont les tours sont résorbés, le plancher séparatif s'amincissant graduellement au point de disparaître complètement vers le sommet, cornme cela a lieu chez Conus; tandis que chez Cryptoconus, au contraire, le plancher séparatif conserve à tout âge une épaisseur uniforme, de sorte que la coupe axiale de la coquille montre une série de loges analogue, à

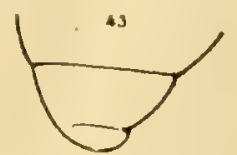

I'IG, 43. celles des Pleurolomidx. Comme on ne peut pas toujours sacrifier des exemplaires rares, pour vérifier l'existence de ce caractère distinctif, le 
Conorbis

paléontologiste peut se guider d'apris les différences suivantes: Ccnorbis a la columelle bien plus droite que Cryptoconus, son ouverture a des bords plus parallèles, son canal est subéchancré au lieu d'être arrondi à l'exiréinité antérieure, sa forme générale est plus biconique, son sinus labial est plus arrondi, enfin son embryon est moins paucispiré et plus mamillé au sommet. Le genre Conorlis n'est connu, jusqu'i présent, qu'à l'élat lossile, à la partie inférieure des terrains tertiaires; cependant j'ai vu, dans la coll. Dautzenberg, un individu de Conus coromandelianus, Smith, qui ressemble beancoup, par sa forme extérieure, aux véritables Conorlis; mais il faudrait vérifier si la coupe axiale présente les mêmes caractères, et, en outre, il resternit un hiatus peu explicable entre l'Oligocène et l'Epoque actuelle.

Répart. Stratigr.

Senoniex...... Line espèce très douteuse, à l'état de moule, dans les couches de Rio Pabas au Brésil, attribuées an Crítacé supérieur ( $C$. restitulus, White), d'après la Monogr. de White.

Eocene....... Quelques espẻces, outre le type, dans le bassin angloparisien (C. seminudus et alalus, Edw. Pl. amphiconus, Sow. marginata, Isamk. subangulata, Desh. C. Cquipartitus, Cossm.), ma coll.; une espèce dans le Claibornien du Mississipi ( $C$. alatoideus, Aldr.), ma coll.

Oligocexe..... Plusieurs espèces dans le Tongrien de l'Allemagne du Nord (C. procerus, Beyr. Deshayesi et Grotriani, v. Kœen.), d'après la Monogr. de M. von Koenen; une espece incertaine à Gaas, dans le bassin de l'Adour ( $P$ l. marginata, Grat. non Lamk.), d'après la note de M. von Koenen; autre espece et ses variétés dans le 'longrien du Piémont et du Vicentin (C. prolensus, Mich $\left.{ }^{\mathrm{i}}\right)$, ma coll. et d'apris la Monugr. de M. Sacco.

\section{HEMICONUS, Cossmann, 1889.}

Strombiforme; sutures plissées; embryon globuleux.

Hemiconus, sens. str.

Type: C. stromboides, Lamk. Eoc.

'laille petite; forme biconique, strombüle; spirr grinéralement imale au tiers de la longueur totale; embryon lisse, pancispiré, 
globuleux, à nucléus obtus et légèrement dévié; tours convexes ou subanguleux, ornés sur l'angle de tubercules plus ou moins apparents et assez écartés, excavés en arrière et invariablement plissés par les accroissements contre la suture inférieure ; dernier lour grand, souvent orné d'une couronne inférieure de tubercules, écartés de la suture, parfois très obsolètes; surface couverte de filets spiraux plus ou moins apparents, quelquefois crénelés par les accroissements. Ouverture à bords presque parallèles, terminée en avant par un canal large, indistinct, sans échancrure à son extrémité ; labre un peu arqué, entaillé sous l'angle postérieur par une sinuosité très peu profonde; bord columellaire rectiligne sur la plus grande partie de sa hauteur, légèrement déprimé en avant, avec une torsion interne presque cachée dans l'ouverture, et située vers le cinquième de la hauteur de celle-ci ; rainure pariétale peu profonde, parfois peu visible.

Diagnose refaite d'après un échantillon de l'espèce type du calcaire grossier de Grignon (Pl. VIII, fig. 1 et b), coll. Bourdot. Embryon grossi (Fig. 44), d'après un individu de la Ferme de l'Orme.

Rapp. et diff. - Ce genre se distingue de Conorbis, non seulement par sa couronne de tubercules qui s'oblitère sur quelques espèces, mais encore par son labre moins arqué et par son sinus peu profond, enfin par sa rainure pariétale qui le rapproche de Conus; mais il s'écarte de ce dernier genre par sa forme de Strombus, par son bouton embryonnaire, par sa rainure pariétale peu profonde; d'ailleurs sa spire est plus élevée que celle de Stephanoconus, dont l'échancrure labiale est également peu profonde;

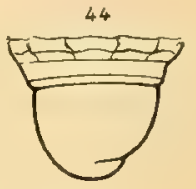

FIG. 44. au contraire, on distingue Hemiconus de Conospira qui a aussi la spire élevée, par son échancrure moins profonde, par ses tours non étagés, par l'aspect tout différent des tubercules du dernier tour, par sa surface ornée, par sa rainure moins large et moins profonde, etc.; en outre, la torsion de la columelle est beaucoup moins visible que dans la plupart des formes de Conus, à spire couronnée. On peut donc admettre que c'est un genre tout à fait distinct, qui forme un lien de transition entre Conorbis -et Conus, mais se rapprochant davantage de ce dernier, dans la même sous-famille, puisque les tours sont résorbés et qu'il existe une rainure pariétale. 
Répart. Stratigr.

Eocexe........ Une espèce dans le Suessonien et plusieurs dans le Parisien du bassin anglo-parisien et de la LoireInférieure (C. bicaronalus, Mell, stromboides. I.amk. disjunclus, granatinus, Defrancei, turbinopsis, Desh. costiger", Cussm. lineatus el scabriculus, Sol. Tromelini, Vass. peraralus, Cossm.), ma coll.

Oligocene...... Une espèce dans les environs d'Ltampes el dans le bassin de Mayence (C. symmelricus, Desh.; une espèce dans le Tongrien inférieur de l'Allemagne du Nord (C. insculptus, v. Kion.), d'après la Monogr. de M. von kixnen.

Mrocene....... P'lusieurs espèces dans le bassin de l'Adour, dans l'Helvétien d'llalie et le 'Tortonien du hassin de Vienne $\left(C\right.$. granulifer, Grat. ornatus, Mich ${ }^{\text {i }}$, dertogranularis, Sacco, Stachei, Ilorn. et Auing.), d'apres l'Atlas de Grateloup et les Monogr. de Sacco et de Hornes et Auinger.

Phocene....... Une espèce et ses variétés dans l'Astien des environs de Turin (C.granularis, Borson), d'après la Monogr. de M. Sacco.

CONUS, Linné, 1758.

(= Rhombus, Montf. 1810).

Forme conique ou conoïde; surface lisse ou striée spiralement ; spire à tours embrassants, loujours plus courte que l'ouverture qui est étroite, à bords parallèles, terminée en avant par un canal tronqué sans échancrure; labre 'mince, peu arqué, entaillé près de la suture par une sinuosité qui coincide avec la rampe inférieure du dernier tour; bord columellaire rectiligne sur la plus srande partic de sa hauteur, avec un pli tordu plus ou moins visible à la partie antérieure, et une petite rainure pariétale dans l'angle inférieur.

Observ. - Le type du genre Conus est, d'après Lanarck (1798, confirmé en 1801), C. marmoreus, L. caractérisé par sa spire courte, par les grosses crénelures aiguës qui couronnent les tours de spire, par son galbe ì peu près régulièrement conique, en général assez étroit. Aucun auteur n'a encore, à ma connaissance, signalé la rainure spirale qui existe à la partie inférieure de l'ouverture, sur la paroi opposéc au sinus labial : cette rainure est obsolète, large et peu protonde chez $C$. marmoreus, mais elle 
Conus

existe invariablement chez toutes les espèces vivantes ou fossiles que j'ai étudiées, dı moins quand elles ne sont pas trop roulées. La torsion de la columelle, située au quart de la hauteur de l'ouverture du côté antérieur chez C. marmoreus, est aussi un caractère commun à tous les Conus : elle produit un pli plus ou moins saillant, correspondant à la cessation du bord columellaire très étroit qui s'enroule à l'intérieur de l'ouverture. Les linéoles spirales et colorées des coquilles vivantes laissent souvent des traces un peu saillantes qui pourraient faire croire que la surface du dernier tour n'est pas lisse; mais cette surface est lisse, en réalité, chez C. marmoreus, el chez la plupart des espèces classées dans le groupe Marmorei de Weinkauff, qui se compose de formes parfaitement typiques. Du côté antérieur, on remarque invariablement des cordons obliquement enroulés sur la base et sur le cou du canal : ils sont d'abord obsolètes et l'on n'en constate l'existence qu'au toucher, puis ils deviennent plus saillants vers l'embouchure du canal.

La dénomination Rhombus, Montf est synonyme de Conus $s, s$., attendu que le type de Montfort est $C$. imperialis, $L$. qui est une espèce couronnée comme C. marmoreus: il est vrai que Montfort admettait comme type du genre Conus, C. generalis, L. qui est une tout autre forme; mais cette in erprétation, postérieure de douze années à celle de Lamarck, ne peut être admise : il est done correct d'éliminer Rhombus. Quant à Coronaxis, Swains. les espèces auxquelles peut être appliquée cette détermination me paraissent intermédiaires entre Conus, s. s. et Stephanoconus : c'est donc encore probablement un synonyme de ces deux groupes.

Stephanoconus, Mörch, 1852. Néotype: $C$. cedonulli, L. Viv.

Galbe à peu près conique; spire médiocrement saillante, couronnée de tubercules obtus près de la suture supérieure de chaque tour; stries spirales sur la rampe inférieure, parfois sur toute la surface du dernier tour ; cordons écartés et parfois granuleux sur la région antérieure de la base. Ouverture un peu plus étroite en arrière qu'en avant; labre arqué, avec une échancrure inférieure peu profonde; columelle tordue un peu plus haut que le quart de la longuear de l'ouverture; rainure pariétale étroite et profonde.

Diagnose faile daprès un échantillon de l'espèce type des Antilles, el d'après une espèce plésiotype de l'Eocène supérieur de Cresnes, C. cresnensis, Morlet (Pl. VIII, fig. 19 et 23), ma coll.

Observ. - Le premier Slephanoconus. cité dans la liste de Mörch est 


\section{Conus}

C. leucosticlus, mais c'est une espice extrêmement voisine de $C$. nebulosus, Sol. (cedomelli, L.) qui est beaucoup plus commun et plus connu : tel est le motif pour lequel la plupart des auteurs indiquent $C$. cedomulli, comme exemple de celte section. D'ailleurs Mörch inserit $C$. nebulosus, comme synonyme de leucosticlus (ce qui ne serait pas exact, d'après le Manuel de Tryon), de sorte que le choix de C. cedonulli, comme néotype parait confirmé par l'auteur lui-même.

Rapp. et diff. - Les caractères qui permettent de distinguer Stephanoconus, de Conus, s. $s$., sont d'une importance tout ì fait secondaire: lis spire est un peu plus allongée, les tubercules sont plus obtus que les crénelures de $C$. marmoreus, et sont même souvent it demi effacés, le galbe du dernier tour est un peu moins conique, plus ovalement atténué en arrière, l'ouverture a les bords moins parallèles, le labre est plus arqué, la rainure pariétale est plus profonde, enfin la torsion columellaire est placée un peu plus en avant. Ces différences ne sont pas absolument constantes, il y a des passages évidents d'une forme in l'autre, de sorte qu'à ne considérer que la coquille, on ne peuit admettre au plus Stephanoconus que comme une section de Conus.

Répart. Stratigr.

Sexonien....... Une espèce probable dans la Craie de Californie (C. Remondi, Gabb.) d'après la Monogr. de Gabb. et IVhitney.

Eocenr........ Phusieurs espèces dans le bassin de Paris, dans la Loire inférieure et aux environs de Thun $(C$. crenulatus, calvimontensis et sulnifer, Desh., cresnensis, Morlet), ma coll., coll. Dumas, et d'après MayerEymar; autre espéce probable dans l'Australie du Sud (C. hamiltonensis, Tate) d'après la figure donnée par l'auteur.

Oligocene..... Une espèce douteuse, peut-être Comnspira, dans le Tongrien de l'Allemagne du Nord (C.plicalilis, von Kœn.) d'après la Monogr. de II. von Konen; deux espèces dans le Tongrien de l'Italie septentrionale (C. Ighinai, Michti, carcarensis, Sacco) d'après la Monogr. de M. Sacco.

Mroceve....... Une espèce dans le bassin de l'Adour (C. subricobaricus, d'Orb.) d'après l'Atlas de Grateloup; lir même espèce et deux autres dans l'Helvétien des environs de T'urin (C. Gastaldii et Bredai, Mich" ${ }^{1 i}$ ) d'après la Monogr. de M. Sacco.

P'Liocene....... Une espèce douteuse dans les couches récentes de Java (C.ornatissimus, Mart.) d'après la Monogr. de II. Martin. 
Epoque actuelce. Plusieurs espèces, outre le type, aux Antilles, aux iles Moluques, aux Philippines, etc..., classées dans le groupe Variz, d'après le Manuel de Tryon.

Conospika, de Gregorio em. 1890.

Type: $C$. antedituvianus, Brug. Plioc.

(= Conitithes, Swains, 1840, non Conilites, Schloth. 1820, nec Lamk. 1822).

Forme étroite, biconique; spire étagée, à galbe conique; embryon proboscidiforme, conoidal, composé de trois tours lisses et subulés, à nucléus obtus et subdévié; tours en gradins, ornés de crénelures sur l'angle médian, excavés entre cet angle et la suture inférieure, sillonnés sur la partie plane et antérieure; dernier tour grand, à profil parfaitement conique, généralement lisse, sauf sur le cou du canal où s'enroulent des sillons serrés et profonds: la couronne inférieure de crénelures porte invariablement deux ou trois sillons spiraux assez profonds, rarement effacés sur les individus les plus adultes, et donnant aux tubercules l'aspect bitide ou trifide. Ouverture étroite, à bords absolument parallèles, tronquée à la base, sans aucune échancrure; labre arqué, surtout en arrière, et très profondément entaillé par un sinus arrondi, sur la rampe contiguë à la suture; bord columellaire formant une étroite carène qui s'enfonce comme un pli tordu à la partie antérieure de la columelle ; rainure pariétale large et profonde, tout à fait cachée dans l'angle inférieur.

Diagnose refaite d'après un échantillon de l'espèce type du Plaisancien de Biot (PI. VIII, fig. 7-8), ma coll. Embryon grossi (Fig. 40̃̈) d'après un individu de C. Lebruni, Desh. provenant du calcaire grossier de Trye (Oise).

Observ. - Le même type a été désigné, dès 1840, par Swainson sous le nom générique Conitithes, qui fait double emploi avec Conilites, déja employé antérieurement par Schlotheim ou par Lamark: c'est done bien la dénomina-

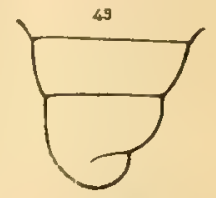

Fic. ii., 
tion proposée par M. de Gregorio qu'il faut reprendre, mais en lui donnant une désinence plus correcte; en effet le nom Conospirus, qu'avait proposé M. de Grégorio, est un solécisme ( $\sigma \pi \varepsilon ! p \alpha$, la spire); j'ai par conséquent corrigé celle dénomination dont li désinence doit être féminine.

Rapp. et diff. - Celte section se distingue de Slephanoconus, par sa sphère encore plus élevée et étagre en grradins, avec des crénelures plus saillantes et toujours divisées par des sillons transversaux, par son ouverture à bords plus parallèles, par sa lorsion columellaire plus cachée.

Répart. Stratigr.

Locne....... Plusieurs espices dans le bassin anglo-parisien (C. parisiensis et Lobruni, Desh. concinmus, Sow.), ma coll.; une espèce différente dans la Loire inférieure (C. Bareti, Vass.), ma coll.; deux autres espèces dans le Claibornien de l'Alabama et du Mississipi (C. protractus ', Meyer et subuliadema, de Greg.), ma coll.

Oligocene...... Une espèce dans le Tongrien de l'Allemagne du Nord et de Belgique (C. Beyrichi, v. Koen.), ma coll.

Mrocine....... Une espèce caractéristique dans l'Helvétien de la Touraine, dans le Tortonien du bassin de Vienne, des environs de Turin, des Landes et du l'ortugal (C. Dujardini, Desh.), ma coll.; le type, ses variétés el une autre espece dans l'Helvétien et le Tortonien des environs de Turin, ainsi qu'à Saubrigues dans l'Aquitaine (C.Bronni, Mich ${ }^{i i}$ ) d'apres la Monogr. de II. Saccoet ma coll. ; autre espece dans l'Aquitanien des Landes et du Bordelais ( $C$. aquilanicus, Mayer), ma coll.; une espice peut-itre distincte, quoique jeune, dans le bassin de Vienne (Lept. Bevwerthi, H. el $\Lambda$.) d'après la Monogrr. de Hoernes et Auinger.

P'Lrocene....... I.e type et C. Bronni, dans le Plaisancien des Alpes maritimes et d'ltalie, ma coll.

Lithocovus, Mörch 1852. Néotype; C. millepunclatus, Lamk. Viv.

Forme conique; spire généralement peu saillante, à galbe extraconique, parfois même presque plane, de sorte que la coquille peut se tenir debout sur son sommet; embryon pauci-

I Gest C. parvus, II. Len, qui ne peut conserver ce nom. déja cmploye en 1820 par Borson. 
spiré, sourent globuleux, à nucléus très obtus; tours non crénelés, légèrement excavés et spiralement sillonnés, séparés par de profondes sutures; dernier lour embrassant à peu près toute la coquille, à galbe subconique, parfois un peu excavé au milieu, atténué et arrondi en arrière vers la périphérie de la spire; surface ordinairement lisse, sauf quelques sillons très écartés à la base. Ouverture à bords parallèles du côté postérieur, légèrement dilatée vers le quart antérieur de la hauteur, tronquée et faiblement échancrée à l'extrémité du canal ; labre assez oblicque, à peu près rectiligne, largement échancré en arrière; bord columellaire subitement déprimé du côté antérieur et séparé par cette dépression d'un bourrelet obsolète qui correspond aux accroissements de l'échancrure antérieure du canal ; rainure pariétale très large et superficielle, souvent peu visible.

Diagnose faite d'après une espèce plésiotype, communeà tous les niveaux du terrain tertiaire supérieur, C. Mercali, Brocchi, du Tortonien de Potzleinsdorf dans le bassin de Vienne (Pl. VIII, fig. 9-10), ma coll. Embryon anormal de $C$. pullulescens, Tate (Fig. 46) d'après un individu de l'Eocène de l'Australie du Sud, ma coll.

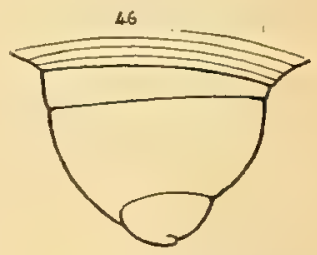

Fig. 46 .

Rapp. et diff. - Cette forme pourrait être prise pour le type conique par excellence, surtout quand la spire est peu saillante: elle se distingue de Conus, s. s., non seulement par l'absence de crénelures, mais par le coude que forme en avant le bord columellaire, par l'inclinaison plus oblique du labre, par sa rainure pariétale moins étroite, moins profonde ; enfin, le bouton embryonnaire est différent de celui des espèces à spire couronnée de crénelures ou de tubercules.

Répart. Stratigr.

Senoniex....... Une espèce douteuse, à l'état de moule, dans les couches de Rio Pabas au Brésil, attribuées au Crétacé supérieur $(C$. condilorius, White) d'après la Monogr. de W'hite.

EOCExE....... Une espèce aberrante dans le bassin anglo-parisien et dans le Vicentin, à spire souvent un peu élevée et crénelée sur les premiers tours, à embryon un peu 
plus long que la forme typique ( $C$. diversiformis, Desh.), ma coll.; variété plus plane de la même espece, à Bracklesham (C. Edwardsi, Desh.), ma coll.; espèce voisine dans les Alpes bavaroises (C. planus, Schauroth), ma coll.; autre espèce typique dans le Claibornien de l'Alabama (C. sauridens, Conr.), ma coll.; plusicurs espèces dans l'Australie du Sud (C. Dennanti, cuspidalus, ligatus, Tate, pullulescens, 'T. Woods), ma coll.; deux espèces dans les couches nummulitiques de l'Inde ( $C$. militaris et brevis Sow.) d'après la Monogr. de d'Archiac et Haime.

Ougocrne...... Liespèce éocénique dans le Vicentin, peut-être distincte $(C$. diversiformis, Desh.), ma coll.; autre espèce dans le Tongrien de la Ligurie $(C$. ineditus, Mich ${ }^{\text {ii }}$ ) d'après la Monogir. de M. Sacco.

Mrocene ....... L'espèce plésiotype ou ses variétés, dans le I,anghien, l'Helvétien et le Tortonien de l'Aquitaine, do la Touraine, de l'Italie et du bassin de Vienne, ma coll.; autre espèce voisine dans les Landes et en Serbie (C. tarbellianus, Grat.), ma coll. ; deux autres espèces dans l'Ilelvétien et le Tortonien des environs de 'Turin (C. subacuminatus d'Orb., antiques, Lamk.) d'après la Monogr. de M. Sacco; plusieurs espèces diflérentes dans le bassin de Vienne et en Portugal (C. Tietzei, Neumayri, hungaricus II. et A., cacellencis, da Costa) d'après la Monogr. de Hoernes et Auinger el de da Costa.

Pliocene....... Le plésiotype dans l'Astien des Alpes maritimes, ma coll., et dans le Plaisancien d'Italie avec une espèce très voisine ( $C . A$ ldrovandii, $\mathrm{Br}$.) d'après la Monogre. de M. Sacco el le Catalogue de M. Foresti; plusieurs espèces dans les couches récentes de Javi C. Hardi, odengensis, djarianensis, Mart., d'apres la Monogr. de M. Martin; une espèce dans les couches récentes de Karikal dans l'Inde $C$. malaccanus, Ilwass, coll. Bonnet.

Epoque actuelte... Nombreuses espèces dans toutes les mers, classées dans les groupes Lillerali et Virgines, d'après le Manuel de Tryon.

Dendroconus, Swainson, 1840. Type: C. figulinus, Lin. Viv.

Forme un peu ovale; spire courte, subulée, à galbe légère- 
ment extraconique; embryon globuleux, parfois proboscidiforme généralement paucispiré, à nucléus aplati; tours un peu convexes, les premiers souvent crénelés, les suivants quelquefois ornés de stries spirales; dernier tour lisse, embrassant presque toute la coquille, à galbe arrondi en arrière à la périphérie de la spire. atténué et faiblement excavé à la base, sur laquelle apparaissent des sillons obliquement enroulés sur le cou du canal. Ouverture à bords non parallèles, un peu plus dilatée à l'embouchure du canal, qui est légèrement échancré à son extrémité antérieure; labre à peine arqué, presque vertical, avec un sinus large et très peu profond du côté postérieur ; bord columellaire imperceptiblement tordu el à peine sinueux du côté antérieur ; dépression pariétale très obsolète.

Diagnose faite d'après un échantillon de l'espèce type, et d'après une espèce plésiotype fossile, $C$. Eschroegi, da Costa, de l'étage Tortonien de Cacella en Portugal (Pl. VIII, fig. 2 et 5), ma coll. Embryon grossi (Fig. 47), d'après un échantillon de C. piruloides, Doderl. provenant du Langhien de Peloua (Gironde), ma coll.

Rapp. et diff. - Ce sous-genre se distingue aisément de Lithoconus, qui a également une spire courte, par sa forme moins conique, plus ovale; par son ouverture à bords moins parallèles, et par son bord columellaire à peine coudé en avant: par son labre non oblique, moins échancré en arrière. Si on restreint Dendroconus au type et aux formes qui s'y rattachent. étroitement, on peut à la rigueur en disjoindre plusieurs sections, ou au moins une, ainsi qu'on le verra ci-après : mais je me hâte d'ajouter que les passages d'une forme à l'autre se font par des intermédiaires tellement nombreux et variés, que ces subdivisions n'ont, à mon avis, qu'une valeur tout à fait artificielle. Comme d'ailleurs la dénomination créée par Swainson a la priorité sur celles qu'a proposées Mörch, c'est bien à Dendroconus

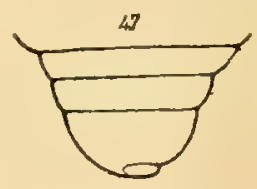

FIG. 47. qu'il faut réserver le nom de sous-genre, tandis que les autres coupes ne seraient au plus que des sections de ce sous-genre.

Répart. Stratigr.

Mrocexe......... Plusieurs espèces dans le Langhien des environs de Bordeaux, dans l'Helvétien et le Tortonien du Portugal et d'Italie, dans le bassin de Vienne 
(C. piruloines, Doderl. betulinoides, Lamk, Berghausi, Mich. Eschwegiet subraristriatus, da Costa, maculosus, Grat. fuscocingulatus, Bronn, moravicus voslauensis, Loroisi et Vaceki, II. et $\Lambda$.), ma coll. et d'après les Monogr. de da Costa, de M. Sacco, de Ilornes et Auinger.

Phiocene........ Deux des mêmes espèces dans le Plaisancien el l'Astien d'Italie (C. betulinoides, Isamk. Berghausi Mich.), d'après la Monogr. de M. Sacco; deux espèces dans les couches récentes de Java $(C$. glaucus, Hwass et Hoschlelteri, Mart.), d'après la Monogr. de M. Martin.

Epopve actuelle.. Environ huit espèces avec leurs variétés, dans les mers chaudes, d'après le Manuel de 'Tryon.

Ghelyconus, Mörch, 1852. Type: C. testudinarius, Mart. Viv. (= Pionoconus et Phasmoconus, Mörch, 1852.)

Forme ovoïdo-conique, assez étroite; spire en général élevée, à galbe conique ou conoïde; dernier tour grand, subanguleux à la périphérie de la spire, presque entièrement lisse, atténué à la base sur laquelle s'enroulent des cordonnets plus ou moins obsolites. Ouverture à bords à peu près parallèles, plus dilatée cependant du côté antérieur, et terminée par un canal court, non échancré; labre presque rectiligne au milieu, largement arqué en arrière, entaillé par un sinus peu profond et aboutissant perpendiculairement à la suture; bord columellaire étroit et fortement tordu en avant vers le quart de la hauteur; rainure pariétale assez large, très oblique, creusée dans une callosité dont le rebord la sépare de la gouttière située dans l'angle inférieur de l'ouverture.

Diagnose faite d'après une espèce plésiotype fossile, C.Nox, Br. du Tortonien de Saubrigues (PI. VIII, fig. 20 et 22), ma coll.

Observ. - La première espèce de Chelyconus citée dans lia liste de Mörch est $C$. testudinarius, espèce très voisine de $C$. spectrum, que Fischer a indiquée comme exemple, probablement parce qu'elle est plus connue, tandis que Tryon s'écarte davantage de la forme initiale en indiquant C. achatina, Chemn.; il place d'ailleurs dans un autre gronpe $C$. magus, 
type du sous-genre Pionoconus, Mörch, que je considère comme synomyme de Chelyconus, attendu que $C$. magus ne diffère pas génériquement. de $C$. lestudinarius. En réalité, comme il s'agit d'une section qui comprend des formes extrềmement variables, il n'est pas étonnant qu'il règne une grande incertitude dans le classement des espèces qu'on peut rapporter à Chelyconus ; mais l'interprétation de Fischer, conforme à celle d'Adams, paraît la plus rationnelle: c'est également celle qu'a adoptée M. Sacco pour les espèces fossiles du Piémont et de la Ligurie, et je ne puis mieux faire que de suivre cet exemple, sous la réserve que Chelyconus n'est qu'une section du sous-genre Dendroconus.

Rapp. et diff. - Il n'est pas aisé de fixer des caractères distinctifs et bien tranchés entre Dendroconus et Cholyconus : en général, ces derniers ont une forme plus étroite et une spire plus allongée, à galbe plus conoïde un angle plus ou moins net à la périphérie inférieure du dernier tour, tandis que Dendroconus est parfaitement arrondi ; l'absence complète d'échancrure à l'extrémité du canal, la torsion plus forte du bord columellaire, la profondeur plus grande de la rainure pariétale qui est très oblique, sont encore des caractères qui, quoique fugitifs, permettent à la rigueur de séparer Chelyconus. Mais c'est la limite de ce que l'on peut admettre comme subdivision de Dendroconus, si l'on veut éviter d'ètre entrainé à une multiplicité excessive des sections complètement inutiles, en disproportion avec la classification plus sobre des autres familles: c'est pourquoi j'ai rejeté Pionoconus et Phasmoconus.

Répart. Stratigr.

Mrocene......... Nombreuses espèces dans le Langhien de l'Aquitaine, dans le Tortonien et l'IJelvétien du Portugal et d'Italie, dans le bassin de Vienne $(C$. burdigalensis et gallicus, Mayer, anellana et clavatus Lamk. ponderosus. Br. tauroreclus, montisclavus, dertogibbus et Mari, Sacco, Puschi, Mich. lapugyensis, oliveformis, Suessi et prxlongus, H. et A, oboesus, Mich. raristrialus, Bell. et Mich.parvus, Borson. laurinensis, Bell. et Mich. medilerraneus, Brug. Belus, d'Orb.), ma coll. et d'après les Monogr. de M. Sacco, de Hœrnes et Auinger.

Pliocexe........ Nombreuses espèces dans le bassin du Rhône, le Roussillon, les Alpes maritimes et l'Ltalie (C. Deshayesi, Bell. et Mich. ponderosus, Br. lxviponderosus, Sacco, Nox, Br. Coryneles, Font. pirula, striatulus et pelagicus, Br. medilerraneus, Brug, gastriculus Doderl. bilorosus, Font. ventricosus, Bronn.), ma coll. el d'après les Monogr. de Fontan- 
nes et de M. Sacco; une espèce sénestre dans les couches de Caloosahatchie en Floride ( $C$. adversarius, Conrad = Tryoni, Ilcilp.) d'après les Mlonogr, de Ileilprin et de M. Dall.

Epoque acturle..: T'rès nombreuses espéces exotifues et une espèce méditerranéenne, d'après le Manuel de Tryon, qui les classe: soit dans le groupe Magi, soit dans les Achatini, soit dans le groupe Dauci.

Leptoconus, Swainson, 1840. 'Type: $C$. grandis, Sow. et néotype sec. auct. : C. amiralis, Lin. Viv. (= Rhisoconus, Mörch, ex parte)

Forme conique; spire assez courte, généralement étagée, à galbe extraconique; tour's en gradins, excavés et sillonnés sur la rampe siluée au-dessous de l'angle qui les divise en deux régions inégales, la région antérieure cylindrique et lisse se réduisant parfois à un gradin très étroit ou presque nul; dernier tour à profil à peu près rectiligne, généralement lisse dans la moitié inférieure, sillonné ou orué de filets et atténué vers la base. Ouverture à bords à peu près parallèles, subitement dilatée en avant, terminée par un canal assez large, non échancré; labre un peu arqué, profondément entaillé sur la rampe postérieure; bord columellaire très fortement tordu vers le cinquième de la hauteur de l'ouverture, du côté antérieur; dépression pariétale mal limitée, à peu près horizontale.

Diagnose faite d'après une espèce plésiotype fossile de l'Eocène moyen de Grignon, C. deperdius, Brug. (Fig. 48), ma coll.

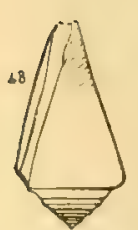

Rapp. et diff. - Cette section se distingue assez aisément de Dendroconus et Chelyconus par son galbe plus conique et par ses tours en gradins, excavés au-dessous de l'angle; si on la compare à Lithoconzes, on l'en distingue par son canal non échancré, par son labre non oblique, par son sinus beaucoup plus profond, surtout par sa spire plus étagée. Il y a lieu d'y réunir la plupart des Rhizoconus: le type de ce sous-genre de Fri. 4s. Mörch est $C$. miles, qui ne diffère pas génériquement de $C$. ami. ralis, mais d'autres Rhizoconus appartiennent aussi à la section Chelyconus. 
Répart. Stratigs.

Senonien .......

Eocene ........ Plusieurs espèces dans le calcaire grossier du bassin de Paris (C. deperditus, Brug. derelictus, turriculatus et incomptus, Desh.), ma coll. ; une espèce dans les couches de Selsey, en Angleterre (C. selseiensis, Gardn. = Lamarcki, Edw. non Kiener).

Oligocens ...... Une espèce dans le bassin de l'Adour (C. Graleloupi, d'Orb.), ma coll. ; autre espèce dans le Tongrien de l'Allemagne du Nord (C. Evaldi, v. Kœen.), d'après la Monogr. de M. von Konen).

Mrocene....... Plusieurs espèces dans l'Helvétien et le Tortonien d'Italie, dans le bassin de Vienne $(C$. Allionii, $\mathrm{Br}$. elatus et oblitus, Mich. tauroelatus, Sacco, Rhiz. Tschermaki, H. et A.), d'après les Monogr. de M. Sacco et de Hœrnes et Auinger; une espèce dans le Langhien des environs de Bordeaux (C. Saucatsensis, Mayer), ma coll.

Pliocene ...... Trois espèces dans le Plaisancien et l'Astien des Alpes maritimes et d'Italie (C. Brocchii, Bronn, virginalis et canaliculatus. Br.), ma coll. et d'après la Monogr. de M. Sacco.

Epoque acturle. Nombreuses espèces exotiques de la section Amirales, d'après le Manuel de Tryon. 


\section{AN NEXE}

$1{ }^{\circ}$ Notes complémentaikes reitatives a la Première livraison.

Depuis la publication de notre premiire livraison, quelques rectifications ou additions ont été faites à la classification des genres d'Opisthobranches.: le but des notes qui suivent est de mettre à jour cette classification, et de tenir compte soit des erreurs qui m'ont été signalées, soit des faits nouveaux que j'ai pu observer, soil des publications récemment faites par d'autres auteurs.

\section{ACT EON, Montf. 1810.}

Répart. Stratigr. - Je n'ai pu mentionner (p.46) dans les couches crétaciques, " aucune espèce certaine en Europe "; celte lacune est comblée, ainsi qu'on le verra ci-dessous:

Sexonien ...... Une espèce bien caractérisée dans le Santonien inférieur des Bains de Rennes (Torn. Beaumonti, d'Arch.) et une autre espèce nouvelle (Acl. suljunceus, Cossm.) figurée dans le Bulletin du Congrès de Carthage (Assoc. franç. 1896), coll. de Grossouvre.

Solidula, F. v. Waldh. 1807.

Répart. Stratigr. - Ce sous-genre n'a été indiqué que dans l'Eocène et le Miocène; il faut $y$ ajouter désormais :

Pulocene ...... Une espèce certaine dans les couches récentes de la Nouvelle-Zèlande (Torn. alba, Hutton), d'après la figure donnée par l'auteur. 
TORNATELLAA, Conr. 1860.

Répart. Stratigr. - Au point de vue de l'extension géographique de ce genre, pendant la période jurassique, il est intéressant de signaler le gisement ci-après :

Bajociex....... Une espèce analogue à T. Lorierei dans les couches à Amm. Humphriesianus du Chili (Act.manglasensis, Möricke) d'après la figure donnée par l'auteur.

\section{ACT EONINA, d'Orb. 1847.}

Observ. - Dans la ä9e livraison du “ Manual of Conchology » (p. 172), M. Pilsbry attribue au genre Actronina deux espèces vivantes, l'une assez grande, l'autre très petite, qui ne me paraissent pas appartenir à ce genre, ni à aucune des subdivisions qu'il comporte dans les terrains secondaires. En premier lieu, autant qu'on peut en juger par des figures, les deux espèces ne sont évidemment pas du même genre: la plus grande, $A$. edentula, Watson, est ventrue et finement striée dans le sens spiral, sa columelle est calleuse, et son ouverture est arrondie à la base; sa spire est assez courte, la coquille n'a pas la forme ni l'ornementation des Ovactæonina, qui en sont d'ailleurs séparées par une longue période géologique; il est probable que c'est une forme nouvelle, à rapprocher des Aclæonidxa, si ce n'est même un grand Actæoon dont le pli est peu visible. Quant à la petite espèce, $A$. charis, Watson, elle est aussi striée et assez ventrue, mais sa columelle est mince, subtronquée en avant, le bord columellaire se détache de la base du côté antérieur; la forme de l'extrémité antérieure de l'ouverture ressemble à celle de Bullinula, quoi qu'il n'y ait pas d'échancrure au contour, ni de bourrelet basal; peut-être cette coquille doit-elle être rapprochée des Hydatina, dont elle se distinguerait par sa spire allongée. Il appartient aux auteurs qui possèdent des exemplaires de ces deux formes vivantes, de leur donner des noms génériques et d'en fixer le classement; mais je ne puis les admettre comme représentant actuellement le genre secondaire Actæonina.

\section{Ptychocylindrites, Cossm. 1895.}

Répart. Stratigr. - Ce sous-genre n'a été signalé que dans le sousélage Ptérocérien du Jura ; il y a lieu d'ajouter le niveau ci-après, qui prolonge son existence.

Portlaxdex.... Une espèce, plus étranglée en avant que la forme typique, dans le calcaire de Folpengue, près d'An- 
goulème ( $P$. strangulatus, Cossm.), coll. Jolly, d'après la "Contribution à la Pal. franç. des terr. jurass. Gastrop., Opisthobr. ».

\section{ACTAONELLA, d'Orb. 1842.}

Observ. - J'ai indiqué que le type de ce genre est $A c t$. lxvis, Sow. de Gosau (non d'Orb.), c'est-i-dire précisément la coquille que j’ai décrite sous le nom $A$. terebellum (p.148, pl. II, fig. 20): il en résulte que celle d'Uchaux, qui est bien différente et que d'Orbigny a réunie à tort avec A. lavis, doit recevoir un autre nom. Je l'ai dénommée A. uchauxiensis (Assoc. franç. Congrès de Carthage, 1896). Mais, comme elles appartiennent toutes deux au même genre, cela ne modifie pas la dénomination dugenre, qui aura désormais pour néotype $A$. uchauxiensis, nob., c'est-idire la coquille que d'Orbigny avait en vue, quand il a créé le genre.

Répart. Stratigr. - Il y a lieu d'ajouter deux niveaux qui comblent certaines lacunes:

Cenomanien.... Une espèce dans les couches du col de Schiosi, en Vénétie (Volv. schiosensis, Bohm), d'après la figure donnée par l'auteur.

Garumien...... Une petite espèce certaine dans l'A riège (Act. olivæ formis, Mleiss.) coll. Jolly.

Trochact

Répart. Stratigr. - Quelques indications complémentaires, relatives ì l'extension géographique.

Cenomaniex..... Une espèce dans les couches du col de Ichiosi, en Vénétie (Conus Schiosensis, Bohm), d'après la figure de l'auteur, qui m'alfirme cependant qu'il n'aperçoil pas de traces de plis columellaires : en tous cas, ce niest pas un Conus à ce niveau, ni même une Gosavia, puisque la surface est lisse et qu'il n'y a pas de sinus.

Ganumien..... Une espèce certaine à Auzas dans l'Ariège ( $A$ ct. Baylei, Leym.), coll. Jolly.

Retusa, Brown, 1827.

Répart. Stratigr. - L'existence de ce sous-genre n'a été signalée, à l'étage Turonien, que dans l'Inde; le renseignement suivant en complètera l'extension géograplique: 
Tunoniex...... Deux échantillons certains dans le sous-étage Provencien de Monthiers dans la Charente (Relusa Jollyi, Cossm. Assoc. franȩ. Congrès de Carthage, 1896), coll. Jolly.

Plicobulla, Cossm. 1895. Type: P. Dumasi. Cossm. Eoc.

(Moll.Eoc. Loire infér. Bull.Soc.Sc. nat. Ouest, $n^{\circ} 4$, p. 193, pl. III, fig. 8-9).

Forme ventrue, ovoïde; spire étroitement perforée au sommet, perforation partiellement occluse par un épaississement du labre; dernier tour embrassant toute la coquille, lisse, sauf aux extrémités qui portent des stries spirales. Ouverture assez étroite, à

- peine dilatée et versante en avant; labre épaissi à l'intérieur, peu arqué, formant, avant de se raccorder au sommet, un bec ou un crochet dont la callosité s'applique presque totalement sur la perforation apicale; columelle excavée, portant au milieu un fort pli lamelleus et oblique, dont la carène extérieure limite en avant un bord columellaire évasé et calleux, et se raccorde avec le bord supérieur par une courbe continue, sans aucune apparence de troncature de la columelle.

Diagnose faite d'après un individu de l'espèce type, provenant de la Close dans la Loire inférieure (PI. VIII, fig. 3-4), ma coll.

Rapp. et diff. - Ce sous-genre se distingue de Bulla et Acrocolpus par son pli columellaire, saillant et caréné; de Cylichnella, par la position de ce pli, par l'absence d'un second pli postérieur, et par son sommet plus étroitement perforé, en partie clos par l'épaississement du labre ; de Roxania, par son pli columellaire, par l'absence de troncature à la base de la columelle; de Bullinella et de Cylichnina, par la saillie lamelleuse du pli columellaire, au lieu d'une torsion simplement coudée de la columelle. Ce sous-genre prend place, à côté de Cylichnella, dans le genre Bullinella, quoique la forme versante de l'ouverture à la base ressemble beaucoup à celle de Bulla; mais la plication de la columelle rattache Plicobulla à Butlinella, dont la columelle porte toujours un renflement ou une torsion pliciforme, qui n'existe jamais chez Bulla, Haminea ou Acrocolpus. 
Répart. Stratigr.

Eocise. .........
L'espèce type dans les conches parisiennes du bassin de Sallié et de Camplon, pres Nantes, coll. Dumas, ma coll.; autre espèce dans le Claibornien de Jackson, aux Etats-Unis (Bulla bilmucala, Meyer), ma coll.

\section{BULLOPSIS, Conrad, 1858.}

(Essais de l'al. comp. 1, p. 111, tig. 40.)

Test assez épais; forme ovale ventrue, tronquée au sommet; spire visible au fond d'une excaration occupant le tiers du diamètre de la troncature; nucléus embryonnaire Irès petit, au centre de l'excaration apicale; surface ornée de sillons spiraux écartés et de larges bandes de coloration brune, séparées par des intervalles plus larges encore. Ourerlure piriforme, dilatée en avant, non sinueuse à la base qui ne porte aucune trace de bourrelet, labre mince, un peu oblique à gauche de l'axe, du côté antérieur, non sinueux en arrière et se raccordant perpendiculairement à l'avant-dernier tour; bord colunellaire large et vernissé, appliqué sur la base, portant vers le haut deux gros plis obliques el lamelleux, extérieurement limité par une carène qui se raccorde sans sinuosité avec le contour supérieur.

Diagnose refaite d'après des échantillons de l'espèce type, $B$. crelacea, Conr. provenant de Ripley dans la Craie du Mississipi (I'l. IV, fig. -6), collection du Musée national de Washington, obligeamment communiqués par cette administration.

Observ. - Dans l'incertitude oủ je me trouvais, au sujet des véritables caractères de cette coquille, qui ne m'était connue que par une figure, j'ai classé le genre Bullopsis dans la famille Aplustride, à còté de IIydalina, à cause de la troncature du sommet de la spire, qui est largement visible. L'examen des types qui mont élé envoýs en communication par la Direction du Vusée de Washington (Smithsonian Institute) modifie complètement mon opinion primitive sur la position systématique de ce genre: aucun de ces trois échantillons munis de leur test, en parfait itat de conservation, ne montre de sinuosité basale, comme il en existe chez $H y d a-$ lina; leur test est beaucoup plus épais que ne l'est gẻnéralement celui des 
Aplustridx; mais ils se distinguent surtout par leur bord columellaire qui, au lieu d'ètre mince el transparent, est calleux, vernissé, opaque, et muni de deux plis : il n'est pas possible de rapprocher de telles coquilles des Hydatina, par le simple motif que la spire est visible. Pour trouver une forme, un labre et un bord columellaire analogues, il faut les comparer aux Bullidæ; aussi c'est dans cette famille que je propose actuellement de classer Bullopsis, el de l'admettre à titre de genre distinct, caractérisé non seulement par sa plication columellaire tout à fait inattendue, mais encore par sa spire largement découverte.

Répart. Stratigr. - Il n'y a rien à ajouter à ce que j'ai précédemment indiqué : l'espèce type est la seule qu'on connaisse jusqu'à présent : le terrain dans lequel elle a été recueillie est une sorte de grès vert et sableux, où le test des coquilles se conserve, quoique fragile. Les géologues américains considèrent ce terrain comme appartenant à l'époque crétacique, mais il est difficile de fixer sa position synchronique, relativement aux couches crétacées de l'Europe.

\section{BULLINELLA, Newton, 1891.}

Répart. Stratigr. - Lorsque j’ai signalé, avec un point de donte, ce genre dans le Sénonien de l'Inde, je n'avais pas à ma disposition le Mémoire de d'Archiac sur le Crétacé des Corbières; pour combler cette lacune, il $y$ a lieu d"indiquer :

Sexoriex....... Une espèce à peu près certaine dans le Santonien des Bains de Rennes (Bulla Palassoni, d'Arch.), d'après la figure du Bull. de la Soc. géol. de Fr. 18 วั4.

ROXANIA, Leach, sec. Gray, 1847.

Répart. Stratigr. - Je n'ai pu indiquer l'existence de ce genre que dans la Craie du Missouri, et avec peu de certitude; gràce à de nouveaux matériaux, je signale :

Sexoxiex ...... Deux espèces à peu près certaines dans le Santonien des Corbières, l'une à Bains de Rennes (Bulla ovoides, d'Arch.), d'après la figure du Bull. de la Soc. geol. de Fr. 18004 ; l'autre à Sougraignes, dans l'Aude (Roxania Peroni, Cossm.), décrite dans le Bull. du Congrès de Carthage de l'Assoc. franç. 1896, coll. de Grossouvre. 
Acrostema, Cossm. 1889.

Répart. Stratigr. - Ce sous-genre n'a pas élé signalé avant l'ćpoque tertiaire; or, en examinant le Mémoire précité de d'Archiac, on peut ajouter :

Senonien...... Une espèce presque certaine dans le Santonien de Bains de Rennes (Bulla Baylei, d'Arch.), d'après la figure du Bull. de la Soc. géol. de lir. $18 \% 4$.

Prrunculus, Pilsbry, 1894. Type: Sao piriformis, Ad. Viv.

Observ. - Ce sous-genre, créé dans la $60^{\circ}$ livraison du " Manual of Conchology" de Tryon et Pilsbry (p. 229), est destiné à remplacer Sao, \d. 1830 (non Billberg, 1829, Crust.); il contient des coquilles dont deux espèces seulement ont été figurées, mais qui me paraissent, d'après ces figures, très voisines de Mnestia ou d'Alicula. L'auteur le place dans la famille Tormatinidie, comme sous-genre de Rehesa, ainsi que Cylichina d'ailleurs. Je me borne à enregistrer cette opinion, et je n'ai pas à la discuter, le sousgenre dont il s'agit n'étant pas connu à l'état fossile; mais je ne crois pas. que Cylichnina appartienne à la famille Tornatizidx.

Micromelo, Pilsbry, 1894. Type: Bulle undata, Brug. Viv.

Observ. - Ce genre a été proposé pour des coquilles bulliformes, excessivement minces, à spire apparente, qui avaient été classées dans le genre Hydatina, ou même Bullina, Fér., mais qui en diffèrent par leur surface ornée de quelques stries spirales très écartées, et par le nombre des tentacules du disque céphalique (deux au lieu de quatre). Je ne connais aucun fossile qui présente ces caractères.

Oligoptycha, Meek, 1876.

Répart. Stratigr. - Ce sous-genre ne m'était jusqu'i présent conıu que par la figure donnée par Meek, dans son Mémoire sur le terrain crétacique du Missouri: depuis l'impression de la première livraison de ces "Essais ", j’ai eu la satisfaction de constater l'existence, en France, d'une coquille qui paraît se rapporter complètement à la forme américaine:

Senonien....... Une espèce probable dans le Santonien inférieur de l'Aude à Sougraignes (O. Grossouvrei, Cossm. Assoc. firanc. Congrès de Carthage, 1896), coll. de Grossourre. 
ERIPTYGHA, Meek. 1876.

Répart. Stratigr. - Ce genre n'a pas encore été signalé en France, dans la Craie tout à fait supérieure; je puis actuellement combler cette lacune.

Senoniev....... Une espèce, dont j’ai vérifié le pli bifide, dans le Campanien de Villambleur, Dordogne (Avellana royana, d'Orb.), coll. Jolly.

\section{Parascutum, Cossm. 1892 (non Williamia, Monts.).}

Observ. - Il résulte d'une communication, qui m'a été faite par M. Jolly, d'un échantillon de Williamia Gussoni, Costa, qu'on ne peut établir aucun rapprochement entre cette espèce et Umbrella Raincourli, nob. des environs de Paris. Dans ces conditions, ainsi que je le prévoyais, il y a lieu de reprendre le nom Parascutum que j'ai proposé pour la coquille fossile, d'en faire un sous-genre distinct, et de lui appliquer la diagnose (p. 137) que j'ai donnée d'après cette espèce, que je considérais à tort comme un plésiotype de Wrilliamia: elle devient done l'espèce type du sous-genre f'arascutum.

\section{ACRORIA, Cossmann, 1885.}

Observ. - L'espèce pliocénique de San Pedro, dénommée A. dubia, par M. Bergeron, dans son rapport sur la Mission d'Andalousie, ne me paraît pas appartenir au genre Acroria, à cause de sa forme symétrique qui rappelle plutôt les Scutum, et parce qu'elle est dépourvue de la dépression siphonale qui caractérise, en général, toutes les formes que j’ai placées dans la famille Acroriide.

\section{Description des espèches inédites, CitéES DANS CETTE LIVRAISON.}

Ptygmatis carentonensis, nov. sp. $\quad$ Pl. IV, fig. 3.

Forme trapue, conique; spire courte; tours plans ou légèrement évidés, un peu en gradins, à sutures bordées par une rampe arrondie; surface à peu près lisse; dernier tour atteignant les deux cinquièmes de la longueur tolale, séparé de la base par un 
angle péripherifue en scunćral arrondi, parfois subcarćné ; hase obliquement déclive, non convexe, quelquefois subexaréc. Ouverture rhomboirdale, à section quinquelobée par des plis lamclleux et très saillants, un au labre, trois à la columelle, le pli pariétal plus mince et moins élevé que les autres; perforation ariale très étroite, presque entièrement recouverle par le bord columellaire, sauf à l'extrémité du bec antérieur de l'ouverture.

Dis. - Longueur probable, 56 mill.; diamètre, 20 mill.; dernier tour de face, 97 mill.

Rapp. et diff. - Pour séparer cette espèce de $P$. Requicni, d'Orb. qui existe aussi dans la Charente (coll. Arnaud), je me fonde sur trois caractères différentiels qui me paraissent avoir une réelle constance: d’abord l'angle spiral, ou plutôt le rapport de la longueur au diamètre, qui est à peine de 3 dans l'espèce décrite par d'Orbigny, tandis que chez. notre espèce, beaucoup plus trapue, la base atteint presque la moitié de la longueur; en second lieu, tandis que la hauteur du dernier tour de $P$. Requienine représente guère que les $̋ / 18$ de la longueur, elle en atteint les $2 /$ ŏ chez $P$. carentonensis, c'est-à-dire une proportion presque moitié plus grande; enfin, les lours de notre espèce sont légèrement étagés en gradins arrondis, tandis que d'Orbigny indique dans la Paléontologie uno forme subulée, des tours séparés par des sutures linéaires; mème le plus grand des individus de la Charente que je rapporte à $P$. Requieni (comme l'a fait M. Coquand d'ailleurs) a les tours un peu imbriqués en avant. II y a done des motifs sérieux pour séparer ces deux formes, et je ne puis en donner de meilleure prenve qu'en les faisant figurer l'une à côté de l'autre.

Gisemext. - Charente: Châteauneuf, à la Peilleterie. Un individu de $P$. carentonensis (Pl. IV, fig. 3 ); un individu de $P$. Requieni (Pl. IV, figure 2); coll. Arnaud. - Etage Turonien, sous-étage Provencien, niveau H. (sec. Arnaud).

Nerinella subaequalis, [d'orb.].

Pl. IV, fig. I.

1819. Merinca subrequalis, d'Orb. Pal. fr. crét. t. 11, p. 93, pl. CLXII, fig. ت̈. 1850. Nerinea subequalis, d'Orb. Prod. $21^{\circ}$ ét., p. 19l, no 34.

Forme étroite, cylindracée; spire longue, subulée; tours presque plans ou faiblement évidés, dont la hauteur atteint les trois quarts de la largeur; sutures linéaires, situées sur un faible renflement; surface entièrement lisse: dernier tour peu élevé, 
anguleux à la périphérie de la base, qui est déclive et imperforée. Ouverture étroite, rhomboïdale, canaliculée en avant; labre muni, à l'intérieur, d'un gros pli médian; pli columellaire bordant le canal antérieur; pli pariétal très écarté du précédent et beaucoup plus mince.

Drм. - Longueur probable, 24 mill.; diamètre, 24 mill.

Onserv. - J'ai repris la description de cette espèce déjà connue, d'une part, parce qu'elle n'a été décrite que d'après un moule, tandis que l'échantillon ci-dessus décrit est muni de son test, et que j'en ai étudié de nombreux individus dans le même état de conservation; d'autre part parce qu'elle est un exemple frappant de la difficulté qu'on éprouve souvent à séparer certaines Nerinella des Nerinea typiques : ce n'est guère que par son galbe droit et subulé par l'écartement considérable du pli columellaire et du pli pariétal, qu'on peut fixer le classement générique de N. subxqualis, qui ressemble évidemment à certaines Nerinea peu trapues, ne fùt-ce que par sa grande taille, par exemple, à $N$. Aunisiana. La même incertitude existe pour le classement de certaines formes bajociennes, c'est-à-dire au début de l'apparition des Nerineidæ; ici, au contraire, c'est à l'étage Turonien, en d'autres termes, tout près de la disparition de cette famille, qu'il semble se produire une nouvelle soudure entre les deux genres; au contraire, dans les terrains jurassiques moyen et supérieur, comme à la base de la période crétacique, leurs caractères différentiels sont beancoup plus tranchés et présentent le maximum d'écart, coïncidant précisément avec la période du plus grand développement de la famille. Je me borne à signaler cette anomalie, qui est quelque peu en contradiction avec la théorie de l'éventail auquel j'ai, dans la première livraison de ces "Essais ", comparé la genèse morphologique des Opisthobranches.

Giscuent. - Charente : Châteauneuf, à la Pelleterie, une docizaine d'échantillons avec leur test $(\mathrm{Pl}$. V, fig. 1), coll. Arnaud. - Étage Turonien, sous-étage Provencien, niveau $\mathbf{H}$. (sec. Arnaud).

Asthenotoma Tatei, nov. sp.

Pl. VI, tig. 29.

Taille assez petite; forme étroite, subulée; embryon obtus, en goutte de suif ; spire longue, composée, outre l'embryon, de sept tours, le premier costulé, les suivants ornés de quatre petites carènes spirales, entre lesquelles il existe, pour trois des interstices, un filet plus fin; tous les intervalles des carènes sont décussés par de fins plis d'accroissement, sinueux et serrés; dernier 
tour un peu plus grand que le tiers de la longueur, à base excavée, terminé par un canal peu allongé et obliquement infléchi, sans échancrure à son extrémité antéricure. Ouverture assez large en arrière, subitement rétrécie en avant; labre arqué, muni d'une échancrure large et triangulaire, assez loin de la sulure à laquelle il aboutit obliquement; columelle courdée, sans ancune trace de pli sur le coude; bord columellaire étroit, peu calleux, se terminant en pointe un peu au-dessus du coude de la columelle, sans atteindre l'extrémité du canal.

Dim. - Longueur, 15 mill.; diamètre, 4 mill.

1R. D. - Celte espèce a tout à fait l'aspect d'A. Basteroli, quoiqu'elle ait cependant un canal un peu moins tronqué et un embryon beaucoup plus obtus encore. L'absence complète de plis columellaires et l'existence d'un sinus bien visible ne permettent pas de la classer dans la section Endiatoma, quoiqu'elle se rapproche d' $E$. quadricincla par son canal un peu plus long et plus coudé que celui des Asthenotoma; d'ailleurs, elle n'a pas l'embryon conoïdal du type de cette section. Si on compare notre espèce à $A$. consulitis, qui est aussi un Asthenoloma d'Australie, on trouve qu'elle a la spire plus subulée, les tours moins convexes, le canal plus long, l'ornementation différente, etc.

Gis. ET roc. - Australie du Sud, deux échantillons donnés par M. Bonnet (Pl. VI, fig. 29), ma coll. Eocène

Daphnella ponteleviensis, non. sp. Pl. VII, fig. 9-10.

? Daphnella Salinasi, Dollf. Dautz. Etude prélim. faluns 'Tour. (non Calc.).

Taille petite; forme ovale, buccinoïde; spire courte, à galbe subconoïdal; embryon lisse, obtus, paucispiré? quatre tours convexes, outre l'embryon, munis d'une rampe légèrement excavée au-dessus de la suture, cancellés par une quinzaine de côtes un peu obliques, et par quatre cordons spiraux, entre lesquels il existe des filets plus fins; dernier tour supérieur aux deux tiers de la hauteur totale, arrondi a la base sur larguelle l'ornementation se prolonge, terminé par un canal court et tronqué, un peu intléchi à droite, sans échancrure à son extrémité el sur le cou duquel 
s'enroulent des filets obliques. Ouverture ovale, peu allongée: labre arqué, peu épais, entaillé contre la suture par un sinus peu profond; columelle excavée en arrière et au milieu, à peine infléchie en avant; bord columellaire mince, peu distinct.

Drм. - Longueur, 5 1/2 mill.; diamètre, 3 mill.

R.D. - Se distingue de D. Salinasi par sa forme et sa spire plus courtes, par son. ornementation plus régulièrement cancellée; e'est bien une Daphnella, quoique l'embryon soit assez obtus, probablement par suite de l'usure qu'ont subie la plupart des coquilles des faluns de la Touraine. Cependant les individus que m'a ultérieurement communiqués M. Dollfus sont un peu plus élancés que celui qui m’a servi de type, leurs tours sont plus arrondis, et le treillis parait plus fin, parce que la surface est plus fraîche; mais ce ne sont pas des D. Salinasi.

Gis. et Loc. - Pontlevoy (Pl. VII, fig. 9-10), ma coll. - Helvétien.

Mitromorpha subulata, nov. $s p$.

Pl. VIII, fig. 21.

Taille très petite; forme ovoïdo-biconique; spire très courte et subulée; embryon subglobuleux, composé d'un tour et demi, à nucléus obtus; quatre tours presque plans, séparés par des sutures peu profondes, ornés de sillons spiraux et obsolètes qui ne persistent, sur les derniers tours, qu'à leur partie inférieure, au nombre de trois ou quatre seulement; dernier tour égal aux deux tiers de la longueur totale, peu ventru, orné de quatre sillons en arrière, qu'une zone lisse sépare des sillons de la base: celle-ci est déclive et se joint au cou du canal presque sans inflexion. Ouverture étroite, terminée en avant par un canal court, à peine distinct, sans échancrure à son extrémité; labre à peu près rectiligne, avec une sinuosité postérieure à peine indiquée; portant à l'intérieur un rang de denticules inégaux, très petits et peu saillants; columelle non sinueuse, portant au milieu deux plis assez écartés, un peu épais à l'entrée de l'ouverture, puis plus minces et plus obliques dans leur enroulement interne; bord columellaire mince et peu distinct, se terminant en pointe effilée contre l'extrémité du canal. 
Dim. - Longueur, $41 / 2$ mill.; diamètre, 2 mill.

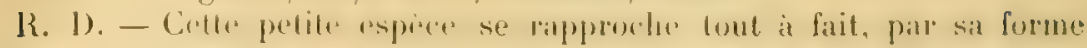
et par sa columelle, de $M$. lirata, qui est le type du genre Mitromorpha, Adams: tontefois, la diagnose de enthe coquille, qui provienl des mees du Jitpon, nindique aucune denticulation a linterienr du labre, probatblement parce que l'exemplaire décrit n'était pas adulte; en outre, les tours de notre espèce sont sculement sillonnés, tandis que ceux des autres formes qu'on classe dans le genre Mitramorpha sont parfois cancellés. Quoi qu'il en soit, je n'hésite pas à attribuer au genre d'Adams la petite coquille du gisement de Gourbesville, el celte assimilation me permet d'avoir une opinion définitive sur le classement de ce genre: en effet M. Subulala me parait voisin de Cordieria, à cause de son sinus peu profond, de ses deux plis columellaires et de son embryon tout a fait identique; elle s'en écarte cependant par les denticulations internes de son labre et par sa forme de Conomitra. D'autre part, il ne parait pas possible de la placer dans la famille Mitridx, puisqu'elle possède un léger sinus labial, et que son canal n'est pas échancré à l'extrémité antéricure.

Grs. Ex Loc. - Gourbesville, unique (Pl. VIII, fig. 21), ma coll. Pliocène, avec les Astarte et Raincourtia incilis. 


\section{TABLE ALPHABÉTIQUE}

DES

FAMILLES, GENRES, SOUS-GENRES, ETG.

Les noms en italiques sont ceux des synonymes.

\begin{tabular}{|c|c|c|c|}
\hline & ges. & & \\
\hline 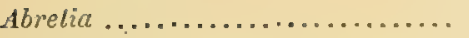 & 52 & Calliotectum ............ & \\
\hline 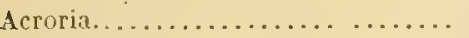 & 171 & Campichia ................... & \\
\hline Acrostemma ................. & 170 & 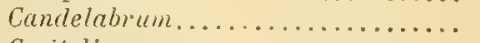 & \\
\hline 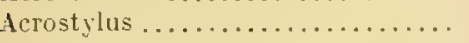 & 29 & 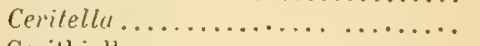 & \\
\hline 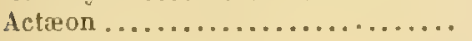 & 165 & 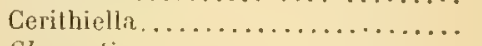 & \\
\hline 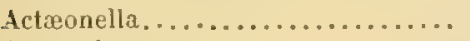 & 166 & Chanvelia.................... & \\
\hline 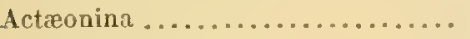 & 165 & Chelyconus.................. & 160 \\
\hline 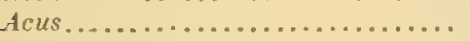 & 52 & 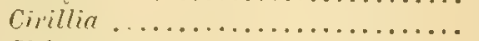 & 121 \\
\hline Aforia...................... & 64 & Cilharopsis .................... & 63 \\
\hline yacrum ................... & 137 & Clalhromangilia................. & 117 \\
\hline $\operatorname{rin} x \ldots \ldots \ldots \ldots \ldots$ & 71 & $1] a \ldots \ldots \ldots \ldots \ldots$ & 121 \\
\hline 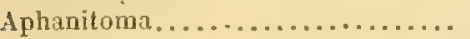 & 106 & $a \ldots \ldots \ldots \ldots \ldots \ldots$ & $10 x$ \\
\hline 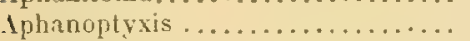 & 34 & 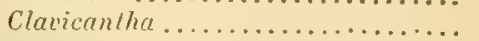 & 6.9 \\
\hline Ipiotunia .................. & 73 & 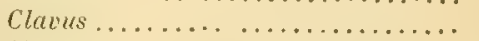 & \\
\hline ella..................... & il & Clionella .................. & 62 \\
\hline 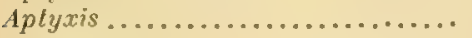 & .41 & Clinura .................. & If \\
\hline ella ....................... & 142 & Cochlespira.............68 et & $9 \%$ \\
\hline 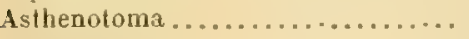 & 104 & 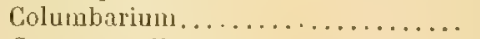 & $6 f^{\prime}$ \\
\hline 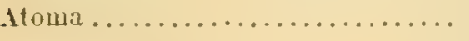 & 126 & 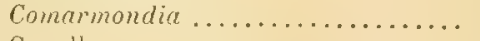 & 128 \\
\hline & & $\ldots \ldots \ldots \ldots \ldots \ldots \ldots \ldots$ & \\
\hline$\ldots$ & 39 & $\ldots \ldots \ldots \ldots \ldots \ldots \ldots \ldots$ & 140 \\
\hline toma $. . . \ldots \ldots \ldots \ldots \ldots . . .$. & 101 & $\ldots \ldots \ldots \ldots \ldots \ldots \ldots \ldots$ & $10 \%$ \\
\hline 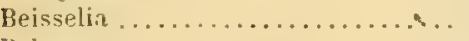 & 113 & Conopleura.................... & ti3 \\
\hline & 89 & 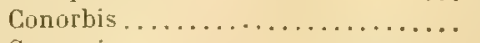 & $1: 9$ \\
\hline 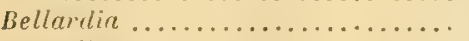 & 128 & spira ..................... & 1:ii; \\
\hline 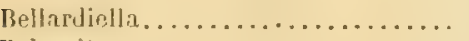 & $12 S$ & Conus............. 142 et & $1: i 2$ \\
\hline Belomitra ..................... & 63 & 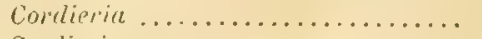 & 121 \\
\hline 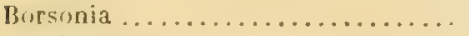 & 96 & 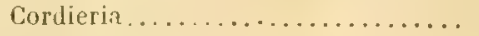 & 98 \\
\hline 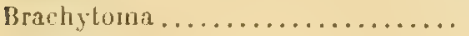 & 62 & 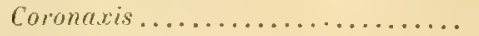 & $14: \frac{1}{2}$ \\
\hline 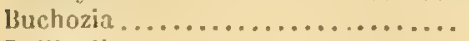 & 91 & 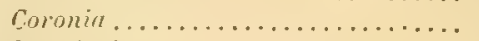 & \\
\hline$\ldots \ldots \ldots \ldots \ldots \ldots \ldots \ldots$ & 169 & 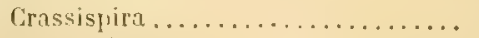 & \\
\hline$\ldots \ldots \ldots \ldots \ldots \ldots \ldots \ldots \ldots$ & $16 \mathrm{~S}$ & Crissopleura .................. & \\
\hline
\end{tabular}




\begin{tabular}{|c|c|c|c|}
\hline & I'ages. & & l'ats \\
\hline Cryplocomas $\ldots . . \ldots \ldots \ldots \ldots \ldots$ & $11 T$ & $\ldots \ldots \ldots \ldots, \ldots \ldots \ldots$ & 20 \\
\hline 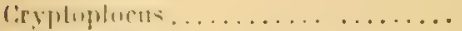 & í & & \\
\hline 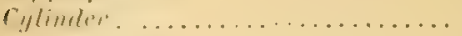 & $1: 3$ & himenin. & $11:$ \\
\hline 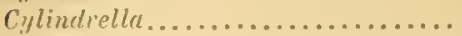 & 142 & & \\
\hline 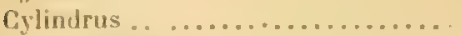 & 143 & 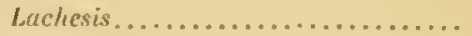 & $9 i$ \\
\hline 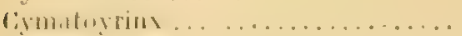 & 84 & Leptoconus ..................... & 162 \\
\hline 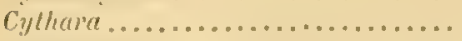 & 120 & Leucosyrinx................... & $7 \mathrm{i}$ \\
\hline 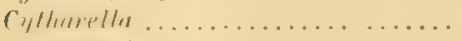 & 117 & 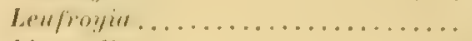 & $1: 21$ \\
\hline 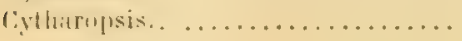 & 6i.) & Lienundiu .................... & $1: 1$ \\
\hline & & Lithoconus .................. & 157 \\
\hline Daplonella ................... & 124 & & \\
\hline gela $\ldots \ldots \ldots \ldots \ldots \ldots \ldots$ & 93 & 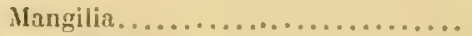 & 117 \\
\hline rirt ................... & 121 & liclla ................ & $11 !$ \\
\hline 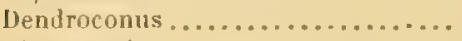 & 139 & ioptyxis................... & 30 \\
\hline$i s, \ldots \ldots \ldots \ldots \ldots \ldots$. . . . & 31 & loma................. & fi\} \\
\hline$\ldots \ldots \ldots \ldots \ldots \ldots \ldots \ldots \ldots$ & $12 \%$ & gelo................... & 170 \\
\hline Dolicholoma.................... & 101 & 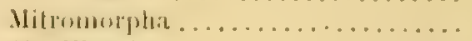 & 100 \\
\hline 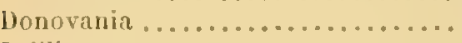 & 94 & 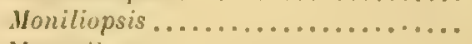 & 82 \\
\hline 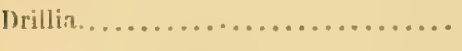 & 82 & 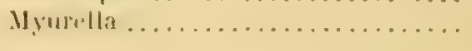 & 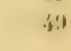 \\
\hline 1 is ................. & $4 \%$ & 1ea...................... & 25 \\
\hline$\ldots \ldots \ldots \ldots \ldots \ldots \ldots$ & 106 & n. $\ldots \ldots \ldots \ldots \ldots \ldots \ldots$ & 23 \\
\hline Nitita $\ldots \ldots \ldots \ldots \ldots \ldots \ldots$ & $\ddot{~}$ & 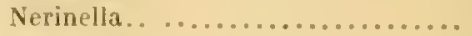 & 35 \\
\hline vina . . . . . . . . . . . & sil & ..................... & $9 \xi$ \\
\hline$\ldots \ldots \ldots \ldots \ldots \ldots \ldots \ldots \ldots$ & 103 & . . . . . . . . . . . . . & $\$ 6$ \\
\hline ch $\ldots \ldots \ldots \ldots \ldots \ldots \ldots$ & 171 & 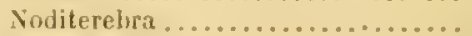 & $\dddot{i 1}$ \\
\hline 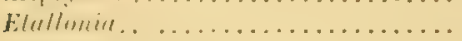 & $9 !$ & Vuberuln $\ldots \ldots \ldots \ldots \ldots \ldots \ldots$ & $1: i$ \\
\hline & bít & & \\
\hline n & 120 & nligoptyohat... & 171 \\
\hline 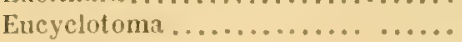 & 63 & 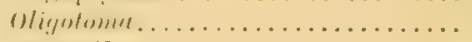 & 111 \\
\hline 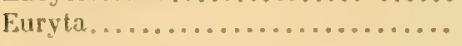 & 54 & ilus...................... & 120 \\
\hline & & (1хуастиш.................... & $8: 2$ \\
\hline 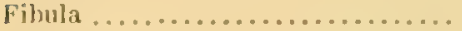 & 13 & & \\
\hline Q & 94 & L 15 & il \\
\hline Fusoterebra..................... & 57 & mella................. & 117 \\
\hline & & .................. & 171 \\
\hline$\ldots \ldots \ldots \ldots \ldots$ & 6.2 & CHIATA............... & 461 \\
\hline$\ldots \ldots \ldots \ldots \ldots \ldots \ldots \ldots \ldots$ & 143 & 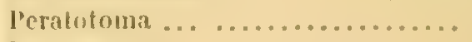 & 13: \\
\hline 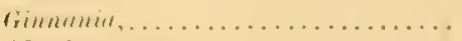 & $1: 31$ & Pיитипа . . . . . . . . . . . . & lis \\
\hline Glyphostoma .................. & 124 & arplysis................. & 21 \\
\hline 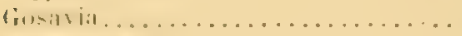 & 1116 & conns................... & 160 \\
\hline 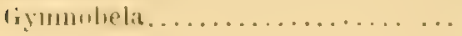 & 6.3 & 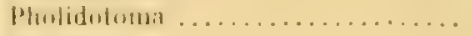 & $11: 2$ \\
\hline & & & 121 \\
\hline Il $x^{*}$ & 92 & onia................. & $9 S$ \\
\hline II:I! & $1: 3: 1$ & .................... & 98 \\
\hline$\ldots \ldots \ldots \ldots \ldots \ldots \ldots$ & 53 & amus ................... & 160 \\
\hline $1 \mathrm{~s} \ldots \ldots \ldots \ldots \ldots \ldots \ldots$. & 151 & fusin... ................. & 64 \\
\hline 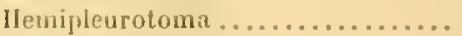 & 78 & 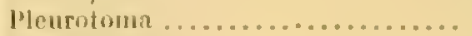 & 75 \\
\hline Hermes ...................... & 143 & Pleurotomella................. & 133 \\
\hline Heterestermat......... & $1 \pm N$ & 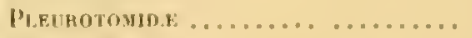 & 58 \\
\hline terma... & $6 i$ & Plierobullat...... & 167 \\
\hline Homotoma..............128 et & $13: 5$ & Prirmus....... & $1: 39$ \\
\hline & & 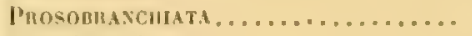 & 46 \\
\hline & 17 & 0 & lii \\
\hline ITIEK & 16 & I'se'udormphilumue ............... & 37 \\
\hline
\end{tabular}


DES FAMILLES, GENRES, SOUS-GENRES, ETC.

\begin{tabular}{|c|c|c|c|}
\hline \multicolumn{2}{|c|}{ Pagus. } & \multicolumn{2}{|r|}{ Pagis. } \\
\hline Pseudotoma.................... & $14 b$ & 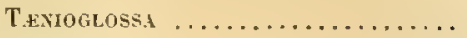 & 46 \\
\hline Ptychocylindrites............... & 165 & 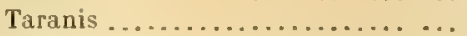 & 63 \\
\hline 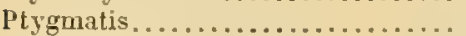 & 32 & 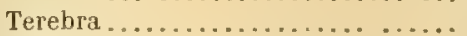 & 49 \\
\hline 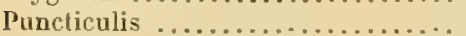 & 142 & Terebrida. $\ldots \ldots \ldots \ldots \ldots \ldots$ & 46 \\
\hline Pusionella $\ldots \ldots \ldots \ldots \ldots \ldots \ldots$ & 36 & Terebrit ma . . . . . . . & 110 \\
\hline Psrunculus ................... & 170 & Terebrum..................... & 48 \\
\hline & & Teres ........................ & 130 \\
\hline 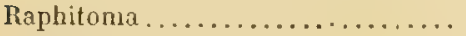 & 131 & 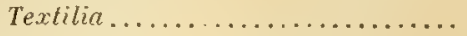 & 143 \\
\hline Retusa .................. & 166 & Theliconus ................. & 143 \\
\hline Rlizoconus.................. & 162 & Thesbia.................... & 136 \\
\hline Rhombus...............142 et & 152 & 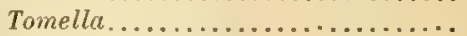 & 68 \\
\hline Rollus..................... & 143 & Tornatella...$\ldots \ldots \ldots \ldots$ & 165 \\
\hline Rostellites $\ldots \ldots \ldots \ldots \ldots \ldots \ldots \ldots$ & 114 & Trachelochetus ................... & 67 \\
\hline 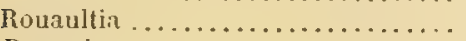 & 93 & 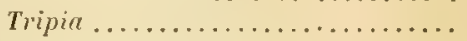 & 83 \\
\hline 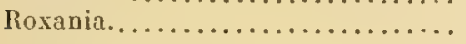 & 169 & Trochactieon................... & 166 \\
\hline & & Trochalia ..................... & 43 \\
\hline Scobinella.................... & 107 & 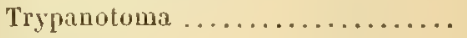 & 109 \\
\hline 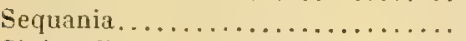 & 13 & Trbiferido. . . . . . . . . . . . . & 12 \\
\hline Sinistrella................. & 110 & Tuliparia ..................... & 143 \\
\hline Smilhia.................. & 131 & Turvicula $\ldots \ldots \ldots \ldots \ldots \ldots \ldots$ & 69 \\
\hline Solidula............... & $16 \mathrm{f}$ & Turris $\ldots \ldots \ldots \ldots \ldots \ldots \ldots \ldots \ldots$ & $7: 3$ \\
\hline Spineoterebra $\ldots \ldots \ldots \ldots$ & 55 & 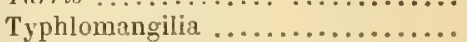 & 63 \\
\hline 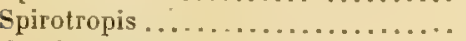 & 88 & & \\
\hline 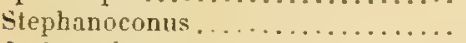 & 153 & Vielliersiu.................. & 131 \\
\hline Strioterebrum .................. & 49 & 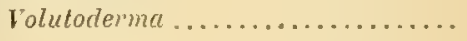 & $11^{\prime}$ \\
\hline Strombina.............. 13 et & 80 & & \\
\hline Subula..................... & 52 & Zafra. & 63 \\
\hline 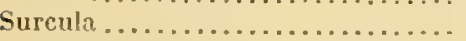 & 69 & $\ldots \ldots \ldots \ldots \ldots$ & 91 \\
\hline 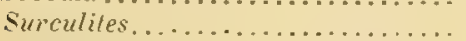 & 69 & Zelin ..................... & $10 T$ \\
\hline ystenope. & 133 & & \\
\hline
\end{tabular}

Tours. - Imprimerie Drstis FrRéres. 


\section{PLANCHE 1}

1-2. Itielita cabanetiana, (d'Orb.).

3-4.

id.

5. Pseudonerinea Clauenexsis, de Lor.

6. Psecdonerinea Clytia, (d'Orb.).

7-8. P'seudonerinea Clio, (d'Orb.).

9. Fibcla nudiformis, Piette.

10. Itrevia canaliculata, (d'Orb.).

11.

id.

12-13. Campichia truxcata, (Pict. et Camp.).

14-15. Exdiaplocus Muxieri, (Rig. et Sauv.).

16. Nertined salinensis, d'Otb.
Oyonnax

Valfin

Blauen

Perreuse

Oyonnax

Maisoncelle

Uchaux

Uzès

Châtillon

llidrequent

Noiron
Kimm, réd $1 / 2$

Kimm. gr. nat.

haur. gr. nat.

Raur. rédon 1/2

Kimm. gr.nat.

Bath. gr. nat.

Turon. gr. nat.

Turon, gr. nat.

Urgon. gross' 3

Bath. gross $4 / 3$

Portl. rédou 1/3 
Essais de Paléoconchologie, M. Cossmann. (2e livr.)

P1. I
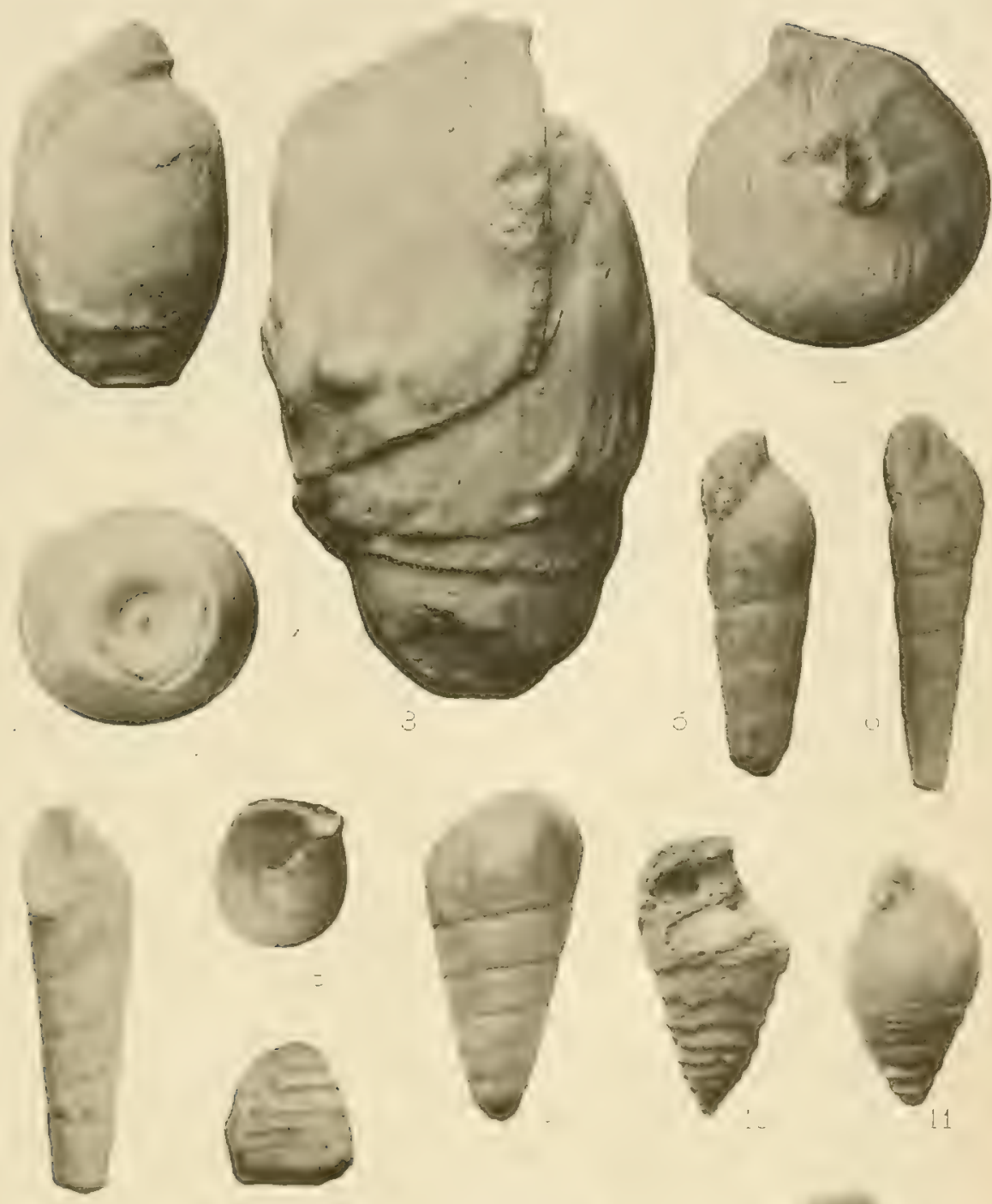

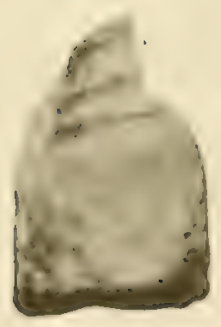

1

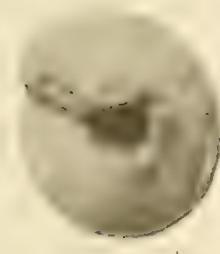

$\therefore$

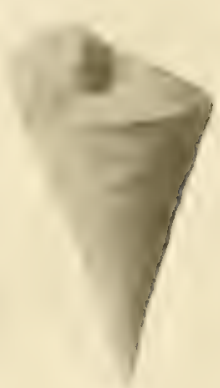

$\because$

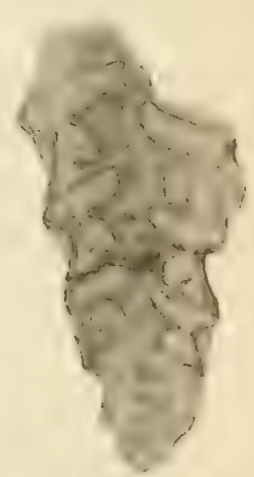

1 




\section{PIANCHE II}

1. Phaseroptyxis moreana, (d’Orb.).

2. Nehinea trbercclosa, Defr.

3. Ptyguatis bucxtrutaxa, Thurm.

4. Prygmatis carpatuica, Zeuschner.

5. Drozoptyxis Moxilifer.1, (d Orb.).

6. Aphanoptyxis Defander, (Desl.).

7-8. Trochalia patella, (Pjelte).

9-11. Nerinella Grossuuvei, Cossm.

12. Crymtoploces depresses, (Yoltz). 13-14.

Merry-s.-Yonne
Coulanges-s.-Yonn
Wagnon
Valfin
Le Mans
Ilidrequent
Rumigny
Vendée
Haute-Saûne
Valfin

Raur. gr.nat.

Raur. rédon 1/:

Oxford. gr. nat.

Kimm. gr. nal.

Génom. rídoo 1/3

Bath. redos 1/2

Bath. gr. nat,

Hettang. gross' $3 / 4$

Séquan. rédon 1/2

Kimm. redon 1/2 

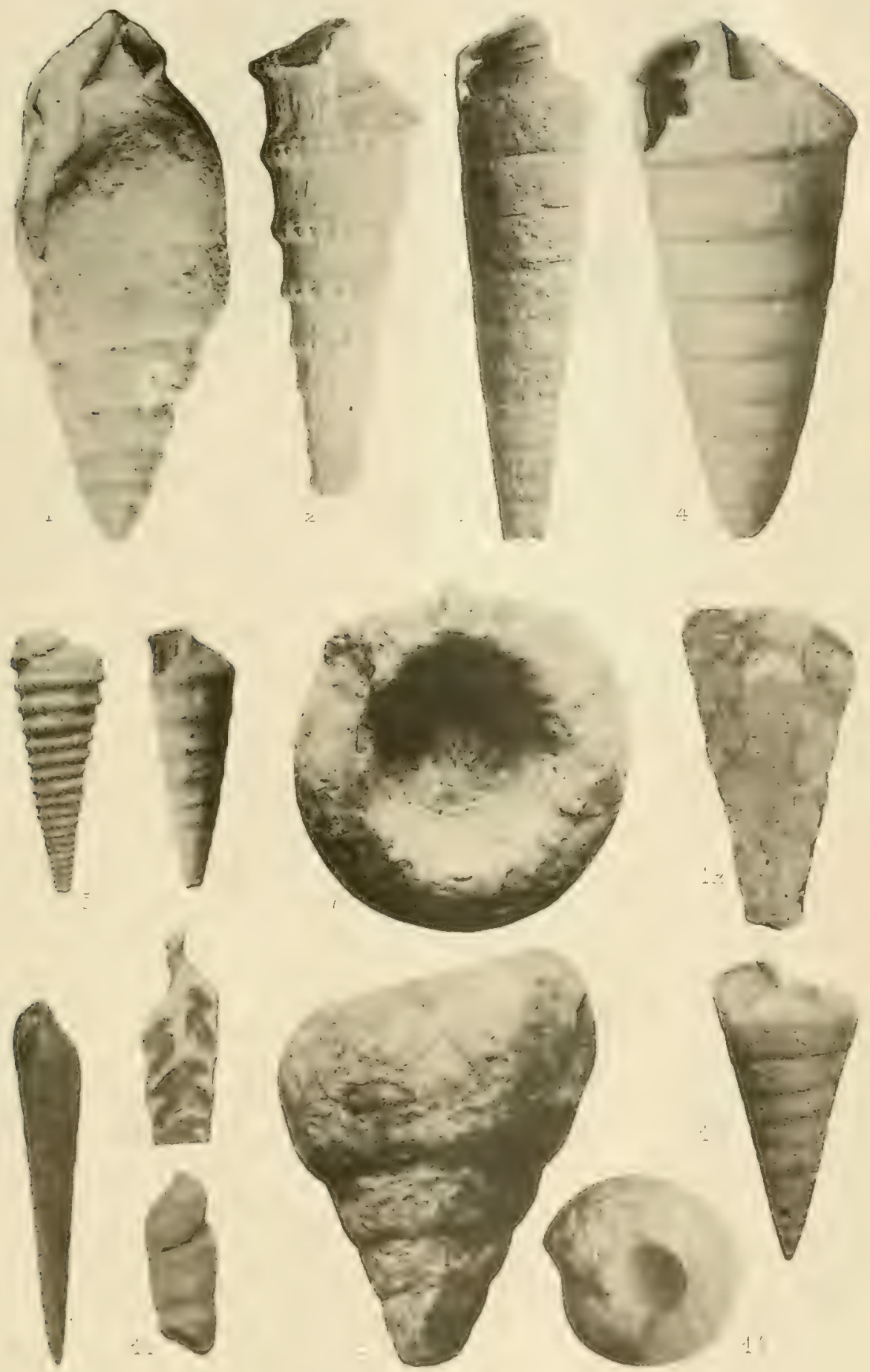




\section{PLANCHE III}

1-4. Sequania Lorioli, Cossm.

5-6. Acrostylus tainodosus, (Voltz).

7.

id.

8. Nerinea tuberculosa, Deft.

9. Aptyxiella sexcostata, (d'Orb.)

10. Aptyxiella hupellexsis, (d'Orb.).

11-12. Nerinela tornatela, (Yoltz).

13-14. Bactroptris implacata, (d'Orb.).

\begin{tabular}{|c|c|c|}
\hline Tonnerre & Séquan. & gr. nat. \\
\hline Yoiron & Portl. & gr. nat. \\
\hline Lods & Porti. & gr. nat. \\
\hline Puisenx & Raur. & réd ${ }^{\circ 0} 1 / 2$ \\
\hline Isa Hochelle & séquan. & gr. nat. \\
\hline La Irochelle & séquan. & gross' 2 \\
\hline Châtel-Censoir & Raur. & gross' 2 \\
\hline llidrequent & Bath. & gr. nat. \\
\hline
\end{tabular}




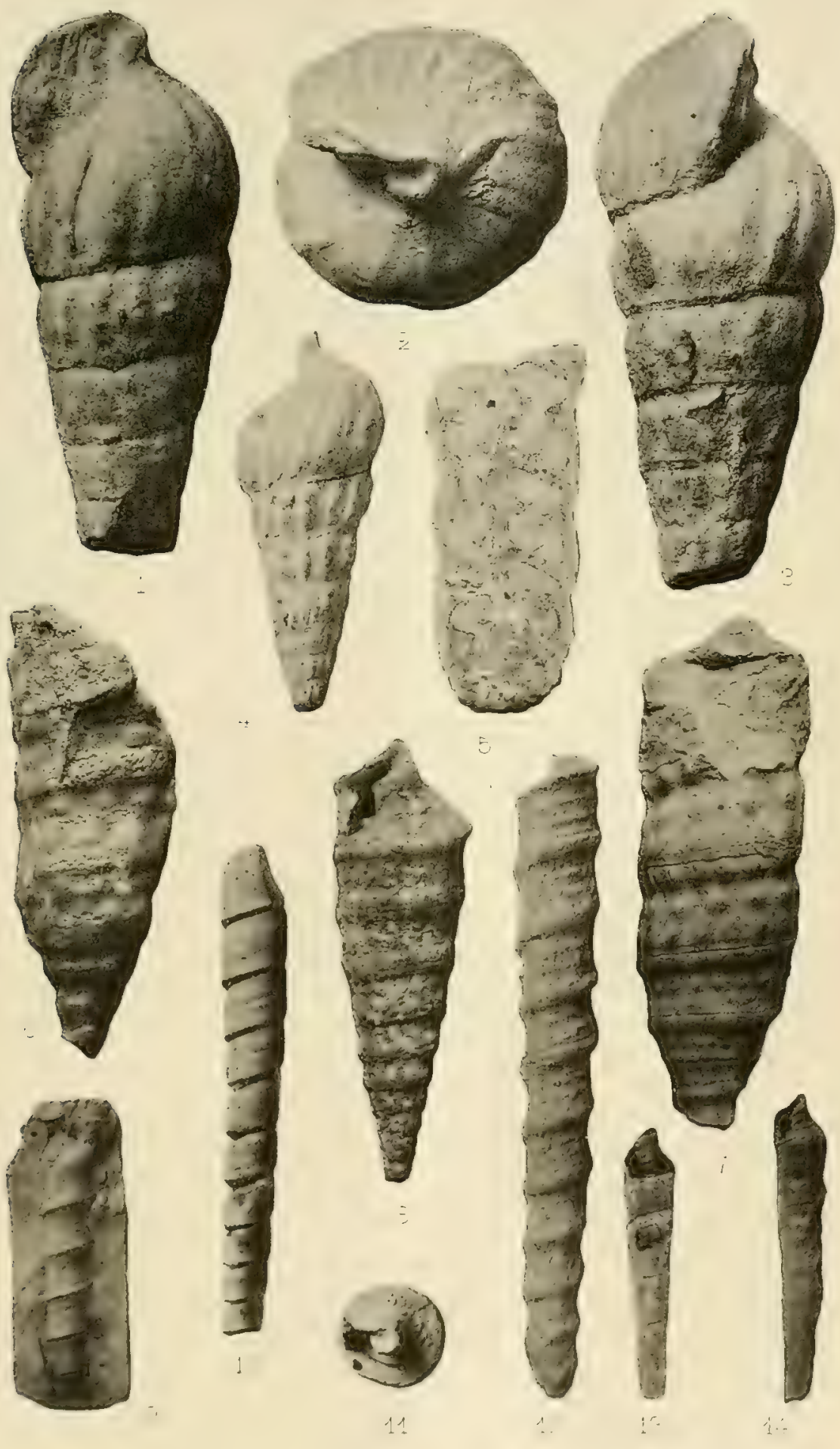






\section{PJANCHE IV}

\begin{tabular}{|c|c|c|c|}
\hline 1. Nerinella stbagcilis, (d'Orb.). & Chàtenuneuf & Turon. & $\operatorname{rin} 1 \cdot 01 / 2$ \\
\hline$\therefore$ Prvgmatis Requemi. (d'Orb.). & Chàteauneuf & Turon. & gr. nat. \\
\hline 3. Ptygiatis carentoxexsis, Cossm. & Chàteauneul & Turon. & gr. nat. \\
\hline 4-6. Bullopsis cretacea, Conrad. & Ripley & crét. & gross 2 \\
\hline i. Subela fuscata, (Brocchi). & Sancats & Mioc. & gr. nat. \\
\hline id. & Manthelan & Minc. & réd 1/2 \\
\hline 9. Pusionella tauronifit, Sacco. & Golli Torinesi & Mioc. & gr, nat. \\
\hline 10. MelinioptyXis altamahis, (Cossm.). & Montarlot & Bath. & gr. nat. \\
\hline 11. Terebra acuminata, Borson. & Vezza d liba & Pioc. & gr. nat. \\
\hline 12. Eunyta Nodosoplicata, (Dunker). & Antilles & Viv. & gr. nat. \\
\hline 13. Mrunela plocenica, (Font.). & Gannes & Hlioc. & gr. nat. \\
\hline 14. Fusoterebra terebrina, (Bon.). & Santa-Agata & Nioc. & grr. nat. \\
\hline 15-16. Hastula PLiCatela, (Lamk.). & Villiers & Foc: & gr. nat. \\
\hline 17-18. Trachelochetus desmius, (Edw.). & Barton & Eoc. & (gross 2 \\
\hline 19. Clavatela spinosa, (Grat.). & Peloua & Mioc, & gr. nat. \\
\hline 20. SPINeoterebra spinulosa, (Doderl.). & Stazzano & Mioc. & gr. nat. \\
\hline 21. Noditerebra gexicllata, (Tate). & Sustralie Sud & Foc. & $\cos \operatorname{coss}^{2} 2$ \\
\hline
\end{tabular}




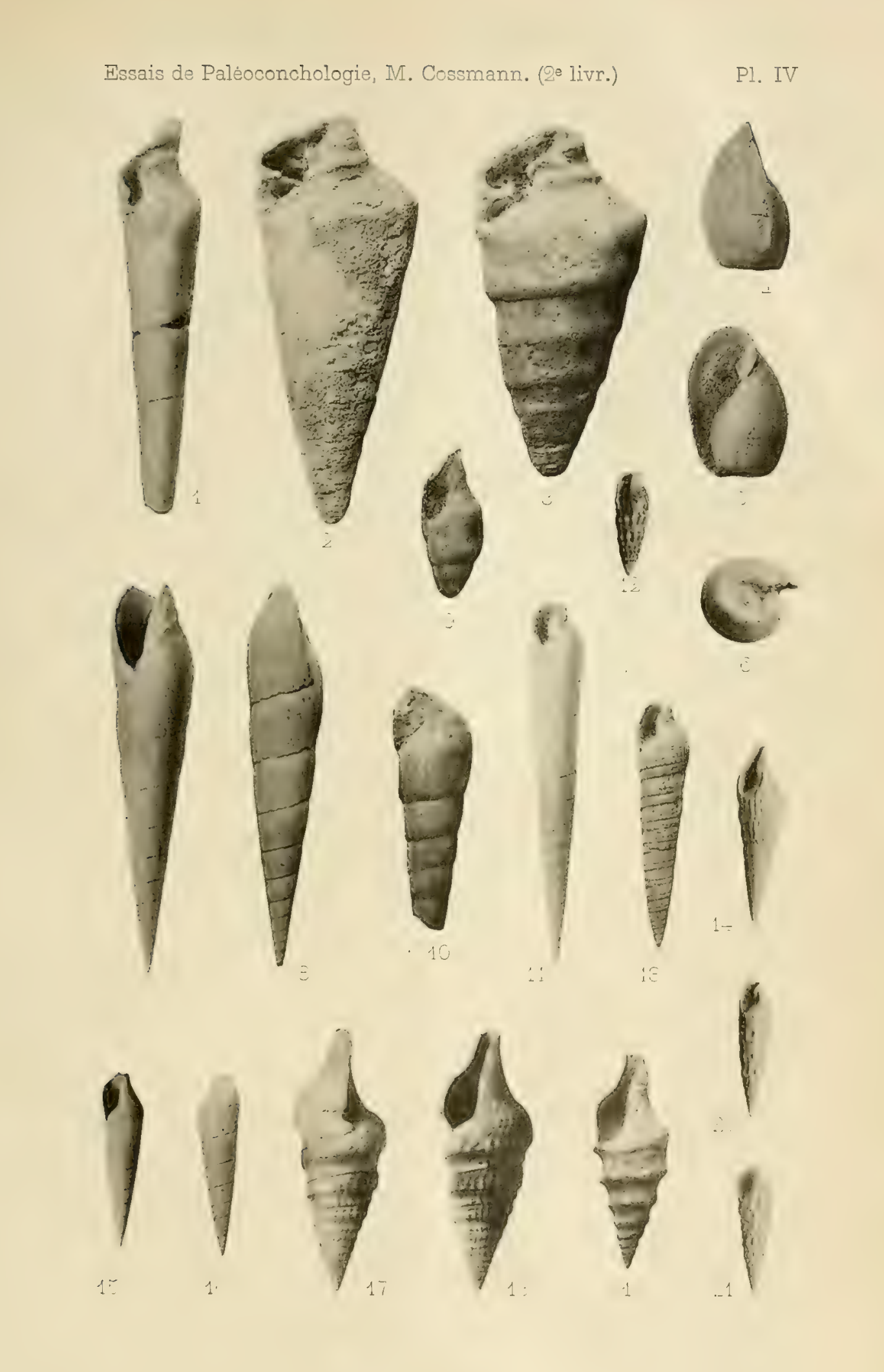






\section{PLANCHE I}

\begin{tabular}{|c|c|c|c|}
\hline 1. Perroxa Jouaxietr, (Desm.). & Lapugy & Mioc. & gr. nat. \\
\hline 2. Clavatula romaxa, (Defr.). & Toscane & Plioc. & nr. nat. \\
\hline 3-4. Surcula thaxsversaria, (Lamk.). & Parnes & Eoc. & grr. nat. \\
\hline 5-6. Axcistrosyrixx terebralls, (Lamk.). & Parnes & Eoc. & gross'2 \\
\hline 7-8. Aplotoma pirulata, (Desh.). & Cuise & Eoc. & $\operatorname{gross}^{1} 3 / 2$ \\
\hline 9-10. Hemipleurotoma denticula, (Bast.). & Léognan & Mioc. & gross' $3 / 2$ \\
\hline 11-12. Plecrotoma turricula, (Brocchi). & Biot & Pline. & gr. nat. \\
\hline 13. Perroxa semiargisata, (Lamk.). & Saucat: & Mioc. & gr. nat. \\
\hline 14-15. Plevrotoma kotata, (Brocchi). & Cannes & Plioc. & gr. nat. \\
\hline 16. id. & Biot & Plioc. & $\operatorname{gross}^{1} 3 / 2$ \\
\hline 17-18. Oxvachux obliteratum, (Wesh.) & Mouchy & Eoc. & gross 12 \\
\hline 19. Clinura Galliope, Bell. & Sienne & Plioc. & gr. nat. \\
\hline 90-21. Hempleurotoma Giebeli, (Bell.). & Salles & Hioc. & gross' 2 \\
\hline 22-23. Crassiptra axgulosa, (Desh.). & Villiers & Eoc. & gross $^{2} 3$ \\
\hline 21-25. Cymatosyrunx simplex, (Desh.). & Villiers & For: & gross $^{i} 2$ \\
\hline 26-27. Sprnotropis carlixati, (Phil.). & Finmark & Viv. & gr. nat. \\
\hline 28-29. Doxovasis mixiss, (Montg.). & Palerme & Post-plioc. & $\operatorname{gross}^{2} / 4$ \\
\hline 30-31. Dapunobela juxcea, (Sow.). & Barton & Eoc. & gr. nat. \\
\hline
\end{tabular}



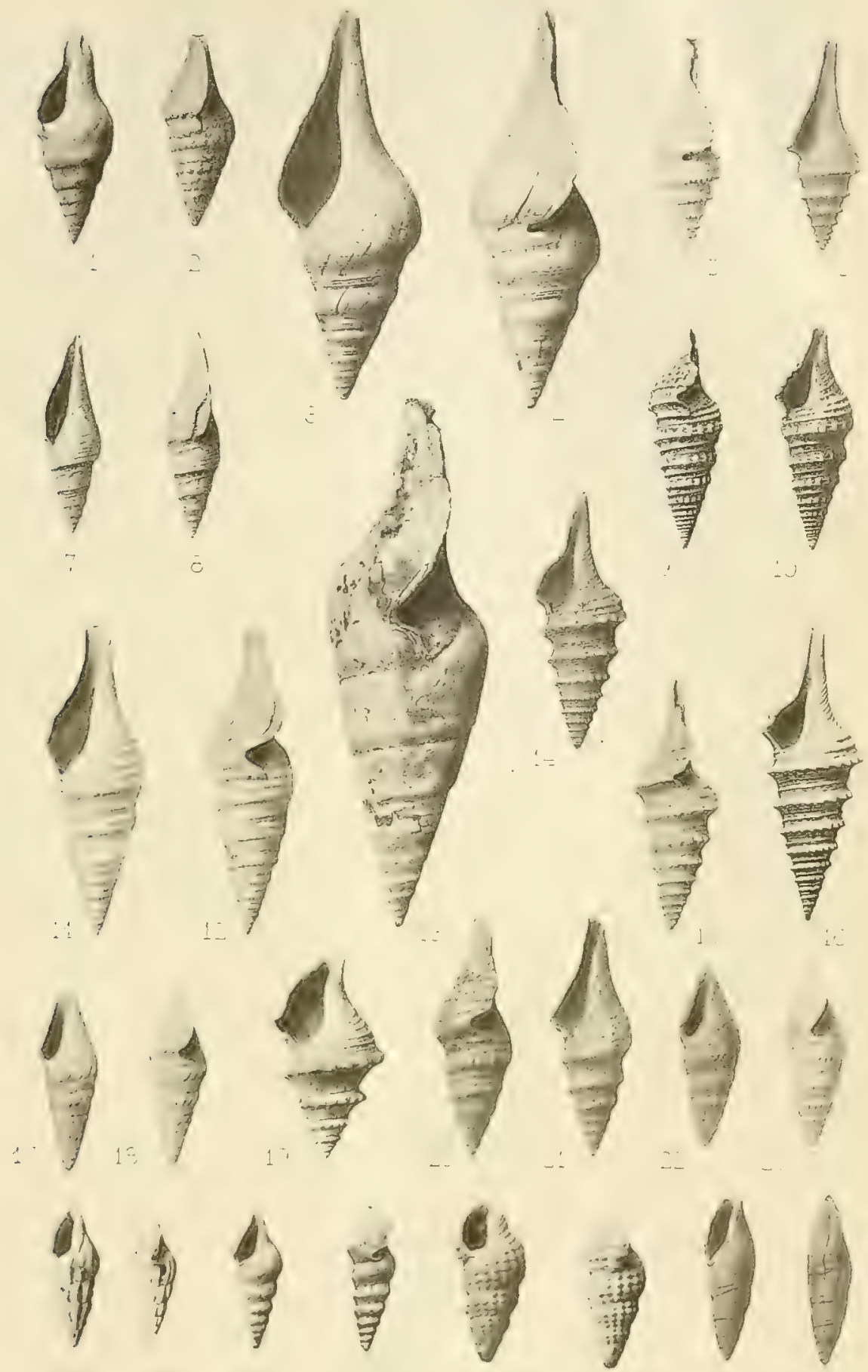




\section{PIANCIIE VI}

1-2. Eopleunotona cunricosts, (Lamk.). 3era. Drilla Allowi, Bell.

4. Aphanitoma libeilum, (Bon).

(6-7. Crassiepiata Brocchi, (Bon.).

8-9. Buchoza IEwothoNe, (Tate).

10-11. Bela pulcira, (Tate).

12.-13. Buchozia ctmaneila, (Lamk.).

14-1:i. Hednopleva sexaygularis, Montg.

16-17. Rouaulti subterebrilis, ibell.

18etzo, Borsonia phima, bell.

19. Batuytoma cataphracta, (Brocchi).

-1-23. Condema calvinowtexsis, (Desh.).

23-2i. Astuexogoma Bisteitoti, (Desm.).

2:i-20. Epalxis vextricosa, (Lauk.).

27-2y. Taypanotona temebraforms. (Meyer).

99. Asthenotoma Tatei, Cossin.

:30. Endiatoma Quanicixcta, (Cossm.).

:11-i:- Amblyacrum negosem, (Desh.).

:33-33. Bellardella texthls, (Brocchi)。

33. Scobinelat i.nyplicati, Gabb.

:it-3:- Claturelea Muleti, (Mesm.).
Villiers

Biot

Stazzano

Ciannes

Australie sud

Australie Sur

Réquiécourt

Turin

Tetti Borelli

T'urin

Saubrigues

Chaussy

saurats

Le Guépelle

Newton

Australie Sud

Saint-Gobain

Mouchy

Biot

lacksorı

pelonia
Boc. gross 2

Plioc. gr. nat.

Mioc. grosst 2

Plioc. gr. nat.

Eoc. gross' 2

Eoc. gr, nat.

Foc. gross' 5 .

Plioc. gross'?

llior. gr. nat.

Mioc. gross $3 / 2$

Mioc. gr, nat.

Eoc. gr. nat.

Mioc. gross' 2

Enc. gr. nat.

Enc. gross ${ }^{1} 3$

Enc. gross

Jioc. gross ${ }^{2}-2$

Eoc. $\quad$ gross 9

Plioc. nesos ${ }^{t}=$

Eoc. grosst

lloc. gr. nat. 
Essais de Paléoconchologie, Mr. Cossmann. (2e livr.)

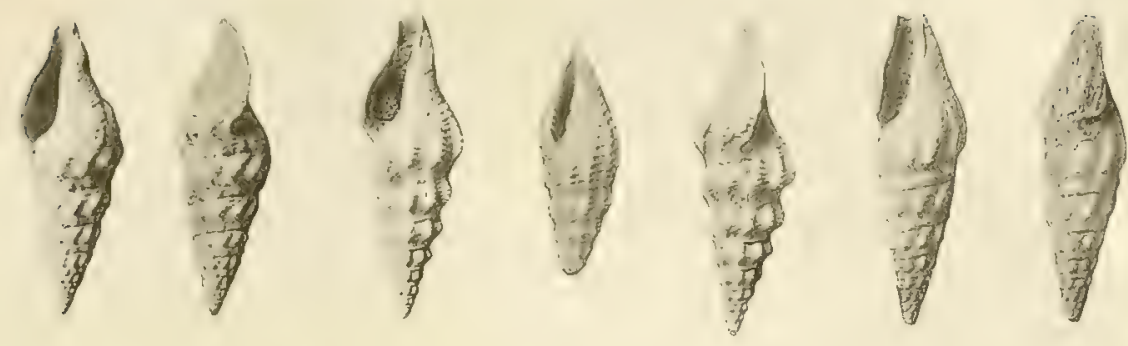

1) $=9 \geqslant 9$

1496193

193919

$3 \Rightarrow 3912$ 




\section{PLANCHE VII}

1-2. Plevrotonella polycolpa, (Cossm.).

; - - . Teres axceps, (Eichw.)

i-fi. Peratotoma strarella, (Lamk.)

7-s. Tuespia menotom, Cossm.

110. Daphella poxteleviensis, Cossm.

11-12. Psecdotoma Bonelli, Bell.

13. Mavgliella multinileata, (Desh.).

14. Mangilia quabrillum, (Dujard.).

15at19. Beisselia sfeciosa, Holz.

16ei18. Rostellites fenestritus, Romer.

17. AтOMa nуротнетіс, Bell.

20-21. Cayptocoses fllosus, (Lamk.).

2.-23. Sinistaella Anericaxa, (Aldr.).

2.-2\%. Maxgilia costata, (Donor.).

20-27. Gosavia sugamosa, (Zek.).

28. Halia helcoloes, (Brocchi).

29-30. Ditoma Axgusta, (Jan),

31-32. Daphella Ronaxi, (Libas.).

33. Lugithara maranelloides, (Reeve). 34-35. Genotia Craveri, Bell.
Mouchy

Cannes

Villiers

Bois de Perthes

Pontlevoy

Vöslau

Méditerranée

Pontlevoy

Vaals

fianls

Santa-Agata

Villiers

Jackson

Biot

Gosiu

Italie

Biot

Mbenga

Philippines

sienne
Eoc. Erossi

Plioc. gross 4

Eoc. gross' 5

Eoc. gross

Mioc. gross' 4

Mioc. gr. nat.

Viv. gross' 4

linc. gross 4

Sén. ur. nat.

Sén. gr. nat.

Hioc. gross' $3 / 2$

Foc. gr. nat.

Eoc. gross $5 / 2$

Plioc gross' 2

Turon. gr. nat.

Ploc. gr. nat.

Plioc. gross 3

Plioc. gross 2

Viv. $\quad \operatorname{gross}^{2} 5 / 2$

plioc. gr. nat. 
$9393 \div 373$
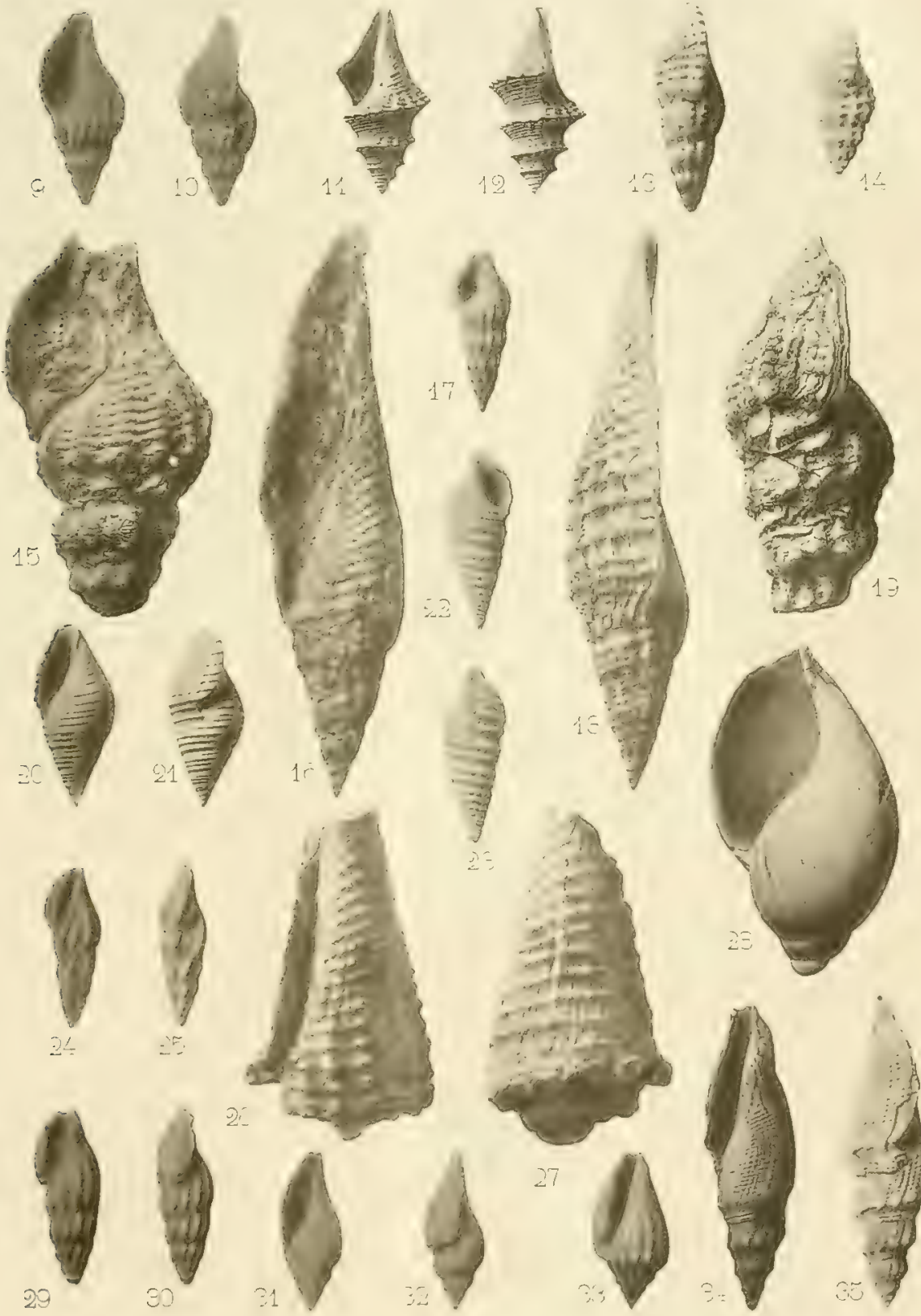

M. Pissarro, photogo

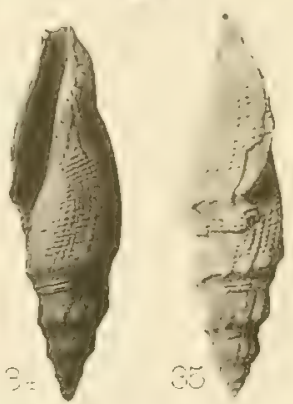

Sohier a Paris 




\section{PLANCIE VIII}

\begin{tabular}{|c|c|c|c|}
\hline lef6. IIEMconus strombonbes, (Lank.). & Grignon & Eoc. & pr. nat. \\
\hline Det:". Dexunocoxus Eschwegr, (da Costa). & Ciacella & Mioc. & gr. nat. \\
\hline 3-t. Plicobllla Dumisi, Cossin. & La Close & Enc. & gross' 3 \\
\hline 7-8. CosospikA Axteuiluvina, (Brug.). & Biot & l'lioc. & gr. nat. \\
\hline 9-10. Lithoconus Mercati, (Brocchi). & Putzleinsdorf & Mioc. & gr. nat. \\
\hline 11. Pseudotoma intorta, (Brocchi). & Caunes & P'lioc. & gr. nat. \\
\hline 12. Bathytoma Catapibact, (Brocchi). & Saubrigues & Minc. & gr. nat. \\
\hline 13. Rostellites texana, Conrad. & Kaufman & Ciét. & gr. nat. \\
\hline 14. Batuytona Cataphinacta, (Brocchi). & Biot & Plioc. & trr. nat. \\
\hline 15. Pholidotoma subiemtigoxi, (d'orb.). & Saint-Cyr & sen. & gr. nat. \\
\hline int. Coxomis dormitor, (Sow.). & Barton & Eoc. & $\operatorname{gross}^{\imath} 3 / 2$ \\
\hline 17. Raphitomi plicitella, Jan. & Biot & Plive. & gr. nat. \\
\hline M123. Stephaxocoxus chesnexsis, (Morlet). & Cresnes & Eoc. & ur. nat. \\
\hline 2. CHelyconts No.E, (Brocchi). & Saubrigues & Mioc. & gr. nat. \\
\hline 21. Mitnomorpha sunurata, Cossm. & Gourbesville & Plioc. & gross ${ }^{\imath} 4$ \\
\hline
\end{tabular}


Essais de Paleoconchologie, M. Cossmann. (2e livr.)

Pl. VIII

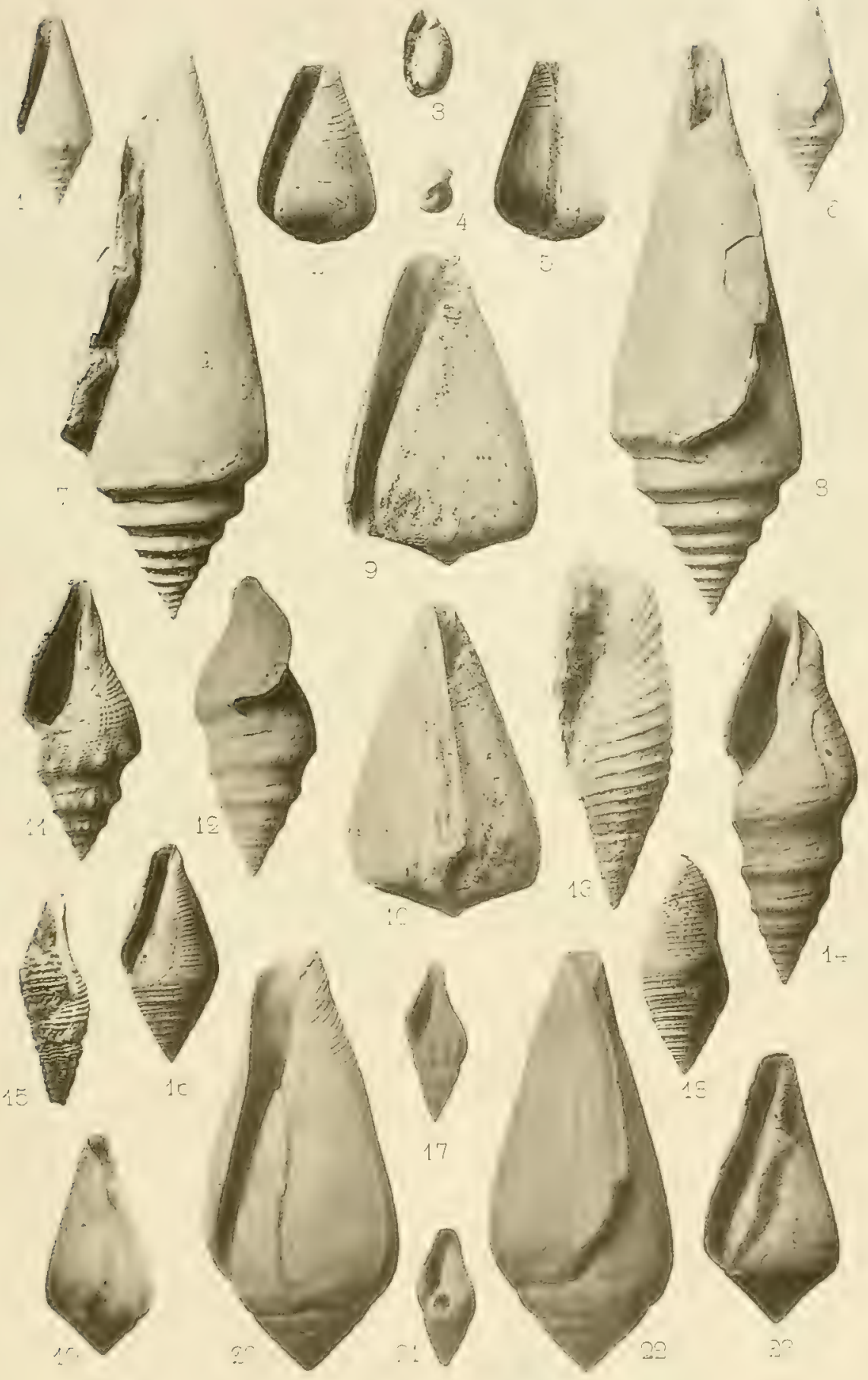

Sohier a Paris

II Jissarno, plotogr. 



\section{ESSAIS}

DE

\section{PALÉOCONCIIOLOGIE COIPARÉE}




\section{OUVRAGES DU MÊME AUTEUR}

Appendices au Catalogue illustré des coquilles fossiles de l'Eocène des environs de Parjs, avec la table analytique complète de toutes les espèces du Bassin parisien, et

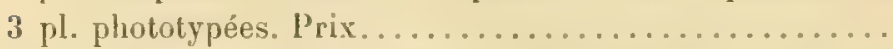

Revision sommaire de la Faune du terrain Oligocène marin aux environs d'Étampes (1891-1893). 3 pl. lithoEraphifies. Prix.

$10 \mathrm{fr}$.

12 fr. 50

Sur quelques formes nouvelles des faluns du Bordelais

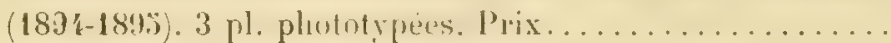

Observations sur quelques coquilles crétaciques recueillies en France (1896-1898). 3 pl. phototypées. Prix.

Description d'Opisthobranches éocéniques de l'Australie du Sud (1897,. y pl. phutolypies. Prix.............

Estudio de alcunos moluscos eocenos del Pireneo Catalan (1898). õ pl. phototypées. Prix................ Mollusques éocéniques de la Loire inférieure (18931898). 1! pl photolypies. l.r vol. Prix..............

Essais de Palẻoconchologie comparẻe (1896-1899). Les trois premières livraisons ensemble, prix............ Revue critique de Paléozoologie, $3^{\text {e }}$ année (1899).

P'rix de l'ahounement annuel. . . . . . . . . . . . . . .

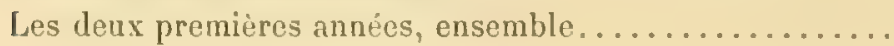

$6 \mathrm{fr} . "$

$5 \mathrm{fr}$.

$3 \mathrm{fr} . "$

5 fr. "

$30 \mathrm{fr}$.

$55 \mathrm{fr} . "$

8 ir. " $15 \mathrm{fr}$.

S'adresser $\dot{a}$ l'Auteur, 9:, rue de Maubeuge.

Envoi franco contre mandat postal. 


\section{ESS A IS}

DE

\section{PALEOCONCHOLOGIE}

\section{GOMPAREE}

par M. COSSMANN.

TROISIÉME LIVRAISON

(Avril 1899)

\section{PARIS}

CHEZ L'AUTEUR

95, Rue MaUdeuge, 90̃
COMPTOIR GÉOLOGIQUE

53 , RUE MonsieUn-LE-PRINCE, 53 



\section{TOXOGLOSSA (Srite)}

\section{CANGELLARIIDE}

Forme oroïde, parfois subturriculée; protoconche( ${ }^{(1)}$ paucispirée, globuleuse, obtuse, à nucléus en goutte de suif ; surface généralement cancellée: ouverture plus ou moins trigone, avec une r.routtière dans l'angle postérieur, terminée en avant par un canal rudimentaire ou par un bec à peine échancré ; labre généralement incliné, épais ou mème variqueux, costulé ou crénelé à lintérieur; columelle plus ou moins incurvée, se terminant en pointe à son extrémité antéricur's, portant deux ou trois plis spiraux, quelquefois tris obliques, et dont le plus élevé se confond souvent avec la torsion columellaire.

Observ. - Le classement de cette Famille a, de tout temps, donné lieu is les controverses, et actuellement encore il ne paraît pas définitivement fixé.

Linné, - et après lui, Cuvier, - avaient placé Cancellaria près de Tolula et, de Mitra, à cause des plis de la columelle; au contraire, Lamarck ramenait ce Genre près de Turbinella, et Blainville, entre Ricinula et Purpura. Dishayes. qui avait eu lor'casion d'étudier l'animal, lui attrihuait plutil dru alfinités avie les Plicacés; mais, dans son Etude sur les fossiles In Bassin de Paris, il le classa immédiatement avant Cerithirm, c'est-àdire à la limite entre les Ilolostomes et les Siphonostomes. Plus récemment. Fischer, ayant conslaté que la radule de Cancellaria a la mème

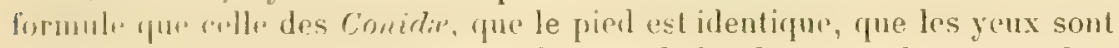
situés de la même manière, c'est-à-dire sur le bord externe des tentacules,

1) Jadopte la dénomination "protoconche », que M. Geo. Harris, de Lomires, a recemuent proposie, pour remplacer le mot « embryon ou l'expression \& tours embrynnaires $\$$ : ce nouvean terme est non seulement plus précis, mais encore cn correspondan:e avec la dénomination «prodissoconche \$, employée pour les réléeypordes. 
a rapproché cette Famille des Toxoglosses. Tryou aussi la place près des Terelridx, qui sont des Toxoglosses, mais avant les Strombidie, qui s'en écartent cependant beaucoup. Enfin, en dernier lieu, II. Jousseaume, qui a fait une élude très attentive d'un grand nombre de Cancellaires actuelles, et qui a été l'rappé de l'analogie apparente de $C$. cancellata avec les Genres Persona el Plesiotrilan, soutient que cette Famille doit ètre classéce pre's des Tritonidie.

De toutes ces hypothèses, celle de Fischer me parait être la plus raisonnable: elle est fondée sur les analogies les plus sérieuses de l'organisation analomique de l'animal de Cancellaria; mème, si l'un en examine attentivement la coquille, on constate que sa protoconche globuleuse et obtuse, à nucléus embryonnaire en goutte de suif, n'a aucun rapport avec celle des Trutonide, tandis qu'elle se rapproche davantage de celle des Turbinellidie, des Volutidx et de certuins Conus de l'Locene exotique. Quant à la plication de la columelle, il est évident qu'elle ressemble plus à celle des Volutide quaux dents que porte la columelle des Trilonida. II est vrai que l'absence d'un véritable canal siphonal, et surtout d'une échancrure basale, à la partie antérieure de l'ouverture, ćcarte Cancellaria de Voluta; mais il y a, d'autre part, dans la Famille Maryinellide, située dans le voisinage, des coquilles presque holostomes, et, en outre, cerlains Conidxe ne sont guère échancrés à la base.

C'est pourquoi je persiste à penser que l'étude des Cancellariida doit venir immédiatement après celle des Conidit.

Pendant une cinquantaine d'années, le Genre Cancellaria a été à peu près le seul composant cette l'amille (sauf Trigonostoma 18ュ6, et Admele 1842); mais, en 1833 , les frères Adams y ont introduit quelques coupes nouvelles, exclusivement fondées sur la forme el sur l'ornementation de la coquille; puis, en 1888, M. Jousseaume, révisant l'arrangemen de ses prédécesseurs, a proposé de diviser les Cancellariide en 23 Grenres, dont la plupart sont nouveaux, et dont plusicurs s'appliquent à des types fossiles. Si l'on y ajoute trois ou quatre autres Sections, ultérieurement proposées, soit par moi, soit par M. Sacco, pour des formes tertiaires, et deux Genres du Crétacé d'Amérique, on arrive à une trentaine de dénominations, dans lequelles il est indispensable de mettre de l'ordre.

En effet, dans sa division, M. Jousseaume a attribué le nom de Genre à toutes les coupes qu'il a proposées, quoique quelques-unes ne présentent entre elles que des différences bien légères, tandis que d'autres ont des caractères différentiels d'une valeur bien supéricure. Or j'ai déjà eu l'occasion, dans la préface de ces lissais, de démontrer la nécessité de ne pas mettre toutes les subdivisions d'une lamille sur le mème plan; ici, cette méthode est plus que jamais nécessaire pour faciliter le classement, et l'ischer l'a déja indiquée dans son Manuel, en rappelant que les Cancellaires sont généralement réparties en trois groupes: 'Trigonostomes, P'urpurilormes el Mitriformes.

Done, tout en admettant une première division de cette lamille en 
groupes, que je transforme même en Sous-Familles, je crois indispensable d’y établir, comme dans les autres Familles, des Genres, des Sous-Genres et des Sections; à cet effet, il s'agit de déterminer quel doit être le critérium des caractères génériques, sous-génériques et sectionnels. Or, dans la Famille en question, il faut examiner, outre la forme générale de la coquille, tout d'abord, l'absence ou la présence d'un ombilic, et surtout d'un bourrelet ombilical, aboutissant à l'extrémité du bec, et reproduisant les accroissements de l'échancrure, quand il y en a une; ensuite, le nombre et la disposition des plis de la columelle, l'inflexion de cette columelle, soit à son extrémité, soit au milieu de sa hauteur; enfin le développement du canal siphonal, qui se réduit souvent à une échancrure, ou même qui disparait complètement. Ces caractères sont très importants au point de vue morphologique, et ils doivent servir à distinguer les Genres. Au contraire, l'existence d'un bord columellaire plus ou moins calleux, de crénelures, de costules ou de simples stries à l'intérieur du labre, de varices sur la surface, l'obliquité plus ou moins grande des plis columellaires, les variations de la gouttière dans l'angle inférieur de l'ouverture me paraissent être des caractères sous-génériques ou sectionnels, tout au moins chez les Cancellariidx. Enfin l'ornementation, très riche chez cette Famille, doit principalement servir à distinguer les espèces d'un même Genre, d'un même Sous-Genre, d'une mème Section.

Tel est le sens dans lequel est conçu le Tableau(') ci-après :

(1) On remarquera, dans ce tableau et dans ceux des autres Fumilles, rue nous séparons les Sous-Familles par des astérisques * , correspondant aux coupures a faire subir au texte; il doit donc être entendu désormais que le signe *, placé au-dessus d'un nom de Genre, indique que ce genre et ceux qui le suivent appartiennent à une Sous-Famille distincte de celle dans laquelle sont classés les Genres précédents. 
Tableau des Genres, Sous-Genres et Sections.

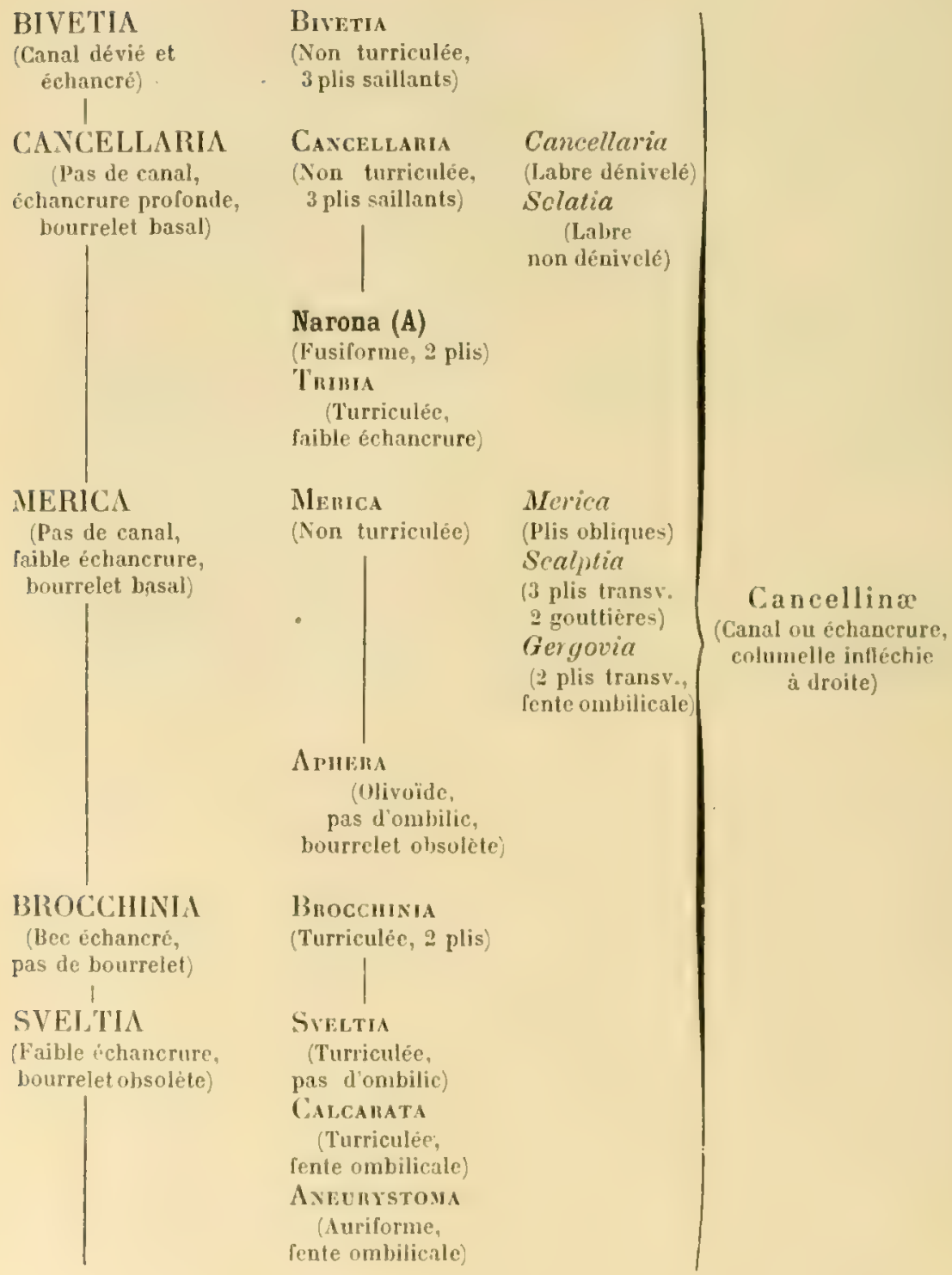




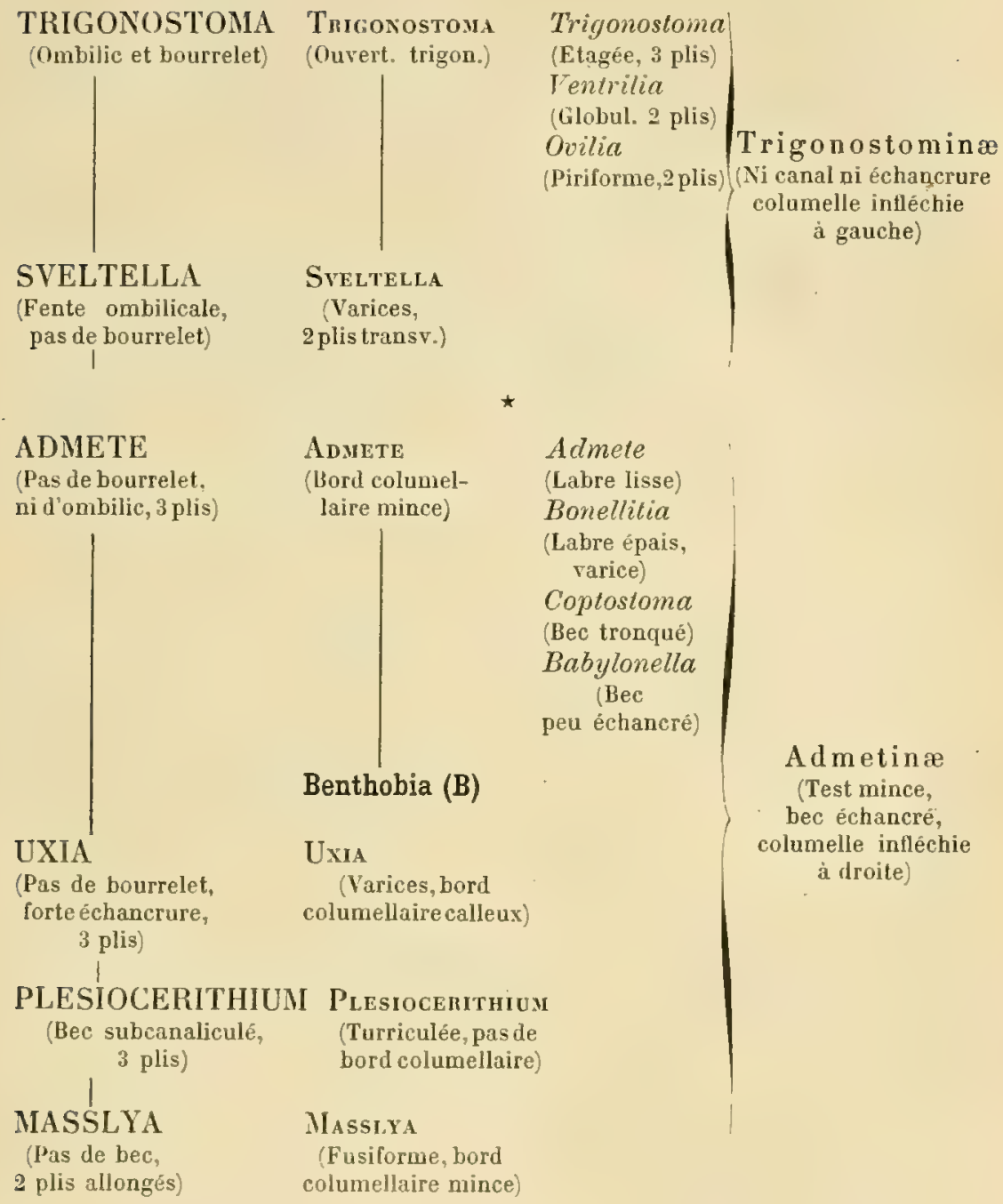

Genres non signalés à l'ẻtat fossile.

A. - Narona, 1I. et A. Adams, 1853. - Type : C. clavatula Sow. Coquille fusiforme, dont l'ouverture se termine par un bec subcanaliculé, large, profondément échancré; pas d'ombilic; bord columellaire peu étendu; deux plis transverses à la columelle; labre avec une dénivellation antérieure, semblable à celle qui caractérise Cancellaria, sensu striclo. 
Il. n'y a guère que le Genre Tribia qu'on puisse, à cause de sa forme, rapprocher de Narona; mais il en differe par sa taille plus grande et par ses tours moins étagés, par le nombre et par la disposition de ses plis, par son bec beancoup plus court et plus étroitement échancré, par sa columelle beaucoup moins allongée, par son bord columellaire plus étalé.

B. - Bғатиов а, Dall, 1889. - Type: B. Tryomi Dall. Forme buccinoïde; surface presque lisse; base imperforée; columelle très excavée, coudée en avant, ou elle forme le bec basal.

L'auteur indique que ce Genre differe d'Admele par l'absence de plis columellaires; toutefois on remarque que les plis s'effacent presque totalement à l'entrée de l'ouverture de quelques Admele, par exemple, chez A. Couthouyi, que certains auteurs considèrent même comme une variété d'Admete viridula. Je présume done que Benthobia est à peine une Section distincte d'Admete.

\section{Genres à éliminer de la Famille Cancellariidæ.}

Plesiotriton, Fischer, 1884. - Type : C. volutella Lamk. (Eocène). M. Jousseaume affirme que la Famille Cancellariicke a, par quelques-uns de ses membres, des affnités avec Plesiotriton, que Fischer a décrit comme Section de Triton (Lampusia), et il en conclut que celle Famille doit être rapprochée des Trilonidæ. J'ai déjả indiqué ci-dessus pour quels motifs il me paraît inadmissible de classer des Toxoglosses, tels que Cancellaria, dans une subdivision tout à fait différente par sa radule, celle des Tanioglosses; il me reste à expliquer pourquoi Plesiotriton, dont on ne connaît pas la radule, puisque c'est un Genre exclusivement fossile, ne peut être rapproché des Cancellariidie, et doit rester dans la Famille Tritonidie. Il est vrai que, par ses varices, ses plis columellaires, ses crénelures labiales et sa protoconche globuleuse, Plesiotriton ressemble beaucoup à certains Uxia, par exemple à $U$. hypermeces, du Calcaire grossier, qui est une exagération de forme du type d'Uxia (U. costulata); mais il y a deux caractères qui s'opposent à ce que ce rapprochement soit poussé plus avant: d'abord la sinuosité du labre, proéminent en avant. excavé en arrière clıez Plesiotriton, tandis qu'en général, clıcz les CancelIariidx, le labre a une inclinaison inverse, oblique à gauche de l'axe du côté antérieur, presque vertical chez Uxia, jamais oblique à droite de l'axe; ensuite l'entaille profonde du canal de Plesiotriton n'a aucun rapport avec le bee des Cancellarizdx, qui n'est échancré que quand on l'observe en plan, tandis que l'entaille des Trilonidx est visible, même quand on regarde la coquille du côté du dos.

Monea, Conmu, 1860. - Type : M. cancellaria Conr. (Sénonien). Les avis sont très partagés au sujet de la classification de ce Genre: Conrad et Gabb l'ont placé dans la Famille Purpuridx, Meek et Tryon dans les 
Cancellariidx, tandis que Whitney l'a tout récemment rapproché de Sistrum. Gràce à l'obligeante communication, qui m'a été faite par M. Słanton, de deux échantillons de l'espèce-type, j’ai pu me convaincre que cette coquille est exactement un Purpura largement ombiliqué, avec un pli columellaire antérieur un peu plus plus fort que ne l'est ordinairement celui des Purpurida ; la forme excavée de la columelle, la surface un peu aplatie du 'bord columellaire, l'échancrure très profonde de la base, à laquelle aboutit une large rainure encadrée de deux carènes, l'obliquité du labre qui présente une légère sinmosité près de la suture, enfin l'ornementation elle-même, sont autant de caractères qui plaident en faveur de l'opinion de Conrad et de Whitney, et excluent cette coquille de la Famille Cancellariidx. J'ajoute que, si l'on voulait intercaler Morea dans celte-dernière Famille, on serait fort embarrassé, car elle a une échancrure de Cancellariid $x$ et une columelle de Trigonostominx; en outre, quand les plis s'effacent chez les Cancellaires, c'est toujours le pli antérieur qui disparaît le premier, et il reste généralement une trace des plis médians, tandis que $M$. cancellaria a la columelle tout à fait lisse et creuse au milieu et un fort pli antérieur; d'autre part, l'embryon me semble moins globuleux que celui des Cancellariidx, il a plutôt l'aspect déprimé ; enfin, - - et cet argument a sa valeur, - les Cancellinæ n'ont commencé à apparaître que dans les terrains tertiaires supérieurs, et l'on ne trouverait aucune corrélation entre ce Genre sénonien et ses congénères. Je suis done d'avis que Morea est mieux à sa place dans la Famille Purpuridx. A l'appui de ce qui précède, je erois utile de donner une figure de $M$. cancellaria (PI. II, fig. 16), d'après un échantillon d'Eufaula (Alabama), provenant de la formation Ripley, qui est assimilée à noțre Sénonien supérieur.

Aduetopsis, Meek, 1872. - Type: A.gregaria Meek(Sénonien). M. Stanton m'ayant communiqué trois échantillons d'une espèce de ce genre $(A$. subfusiformis Meek), souvent confondue avec l'espèce-type, j'ai pu me con-

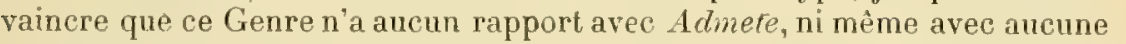
forme de Cancellariidx: le pli tordı et très saillant, qui existe à la partie antérieure de la columelle, ne ressemble pas du tout au pli des Admetinx; en ontre, les accroissements de l'échancrure se font sur une callosité basale, qui est extérieurement limitée par une carène aiguë, et cette disposition. s'écarte absolument de tout ce qu'on observe chez la Famille en question; entin les costules crénelées et curvilignes (qui forment l'ornementation, souvent effacée sur le dernier tour, où elles sont remplacées par des plis d'accroissement peu visibles), ont une direction oblique en sens inverse de l'inclinaison du labre des Cancellariidx, c'est-ì-dire rétrocurrente vers la suture. Même ce dernier caractère me fait hésiter à rapprocher $A$ dmetopsis des Nasside, auxquels il ressemblerait par son échancrure et sa carène basale, mais qui ont des costules ou des accroissements antécurrents. En attendant, je donne une figure d'A. subfusiformis (Pl. II, fig. 17), d'après laquelle le lecteur se convaincra que ce n'est pas une coquille de Cancellaire; l'échantillon figuré vient de l'Utah, Cedar City (Colorado formation). 
Turuxopsis Conrad, 1860. - Type: T. Hilgarde Conr. (Sénonien). D’après M. Dall. qui m'a obligeamment envoyé la copie ci-contre Fig. 1) de la figure originale, 'Turbinopsis est synonyme postéricur de Modulus, Gray 1847. Cen'est pas du tout un membre de la lamille

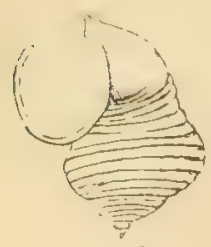
Cancellarida, comme le croyait Conrad, probablement abusé par le vaste entonnoir ombilical de cette coquille, semblable à celui des Trigonostoma; en effet, la columelle parait arrondie, absolument dénuée de plis, l'ouverture est subcirculaire, et le bec antérieur, auquel aboutit la carène circo-ombilicale, est mutilé, de sorte qu'on est réduit à une restauration hypothétique, quant à sa forme.

FIa.1.- Turbinop- M. Dall a indiqué celte rectification, dans la seconde sis Hilgarti, Conr. partie de sa Monographie de la Floride, p. 293. Turbinopsis Hilgardi a été décrit et figuré dans le "Journ. Acad. sc. nat. Philadelphie ", 2 érie, vol. IV, p. 289, pl. XLVI, fig. 29; ce fossile provient de Tippah Co. Missouri, localité de la formation "Ripley " correspondant à notre Sénonien supéricur.

BIVETIA, Jousseaume, 1888.

$(=$ Bivetopsia, Jouss. 1888).

Bivetia, sensu stricto. Type : Cancellaria similis, Sow. Viv.

Taille assez grande; forme ovoïdo-conique, plus ou moins globuleuse; spire souvent étagée, à galbe conique; protoconche lisse, obluse, assez pelite, paucispirée ; tours peu nombreux, cancellés et variqueux. Ouverture courte, large, avec une étroite gouttiire échancrant un peu le péristome dans l'angle inférieur, terminéc en arant par un canal court, profontément échancré, auquel aboutit un bourrelet écailleux qui circonscrit la fente ombilicale; labre épais, obliquement incliné à gauche de l'axe, du côté antérieur, costulé à l'intérieur, lacinié sur son contour; columelle un peu renflée au milieu, légèrement incurvée en avant veŕs l'échancrure basale, munie de trois plis épais, croissant d'avant en arrière, l'inférieur formant une lamelle presque transversale, landis que le pli antérieur se relie obliquement à la courbure de la columelle: 
Bivetia

bord columellaire largement étalé sur la base, mince en arrière, plus calleux en avant, portant souvent des rides entre les plis et sur la région postérieure, recouvrant partiellement la fente ombilicale.

Diagnose refaite d'après un plésiotype du Pliocène de Biot: Canc. subcancellata d'Orb. $(=C$. cancellata $\mathrm{Br}$.non L.) $-(\mathrm{Pl}$. I, fig. 1-2); ma coll.

Observ. - Si l'on prend pour type du Genre Cancellaria Lamk, la première espèce décrite par cet auleur ( $C$. reticulata), et si l'on admet les différences génériques, ci-après résumées, qui séparent cette espèce de C. cancellata, la création du Genre Bivetia (Bivet, Adanson) est tout à fait justifiée: il représente la plus canaliculée et la plus ćchancrée des formes de Cancellariidx; mais le canal, au lieu d'être rejelé à l'extérieur, comme chez les Volutidie ou les Buccinidx, est au contraire dévié à gauche par l'inflexion de la columelle; c'est un caractère typique et familial. Quant au bourrelet basal, il est extrêmement saillant chez Bivetia, parce que l'échancrure antérieure est profonde; les écailles qu'il porte sont formées par les accroissements de cette échancrure. En résumé, si le Gonre Cancellaria était à créer, c'est plutôt le type de Bivelia que $C$. reticulala qu'il faudrait prendre; mais les règles de la nomenclature s'opposent à ce qu'il en soit ainsi.

En ce qui concerne Bivetopsia Jouss. (qu'il eût été plus correct de dénommer Bivetopsis), le type est C. chrysostoma Sow.; l'auteur indique qu'il se distingue "par le méplat des tours de spire, par l'absence, sur le " péristome, d'une échancrure formée par le canal postérieur, et par la " présence de plis et granulations sur l'enduit et le bord columellaire " (caractères auxquels on pourrait ajouter l'existence d'un ombilic plus large, et la brièveté ainsi que la direction un peu différente du canal antérieur). J'estime que ce sont là des différences purement spécifiques; on passe, en effet, d'une forme à l'uutre, par des intermédiaires pour le classement desquels on serait singulièrement embarrassé : Bivetopsia est done, à mon avis, synonyme de Bivelia.

\section{Répart. stratigr.}

Mrocene. - Une espèce voisine du type, et ses variétés, dans le Tortonien et l'llelvétien d'Italie; $C$. dertonensis Bell., d'après M. Sacco; l'espèce plésiotype dans le bassin de Vienne, d'après la Monographie de MM. Ilœrnes et Auinger. Une espèce dans le Miocène de la Jamaïrue; C. Mocrei, Guppy, d'après la ligure.

Pliocexe. - L'espèce plésiolype et ses variélés dans le Plaisancien et l'Astien des Alpes-Maritimes et d'ltalie, ma coll., coll. Bourdot; la 
même, dans la province de Barcolone, d'après la Monograplice d'Almera et Bolill. Une espëce voisine dans les couches supérieures de Java; C. neglecta Martin(').

Epopue-acturlez, - Quatre ou cinq espèces, sur les côtes d' $\Lambda$ frique et d'Amérique, dans la Méditerranée, d'après le Manuel de Tryon, et les Mollusques du Roussillon (Daulz. Dollf. Bucq.).

\section{CANGELLARIA, Lamarck, 1799. \\ (= Cancellarius Montf. 1810; = Buccinella Perry ; = Plicaria Fabr. 1823).}

Canceilaria, sensu stricto. Type : C. reticulata, Lin. Viv. (= Euclia H. et A. Adams 1853.)

Taille assez grande; forme ovoïdo-conique; tours réticulés. Ouverture ovale, dépourvue de canal antérieur, profondément échancrée à la base, avec un gros bourrelet aboutissant à l'échancrure; labre finement costulé à l'intérieur, muni, du côté anlérieur, d'une dénivellation peu profonde, qui rappelle le sinus des Sirombidr : columelle presque droite, portant trois plis saillants, transverses, l'inférieur plus épais que les deux autres; bord columellaire large et calleux.

Diagnose complétée d'après le type vivant.

Observ. - Je réunis Euclia à Cancellaria, car le type (C. cassidiformis Sow.) ne diffère que par son ornementation, tandis que tous les caractères essentiels sont identiques.

Rapp. et diff. - Il y a, chez les véritables Cancellarin, un caractìre important sur lequel İ. Jousseaume a appelé mon attention ; c’est l'existence, à la partie antérieure du contour du labre, d'une dépression ou dénivellation, formant un sinus latéral, comparable à celui des Strombus, quoique beaucoup moins profond; or ce sinus n'existe pas chez Bivetia, ce qui permet de séparer facilement les espèces des denx Genres, indépendamment du canal, qui existe chez Bivetia et qui fait défaut chez Cancellaria.

(1) Cette dénomination fait double emploi avec un $C$. neglec/a. Michelofli. 1861; je propose donc, pour l'espece de Java: B. Martini, nob. 
Répart. stratigr.

Cancellaria

Mrocene. - Deux espèces bien caractérisées, dans le Tertiaire de la Jamaïque : C. lavescens et Barrelti Guppy, d'après les figures données par cet auteur; l'espèce-type dans le Texas, d'après M. Gilb. Harris ; autre espèce dans le Miocène de la Californie: Euclia velusta Gabb, d'après la figure publiée par l'auteur.

Pliocexe. - L'espèce-type dans la Caroline du Sud, d'après M. Dall ; autre espèce dans les couches attribuées au Pleistocène, en Californie: Euctia tritonidea Gabb, d'après la figure publiée par l'auteur.

Epoque actuelle. - Nombreuses espèces dans le golfe du Mexique, les mers de Chine, la Polynésie, la Nouvelle-Galles du Snd, d'après le Manuel de Tryon.

Solatia, Jousseaume, 1888. Type: C.piscatoria, Gm. Viv.

Forme ovoide et trapue : spire plus ou moins longue, quelquefois étagée, à galbe conique; protoconche lisse, petite et saillante; tours cancellés et subépineux; base ombiliquée, avec un bourrelet très proéminent et assez étroil, garni de lamelles qui marquent les accroissements de l'échancrure. Ouverture généralement dilatée, avec une étroite gouttière dans l'angle inférieur, entaillée en avant par une échancrure profonde et peu large, à laquelle aboutit le bourrelet basal; labre oblique, un peu épaissi, lisse ou orné de filets internes, dépourvu de dénivellation sinueuse du côté antérieur; columelle droite dans son ensemble, un peu excavée au milieu, portant deux plis obliques, peu visibles, enfoncés à l'intérieur, et un troisième pli confondu avec la torsion antérieure; bord columellaire large et calleux, détaché de l'ombilic.

Diagnose refaite d'après un échantillon fossile de l'espèce-type, provenant de l'Astezan (Pl. I, fig. 3), coll. Bourdot; vue de l'échancrure d'une espèce plésiotype : C.Barjonse da Costa, du Tortonien du Portugal (Pl. I, fig. 15), ma coll.

Rapp. et diff. - Séparé, avec raison, de Cancellaria, ce Sous-Genre s'y rattache par son échancrure basale, et par la forme générale de la coquille; mais il s'en écarte par ses plis columellaires, qui sont sonvent très effacés, beaucoup moins transverses que ceux de $C$. reticulata; en outre, an lieu d'être convexe par suite de la saillie de ses plis, la columelle est excavée 
entre eux, et, comme ils sont minces, ce creux parait encore plus visible, quoique cependant la columelle ne soit pas réellement incurvée; son extrémité antérieure n'est pas déviée vers l'axe, elle se rejelte, au contraire, vers l'extérieur, puis elle se termine en pointe sur le bord de l'échancrure. D'autre parl, le labre est toujours dépourvu de la dénivellation strombique qui caractérise Cancellarias. s. et Narona; entin l'ombilic, généralement clos chez les véritables Cancellaria, est au contraire ouvert ehez Solatia.

Répart. stratigr.

Mrocexe. - L'espèce plésiotype ci-dessus figurée, dans le T'ortonien du Portugal, de Monte Gibbio et des Landes, ma coll.; la mème et une espèce voisine: $C$. Westiana Grat, dans le Tortonien de la Catalogne, d'après la monographie d'Almera et Botill. Une espẻce un peu aberrante, dans le Maryland : C. Luata Conr, ma coll.; une espèce probable dans le Miocène de llaïti : $C$. epistomifera Guppy, d'après la figure publiée par cet auteur.

Phocexi. - L'espèce-type dans l'Astezan, coll. Bourdot; autre espèce ou variété, dans le Plaisancien et l'Astien d'Italie: C. hirta Br., ma coll. Une espèce dans le Tertiaire de la Floride: C. Conradiana, d'après la Monographie de M: Dall.

Epopve actuelle. - Trois espèces, d'apres M. Juusseaume, sur la côte occidentale d'Afrique et au Japon, d'après le Manuel de Tryon.

'l'ribta, Jousseaume, 1888. Type: C. Angasi, Crosse. Viv.

Forme turriculée, étroite; spire assez longue, ètagée; protoconche paucispirée, à nucléus saillant et dévié; lours cancellés ou épineux, bordés d'une large rampe au-dessus de la suture; base faiblement ombiliquée, avec un bourrelet médiocrement saillant, large et sublamelleux. Ouverture subtrigone, à peu près dépourvue de groultière postérieure, terminée en avant par un bec étroit, peu profondément échancré, un peu rejeté en arrière, auquel aboutil le bourrelet basal; labre presque droit, en biseau, épaissi et paucicostulé à l'intéricur; columelle droite sur la plus grande partie de sa longueur, tordue ou intléchie à droite vers le hec antérieur, munie de deux ou trois plis minces, peu saillants et peu obliques; bord columellaire peu épais, un peu élargi en arrière, très étroit 
Cancellaria

le long de la fente ombilicale qu'il recouvre incomplètement, terminé en pointe à la naissance du bec basal.

Diagnose refaite d'après un plésiotype fossile: $C$. tribulus $\mathrm{Br}$., du Messinien d'Orciano (Pl. I, fig. 9), coll. de l'Ecole des Mines; autre échantillon (Pl. I, fig. 10), ma coll.

Rapp. et diff. - La coquille ci-dessus décrite semble, à première vue, s'écarter considérablement du type de Cancellaria; cependant ce n'est, à mon avis, qu'un Sous-Genre, parce que plusieurs des caractères essentiels procèdent évidemment de ceux de ce Genre: d'abord l'échancrure, un peu moins profonde, il est vrai, que chez $C$. Barjonæ, et moins large que celle de $C$. reticulata; ensuite la columelle, qui a bien linflexion antérieure et caractéristique des Cancellaria; les plis sont peu saillants, comme chez Solutia ; l'ombilic est presque aussi clos que celui de Cancellaria, moins ouvert que celui de la plupart des Solatia; enfin le bord columellaire est peu développé, et la gouttière inférieure de l'ouverture est à peu près nulle. Si l'on compare Tribia au Sous-Genre Narona, on trouve qu'il en diffère par ses plis, au nombre de trois, au lieu de deux, plus obliques; par son bec plus court et moins échancré ; mais les autres caractères sont à peu près identiques, de sorte que la similitude des deux formes est très grande.

Répart. stratigr.

Mrocise. - L'espèce plésiotype ou ses variétés: $C$. uniangulala, dans le Tortonien de Stazzano, d'après M. Sacco; autre espèce dans le bassin de Vienne, C. Dregeri R. Hœrn., d'après la Monographie de MM. Hœrnes et Auinger. Une espèce bien caractérisée, dans la formation santacruzienne de Patagonie: C.gracilis Ihering, d'après la figure publiée par l'auteur.

Pliocexe. - L'espèce plésiolype dans l'Astien du Piémont, d'après M. Sacco, et dans le Plaisancien de l'Italie centrale, ma coll., coll. de l'Ecole des Mines.

Eroque actuelce. - Deux espèces: le type et une espèce méditerranéene, d'après $M$. Jousseaume.

MERIGA, H. et A. Adams, 1853. $=$ Nevia Jouss. 1888; = Contortia, Sacco 1894).

Merica, s.str. Type:C.melanostoma, Sow.(=asperella L.k.) Viv.

Taille assez grande ou moyenne; forme ovoïde, oblongue; spire assez longue, pointue, généralement élagée, à galbe conique; 
Merica

protoconche lisse, paucispirée, subglobuleuse, à uncléus oblus; tours cancellés, parfois presque lisses et éburniformes, a sutures profondes ou canaliculées, presque toujours munies d'une rampe à la partic inférieure; base imperforée, avec un bourrelet arondi, dépourvu de lamelles. Ouverture ovale, assez large, avec une gouttir're obsolète dans l'angle inférieur, terminée en avant par un bec assez large, peu profondément échancré, auquel aboutit le bourrelet basal; labre presque vertical, taillé en biseau, lisse ou très finement plissé à l"intérieur; columelle droite, à peine inllechie vers l'extérieur à son extrémilé le long du hec antérieur, munie de trois plis obliques, minces et peu saillants, parfois entrembilés de rides; bord columellaire assez large, peu épais, recouvrant complitement la région ombilicale, a contour cxtérieur rectiligne, se terminant en pointe sur le bord du bec basal.

Diagnose rectifiée et complétée d'après deux espèces plésiotypes: l'une désignée par M. Jousseaume, C. Basteroli Desh., du Langhien de l'ont-P'ourquey, protoconche grossie (Fig. 2 ci-contre), ma coll.; l'autre, du Miocène de l'Australie du Sud, C. voannoniensis Tate (11. I, fig. 7), ma coll.

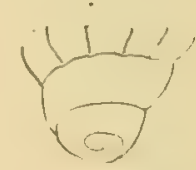

Fis. 2. - I'rotuconche de M.Basleroli, Desh.

Rapp. et diff. - Intermédiaire entre les deux Sous-Familles Cancellinie el Trigonostominx, ce Genre se rattache à la première par sa columelle droite et infléchie vers l'extérieur à son extrémité, par sonéchancrure basale, quoique celle-ci soit moins profonde que chez Cancellaria, el que chez ses deux Sous-Genres Solatia et Tribia. Merica se distingue, en outre, par l'absence d'ombilic, par son bourrelet non lamelleux, par son labre plus vertical, par ses plis moins saillants que ceux de Cancellaria, mais mieux marqués que ceux de Solatia, etc.

Observ. - D'après la compariison des deux diagnoses de M. Jousseaume, et si l'on fait abstraction de l'ornementation, Nevia est absolument synonyme de Merica : le type (C. spirata Lamk.) a beaucoup d'analogic avec certaines espèces que $\mathbf{M}$. Jousseaume a lui-même désignées comme de vrais Merica (C. Spengleriana Desh., par exemple); il y a des Merica à peine costulés, et des Nevia qui ne sont pas absolument lisses, de sorle que, d'un groupe à l'autre, il y a des transitions graduelles : e'est ce qui démontre l'inutilité de celle nouvelle coupe. 
Ierica

Quant à Contortia, Sacco, que j'ai précédemment identifié avec Babylonella Conr., j'ai constaté que le type ( $C$. conlurta Bast.) est un Merica tout à fait typique; il n'y a donc aucun motif pour admettre Contorlia comme Sous-Genre distinct; d'ailleurs, cette dénomination n'aurait pas pu ètre conservée, puisqu'elle fait un double emploi évident avec Contorta Mühl. 1841.

Répart. stratigr.

Oligocene. - Une espèce classée comme Contortia, dans le Tongrien

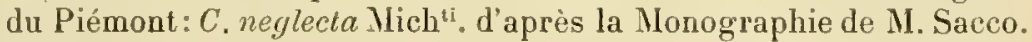

Mrocene. - Plusieurs espèces, outre les deux plésiotypes ci-dessús cités, du Bordelais et de l'Australie du Sud, dans le bassin de Vienne: C. Heberlana M. Horn., C. Saccoi et ausbriaca R. Hœern., d'après la Monographie de MM. Inernes et Auinger; C. taurofoveolata Sacco, dans le Tortonien du Piémont; $C$. contorta Bast., dans le Langhien du Bordelais et dans l'Helvétien de l'Anjou, coll. de l'Ecole des Mines: la mème dans l'Helvétien du Piémont; C. derlocontorla Sacco, dans le Tortonien du Piémont ; C. tauropercostata dans l'Helvétien, d'après la Monographie de M. Sacco; une espèce dans les couches d'Edeghem : C. exBellardii Sacco, ma coll., coll. de l'Ecole des Mines. Une espèce dans le Maryland et le New-Jersey, C. allemata Conr., d'après la Monographie de Whitfield.

Plocene. - Une espèce bien caractérisée, dans le Plaisancien et l'Astien du Piémont et de la Sicile : C. Altavillæ Libassi, d'après M. Sacco. L'espèce-type à Karikal, coll. Bonnet, et dans les couches supérieures de Java, d'après M. Martin, avec une autre espèce nouvelle : $C$. Verbeeki Mart.

Epoque actuelle. - Nombreuses espèces dans toutes les mers, fide Adams et Jousseaume.

Scalpti, Jousseaume, 1888. Type: C. obliquata, Lamk. Viv.

Taille moyenne; forme ovoïde, plutôt ventrue; spire assez courte, subétagée; protoconche lisse, globuleuse, paucispirée. à nucléus petit, un peu saillant; tours cancellés, canaliculés près de la suture; base étroitement ombiliquée, avec un bourrelet peu saillant, parfois sublamelleux. Ouverture subtrigone, élargie au milieu, munie en arrière de deux gouttières divergentes, que sépare un rentlement arrondi, terminée en avant par un bec excessivement court et à peine échancré, auquel aboulit le bour- 
relet basal; labre à peine incliné en profil, dilaté de face en courbe arrondie, taillé en biseau, épais et costulé à l'intérieur ; columelle droite, à peine infléchie à l'extérieur, à son extrémité, munie de Irois plis obliques, les deux postérieurs égaux, assez saillants, l'antérieur souvent confondu avec la torsion de la columelle; bord columellaire assez épais, ridé, délachẻ de l'ombilic.

Diagnose complétíe d'après une espèce vivante typique: $C$. crenifera Sow., ma coll.; et d'après des plésiotypes du Tortonien de Slazzano: S. dertoscalala Sacco (PI. I, fig. 8), coll. du Musée de T'urin, communiqués par M. Sacco.

Rapp. et diff. - Scalptia diffère de Merica par quelques caractires qui justifient la séparation d'une Section, mais pas davantage : d'abord l'existence d'une double gouttière dans l'angle inférieur de l'ouverture, conséquence de sa forme subrigone; ensuite l'échancrure basale, qui est encore un peu moins profonde, et l'ombilic qui n'est pas clos; enfin les plis, qui sont plus transverses, plus épais, plus égaux. Chez les individus adultes, l'inflexion columellaire el l'échancrure basale ont une tendance à s'atténuer, de sorte qu'on pourrait penser que ce sont des Trigonostomine; cependant leur columelle n’est jamais aussi nctlement déviée vers la gauche que chez Gulia, par exemple, et ils conservent toujours une légère sinnosité sur le contour supérieur de l'ouverture; enfin leur ombilic est beaucoup moins largement ouvert.

\section{Répart. stratigr.}

Mrocexe. - L'espèce plésiolype ci-dessus décrite, avec quelques variétés, dans le Tortonien du Piémont et de l'Italie centrale, d'aprés M. Sacco et coll. de l'Ecole des Mines; autre espéce (classéc comme Gulia par M. Jousseaume), dans le Langhien du Bordelais: C. Deshayesi Desm., ma coll.

Epopue actuelde. - Nombreuses espèces dans l'Océan Indien, la Polynésie, les mers de Chine, la mer Rouge, d'après II. Jousseaume et d'après le Manuel de Tryon.

Gergovia (1), nov. sect. Type: $C$. platypleura, Tale. Eoc.

T'aille petite; forme ventrue, ovoïdo-conique; spire un peu allongée, étagée, à galbe légèrement conoïdal; protoconche lisse,

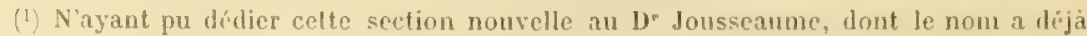
clé employé en histoire nalurelle, je choisis le nom de la rue habite, lans Paris, jar notre savant eomfrive. 
paucispirée, globuleuse, à nucléus en goutte de suif; tours plans, munis à la suture d'une profonde et large rainure, canaliculée, crénelée par des côtes aplaties ou obsolètes, que traversent des filets spiraux; base arrondie, perforée par une fente ombilicale assez étroite, que circonserit un gros bourrelet arrondi. Ouverture ovale, assez large à lá partie inférieure, où elle paraît dépourvue de gouttière, terminée en avant par un bec étroit et échancré, auquel aboutit le bourrelet basal; labre mince, un peu oblique, intérieurement muni de costules peu nombreuses, qui commencent à une certaine distance du bord et se prolongent à l'intérieur ; columelle presque droile, légèrement infléchie vers l'extérieur à la naissance du bec, munie de deux plis médians, égaux et transverses; bord columellaire nul en arrière, où le péristome est interrompu, étroit et détaché de l'ombilic du côté antérieur, se raccordant au contour supérieur de l'échancrure.

Diagnose faite d'après un échantillon de l'espèce-type de Muddy Creek (Pl. I, fig. 6), ma coll.

Rapp. et diff. - Par ses deux plis columellaires, par sa forme générale et par sa fente ombilicale, cette petite coquille a certainement des points de ressemblance avec un autre Genre éocénique que l'on trouvera ci-après, Sveltella: mais elle s'en distingue essentiellement par" son bec échancré et par son bourrelet basal, par l'absence de varices et par sa rampe suturale. C'est une forme bien distincte, que je crois plutôt proche de Merica, dans le voisinage de Scalplia, près de qui je la place, à titre de nouvelle Section du même Genre Merica.

Répart. stratigr.

EOcExe. - L'espèce-type dans l'Australie du Sud, ma coll.

Aphera, H. et A. Adams, 1853. Type: C.tessellata, Sow. Viv.

Test épais. Taille moyenne; forme olivoïde; spire courte, à galbe conoïlal; proloconche lisse, paucispirée, petite, non globuleuse; tours un peu convexes, à sutures profondes, non canaliculées, 
ornés de plis obliques d'accroissement, cancellés on plutil décussés, ponctués dans les intervalies par des sillons spiraux; dernier tour très grand, ovale, à base imperforée, presque dépourvue de bourrelet, avec un léger renflement sur le cou. Ouverture semilunaire, munie en arrière d'une étroite goultière, terminée en avant par une échancrure large et peu profonde; labre un peu incliné, antécurrent vers la suture, épais, crénelé ou costulé à l'intérieur ; columelle un peu excavée en arrière, un peu infléchie à droite du côlé antérieur, munie de deux on trois plis épais, obliques, les deux postérieurs plus saillants, l'antérieur disparaissant parfois ou se confondant avec l'inflexion de la columelle; bord columellaire épais, calleux, largement étendu sur la base et quelquefois chagriné en arrière, se raccordant en avant avec le contour supérieur de la sinuosilé basale.

Diagnose refaite d'après un plésiotype de l'Helvétien du Piémont: C. Bromi Bell. (Pl. I, fig. 11), coll. du Musée de Turin.

Rapp. et diff. - Les différences entre cette coupe et Merica n'ont, à mon avis, qu'une importance sous-générique: outre la forme générale de la coquille, il y a le développement du bord columellaire, la diminution de l'échancrure basale, l'embryon moins développé, l'absence.presque totale de bourrelet basal, entin l'inclinaison du labre. M. Sacco, qui a classé, avec raison, le plésiotype ci-dessus décrit, dans le groupe Aphera (mais en attribuant à ce groupe une valeur générique), y rapporte également une coquille qu'on trouvera ci-après dans un nouveau Sous-Genre: C. Dufouri Grat. La figure qu'il en donne (1'l. III, lig. 76) me parait être simplement une variété de $C$. Bronni, et elle diffère complètement de l'espèce de Grateloup, principalement par l'absence de rampe suturale el par son échancrure basale.

Répart. stratigr.

Mroceae. - Le plésiolype el ses variétés, dans l'llelvétien des environs de Turin; autre espèce dans ces mèmes grisements: A. avatocrassa Sacco, d'après la ligure publiée par cel auteur.

Eropue actulle. - Le type sur les côtes occidentales de l'A mérique centrale, d'après le Manuel de 'Tryon, coll. de l'Ecole des Mines. 
BROGGHINIA, Jousseaume, 1888.

Brocchinia, sensu stricto. Type: C. mitræxormis, Br. Plioc.

Taille petite; forme étroite, turriculée ; spire longue, non étagée, à galbe conique; protoconche lisse, paucispirée; tours convexes en arant, déprimés en arrière vers la suture, ornés de filets spiraux, obtusément costulés sur leur convexité; dernier tour très court, arrondi à la base qui est complètement imperforée et dépourvue de bourrelet. Ouverture ovale, petite, avec une étroite gouttière dans l'angle inférieur, terminée en avant par un bee un peu contourné, large et peu profondément échancré sur son contour supérieur; labre oblique, un peu courbe, faiblement épaissi, costulé à l'intérieur; columelle droite, faisant un angle de $130^{\circ}$ avec la base de l'avant-demier tour, infléchie vers la droite à son extrémité antérieure, ò̀ elle disparait sans se prolonger jusqu'au bord du bec; deux plis transverses, peu saillants, plus une torsion antérieure pliciforme; bord columellaire étroit, un peu calleux, à contour sinueux, se raccordant avec le bec antérieur.

Diagnose refaite d'après des échantillons de l'espèce-type, du Plaisancien de Bologne (Pl. I, fig. 22), ma coll.

Observ. - Le classement de cette coquille est embarrassant : par son test épais, par son bord columellaire calleux, par son bec échancré et par sa columelle infléchie à droite, elle appartient évidemment à la Sous-Famille Cancellarinæ; mais, comme elle n'a pas de bourrelet, elle se rapproche de Svellia, quoiqu'elle n'y ressemble ni par sa forme, ni par son ornementation. Nême sa protoconche, qui a la forme d'un dé cylindrique avec un nucléus très petit et saillant (Fig. 3 ci-contre), a un aspect tout particulier, et contribue encore à augmenter l'ambiguîté de ses caractères. Si l'on ne tenait pas comple de sa columelle plissée, ni de

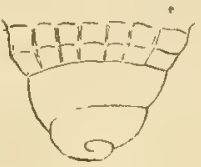

Fia 3. - Brocchinia mitroformis, Brocchi. son bec peu échancré, qui n'est pas un véritable canal, on pourrait presque la confondre avec certains Siphonalia du groupe Coptochetus; mais, outre ces différences, elle n'a pas l'embryon dévié des espèces de ce Genre. 
Répart. stratigr.

Eocexe. - Une petile espece douteuse dans l'Australie du Sud el la Tasmanie: C. Etheridgei Johnst, ma coll.

Mrocese. - L'espèce-type et ses variétés, ainsi qu'une espèce voisine: B. crassinodosa Sacco, dans le Tortonien du Piémont, d'après la Monographie de M. Sacco; la même dans le Tortonien du Bordelais, coll. de l'Ecole des Mines, et dans le Tortonien de la Brelagne, ma coll.; la même el une espèce voisine: $C$. bicarinala Iloern., dans le bassin de Vienne, d'après la Monographie de MIM. Ifornes et Auinger.

P'Liocere. - L'espèce-type dans le Plaisancien des Alpes-Maritimes et d'Italie, ma coll.; la même dans le Crag d'Angleterre avec une espèce probable : C. avara Say, d'après la Monographie de S. Wood. Une espèce nouvelle dans le Cotentin, à Gourbesville : B. rissoiæformis nob. (voir l'annexe ci-après, Pl. II, fig. 15), ma coll.

\section{SVELTIA, Jousseaume, 1888.}

Sveltia, sensu stricto.

Type: C. varicosa, Br. Plioc.

Taille assez grande; forme turriculée; spire allongée, à galle conique; procolonche lisse, paucispirée, turbinée, à nucléus petit et obtus; tours convexes, subanguleux, à sutures profondes, non canaliculées, ornés de costules axiales et de filets spiraux plus ou moins fins, avec de courtes épines à l'intersection de l'angle el des costules; hase non ombiliquée, à peu près completement défourvue de bourrelet. Ouverture ovale, presque sans gouttière dans l'angle inférieur, terminée en avant par une échancrure à peine visible; labre un peu ollique, laillé en bisean, épaissi et costulé à l'intérieur, à quelque distance dubord ; columelle un peu excavée. faiblement déviée et rejetée à l'extérieur vers son extrémité, munio de deux ou trois plis, l'antérieur bien distinct sur quelrues individus tres adultes; bord columellaire calleux, conservant la même largeur sur presque toute son étendne.

Diagnose refaite d'après un échantillon de l'espèce-type du Plaisancien de Castell'Arquato (P'. I, fig. 19-20), ma coll.

Observ. - Le classement de ce Genre est difficile, parce qu'il a des caractères intermédiaires entre les Caucellarina et les Trigonostomine; 
sa columelle est déjà un peu incurvée, mais elle ne s'infléchit pas vers l'axe, comme celle de Trigonosloma; en outre, son ouverture n'est pas trigone. D'autre part, M. Jousseaume indique qu'elle porte deux plis, tandis que j'ai constaté, chez quelques individus de l'espèce-type, un troisième pli antérieur, bien distinct de la torsion columellaire. Enfin l'échancrure est tellement peu indiquée; à la base de l'ouverture, que Sveltia se rattache plutôt, à ce point de vue, aux formes suivantes; toutefois la base ne porte qu'un indice de bourrelet. Aussi ai-je, en définitive, placé Svellia dans les Cancellarinie.

Rapp. et diff. - On distingue ce genre de Nárona; qui a presque la même forme en apparence, par son échancrure beaucoup moins profonde et par sa columelle un peu excavée, par l'absence de bourrelet sur la base, et de gouttière dans l'angle inférieur de l'ouverture.

\section{Répart. stratigs.}

Eocexe. - Une espèce typique, dans le Claibornien des Etats-Unis: C. alveáta Conr., ma coll.

Orrgocene. - Une espèce dans le Tongrien du Piémont : C. ablita Mich $^{\text {ti }}$, d'après M. Sacco; autre espèce douteuse, dans le Stampien des environs de Paris: C. Baylei Bez., ma coll.

Mrocexe. - L'espèce-type dans le Tortonien du Portugal, du Bassin de Vienne et de l'Italie centrale, ma coll.; plusieurs autres espèces dans l'Helvétien et le Tortonien du Piémont: C. miocænica Doderl. C. parvolurrila, derloscalata Sacco, C. Taurinià el intermedia Bell., d'après la Monographie de M. Sacco; dans le Bassin de Vienne: C. inermis Pusch, C. Suessi R. Hoern., d'après la Monographie de MM. Hœrnes et Auinger; dans le Tortonien de la Catalogne: C.cf: inermis, d'après MM. Almera et Bofill ; une espèce dans les couches d'Edeghem en Belgique: C. Lajonkairei Nyst, ma coll. Une nouvelle petite espèce dans le Tortonien de Saubrigues: S. colpodes nob. (Voir l'annexe ci-après, Pl. II, fig. 18-19).

Pliocene. - Le type aans le Plaisancien de Toscane et de Bologne, ma coll.; la même espèce dans le Plaisancien de la Catalogne, d'après MII. Almera et Bofill; plusieurs variétés de $C$. intermediè Bell. et du type, dans le Plaisancien du Piémont, d'après la Monographie de M. Sacco.

Calcarata, Jousseaume, 1888. Type: C. calcarata, Br. Plioc.

Taille assez grande; forme étroite, turriculée; spire longue, à galbe conique; protoconche lisse, turbinée, un peu déviée; tours carénés, épineux, faiblement cancellés; base perforée par un ombi- 
Srellia

lic plus ou moins ouvert, circonscrit par un bourrelet assez saillant, sur lequel les côtes forment des épines ou des lamelles r'ugueuses. Ouverture ovale ou subtrigone, avec une seule goutlière obsolète dans l'angle inférieur, terminée en avant pàr un bec plus ou moins aigu, tris faiblement échancre: Iabre un peu oblique, épaissi par la dernière côte, muni de minces filels à l'intérieur; columelle droite, presque sans inflexion à son extrémité anlérieure, avec trois plis, celui du milieu plus oblique que les deux autres; bord columellaire assez épais, peu étalé, se raccordant en avant avec le bec basal.

Diagnose refaite d'après un échantillon de l'espèce-type du Plaisancien de Sienne (Pl. I, fig. 4), coll. Bourdot; et d'après un plésiotype du Plaisancien de Biot, dans les Alpes-Maritimes: C. lyrata Br. (P. I, fig. : 3), ma coll.

Rapp. et diff. - Outre la différence de forme, qui est réellement importante, le Sous-Genre Catcriala se distingue de Merica et de Scalptia: par la disposition de ses plis columellaires, dont le médian est le plus oblique; par sa columelle encore moins inlléchie du côté antérieur; par son échancrure extrêmement faible, surtout à l'àge adulte; par sa protoconche moins globuleuse, à nucléus embryonnaire plus petit. En outre, si on le compare à Scalptia, on trouve qu'il n'a qu'une scule gouttière postérieure, et que son labre est moins dilaté au milieu; enfin le labre est un peu plus oblique que chez Merica.

J'ai placé Calcarata dans le genre Svellia, qui a presque la même forme, avec une ornementation différente; il est vrai que sa base est plus largem 'nt ombiliquée et munie d'un bourrelet plus saillant; mais l'échancrure de l'ouverture est aussi faible que celle de Sreltia, et sa protoconche est à peu près pareille.

D'autre part, il est incontestable que Calcarata a de nombreuses analogies avec Trigonostoma: si on compare les individus arlultes, on trouve que leur columelle n'a presque plus aucune déviation vers la droite, et que leur échancrure se réduit à une bien faible sinuosité du contour supérieur; néanmoins il n'y a pas identité complète entre les deux formes, on pent clone encore admettre, à la rigueur, que ces individus appartiennent a la Sous-Famille Cancellinx, avec une oblitération - due à leur àge des caractires des échantillons plus jeunes, pour lesquels le doute n'est pas possible. Il jésulte de ce fait que, pour la comparaison et le classement des Genres des Gastropodes, il n'est pas plus sur de prendre des exemplaires trés àgés que des exemplaires trop jeunes. 
Répart. stratigr.

Mrocene. - L'espèce-type dans le Tortonien du Portugal et du Piémont, ma coll.; dans le bassin de la Vienne: le plésiotyp̉e, ma coll., et l'espèce-type, d'après la Monog raphie de MM. Hornes et Aninger.

Pliocene. - liespèce-type dans le Plaisancien des Alpes-Maritimes et d'Italie, ma coll., coll. Bourdot; le plésiotype ci-dessus figuré, dans le Plaisancien de la Catalogne, des Alpes-Maritimes et d'Italie, ma coll.; dans le Plaisancien de la Catalogne : variétés du type, $C$. quetdrulata, et du plésiotype, $C$. angusta Almera et Bofill, d'après la Monographie de ces auteurs.

Aneurystoma ( $\left.{ }^{1}\right)$, nov. subgenus. Type: C. Dufouri, Grat. Mioc.

Taille au-dessous de la moyenne; forme ovale, auriculaire; spire courte, étagée, à galbe un peu conoïdal; protoconche lisse, déprimée, paucispirée, à nucléus petit et obtus; tours à peine convexes, munis d'une étroite rampe aplatie près de la suture, élégamment cancellés, dépourvus de varices; dernier tour très grand par rapport à la spire, ovoïde à la base qui porte une étroite fente ombilicale, bordée par un mince cordon crénelé. Ouverture dilatée, ovale, versante et dépourvue de gouttière à sa partie inférieure, à peine anguleuse à son extrémité antérieure, sans aucun bec ni aucune échancrure; labre assez mince, oblique, un peu incurvé en profil, largement développé, lacinié sur son contour, et costulé à l'intérieur, à une certaine distance du bord; columelle un peu excavée au milieu, faiblement infléchie vers la droite à son extrémité antérieure, munie de trois plis obliques, inégaux et inéquidistants, les deux antérieurs plus rapprochés; bord columellaire peu épais, très largement étalé sur la base danssa région inférieure, étroit et détaché de la fente ombilicale, se terminant en pointe à l'angle supérieur.

Diagnose faite d'après un échantillon de l'espèce-type, provenant du Tortonien de Saubrigues (PI. I, fig. 23-24), ma coll.

Rapp. et diff. - Ce nouveau Sous-Genre doit être évidemment placé dans le voisinage de Sveltia; car, si l'on compare les deux diagnoses, on

(1) Aveupus, dilaté; roux, bouche. 
Sveltia

trouve qu'elles ne diffèrent que par des caraclères d'une importance sousgénérique, fels que la forme, l'ornementation, l'ombilic, la disposition des plis; mais la protoconche, la courbe de la columelle, l'inclinaison du labre, l'extrémité antéricure de l'ouverture, sont tout à fait semblables; l'absence d'une goutlière inférieure, la présence d'un bourrelet rudimentaire, sont également des indices d'une grande affinité entre ces deux formes, malgré leur aspect extérieur tout à fait différent. M. Sacco, dans sa grande Monographie, a proposé de classer C. Dufouri dans le Sous-Genre 4 phera, bien que ce dernier ait pour type une coquille échancrée à la base, à columelle très calleuse, munie de deux plis principaux et de plis secondaires, avec un labre très épais et crénelé à l'intérieur; brel, il n'y a, selon moi, aucune ressemblance entre Aphera lessellata et Aneur. Dufouri.

\section{Répart. stratigr.}

Erraxe. - Une espèce bien caractérisée dans le Sud de l'Australie: C. gradata Tate (non Hornes) ('), ma coll.; une espèce dans le Claibornien des Etats-Unis : $C$. diclyella Cossm., ma coll.

Mrocexa. - L'espèce-type dans le Tortonien des Landes, ma coll. et dans le bassin de Vienne, d'après M. R. Hoernes.

\section{TRIGONOSTOMA, Blainville 1826.}

'T'RIgonostoma, sensustricto. Type: $C$. trigonostoma, I)esh. Viv.

Taille moyenne ou assez grande; forme turriculée; spire disjointe ou très étagée, à galbe conique; protoconche lisse, paucispirée, formant un petit bouton arrondi et obtus; tours carénés, avec une large rampe lisse et excavée au-dessus de la suture, cancellés sur leur région antérieure; base très largement ombiliquée, avec une carène plissée, aboutissant aubec antérieur. Ouverture complètement trigone, munie d'une gouttière non échancrée à l'angle inférieur et à son extrémité antérieure; labre vertical, taillé en biseau, costulé à l'intérieur ; bord columellaire légèrement concave, à peine infléchi vers l'axe en avant, muni de trois plis dont deux assez saillants et enfoncés, l'antérieur souvent très

1) Il y a lieu de corriger ce double emploi; je propose donc: A. Tatei, nol 
Trigonostoma

effacé chez les individus adultes; bord columellaire étroit, épais, lisse, faisant un angle à son point de jonction avec le bec antéricur.

Diagnose refaite d'après le type vivant, et d'après un plésiotype de l'Eocène de Claiborne: C. impressa Conr. (Pl. I, fig. 2כ), ma coll. ; protoconche grossie de la même espèce (Fig. 4 ci-contre); autre plésiotype de l'Astezan: C. umbilicaris $\mathrm{Br}$. (Pl.II, fig. 1-2), coll. du Musée géol. de Turin, communiqué par M. Sacco; vue en plan d'une autre espèce de l'Astezan : C. scabra (Pl. I, fig. 13), coll. de l'Ecole des Mines.

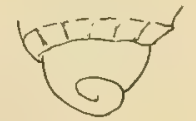

Fı. 4. - Trigonostoma impressum Conr.

Rapp. et diff. - Ce n'est pas seulement par sa forme étagée, scalaroïde, ou par son ouverture trigone, que ce Genre se distingue des Cancellinæ; mais c'est surtout par l'inflexion de la columelle, qui est creuse au milieu, et qui se dévie à son extrémité antérieure vers l'axe de la coquille, au lieu de se rejeter plus ou moins visiblement à l'extérieur, comme cela a lien chez les coquilles de la précédente Sous-Famille. En outre, bien qu il $y$ ait un bec à la base de l'ouverture, celle-ci n'est nullement échancrée, de-sorte que ses deux bords se joignent sans former aucune sinuosité appréciable, quand on regarde la coquille en plan du côté de la base. D'autre part, l'ombilic étant très largement ouvert en entonnoir, n'est pas circonscrit par un bourrelet, mais par une carène ou crête plus ou moins tranchante, sur laquelle les côtes axiales découpent des crénelures en chevrons, parlois très saillantes, ou même subépineuses. Les plis de la columelle sont au nombre de trois, minces et obliques; ils sont profondément situés, et on ne les aperçoit bien qu'en sondant l'intérieur de l'ouverture; celui du lıaut, quand il n'est pas oblitéré par l'àge, est toujours distinct de la torsion de la columelle.

Répart. stratigr.

Eocrxe. - Plusieurs espèces dans le Claibornien de l'Alabama: C. babylonica Lea, C. gemmala et impressa Conr., C. propegemmala de Greg., ma coll.

Oligocexe. - Une espèce donteuse dans le Tongrien du Piémont (ficle Sacco).

Mrocexi. - Plusicurs espèces dans le Tortonien des Landes: C. spinifera Grat., ma coll., C. umbilicaris Br., coll. Bourdot; dans le Tortonien du Piémont et du Bassin de Vienne: ('. gradala et Michelini Bell., C. subacuminala d'Orb., C. canaliculala Hoern. C. Schrokingeri et hidlasensis R. Iloern., d'après les Monographies de MM. Sacco et R. Hornes; l'une d'elles: C. canaliculala, dans les 
couches d'lideghem, coll. Bourdot; une variété de $C$. gradala dans le Tortonien de la Catalogne: C. Masferreri Alm. et Bof., d'après la Monographie de MIM. Almera et Bofill.

P'llocene. - P'lusieurs espèces dans le Plaisancien d'Italie: C. umbilicoris Br., C. Bellardii de Stef., C. scabra Desh., C. ampullacen Br., d'après la Monographie de M. Sacco; cette derniere espèce, et une autre, voisine de $C$. spinifera: C. fovealn $\mathrm{Alm}$. et Bol., dans le Plaisancien de la Catalogne, d'après la Monographie de MIM. Almera et Bofill. Une espèce dans le Pliocène des Etats-Unis: Co sericea Dall, d'après l'étude de cet auteur sur le Tertiaire de la Floride. Deux espèces bien caractérisées, dans les couches récentes de Java: C. ljibaliungensis Mart, et $C$. crispala Sow., d'après la Monographie de M. Martin; cette dernière dans le Pliocene de Karikal, coll. Bonnet.

Epopue actuelle. - Quatre espèces, outre le type, à Ceylan, à la Nouvelle-Guinée, sur les cûtes de l'Amérique centrale, d'aprìs 11. Jousseaume et d'après le Manuel de Tryon.

Ventrilia, Jousseaume 1888. Type: V.ventrilia, Jouss. Viv. (=Gulia, Jouss. 1888).

Taille grande; forme ventrue, ovoïle; spire étagée, largement canaliculéa la suture, à galbe conique; protoconche petite, whobuleuse, lisse, paucispirée, à nucléus un peu dévié; tours cancellés, avec une rampe postérieure fortement crénelée; base plus ou moins largement ombiliquée, portant un large bourrelet arrondi. Ouverture sublrigone, avec une gouttiorétroite et jrofonde dans l’angle inférieur de gauche, terminée en avant par un angle arrondi, sans canal ni échancrure; conlour supérieur à peine sinueux au point où aboutit le bourrelet basal; labre assez épais, lisse à l'inlérieur, ou muni de nombreux filets minces el paralleles, très nbliquement inclinc à qauche de l'ax", du cotéanterieur ; columelle très concave, portant deux plis très obliques et peu saillants, une torsion antérieure rudimentaire remplace le troisième pli; hord columellaire très large et très épais, détaché de l'ombilic, portant quelquefois des rides obsolètes, à la place du pli antérieur. 
Diagnose refaite d’après un plésiotype du Burdigalien de Léognan: C. acutangula Faujas (Pl. I, fig. 12 et 14), ma coll.

Observ. - La description ci-dessus, faite d'après un échantillon de l'espèce-type du Genre Gulia Jouss., ne diffère de la diagnose du Genre Ventrilia, que par des nuances d'une valeur puremeni spécifique; ces différences ne portent que sur la forme et l'ornementation de la coquille, sur l'existence ou l'absence de plis à l'intérieur du labre, - et cela tient souvent à l'àge des individus qu'on étudie. Dans ces conditions, il me paraît évident qu'il y a eu, de la part de l'auteur de ces deux Genres, une superfétation de nomenclature, qui est peut-être due à ce que le premier (Gulia) a été uniquement créé pour des espèces fossiles, tandis que l'autre (Ven(rilia) ne comprend que des coquilles vivantes: or il est notoire que la fossilisation comporte une modification du test, qui a généralement de l'influence sur quelques caractères d'importance secondaire. Je n'hésite donc pas à considérer ces deux Genres comme synonymes; mais j'aurais préféré, si cela eût été possible, sans violer les règles de priorité, conserver Gulia, plutôt que T'entritia, qui est précisciment le nom de l'espèce-type.

Rapp. et diff. - La coquille adulte de Ventrilia se distingue de Cancellaria: par l'absence complète d'échancrure sur le contour supérieur de l'ouverture, qui est à peine entaillée dans le jeune àge; par sa columelle incurvée, munie de plis olyliques, se réduisant généralement à deux; en outre, l'ombilic est plus ouvert, le bord columellaire est bien plus largement étalé sur la base; enfin l'ouverture est, dans son ensemble, plus trigone. D'autre part, Ventritia se distingue de Trigonostoma, - qui est de la même Sous-Famille, - par son ombilic moins large et par son bourrelet moins caréné, par sa columelle encore plus incurvée, par ses plis columellaires moins saillants et ordinairement moins nombreux; mais il y a, surtout en ce qui concerne les plis columellaires, des espèces intermédiaires qu'il est bien difficile de classer dans une de ces subdivisions plutôt que dans l'autre, de sorte qu'à mon avis Ventrilia ne doit être pris que comme une Section de Trigonostoma; peut-être même eût-il été préférable de ne pas l'en séparer, et, en tous cas, il est d'autant moins admissible de subdiviser encore Ventritia et de conserver Gulia.

\section{Répart. stratigr.}

Eocene. - Une espèce globuleuse, à large ombilic et à deux plis, dans l'Australie: $C$. calvulata Tate, ma coll.

Mrocene. - Le plésiotype $(C$. acutangula) dans le Burdigalien de l'Aquitaine, ma coll., dans l'Helvétien de l'Anjou, coll. Dumas, dans le Tortonien du Piémont (fide Sacco); une espèce voisine, dans le Bassin de Vienne: C. Puschi R. Hœrn., d'après la Monographie de MM. Hornes et Auinger. Plusieur's autres espèces dans le Burdiga- 
lien de l'Aquitaine: C. Geslini Bast., ma coll., C. trochlearis, coll. Jumas; dans le Tortonien du Comtat Venaissin: C. druentica, Gaudryi et Deydieri liontannes, d'après les figures données par l'aulcur; autre espèce: C. scrobiculala Hœrn., dans le bassin de Vienne (fide li. Ilornes), et dans le Tortonien d'llalie, ma coll.

P'LIOCEXE, - Une espèce bien caractériscée dans l'Istien d'Italie : $C$. cassiclea Br., coll. de l'École des Mines. Plusieurs espèces dans la Caroline du Sud: C. lenera Phil., C. subthomasie Dall, d'après la Monographie de cet auteur sur le Tertiaire de la I'loride. Une espece probable aux Açores: C. parcestriata Bronn, d'après la figure donnée par M. Mayer-Eymar.

Epoque actuele. - Cinq ou six espèces, sur les côtes d'Amérique el aux Philippines, d'après M. Jousseaume.

Ovilia, Jousseaume, 1888. Type: C. doliolaris, Bast. Mioc.

Taille moyenne; forme globuleuse, presque sphérique ou piroïde; spire très courte, le dernier tour formant toute la coquille, ornée de costules ou de rubans spiraux, et décussée par des stries d'accroissement; protoconche lisse, pelite, paucispirée, à mucléus un peu saillant; tours peu nombreux, cerclés, à sutures canaliculées; dernier tour très ventru, orné comme la spire, jusque sur la base qui est largement ombiliquée à l'âge adulte, arec un gros bourrelet arrondi, non lamelleux, mais plissé. Ouverture large, piriforme, avec une gouttière échancrant le péristome, dans l'angle inférieur, terminée ell avant par un bec étroit, recourbé, et entaillé par une échancrure assez profonde, quand la coquille a atteint sa taille définitive; labre dilaté, arrondi, lacinié à l'intérieur; columelle excavée, munic de deux plis peu visibles et très enfoncés à l'intérieur; bord columellaire mince ct largement étalé en arrière, formant en avant une étroite lamelle détachée de l'ombilic.

Diagnose refaite d'après un échantillon de l'espèce-type, du Burdigalien de Saucals (1'l. II, fig. 4-ẽ), coll. de l'Ecole des Mines.

Rapp. et diff. - Il y a de réelles différences entre ce Sous-Genre et les autres Sections du Genre Trigonostoma: d'abord la forme dolioïle de la 
Trigonostoma

coquille, son labre arrondi et son ouverture piriforme, parfois échancréc en avant; l'ornementation non cancellée est aussi un caractère distinctif, dont il y a lieu de tenir compte dans une certaine mesure. Les plis ressemblent beaucoup à ceux de Ventrilia, et lombilic est aussi largement ouvert que chez les Trigonostoma typiques. Malggré l'échancrure adventive de la base, je n'hésite pas à classer ce Sous-Genre dans la Sous-Famille Trigonostominæ, à cause de l'inclinaison de la columelle vers l'axe; en effet, l'échancrure est entaillée aux dépens du bourrelet basal, et elle ne commence à se contourner qu'au-delà de l'extrémité de la columelle, sans modifier son inclinaison typique.

\section{Répart. stratigr.}

Mrocexe. - L'espèce-type dans le Burdigalien de l'Aquitaine, coll. de l'Ecole des Mines, ma coll.; la même (var. umbilicina Sacco) dans l'Helvétien du Piémont, coll. du Nusée géol. de Turin; autre espèce presque lisse, dans l'Helvétien du Piémont: C. Bernarrli Mayer, d’après la Monographie de M. Sacco.

Eroque actuelle. - Deux cspèces (dont une à columelle triplissée?), sur les côtes du Pérou, d'après M. Jousseaume.

\section{SVELTELLA, Cossmann, 1889.}

SVELTELLA, sensu stricto.

Type: C. quantula, Desh. Eoc.

Taille très petite; forme turriculée, étroite, fusoïde; spire longue, à galbe conique; protoconche lisse, petite, paucispirée, à nucléus obtus; tours convexes, non étagés, variqueux, cancellés; base ovale, atténuée, avec une fente ombilicale très étroite, non bordée par un bourrelet. Ouverture subtrigone, munie d'une gouttière peu apparente dans l'angle inférieur, terminée en avant par un bec court, pointu, sans échancrure sur son contour supérieur ; labre épaissi par une faible varice, un peu sinueux ét excavé en arrière, crénelé à l'intérieur ; columelle à peu près droite, non intléchie en avant, se raccordant en courbe avec le contour supérieur du bec, munie de deux plis transverses et très rapprochés, au milieu de sa hauteur, sans aucune apparence d'un troisième pli antérieur ; bord columellaire étroit, presque nul en arrière, détaché de la fente ombilicale en avant. 
Diagnose faite d'apries un échantillon de l'espécc-lype, du Calcaire grossier de Parnes (Pl. I, fig. 2I), coll. Bourdot.

Rapp. et diff. - Ce Genre se distingue de Srellia par sa pelite taille, par son ouverture subtrigone, plus pointue et encore moins échancrée à la base, par ses plis columellaires transverses et médians, par ses varicus obsoletes et par sa fente ombilicale. On ne peut le rapprocher de Trigonostoma, à cause de sa forme non étagée, de l'absence d'ombilic et de bourrelet basal. D'autre part, il est facile de le distinguer, à première vue, des Uxia qui se trouvent dans les mêmes gisements, it cause de sa plication et de l'absence d'échancrure basale. Dans ces conditions, Sveltella est un Genre bien distinct, et non pas seulement une Section, comme jo le croyais d'abord, quand je l'ai instituée, en 1889, dans le $\mathbf{4}^{\mathrm{e}}$ fascicule de mon "Catalogue illustré " (p. 226).

Répart. stratigr.

Eocene. - Quatre espèces, y compris le type, aux trois niveaux du Bassin de Paris: C. Bezançoni de Rainc. C. semiclathrala Morlet, C. nana Desh., ma coll. Deux espèces dans le Claibornien des EtatsUnis: C. parva Lea, ma coll., C. mericana, d'après la figure donnée par M. Gilb. Harris. Une espèce à plis bifurqués, dans le Bassin de Nantes: C. bifurcoplicala Cossm., coll. Dautzenberg; une espèce bien caractérisée dans le Bartonien d'Angleterre: $C$. microstoma Newton, d'après la figure donnée par l'auteur. Une espèce dans l'Australie du Sud: C. capillata Tate, ma coll.

Oligocene. - Deux espèces dans l'Oligocène inférieur de l'Allemagne du Nord: C. hordeola et nitida von Konen, d'après la Monographie de cet auteur.

Mocene. - Une espèce typique, dans le Tortonien des Landes: S. Dumasi nov. sp. (voir l'annexe ci-après, pl. II, fig. 12); une espèce dans l'Helvétien du Piémont: $S$. fusospinosa Sacco, d'après la Monographie de cet auteur.

Eroque actulle. - Trois espèces bien caractérisées: au Japon, sur les côtes du Chili et aux îles Canaries, d'après les figures du Manuel de Tryon(').

(1) Liune d'elles (C. parra Phil.) doit changer de nour, pour cause de ilouble emploi avec l'espèce de Lea, ci-dessus citée; je propose en conséłuence: S. Philippii, nob. 
ADMETE, Kröyer, 1S42.

AdMete, sensu stricto.

Type: A. virudula Fabr. Viv .

Test peu épais. Taille au-dessous de la moyenne; forme buccinoïde; spire un peu allongée, pointue, à galbe conique; protoconche lisse, petite, obtuse; tours convexes, non étagés à la suture, souvent costulés et toujours ornés de filets spiraux, qui persistent seuls sur la base, larquelle est complètement dépourvue d'ombilic et de bourrelet. Ouverture ovale, sans gouttière postérieure, terminée en avant par un bec recourbé et échancré; labre mince, oblique, en courbe arrondie au milieu, lisse à l'intérieur ; columelle un peu excavée en arrière, tordue en avant et rejetée à l'extérieur comme le bec, munie de trois plis obliques, égaux, parallèles, peu saillants, dont l'antérieur coïncide avec la torsion columellaire et se raccorde sans discontinuité avec le bec basal ; bord columellaire nul à la partie inférieure, très mince et peu distinct en avant.

Diagnose refaite d'après des échantillons de l'espèce-type, fossile du Crag de Butley (Pl. I, fig. 26), ma coll.

Observ. - C'est avec raison que la plupart des auteurs admettent cette coquille comme type d'un Genre absolument distinct de Cancellaria; le peu d'épaisseur du test et l'habitat boréal de ce mollusque indiquent déjà qu'il s'agit d'un animal dont l'organisation doit être différente. Je vais même plus loin en proposant Admele comme Genre-type d'une SousFamille distincte: A duetix , dont les membres sont invariablement caractérisés par la contorsion de leur bec antérieur, par l'absence de bourrelet basal, par la diminution ou la disparition complète du bord columellaire, enfin par la disposition particulière du pli antérieur, dont le prolongement ininterrompu limite le bec et l'échancrure basale. Il arrive sonvent que les deux autres plis sont tellement enfoncés à l'intérieur de l'ouverture qu'on pourrait croire quil n'y a que le premier; cela dépend de l'áge de la coquille, et de l'état de conservation du labre, qui ne permet 
d'examiner la columelle ì l'intérieur que quand il est mutilé, - ce qui arrive fréquemment, parce qu'il est mince. C'est à cette cause qu'il faut altribuer les différences profondes que l'on constate, pour la plication columellaire, lorsqu'on passe en revue les figures reproduites par les auteurs qui ont publié des espèces d'Admete.

Répart. stratigr.

Plocexe. - L'espèce-type dans le Crag, ma coll.

Epopue actuelde. - Plusicurs espèces ou variétés du type, dans les régions boréales ou australes (Ile de Kuerguélen), d’après le Manuel de Tryon.

Bonelitita, Jousseaume, 1888. 'Type: C. Bonellii, Bell. Pliec.

$$
(=\text { Admetula, Cossm. 1889). }
$$

Taille moyenne; forme ovoïde, buccinoïde; spire médiocrement allongée, non étagrée, à galbe conique; proloconche lisse, peu saillante, paucispirée, à nucléus parfois un peu rétus, de sorte que le sommet embryonnaire semble aplati; tours convexes cancellés, presque toujours variqueux, dépourvus de rampe suturale; base convexe, sans aucune fente ombilicale, ni aucunc trace de bourrelel. Ouverture ovale, dépourvue de gouttière dislincte dans l'angle inférieur, terminée en avant par un bec assez. large, un peu contourné et rejeté vers la droite, à peine échancré sur son contour supérieur; labre peu épais, muni, à quelque distance du bord, de costules internes correspondant à la dernière varice: columelle un peu excavée en arrière, tordue au bord du bec, portant trois plis inégaux, les deux inférieurs un peu plus obliques el moins saillants que la lamelle antérieure qui se raccorde avec le contour supérieur du bec; bord columellaire très court, s'enfonçant en spirale dans l'intérieur de l'ouverture, ver's la moilié de la hauteur de la columelle, immédiatement soiis les plis, et formant en avant un rebord peu calleux, très étroil, qui ne se raccorde pas avec le bec. 
Admete

Diagnose refaite d'après un échantillon de l'espèce-type, du Plaisancien de Biot (Pl. I, fig. 18), ma coll.; et d'après un plésiotype de l'Eocène supérieur de Barton: C. evulsa Sol. (Pl. II, fig. 6-7), ma coll.

Observ. - Ainsi que l'a fait remarquer M. Sacco, dans sa Monographie des Mollusques tertiaires du Piémont, il y a des individus de $C$. Bonellii qui ont des varices, de sorte que la principale différence, que j'avais signalée entre $A$ dimetula et Bonellitia, n'a pas le caractère de constance que je Iui attribuais, quand j'ai proposé Admetula (Catal. illustré IV, p. 228, 1889). D'autre part, après un nouvel examen comparatif des types de ces deux sections, j'ai constaté que les autres caractèrés sont à peu près identiques, même la disposition des plis et la forme de l'embryon; il n'y a donc aucun motif pour maintenir la séparation que j'ai arbitrairement faite. Toutefois il est bien regrettable que les lois de la priorité m'obligent à conserver une dénomination aussi mal formée que Bonellitia: strictement, au point de vue de l'orthographe, elle ne fait pas double emploi avec Bonellia Desh. 1838 (= Niso); mais, comme c'est à Bonelli, et non pas à Bonelliti, qu'est dédié le Genre de M. Jousseaume, il y a virtuellement un double emploi qu'eût évité l'adoption du nom Admelula, que j'ai proposé une année plus tard.

Rapp. et diff. - Il y a de réelles différences entre Bonellitia et Admele: d'abord.le test est un peu plns épais chez Bonellitia, qui porte généralement des varices; ensuite les plis columellaires sont moins réguliers, moins parallèles que ceux d'Admete; d'autre part, le bee est moins long, moins échancré, moins contourné; en outre, le bord columellaire est un peu plus visible du côté antérieur; enfin, ainsi que l'indique la Fig. 5 ci-contre $(B$. exulsa), la protoconche est un peu différente, plus aplatie au sommet. Cependant ces caractères distinctifs ne me paraissent pas dépasser la valeur d'une Section; M. Jous -

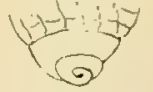

Fia. 5. - Bonellitia evulsa. Sol. seaume lui-même, qui attribue à toutes ses divisions l'importance de Genres, reconnaît que Bonellitia est très voisin d'Admete. C'est une preuve de plus de la nécessité d'admettre, dans la classification de chaque famille, les trois degrés (Genres, Sous-Genres et Sections), qui permettent de grouper plus rationnellement, selon leurs affinités, les coquilles avec une méthode, en quelque sorte, hiérarchique.

\section{Répart. stratigr.}

Sexoniex. - Une espèce douteuse dans la Craie de Maëstricht : C. similis Kaunhowen, d'après la Monographie de cet auteur(').

(1) Il y a lieu de changer ce nom spécifique, qui fait double emploi avec l'espèce vivante de Sowerby; je propose, pour l'espèce da Limbourg: B. præevulsa nab. 
Aimete

Eocene. - Six espèces, outre le plésiotype ci-dessus figuré, aux trois niveaux du Bassin de Paris, et l'une d'elles en Angleterre: $C$. dubia Desh., C.leviuseula Sow., C. striatulata Desh., C. sinuosa, Bemayiel sphericula Cossm., ma coll. et coll. Bernay; une espéce probable dans le Vicentin, à San Giovanni llarione : $C$. margaritala Vinassa de Regny, d'après la figure donnée par l'auteur. Plusieurs espèces bien caractérisées, aux Etats-Unis : C. torliplica Conr. C. alvaniopsis el Pemrosei Gilb. Harr., ma coll. Une autre espèce typique dans l'Australie du Sud : C. varicifera Ten. Woods, ma coll.

Oligocene. - Nombreuses espèces dans le Tongrien de la Belgique et de l'Allemagne du Nord : C. pseudoevulsa et subevulsa d'Orb. ma coll., C. levigata, lumida, lumescens, rugosa, lima, tenuistriala, interstrialis, ovata von Konen, C. nitens Beyr., d'après la Monograplie de M. von Koenen.

Mrocene. - Plusieurs espèces dans l'llelvétien et le Tortonien du Piémont: C. Bonellii Bell. C. serrata Bronn, C. taurinia et multicostata Bell., C. tauroconvexula Sacco, d'après la Monographie de cet auteur; l'une d'elles: C. serrata, dans l'Helvétien de l'Anjou, coll. Dumas; une autre : $C$. taurinia, dans l'llelvétien de la Touraine, coll. Dumas.

Pliocene. - Deux des espèces précilées, dans le Plaisancien des Alpes-Maritimes et du Piémont: C. serrala et Bonellii, ma coll.; les mêmes dans le Plaisancien de la Catalogne, d'après la Monograplie de MM. Almera et Bofill.

Coprostous, nov. sect.

Type: C. quadrata, Sow. Eoc.

Taille au-dessous de la moyenne; forme limnéoïde; spire un peu allongée, subulée, à galbe conique; proloconche lisse, paucispirée, obtuse, à nucléus petit, non rélus ; lours un peu convexes, à sutures profondes, finement cancellés, non variqueux; base ovale, imperforée, sans bourrelet. Ouverture fusoïde, étroitement caualiculée dans l'angle inféı'ieur, subtronquée ct échancréc en avant; labre oblique, assez mince, lacinié à l'intéricur" ; columelle régulièrement excavée, munie de trois plis, les deux inférieurs obliques et presque paralliles, l'antirieur plus lamelleux, tout a fait transverse, formant la troncature du bec échancré; pas de bord columellaire, mais seulement une callosite indistincte entre les plis. 
Diagnose établie d'après des échantillons de l'espèce-type de Barton (PI. II, fig. 9-10), ma coll. ; espèce plésiotype, à labre plus droit et à tours sillonnés, dans le Calcaire grossier de Chaussy: $C$. chaussyensis Cossm. (Pl. II, fig. 11), coll. Bourdot.

Rapp. et diff. - Je ne puis classer cette singulière coquille dans aucune des deux Sections précédentes; elle s'écarte d'Admele par la forme tout à fait tronquée du bec antérieur, par le pli columellaire qui ne se contourne pas obliquement, comme chez $A$. viriclula; et qui forme, au contraire, une lamelle presque horizontale; cette disposition se rapproche, il est vrai, du pli antérieur de Bonellitia, mais jamais, chez ce dernier, la troncature du bec n'est aussi nette sur le cou, du cóté de la base; en outre, Coptostoma n'a pas de varices, il a le labre lacinié et non costulé; enfin la protoconche n'est pas rétuse, et le nucléus embryonnaire fait une petite saillie. Il me paraît donc indispensable de séparer, en créant cette nouvelle Section, C.quadrata que M. Jousseaume a confondu avec Merica, quoiqu'il appartienne à une autre Sous-Famille, et que M. Sacco place dans le Genre Aphera, précisément remarquable par son large bord collumellaire. D'autre part; Coptosloma ne peut se confondre avec Aneurystoma, quoique sa forme soit analogue, parce que ce dernier n'a pas d'échancrnre basale, et qu'il possède un large bord columellaire.

\section{Répart. stratigr.}

Eocene. - L'espèce-type dans le Bassin anglais, ma coll.; le plésiotype dans le Calcaire grossier des environs de Paris, coll. Bourdot.

Oligocexe. - Une variété de l'espèce-type, dans le Tongrien de l'Allemagne du Nord: C. planistria von Konen, d'après la Monographie de cet anteur.

\section{Babylonella, Gonrad, 1865. Type : C. elevata, Lea. Eoc.}

Taille petite; forme étroite, fusoïle; spire longue, non étagée, à galbe conique; protoconche lisse, paucispirée, à nucléus non saillant; tours convexes, à sulures peu profondes, cancellés, variqueux; base ovale, alténuée, imperforée, sans bourrelet. Ouverture ovale, courte, sans gouttière postérieure, terminée en avant par un bec très court et peu échancré; labre très oblique, épaissi par la dernière varice, crénelé à l'intérieur ; columelle à peu près verticale, faisant un angle de $150^{\circ}$ avec la base de l'avant-dernier 
Admete

tour, munie de trois plis obliques, les deux inférieurs plus saillants et plus écarlés, l'antérieur plus oblique. souvent peu visible, se raccordant presque sans inflexion avec le contour supéricur du bec; bord columellaire très mince, se l'éduisant à une couche de vernis vis-à-vis des plis.

Diagnose refaite d'après un échantillon de l'espéce-lype, de Claiborne (Pl. II, fig. 8), ma coll.

Rapp. et diff. - Cette coquille a les rapports les plus intimes aveo Bonellitia et Admele; aussi je comprends que, quand on n'a à sit disposition que les figures imparfaites de l'ouvrage de Lea, on la place comme l'a fait M. Sacco, dans le genre Adnete. T'outefois, elle se distingue de ces deux Sections par la disposition de ses plis, l'antérieur est moins saillant et plus oblique que les deux autres, de sorte que le bec est moins contourné que celui d'Admele, moins échancré que celui de Bonellitia, et surtout que celui de Coplostoma, chez qui la disposition des plis est précisément inverse. Les varices, l'ornementation, les crénelures du labre, rapprochent davantage Babylonella de Bonellitia, de sorte que, si je n'attachais pas une réelle importance, d'me valeur "sectionnelle", à la disposition des plis, à la profondeur de l'échanerure du bee, el à la forme générile, jaurais substitué la dénomination Babylonella, bien antéricure, au nom Bunellitia, dont j’ai signalé ci-dessus la formation incorrecte.

\section{Répart. stratigr.}

Senoxies. - Une espèce bien caractérisée, daus les sables de Vaals, près Aix-la-Chapelle: $G$. nitidula Mull., coll, de "Technische Hochschule », communiquée par M. Holzaplel.

Eockse. - L'espèce-type dans le Claibornien des Etats-Unis, ma coll. Ourgocene. - Une espèce dans le Tongrien de la Belgique et de l'Allemagne du Nord, et dans le Stampien du bassin de Mayence, confondue avec $C$. subungulosa par $\mathbf{1 1}$. von Koenen, mais évidemment distincte: C. minula Braun, ma coll.

Mrocene. - Une espèce dans le bassin de Vienne et dans le P'iémont: C. Nysli Iloern., d'après la Monographie de M. Sacco.

P'liocexa. - Une espèce dans le Plaisancien d'Italie, classéc par 11. Sacco dans le genre Admete, comme var. de C. fusiformis Cantr.: C. urcianensis d'Ane., ma coll.; autre espèce de l'Astien du Piémont, confondue avec $C$. costellifera Sow., d'apres la Monographie de 11. Sacco; deux espèces dans le Crag d'Angleterre : C. subanyulosa et yracilenta S. Wood; d'après la Monographie de cet auteur. 
UXIA, Jousseaume, 1888.

UxiA, sensu stricto.

Type : C. costulata, Lamk. Eoc.

Taille au-dessous de la moyenne; forme ovoïde, plus ou moins allongée; spire conoïde, de longueur variable; protoconche lisse, globuleuse, paucispirée, formant généralement un gros bouton obtus, à nucléus aplati ou un peu rétus; tours un peu convexes, costulés, cancellés ou réticulés, séparés par des sutures presque toujours canaliculées; varices axiales irrégulièrement disséminées sur toute la surface, jusque sur le dernier tour, qui est ovale, plus ou moins ventru; base imperforée, sans aucun bourrelet. Ouverture ovale, assez étroite, ordinairement peu élevée, avec une étroite gouttière dans l'angle postérieur, tronquée en avant par une échancrure assez profonde; labre presque vertical, épaissi par la dernière varice, crénelé à l'intérieur; columelle droite, munie de trois plis égaux et parallèles, peu obliques et épais, l'antérieur confondu avec la torsion columellaire, se raccordant sans discontinuité avec le contour supérieur de l'échancrure; bord columellaire large et calleux, souvent ridé ou même denté dans sa région postérieure, un peu détaché en avant, et se terminant en pointe contre l'échancrure.

Diagnose refaite d'après un échantillon de l'espècetype, provenant du calcaire grossier de Villiers (Pl. I, fig. 16-17), ma coll.; protoconche grossie (Fig. 6 ci-contre).

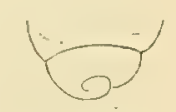

Fra. 6. - Uria costulata, Lamk.

Rapp. et diff. - Quoique Uxia se rapproche des Cancellarinæ par son échancrure basale et par la forme de sa columelle, je le place dans la Sous-Famille Admetinæ, à cause de la disposition du pli antérieur, qui se prolonge et se raccorde avec le contour supérieur, tandis qu'il est toujours distinct chez Merica, par exemple; en outre, comme l'indique la figure 6 ci-dessus, la protoconche est beaucoup plus globuleuse et disproportionnée que chez aucun des premiers Genres de Cancellarinx, et le nucléus embryonnaire est rétus, comme chez la plupart des Admetinx; enfin le labre se termine un peu plus en avant que le bord opposé, au point où il fait une courbe pour former le contour supérieur de l'échan- 
crure. Les crénelures internes du labre se transforment, chez certaines espèces, en de véritables dents, comme chez les Tritonidæe, le bord columellaire est beaucoup plus étendu en arrière, et plus épais en avant que chez les autres Admetinx.

\section{Répart. stratigr.}

Senoximx. - Une espèce bien caractérisée, dans les sables de Vaals près Aix-la-Chapelle: C. Dunkeri, d'après le type communiqué par 1I. Holzapfel; deux espèces probables dans la Craie de Maëstricht: C. Kunraedensis et minima (1) Kaunhowen, d'après les figures des empreintes et contremoulages de la Monographie de cet auteur. Une espèce douteuse dans la Craie de New-Jersey : Merica suballa, Conr., d'après la figure de la Monographie de Whitfield.

Pareocene. - Deux espèces certaines dans les sables de Bracheux: C. infraeocanica Cossm., ma coll., C. Cloezi Cossm., d'après mon Catalogue de l'Eocène; plusieurs espèces dans le Calcaire de Mlons: C. Malaisei, Duponti, Mourloni, Crepini, incompla Briart et Cornet, d'après la Monographie de ces auteurs.

Eocene. - Nombreuses espèces aux trois niveaux du Bassin parisien: C. costulata Lamk. C. Thablola Bayan, C. diadema Watelet, C. cremulata, delecta, sepurala, denfifera Desh. C. Danieli, Cossmanni et multiensis Morlet, C. anırusta Wat, C. parnensis Cossm., etc., ma coll. ; quelques espèces dans le Bartonien d'Angleterre: C. nassieformis Wood, ma coll. Une espèce typipue dans l'Australie du Sud: C. epidromiformis Tate, ma coll.

Oligocene. - Plusieurs espèces dans le Stampien du bassin de Mayence: $C$. ringens Sandb., ma coll., C. Brauniana Nyst, coll. de l'Ecole des Mines; plusieurs espèces dans le Tongrien inférieur de l'Allemagne du Nord et de la Belgique : C. labratula, cgregia, harpa von Koen, C. granulata Nyst, d'après la Monographie de M. von Kónen; une espèce dans le Tongrien du Piémont: $C$. deperdita Mich.ti, d'après M. Sacco.

Mrocexe. - Une espèce dans le Tortonien de Saubrigues: C. cr. Uuccinulu Lamk., ma coll.

\section{PLESIOGERITHIUM, Gossmann, 1889.}

Plesiocerithum, sensustr. Type : Canc. Magloirei, Mell. Eoc.

Taille pelite; forme turriculée, cérithiale; spire assez longue, scaliforme, à galbe conique; protoconche lisse, globuleuse, à

(1) Cette dénomination fait double emploi avec l'espéce virante de Reeve; je propose donc de la remplacer par: U. Kaunhoweni nol. 
Plesiocerithium

nucléus petit et peu saillant; tours étagés par une rampe déclive au-dessus de la suture, ornés de carènes saillantes sur la partie antérieure, et de lamelles d'accroissement qui persistent seules sur la rampe inférieure, avec des nodosités à leur intersection; dernier tour court, orné comme la spire, à base un peu excavée, imperforée, sans aucune trace de bourrelet sur le cou, qui est à peu près droit.

Ouverture trapézoïdale, avec une gouttière dans l'angle inférieur, terminée en avant par un bec rétréci et échancré, à peine dévié vers l'extérieur ; labre mince, oblique, lisse ou légèrement lacinié à l'intérieur; columelle droite, ou à peine excavée, munie de trois plis obliques, les deux inférieurs s'enroulant jusque sur le cou, l'antérieur limitant le bec subcanaliculé; pas de bord columellaire.

Diagnose complétée d'après des échantillons de l'espèce-type, d'Aizy et de Sapicourt, dans le Suessonien (Pl. II, fig. 3), ma coll.

Rapp. et diff. - Quoique cette coquille ait une forme et une ornementation absolument différente de celles des autres $A d m e t i n x$, elle se rattache cependant à cette Sous-Famille par le peu d'épaisseur de son test, par l'absence de bourrelet et de bord columellaire, enfin par la disposition du pli antérieur, qui contourne le bec; mais elle est particulièrement caractérisée par le prolongement des deux plis inférieurs, qui continuent, sur le cou, comme des chaînettes faisant partie de l'ornementation de la base. Son ornementation cancellée et lamelleuse a plutôt de l'analogie avec celle de Cerithioderma Conr. (= Mesostoma Desh.); mais, outre que sa protoconche est beancoup plus globuleuse, les plis de sa columelle et l'échancrure de son bec antérieur ne permettent pas de pousser plus loin ce rapprochement.

Répart. stratigr.

Eocexe. - L'espèce-type, extrêmement rare, dans le Suessonien du Nord du bassin de Paris.

MASSLYA, H. et A. Adams, 1853.

Masslya, sensu stricto. Type : $\mu_{\text {. com }}$ comata, Hinds. Viv.

Taille au-dessous de la moyenne, forme étroite, fusoïde; spire courte. à galbe un peu conoïdal; protoconche lisse, globuleuse, à 
nucléus petil el peu saillant; tours convexes, séparés par des sutures peu profondes, ornés de rides axiales et de sillons spiraux, non variqueux; dernier tour très grand par rapport à la spire, ovale, alténuè à la base, qui est haute, imperforée, dépourvuc de bourrelet. Ouverture fusoïle, assez ćtroite, munie d'une gouttière anıuleuse à sa partie inférieure, terminée en avant par une large échancrure ou sinuosité basale, sans bec; labre presque droil lépaissi avec l'åge et costulé à l'intérieur]; columelle excavẻe en arc dans toute sa hauteur, infléchie à droite en avant, munie de deux plis très obliques et peu saillants, le troisième confondu avec la torsion columellaire antérieure; bord columellaire à peu près nul en arrière, étroit, à peine calleux vis-à-vis des plis.

Diagnose refaite (sauf les sept mots entre crochets qui ne s'appliquent pas), d'après un plésiotype du Tortonien de Saubrigues: C. Laurensi Grat. (Pl. II, fig. 13-14), ma coll.

Observ. - Ce n'est pas sans hésitation que je rapporte ce fossile à un Genre, qui ne m'est connu que par une figure, plus ou moins exactement reproduite dans le Manuel de Tryon; cependant les caractères sont à peu près identiques, et je suis confirné dans cette opinion par une interprétation analogue de M. Sacco, au sujet d'une autre espèce très voisine de mon plésiotype. Dans ces conditions, il eût été téméraire de proposer une dénomination nouvelle, avant d'être absolument sùr que ces formes fossiles s'écartent réellement de l'espèce vivante. Quant au classement du Genre Masslya, on voit, par la diagnose ci-dessus, que c'est une forme de la Sous-Famille Admetinx, qui diffère d'Admete par des caractères, importants il est vrai, mais qui s'en rapproche par le peu d'épaisseur du test et du bord columellaire, par l'absence d'un bourrelet basal, de sorte que le classement que je propose n’a rien d'anormal, malgré ces différences.

Rapp. et diff. - On distingue Masslya d'Admete: par sa faible échancrure basale, par sa columelle moins tordue, par la disparition du troisième pli antérieur; mais cest surtout de Coplostoma que Masslya se rapproche par sa forme générale; toutefois il s'en écarte complètement par la sinuosité du contour supérieur, au lieu d'une échancrure, et par l'absence d'une lamelle transverse à l'extrẻnité antérieure lle la columelle. Quant au rapprochement que $\mathbf{M}$. Sacco indique entre $C$. Laurensi et C. Dufouri, il me parait inadmissible, et il a dûtre causé par la défectıosité des figures de l'Atlas de Grateloup, que M. Saceo avait seulement 
à sa disposition; mais il suffit d'avoir les échantillons des deux espèces sous les yeux, pour se convaincre que $C$. Laurensi n'est pas le jeune âge de $C$. Dufouri, et que même ces deux coquilles appartiennent à deux Sous-Familles tout à fait distinctes.

Répart. stratigr.

Mrocexe. - Outre le plésiotype du Tortonien des Landes, ci-dessus décrit, et cité par M. von Kœnen dans le Langhien de l'Allemagne du Nord, par M. R. Hœrnes dans le Bassin de Vienne, une espèce dans l'Helvétien du Piémont: C. labrosa Bell., d'après la Monographie de M. Sacco.

Epoque actuelle. - L'espèce-type, rarissime, dans la baie de Guayaquil, d'après le Manuel de Tryon.

\section{RHACHIGLOSSA (Schizopoda)}

OLIVID E, d'Orbigny.

Coquille, lisse, polie, généralement étroite et allongée; spire assez courte, partiellement ou totalement recouverte par un vernis calleux, qui est le prolongement du bord columellaire; dernier tour grand, ovoïde, dont la surfacedorsale porte, le plus souvent, une zone médiane non vernissée, avec des lignes axiales d'accroissement; au-dessus de cette zone, existe toujours un épaississement calleux et verni. dénommé "limbe basal ", et formé par les accroissements de l'échancrure antérieure.

Ouverture souvent très étroite, munie en arrière d'une gouttière creusée dans la callosité columellaire et entaillant la sulure plus ou moins profondément; l'échancrure, qui tronque la partie antérieure de l'ouverture, est assez large, souvent très profonde, toujours épaissie sur son contour supérieur; labre assez épais, lisse à l'intérieur, presque vertical, rétrocurrent en arrière, souvent muni, sur son' contour, d'un denticule antérieur qui correspond à un sillon compris entre le limbe et la zone non vernissée; 
columelle tordue plus on moins obliquement, munie d'un bourrelet antérieur et spiral, qui porte souvent des plissements; le reste du bord columellaire est calleux, et quelquefois ridé en arrière; opercule non constant.

Observ. - Cette lamille est homogène; les coquilles que l'on y classe se distinguent par le vernis que sécrète leur mantean, sur toute la surface de la spire et sur la partie antérieure de la base; la torsion antérieure de la columelle est également caractéristique, bien différente des plis que l'on constate chez les Volutidx et les Marginellidie. Enfin le labre est toujours muni, en arrière, d'une sinuosité rétrocurrente, qui coïncide avec la suture.

La Famille Olividre est actuellement divisée en deux Sous-Familles: Olivinx et Ancillinx, selon que les sutures sont rainurées, ou qu'elles sont recouvertes par le vernis qui envahit toute la spire. Quant à la troisième division, indiquée dans le Manuel de 'Tryon (Harpinix), elle a été séparée, avec raison, par Troschel, comme une Famille distincte, que nous étudicrons après celle-ci.

L.es Olividx ne commencent guère à apparaitre, d'une manière absolument certaine, qu’à la partie tout à fait supérieure du Système crétacique, et leur développement va en croissant jusqu'à l'Lipoque actuelle.

Tableau des Genres, Sous-Genres et Sections.

\begin{tabular}{|c|c|c|c|}
\hline $\begin{array}{l}\text { OH_IVA } \\
\text { (Plis et } \\
\text { rides transverses } \\
\text { sur tout } \\
\text { le bord columellaire) } \\
\text { | }\end{array}$ & $\begin{array}{l}\text { Oliva } \\
\text { (Forme ovoildo- } \\
\text { cylindrique, } \\
\text { protoconche obtuse) }\end{array}$ & $\begin{array}{l}\text { Oliva } \\
\text { (Plis serrés, } \\
\quad \text { rides } \\
\text { nombreuses) } \\
\text { Neocylindrus } \\
\text { (Subcylindrique, } \\
\text { quatre plis) } \\
\text { Strephona } \\
\text { (Ovolie, } 3 \text { plis, } \\
\text { rides épaisses) } \\
\text { Carmione (A) } \\
\text { (Oroïle. } \\
\text { cote columellaire) } \\
\text { Galeolella (B) } \\
\text { (Spire recouverte. } \\
\text { plis ceartés) }\end{array}$ & $\begin{array}{l}\text { Olivino } \\
\text { (Sutures } \\
\text { rainurees) }\end{array}$ \\
\hline
\end{tabular}




\section{OLIVANCILLARIA Olivancillaria}

(Plis et rides obliques

sur tout Je bord colum.)

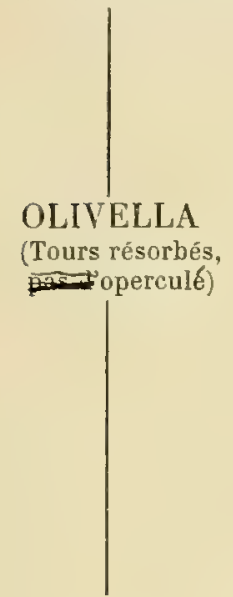

ANCILLA

(Columelle plissée)

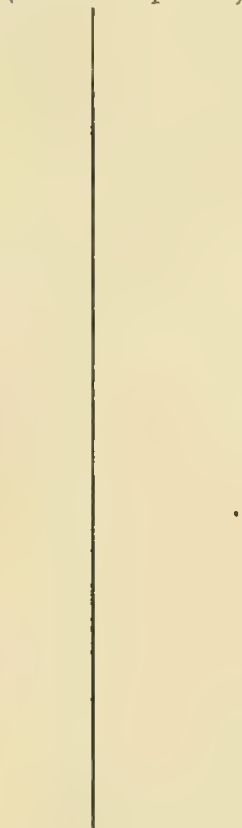

MONOPTYGMA

(Un gros pli médian)
(Forme ventrue,

protoconche globul.)

\section{Agaronia Agaronia \\ (Forme élancée, Columelle \\ protoconche excavée) \\ pointue) \\ Anazola (G) \\ (Columelle \\ bombée)}

\begin{tabular}{cl|c} 
Orrvata & Olivella & Olivin \\
(Columelle & (Plusieurs plis) & (Suite) \\
excavée, & Dactylidia & (Sutures \\
pas derides) & (Un pli et des & rainurées)
\end{tabular}

plissements

Callianax

(Un seul pli

large et bifide)

\section{LAMPRODONA}

(Columelle droite, rides)

$\begin{array}{ll}\text { Avciula } & \text { Ancilla } \\ \text { (Non ombiliquée, } & \text { (Pas dedenticule) } \\ \text { plis peu obliques) } & \text { Sparella } \\ & \text { (Denticule labial) } \\ & \text { Alocospira } \\ & \text { (Sillons spiraux) } \\ & \text { Baryspira } \\ & \text { (Sinus à la base } \\ & \text { delacolumelle) } \\ & \text { Ancillina } \\ & \text { (Plis effacés) }\end{array}$

\section{Eburna (D)}

(Ombiliquée)

Ghiloptygma (E)

(Dent pariétale)

Tortoliva

Tortoliva

Plis

très obliques, spire courte)

(Sutures visibles)

Sparellina

(Sutures invisibles)

Olivula

(Surtace ornée)

\section{Anaulacia (F)}

Cymbiforme,

pas de callosité

columellaire)
Ancillinæ

(Sutures comblées 


\section{Genres, Sous-Genres et Sections non signalés à l'état fossile.}

A. - Cammone, Gray, 1858. - Type: O. inflaln Lamk. Remarqualile par sa forme ovale, par sa spire courte, presque rétuse, avec une callosité très saillante, bordant la rainure suturale; le principal caractère est l'existence invariable d'une côte rugueuse, qư sépare la récrion des plis columellaires de celle des rides pariétales; en outre, le bord columellaire est très ètalé en avant, sur le limbe basal.

B. - Galeola, Gray, 18:8. - Type: O. cameola Lamk. Cette coquille, assez petite, se distingue par la callosité tecliforme qui recouvre sil spire, d'ailleurs trìs courte, de sorte que la rainure suturale ne fait qu'une seule circonvolution; trois plis columellaires, dont l'écartement augmente d'avant en arrière; bord columellaire peu calleux. Je ne connais pas d'autre espèce que le type, dans cette Section. Toutefois la dénomination Galeola, déjà employée par Klein, en 1734, ne peut être conservée; je propose done d'y substituer: Galeolella, nobis.

G. - Avazola, Gray, 18š8. - Type: O. acuminata Lamk. Par sa forme et par sa protoconche, cette Section se rapproche beaucoup plus du SousGenre Agaronia, que d'Olivancillaria s. s., comme l'a indiqué lïischer; elle se distingue, d'ailleurs, des denx par la courbure de son bord columellaire, qui ressemble plutôt à celle d'Oliva s. s.

D. - Eвurn, Lamk. 1801 (sensu primitivo, non Dipsaccus Klein). - Type: A. glabrala Lin. Forme d'Ancilla ventru, à columclle très excavée, dont le bord externe ne recouvre pas la fente ombilicale, largement ouverte jusque vers la partie inférieure de l'ouverture; de cet ombilic sortent: un bourrelet calleux, contigu à celui qui porte les plissements très obsoletes de la columelle; et un large limbe, bordé en dessous par une étroite rainure, à laquelle correspond un denticule labial. Fischer a fait remarquer que Lamarck, après avoir créé Eburna pour celte espèce, y a ajouté, en 1822, d'autres coquilles bucciniformes, et a ainsi recomposé exactement le Genre Dipsaccus Klein 175\%3), qui s'applique à ces dernières coquilles; il y a done lieu de conserver Ebu’na pour désigner la coquille ancilliforme.

E. - Сйoptrova, 11. et A. Adams, 1833. - Type: A. exigua Sow. Forme de Sparella, à test épais et vernissé, à spire courte et olivoïde, avec un petit bouton embryonnaire; l'ouverture est courte et assez. Iongue; la columelle porte un bourrelet, avec un ou deux plissements obliques et Irès obsolètes; mais le bord columellaire est muni, en arrière, d'une grosse dent pariélale, saillante et transverse, que les auteurs ont jusqu'i présent confondue avec un pli spiral. Je crois qu'il importe de rectifier cette erreur grave; on doit remarquer, en effet, que, par la position même qu'oceupe celte dent, à l'angle inférieur de l'ouverture, beaucoup plus bas que la columel!e, ce ne pourrait ètre tout au plus qu'un pli pariétal; mais, comme on pent le vérifier sur la figure que j'en donne (PI. III, 
fig. 19), cette protubérance ne s'enfonce pas en spirale dans l'ouverture: c'est donc bien une dent isolée. Dans ces conditions, il serait inadmissible de réunir Chiloptygma au Genre Monuptygma, comme l'a proposé Tryon ; ce dernier possède un véritable pli columellaire, tandis que Chiloptygma se rattache au Genre Ancilla, puisque c'est, en définitive, un Sparella auquel est ajoutée une dent pariétale.

F. - Axaulacia, Gray, 1847 (= Cymbancilla, Fischer 1881). - Type: A. mauritiana Desh. Forme de Cymba, à spire extrêmement courte et yernissée, à ouverture très ample; la columelle, tout à fait droite, ne porte qu'un seul plissement très oblique et très obsolète, sur un bourrelet peu saillant, séparé du limbe par une large dépression; il n'y a pas de callosité columellaire; l'échancrure basale se réduit ì une large troncature.

\section{Genre à éliminer de la Famille.}

Axcinlopsis. Conrad, 186å. - Type: A. aililis Conr. Eocène. Dans le "Check list " du "Smithsonian Institute ", Conrad a désigné sous ce nom plusieurs coquilles ( $A$. allitis, scamba, subgiobosa et tenera) classées dans la Famille Dactylidie (= Otividx). Le type de ce Genre, qu'il n'a pas caractérisé, est vraisemblablement la première de ces coquilles: A. altilis, qui est un Buccinanops absolument certain, d'après la comparaison que j'ai faite d'un excellent individu de celte espèce, que je possède de Claiborne. La seconde espèce ( $A$. scamba) a une forme d'Ancilla encore plus trompeuse, et cependant ses autres caractères sont exactement ceux des Bullia. Or l'animal de Buccinanops et de Bullia est complètement de la Famille Nassidx, et n'a aucun rapport avec celui des Ancillinx. La coquille elle-même présente des différences capitales, telles que la forme excavée de la columelle, qui ne porte jamais de pli ni de bourrelet tordu, ou la spire qui, dans la partie non recouverte par la callosité, porte une ornementation axiale, surtout visible vers le sommet, tandis qu'on n'en observe pas la moindre trace chez les Olividx. Il résulte de là qu'Ancillopsis est synonyme de Buccinanops ou de Bullia, el qu'il n'y a pas lieu del'admettre dans la Famille olivida.

OLIVA, Bruguière, 1789.

$$
\begin{gathered}
\text { (=Daclylus, Klein 1753;= Porphyria, Bolten 1798, non } \\
\text { Porpleyria, Briss. 1760; = Ispidula, Gray 1847). }
\end{gathered}
$$

Taille très variable, plutôt grande ou moyenne; forme ovoïdocylindrique; spire très courte, subulée; protoconche paucispirée, 
ghobulcuse, à nucléus obtus, non saillant; lours plans ou concaves, séparés par de profondes rainures, que borde une callosite spirale; base du dernier tour portant, en avant, un limbe calleux, divisé en plusieurs zones, et aboutissant à l'échancrure antérieure. Ouverture presque aussi haute que le dernier tour, très étroite ou linéaire en arrière, peu dilatée en avant, à bords souvent parallèles, cntaillée dans la rainure suturale, profondément et largement échancrée à la base; labre épais, lisse à l'intérieur, presque vertical, rétrocurrent au-dessus de la rainure suturale; columelle courte, oblique ou excavée; hord columellaire calleux, plissé ou ridé sur toute sa hauteur, les plis antérieur's correspondant généralement aux divisions du limbe basal.

\section{Type (auctorum): O. porphyria, Linné.}

Neocylindrus, Fischer, 1883. Type: O. tessellata, Lamk. Viv.

Forme subcylindrique; spire un peu acuminée; labre obtusément borlé à l'extérieur; columelle excavée, munie de trois plis principaux assez saillarts, minces, obliques, et de plissements accessoires; bord columellaire portant un certain nombre de rides courles, paralliles et transierses; limbe basal limité par une stric, avec un bourrelet très obtus, compris entre deux dépressions faiblement excavées, et correspondant aux accroissements de l'échancrure.

Diagnose faite d'après un plésiotype du Miocène des États-Unis: O. carolinensis Conr. (PI. II, fig. 20 et 21), ma coll.; autre plésiotype du Miocène de Mérignac: O. Dufresnei Bast. (PI. Il, fig. 30-31), ma coll.

Observ. - La synonymie du genre Oliva est très contestée; les auteurs qui, comme Fischer, ont fréquemment adopté des dénominations de Klein, quand elles sont correctement formées et binominales, proposent de reprendre Dactylus, quoique ce nom soit antérieur à l'édition-type de Linné, (qui, aux termes des règles fixées par les Congrès, sert de point 
Oliva

de départ à la nomenclature. Cependant Fischer lui-même conserve Oliva, ct il se borne à ajoutor à la fin que le Genre devrait plulôt porter le nom Dactylus; il a donc hésité, comme la grande majorité des conchyliologistes, à remplacer une dénomination universellement admise, par un nom exhumé, si je puis m'exprimer ainsi. Je suis cet exemple, et j'adopte Oliva, de préférence à Dactylus. Quant à. Bellardi, il a repris Porphyria, que je considère comme complètement synonyme d'Oliva, puisque l'espèceIype (O. textilina) ne diffère que par des caractères spécifiques de l'espèce considérée comme le type dı Genre Oliva; d'ailleurs il existait déjà, avant Bolten, un Genre Porphyrio chez les Oiseaux. Enfin, en ce qui concerne Ispidula Gray (qui devrait s'écrire Hispidula), j'ai vainement cherché par quels caractères, autres que la taille el l'ornementation, l'espèce-type (O. hispidula Lamk.) se distingue d'O. porphyria, et je déclare que si, comme espèces vivantes, il est possible de séparer ces deux coquilles, il est matériellement impossible d'y trouver des différences sectionnelles, surtout à l'état fossile.

Dans l'énumération des Sections que Fischer a admises dans le Genre Oliva, est indiquée une nouvelle coupe Neocylindrus, dont il a simplement désigné l'espèce-type; or il se trouve que c'est précisément à cette Section qu'il y a lieu de rapporter les espèces du Tertiaire supérieur, qui ne sont pas de véritables Oliva, tandis que les autres Sections, créées par Gray ou par Mörch, n'ont pas de représentants à l'état fossile, et ne se distinguent guère de la forme typique. J'ai comblé cette lacune en donnant ci-dessus une diagnose complète de Neocylindrus, qui n'avait pas encore été caractérisé d'une manière précise, et j'indique ci-après quelles sont les diflérences qui permettent de le séparer d'Oliva.

Rapp. et diff. - Neocylindrus se distingue d'Oliva par son galbe subeylindrique, par ses plis columellaires moins nombreux et plus saillants, au nombre de trois en général, anxquels s'ajoutent parfois, du côté antérieur, quelques plissements fins et serrés, tandis que, chez Oliva, tous ces plissements sont égaux, peu visibles et qu'on en compte cinq ou six au-dessus de la rainure qui limite la région columellaire antérieure; les rides pariétales, situées au-dessous de cette région, sont moins serrées et plus transverses chez Neocylindrus; d'autre part, le bord pariétal présente généralement, du côté postérieur, une légère dépression excavée. Enfin, tandis que le rebord calleux des tours de spire est contigu à la suture, chez Oliva et chez la plupart de ses autres Sections, il s'étale presque jusqu'à la moitié de la hauteur de chaque tour, chez Neocylindrus. Ce sont là des différences peu importantes, et susceptibles, tout au plus, de caractériser une Section, sans avoir même une valeur sous-générique; d'ailleurs Fischer lui-même n'a proposé Neocylindrus que comme Section d'Oliva.

Répart. stratigs.

Mocexe. - Les deux espéces plésiotypes ci-dessus figurées, dans le 
Langhien du Bordelais et dans la Caroline du Sud, ma coll.; la premiere existe aussi dans le Buldérien de Belgique, ma coll., dans l'Helvétien de la Touraine, d'après la liste préliminaire de MM. Dollfus et Dautzenberg, dans l'Helvétien de l'Anjou, coll. Dumas, dans l'Helvétien de la Vienne, coll. Courjault. Plusieurs espèces dans l'Helvétien du Piémont: Porphyria maryinata, sealaris, curta, picholina, cylindracea, malthata, longispina, inflata el fusiformis ('). Bell., ma coll. et d'après Bellardi. Une espéce dans les couches de Galveston (T'exas), rapportée par M. Gilbert Llarris à O. reticularis Lamk., d'après la figure de cet auteur.

Plioceri. - Une espèce actuelle dans les couches de la Floride : $O$. litterata Lamk., d'après $\mathrm{M}$. Dall qui y réunit d'ailleurs $O$. carolinensis du Miocène. Plusieurs espèces dans les couclies récentes de Java: O. sondiana, tricincla, tjaringinensis Martin, O. mfa. Duclos, d'après la Monographie de M. Martin. Une autre espece vivante, dans le gisement de la Martinique : O. veticularis Lamk., ma coll.; deux espèces actuelles dans les couches récentes de Karikal : O. irisans et mustelina Lamk., coll. Bonnet.

Epoque actuelle. - Nombreuses espèces dans les mers exolinues, d'après Fischer el d'après le Manuel de Tryon.

Strephora, Mörch, 1852. 'Type: O. flammulata, Lamk. Viv.

Taille moyenne; forme ovoide; spire courte, extraconique; protoconche globuleuse, polygyrée, à nucléus obtus sans saillie; tours plans, subulés, séparés par des sutures étroitement rainurées, sans callosité spirale apparente; limbe basal calleux, peu distinct à sa limite inférieure. Onverture rétrécie en arrière, un peu dilatée en avant, à bords non parallèles; labre médiocrement épais, non bordẻ, lisse à l'intérieur, vertical, rétrocurrent à la suture; columelle courte, à peine excavée, munie de trois plis épais, peu saillantic el souvent bifides; bord columellaire, mince, peu visible, muni de rides pariétales, larges, peu nombreuses, quelquefois bifides.

(1) Ces deux dernières espèces doivent changer de nom, pour cause de double emploi: a. la place d'o. inflala, je propose: 0 . Bellardii nob., et pour remplacer 0 . fusiformis: 0 . ceppiensis nab. 
Diagnose refaite d'après l'espèce-type vivante, fossile dans le Bassin de Vienne: O. flammulala, provenant de Lapugy (Pl. II, fig. 29), ma coll.

Rapp. et diff. - Celte section se distingue d'Oliva et de Neocylindrus, par ses plis et par ses rides moins nombreux et épais, généralement bifides, par sa callosité columellaire et juxtasuturale, peu épaisse, à peine visible; en outre, le galbe de la coquille est plus ovoïde que celui de Neocylindrus. La spire est plus allongée que celle de Camione, qui a d'ailleurs une callosité juxtasuturale beaucoup plus épaisse, et un bord columellaire très large. Malgré ces différences, Strephona n'est tout au plus qu'une Section du Genre Oriva. Ce n'est pas sans difficulté que j’ai réussi à grouper ces caractères distinctifs, qui n’ont jamais été signalés jusqu'à présent, pour justifier la conservation des dénominations eréées par Mörch ou par Gray, sur la simple désignation du type qu'ils avaient en vue.

Répart. stratigr.

Mucexe. - L'espèce-type dans le Tortonien de Lapugy, d'après M. R. Hœrnes [contestée par Bellardi, qui la réunit, à tort, avec Neocylindrus Dufresnei, tandis que j'ai vérifié que mon échantillon est identique à ceux vivant dans les Indes Occidentales]; la même espèce dans le Tortonien des Landes, coll. Dumas.

Pliocexe. - Une espèce de l'époque actuelle, dans les couches récentes de Java : O. austra?is Duclos, d'après la Monographie de M. Martin.

Epopue actuelle. - Plusieurs espèces aux Antilles et dans la mer des Indes, d'après le Manuel de Tryon.

OLIVANGILLARIA, d'Orbigny, 1839.

(=Utriculina, Gray 1847; = Claneophila, Gray 1858;

$=$ Lintricula, H. et A. Adams 1853; = Scaphula, Swains., non Benson, nec Mégerle).

Forme ventrue ou élancée; protoconche globuleuse ou pointue; spire plus ou moins courte, généralement subulée; sutures rainurées; limbe basal assez large; ouverture un peu dilatée, très largement échancrée à la base; labre mince. courbe, rétrocurrent à la suture; columelle tordue en avant, excavée au milieu, munie de plis très obliques et enroulés sur un bourrelet calleux, 
qui est hien distinct du limbe: rides pariétales obliques, souvent peu visibles.

Type: O. Braziliana, Lamk. Viv.

Agrronia, Gray, 1839.

Type: O. hiatula, Gm. Viv. (= Hialula, Swains. 1840, non Mod. 1793, nec Lacép. 1800.)

Taille assez grande; forme élancée, ovoïdo-conique; spire un peu allongée, subulée, pointue; protoconche petite, paucispirée, à nucléus arrondi et subdévié; sutures étroitement rainurées; lours un peu convexes en arrière, un peu excavés en avant, audessous de la callosité spirale qui borde la rainure suturale; demier tour ovale; limbe basal très large, calleux, avec un renflement médian très obsolète, qui correspond aux accroissements de l'échancrure. Ouverture rétrécie ell arrière, où elle se termine par une goutlière aiguë, dilatée en avant, et tronquée à la base par une échancrure largement arrondie et assez profonde; labre mince, non bordé, lisse à l'intérieur, presque vertical, un peu sinueux, légèrement proéminent au-dessous du point où aboutit le limbe, rétrocurrent sur la rainure suturale; columelle excavée, avec un large pli tordu à son extrémité antérieure, et cinq plissements beaucoup plus petits et très obliques, dans sa région médiane; enfin quelques rides pariétales non moins obliques et presque imperceptibles; loord columellaire peu distinct du limbe.

Diagnose refaite d'après des échantillons de l'espèce-type, et d'après un plésiotype du Miocène de Saucats; O. Basterolina I)efr. (Pl. II, lig. 21 et 23), ma coll.; autre plésiotype éocénique, du Bois Gouët, dans les environs de Nantes: O. Dubuissoni Vass. (I'I. II, fig. 22), ina coll.

Observ. - En ce qui concerne d'abord le Genre Olivancillaria, Utricula et Claneophila sont complètement synonymes; quant à Lintricula qui remplace Scaphula, déjà employé quatre fois en Ilistoire naturelle, Fischer indique comme type: 0 . vesica $\mathrm{Gm}$, probablement par suite d'une erreur 


\section{Olivancillaria}

typographique; or Tryon, dans son Manuel, n'a répertorié que $O$. vescita Gm., qu'il considère comme synonyme de 0 . auricularis Lamk., c'est-àdire d'une espèce extrêmement voisine d'O. Braziliana, qui est le type du Genre Olivancillaria; d'ailleurs, les caractères qu'indique Fischer, pour le Sous-Genre Lintricula, sont exactement ceux d'O. Braziliana, de sorte que le doute sur celte identité générique n'est pas possible, et que Lintricula doit tomber en synonyme d'Olivancillaria.

Quant à la dénomination Hiatula Swainson, outre qu'elle s'applique aux mêmes formes qu'Agaronia, - ce qui la rend superflue, - elle ne pourrait ètre conservée, Lacépède l'ayant, dès le siècle dernier, appliquée à un Genre de Poissons.

Rapp. et diff. - La séparation du Genre Olivancillaria, et particulièrement de son Sous-Genre Agaronia, est amplement justifiée.

Tout d'abord, si on compare Olivancillaria avec Oliva et avec ses Sections, on trouve : non seulement que la columelle est excavée et beaucoup plus obliquement plissée, que les rides pariétales y sont à peine indiquées, que l'ouverture est tout à fait différente, plus dilatée, et que l'échancrure basale est très large, moins profonde; mais encore, que le limbe basal est beaucoup plus large, et surtout que le labre a une saillie proéminente en avant, comparable à celle qui caractérise le Genre Olivella, et correspondant déjà à un indice d'existence d'une zone assez large, au-dessous du limbe, sur le milieu de la surface dorsale du dernier tour; cẹtte zone n'est pas nettement délimitée, mais elle est indiquée par le zigzag des stries d'accroissement. En résumé, Olivancillaria est comme le trait d'union entre Oliva et Olivella.

Si l'on compare maintenant Agaronia à Otivancullaric s. s., on remarque: non seulement une différence capitale dans la forme de la coquille, subglobuleuse chez $O$. Braziliana, élancée chez $A$. hialula; mais, en outre, une disposition tout autre de la protoconche, qui est bien plıs petite chez Agaronia; enfin la callosité juxtasuturale des tours de spire est moins forte que chez Olivancillaria, de sorte que le sommet de la spire n'a pas la même apparence d'un petit bouton en saillie sur un ellipsoïde, et que la spire est, au contraire, subulée et pointue.

\section{Répart. stratigr.}

Eocene. - Deux espèces bien caractérisées par l'obliquité de leurs plis, dans le Bassin de Nantes: O. Dubuissoni Vass. et O. oxyspira Cossm., ma coll. Une autre espèce dans le Claibornien des ÉtatsUnis : O. alabamiensis Conr., ma coll.

Mrocene. - Le plésiotype ci-dessus signalé, dans le Langhien du Bordelais, ma coll.; une espèce dans l'Ilelvétien de la Touraine: O. plicaria Lamk., coll. Dumas, détermination d'après la liste préliminaire de MM. Dolllus et Dautzenherg.

Phocene. - Une espèce vivante, dans les couches récentes de Java : 
Olivancillaria

O. subulata Lamk., et var. onlengensis Martin, d'après la Monographie de cet anteur.

Epopue acturcle. - Quelques espèces au Brésil, sur les côtes occidentales d'Afrique, et dans l'Australasie, d'après le Manuel de Tryon.

OLIVELLA, Swainson, 1835.

Taille moyenne ou assez petite; cloisons internes des tours résorbées; plis columellaires obliques; opercule ovale.

Olivelua, s. str. Néolype (sec. Ficher): O. jaspidea, Gm. Viv. (=Olivina, d'Orb.1839; = Micans,Gray. 1858).

Forme ovoïdo-conique; spire un peu allongée, aiguë, subulée; proloconche petite, subglohuleuse, pancispirée, à nucléus un peu dévié; tours non convexes, divisés en deux régions par la callosité vernissée qui borde la rainure juxtasuturale, et qui s'étend plus ou moins larçement, limitée en dessous par une faible dépression; limbe basal calleux, souvent assez large, partagé en deux zones, dont l'antérieure correspond aux accroissements de l'échancrure; au-dessous du limbe, la surface dorsale du dernier tour porte généralement une étroite bande moins vernissée, surtout chez les espèces fossiles, limitée par une ligne que forme la déviation coudée des accroissements du test, et qui aboutit à une sinuosité du labre.

Onverture très étroite en arrière, avec une gouttière profondément échancrée dans la suture, un peu dilatée en avant, et largement entaillée dans la callosité du limbe basal; labre presque vertical, proéminent en avant vis-à-vis du limbe, arrondi et rétrocurrent vers la suture; columelle excavée au-dessous des plis, qui sont au nombre de quatre ou cinq, un peu obliques, inégaux, prolongés sur le bord presque jusque sur la base; très rarement, des rides pariétales au-dessous de l'excavation de la 
columelle; bord columellaire quelquefois très calleux cn arrière, confondu en avant avec le limbe.

Diagnose complétée d'après des échantillons de l'espèce-type, et d'après un plésiotype de l'Eocène du Bois Gouët, dans le Bassin de Nantes: O. impressa Vass. (Pl. III, fig. 14-15), ma coll. Proto-conche grossie d'O. mitreola Lamk. (Fig. 7 ci-contre).

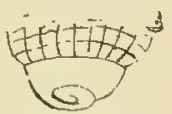

Frg.7.-Olicellamitreola, Lamk.

Observ. - Le type du Genre Olivella n'étant pas explicitement désigné par Swainson, je prends, à l'exemple de Fischer, comme néotype, O. jaspidea qui résume les caractères principaux de la diagnose, et qui est l'une des espèces les plus répandues; c'est d'ailleurs un groupe moins riche en espèces qu'Oliva, et quand on n'a pas la ressource de la coloration pour les distinguer les unes des autres, il est bien difficile de les séparer. La dénomination Olívina d'Orb. est citée par Fischer comme synonyme d'Olivella; Tryon n'en fait même pas mention, et Zittel l'indique comme Section d'Olivella, en l'attribuant à Mörch. Je n'ai pas davantage les éléments nécessaires pour contrôler la synonymie de Micans Gray ; c'est d'ailleurs un simple adjectif que je vois, avec satisfaction, disparaître de la nomenclature.

Rapp. et diff. - Les véritables caractères différentiels, qui justifient la séparation du Genre Olivella, sont d'une constatation très difficile pour les paléontologistes : l'anatomie de l'animal, la résorption des cloisons internes, et l'existence d'un opercule. Cependant, à défaut de ces caractères, on peut encore se guider d'après des indices moins constants, moins nets : d'abord l'excavation de la columelle au-dessous des plis antérieurs, et l'absence de rides sur la région pariétale; ensuite l'existence d'une zone moins brillante que le reste de la surface, au-dessous du limbe basal, zone dont le Genre Olivancillaria porte déjà la trace; enfin la spire est généralement plus allongée que celle d'Otiva.

Si l'on compare Olivella avec Olivarcillaria, qui a aussi une spire allongée, une columelle excavée et une zone dorsale faiblement indiquée, on remarque qu'Olivella a, en général, l'ouverture moins dilatée en avant, et surtout que les plis columellaires sont beaucoup moins obliques, moins tranchants et moins écartés, mais plus nombreux que ceux d'Olivancillaria.

Répart. stratigr.

Senonien. - Une espèce dans les couches crétaciques supérieures de Fort-Téjon: O. Matherosoni Gabb., d'après la figure de la Paléontologie de la Californie. 


\section{Olivella}

Phleocene. - Une espèce très élancée, dans le Calcaire de Mons: O. acula Br. et Corn., ma coll.

Eocrane. - Plusients espèces bien caractérisées, dans le Bassin de Paris : O. Laumonti et mitreola Lamk., O. micans et nitidula Desh., O. Marmini Mich., ma coll.; dans le Bassin de Nantes: O. impressa et gibbosula Vass., ma coll.; dans le Vicentin: O. Juliellx de Gregorio, d'après la figure donnée par l'auteur. Une espèce dans le Claibornien de l'Alabama: O. bombylis Conr., ma coll.

Olicocese. - Une espèce rapportée à $O$. mitreola, mais probablement différente, dans le Tongrien inférieur de l'Allemagne du Nord, d'après la Monographie de M. von Koenen; autre espèce dans le Stampien du Bassin de Paris et à Gaas (Landes) : O. Prestroichi Mayer, d'après MM. Cossmann et Lambert. Une espèce bien caractérisée, dans les couches de San Gonini (Vicentin) : O. requalis Fuchs, d'après la figure donnce par cet auteur.

Mrocene. - Une espèce dans le Langhien du Bordelais: O. Graleloupi d'Orb., ma coll.; plusieurs espéces dans l'Helvétien des environs de Turin : $O$. crassimegosa, lumida Bell., d'après la Monographie de Bellardi. Une espèce dans l'Australie du Sud: 0 . mymphalis Tate, ma coll. Une espèce dans les couches de Galveston: O. subtexana Harr., d'après la figure donnée par M. Gilbert IIarris.

Plrocexe. - Une espèce voisine de $O$. nivea Gm., dans les couches récentes de la Martinique, ma coll.

Epoque actuelle, - Nombreuses espèces aux Indes occidentales, dans les mers de Chine et en Australie, d'après le Manuel de Tryon.

Dactylioia, H. et A.Adams, 1853. Type: O. mutica, Say. Viv.

Taille petite; forme ventrue; spire courte, conique; tours plans, subulés; limbe basal peu larece. ()uverture courte, a bords presque parallèles, largement échancrée à la base; labre mince, à contour un peu convexe, à peine rétrocurrent vers la suture; columelle un peu excavée, fortement tordue en avant par un pli très saillant, au-dessous duquel il y a des plissements obliques et peu visibles, assez serrés; callosité columellaire très épaisse, s'étendant en arrière sur toute la surface de l'avant-dernier tour, appliquée en avant sur le limbe. 
Diagnose faite d'après un échantillon de l'espèce-type, provenant des côtes de la Caroline du Nord (Pl. II, fig. 2气-26), ma coll.

Rapp. et diff. - On peut, à la rigueur, admettre cette Section comme distincte d'Olivella, à cause de son pli antérieur tordu, et de la forte callosité qui recouvre toute la hauteur des tours de spire; en outre, le labre a une disposition un peu différente, et on n'aperçoit pas de zone moins vernissée sur la surface dorsale. A défaut de plésiotype foșsile, j’ai fait figurer un échantillon de l'espèce vivante, qui est d'ailleurs peu connue.

\section{Répart. stratigr.}

Mrocese. - L'espèce-type dans les couches de Saint-Domingue et de la Caroline du Nord (sub. nom. O. duplicala Conr.), d'après Gabb et d'après la Monographie de M. Dall sur la Floride.

Pliocexe. - La même espèce dans les couches de Caloosahatchie (Floride), d'après M. Dall.

Epoque actuelle. - Plusieurs espèces sur les côtes d'Amérique, d'après le Manuel de Tryon.

Gallianax, H. et A. Adams, 1853.

Type: O. biplicata, Sow. Viv.

Taille moyenne; forme ovoïde, ventrue; spire assez courte, à galbe conique; protoconche petite, obtuse; tours plans, séparćs par des rainures étroites et très profondes, presque complètement recouverts par la callosité spirale; dernier tour très grand, renflé en arrière, ovalement atténué à la base, qui porte un limbe assez large et limité par un sillon oblique. Ouverture assez grande, très étroite en arrière, dilatée au milieu, et profondément échancrée à la base; labre vertical, arrondi en quart de cercle et rétrocurrent vers la suture; columelle tordue en avant par un large pli bifide, entièrement dénuée de rides ou de plissements, dans la partie excavée qui est située au-dessous de ce double pli ; callosité columellaire souvent très épaisse en arrière.

Diagnose refaite d'après le type vivant, et d'après un plésiotype de l'Eocène de Barton: O. Brunderi Sow. (Pl. II, fig. 27), ma coll.

Rapp. et diff. - Celle Section se distingue d'Olivella par sa forme 
ventrue, par son mique pli bifide, sans rides ui plissements au-dessous de lui, par son ouverture plus large, et par sa callosité columellaire qui recouvre une plus grande largeur des tours de spire. Si on la compare à Dactylidia, qui a aussi une forme ventrue et une très forte callosité columellaire, on remarque immédiatement qu'elle s'en distingue par son pli bifide et par l'absence d'autres plissements.

Répart. stratigr.

Eocexe. - Le plésiotype ci-dessus figuré, dans le Bassin angloparisien, ma coll.

Mrocexe. - Une espèce douteuse dans l'Helvétien des environs de Turin : O. olliquata, Bell., ma coll.

Phocene. - Une espèce dans les conches à silex de Tampa (Floride): O. lata Dall, d'après la Monographie de cet auteur.

Epope actuelle. - Deux espèces: l'une (le type) su les côtes de Californie; l'autre en l'atagonie, d'après le Manuel de Tryon.

Lampronoma, Swainson, 1835. Type: 0 . volutella, Lamk. Viv.

$$
\text { (= Ramola, Gray 1858). }
$$

Taille au-dessous de la moyenne; forme assez étroite, cylindracée, peu atténuée en avant; spire un peu allongée, subulée, à galbe parfaitement conique; protoconche subglobuleuse, paucispirée, à nucléus très obtus, plus petite chez le type vivanl que chez les plésiotypes fossiles, la disproportion entre l'embryon et la spire, décroissant à mesure que l'on se rapproche de l'Epoque actuelle, à partir de l'Eocène; tours plans, séparés par de profondes rainures, presque totalement recouverts par la callosité spirale, qui est peu épaisse; dernier tou grand, non ventru, à peine plus étroit à la base qu'en arrière; limbe calleux, divisé par un sillon en deux zones inégales, sans région non velnissée audessous de lui.

Ouverture longue, étroite, très anguleuse en arrière, à peine dilatée en avant, où elle est largement et profondément échancrée; labre mince, à contour un peu incliné à droite de l'axe du côlé antérieur, rétrocurrent vers la suture; columelle faiblement et 
Olivella

obliquement tordue à la base, non excavée au milieu, à peu près rectiligne dans son ensemble, munie, vis-à-vis le limbe, de cinq à huit plis égaux, équidistants, très obliques, médiocrement saillants, et au dessous, de rides pariétales souvent peu visibles; bord columellaire très mince, à peine plus épaissi dans l'angle inférieur de l'ouverture.

Diagnose faite d'après le type vivant et d'après un plésiotype du Miocène de Dax: O. subclavula d'Orb. (PI. II, fig. 28), ma coll.

Rapp. et diff. - Par ses plis et ses rides columellaires, aussi bien que par l'absence d'une zone non vernissée sous le limbe, ce Sous-Genre se rapproche plus des véritables Oliva que, d'Olivella, avec lequel il n'a de rapports que par sa forme élancée et par sa spire allongée. Fischer en fait une Section d'Olivella, tandis que Tryon le place au début des Olina, comme une forme intermédiaire entre les deux Genres; on ne sera complètement fixé que quand on aura vérilié si les cloisons intemes des tours se résorbent, et si l'animal possède un opercule, comme il en existe chez Olivella. Lamprodoma n'est d'ailleurs représenté, à chaque niveau, que par un très pelit nombre de lormes.

\section{Répart. stratigr.}

Eocexe. - Une espèce dans l'Australie du Sud : 0 . angustala Tate, ma coll. (V'ue de l'embryon grossi, Fig. 8 cicontre ; autre espece dans les conclues nummulitiques de la chaine d'Hala (Inde): O. pupa Sow., d'après la Monographie de d'Archiac et Haime.

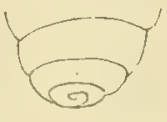

Oligocexe. - Une espèce bien caractérisée dans le Fig 8. - LamproVickshurgien des Etats-Unis: O. mississipiensis rloma angustatu, Conr., ma coll.; une espèce douteuse dans le ViTate. centin: O. Zilleli Fuchs, d'après la figure publiée par l'auteur, qui indique que la columelle n'est pas ridée (?).

Mrockxe. - L'espèce plésiotype ci dessus figurée, dans le Langhien du Bordelais, ma coll.; dans le Tortonien de l'Italie, d'après Bellardi; Jans le Bassin de Vienne, d'après la Monographie de MM. R. Hornes et Auinger (toutefois cette dernière provenance est contestée par Bellardi). Une espèce dans les couches ce Galveston: O. galveslonensis Harr., d'après la diagnose et la figure données par M. Gilbert Ilarris.

Pt.rocrax. - Une espèce incertaine dans les couches récentes de la Nouvelle-Zélande: 0 . neozelandica Hulton, d'après la description publiée par cet auteur.

Epopue actuelze - L'espèce-type dans les Antilles, ma coll. 


\section{ANGILLA, Lamarck, 1799. \\ (=Anaulax Roisy 1805; = Ancillaria Lamk. 1811; \\ - = Ancillus Montf. 1810.)}

Sutures recouvertes par un émail vernissé, qui cache généralement toute la spire; limbe basal calleux et luisant, correspondant aux accroissements de l'échancrure; zone dorsale non vernissée, plus ou moins large. Ouverture plus ou moins dilatée, ordinairement tronquée par une large échancrure basale; labre peu convexe, rétrocurrent vers la suture; columelle fortement tordue, plissée en avant, excavée au milieu ; bord columellaire très calleux, surtout en arrière.

Ancilla, s. restr. [Cossm.] Néotype: A. buccinoides, Lk. Eoc. (= Amalda H. et A. Adams 1853; = Sandella, Gray 1857.)

- Taille grande; forme ovoïdo-conique; spire assez longue, pointue, subulée; protoconche petite, globuleuse, paucispirée, à nucléus obtus et dévié; tours non convexes, à sutures indiquées, sous le vernis qui les recouvre, par une dépression plus ou moins visible, parfois très profondément excavée; sur l'avant-deruier tour et le dernier tour, la callosité vernissée est limitée par un sillon, qui forme une suture artificielle, à quelque distance de la dépression suturale; dernier tour grand, ovoïde, plus ou moins ventru, avec une large zone non vernissée qui est plus visible chez les échantillons fossiles que sur leurs congénères de l'Epoque actuelle, atténué ou même étranglé à la base qui porte un limbe très calleux, assez large, divisé par un sillon médian aboutissant au milieu et au bas de l'échancrure.

Ouverture à peu près égale à la moitié de la hauteur tolale, entaillée en arrière dans le vernis calleux qui recouvre la suture, 
largement échancrée à la base par un profond sinus, muni d'un rebord en biseau; labre mince à son contour, lisse à l'intérieur, à peu près vertical, un pelı convexe, arrondi en avant, sinueux et un peu rétrocurrent en arrière; columelle droite, coudée à sa jonction avec la base de l'avant-dernier tour, très brièvement tordue à son extrẻmité antérieure, portant en avant quatre ou cinq plis obliques, égaux et peu saillants; bord columellaire épais, peu étalé sur la base, cachant les plis antérieurs dans l'intérieur de l'ouverture.

Diagnose refaite d'après un échantillon du néotype, du Calcaire grossier de Villiers (Pl. III, fig. ö-6), ma coll.

Observ. - Ainsi que l'a indiqué Fischer, dans son Manuel, la dénomination Ancilla, qui ne fait nullement double emploi avec Ancylus, doit être conservée, de préférence à Ancillaria, comme étant la première en date; d'ailleurs, si le double emploi eût réellement existé, la correction Ancillaria, faite par Lamarck en 1811, n'aurait pu être admise, puisque Anaulax est antérieur et que ce nom s'applique effectivement à la même coquille; il en est de même pour Ancillus, qui n'est, au surplus, que le terme masculin d'Ancilla.

En ce qui concerne le choix du type de ce Genre, il y a une incertitude complète, motivée en partie par l'élimination successive des espèces qui ont été ultérieurement prises comme types de Sous-Genres ou de Sections par d'autres auteurs. Fischer n'indique, dans son Manuel, aucune espèce vivante pour Ancilla s. s., et il se borne à citer comme exemple fossile: A. subulata Lamk., qui est simplement une variété d'A. buccinoides, dans les sables du Suessonien. Dans le "Nanuel of Conchology " de Tryon, la première espèce citée est : A. cinnamomea Lamk., dont l'une des variétés est précisément $A$. ventricosa Lamk., c'est-à-dire le type de la section Sparella qui, comme on le verra ci-après, présente des caractères distinctifs suffisants. Dans ces conditions, comme rien ne prouve que Lamarck n'ait pas eu effectivement en vue la forme fossile, quand il a créé le Genre Ancilla, il n'y a pas d'obstacle à ce que l'on admette désormais, comme néotype, $A$. buccinoides, espèce caractéristique et bien connue, du Calcaire grossier des environs de Paris, la plus ancienne, en date, des Ancilla éocéniques.

Cela posé, il suffit de rattacher à ce néotype celles des espèces vivantes qui ont la même forme et qui présentent les mêmes caractères génériques, c'est-à-dire principalement: A. Tankervillei Sow. que II. et A. Adams ont précisément pris pour type de leur Genre Amalda, et que Gray a 
Ancilla

choisi comme type de son Genre Sandella; il n'y a, en eflet, entre celte coquille et $A$. buccinoides, d'antres différences que dans l'excavation un peu plus profonde qui indique la position des sutures sous le vernis calleux. Ces deux dénominations doivent done être considérées comme synonymes d'Ancilla (sensu restricto).

Rapp. et diff. - Comparé aux Olivinie, Ancilla s'en distingue surtout par ses sutures que comble le vernis dont est recouverte toute la spire, sauf la zone dorsale du dernier tour; le labre est moins profondément rétrocurrent en arrière; enfin le limbe basal est divisé par un sillon, au lieu d'un bourrelet.

\section{Répart. stratigr.}

Senonien. - Il y a lieu d'éliminer A. crelacea Müller, qui, d'aprés la Monographie de M. Holzapfel sur la Craie d'Aix-la-Chapelle, ne provient pas d'un gisement crélacique. Quant à A. elongala(') Gabb, du Crétacé supérieur de la Californie, c'est un moule interne; mais Gabb affirme que la contre-empreinte a bien les caractères superficiels des Ancilla, et notamment, que les sutures y sont oblitérées; ce serait donc un ancêtre d'A. buccinoides.

Paleocene. - Une espéce confondue avec A. buecinoides, mais probablement nouvelle, dans le Calcaire de Mons, d'après Briart et Cornet.

EOCENe. - Outre le néotype, trois espèces dans le Bassin de l'aris : A. Lamarcki, obesula, glandina Desh., ma coll.; autre espèce voisine d'A. buccinoides, dans le Vicentin: A. pinoides de Greg. (à l'exclusion des variétés qui sont bien distinctes), d'après la Monographie de $M$. de Gregorio. Une espèce très étroite, dans l'Australie du Sud: A. lanceolata Tate, ma coll.

Uligocsie. - Une espece confondue avec 1. buccinoidles, mais vraisemblablement distincte, dans les couches de Ileadon et de Brockenhurst, en Angleterre, ma coll.

Mrocene. - Une espèce de petite taille, dans l'Helvétien du Piémont: A. Sismontiana d'Orb. ma coll.

P’hocene. - Une grande espéce dans les couches récentes de Java : A. Vernedei Sow., d'après la Monographie de M. Martin.

Épove acterles. - Deux ou trois espèces, dans les Indes occidentales, les mers de Chine, l'Australie et l'Océan Indien, d'après lo Manuel de Tryon.

(1) Quel rue soit le Genre anquel appartient réllement ce fossile, il ne peut itre conservé avec le nom elongala, qui avait été employé, dès 1847, par Michelolli; je propose, pour le remplacer : A. Gabbi, nobis. 
Sparflla, Gray, 1857.

Type : A. ventricosa, Lamk. Viv.

Taille moyenne; forme ventrue ou olivoïde; spire très courte, subulée, conoïde, souvent mucronée à la pointe, par la saillie de la protoconche paucispirée, dont le nucléus est terminé en goutte de suif ; tours complètement recouverts par la callosité vernissée, à sutures indistinctes; dernier tour très grand, ovale, atténué en avant, non vernissé sur les deux tiers environ de sa surface dorsale; entre cette zone terne et le limbe basal, qui est calleux et luisant, s'étend une bande étroite, encore plus terne, encadrée par deux sillons superficiels, qui correspondent à une double inflexion des stries d'accroissement.

Ouverture peu élevée, assez large, rétrécie dans l'angle inférieur, terminée en avant par une très large et peu profonde échancrure; labre à peu près vertical et rectiligne, peu rélrocurrent en arrière, portant invariablement un denticule antérieur, auquel aboutit l'un des deux sillons de la surface dorsale; columelle excavée, très obliquement tordue à la base, avec cinq ou six plissements obliques, souvent très obsolètes; bord columellaire assez mince en avant, calleux, et largement étalé du côté postérieur, envahissant toute la spire, jusqu'à une faible distance du sommet.

Diagnose faite d'après trois plésiotypes fossiles: $A$. dubia Desh. (Pl. III, fig. 7), de l'Eocène moyen de Villiers; A. aperta Vasseur (Pl. III, fig. 12), du Bois Gouët près de Nantes; $A$. obsoleta Br. (PI. III, fig. 13), du Miocène supérieur de Saubrigues; tous les trois de ma collection.

Rapp. et diff. - Outre la formo générale, qui est différente, et la callosité columellaire, qui est beaucoup plus épaisse en arrière, el qui comble plus complitement les sutures, Sparella se distingue surtout par l'existence d'un denticule à la partie antérieure du labre, tandis qu'il n'y a aucune saillie sur le contour du labre d'Ancilla s. $s$. Ce denticule correspond à l'étroite bande comprise entre le limbe ct la zone non vernissée, bande qui n'existe jamais chez $A$. buccinoides, ni chez ses congénères. Toutefois ces différences, malgré leur constance, ne méritent pas, à mon avis, qu'on attribue 
à Sparella plus que la valeur d'une Section démembrée aux dépens du Genre principal.

Répart. stratigr.

Paleocexe. - Une espèce à bande et à denticules bien visibles, dans les couches de Copenhague: A. flexuosa von Ḱœnen, d'apres la ligure donnée par cet auteur.

Eocene. - Outre les deux plésiotypes ci-dessus figurés, plusieurs autres espèces dans le Bassin de Paris: A. olivula Lamk., A. arenaria Cossm., ma coll,; dans le Bassin de Nantes: A. Ripaudi et Douvillei Vass., ma coll.; dans le Bartonien d'Angleterre: A. fusiformis Dixon, ma coll. Deux espèces dans les couches nummulitiques des environs de Pau : A. spissa et nana A. Rouault, d'après les figures données par cet auteur. Plusieurs espèces dans l'Australie du Sud: A. pseuclaustralis et ligata Tate, A. Hebera Ilutton, ma coll. Dans le Midway-stage des Etats-Unis: A. mediavia Gill. Harris, ma coll.

Oligocene. - Une espèce non figurée, dans le Piémont: A. ligustica Bell. d'après la Monographie de Bellardi. Plusieurs espèces dans le 'I'ongrien inférieur de l'Allemagne du Nord: A. intermedia, obovala, unguiculata von Kœnen, d'après les figures données par l'auteur; dans les couches de Cassel : A. Karsteni Beyr., ma coll.

Mrocene. - Outre le plésiotype ci-dessus figuré, - qui est répandu : dans le Tortonien des Landes, de la Bretagne, d'Italie, du Bassin de Vienne, ainsi que dans l'Ilelvétien de la Touraine, ma coll., dans l'Allemagne du Nord et à Edeghem, d'après M. von Kionen, - il y a lieu de signaler encore - une espèce dans le Bassin de Vienne : A. Austriaca R. Ilorn., d'après la Monographie de MII. Ilornes et Auinger; une autre espèce dans l'Helvétien du Piémont: A. Soncerbyi Mich. d'après la Monographie de Bellardi. Une espèce douteuse dans les couches à silex de la Floride : $A$. Shepardi Dall, d'aprís la figure donnée par l'auteur.

Pliocene. - Une espèce vivante et typique dans les conches de Karikal : A. cinnamomea Lamk., coll. Bonnet; la même dans les couches récentes de Java, d'après la Monographie de M. Martin.

Lipoque actuelle, - Plusieurs espèces ou variétés du type, dans la mer Rouge, le golfe Persique, la Polynésie, etc., d'après le Manuel de Tryon.

Alocospira, nov. sect. Type : A. papillata, Tate. Mioc.

Taille moyenne; forme olivoïde, un peu ventrue; spire peu allongée, à galbe conoïdal, incomplètement recouverte par une 
Ancilla

callosité assez mince, qui s'étend à peine au-delà de l'axe de la coquille; protoconche formant un minuscule bouton saillant; tours de spire subulés, séparés par une dépression peu profonde qui indique la position des sutures sous le vernis, et ornés de sillons spiraux plus ou moins obsolètes, qui séparent des cordonnets peu saillants; dernier tour ovale, régulièrement atténué en avant, non sillonné au-dessus de la limite du vernis, avec une zone non vernissée assez haute; une profonde rainure encadrée de deux stries sépare celte zone du limbe basal, qui est lui-même divisé en deux régions par une dépression bien marquée, correspondant aux accroissements de l'échancrure.

Ouverture peu dilatée, ovale au milieu, anguleuse en arrière, tronquée en avant par une échancrure large et peu profonde; labre mince, presque droit, avec un denticule vis-à-vis du sillon inférieur au limbe; columelle un peu excavée en courbe régulière, tronquée en avant, près de l'échancrure, portant quatre plis obliques, inégaux et inéquidistants, le postérieur plus épais et plus écarté; bord columellaire mince et peu calleux, sur lequel se prolongent parfois quelques-uns des sillons de la spire.

Diagnose établie d'après des échantillons de l'espèce-type, du Tertiaire supérieur de l'Australie du Sud (Pl. III, fig. 8-9), ma coll.

Rapp. et diff. - J'ai hésité à séparer cette nouvelle Section de sparella, précisément au mornent où je réunissais ensemble plusieurs des coupes antérieurement proposées, et insuffisamment caractérisées à mon avis; cependant Alocospira se distingue par des différences sectionnelles tellement nettes et constantes, que je ne puis considérer les coquilles de ce groupe comme de véritables Sparella: d'abord la faible épaisseur de la callosité du bord de l'ouverture, ensuite l'ornementation spirale et tout à fait anormale de la spire, enfin la petitesse de la protoconche. Comparé à Ancilla s. s., Alocospira s'en écarte, non seulement par ces caractères, mais en outre, par l'existence d'un sillon bien rainuré sous le limbe basal, et d'un denticule correspondant sur le contour du labre, par l'excavation plus l'égulière de la columelle, par ses plissements moins égaux. Ainsi qu'on le verra ci-dessous, Alocospira est une forme exclusivement australasienne. 
Répart. stratigr.

Eocrse. - Uneespice assez étroite, dans l'Australie du Sud: $\Lambda$. sublevis, T. Noorls, ma coll.

Mrocene. - L'espèce-type dans l'Australie du Sud, ma coll.

Phocise. - Une espèce parfaitement caractérisée, dans les conches récentes de Java: $\boldsymbol{A}$. Junghuhni Martin, d'après la figure donnée par cet auteur.

Epoque actuelle. - Une espèce et ses variétés, dans les mers de l'Australie: A. marginata Lamk., ma coll., et d'après le Manuel de Tryon.

Baryspira, Fischer, 1883. Type: A. australis, Sow. Viv.

Taille assez grande; forme très ventrue, variable selon l'âge de la coquille, presque toujours anguleuse en arrière; spire assez courte, à galbe conique à partir de l'angle postérieur; protoconche très petite et pointue; tours entièrement recouverts par une épaisse callosité vernissée, qui ne laisse aucune trace des sutures; dernier lour ovoïdo-cylindrique, très alténué en avant, en partie recouvert par le vernis, et ne portant qu'une étroite zone non vernissée, séparée par un large sillon du limbe basal et calleux, qui est divisé en deux régions par une strie accompagnée d'une dépression.

Ouverture à peine supérieure à la moitié de la longueur totale, dilatée au milieu, rétrécie à ses deux extrémités, avec une double gouttière obsolète dans l'angle inférieur, terminée en avant par une profonde échancrure; labre presque vertical, muni d'un cran antérieur qui correspond au sillon sous le limbe, légèrement sinueux et rétrocurrent vers la suture; columelle largement Axcavée en arc de cercle, se terminant en avant bien en deçà de l'extrémité de l'ouverture, sur le bord d'un sinus creusé dans l'épaisseur d'un bourrelet; ce dernier est plissé dans le jeune âge, à peu près lisse chez les individus adultes, et séparé, par une profonde dépression, d'une arête assez saillante limitant la région ombilicale d'où sort le limbe basal. 
Ancilla

Diagnose complétée d'après des échantillons d'un plésiotype du Mliocène : $A$. glandiformis Lamk., du Burdigalien de Saucats (Pl. III, fig. 1, 2), du Tortonien de Saubrigues (Pl. III, fig. 3), de l'Helvétien de Bossée (Pl. III, fig. 4), tous les trois de ma collection.

Rapp. et diff. - Cette Section se distingue des formes précédentes par des caractères beaucoup plus tranchés, non seulement par son galbe ventru, anguleux en arrière, rétréci du côté antérieur, et par l'épaisse callosité qui recouvre toute la spire, mais encore par sa columelle arquée, et surtout par le sinus qui existe à l'extrémité du bourrelet colımellaire, à la place où, chez Sparella, il n'existe qu'une troncature oblique; enfin, la faible largeur de la zone non vernissée sur la face dorsale, le dédoublement de la gouttière postérieure de l'ouverture, le faible sinus rétrocurrent du labre, complètent l'ensemble des caractères différentiels qui justifient la création proposée par Fischer; j'ai d'ailleurs choisi, comme type, la première des deux espèces qu'il cite, dans son Manuel, à titre d'exemple de la section Baryspira. Toutefois ce n'est, à mon avis, qu'une Section d'Ancilla; car il y a des espèces qui, avant d'avoir alteint la taille adulte, se rapprochent beaucoup de Sparella, et qu'on ne peut en séparer qu'à la condition d'examiner de très près les caractères distinctifs dont il vient d'être question.

\section{Répart. stratigr.}

Oligocexe. - Une espèce dans le Tongrien des Landes: A. subinflata d'Orb., ma coll.; une autre espèce dans le Vicentin: A. anomala Schl., ma coll.

Mrocene. - L'espèce plésiotype ci-dessus figurée, avec de nombreuses variétés, répandue dans presque toute l'Europe, ma coll.; une autre espèce moins ventrue, dans l'Helvétien et le Tortonien du Piémont : A. patula Doderl., d'après la Monographie de Bellardi; variété coniforme, peut-être distincte, dans l'Helvétien de la Touraine (Pl. III, fig. 4), ma coll.

Pliocene. - L'espèce-type dans les couches récentes de Java, d'après la Monographie de M. Martin, et dans les dépôts de la NouvelleZélande, d'après M. Hutton.

Epoque actuelle. - Plusieurs espèces voisines ou variétés du type, dans les mers d'Australie, et au cap de Bonne-Espérance, d'après le Manuel de Tryon.

Ancillina, Bellardi, 1882. Type:A. pusilla, Fuchs. Mioc.

Taille très petite; forme étroite, subulée; spire un peu allongée, à galbe conoïdal, surlout au sommet, recouverte par une callosité 
vernissée; protoconche un peu étagrée, à nucléus petit et saillaut; tours croissant rapidement, à sutures à peine indiquées sous le vernis; dernier lour très grand, ovoïdo-conique, arrondi à la base, avec une zone non vernissée qui s'étend sur la moitié environ de sa hauteur; une fine rainure la sépare du limbe basal, qui est calleux et divisé en deux régions très inégales. Ouverture très courte, ovale, peu anguleuse et dépourvue de gouttière postérieure, dilatée en avant et tronquée par une échancrure basale peu profonde ; labre mince, droit, à peine rétrocurrent sur la suture; columelle faiblernent excavée, très obliquement tordue à son extrémité antérieure, munie d'un bourrelet étroit et aplati, qui ne paraît porter aucune trace de plissements; bord columellaire assez large, calleux, surtout dans l'angle inférieur, où la callosité s'étend jusqu'à la moitié de l'avant-dernier tour.

Diagnose refaite d'après un échantillon de l'espèce-type, de l'Helvétien de Pontlevoy (Pl. III, fig. 18), coll. de l'Ecole des Mines.

Rapp. et diff. - Cette petite coquille ressemble à un Melanopsis; aussi Bellardi l'a-t-il classée dans un groupe tout à fait distinct, non seulement à cause de la brièvelé de son ouverture, mais encore à cause des caractères de sa columelle non plissée, et de l'absence d'une grouttière dans l'angle inférieur de l'ouverture. Cependant ces différences n'ont, à mon avis, que la valeur d'une Section, attendu que les proportions relatives de l'ouverture et de la spire varient beaucoup chez Sparella, et que chez certains individus même, les plissements du bourrelet columellaire ont une tendance à s'effacer. Je n'aurais donc probablement pas conservé la Section Ancillina distincte de Sparella, si je n'avais eu l'occasion d'en étudier la protoconche, qui est absolument différente; c'est un caractère distinctif assez important, et précisémentle seul qu'aucun auteur n'ait encore signalé. Or il existe, dans l'Eocène inférieur du Bassin de Paris, un très petit $A$. arenaria Cossm., qu'on pourrait être tenté de classer dans cette Section, à cause de sa petite taille et de son ouverture courte; mais, outre que cette espèce a un bourrelet columellaire plissé et une gouttière dans l'angle inférieur de l'ouverture, j'ai vérifié qu'elle a une protoconche obtuse: c'est donc bien un Sparella, comme je l'ai catalogué ci-dessus.

Répart. stratigr.

Mrocexe. - L'espèce-type ci-dessus fignurée, dans l'llelvétien de la Touraine, coll. de l'Ecole des Mines; dans le Tortonien du Bassin 
de Vienne, d'après MM. Hœrnes et Auinger; dans l'Helvétien du Piémont, d'après la Monographie de Bellardi.

Tor toliva, Conrad, 1865.

Type: Oliva texana, Conr. Eoc.

(=Ancillarina, Bell. 1882.)

Taille au-dessous de la moyenne; forme subcylindrique, peu dilatée en avant; spire très courte, à galbe conoïdal, incomplètement recouverte par la callosité vernissée; protoconche globuleuse, paucispirée, à nucléus en goutte de suif, formant un petit bouton saillant sur la spire; deux ou trois tours (outre les tours embryonnaires), croissant rapidement, à sutures obliques, bordées, profondes, toujours visibles jusqu'à l'avant-dernier tour, quelquefois même non comblées jusqu'au dernier tour, qui est à peine ovalisé, peu alténué du côté antérieur, el qui forme presque toute la coquille; surface dorsale exempte de vernis dans la plus grande partie de sa hauteur, portant quelquefois (surde jeunes individus) des traces de stries spirales, et marquée par les stries d'accroissement, qui font un coude à gauche sur un étroit ruban, au-dessous d'un limbe large et calleux, correspondant aux accroissements de l'échancrure.

Ouverture très allongée, subtriangulaire, très étioile en arrière, où une gouttière entaille la callosité dans la suture, largement et peu profondément échancrée à la base, où un large rebord, visible sur le limbe, quoique obsolète, suit extérieurement le contour de l'échancrure; labre à peu près vertical, avec un petit cran antérieur correspondant à la déviation des accroissements, peu rétrocurrent en arrière vers la suture; columelle très longue, un peu incurvée, presque verticalement tordue par un bourrelet subcaréné, qui porte plusieurs plissements très obliques; bord colnmellaire assez mince au milieu, calleux en arrière, peu étalé sur la base. 
Diagnose refaite d'apres des échantillons d'une espèce plésiotype du Calcaire grossier de Mouchy: A. canalifera Lamk. (II. III, lig. 16-17), ma roll. Protoconche grossie de la même espèce (Fig. 9), ci-contre).

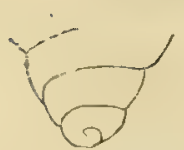

Fis. 9. - Tortoliva cunalifera, Lamk.

Observ. - Vérification faite d'après la figure d'Oliva lexana, il n'est pas possible de contester l'identité générique de cette espèce avec le type du Genre Ancillarina Bell.; ce dernier est, par conséquent, synonyme de Torloliva, qui est bien antérieur. Fischer a d'ailleurs signalé cette éventualité, mais avec un point de doute, qui est actuellement levé; quant à Tryon, il émet l'avis que Fortoliva est synonyme d'Agaronia, hypothèse qui me paraît absolument dénuée de fondement.

Rapp. et diff. - Ce n'est pas seulement par sa forme et par ses sutures visibles, que ce Sous-Genre se distingue d'Ancilla, mais encore par ses plis très obliques, par le rebord de l'échancrure basale, et par l'absence d'un sillon divisant le limbe calleux. Si on le compare aux Olivinx, on remarque que les sutures, quoique parliellement visibles, ne sont pas rainurées, et que les plis columellaires sont tout à fait différents de ceux des Agaronia, par exemple.

\section{Répart. stratigr.}

Eocene. - L'espèce plésiotype ci-dessus figurée, et ses variétés, aux trois niveaux du Bassin de Paris, dans le Bassin de Nantes, dans le Bartonien d'Angleterre, ma coll. L'espèce-typé dans le Texas, d'après le Manuel de Tryon.

Obigocexe. - Une espèce assez variable, dans le Tongrien inférieur de l'Allemagne du Nord: $A$. canatis von Konen, d'après les figures données par l'auteur; une autre espèce dans les environs de Gênes: A. apenninica Bell., d'après la figure donnée par l'auteur.

Mrocrane. - Une espèce dans le Burdigalien du Bordelais, et dans l'Helvétien des Landes: A. suturalis Bon., ma coll.; la même dans l'Helvétien du Piémont, d'après la Monographie de Bellardi; une espèce voisine du type, mais distincte, dans l'Helvétien de T'ouraine: A. subcanalifera d'Orb., d'après la liste préliminaire de MM. Dollfus et Dautzenberg.

Sparellina, Fischer, 1883. Type: A. candida, Lamk. Viv.

Taille au-dessous de la moyenne; forme olivoïde, étroite; spire très courte, à galbe conoïdal, complètement recouverte par le vernis, sauf la protoconche paucispirée, qui forme un petit 
Ancilla

bouton brillant, globuleux et obtus; tours très peu nombreux, à sutures invisibles, le dernier formant presque toute la coquille, en général peu ventru, dépourvu de zone non vernissée, séparé du limbe basal, qui est très large, par un sillon étroit; limbe peu calleux, divisé en deux régions inégales par une ligne oblique et superficielle.

Ouverture très allongée, rétrécie dans l'angle inférieur, où une gouttière entaille la suture, dilatée en avant, largement et peu profondément échancrée à la base; labre à peu près vertical, portant en avant un denticule très petit et pointu, qui correspond au sillon sous le limbe, sinueux et peu rétrocurrent en arrière sur la suture, prolongé, au-delà de celle-ci, par des stries antécurrentes, jusque sur le vernis de l'avant-dernier tour; columelle égale à la moitié de la hauteur del'ouverture, faisant un angle très ouvert avec la base de l'avant-dernier tour, garnie d'un large bourrelet antérieur, qui est séparé du limbe par une large rainure, et qui est muni de six ou sept plissements très obliques et peu saillants; bord columellaire peu calleux, non étalé.

Diagnose complétée d'après des échantillons fossiles de l'espècetype, provenant du Pliocène de Karikal (Pl. III, fig. 20-21), coll. Bonnet.

Rapp. et diff. - Cette Section diffère de Tortoliva: non seulement parce que ses tours sont invisibles sous le vernis de la spire, mais encore parce que le dernier tour ne porte pas de zone non vernissée, par son denticule labial plus pointu, par sa columelle plus courte, faisant un angle avec la base de l'avant-dernier tour, et munie d'un bourrelet plus large, avec des plissements plus nombreux et plus égaux. Si on la compare à Sparella, on trouve que sa spire est plus courte, que son ouverture est beaucoup plus allongée, qu'elle est dépourvue de la zone dorsale qui existe toujours chez Sparella, enfin et surtout, que les plis columellaires sont beaucoup plus obliques. Elle n'a pas le galbe ventru de Baryspira, ni sa columelle excavée, ni son sinus à l'extrémité antérieure. C'est donc avec juste raison que lischer a séparé cette Section, tout en la rapprochant de Tortoliva.

Répart. stratigr.

Plocene. - L'espèce-type dans les couches de Karikal (identique aux 
individus actuels, que je possède précisément de Karikal même): autre espèce vivante, dans les couches récentes de Java: 1 . ampla Gmelin, d'après la Monographie de M. Martin.

Epoque actuelle. - Deux espèces, peut-être identiques, dans l'Océan Indien, ma coll.

Olivula, Conrad, 1832.

Type: O. staminea, Conr. Eoc.

Taille moyenne; forme subcylindrique, étroite; spire tres courte, incomplètement recouverte par la callosité, à galbe conoïdal ; protoconche formant un petit bouton proboscidiforme, à nucléus obtus; tours peu nombreux, parfois étagés aux sutures, qui sont loujours imprimées sur la callosité non vernissée; dernier tour formant presque toute la coquille, légèrement ovale au milieu, à peine atténué du côté antérieur; surface couverte de sillonsspiraux, réguliers, très fins, croisés par des plis d'accroissement irréguliers, qui persistent seuls sur la couche calleuse de la parlie inférieure du dernier tour et de la spire, et qui font un angle de $90^{\circ}$ environ, à la hauteur de la suture; base un peu atténuée, avec une nouvelle dépression oblique, à une grande distance du limbe basal, rui est subdivisé en trois régions à peu près égales par deux gradins, celle dumilieu correspondant aux accroissements de l'échancrure.

Ouverture longue, peu rétrécie en arrière, où une gouttjère assez large entaille profondément la suture, dilatée en avant, où elle est tronquée par une large échancrure; labre un peu épais, lisse à l'intérieur, presque vertical, dépourvu de denticule antérienr, subitement rétrocurrent à la gouttière suturale; columelle à peine excavée, tordue au milieu par un bourrelet, qui est isolé du limbe par une profonde rainure, et qui porte six plis tris obliques, croisiant d'arant en arrière; bord columellaire mince et peu étalé.

Diagnose refaite d'après des échantillons de l'espèce-type, de Claiborne

(Pl. III, fig. 10-11), ma coll.

Rapp. et diff. - Contrairement à l'opinion que j'ai précédemment exprimée, à deux reprises (Catal. Eoc. Suppl. App. II, p. 41, et Moll. éoc. 
Ancilla

Loire-Infér., I, p. 321), je considère actuellement comme distincts Tortoliva et Olivula qui, après un examen plus approfondi, présentent les différences sectionnelles ci-après résumées : en admettant même que l'on ne tienne aucun compte de l'ornementation spirale, qui n'est pas toujours completement effacée chez les jeunes individus de Tortoliva, et que l'on n'attache pas d'importance à l'absence d'un cran ou d'un denticule à la partie antérieure du labre, par suite de l'oblitération du ruban dorsal chez Olivula, il y a lieu d'observer que le limbe basal est divisé en trois zones chez cette dernière Section, tandis qu'il n'y en a que deux chez Torloliva; en outre, les plissements columellaires sont moins verticaux chez Olivula; ils sont moins nombreux et croissent plus régulièrement; enfin la callosité inférieure s'élève moins haut sur le dernier tour; elle est mieux limitée et plus fortement plissée par les accroissements, qui font un coude bien plus aigu sur la suture, et celle-ci n'est jamais imprimée au dernier tour de Tortoliva, comme elle l'est chez Olivula.

Répart. stratigr.

Eocene. - Une espèce dans le Claibornien des Etats-Unis, ma coll.

MONOPTYGMA, Lea, 1833.

Monoptygma, sensu stricto. Type: M. limneoides, Conl. Eoc.

Taille petite, ou à peine moyenne; forme ancilloïde, en fuseau; spire un peu allongée, subulée, à galbe conique, aiguë au sommet, entièrement recouverte par le vernis; protoconche obtuse et paucispirée; tours peu nombreux, à sulures absolument indistincles; dernier tour grand, ovale et un peu renflé au milieu, régulièrement atténué à la base, paraissant dépourvu de zone non vernissée sur sa surface dorsale, sauf à peu de distance au-dessous du limbe, où l'on distingue d'abord une strie oblique, puis un large ruban terne; limbe basal peu calleux, large, oblusément divisé en trois régions.

Ouverture peu allongée, à peine dilatée, avec une gouttière très obsolète dans l'angle inférieur, terminée en avant par une échancrure assez large et très peu profonde; labre assez mince, légìrement convexe, à peine rétrocurrent vers la suture; columelle 


\section{Monoptygma}

excavée en avant, avec un bourrelet faiblement calleux, étroit, non plissé, dont l'enroulement tordu forme, au milieu de la hauteur de l'ouverture, une énorme saillie, lamelleuse et spirale, au-dessons de laquelle le bord columellaire est encore excavé; callosité peu épaisse, large, un peu étalée sur la base, s'étendant en arrière sur l'avant-dernier tour.

Diagnose faite d'après des échantillons de l'espèce-type, de Claiborne dans l'Alabama (Pl. III, fig. 24-25), ma coll.

Rapp. et diff. - Bien que cette coquille ait la forme caractéristique d'un Ancilla, elle doit ètre classée dans un Genre complètement distinct, non seulement à cause de la disparition des plis sur la partie antérieure de la columelle, qui ne porte qu'un bourrelet excavé et très étroit, mais encore à cause de la saillie que forme la torsion de ce bourrelet, beancoup plus bas que les plissements des Ancilla; c'est bien une lamelle spirale, qui s'enfonce dans l'ouverture qu'elle rétrécit au milieu, et ce n'est pas une dent, ou une protubérance calleuse, comme celle de Chiloplygma. Il y a donc là un caractère générique, d'une importance exceptionnelle, qui justifie la séparation complète de cette forme. Le vernis calleux s'étend d'ailleurs, sur le dernier tour, beaucoup plus en avant que chez la plupart des Ancillinæ; il ne reste sous le limbe qu'un étroit ruban, dont la surface rugueuse est striée par les accroissements.

Répart, stratigr.

Eocene. - L'espèce-type, également connue sous le nom de $M$. alabamiensis Lea, ainsi que ses variétés : $A$. curta Conr, etc., dans le Claibornien des Etats-Unis, ma coll.

HARPIDA, Troschel.

Coquille ventrue, généralement costulée, à spire assez courte; protoconche globuleuse; ouverture ample, échancrée en avant par un sinus plus on moins profond, auquel aboutit un bonrrelet hasal ; labre droit, épaissi par la dernière côte, légèrement sinueux en arrière, et antécurrent vers la suture; columelle inclinée vers l'axe à son extrémité antérieure, un peu excavée, non plissée, avec 
un léger bombement indiquant l'enroulement du bourrelet basal sous le vernis du bord columellaire, qui est plus ou moins étalé sur la base, et parfois jusque sur l'avant-dernier tour. Pas d'opercule.

Rapp. et diff. - Celle Famille a été créée par Troschel, aux dépens des Olivida, et cette séparation est justifiée : non seulement à cause des différences que présente l'anatomie de l'animal, dans la forme du pied et dans la formule de la radule; mais aussi à cause des caractères de la coquille, qui a un galbe et des ornements bien distincts, et surtout à cause de la disposition de la columelle, qui n'est pas tordue en avant par un bourrelet plissé, mais qui atteint ou dépasse le niveau de l'échancrure basale, en s'inclinant légèrement vers l'axe, au lieu de rejoindre le contour supérieur en se recourbant vers l'extérieur, comme cela a lieu chez Oliva et chez Ancilla. A ce dernier point de vue, Harpa se rapproche davantage des Volutidx; mais, outre que la columelle n'est pas plissée, le labre se termine en arrière par un sinus peu profond, dont le contour est antécurrent vers la suture, et les côtes, quand il y en a, suivent cette inflexion, de sorte qu'elles recouvrent la rainure suturale.

\section{Tableau des Genres, Sous-Genres et Sections.}

\begin{tabular}{|c|c|c|}
\hline $\begin{array}{l}\text { HARPA } \\
\text { (Columelle } \\
\text { non tordue) }\end{array}$ & $\begin{array}{l}\text { Harpa } \\
\text { (Costules } \\
\text { axiales) }\end{array}$ & $\begin{array}{l}\text { Harpa } \\
\text { (Bord columellaire } \\
\text { étalé) } \\
\text { Eocithara } \\
\text { (Bord columellaire } \\
\text { détaché) }\end{array}$ \\
\hline $\begin{array}{l}\text { CRYPTOCHORDA } \\
\text { (Columelle légèrement } \\
\text { tordue en avant) } \\
\end{array}$ & $\begin{array}{l}\text { Conptochorda } \\
\text { (Surface lisse) } \\
\text { Silia } \\
\text { (Côtes obtuses) }\end{array}$ & \\
\hline
\end{tabular}

HARPA, Lamarck, 1799. (= Cithara, Klein 1753.)

HARPA, sensu stricto.

Type: H. ventricosa, Lamk. Viv.

Taille souvent grande; forme ventrue, ovale, arrondie; spire courte, étagée, à gaalbe à peu près conique; protoconche lisse, 
petite, globuleuse, à nucléus planorbulaire; tours anguleux ou arrondis, avec une rampe suturale, oblique ou excavée, partiellement ou même entièrement recouverts par un vernis qui empâte les côtes; dernier tour très grand, orné de côtes un peu courbées, généralement lamelleuses, dont les intervalles sont treillissés: bourrelet basal étroit et saillant, linité à l'extérieur par une dépression profonde, et sur lequel les côtes, en se repliant, forment des crochets, indiquant les arrêts de l'accroissement de l'échancrure.

Ouverture très dilatée, dépourvue de gouttière dans l'angle inférieur, terminée en avant par une échancrure arrondie, à laquelle aboutit intérieurement une gouttière obsolète; labre vertical, un peu épaissi à son contour par la dernière côte, qui forme en arrière une sinuosité peu profonde et se replie à droite sous le vernis de l'avant-dernier tour, dans l'épaisseur duquel elle se perd; columelle peu incurvée, l'ejetée vers l'axe en avant, portant au milieu un très faible bombement, qui correspond à l'enroulement du bourrelet basal; bord columellaire lisse, calleux en avant, mince en arrière, recouvrant non seulement la région ombilicale, mais une partie de la base, l'avant-dernier tour, et quelquefois même les premiers, jusqu'à la protoconche.

Diagnose complétée d'après des échantillons de l'espẹç-type, et d'après un plésiotype du Miocène des environs de Bordeaux: Harpa Brochoni Benoist (Pl. IV, fig. 3), coll. Degrange-'Touzin.

Observ. - L'adoption du nom Harpa, de préférence à Cïlhara, ne doit donner lieu à aucune hésitation, dès l'instant qu'aux termes des règles de la nomenclature, fixées par le Congrès de Bologne, les écrits de Klein antérieurs à la douzième édition de Linné (1766), et non basés sur la méthode binominale, n'ont aucun droit de priorité, quant aux noms de Genres. Cependant, dans son Manuel, Fischer attribue à Rhumphius (170z) le nom Harpa; mais il doit être entendu que c'est uniquement parce que Lamarck a repris cette dénomination, qu'elle a prévalu sur toute autre.

Répart. stratigr.

Origocexe, - Une espèce dans le l'iémont, plus voisine des formes 
vivantes que des Eocithara éocéniques: $H$. Bellardii Sacco, d'après la Monographie de cet auteur.

Mrocene. - L'espèce plésiotype ci-dessus figurée, et encore inédite, dans le Burdigalien de I'Aquitaine, coll. Degrange-Touzin. Autre espèce dans l'Helvétien du Piémont : $H$. Josephinæ Sacco, d'après la Monographie de cet auteur.

Epoque actuelle. - Plusieurs espèces dans les mers tropicales̄, ma collection.

Eocithara, Fischer, 1883. Type: Harpa mutica, Lamk. Eoc.

Taille moyenne; forme ventrue; spire peu allongée, à galbe conique; protoconche lisse, globuleuse, composée de trois tours, à nucléus déprimé et obtus; lours convexes, séparés par des sutures peu profondes, non vernissées; dernier tour grand, ovale, arrondi en arrière, orné de lamelles plus ou moins écartées, un peu sinueuses, antécurrentes à la suture, sur laquelle elles se replient et qu'elles recouvrent d'une manière presque continue; surface treillissée plus ou moins finement dans l'intervalle des côtes.

Ouverture médiocrement dilatée, avec une gouttière dans l'angle inférieur, munie en avant d'une étroite et profonde échancrure; labre légèrement incurvé, épaissi par la dernière côte, à peine sinueux à la suture, et se raccordant avec le bord opposé; columelle un peu bombée au milieu par l'enroulement spiral du bourrelet sous la callosité dı bord, légèrement infléchie vers l'axe à son extrémité antérieure; bord columellaire calleux, assez large, quoique peu étalé, limité du côté de la base dans toute son étendue, ne s'étendant pas sur l'avant-dernier tour, détaché en avant, et découvrant généralement une petite fente ombilicale.

Diagnose faite d'après un échantillon de l'espècetype, du Calcaire grossier de Chaussy (Pl. III, fig. 22-23), ma coll. Protoconche de la même espèce, grossie (Fig. 10 ci-contre).

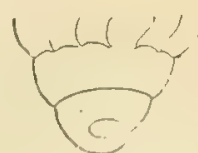

Fı. 10. - Eocithare mulica, Lamk.

Rapp. et diff. - La séparation de cette Section, proposée par Fischer dans son Manuel de Conchyliologie, est fondée sur quelques caractères 
II arpa

différentiels, dont j'ai vérifié la constance : d'abord et surtout la disposition du bord columellaire, qui furme une lèvre calleuse assez large, non étalée sur la base, ni sur les tours de spire, et limitée à l'extérieur par un biseau bien distinct; ce bord se détache, en outre, du côté antérieur et découvre une fente ombilicale, plus ou moins profonde, au lieu de s'étendre jusque sur le bourrelet basal; d'autre part, l'échancrure siphonale est plus étroite et plus profondément entaillée dans ce bourrelet, de sorte que, quand on regarde la coquille du côté du dos, cette entaille forme presque un demi-cercle; enfin les costules se replient plus complètement sur la suture, et elles la recouvrent en se joignant les unes aux autres; toutefois ce dernier caractère est moins visible chez les Eucithara de l'Australie du Sud, qui ont d'ailleurs une protoconche plus F'1. 11. - Eocilhara glohuleuse, ainsi que je l'ai constaté, d'une manière gélenuis, Tate. nérale, sur la plupart des fossiles de cette provenance, qui ont fréquemment des embryons très aberrants; on s'en convaincra par l'inspection de la Fig. 11 ci-contre, qui représente la protoconche d'E. temis Tate.

\section{Répart. stratigr.}

Eocexe. - Deux espèces dans le Bassin de Paris: le type et H. elegans Desh., ma coll.; cette dernière espèce dans le Bassin de Nantes, coll. Bourdot. Plusieurs espèces dans l'Australie: H. sulcosa, lamellifera, pachychila, spirata, tenuis, T'ate, ma coll.

Oligocese. - Une espece probable, dans le Tongrien de Gaas: H. submutica d'Orb.(=H. mutica Grat.), d'après l'Atlas de Grateloup.

CRYPTOCHORDA, Mörch, 1858.

(- Buccinopsis Bayle in coll., non Jeffreys 1867, nec Conrad 1857; = Harpopsis Mayer-Eymar 187\%.)

Cryptochorda, s. str.'I'ype: Buccinum stromboides, Herman. Eoc.

'T'aille assez grande; forme ovoïde, un peu ventrue; spire peu allongée, faiblement étagée aux sutures, presque entièrement recouverte par le vernis; protoconche lisse, globuleuse, composée de quatre tours, formant une petite calotte subulée, à nucléus en goutle de suif; tours arrondis, avec une légère dépression près de la suture, qui n'est pas visible à cause de l'émail; dernicr tour 
Cryptochorda

grand, ovale en arrière, excavé à la base, souvent plissé par des accroissements irréguliers, portant, sur la dépression basale, cinq ou six filets obliques; bourrelet d'accroissement de l'échancrure à peine saillant, limité par une côte oblique, marqué par des crochets obsoletes.

Ouverture un peu dilatée, avec une goultière entaillée dans l'angle inférieur, terminée en avant par une très profonde échancrure; labre presque vertical, épaissi et bordé à son contour, sinueux vers la suture; columelle avec une double inflexion en $S$, excavée en arrière, bombée au milieu par-l'enroulement du bourrelet basal sous le vernis, faiblement tordue et incurvée vers l'axe, du côté antérjeur où elle se termine plus haut que le bord opposé, à l'angle supérieur, de l'échancrure; bord columellaire mince, vernissé, étalé sur toute la base du dernier tour, et envahissant la spire.

Diagnose refaite d'après des échantillons de l'espèce-type, du CaIcaire grossier de Mouchy (Pl. IV, fig. 1 et 4), ma coll.

Observ. - Fischer a rectifié, dans son Manuel, la dénomination de ce Genre, et il a rétabli le nom antérieurement proposé par Mörch, de sorte qu'il y a lieu de reléguer dans la synonymie Harpopsis, que Mayer a créé, dans son Mémoire sur les environs d'Einsiedeln, dans l'intention de corriger un double emploi, non publié par Bayle, mais inscrit sur les étiquettes de la Collection de l'Ecole des Mines de Paris.

Rapp. et diff. - Le classement de ce Genre, exclusivement connu à l'état fossile, a élé l'objet de tergiversations: Mayer-Eymar l'a rapproché des Harpidze, et il l'a baptisé Harpopsis; Fischer le classe, au contraire, dans la Famille Volutidæ, en se basant sur l'analogie de la coquille en question avec celle de Zidona; en ce qui me concerne, j'ai, à deux reprises (Catal. Toc., 1889, IV, p. 192, et Mall. Eoc. Loire-Infér., 1896, I, p. 97), adopté cette opinion, et j'ai même insisté sur les motifs donnés par Fischer en faveur de ce rapprochement. Cependant, aujourd'hui, après un nouvel examen comparatif, j'en reviens à l'avis de Mayer, et je suis d'avis que Cryplochorda est une forme de Harpidx.

En effet, autant que je puis en juger par la ligure du Manuel de Tryon, Zidona (à part le prolongement anormal de son sommet) a la columelle véritablement plissée, incurvée dans toute sun étendue, le labre non échancré à la suture; tandis que Cryptachorda porte simplement, 
Ciryptochorda

comme tous les Harpa, sur sa columelle bisinueuse, la trace très obsolète de l'enroulement du bourrelet basal; en outre, le contour de son labre forme, à la suture, un crochet qui rappelle tout à fait celui d'EOcithara; il est vrai que $C$. stromboicles s'écarte des espèces de celte dernière Section par sa surface à peu près lisse, par sa spire vernissée, par son bourrelet non saillant, et par les stries obliques de sa base; mais, comme la columelle a exactement la même disposition, que la protoconche se rapproche plus de celle des Harpidx que des embryons de Volutidx, la prépondérance des caractères semblables à ceux de la première de ces deux Familles justifie le classement que j'adopte, tandis que les caracteres différentiels ont une importance qui ne nécessite que la séparation d'un Genre distinct de Harpa.

\section{Répart. stratigr.}

Paleocene. - L'espèce-type dans le Calcaire de Mons, avec une autre espèce : Harpopsis tritonoides Briart et Cornet, d'après la Monographie de ces deux auteurs.

Eocene. - L'espèce-type aux trois niveaux du Bassin de Paris, dans le Bartonien d'Angleterre, dans le Bassin de Nantes, ma coll.; la même dans le Parisien du Nord de la Suisse, d'après M. MayerEymar. Une autre espèce aux Etats-Unis : C. Mohri Aldrich, d'après la figure donnée par cel auteur.

? Silia, Mayer-Eymar, $1877\left({ }^{1}\right)$. Type: Harpa Zitteli, Mayer. Eoc.

"Coquille bucciniforme, enroulée; base terminée par un canal

" court, recourbé, échancré; spire courte, conique; tours con" vexes, à sutures simples; dernier tour très grand, allongé; " labre épais, flexueux. Ouverture allongée, étroite; columelle " presque droite, callosité mince, étroite, obscurément plissée " au milieu; accroissements du canal marqués sur un bourrelet "caréné et plissé. "

Diagnose traduite d'après celle de l'auteur; reproduction originale de l'espèce (Fig. 12 ci-contre).

Observ. -... N'ayant pas sous les yeux le type de ce Sous-Genre, je ne puis en proposer la suppression d'après l'inspection seule de la figure; mais il me semble que Fia. 12. - Silia Zil-
leli, Mayer.

(1) Umgegend ron EinsiedeIn, p. 59, 11. 111, tig. 5.

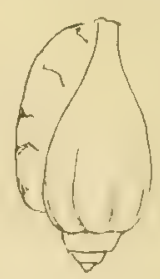


Cryptochorda

cette nouvelle subdivision créée d'après un simple moule, n'a aucune valeur; il est possible que ce soit un Cryplochorda, dont les accroissements aient laissé une trace à l'intérieur du test.

Rapp. et diff. - Mayer indique que Silia se dislingue de Harpa par ses côtes obliques, qui ne se replient pas sur la suture, et que sa forme le rapproche de Harpopsis (Cryptochorda), dont la columelle a exactement la même disposition. Je me borne ả le placer près de ce dernier Genre, jusqu'à ce que l'examen de meilleurs matériaux ait permis de dissiper toute incertitude.

\section{Répart. stratigr.}

Eocene. - L'espèce-type dans le Parisien du Nord de la Suisse, d'après M. Mayer-Eymar.

MARGINELLIDA, Jousseaume, 1875.

Coquille ovale ou subconoïdale, à spire proéminente ou cachée; protoconche obtuse; surface luisante et émaillée, rarement plissée, jamais sillonnée; sutures recouvertes par le vernis; ouverture étroite, faiblement échancrée à la base, ou à peine sinueuse; labre épaissi à l'extérieur, souvent crénelé à l'intérieur; columelle munie de plis décroissant d'avant en arrière, tantôt lamelleux, tantôt épais. - Pas d'opercule.

Observ. - La classification des Genres, Sous-Genres et trop nombreuses Sections, dont se compose actuellement cette Famille, est extrêmement embarrassante; les caractères distinctifs s'enchevêtrent tellement qu'on est dans l'alternative soit de multiplier exagérément ces subdivisions, soit de les réunir presque toutes entre elles, pour n'en faire que deux ou trois groupes. Depuis Swainson et Gray, qui y admettaient seulement quatre Genres, depuis Adams qui n'en conservait que trois, depuis Kiener, Sovverby et Reeve, qui les rejetaient tous et qui désignaient toutes ces coquilles sous l'unique dénomination Marginella, l'étude plus attentive des caractères de la coquille a conduit les conchyliologistes modernes à proposer de nouvelles coupes; M. Jousseaume arrive ainsi à quatorze Genres, et Fischer admet quinze Genres, SousGenres ou Sections; l'arrangement de Weinkauff, partiellement adopté par Tryon, comprend deux divisions principales, selon qu'il existe un sinus basal ou qu'il n'y en a pas, et trois Sections dans chacune de ces divisions, avec plusieurs groupes dans cliaque Section. Ce dernier classe- 
ment, plus méthodique que les précédents, se rapproche de celui quue j’ai établi ci-après, en ce sens qu'il fait intervenir l'échancrure basale, et par conséquent, le limbe calleux de la surfice dorsale; ce caractére, joint à celui de la disposition des plis, m'a permis d'aboutir à un tableau à peu près satisfaisant des subdivisions à conserver dans cette nombreuse Famille.

\section{Tableau des Genres, Sous-Genres et Sections.}

\begin{tabular}{|c|c|c|}
\hline $\begin{array}{l}\text { MARGINELLA } \\
\text { (4 plis, } \\
\text { pas de limbe basal) }\end{array}$ & $\begin{array}{l}\text { Marginelua } \\
\text { (Sinus basal, } \\
\text { spire snillante) }\end{array}$ & $\begin{array}{l}\text { Maryinella } \\
\text { (Surface lisse, } \\
\text { libre uni) } \\
\text { Faba } \\
\text { (Surface costulée, } \\
\text { labre denticulé) } \\
\text { Serrata } \\
\text { (Forme étroite, } \\
\text { labre denticulé) } \\
\text { Eratoideu } \\
\text { (Forme ventrue. } \\
\text { labre denté) } \\
\text { Dentimaryo } \\
\text { (Une dent labiale) } \\
\text { Canalispira (A) } \\
\text { (Sutures canaliculées) }\end{array}$ \\
\hline & $\begin{array}{l}\text { Volvaniva } \\
\text { (Cylindrique, } \\
\text { labrecontracté) } \\
\qquad .\end{array}$ & $\begin{array}{l}\text { Volvarina } \\
\text { (Labre épais, } \\
\text { non bordè) } \\
\text { Neovolvaria (B) } \\
\text { (Labre aigu) } \\
\text { Balanetta (G) } \\
\text { (Spire cachée) }\end{array}$ \\
\hline & $\begin{array}{l}\text { Glabizla } \\
\text { (Sinus basal } \\
\text { à peine échancré) } \\
\end{array}$ & $\begin{array}{l}\text { Glabella } \\
\text { (Spire saillante) } \\
\text { Bullata (D) } \\
\text { (Spire cachéc) }\end{array}$ \\
\hline $\begin{array}{l}\text { CRYPTOSPIRA } \\
\text { (Plus de } 4 \text { plis, } \\
\text { limbe basal) }\end{array}$ & $\begin{array}{c}\text { Convtospilia } \\
\text { (Spire visible) } \\
\end{array}$ & $\begin{array}{l}\text { Gryptospira } \\
\text { (Labre épais } \\
\text { et lisse } \\
\text { Euryentome } \\
\text { (Labre crénelé } \\
\text { et échancré) } \\
\text { Gibberula } \\
\text { (Labre crénele, } \\
\text { non bordé) }\end{array}$ \\
\hline & $\begin{array}{l}\text { Glosia }(\mathrm{E}) \\
\text { (Spire recouverte) }\end{array}$ & \\
\hline $\begin{array}{l}\text { PERSICULA } \\
\text { (Cypréiforme } \\
\text { limbe basal) } \\
\mid\end{array}$ & $\begin{array}{l}\text { Prasucula } \\
\text { (Spire dépriméc } \\
\text { ou cachée) } \\
\text { Cystiscus (F) }\end{array}$ & \\
\hline
\end{tabular}


Genres, Sous-Genres et Sections non signalés à l'état fossile.

(A). Caxalispina, Jousseaume 1870̈. - Type: M. olivellæformis Jouss. "Coquille facile à distinguer des autres groupes par sa suture canaliculée, comme dans les Olives. „ D’après la figure, la spire est plutôt étagée par une rampe aplatie que canaliculée à la suture; toutefois, comme l'auteur insiste, dans le texte, sur cette rainure suturale, linéaire, identique à celle des Oliva, il est probable que le dessinateur a mal interprété les caractères de l'échantillon-type. J'ajoute que le labre est liré -à l'intérieur et que l'ouverture est un peu dilatée en avant.

(B). Neovolvaria, Fischer 1883. - Type: M. pallida Lin. Cette Section ne semble distincte de Volvarina s. s., que par son labre aigu; comme il est déjà difficile de trouver des différences génériques entre Volvarina et Marginella, il paraît excessil de baser une nouvelle subdivision sur la minceur du labre, qui peut être attribuée à ce que les échantillons ne sont pas adultes. La plupart des auteurs, Tryon entre autres, confondent V. pallida avec Volvaria Lamk., qui, comme on le verra ci-après, n'appartient pas à la Famille-Marginellidie.

(C). Balanetta, Jousseaume 187.0ّ. - Type: M. Baylei Jouss. Cette Section se distingue de Volvarina par la disparition complète de la saillie de la spire, de sorte que la coquille ressemble à un Bulla, ou plutôt à un Bullinella. Les autres caractères: contraction du labre, plis columellaires, galbe général, sont les mêmes que chez Volvarina.

(D). Bullata, Jousseaume 1870 (= Volulella Swainson 1840, non Perry 1811). - Type : $M$. bullata Born. Par ses quatre plis columellaires el par l'absence de limbe basal, cette coquille se rattache au Genre Marginella; mais, par son sinus basal à peine creusé, elle appartient, en réalité, au Sous-Genre Glabella; elle ne s'en distingue, d'ailleurs, que par sa spire entièrement cachée, et recouverte par une couche de vernis qui comble complètement l'exeavation apicale. Le labre est bordé, lisse à l'intérieur; la gouttière postérieure de l'ouverture atteint presque le sommet. M. Jousseaume a corrigé, avec raison, le double emploi qui a échappé à Swainson; j'ignore pourquoi Fischer se borne à citer Bullata comme synonyme de Volutella.

(E). Closia, Gray 18aั7. - Type: $M$. Sarda Kiener. Coquille ovoïde et globuleuse, à spire cachée par le prolongement du bourrelet labial, qui est denticulé à l'intérieur; columelle à quatre plis, les deux antẻrieurs saillants et extérieurement soudés entre eux. Quoique ce Sous-Genre se rapproche de Bullata, et par conséquent, des Marginella à quatre plis, l'existence d'un limbe basal, bien limité, me décide à le placer dans le Genre Cryplospira; ce limbe correspond, d'ailleurs, à une échancrure profonde du contour supérieur, tandis que Bullata a un sinus basal à peine indiqué.

(F). Cxistiscus, Stimpson 186ə.- Type: C. capensis Stimpson (non 
M. capensis Dunk.; $=\boldsymbol{M}$. cysticus Redfield). Ce Genre a tout it fait la même diagnose que Gibberula, sauf que le nombre des plis columellaires est limité à quatre, et qu'on ne fait pas mention de rides columellaires, la figure n'en indique pas, d'ailleurs. Mais l'animal est différent de celui de Marginella, et ces différences ont paru suffisantes pour motiver la création d'un Genre, contesté par certains auteurs; dans ces conditions, il est possible que certaines espèces fosiles, classées comme Gibberula, aient eu, en réalité, un animal de Cystiscus; il ne serait alors possible de les distinguer qu'en s'assurant bien qu'elles ne portent pas plus de quatre plis à la columelle.

\section{Genres à éliminer de la Famille.}

Paciýbaturox, Gaskoin 1803. - Type: P. marginelloideum Gask. Fischer a classé, avec un point de doute, ce Genre dans la f'amille Marginellidx, en faisant remarquer que, si son aspect est celui d'un Cassis, ses autres caractères le rapprochent, soit de Maryinella, soit de Cyprace. J'avoue que je ne puis saisir aucun rapport entre cette forme et l'une quelconque des subdivisions des Marginellide; la spire et le dernier tour sont ornés, le sommet est aigu, les rides columellaires et pariétales sont très étalćes sur le bord, enfin l'échancrure basale est bien plus profonde. Je ne puis donc admettre le classement proposé par Fischer, et je me range à l'avis de Chenu, de Tryon, etc., qui placent Pachybathron dans les Cassididie.

Micnovoluta, Angas, 1877. - Type : $M$. australis Angas. Liunique petite espèce, qui représente ce Genre, a une forme et des plis de Mil\%a, croissant d'avant en arrière, une protoconche papilleuse, le labre mince, un peu contracté à la base, des sutures bien marquées, la surface lisse et luisante; enfin elle n'a pas d'échancrure basale. Je ne trouve, dans ces caractères, aucun motif pour classer Microvoluta dans les Marginellidx, comme l'a proposé Fischer, avec un point de doute. Je trouve, au contraire, que cette coquille se rapproche beaucoup plus soit des Milridx, soit des Volutidx, et on verra plus loin que j'admets que c'est une forme intermédiaire entre ces deux dernières Familles.

Erato, Risso 1826. - Type: E. lavis Donovan. Beaucoup d'auteurs, - notamment Jousseaume et Tryon, - classent ce Genre dans les Margineliidx, à cause de la similitude de la coquille avec la forme extérieure de Gibberula ou de Persicula. Toutefois l'animal d'Eralo a des caractères différents. Fischer a fait remarquer, en effet, que les organes de cet animal, et principalement sa radule, sont identiques à ceux de Trivia, que c'est un Mollusque très actif, comme les Cyprxa; enfin que, même en ce "fui concerne la coquille, dont les couleurs sont tris vives, comme chez tous les Cypraidæ, les plis columellaires ne se montrent qu'à l'âge adulte, en même temps que les denticulations du labre, tandis que, chez Margï- 
nella, les plis columellaires sont apparents à tout âge, bien avant lés crénelures labiales, quand elles existent. Pour tous ces motifs, il me parait qu'il y a lieu de laisser Erato dans la Famille Cypræidx.

MARGINELLA, Lamarck, 1801.

(= Porcellana, Adanson 1757, sec. Fischer)

Marginella, sensu stricto. Type: Voluta glabella, Lin. Viv. (= Simplicoglabella, Sacco 1889)

Taille rarement grande; forme ovoïde ou ovale-conique, ventrue en arrière; spire saillante, courte en général, au plus égale à l'ouverture; protoconche paucispirée, obtuse, recouverte par le vernis de la spire, à nucléus déprimé; tours subulés, à sutures linéaires, à peine marquées; surface entièrement lisse et vernissée, dernier tour plus ou moins renflé et arrondi du côté postérieur, régulièrement atténué à la base, qui ne porte aucune trace de limbe à son extrémité antérieure.

Ouverture allongée, assez étroite, surtout en arrière, avec une gouttière un peu échancrée dans l'angle inférieur, tronquée en avant par une faible échancrure basale; labre épais, extérjeurement bordé par un bourrelet, qui se prolonge jusque sur le contour supérieur, lisse à l'intérieur, à profil presque vertical, faiblement rétrocurrent près de la suture; columelle oblique, à peu près rectiligne, un peu tordue en avant, munie de quatre plis écartés, peu épais, l'antérieur presque vertical, se raccordant avec le contour supérieur, l'inférieur plus saillant et presque transversal; bord columellaire très mince, non distinct du vernis qui couvre toute la base du dernier tour.

Diagnose refaite d'après deux plésiotypes fossiles: $M$. auris-leporis Br., du Pliocène d'Orciano (Pl. IV, fig. 2); M. Slephanix Per. da Costa, du Tortonien de Cacella (Pl. III, fig. 3I); tous deux de ma collection.

Observ. - Pour définir les véritables Marginella, après qu’on en a éli 
Marginella

miné les nombreux Sous-Genres et Sections qui peuvent, à la rigueur, en être distingués, il faut moins s'attacher à la forme de la coquille, qui est assez variable, qu'aux caraclères suivants: surface lisse, absence de denticulations à l'intérieur du labre, plis columellaires assez minces et écartés. Pour le reste, la spire est plus ou moins courte, l'ouverture est plus ou moins échancrée à la base; cependant son contour supérieur forme une sinuosité bien marquée, quand on regarde la coquille en plan, posée sur son sommet. Dans ces conditions, je ne vois aucun motil pour distinguer la Section Simplicoglabella, proposée par M. Sacco pour quelques espèces du Piémont, qui sont des Marginelles typiques, et qui n'ont, comme on s'en convaincra ci-après, aucun rapport avec le groupe Glabella, dans lequel cet auteur place sa nouvelle Section.

Répart. stratigr.

Eocene. - Plusieurs espèces dans le Bassin parisien: M. nilidula Desh., M. entomella Cossm., ma coll.; une espèce probable dans l'Australie: $M$. inermis Tate, ma coll.

Oligocene. - Une espèce dans le Tongrien de la Ligurie: $\boldsymbol{M}$. degensis Bell., d'après la Monographie de $\mathbf{M}$. Sacco; une espèce étroite et à spire courte, dans le Vicentin: M. pancispira Fuchs, d'après la figure publiée par l'auteur; une espèce dans le Tongrien de l'Allemagne du Nord: $M$. grandis von Koenen, d'aprés la Monographie de cet anteur.

Mrocene. - Outre le plésiotype du Portugal, ci-dessus figuré, et qui se trouve aussi en Corse, d'après M. Locard, plusieurs espèces dans I'Helvétien du Piémont: M. Borsoni Bell, M. taurinensis Mich., M. excavata et brevispira Bell., M. affinis Sacco, etc, d'après les figures de la Monographie de M. Sacco; une espèce dans le Bassin de Vienne: M. Sturi R. Horn., d'après MM. Ilœrnes el Auinger.

P'locene. - Le plésiotype ci-dessus figuré, dans le Messinien de la Toscane, ma coll.; la même espèce dans le Plaisancien de l'Andalousie, d'après M. Bergeron.

Epoque acruele. - Plusieurs espèces sur les côtes Ouest de l'Afrique, et sur les côtes Est de l'Ámérique, d'après le Manuel de Tryon.

FABd, Fischer, 1883.

Type: M. faba, Lin. Viv.

(= Glabella Tryon, ex majoreparte, non Glabella Swainson)

Taille médiocre; forme ventrue, conoïdale; spire courte, à salbe conique, couronné; protoconche formant un gros bouton 
obtus; dernier tour renflé ou subanguleux en arrière, orné de côtes épaisses et peu saillantes, sur l'angle obsolète de la partie postérieure, et sur la rampe comprise entre cet angle et la suture; le reste de la surface est lisse, du côté antérieur. Ouverture très étroite, entaillée par une gouttière vers la suture, tronquée à la base par un sinus arrondi, sans échancrure dorsale; labre oblique, très épais, denticulé à l'intérieur, bordé par un bourrelet externe qui ne dépasse pas la suture; quatre plis columellaires peu épais, les deux antérieurs obliques, les deux postérieurs tout à fait transversaux; bord columellaire très mince.

Diagnose faite d'après une espèce vivante, voisine du type: $M$. bifasciata Lin., ma coll.; et d'après un plésiotype de l'Eocène d'Australie -: M. cassidiformis Tate (Pl. IV, fig. 6-7). ma coll.; autre plésiotype de l'Eocène de Ciuppio, dans le Vicentin : $M$. phaseolus Brongn. (Pl. IV, fig. 14), ma coll.

Rapp. et diff. - Fischer n'a pas indiqué, dans son Manuel, les caractères de la nouvelle Section $F a b a$, qu'il a proposée; mais il en a désigné le type, et un examen attentif des caractères de cette coquille m'a convaincu que la création de cette Section est justifiée. Non seulement la spire et la partie postérieure du dernier tour portent des costules qui n'existent jamais chez les vraies Marginelles, mais encore le labre est denticulé à l'intérieur, tandis qu'il est lisse chez Marginella $s . s$.; en outre, la forme générale de Faba est plus trigono-conique, la spire est encore plus courte que celle de $\boldsymbol{M}$. glabella; enfin le bouton embryonnaire semble être plus gros, surtout chez les plésiotypes fossiles, particulièrement chez les formes australiennes, dont la protoconche prend quelquefois un développement anormal.

\section{Répart. stratigr.}

Eocexe. - Deux espèces dans l'Australie du Sud: le plésiotype cidessus figuré, et $\boldsymbol{M}$. Aldingæ Tate. Uné espèce plissée, plus allongée que les précédentes, et plus voisine du type, dans le Vicentin : $M$. phaseolus Brongn., ma coll.

Oligocexe. - Une espèce probable dans la formation santacruzienne de Patagonie: $\boldsymbol{M}$. quemadensis $\mathrm{v}$. Ihering, d'après la description et la figure données par l'auteur (Revista do Museu Paulista, II).

Epoque actuelle. - Plusieurs espèces sur les côtes occidentales de l'Afrique, dans la mer Rouge, et en Australie, d'après le Manuel de Tryon. 
Serrata, Jousseaume, 1875. Type: $M$. serrata, Gaskoin. Viv.

Taille assez petite; forme étroite, fusoïde; spire assez courte, à galbe conoïdal; protoconche tout à fait obtuse, à nucléus en goutte de suif; tours peu nombreux, convexes, à sulures linéaires; surface lisse et vernissée; dernier tour très allongé, ovoïde, régulièrement atténué à la base, qui ne porte aucun bourrelet. Guverture tris étroite, à peine dilatée en avant, faiblement enlaillée par une goultière suturale, tronquée, sans échancrure à la base, par un sinus aussi large qu'elle; labre vertical, un peu incurvé, à peine sinueux en arrière, bordé par une large callosité qui forme un bourrelet peu épais, sur le contour duquel des crénelures internes, fines et serrées, découpent souvent des dents de scie, visibles sur le profil du labre; columelle oblique, munie de cinq plis décroissants, les trois premiers souvent seuls visibles en avant et un peu épais, le quatrième très enfoncé, et le cinquième se réduisant à un renflement parfois impereptible; bord columellaire indistinct sur presque toute son étendue, un peu plus calleux vis-it-vis des trois plis antérieurs.

Diagnose refaite d'après la figure de l'espèce-type, et d'après deux plésiotypes de l'Eocène d'Australie : M. propinqua Tate (PI. IV, fig. 11), et M. Winkleri Tate (PI. IV, fig. 29), ma coll.

Rapp. et diff. - Ce groupe de petites espèces se distingue des vraies Marginelles, non seulement par sa forme générale plus fusoïde, moins ventrue, mais encore par les denticulations internes du labre, et par la disposition de ses plis columellaires, plus épais, moins écartés, auxquels sajoute un cinquième pli rudimentaire, du côté postérieur. Il y a des échantillons sur lesquels les denticulations labiales sont à peine marquées, on même totalement effacées; chez d'autres individus, il ne reste que trois plis columellaires, visibles au premier abord, et il faut une extrème attention pour apercevoir le quatrième; malgré ces variations, je crois, en résumé, que la subdivision, proposée par M. Jousseaume, est admissible, car elle s'applique à un groupe assez homogène de coquilles qu'on sépare sans difficulté de la forme typique de Marginella; mais sous la réserve 
d'attribuer à Serrata la valeur d'une Section seulement, sans en faire un Genre distinct, comme l'a intitulé M. Jousseaume.

Répart. stratigr.

Eocexe. - Les deux plésiotypes ci-dessus figurés, dans l'Australie, ma coll.

Mrocene. - Une espèce dans les couches de la Jamaïque et de SaintDomingue: $\boldsymbol{M}$. coniformis Sotv., d'après la figure publiée par Guppy.

Purocexe. - Une espèce dans la Floride: M. Willcoxiana Dall, d'après la Monographie de cet auteur.

Epoque actuelle. - Quatre ou cinq espèces dans l'Océan Indien, et aux Philippines, d'après M. Jousseaume.

Eratoidea, Weinkauff, 1878. Type : M. margarita, Kiener. Viv. (= Denticuloglabella, Sacco 1889)

Taille assez pelite; forme ventrue, peu allongée, spire courte, à galbe légèrement extraconique; protoconche très obtuse, vernissée comme la spire; tours convexes, séparés par des sutures enfoncées; dernier tour ovale, arrondi el quelquefois plissé en arrière, régulièrement atténué à la base. Ouverture assez courte, étroite, munie d'une goutlière superficielle dans l'angle inférieur, et d'un sinus basal peu échancré à son extrémité antérieure; labre à peu près vertical, non entaillé à la suture, extérieurement bordé par un large bourrelet, intérieurement crénelé par de courtes dentelures, parfois très écartées, dont la dernière en bas forme une saillie plus forte, à quelque distance de la goutlière postérieure; columelle peu incurvée, munie de quatre plis épais, aussi larges que leurs intervalles, les deux antérieurs obliques, les deux postérieurs transverses; bord columellaire peu distinct, formant quelquefois, en arrière, une saillie calleuse et axiale, qui rejoint le dernier pli columellaire, à l'extrémité inférieure de la gouttière.

Diagnose faite d'après un plésiotype du Pliocène de Karikal: M. Bonneli n. sp. (Pl. 111, fig. 27-28), coll. Bonnet.

Rapp. et diff. - J'ai lıésité à conserver cette Section distincte de Serrala qui est antérieure; toutefois, en présence de la forme plus trapue de 
la coquille, des crénelures du labre, et surtout à cause de l'épaisseur des plis columellaires, Eratoidea se distingue assez facilement des espèces allongées et finement denticulées du groupe Serrata; en outre, la gouttière postérieure n'entaille pas le bourrelet du labre, le bord columellaire est plus calleux en arrière qu'en avant, tandis que c'est l'opposé chez $M$. serrala. Pour ces motifs, je n’ai pas supprimé la dénomination proposée par Weinkauff, mais j'ai été obligé de l'interpréter d'une manière très restreinte. J'y réunis d'ailleurs Denticuloglabella, qui ne me parait présenter ancune différence sectionnelle.

\section{Répart. stratigr.}

Eocene. - Deux espèces douteuses dans l'Australie du Sud: $M$. Wentworthi et micula Tate, ma coll.; une espèce dans le Bassin de Nantes: Mr. mirula Cossm., coll. Dumas; deux espèces dans le Claibornien de I'Alabam et dans le Jacksonien du Mississipi: M. constricta Conr., M. constrictoides Meyer, ma coll.

Mrocene. - Une espèce bien caractérisée dans le Tortonien du P’iémont: M. Deshayesi Mich., d'apres la Monographie de M. Sacco. Deux espèces dans les couches de la Nouvelle-Zélande: $M$. conica et ovata (") Ilarris, d'après le Catalogue "Australasian» de M. Géo. Harris. Une espèce dans la Virginie: M. donliculala Conr., et une autre dans les couches à silex de la liloride: M. Neromanni Dall, d'après la Monographie de cet auteur.

Pliocene. - L'espèce plésiotype ci-dessus figurée, avec plusieurs variétés, dans l'Inde française.

Epoque Actuelle. - Quelques espèces sur la côte allantique de l'Amérique.

Stazzania, Sacco, 1889. Type : M. emarginata, Bon. Mioc.

Taille petite; forme ventrue, ovale, biconique; spire courte et obtuse; protoconche formée d'un bouton indistincl sous la couche vernissée; tours peu nombreux, un peu convexes, déprimés aux sutures; dernier tour très grand, renflé en arrière, régulièrement atténué en avant. Ouverture très étroite, à bords parallèles, avec une goultière plus ou moins entailléedans l'angle inlérieur, tronquée en avant par un sinus peu profond; labre oblique, épais, lisse à l'intérieur, faiblement bordé à l'extérieur, aplati dans le plan de

(1) Cette dernière espèce doit changer de nom, pour cause de double emploi avec M. ovala Lea; je propose en conséquence : M. Harrisi, nob. 
l'ouverture, portant souvent une petite protubérance, ou un simple renflement, au-dessus de la gouttière suturale; columelle à peu près rectiligne, avec un pli antérieur oblique et raccordé avec le conlour supérieur, pais trois autres plis égaux, saillants, équidistants, transverses, écrasés ou plutôt bifurqués à leur extrémité, sur le bord columellaire qui est mince et peu distinct.

Diagnose complétée d'après un échantillon de l'espèce-type, du Tortonien de S. Agata (PI. IV, fig. 5), ma coll.; et d'après un plésiotype de l'Eocène du Bois Gouët, près de Nantes : $\boldsymbol{M}$. dicholomo ptycha Cossm. (Pl. IV, tig. 8 et 20 ), ma coll.

Rapp. et diff. - Cette Section est principalement caractérisée par la disposition de ses plis, dont les trois inférieurs sont invariablement terminés, à l'entrée de l'ouverture, par un contrefort triangulaire ou bifurqué, avec deux branches en $V$, parfois tellement ouvertes qu'elles se rejoignent d'un pli à l'autre; il y a un autre caractère distinctif, d'une réelle importance, c'est l'aplatissement du labre sur sa face frontale, qui contribue à rétrécir davantage l'ouverture ; mais cet épaisissement cesse généralement dans l'angle inférieur, avant d'atteindre la gouttière suturale, de sorte qu'il semble exister une sallie dentiforme au-dessus de cette gouttière, quoique, en réalité, le labre ne porte ni crénelures, ni dents. En résumé, la séparation de celte Section est au moins aussi justifiée que celle des précédentes, et dès l'instant qu'on admet celles-ci, il est nécessaire de distinguer aussi Stazzaniu.

\section{Répart. stratigr.}

Eocene. - Plusieurs espèces typiques, dans le Bassin anglo-parisien, et dans la Loire inférieure ou le Cotentin: $M$. bifuloplicala Charlesw., $M$. abnormis Morlet, $M$. fragilis Desh., $M$. dichotomoplycha Cossm., ma coll.; quelques autres espèces parisiennes, à plis seulement écrasés : $M$. conlabulnta et aculangula Desh.; enfin, plusieurs espèces du Calcaire grossier, à plis simplement épais et à renflement labial : M. eburnea Lamk., M. crassula, Edvoardsi, dissimilis Desh., M. Chastaingi Cossm, M. cremulata Desh., ma coll.

Origocexe. - Une espèce dans le Stampien des environs de Paris: M. Bezançoni Cossm. et Lamb., ma coll. Une espèce dans les envivirons de l'érone: $M$. eratoides Fuchs, ma coll. ; trois autres espèces dans le Vicentin : M. obtusa, hugensis et amphiconus Fuchs, d'après les figures publiées par l'auteur; deux autres espèces dans la Vénélie: $M$. Brongniarti Desh. et $M$ I. quinquiesplicata(') Oppenh., d'après

(i) Cette dernière espéce doit changer de nom, pour cause de double emploi arec l'espece vivante. (M. quinqueplicula); je propose en conséquence: M. Oppenheimi, nobis. 
Marginella

les Notes de M. Oppenheim; deux espèces dans les Tongrien de l'Allemagne du Nord : $\boldsymbol{M}$. intumescens et pergracilis von Konen, d'après la Monographie de cet auteur.

Mhocese. - Outre le type, dans le Tortonien du Piémont, une espèce dans le Bassin de Vienne : Mr. eratoformis A. Ilornes et Auinger, d'après la Monographie de ces auteurs.

Dentimargo, nov. sect. Type: $M$. dentifera, Lamk. Eoc.

Taille très petite, forme étroite, fusoïde ; spire assez longue, à peu près égale à l'ouverture; protoconche obtuse etsubgrlobuleuse ; tours un peu convexes; séparés par des sutures profondes et toujours visibles sous le vernis; dernier tour relativement court, ovale, non ventru, atténué et faiblement excavé à la base. Ouverture assez large, avec une goultière anguleuse du côté postérieur, obliquement tronquée par un sinus antérieur très peu profond; labre légèrement convexe, plus ou moins épais, avec un rebord externe parfois aplati, portant à l'intérieur une dent assez aiguë, et quelquefois une costule interne vaguement crénelće; columelle incurvée, munie de quatre plis minces, obliques, presque parallèles; bord columellaire indistinct.

Diagnose établie d'après un échantillon de l'espice-type, du Calcaire grossier de Grignon (Pl. IV, fig. 15), ma coll.

Rapp. et diff. - Il ne m'a pas semblé possible de classer celte petite coquille dans l'une des autres Sections de Marginella précédemment énumérées; elle s'en écarte par sa forme étroite, par sa dent labiale aiguë, et aussi par ses profondes sutures: elle n'a pas de crénelures comme Serrala, et sa spire est plus longue; ses plis columellaires la rapprochent des Marginella typiques; mais, outre qu'elle n'en a pas le galbe extérieur, elle porte une dent labiale, dont on n'aperçoit jamais la trace chez $\boldsymbol{M}$. glabella.

Il est évident que la création de cette nouvelle subdivision est la conséquence du nombre, déjà considérable, de celles qu'on a proposées avant moi; cependant, dans cette Famille dont l'arrangement méthodique est très embarrassant, il faut se résigner : soit à admettre un grand nombre de Sections, soit à réunir toutes les formes sous la désignation unique Marginella; or ce dernier parti me paraît trop sommaire, en présence des 
Marginella

différences réelles que présentent les coquilles qu'on juxtaposerait ainsi sans aucune taxonomie. Toutefois les caractères distinctifs, que j’ai signalés ci-dessus pour Dentimargo, ne dépassent pas l'importance d'une simple Section.

Répart. stratigr.

EOcExE. - Le type et la variété arclata Desh., dans le Bassin de Paris et dans celui de la Loire-Infériéure, ma coll.; une autre espèce dans ce dernier gisement: $\boldsymbol{M}$. suturata Cossm.; une espèce parisienne, à spire plus courte et à bourrelet plus épais: M. hordeola Desh., coll. Cossmann.

Oligocene. - Une espèce très voisine de $M$. arctata, dans le Vicentin: $M$. gracilis( $\left.{ }^{1}\right)$ Fuchs, d'après la figure donnée par cet auteur.

Grabella, Swainson, 1840. Type : M. prunum Gmelin. Viv.

$$
\begin{aligned}
& \text { (= Prunum H. et A. Adams 1853; = Egouena, } \\
& \text { Jouss. 1875; = Porcellana, Conr. 1862) }
\end{aligned}
$$

Taille assez grande; forme olivoïde, quelquefois un peu venIrue; spire très courte, à galbe conoïdal, à sommet pointu; protoconche petite, obtuse et peu distincte; trois ou quatre tours convexes, à sutures déprimées; dernier tour formant presque toute la coquille, ovale, régulièrement atténué à la base qui n'est pas excavée. Ouverture très étroite en arrière, avec une gouttière échancrant souvent le péristome, un peu dilatée en avant, où elle se termine par une sinuosité à peine entaillée; labre légèrement oblique, un peu convexe, très épais, lisse et réfléchi à l'intérieur, bordé par un bourrelet arrondi qui se prolonge autour de la sinuosité basale, et qui remonte presque toujours sur la spire, parfois jusqu'au sornmet, avec une dépression vis-à-vis de la gouttière postérieure; columelle oblique, rectiligne, munie de quatre plis assez épais, les deux antérieurs plus rapprochés l'un de l'autre; bord columellaire souvent calleur et étalé sur la base, toujours limité du côté antérieur, où il se relie avec le bourrelet du contour supérieur.

(1) Il existait déjả $\boldsymbol{M}$.gracilis $\mathrm{Edw}$ (1854); il y a donc lieu de changer le nom de l'espèce vicentine; je propose en conséquence: M. Fuchsi, nobis. 
Diagnose refaite d'après des échantillons de l'espèce-type, et d'après une nouvelle espèce plésiotype, du Pliocène de Karikal : $M$. oligoptycha Cossm (Pl. III, fig. 29-30), coll. Bonnet.

Rapp. et diff. - Ce Sous-Genre se distingue de Marginella par son sinus basal à peine échancré, de sorte que, quand on regarde en plan la coquille posée sur son sommet, le contour supérieur ne paraît presque pas sinueux. D'antre part, les plis columellaires ont une disposition particulière : dans l'espèce que je prends comme plésiotype, les deux plis antérieurs sont très rapprochés, ou mème presque confondus en un seul bifide; enfin le bourrelet du labre se prolonge davantage en arrière; il n'cst pas rare qu'il atteigne le sommet, tandis que, chez les vraies Marginelles, il ne dépasse pas la suture. Les espèces qui ressemblent à $\boldsymbol{M}$. Egouen Adanson, et que M. Jousseaume a groupées dans son Genre Egouena, ont en outre une callosité columellaire largement étalée sur le dernier tour et sur la base; mais ce seul caractère ne me paraît pas suffisamment important pourmoliver la création d'une section distincte de Glabella. Quant à l'rumum Adams, le type ( $\boldsymbol{M}$. marginala Born) ne présente aucune différence générique qui le distingue de $\boldsymbol{M}$. prumum; la seule particularité que je constate est l'énorme développement du péristome, dont la callosité ne laisse apparaître qu'une partie de la surface dorsale.

\section{Répart. stratigr.}

Miocexe. - Une espèce de la Virginie et de la Filoride, qui a servi de type au Genre Porcellana, abandonné depuis par son auteur : M. bella Conrad, d'après le Manuel de Tryon et la Monographie de M. Dall.

Pliocexe. - Le plésiotype ci-dessus figuré, dans l'Inde française (voir la description à l'annexe ci-après).

Pleistociane. - Une espèce encore vivante, dans les couches récentes de Victoria : M. urbinata Sow., d'apris le Catalogue de M. Géo. Harris.

Fipopre actuelle. - Plusieurs espèces sur les côtes occidentales de l'Arrique et sur les côtes des deux Amériques, d'après lo Manuel de Tryon.

Volvarina, Hinds, 1844.

Type: M. triticea, Lamk. Viv.

Taille au-dessous de la moyenne; forme cylindracée, ou ovoïde et étroite; spire très courte, à peine saillante, à galbe conoìdal; protoconche obluse; tours un peu convexes, séparés par des 
Marginella

sutures indistinctes; dernier tour formant les $5 / 6$ ou les $7 / 8$ de la longueur totale, légèrement ovale, atténué du côté antérieur. Ouverture très allongée, rétrécie en arrière, avec une gouttière peu profonde, tronquée en avant par un sinus sans échancrure; labre un peu arqué, contracté vers l'ouverture, peu épais, non bordé à l'extérieur, lisse à l'intérieur, rétrocurrent en arc de cercle contre la suture; columelle peu convexe, munie de quatre plis obliques, situés assez en avant, un peu épais, égaux aux rainures qui les séparent; la quatrième rainure est bordée en dessous par un redan qui ressemble à un cinquième pli; bord columellaire peu calleux, assez étroit.

Diagnose refaite d'après un échantillon de l'espèce-type, et d'après un plésiotype du Tortonien de S. Agata, dans les environs de Turin: M. oblongala Bon. (Pl. IV, fig. 21), ma coll., don de M. Sacco.

Rapp. et diff, - Les coquilles comprises dans ce Sous-Genre forment un groupe assez homogène, remarquable par la brièveté de la spire, et par le galbe cylindracé du dernier tour; cependant ces caractères ne m'auraient pas paru suffisants pour motiver la distinction d'un SousGenre de Marginella, attendu qu'il existe des formes intermédiaires, dont le classement serait absolument incertain, si l'on se bornait à ces deux caractères; mais il y a deux autres différences, signalées par M. Jousseaume, qui justifient davantage la séparation proposée par Hinds, et adoptée par la plupart des auteurs, sans que ni les uns ni les autres aient paru y attacher d'importance: d'abord le labre n'est pas bordé par un bourrelet externe, séparé du reste de la surface, ainsi que cela a toujours lieu chez Marginella; en second lieu, il se contracte vers le milieu de sa hauteur, et il se réfléchit sur l'ouverture, qu'il rétrécit invariablement sur les deux tiers de la longueur de celle-ci. Enfin je remarque que les plis obliques et très antérieurs, que porte la columelle, paraissent plutôt produits par des rainures que par des saillies lamelleuses, à tel point que la rainure inférieure semble bordée par un cinquième pli ; mais, en réalité, ce n'est pas un pli additionnel, c'est seulement un rebord de la région pariétale, sans aucune saillie.

Répart. stratigr.

Eockxe. - Deux espèces douteuses, à labre un peu bordé, dans le Bartonien et le Parisien du Bassin de Paris: M. cylindracea Desh., M. Bouryi Cossm., ma coll. 


\section{Marginella}

Mocexe. - Deux especes dans l'Ilelvétien du P'iémont : $M$. elongata Bell. et Mich., M. parvula Sacco, ainsi que le plésiotype ci-dessus figuré, du Tortonien, d'après la Mlonographie de M. Sacco; une espéce bien caractérisée dans le Bassin de Vienne: M. Haueri, Ii. Il ernes et Auinger, d'après la Monographie de ces auteurs.

Phocexe. - Une espèce dans le Plaisancien de la Ligurie : M. Bellardiana Semper, d'après Bellardi. Une espèce dans les couches récentes de Java : M. tambacana Martin, d'après la Monographie de cet auteur. Une espèce vivant encore sur les côtes de la Géorgie, dans la Floride : $M$. styria Dall., d'après cet auteur.

Epoque actuelle. - Une quarantaine d'espèces, dans la Méditerranée, sur les côtes occidentales d'Afrique, dans le golfe du Mexique, an Cap, dans l'Australasie, d'après la Monographie de II. Joussenume.

\section{GRYP'TOSPIRA, Hinds, 1844.}

Taille moyenne; forme ovale, parfois ventrue en arrière; spire à peine saillante, quoique apparente; limbe basal calleux et bien limité, correspondant aux accroissements de l'échancrure. Ouverture assez étroite, entaillée à son extrémité antérieure; labre plus ou moins épais, lisse ou plissé à l'intérieur;cinq plis columellaires, auxpuels s'ajoutent fréquemment des rides pariétales plus ou moins nombreuses.

Type: M. quinqueplicata, Lamk. Viv.

Observ. - Je ne connais pas de Cryplospira (sensu stricto) à l'état fossile; la forme typique se distingue par ses cinq plis, par son labre lisse, quoique Weinkauff et Tryon y rapportent aussi $\boldsymbol{M}$. encaustica, qui a des denticulations labiales, et qu'ils considèrent comme le jeune âge de $M$.quinqueplicata; je ne partage pas cet avis, et j'estime que les espèces vivantes qui sont dans le même cas appartiennent, de même que $\boldsymbol{M}$. encaustica, à la section Gibberula. Dans sa Monographie des couches récentes de Java, M. Martin cite et figure une variété minor de l'espèce-type de Cryptospira, qui aurait, par conséquent, vécu à l'époque pliocénique. Il figure également, comme provenant des mêmes gisements, une espèce vivante plus étroile: Cryplospira dactylus Lamk., des mers de Chine. N'ayant pu me procurer ces échantillons, pour les faire figurer, je me borne à enregistrer ces citations. 
Eur yentome, nov. sect. Type: $M$. crassilabra (1), Conr. Eoc.

Taille petite; forme ovale, subtrigone; spire courte, mais saillante; protoconche subglobuleuse, obtuse; tours peu nombreux, à sutures visibles; dernier tour très grand, arrondi et ventru en arrière, atténué et excavé à la base; limbe basal peu distinct. Ouverture étroite, à bords presque parallèles, échancrée en arrière par une profonde gouttière qui entaille le péristome ; crure basale peu profonde; labre un peu oblique, très épais, bordé par un gros bourrelet qui est aplati surle flanc, sinueux près de la suture et prolongé par une callosité jusque sur la spire ; crénelures fines, irrégulières et nombreuses sur le contour interne du bourrelet labial; columelle à peine sinueuse, munie d'un pli antérieur très oblique, et de trois à cinq plis transverses, puis de deux ou trois rides pariétales; bord columellaire calleux, largement étalé jusque vers le limbe.

Diagnose établie d'après des individus de l'espèce-type, de l'Eocène moyen de Claiborne (Pl. IV, fig. 9-10), ma coll.

Rapp. et diff. - La profonde échancrure suturale de cette coquille la distingue immédiātement de Cryptospira quinqueplicata; en outre, elle possède des crénelures labiales et plus de plis que l'espèce vivante, sa callosité columellaire est bien plus étendue, et son limbe est à peine apparent. D'autre part, on ne peut la confondre avec Eratoidea, qui n'a jamais plus de quatre plis, et dont le labre n'est pas entaillé à la suture.

\section{Répart. statigr.}

Eocene. - L'espèce-type ci-dessus figurée, dans le Claibornien de l'Alabama, ma coll.; une autre espèce, à plis columellaires bifides, dans l'Australie du Sud : M. sulcidens Tate, ma coll.

(1) Il y a lieu de noter que le nom crassilabra a été employé, aprẻs Conrad et Lea, pour d'autres types de Murginella, par Reeve et par Soverby; les corrections relatives à ces doubles emplois nont pas encore été faites, du moins à ma connaissance. L'espècetype d'Euryentome a pour synonymes: $M$. columba Lea, $\boldsymbol{M}$. anatina Lea, $\boldsymbol{M}$. humerosa Conrad. 
Grbberula, Swainson, 1840. Néotype: Voluta miliaria, Lin. Viv. (=Granula, Jouss. 1875; = Microspira, Conrad 1862.)

T est mince et vitreux. Taille petite; forme ovale, tantôt subpiroïde, tantôt cylindracée; spire à peine proéminente, dont le galbe est souvent confondu avec celui du dernier tour, réduite à un nucléus embryonnaire el obtus, plus un ou deux tours peu distincts et très étroits; dernier tour formant à peu près toute la coquille, arrondi et un peu ventru en arrière, à galbe ovale ou conique du côté antérieur; limbe basal large et calleux, limité par une arête obtuse. Ouverture très étroite en arrière, avec une goullière anguleuse qui n'entaille pas le péristome, à peine plus clilatée du côté antérieur, où elle est profondément échancrée; labre peu épais, un peu oblique et excavé en profil, rétrocurrent en arc de cercle vers la suture, non bordé par un bourrelet externe, lisse ou orné de crénelures internes, minces et transversalement allongées; columelle à peine sinueuse, portant généralement deux, trois ou quatre plis antérieurs, assez épais, plus un nombre variable de plis ou de rides pariétales, beaucoup plus minces et plus horizontales que les plis antérieurs; bord columellaire peu calleux, mais distinct sur toute sa hauteur, appliqué en avant sur une partie du limbe basal.

Diagnose refaite d'après des plésiotypes de l'Eocène: Mr. orala Lea (= larvata Conrad), du Claibornien de l'Nlabama (PI. III, fig. - -6); M. ovulata Lank., du Calcaire grossier de Villiers (I. IV; fig. 1') 1:3); ma coll.

Observ. - MM. Dollfus et Dautzenberg (Moll. Roussillon, I) désignent M. zonata Brug. comme type de cette Section; or cette espèce est de Kiener, et elie est tout á fait différente des formes de ce gronpe; d'autre part, Fischer indique $M$. clandestina comme exemple de Gibberula, tandis que c'est un Fersicula qui n'a pas la spire apparente, comme on le verra ci-après. Dans ces conditions, j'ai dû faire choix d'un néolỵpe, et j'adopte, à cet effet, Voluta miliaria Lin., qui est l'espèce la plus connue de cette Section. 
Cryptospira

Rapp. et diff. - Les petites cocuilles que M. Jousseaume a groupées dans son Genre Granula répondent exactement à la diagnose de Gibberula; il y a donc lieı d'y réunir Granula, comme synonyme postérieur. Ces coquilles s'écartent des Cryptospira typiques : non seulement par leur petite taille et par la minceur de leur test, mais encore par leur labre non bordé à l'extérieur, liré à l'intérieur, par leurs plis columellaires plus nombreux, s'étendant généralement jusque sur la région pariétale. D'autre part, on distingue cette Section d'Euryentome par l'absence d'une échancrure suturale, par la brièveté de sa spire, ainsi que par son labre, qui n'est pas bordée d'un bourrelet et qui s'applique tangentiellement sur la surface de l'avant-dernier tour.

\section{Répart. stratigr.}

Eocexe. -- Outre les deux plésiotypes ci-dessus figurés, nombreuses espèces dans le Bassin anglo-parisien, dans le Cotentin et dans la Loire-Inférieure : $M$. elevala et Frederici Cossm., $M$. pusitin et vittria Edw., M. Cossmanni Morlet, M. acuispira et suboliva Cossm., M. Geslini Vasseur, M. cenchridium Cossm., ma coll. Une espèce ornée de plis axiaux vers le sommet, dans le Claibornien de l'Alabama: M. plicala Lea, ma coll.; autre espèce typique, du même gisement : M. semen Lea, ma coll.

Oligocexe. - Une espèce bien caractérisée, dans le Stampien de Picrrefitte: M. stampinensis Stan. Meunier, ma coll.; plusieurs espèces dans le Tongrien inférieur de l'Allemagne du Nord: $M$. perovalis, globulosa, bidens, conoides, von Konen, d'après la Monographie de cet auteur.

Mrocras. - Une espèce voisine de l'un des plésiotypes, dans le Burdigalien de l'Aquitaine et dans l'Helvétien de la Touraine: $\boldsymbol{M}$. subovulala d'Orb., ma coll.; I'espèce-type dans l'Ilelvétien de la Vienne, ma coll. ; autre espèce dans l'Helvétien de la Touraine: $M$. Hornesi Brus., ma coll. ; la même dans le Bassin de Vienne, d'après MM. R. Hœrnes et Auinger, et dans le Tortonien du Portugal d'après la Monographie de Pereira da Costa ; autre espèce dans le Bassin de Vienne: $\boldsymbol{M}$. minula Horn. et Auinger, d'après la Monographie de ces auteurs. Une espèce des Etats-Unis, type du Sous-Genre Microspira: M. oviformis Conrad, d'après le Manuel de Tryon; deux espèces dans les couches à silex de la Floride : M. ballista et gravida Dall., d'après la Monographie de cet anteur.

P'rocexe. - Une espèce nouvelle, dans les couches récentes de Karikal: $M$. tectiformis, nob. (voir la description dans l'annexe ciaprès); une espèce bien caractérisée dans les couches de Java : $\boldsymbol{M}$. Dijki Martin, d'après la Monographie de cet auteur; plusieurs espices dans le Pliocène de la Floride: M. anchidiella et eulima Dall, d'après la Monographie de cet auteur. 
Epoque acturlez. - Une douzaine d'espèces dans l'Océan Indien, au Cap, en Australie et aux Indes occidentales, d'après M. Jousseaume, et d'après le Manuel de Tryon.

PERSICULA, Schumacher, 1817.

Persicula, sensustricto. Type $: M$. cingulata, Dillw. Viv. (=Rabicea, Gray 1857)

'Taille moyenne ou petite; forme ovoïde plus ou moins globuleuse, parfois assez étroite; spire déprimée, à peine visible, ou totalement recouverte par le prolongement de la callosité du jéristome; dernier tour embrassant toute la coquille, régulièrement ovale jusqu'au limbe basal qui forme une callosité saillante et bien limitée. Ouverture étroite, à bords parallèles, avec une gouttière canaliculée dans l'angle inférieur, et une profonde échancrure à l'extrémité antérieure ; labre un peu oblique, légèrement excavé, médiocrement épais, à peine bordé à l'extérieur, souvent réfléchi à l'intérieur; columelle convexe, munie de plis nombreux qui décroissent d'avant en arrière, le premier très épais, se raccordant avec le contour supérieur.

Diagnose complétée d'après des échantillons de l'espèce-type et de M. comea Lamk., ainsi que d'après un plésiotype du Calcaire grossier de Parnes: M. angystoma Desh. (Pl. IV, fig. 16), ma coll.; autre espèce à callus apical styliforme : $\boldsymbol{M}$. Goossensi Cossm. (II. IV, fig. 17), ma coll.

Rapp. et diff. - L'animal de Persicula est un peu différent de celui de Marginella; le pied est plus étroit, et la formule de la radule est différente; mais, lorsqu'on n'a que les coquilles à sa disposition, la comparaison de Persicula, avec Closia par exemple, est plus difficile. On peut cependant établir une ligne de démarcation entre ces deux formes: non seulement à cause du nombre des plis columellaires (quatre chez Closia seulement), et de l'absence d'un bourrelet labial chez Persicula, mais encore à cause de l'échanerure basale qui paraît être plus profonde chez ce dernier. II est 
incontestable que ces caractères distinctifs sont très fugitifs; aussi la plupart des auteurs ont-ils classé les espèces fossiles, tantôt dans le SousGenre Closia, tantôt dans le Genre Persicula; je n'ai pas échappé à cette erreur, dans mon "Catalogue illustré des coquilles foss. de l'Écoc. des env. de Paris ", où j’ai rapporté à Closia l'espèce que je prends désormais, après un examen plus minutieux, pour plésiotype de Persicula. Quant à Rabicea Gray, je n'aperçois aucune différence générique qui permette de le séparer de Persicula cingulata; c'est une dénomination complètement synonyme, à supprimer selon moi.

\section{Répart. stratigr.}

Eocene. - Outre les plésiotypes du Bassin de Paris, ci-dessus figurés, une autre espèce typique dans les Bassins de Paris et de Nantes: Erato ampulla Desh., ma coll., autre espèce très étroite, dans la Loire-Inférieure : $M$. Dautzenbergi, Cossm., ma coll.

Pliocene. - Une espèce de très petite taille, dans l'Astien des AlpesMaritimes et du Piémont, et dans le Plaisancien de la Toscane: M. clandestina Br., ma coll. Une espèce dans la Caroline : $M$. clacria Dall, et une autre dans la Floride; $M$. amiantula Dall, d'après la Monographie de cet auteur.

Epoque actuelle. - Espèces assez nombreuses, sur la côte occidendentale d'Afrique, dans le golfe du Mexique, sur les côtes du Brésil et én Australie, d'après la Monographie de M. Jousseaume, et d'après le Mlanuel de Tryon.

VOLUTID E, Gray.

Taille généralement grande, ou même très grande; forme allongée, plus ou moins ovale, parfois stromboïde; spire assez courte par rapport au dernier tour; proloconche lisse, très variable, tantôt petite et conoïde, tantôt énorme et bulbiforme, avec un nucléus peu saillant, ou bien, au contraire, mucroné. Ouverture allongée, quelquefois un peu dilatée, tronquée en avant par une échancrure souvent très profonde, quelquefois réduite à une simple sinuosité; labre généralement épais, droit, ou à peine incliné à gauche de l'are, du côté antérieur, peu ou point sinueux en arrière; columelle calleuse, coudée au milieu, faiblement excavée en arrière, très obliquement tordue en avant, 
terminée par une pointe qui dépasse généralement l'extrémilé opposéc du labre, bien au-delà de l'échancrure; plis columellaires extrêmement variables, au nombre de 3 à 5 en général, parfois très obliques, très minces et très inégaux, tantôt épais, subtransverses et presque égaux, décroissant toujours d'avant en arrière; bord columellaire plus ou moins épais, ordinairement étalé sur la base; rarement un opercule.

Observ. - Ainsi qu'on peut s'en rendre compte par la diagnose ci-dessus, les caractères principaux de la coquille des Volutide (forme générule, protoconche, plis columellaires, opercule, etc...) sont essentiellement variables; aussi la classification des nombreux Genres, proposés dans celte Famille, présente-t-elle de réelles difficultés. Gray s'est principalement guidé d'après l'anatomie de l'animal, et ceux qui l'ont suivi (Adams, fischer, etc...) ont surtout observé les différences de la dentition; Crosse, au contraire, s'est presque exclusivement rapporté à la forme de la coquille et aux plis de la columelle. Enfin, tout récemment, dans son importante Monographie du Tertiaire de la Floride, M. Dall a adopté un systeme tout à fait différent, uniquement basé sur la forme de la protoconche.

D’après M. Dall, la coquille embryonnaire des Voluticlie peut être diviséc en deux catégories fondamentales : selon que le nucléus est plus ou muins petit, mais arrondi, non saillant; ou bien selon qu'il forme une pointe mucronée, se délachant des autres tours embryonnaires. Il classe les coquilles de la première catégorie dans la division "Volutoïd series », et celles de la seconde, dans "Scaphelloïd series »; ensuite la premiere catégorie est subdivisée en plusieurs groupes, selon que la protoconclie a un galbe trochiforme, pupiforme, ou bulbiforme; cette classification étant admise, l'anteur a remarqué que les Volutes de la "Volutoïd serie " sont les plus anciennes, et que, plus on descend profondément dans l'ancienneté stratigraphique de la fossilisation, plus le nucléus est petit, de sorte que M. Dall en conclut que les premiers représentants de cette famille paraissent descendre des Fusidie, qui les ont précédés dans leur apparition au fond des mers mésozoïques; tandis que la protoconche des Volutes actuelles est beaucoup plus développée, et que celle de la « Scaphellö̈d serie " ne date que de l'Eocène, et encore avec une certaine atténuation, relativement aux Scaphella récents.

Cie système est certainement très intéressant au point de vue morpliologique; il est même très exact que plusieurs coquilles de Volutidu se rattachent intimement, par l'intermédiaire des Mitridx, aux premiers Fasciolaria; mais il ne peut servir de base à une classification des Volulide, attendu que, ainsi que l'auteur l'a lui-même reconnu, certains Genres de la Famille en question sont à la fois représentés dans plusieurs groupes 
fondés sur la forme de la protoconche; d'autre part, déjà dans l'Eocène, à côté de formes dont l'embryon est aussi petit que celui des espèces crétaciques, on trouve subitement des embryons bulbeux, ressemblant complètement à ceux des Volutes actuelles, surtout dans la région australasienne, qui est la plus riche en Volutidæ, et où les protoconches ont toujours un caractère aberrant que j'ai déjà observé en mainte occasion. Il résulte de là que la gradation insensible, que comporte la théorie de M. Dall, pour passer des protoconches crétaciques aux protoconches de l'époque contemporaine, n'existe pas en réalité, que c'est une question d'habitat régional sur le globe terrestre, et qu'on ne peut, par conséquent, en tirer aucune conclusion absolue, même au point de vue morphologique. Les plis columellaires eux-mêmes ne peuvent pas être d'un grand secours, pour établir l'enchaînement phylogénétique des Volutidx; c'est également un caractère dont l'apparition ne procède pas avec la régularité qu'exige un arbre généalogique. L'échancrure basale, qui ne commence à se montrer que dans les formes éocéniques, subit aussi des variations brusques qui déconcertent l'nbservateur.

C'est pourquoi, fidèle aux principes que j'ai posés dès le début de ces "Essais ", excluant les méthodes qui se guident d'après un seul caractère et qui n'aboutissent qu'à des mécomptes en matière de classification, je préfère adopter une division qui tienne compte, comme je l'ai fait pour toutes les autres Familles, de l'ensemble des caractères, tantôt de la forme générale de la coquille, tantôt de ses plis columellaires, tantôt de sa protoconche, tantôt enfin de son échancrure et accessoirement de son ornementation; puis, quand cette classification est établie d'une manière satisfaisante, je note l'ordre d'apparition des différents Genres dans les couches successives de l'écorce terrestre, et, s'il y a des lacunes inexplicables au point de vue phylogénétique, j'ai du moins la ressource de supposer encore qu'elles seront ultérieurement comblées par la découverte de nouveaux matériaux, provenant des immenses régions fossilifères, encore inexplorées à présent.

Je rappelle, à cette occasion, que j’ai placé dans la Famille Pleurotomidie toute une Sous-Famille Pholidotominx, formée de Genres empruntés à la Famille Volutidx (auctorum), munis de plis columellaires, mais présentant invariablement un caractère commun : la présence d'un sinus sutural, dont les accroissements forment des écailles crépues sur toute la spire. A l'appui de ce système, j'ai fait valoir que la protoconche des Pholidotominie n'a pas de rapports avec celle des Volutidie; or il est évident rue cet argumenl est infirmé par les dernières remarques de M. Dall sur la morphologie de la protoconche des coquilles de cette Famille, qui commence précisément par de petits embryons pendant la période crétacique, d'oir proviennent exclusivement les Pholidolomine. Toutelois cela ne prouve pas davantage que les Pholidotominx ne sont pas mieux à leur place dans la Famille Pleurotomidx, à cause de leur sinus, et malgré leurs plis columellaires; c'est une question discutable et qui ne parait pas 
encore résoluc. En tout cas, il est certain que les Genres Pholidoloma, Rostellites, Beisselia et Gosavia, dont se compose ma Sous-Famille, tries différents par leurs formes et leurs plis columellaires, constituent, par leur sinus sutural et par l'absence d'échancrure basale, un groupe particulier, qui ne pourrait se fondre dans aucun de ceux dont se compose la Famille Tolutidx; de sorte que, quel que soit le parti qu'on prenne ultérieurement, soit en la laissant définitivement dans les Pleurolomidre, soit en la rapprochant de nouveau des Volutidx, il y a lieu de laisser intacte cetle Sous-Famille, qui constitue un groupe à part. Toutefois, comme on le verra ci-après (voir l'annexe), je propose d'y ajouler encore le Genre Ficulopsis Stol. (1867), qui s'y rattache également par son sinus sutural.

Rapp. et diff. - La Famille Volutidx est bien distincte des Marginellidie, quon confondait autrefois avec elle, non seulement par sa protoconche peu obtuse et par sa surface non vernissée, mais cncore par son échancrure en général plus profonde, à l'extrémité antérieure de l'ouverture, et surtout par la disposition de la columelle, qui se termine en avant par une pointe effilée, recourbée vers l'axe de la coquille, et s'élevant plus haut que l'extrémité opposée du péristome. Du côté des Mitridx, la délimitation est aussi bien tranchée, quoique la forme de certains représentants de ces deux Familles soit queliuefois très semblable; le caractère invariable et certain, à l'aide duquel on peut reconnaître une Mitre d'une Volute, c'est l'ordre de décroissance graduelle de l'épaisseur des plis columellaires; tandis que ces plis décroissent d'avant en arrière chez les Volutidx, ils croissent en sens inverse chez tous les Genres de Mitridx; il s'agit, bien entendu, des plis principaux, du côté antérieur de la columelle, car les plissements transverses de la partie inférieure de la columelle et de la région pariétale, quand il y en a, n'obéissent pas à la même règle, et on en constate l'existence chez certaines formes appartenant à chacune de ces deux Familles.

\section{Tableau des Genres, Sous-Genres et Sections}

\section{VOLUTA}

(4 ou 5 plis, épines).

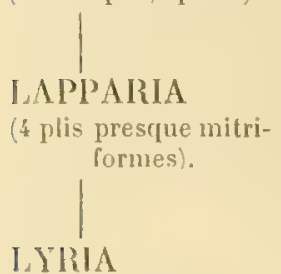

(3 plis, costules).
Voluta

(Protoconche. trochiforme).

\section{Lapparia}

(Protoconche tur-

binée. subscaphelloïle).

Lrria Lyria

(Protoconche bul- (Pas de dent labiale). biforme).

Enæta (A)

(bent tabiale).
Volutinx.

(Plis neu obliqques, échancrure basale et bourrelet). 


\section{CALLIPARA}

(2 plis, subcostulée).

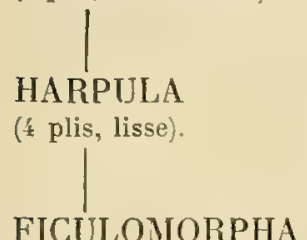

(4 plis, décussée.)

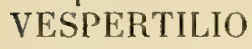

\section{Gallipara (B)}

(Protoconche à nucléus saillant).

Harpula

(Protoconche papilleuse).

\section{Ficulomorpha}

(Protoconche papilleuse).

Vespertilio

(4́plis, épines ou costules). (Prot oconche déprimée,canaliculée, labre mince).

\section{Aulica (G)}

(Protoconche en calotte lisse, sinus labial).

\section{A мовis}

(Protoconche turbinée, labre épais).

\section{LEPTOSCAPHA}

(4 plis obliques, mitriformes).

\section{LEPTOSCAPHA}

(Varices)
Volutinæ (Suile). (Plis peu obliques, échancrure basale et bourrelet).

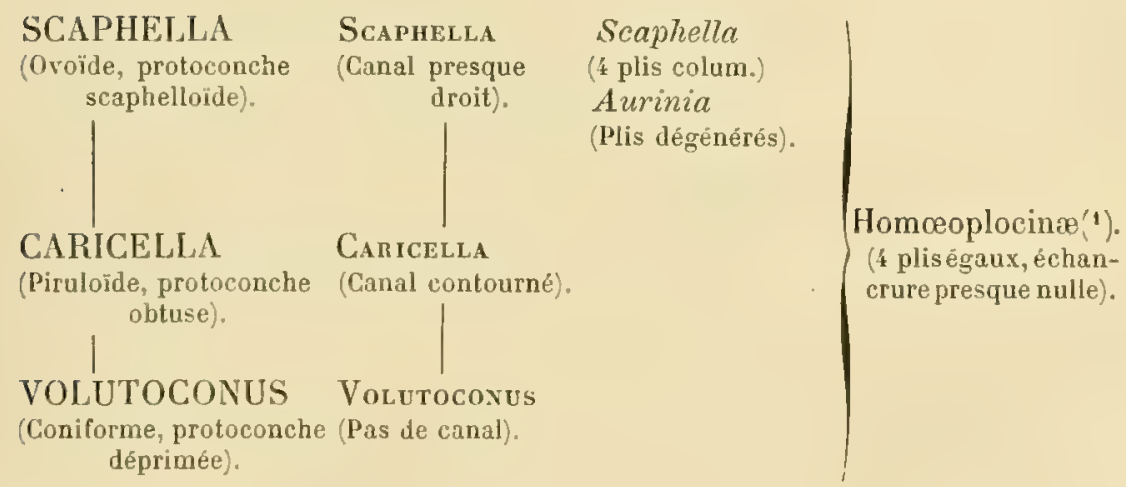

(1) Ou.oเs, semblable; $\pi \lambda_{0 \times 05}$, pli. - Par suite d'une transposition de texte, survenue au cours de l'impression, cette Sous-Famille n'occupe pas, dans le tableau, sa place exacte, aprés les Zicloninæe, à la page $\mathbf{1 0 \xi}$ 


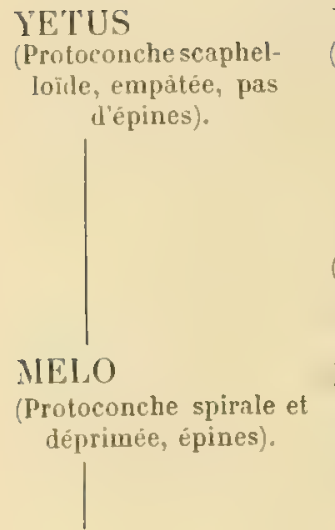

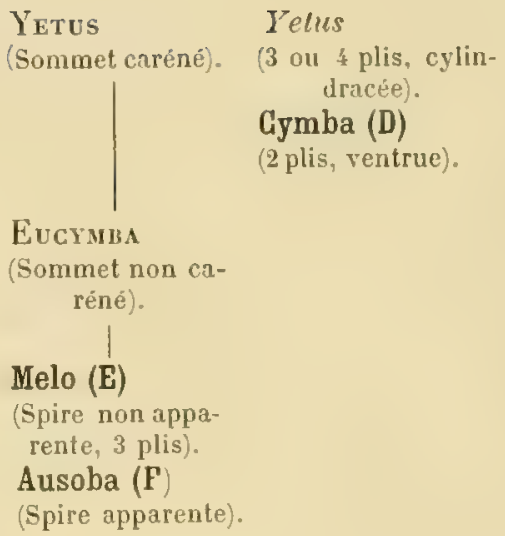

(Spire non apparente, 3 plis).

Ausoba (F)

(Spire apparente).

Telus

(3) \& plis, cylindracée).

Gymba (D)

(2 plis, ventrue).

Cymbinx.

Spire presque nulle, large échancrure, bande basale, colum. tordue).
CYMBIOLA Cymbrola

(Protoconche styliforme). (Spire Jibre, 2 plis).

\section{Zidona (G)}

(Spire empâtée).
Z Zidonina.

(Spire saillante, échancrure et bande basales).

\section{FUIGURARIA Fulguraria (H) \\ (Forme élancée, labre non réfléchi). (Canal rétréci, nom- breux plis). \\ Alcitiofe \\ (Ouverture dilatée, 3 ou 4 plis). \\ PTEROSPIRA \\ Pterospina \\ (Forme subglobuleuse, (Spire saillante, lahre rétléchi). 3 plis). \\ Mamillana (I) \\ (Spire presque nulle).}

Volutobulbinse. (Protoconche bulbeuse, in nucléus latéral, échancrure presque nulle). 


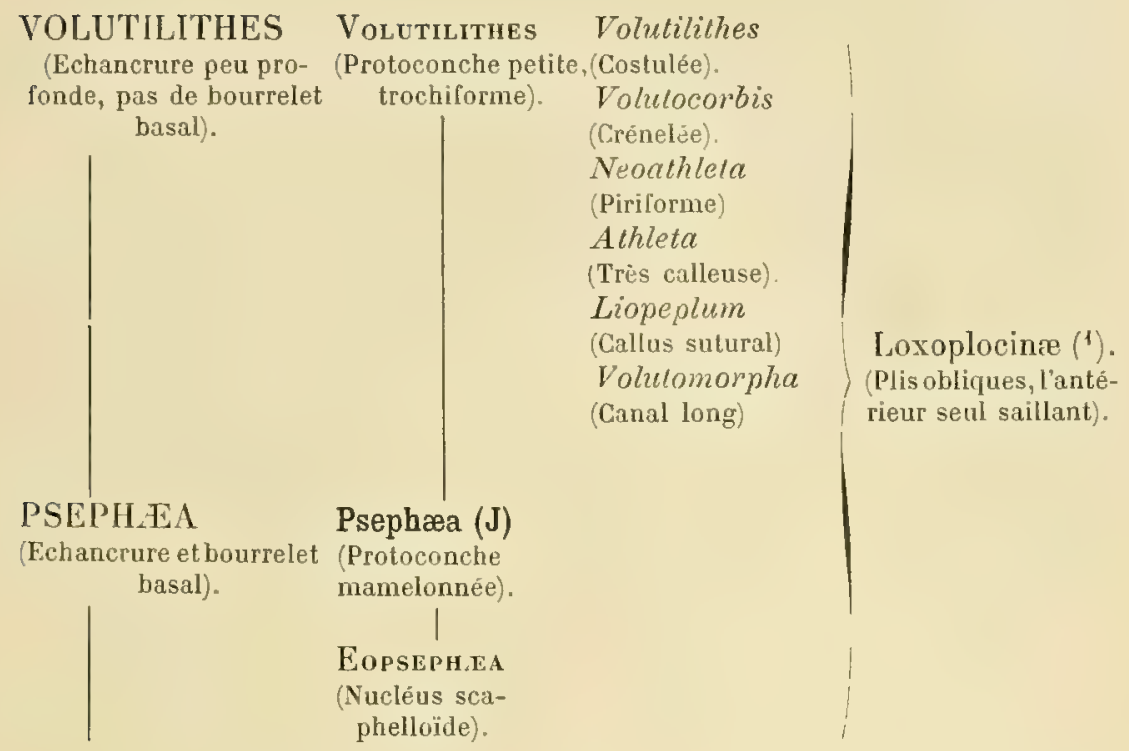

\section{PTYCHORIS PTYChORIS}

(Bulbiforme, péristome (Plis groupés en calleux). avant).

\section{PROVOCATOR Provocator (K)}

(Fusiforme, test émaillé).(Sinus sutural).

\section{PSEUDOCYMBIUMI Pseudocymbium (L)}

(Cymbiforme, spire sca-(Columelle tronquée, sans plis).

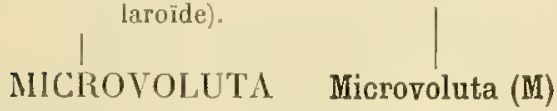

(Mitriforme, pas d'échan- (4 plis obliques, crure). égaux).

\section{Genres, Sous-Genres et Sections, non signalés à l'état fossile.}

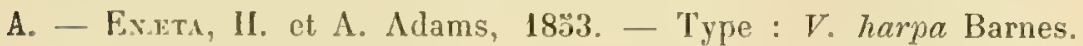
Caractérisée par la dent saillante, qui existe à l'intéricur du labre, cette Section ne comprend que quelques espèces actuelles; tous les autres

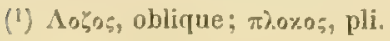


caractères de la coquille me paraissent identiques à ceux de Lyria, de sorte que la séparation d'une Section, d'après cette seule différence, semble peu justifiée.

B. - Cailipara, Gray, 1805\% - Type: V. bullata Swains. Je rapproche ce Genre de Lyria, quoirue la columelle ne porte que deux plis antérieurs; sa forme ovoïde-cylindrique, ses plis d'accroissement, son bourrelet basal, son échancrure profonde, ont en effel une réelle analogie avec les caractères homologues de Lyria; toutefois sa protoconche, à petit nucléus saillant, est un peu différente.

G. - Iulica, Gray, 1817. - Type: V. scapha Gm. (sec. Fischer). La columelle porte quatre plis, dont les deux antérieurs sont assez obliques et assez épais; la protoconche forme une calotte subulée, en segment de splière, dont le nucléus est tout à fait déprimé; enfin le labre, assez épais, est réirocurrent en arrière, et il se raccorde, par une sinuosité échancrée, presque langentiellement avec l'avant-dernier tour, avec une gouttière étroitement canaliculée dans l'angle inférieur de l'ouverture. P'our ces motifs, je pense qu'il y a lieu de conserver Aulica comme un Sous-Genre distinct de Vespertilio, quoique la surface ne soit pas toujours absolument lisse, et que quelques espèces aient une tendance à se garnir d'épines obsolètes, sur le dernier tour.

D. - Crmis, Brod. et Sow. 1826. - Type : V. olla Lin. C'est d'après M. Dall (qui n'admet ni Yetus, ni Cymbium) que je cite, comme type de ce Genre, cette coquille des mers d'Europe, tandis que Fischer, dans son Manuel, indique $T$. proboscidalis, c'est-à-dire le même type que pour $Y e t u s$, ce qui aurait pour effet de faire rentrer $C y m b a$ dans la synonymie de Yetus. En réalité, il y a des différences entre ces deux formes, de sorte que l'adoption des deux dénominations me paraît justifiée : Cymba, tel que je l'interprète ( $V$. olla et $V$. Neptuni), me parait plus ventru, caréné presque à la suture du dernier tour, ce qui supprime la rampe caractéristique de Yetus, à tel point que la coquille se réduit à la protoconche et au dernier tour; en outre, la columelle est plus excavée, elle ne porte que deux plis (chez $V$. olla), et son extrémité antérieure se recourbe vers l'extérieur, au lieu de s'incliner vers l'axe; ce dernier caractère a une importance sérieuse.

E. - Mero, Humphrey, 1797. (= Cymbium Montf, 1810, non Klein 1753). - 'lype : V.diadema Lamk. Ce genre diffère de Yetus par sa protoconche polygyrée, formant une calotte déprimée, non empàtée par le vernis, avec un nucléus central, un peu saillant, non scaphelloïde. En outre, la spire qui se réduit aussi au dernier tour est invariablement couronnéc d'épines; même chez les coquilles qui en paraissent dépourvues, on observe, près de la suture, des épines rudimentaires, formées par des plissements axiaux; enfin la columelle est moins excavée que celle de Yelus, munie de trois plis également minces et oblicues; le bord columellaire est à peine distinct, tant il est mince; les accroissements de l'échancrure forment une bande un peu excavée, limitée à l'extérieur par une côte obtuse. 
F. - Ausoba, H. et A. Adams, 18ว8. - Type : V. cymbiola Chemn. Autant que je puis en juger par la figure, cette coquille doit être classée dans la Sous-Famille Cymbinx, à laquelle elle se rattache par sa forme générale, par ses quatre plis columellaires, obliquement tordus, par son échancrure basale, dont les accroissements sunt indiqués par une bande bien limitée sur la surface dorsale; la protoconche est presque la même que celle de Melo, de sorte qu'en détinitive, Ausoba ne s'en distingue que par sa spire plus apparente, et par un pli de plus à la columelle; j'en conclus que ce n'est qu'un Sous-Genre du précédent.

G. - Zidosd, H. et A.Adams, 18 3 (=Volutella d'Orb. fide Tyron, non Swainson, nec Perry). - Type : I' angulata Swains. Cette coquille s'écarte de Cymbiola par le dépôt calleux ou vernissé, qui recouvre entièrement la spire et le prolongement styliforme de la protoconche, de sorte qu'on n'y distingue aucune suture; en outre, le labre est un peu sinueux et excavé, au lieu d'être oblique et convexe comme chez Cymbiola; les autres caractères étant identiques, j'estime que ce n'est qu'un Sous-Genre de ce dernier. Les 'rères Adams en ont d'ailleurs changé le nom, pour cause de triple emploi.

H. - Fulguraria, Schumacher, 1817. - Type: V. mpestris Gm. L'unique espèce, qui représente ce Genre, est une coquille tout à fait fusiforme, localisée dans les mers de Chine et du Japon, et dont la protoconche subsphérique a attiré l'attention de la plupart des auteurs; ses plis columellaires très nombreux, situés très en arrière, son échancrure presque nulle, l'absence de bourrelet basal, son labre rétrocurrent en arc de cercle vers la suture, sont des caractères beaucoup plus importants que son ornersentation, qui ressemble à celle de Psephxa; de sorte que, quoiqu'en pense Fischer, dans son Manuel, il n'est pas probable qu'on réunira Fulguraria et Psephaa, même quand on connaîtra mieux l'animal. Il est à remarquer qu'il a partout orthographié Fulgoraria, tandis que les autres auteurs écrivent Fulguraria, plus conforme à l'étymologie correcte.

I. - Mamulaxa, Crosse, 1871. - Type: V. mamilla Gray. Je doute que les échantillons que l'on connaît de cette espèce aıent atteint l'âge adulte; leur forme est ovale, allongée, leur labre est mince et leur columelle porte trois plis; enfin leur protoconche est tout à fait disproportionnée et remplace les tours de spire. Mais il est fort possible qu'en vieillissant, cette coquille prenne un aspect très différent; aussi est-il regrettable qu'un Sous-Genre ait été fondé d'après le seul caractère de la forme bulbeuse de la protoconche, surtout quand ce caractère est commun à toutes les autres coquilles comprises dans la même Sous-Famille.

J. - Psephea Crosse, 1871. - Type: V. concinna Brod. Quoique la protoconche de cette coquille soit mamelonnée, au lieu d'ètre trochiforme comme celle de Volutitithes, et qu'elle ait une échanc-ure basale avec un bourrelet, je rapproche ces deux Genres dans la mêne Sous-Famille, à cause de la disposition de leurs plis très obliques, dont l'antérieur seul est saillant. 
K. - Provocaton, Watson, 1881. - Type: Provocator pulcher Watson. - Ainsi que l'a fait remarquer Fischer, dans son Manuel, cette coquille a le sommet émaillé d'un Ancilla, la suture comblée d'un Bullia, le sinus sutural d'un Pleurotomidx, avec deux plis très obliques en arrière, sur la columelle. Cet assemblaçe liybride de caractères appartenant à diverses Familles rend très incertain le classement de Provocator.

L. - l'sendocrumum, Cossm, 1899 (= Wyvillea Watson 1881, non Haswel 1879). - Type: Wyvillea alabastrina Watson. W'après le Manuel de Fischer, e'est une coquille cymbitorme, dont la spire est scalaroïde et élevée, dont le sommet est mamelonné et irrégulier, et dont la columelle, légèrement tordue, est perpendiculaire et ne porte aucun pli; comme elle est abruptement tronquée au milieu de sa longueur, au lieu de s'élever plus haut que le bord opposé, comme cela a lieu chez la plupart des Volutidx, je doute que Wyoillea soit bien à sa place dans cette Famille. En tous cas, j'ai dû changer ce nom de Genre, pour corriger un double emploi avec un Genre de Crustacés bien antérieur.

M. - Micnovolura, Angas, 1877. - 'Type: M. australis Angas. D'après les figures du Manuel de Tryon, ces coquilles ont l'aspect des Mitra; mais elles n'ont pas d'échancrure basale, et leurs plis égaux ne croissent pas d'avant en arrière. Je crois donc, conformément à l'opinion de cet auteur, que c'est un groupe de transition entre les deux Familles; cette opinion me parait beaucoup plus vraisemblable que celle de Fischer qui a rapproché, ainsi que je l'ai signalé ci-avant (p. 82), Micronolulu des Marginellidx.

\section{Genre ou Sous-Genre à éliminer de la Famille.}

Voluromina, Gray, 1847. - 'Type V. Groenlandica Beck. D'après Fischer et d'après le Manuel de Tryon, cette coquille a completement l'aspect d'un Mitra, avec une échancrure basale et un bourrelet, ce qui la distingue de Microvoluta; toutefois Fischer affirme que sa radule la rapproche de Volula; mais il remarque que l'absence d'appendices du siphon, que la forme des tentacules portant les yeux, sont des caractéres anormaux chez les Volutidx, et se rapprochent plutôt de ceux des Mitrixi. Comme, d'ailleurs, il semble que les plis croissent d'avant en arrière, je suis d'avis de classer ce Genre dans les Mitridæ. Quant à la coquille crétacique, que Stoliczka a placée dans ce Genre, elle ne parait avoir aucun rapport avee lui; e'est un fragment, dont les plis columellaires ne sont guère visibles, etdont la surface est couverte de fines stries spirales; je doute que ce soit un Mitridx, et, dans l'état où il se trouve, il est préférable des'abstenir de toute conclusion sur son classement. 


\section{VOLUTA (Rhumphius 1705) Lamarck 1798. \\ (=Volutolyria, Crosse 1877; = Musica Humphrey 1797, fide Swainson 1840)}

VoLUTA, sensu stricto.

Type: Murex musica, d'Arg. Viv.

Test épais et pesant; taille assèz grande; forme biconique, plus ou moins ventrue; spire peu allongée, étagée, épineuse; protuconche lisse, polygyrée, trochoïde, à nucléus un peu saillant et à tour's très convexes; dernier tour grand, médiocrement ovale, couronné d'épines parfois très saillantes, situées au-dessus d'une rampe suturale, et donnant naissance à des costules axiales qui persistent jusque sur la base; dans l'intervalle, la surface est tantôt lisse, tantôt ornée de gros filets spiraux, parfois décussés par des accroissements un peu crépus; base alténuée et excarée jusqu'à la carène qui limite un gros bourrelet correspondant aux accroissements de l'échancrure antérieure.

Ouverture relativement étroite, avec une gouttière anguleuse à la partie inférieure, terminée en avant par une très profonde échancrure contournée; labre vertical très épais, parfois lacinié, à peine sinueux à la suture; columelle calleuse, peu coudée, excavée en crosse à son extrémité antérieure, munie de qualre ou cinq gros plis peu obliques, souvent presque égaux, puis en arrière, de deux ou trois plissements transverses et plus minces, qui disparaissent quelquefois chez certaines espèces; bord columellaire peu étalé, nince en arrière, plus calleux sur le bourrelet basal, dont la carène inférieure correspond au troisième pli columellaire.

Opercule corné, ungruiculé, arqué, à nucléus spiral.

Diagnose faite d'après le type actuel, et d'après un plésiotype du Calcaire grossier de Villiers, près Grignon: V. musicalis Lamk. (Pl. VIl, fig. 4-ŏ), ma coll. Protoconche grossie (Fig. 13 ci-contre).

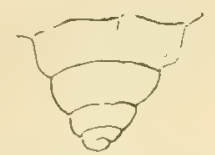

Fig. 12. - Voluta musicalis, Lamk.

Observ. - La désignation de l'espèce-type du Genre Volula a donné 
lieu à quelques errenrs, qu'il importe de rectifier. Ce nom de Genre a été employé par Rlumplius, en $170 \%$, et il n'aurait, par conséquent, aueune valeur, s'il n'avait été stlccessivement repris : par Limné d'abord (Edition X reformata), qui y confondait Mitra, Oliva, Marginella, Columbella; puis par Lamarck (Mém. Soc. hist. nat. Paris, 1798), qui a éliminé de ce Genre les types de Columbella, Marginella, Cancellaria, Mitra, Iurbinella, Ancilla, et qui a expressément désigné, comme type de Voluta (s. res(ricto) : $V$. musica (la "Musique " de d'Argenville). Cette désignation a encore été confirmée par lui, en 1801, dans son "Système des animaux sans vertèbres \%. Gray et tous les auteurs américains ont adopté cette manière de voir. Toutefois Swainson a fait connaître, en 1840, un Genre Musica, qu'il attribue à Humphrey 1797. mais qui n'a ancune valeur, puisqu'il n'a été rendu public que quarante-deux ans après que Lamarck a fixé Voluta; d'ailleurs Swainson lui-même a placé $V$. musica dans son Genre Harpula, et l'on est en droit de conclure qu'il n'attachait, par suite, aucune importance à la dénomination Musica, après l'avoir inopinément ressuscitée.

La question paraissait done résolıe, lorsquu'en 1877, Crosse reprenant, dans le "Journal de Conchyliologie ", la classification des Volutidie, a proposé le nom V'olutolyria pour $V$. musica; Fischer a accepté ce nom dans son Manuel, de sorte qu'il ne cite plus aucun type pour Tolula (s. stricto), ce qui est inadmissible au point de vue de la correcte nomenclature; en outre, Fischer donne Musica comme synonyme de Volutolyria; or il est hien évident que, si l'on admet Musica de préférence à Volula, pour le type $V$. musica, la dénomination Volulolyria tombe également en synonymie.

En définitive, ces deux noms (Musica, Volutolyria) sont purement des synonymes, qu'il y a lieu de faire disparaître de la nomenclature des $V_{0-}$ lutidx, en ne conservant que Voluta, seule dénomination correctement établie.

Rapp. et diff. - Le choix définitif de $V$. musica, comme type du Genre Voluta, me dispense de comparer cette coquille aux autres formes de Volutidx, dont l'énumération va suivre, et dont la séparation sera successivement justifiée. 'Toutefois il n'est pas sans intérêt de faire remarquer qu'au point de vue de la classification d'après la forme de la protoconche, proposée par M. Dall, Voluta appartient à sa "Volutoid series ", deuxième subdivision; le nucléus embryonnaire de cetle coquille est déjà plus développé que chez la plupart des formes éocéniques ou crétaciques, appartenant au Genre Volutilithes, ou à ses Sous-Genres et Sections. Quant à la plication columellaire, elle est très développée, très puissante, et chez certaines espèces éocéniques ( $\boldsymbol{V}$. mitrala, par exemple), les plis sont à peu près égaux, de sorte qu'il est difficile d'y constater la loi de décroissance d'avant en arrière, qui est la base de la séparation entre les Voluliclic el les Mitridu. Cependant, même chez l'espèce que je viens de citer, le pli 
antérieur conserve encore plus d'importance et d'épaisseur que cela n'a lieu chez une coquille de Mitra, dont le pli supérieur est toujours plus faible et plus oblique que les plis infrajacents.

\section{Répart. stratigr.}

Eocene. - Outre le plésiotype ci-dessus figuré, qui existe dans le Bassin de Paris et dans le Vicentin (ma coll.), plusieurs espèces typiques, dans les environs de Paris et dans la Loire-Inférieure : $V$. mitrala Desh., V. Wateleti Desh., V. quinqueplicata Bayan, $V$. Horensi, Desh., $V$. proboscidifera Cossm., ma coll. Une espèce à cinq ou six plis columellaires, dans le Vicentin : V. Bezanconi Bayan, d'après la figure donnée par cet auteur.

Origocene. - Une espèce bien caractérisée dans les couches de Grancona (Vénétie) : V. Bericorum Oppenh., ma collection.

Eroque actuelle. - Trois espèces aux Antilles, sur les côtes d'Afrique et du Brésil, d'après le Manuel de Tryon.

\section{LAPPARIA, Conrad, 1855.}

Lapparia, sensu stricto. Type: Mitra dumosa, Conr. Eoc.

Taille moyenne; forme étroite, biconique, ressemblaint aux Turricula; spire assez longue, à galbe conique; protoconche lisse, grosse, turbinée, à nucléus pointu et scaphelloïde; tours d'abord ornés de filets spiraux, très serrés, et de costules obsolètes, puis devenant peu à peu anguleux, et enfin épineux sur l'angle, avec une rampe faiblement excavée au-dessous de la rangée d'épines; sutures linéaires, ondulées par les costules axiales; dernier tour un peu supérieur à la moitié de la longueur totale, armé en arrière d'une couronne d'épines saillantes et comprimées, entièrement couvert de filets spiraux, qui se prolongent seuls sur la convexité de la base, jusqu'au cou sur lequel s'enroule un large bourrelet, formé par les accroissements curvilignes de l'échancrure antérieure.

Ouverture peu dilatée, à bords presque parallèles, avec une étroite gouttière dans l'angle inférieur, à peine contractée en avant, où elle se termine par une profonde échancrure basale; 
Lapparia

labre presque rectiligne et vertical, un peu arqué en avant, lisse à l'intérieur, médiocrement épais; columelle sans intlexion au milieu, recourbée vers l'axe, et plolongée à son extrémilé antérieure qui se raccorde avec l'échanclure; quatre plis columellaires, l'antérieur un peu moins saillant et un peu plus oblique que les trois autres, qui sont épais et presque transverses; bord columellaire vernissé, mince en arrière, plus calleux dans la région du bourrelet.

Diagnose faite d'après des échantillons de l'espècetype, de l'Eocène supérieur de Jackson, dans l'Etat de Mississipi (Pl. VIII, fig. 8), ma coll.; et d'après une espèce voisine), souvent confondue avec la précédente, provenant de l'Eocène inférieur de Sinithville, dans le Texas: Mitra Mooreana Gabb (Pl. VIII, fig. 9), ma coll. Protoconche de l'espèce-type, grossie (Fig. 14 ci-contre).

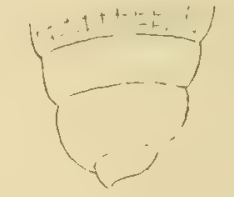

Fig. 14.- Lapporia dumosu, Conr.

Rapp. et diff. - Cette coquille a été décrite dans le Genre Mitra, à cause de la disposition de ses plis columellaires, qui ne décroissent pas d'avant en arrière; toutefois, le pli antérieur étant presque égal aux trois autres, fait qui se produit chez quelques Irolula (par ex. V. mitrata Deslı.), el, d'antre part, tous les caractères extérieurs de la coquille se rapprochant plus des Volutidex que des Mitridie, j'adopte l'opinion de M. Dall qui, se fondant sur la forme de la proloconche seule, place Lapparia daus la première de ces deux Familles. Seulement M. Dall la rapproche de Caricella et de Scaphella, à cause de ce gros embryon, à nucléus pointu; or, ainsi que je l'ai déjà indiqué ci-dessus, il ne faut pas s'en rapporter cxclusivement à la forme de l'embryon pour le classement des Volutidx; le Genre Lapparia en offre la preuve la plus évidente, altendu que, par tous ses autres caractères (échancrure, bourrelet basal, plis transverses, épines, etc.), il s'écarte complitement de la "Scaphelloïd series " de II. Dall, c'est-à-dire de mes Homooplocinx, au milieu desquels il formerait une anomalic tout à fait disparate. Je rapproche, au contraire, Lapparia de Voluta, dont il ne diffère que par sa forme plus étroite et par son embryon subscaphelloüde.

Répart. stratigr.

Paleocexe. - L'espèce plésiotype ci-dessus figurée, dans le " Midway stage " du Texas, ma coll.

EOCExe. - L'espèce-type et une variété, dans le Claibornien et le Jacksonien des Etats-Unis, ma coll. 


\section{LYRIA, Gray, 1847.}

LYria, sensu stricto. Type : Voluta nucleus, Lamk. Viv.

Test épais; taille au-dessous de la moyenne; forme ovoïde, peu ventrue; spire pointue, subulée, un peu étagée, à galbe conique; protoconche lisse, paucispirée, bulbiforme, quoique peu développée, à nucléus à peine saillant et plus ou moins dévié; surface costulée par des plis axiaux assez épais et réguliers, qui forment des crénelures sur la rampe suturale; dernier tour très grrand, régulièrement ovale, atténué et excavé à la base, sur laquelle se prolongent les costules axiales, et qui porte, en outre, des sillons obsolètes, imbriqués, obliques, jusqu'au bourrelet arrondi et contourné qui aboutit à l'échancrure antérieure. Ouverture fusoïde, avec une profonde gouttière dans l'angle inférieur', profondément échancrée à son extrémité supérieure; labre vertical, épais, extérieurement variqueux, lisse à l'intérieur; columelle peu calleuse, excavée en arrière, à peine coudée en avant, munie de trois plis supérieurs, peu obliques, dont deux surtout sont épais, le troisième inférieur un peu plus mince, et au dessous, de nombreux plissements transverses, enfin quelquefois, d'une forte ride pariétale dans l'angle inférieur; bord columellaire assez mince, surtout en arrière, peu étalé, plus calleux sur la région du bourrelet basal.

Diagnose refaite d'après deux plésiotypes de Calcaires grossiers : L. turgidula Lamk., de Damery (Pl. V, fig. 9); et L. harpula Lamk., de Chaussy (PI. VI, fig. 9-10); tons deux de ma collection.

Rapp. et diff. - Ce Genre se distingue de Voluta: non seulement par son ornementation formée de costules serrées, au lieu de cûtes épineuses, mais encore et surtout par sa protoconche bulbeuse, à nucléus dévié, et par ses plis columellaires moins nombreux, disposés d'une manière dill'érente. Il s'en rapproche toutelois par l'épaisseur de son test, par la profundeur de son échancrure antérieure, par son bourrelet basal, par les proportions relatives du dernier tour et de la spire. Les différences avec Lapparia sont plus importantes, quoiqu'elles portent sur les mêmes caracteres : protoconche, plis columellaires, ornementation. 
Répart. stratigr.

Sexoxiex. - Trois espèces bien caractérisées dans le "groupe d'Arrialoor», du Crétacé supérieur de l'Inde méridionale : $L$. formosa, crassicostata et granulosa Stoliczka, d'après la Monographie de cet auteur.

Paleocene. - Une espèce dans le Calcaire de Mons: Toluta Marix Briart et Cornet, d'apris la Monographie de ces auteurs. Deux espèces dans le "Midway stage» de l'Alabama: V. lyroidea el L. Willcoxiana, Aldrich., d'après les figures données par M. Gilbert Harris.

Eocene. - Plusieurs espèces bien caractérisées, dans le Bassin angloparisien, dans la Loire-Inférieure: V. harpula et turgidula Lamk., Lyria Coroni Morlet, V. Branderi Desh., V. costata Sol., V. maga et humerosa Edw., ma coll. el d'après la Monographie de F. Edwards. Deux espèces dans les couches nummulitiques de Pau : $V$. Deshayesi Al. Rouault, coll. de l'Ecole des Mines, et V. Prevosti Al. Rouault, d'après les figures. Une espèce dans l'Australie du Sud : $L$. harpularia 'Tate, ma coll. Plusieurs espèces dans les couches nummulitiques de l'Inde: $V$. jugosa Saw., $V$. Edcarlsi d'Arch., d'après la Monographie de d'Archiac.

Oligocexe. - Une espèce dans les sables de Fontainebleau, dans l'Allemagne du Nord, la Belgique et le Vicentin: V. mólesla Mérian, d'après Sandberger, Nyst, Deshayes: autre espèce dans le Tongrien de Belgique, de l'Allemagne du Nord et d'Angleterre : L. decora Beyr., ma collection; autre espèce dan's l'Allemagne du Nord: L. eximia von Koen. d'après la ficrure; plusieurs espèces dans le 'Tongrien de la Ligurie: $T$. anceps Mich., L. parens Bell., d'après la Mlonographie de Bellardi; une espèce bien caractérisée dans le 'Tongrien de Gaas: $V$. milraformis Crat. (non Lamk.), d'après les figures de l'Atlas du Bassin de d'Adour.

Mrocene. - Une espèce à peu près lisse dans le Bassin de l'Ldour: T. picturata Grat., ma coll. Deux espèces dans l'llelvétien du l'iémont: V. magorum Br., V. taurinia Bon., d'après la Monographic de Bellardi. 'Lrois espèces dans le Tertiaire de Saint-Domingue et dans les couches à silex de la Floride : V. zebra Leach, $V$. pulchella Sow. et $V$. musicina Ileilp. d'après la Monograplie de M. Dall et ma coll.

Pliocene, - Une espèce dans le Crag rouge d'Angleterre, intitulée à tort $V$. modosa, mais bien distinete du Volutilithes de ce nom, d'après la figure de la Monographie de S. Wood.

Hpoque actuelle.- Plusieurs espèces dans l'Australie, l'Ocćan Indien, au Japon, sur les côtes d'Afrique et aux Indes occidentales, d'après le Manuel de Tryon. 
HARPULA, Swainson, 1840.

Harpula, sensu stricto. Type: Voluta vexillum, Chemn. Viv.

'Taille au-dessous de la moyenne, ou même petite; forme ovale ou étroitement fusoïde; spire peu allongée, à galbe conique; protoconche lisse, pelite, papilleuse, à nucléus légèrement dévié ; tours lisses, un peu convexes, séparés par des sutures linéaires et faiblement bordées; dernier tour grand, peu ventru, dépourvu de costules et de stries, atténué à la base, qui porte seulement quelques sillons obliques, enroulés sur le cou et le bourrelet aboutissant à l'échancrure. Ouverture un peu allongée, peu dilatée, munie d'une étroite gouttière dans l'angle inférieur, échancrée en avant par un sinus étroit et profond, qui est rejelé à l'extérieur; labre épais, parfois bordé, presque vertical, sans aucune sinuosité à la suture, portant en avant une petite callosité interne, qui rétrécit toujours l'ouverture à la naissance de l'échancrure basale; columelle excavée en arrière, droite en avant, munie de quatre plis très décroissants, el de plusieurs plissements pariétaux; le pli antérieur est seul épais et se confond ordinairement avec la torsion columellaire; bord calleux, bien limité en dehors.

Diagnose faite d'après un plésiotype du Calcaire grossier de Parnes : V. mitreola Lamk. (Pl. Vll, fig. 7-8), ma coll.

Rapp. et diff. - Les plésiotypes de l'Eocène ne sont pas absolument identiques par leur forme, au type du Genre de Swainson; ils sont plus étroits, plus subulés et ressemblent encore davantage à un Mitra. Toutefois, comme les autres caractères répondent complètcment à la diagnose et à la figure de $V$. nexillum et de $V$. interpunctala Martynn, qui sont les deux représentants de Harpula à l'époque actuelle, je n'liésite pas à confirmer la détermination générique que j'avais déjà proposéc dans mon "Catalogue illustré de l'Eocène ", en 1889, quoiqu'il soit surprenant que ce Genre n'ait pas de représentants entre l'Eocène et l'Epoque actuelle. Outre la décroissance des plis columellaires, auxquels succèdent encore quelques plissements pariétaux, ces plésiotypes fossiles sont caractérisés 
II arpula

par une petite callosité qui rétrécit l'extrémité antérieure de l'ouverture, et qu'on distingue très bien sur la figure des espèces vivantes de Harpula. Ce Genre se rattache aux Volutinz par son échancrure avec bourrelet basal, par son labre épais ainsi que par sa plication columellaire; il s'écarte de Lyria par sa surface lisse et par sa protoconche papilleuse.

\section{Répart. stratigr.}

Eocexe. - Outre le plésiotype ci-dessus figuré, une autre espèce dans les sables bartoniens des environs de Paris: V. intusdentata Cossm., ma coll.

Epopue actuelle. - Deux espèces dans l'Océan Indien, d'après le Manuel de Tryon.

FIGULOMORPHA, Holzapfel, 1888.

Figulomorpha, sensu str. Type: Mitra piruliformis, Mull. Grét.

Taille assez pelite; forme piroïde, ovale, peu allongée; spire très courte, à galbe conoïdal; protoconche papilleuse, peu saillante, à nucléus dévié (fide Holzapfel); tours peu nombreux, un peu convexes; surface entièrement ornée de rubans spiraux et aplatis, décussés par des plis d'accroissement dans leurs interstices; dernier tour très grand, ovale en arrière, excavé à la base, sur laquelle l'ornementation se prolonge régulièrement jusqu'au cou, où l'on distingue un bourrelet obtus, correspondant aux accroissements de l'échancrure antérieure.

Ouverture peu dilatée, semilunaire, avec une étroite goultière dans l'angle inférieur, terminée en avant par un canal un peu rétréci, rejeté en dehors et échancré à l'extrémité par une entaille assez profonde; labre étroit, non sinueux en arrière, mince, muni de quelques plis crénelés à l'intérieur ; columelle excavée en arrière, courbée à droite du côté antérieur, munie de quatre plis épais, les deux antérieurs obliques et rapprochés, les deux postérieurs transverses et plus écartés; bord columellaire assez large, un peu calleux, bien distinct dans toute sa hauteur. 
Ficulomorpha

Diagnose refaite d'après les échantillons-types des sables de Vaals, du Sénonien supérieur (PI. VII, fig. 10-11), coll, de "Technische Hochschule" d'Aix-la-Chapelle, communiqués par M. Holzapfel.

Rapp. et diff. - Au premier abord, ce Genre ressemble complètement à Ficulopsis Stol., qui appartient à la Sous-Famille Pholidotominæ (voir l'annexe ci-après); mais, malgré cette apparence extérieure, Ficulomorpha doit ètre classé dans un groupe tout à fait différent, à cause de l'absence complète de sinuosité et d'échancrure à la partie inférieure du labre, qui est simplement un peu rétrocurrent à son point de jonction avec la suture. Ce Genre s'écarte totalement des autres Volutinæ: non seulement par sa forme piroïde et par son ornementation de Pirula, mais encore par sa protoconche papilleuse, petite comme le sont tous les embryons de Volutidæ crétaciques, et enfin par ses plis columellaires qui forment deux groupes très distincts, deux obliques et deux transverses. Quoique ces différences soient très profondes, et qu'à première vue on ne voie guère de rapports entre Ficulomorpha et Voluta, je place ce Genre dans la Sous-Famille Volutinæ, à cause de son échancrure basale et de son bourrelet, et à cause de l'épaisseur de ses quatre plis.

Répart. stratigr.

Sexoxiex. - L'espèce-type seule, dans les sables d'Aix-la-Chapelle.

VESPERTILIO, Klein, 1753.

Vespertilo, sensu stricto: Type: V.vespertilio, Lin. Viv.

T est un peu épais; taille assez grande; forme stromboïde, généralement ventrue; spire courte, subcostulée sur les premiers tours, devenant épineuse sur les deus derniers; protoconche grosse, polygyrée, à nucléus déprimé, à tours canaliculés et parfois crénelés; dernier tour très grand, couronné au-dessus de la rampe suturale par des épines plus ou moins saillantes et écartées, qui se prolongent sous la forme de costules disparaissant sur la base, tandis que le reste de la surface est lisse; bourrelet basal saillant, correspondant aux accroissements de l'échancrure antérieure. Ouverture à bords presque parallèles, avec une groultière étroitement canaliculée dans l'angle inférieur, terminée 
en avant par une très profonde échancrure; labre mince, presque vertical, lisse à l'intérieur, aboutissant normalement à la suture; columelle peu excavée, lordue et contournée en avant, portant quatre plis écartés et säillants, les deux antérieurs plus obliques el plus épais; bord columellaire un peu calleux, non étalé.

Diagnose faite d'après des échantillons de l'espècetype, et d'après un plésiotype de l'Eocène de l'Australie: V. IVeleli Ten. Woods (PI. IV, fig. 23, et Pl. VI, fig. 8), ma coll. Protoconche grossie (Fig. 15 ci-contre).

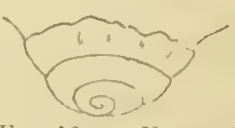

Fig. 16. - Vesperlilio Heldi, Ten. Woods.

Rapp. et diff. - Vespertilio se distingue de Voluta s. s.: par ses plis plus minces, un peu plus obliques, surtout les deux antérieurs; par l'absence de plissement sur la région pariétale; par son labre plus mince, et principalement par sa grosse protoconche, à nucléus presque planorbulaire, qui n'a aucun rapport avec l'embryon trochiforme de $\mathrm{V}$. musicalis. $\Lambda$ côté de ces caractères différentiels, qui sont bien tranchés, il y a, an contraire, entre ces deux genres, des rapprochements qui motivent le classement de Vespertilio dans la Sous-Famille Tolutine; ce sont: non seulement la forme générale, l'ornementation épineuse ou costulée, mais encore la profondeur de l'échancrure, et l'existence d'un bourrelet basal qui correspond aux accroissements de celle-ci. II y a lieu de remarquer que les crénelures de la protoconche, qui caractérisent le type ( $V$. vesperlilio), n'existent pas chez toutes les espèces vivantes du même Genre, et qu'elles manquent absolument chez les plésiotypes fossiles; M. Geo. Harris, dans son "Etude sur les fossiles australasiens du British Museum "; en conclut que ces fossiles appartiennent au Sous-Genre Aulica. Je ne partage pas cet avis, attendu qu'il existe d'autres différences plus constantes entre Tespertilio et Aulica, notamment l'épaisscur des plis columellaires de ce dernier Sous-Genre, la disparition complète de l'ornementation de la surface cliez Aulica, qui a en outre une protoconche non canaliculée, présentant l'aspect d'une calotte lisse, et dont le labre forme un sinus un peu échancré, à son point d'attache contre la suture. Je ne connais d'ailleur's aucun représentant d'Aulica à l'état fossile, tandis que plusieurs des plésiotypes australiens sont presque identiques à $V$. vespertitio.

\section{Répart. stratigr.}

Senonien. - Deux espèces douteuses dans les couches daniennes de 
Maëstricht : V. deperdita Goldf, et $V$.piriformis (') Kaunhowen, d'après la Monographie de cet auteur.

Eocexe. - Outre le plésiotype ci-dessus figuré, plusieurs espèces dans l'Australie du Sud, soit épineuses: $T$. strophodon M. Coy, $V$. strombi formis Johnston $\left({ }^{2}\right)$; soit costulées: T. lirata, nserdolicata, Macdonaldi, Tate, ma coll. Deux espèces probables dans les couches nummulitiques de l'Inde: $Y$. Sismondai et Haimei d'Arch., d'après la Monographie de d'Archiac et IJaime.

Pliocexe. - Deux espèces dans les couches récentes de Java: $V$. ponderosa et gendinganensis, Martin; d'après les figures données par cet auteur.

Epoque actuelle. - Un certain nombre d'espèces localisées dans les mers de l'Australie, aux Philippines, aux îles Moluques, d'après le Manuel de Tryon.

Amoria, Gray, 1855. - Type: Voluta undulata, Lamk. Viv.

Taille moyenne; forme ovale, peu ventrue; spire courle, subulée, à galbe conique ou extraconique; protoconche relativement petite, lisse, turbinée en dôme conoïdal, à nucléus sans saillie; tours à peu près plans, à sutures peu distinctes, lisses et recouverts d'un enduit vernissé qui envahit toute la surface de la coquille; dernier tour très grand, ovoïde, régulièrement atténué à la base, qui est peu ou point excavée, et qui porte un bourrelet obsolète, correspondant aux accroissements de l'échancrure. Ouverture longue, peu dilatée, avec une étroite gouttière canaliculée dans l'angle inférieur, non rétrécie en avant, et terminée de ce côté par une échancrure très profondément entaillée, mais plus étroite que l'ouverture; labre épais, lisse à l'inlérieur, non bordé à l'extérieur, un peu oblique à gauche de l'axe, du côté antérieur, rétrocurrent en arc de cercle à la suture; columelle presque rectiligne, munie de quatre gros plis souvent épais, égaux et équirlistants, quelquefois entremêlés de plis intercalaires ct plus

(1) $r$ piriformis fait double emploi avec l'espèce de Forbes; je propose, pour l'espèce du Limbourg: Voluta kaunhoweni, Vin. de Reg.

(2) Double emploi avec $I$. Strombiformis Desh; je propose donc, pour l'espèce australienne: V. Johnstoni, nob. 
petits; du côté antérieur, la columelle se recourbe vers l'axe, avant de se terminer au bord de l'échancrure; bord columellaire mince, peu calleux, parfois très largement étalé sur la base et sur le bourrelet basal.

Diagnose complétée d'après une variété de l'espèce-type : $V$. Angasi Tate, ma coll.; et d'après un plésiotype du Miocène de l'Australie du Sud: V. Masoni Tate (Pl. V, fig. 10, et PI. VI, fig. 7), ma coll.

Rapp. et diff. - Ce Sous-Genre appartient évidemment au même groupe que Vespertilio et Aulica; par son échanerure et son bourrelet basal, ainsi que par ses plis columellaires, il se rattache à la Sous-Famille typique Volutine; mais il s'écarte: de Voluta et de Lyria par sa surface non ornée et par son embryon; de Vespertitio par l'absence d'épines, par sa protoconche non déprimée ni canaliculée, par son labre épais; enfin d'Aulica, qui est également lisse, par son échancrure bien plus étroite, par sa protoconche beaucoup moins grosse, par sa columelle plus contournée en avant. On peut encore le comparer à Harpula, qui a aussi une forme mitroïde; mais la plication de la columelle est bien différente, la protoconche n'a aucun rapport, et le labre d'Amoria ne porte pas la callosité antérieure, rétrécissant l'ouverture, qui caractérise Harpula.

\section{Répart. stratigr.}

Mrockne. - L'espèce plésiolype ci-dessus figurée, dans l'Australie du Sud, ma coll. Autre espèce probable dans la formation santacruzienne de la Patagonie: V. Patagonica v. Thering, d'après la figure publiée par l'auteur.

Plocene. - L'espèce-type dans les couches récentes de la NouvelleZélande, d'après M. Geo. Harris.

Epoque actuelle. - Plusieurs espèces ou variélés, dans les mers de l'Australie, d'après le Manuel de Tryon.

\section{LEPTOSCAPHA, Fischer, 1883.}

LeptosGapha, sensu stricto. Type: V. variculosa, Lamk. Eoc.

Taille petite; forme de Mitra, étroite, ovale, assez allongée : spire un peu écourtée, à galbe conoïdal; protoconche petite, mamillée, à nucléus indistinct, obliquement subdévié; tours convexes, séparés par des sutures bordées, et ornés de fines stries 
Leptoseapha

spirales; dernier tour grand, ovoïde, non ventru, alténué à la base, qui est un peu excavée contre le bourrelet caréné correspondant aux accroissements de l'échancrure; stries persistant sur la base, où elles sont plus marquées que sur la spire, et obliquement enroulées sur le bourrelet. Ouverture assez courte, un peu dilatée, munie d'une gouttière étroitement canaliculée dans l'angle inférieur, un peu rétrécic à son extrémité antérieure, où clle est tronquée par une échancrure assez profonde; labre verlical, épais, bordé par une varice, à laquelle correspond souvent une varice opposée sur le dernier tour; columelle excavée, munie de quatre plis assez minces et assez obliques, situés en avant, les trois antérieurs presque égaux, l'inférieur souvent peu visible et toujours plus petit; bord columellaire calleux, étroit, limité à l'extérieur par un rebord saillant, se terminant en pointe à l'angle de l'échancrure.

Diagnose complétée d'après des échantillons de l'espèce-type, du Calcaire grossier de Grignon et de Parnes (Pl. VII, fig. 1-2), ma coll. Protoconche grossie (Fig. 16 ci-contre).

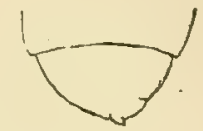

FıG. 16. - Leplosea pha variculosa, Lamk.

Rapp. et diff. - Ce singulier Genre, séparé avec beaucoup de raison par Fischer, est caractérisé par sa forme et par ses varices; il s'écarte des autres divisions mitriformes les Volutidx, telles que Microvoluta qui n'a pas d'échancrure, ou Enxta qui a une dent labiale et une protoconche diflérentes. Je le place à la limite des Volutinx, auxquels il se rattache seulement par son échancrure et par son bourrelet basal; ses plis, sa forme, sa protoconclıe et son ornementation ont plutôt de l'analogie avec Scaphella et avec Aurinia; mais je ne puis rapprocher Leptoscapha des Homcoplocizz, à cause.de son échancrure basale et de ses bourrelets variqueux; d'ailleurs sa proloconche ne parait pas être complètement scaphelloïde, ni bulbiforme. En définitive, c'est une forme aberrante, localisée dans l'Eocène, et qui ne peut fournir aucune indication phylogénétique.

Répart. stratigr.

Eocexe.-L'espece-type dans le Bassin de Paris, ma coll. Une autre espèce bien caractérisée, dans l'Australie du Sud : V. crassilabrum T'ate, d'après la figure publiée par l'auteur. 


\section{YETUS, Adanson, $175 \%$. (=Cymbium, Klein pro parle.)}

Test mince. Taille très grande; forme plus ou moins ventrue; protoconche à nucléus scaphelloïde, empâtée dans un vernis qui en masque les sutures; spire réduite à un seul tour lisse, caréné en arrière, avec une rampe spirale plus ou moins large entre cette carène et la protoconche; base portant en avant une large bande, souvent excavée, limitée par une côte obtuse, et correspondant aux accroissements de l'échancrure antérieure. Ouverture dilatée, avec une large gouttière postérieure, à peine atténuée en avant, et tronquée par une large échancrure, souvent profonde; labre mince, lisse, convexe, peu ou point oblique, avec un sinus échancré sur la rampe inférieure du dernier tour; columelle excavée, parfois très creuse, tordue en avant, se terminant de ce côté par une pointe effilée contre l'échancrure, munie de plis très obliques à peu près égaux; bord columellaire plus on moins épais, largement étalé sur la base et débordant sur la rampe postírieure, plus étroit et plus calleux le long de la bande basale.

YeTUS, sensu stricto.

Type: V.proboscidalis, Lamk. Viv.

Forme cylindracée; large rampe suturale ; columelle munie de trois plis presque parallèles, inclinée vers l'axe à son extrémité antérieure.

Diagnose refaite d'après un échantillon de l'espèce-type, des côtes occidentales d'Afrique (Pl. VII, fig. 9), ma coll.

Observ. - J'adopte la dénomation, rétablie par Fischer dans son Manuel, et empruntée à l'ouvrage d'Adanson qui, dans son Etude sur les coquilles du Sénégel, s'était borné à latiniser les noms barbares que ces coquilles portent dans le pays; er effet, le nom de Cymbium, qui est antérieur à l'édition de Linné, s'applique d'ailleurs à des formes tellement liétérogènes qu'il est inadmissible de lui donner, même en l'interprétant, la 
préférence sur Yetus dont le type est mieux circonscrit. Quant à Cymba, comme je l'ai indiqué ci-dessus (p. 106), il a pour type une forme que je considère comme un peu différente, et par conséquent, je ne puis reprendre cette dénomination, comme le propose M. Dall, darıs sa Monographie du Tertiaire de la Floride, pour l'appliquer à $V$. proboscidalis.

Rapp. et diff. - Ce Genre est le type caractéristique de-ma SousFamille Cymbinx, comprenant les Volutes à spire à peu près nulle, à large échancrure basale, dont la columelle est plusieurs fois tordue sur elle-même en formant des plis plus ou moins obliques. Si l'on se bornait, comme l'a fait M. Dall, à ne tenir exclusivement compte que de la protoconche, on serait conduit à disperser les formes qui composent ce groupe très homogène par l'ensemble de ses caractères, en partie avec les I'oluta, en partie avec les Scaphella; cependant les Cymbinx s'écartent des premiers par leur plication tout à fait différente, des seconds par leur large échancrure basale, des deux par leur spire réduite anx tours embryonnaires, auxquels succède immédiatement le dernier tour. Dans ces conditions, il paraît bien évident que la forme de la protoconche ne peut, quoi qu'en dise notre confrère, servir de base à une classification générale des Volutidx.

Répart. stratigr.

Eocene. - Un fragment bien caractérisé, dans les environs d'Einsiedeln : Cymbium Orbignyi Mayer, d'après la Monographie de M. Mayer-Eymar; un autre fragment plus douteux, dans les environs de Thun : Cymbium helvelicum Mayer, d'après le même auteur.

Plrocene. - Une espèce actuelle en Algérie : $T$. papillata Schum, d'après Fischer.

Epoque actuelle. - Plusieurs espèces ou variétés sur les côtes d'Afrique, ma coll.

Eucrmba, Dall, 1890.

Type: E. ocalana, I)all. Eoc.

Taille assez grande; forme piroïde, subglobuleuse; spire presque réduite aux tours embryonnaires et au seul dernier tour; protoconche large, en calotte déprimée, avec un nucléus scaphelloïde, obtusément proéminent et un peu latéral ; tours ornés de stries spirales: dernier tour lisse, non caréné ni couronné en arrière, seulement arrondi, graduellement atténué à la base, et terminé par un canal allongé, un peu contourné. Ouverture piriforme; labre mince, arqué, rétrocurrent vers la suture; columelle munie de quatre plis égaux et obliques; bord columellaire mince. 
Diagnose composée d'après la traduction de celle de l'auteur; reproduction de la figure du moule interne de l'espèce-type (Fig. 17 ci-contre.)

Rapp. et diff. - Celte coquille ressemble plutôt à un Fulgur qu'à un Voluta; tontefois sa proloconche scaphelloide et ses plis obliques la rapprochent de Yelus, quoiqu'elle s'en écarte par son canal et par ses stries, qui rappellent un peu le Genre Caricella. Én réalité, à l'exception de la proloconche, qui est un pen plus large, j'aroue que je naperçois pas de raisons bien sérieuses pour séparer cette coquille de Caricella, et surtout pour la closser dans les Cymbince plutôt que dans les Homeo.

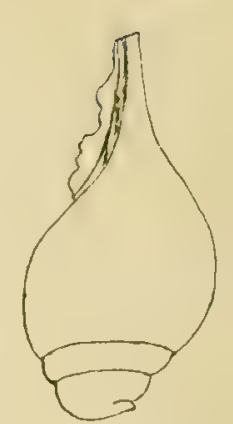

Fis. 17. - Eucymba ocalana, Dall. p'orine, dont elle a les plis columellares; il n'y a qu'un caractíre qui pourrait justifier le rapprochement proposé par M. Dall (Ẻucymba prés de Cymba); malheureusement M. Dall n'en fait pas mention dans sa diagnose, et je n'ai pu le vérifier sur la ligure insuffisante qu'il donne pour le type de son Sous-Genre: c'est l'existence ou l'absence d'une échancrure basale, qui n'existe jamais chez les Homreoplocine, tandis que les Cymbinx en possèdent une très large, avec une bande qui correspond aux accroissements de cette entaille, et dont on n'aperçoit jamais la trace chez Caricella. Ce point resterait done à éclaircir, avant que l'on soit en état de fixer délinitivement la position d'Éucymba dans la classification systúmatique que j’ai précédemment dressée en tableau. En tont cas, jexclus de ce Genre les formes crétaciques citées par M. Dall, qui me paraissent dépourvues d'échancrure, de sorte que, comme on le verra ci-après, je les ai placées dans le Genre Caricella.

Répart. stratigr.

Eocene, - L'espèce-type dans l'Eocène supérieur de la Floride.

GYMBIOLA, Swainson, 1840.

Cymbiola, sensu stricto. Type: V. ancilla, Sol. Viv.

Taillè grande; forme ovale, ventrue, cymbioïde; spire plus ou moins allongée; proloconche lisse, polygyrée, à nucléus scaphelloïde et à circonvolutions irrégulières; dernier tour très grand, 
Cymbiola

anguleux el souvent couronné de nodosités en arrière, médiocrement atténué à la base, qui porte une large bande oblique et subexcavée, limitée par une petite carène, et aboutissant à l'échancrure dont elle contient les accroissements. Ouverture généralement ample, avec une goultière dans l'angle postérieur, terminée enavant par une large et profonde échancrure ; labre un peu oblique, souvent épaissi, lisse à l'intérieur, non sinueux à la suture ; columelle excavée, torduc en avant, se terminant en pointe effilée bien au-delà de l'échancrure, munie de deux plis épais et très obliques; bord columellaire calleux, largement étalé.

Diagnose complété des échantillons de l'époque actuelle; plésiotype fossile du Miocène de Patagonie : V. Ameghinoi, V. Ihering (Fig. $18 \mathrm{ci-}$ contre), reproduction de la figure originale (Revista do Museu Paulista, T. II, 1897, p. 302).

Rapp. et diff. - Je n'ai pu rapporter les coquilles de ce Genre à aucun des autres groupes de Volutidx; en effet, s'il se rapproche des Cymbinx par ses plis tordus, par son échancrure basale et par sa bande dorsale bien limitée, il s'en écarte par la saillie de sa spire, par sa forme buccinoïde ou ancilloïde, par son bord collumellaire calleux, par l'inclinaison du labre, par la disposition de sa protoconche étroite

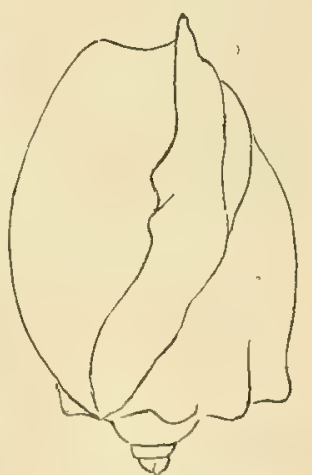

Fig. 18. - Cymbiola Ameghinoi, v. lher. et polygyrée, terminée par un nucléus scaphelloïde.

D'autre part, les plis sont plus obliques et moins nombreux que ceux des Volutinx; les accroissements de l'échancrure forment une bande subexcavée au lieu d'un bourrelet saillant, et la columelle est beaucoup plus arquée. Enfin, si on le compare à Scaphella, à cause de son nucléus scaphelloide, on trouve que les plis columellaires n'ont aucun rapport, que l'ouverture est bien plus échancrée, et que la base porte une bande qui fait totalement défaut chez les Homceoplocine. Dans ces conditions, il m'a paru rationnel d'admettre la Sous-Famille Zidoninx, proposée par les frères Adams, et d'y placer Cymbiola, à côté de Zidona qui a l'embryon encore plus proboscidilorme.

\section{Répart. stratigr.}

Mocrae. - Liespéce plésiotype ci-dessus reproduite, dans la formation santacruzienne de P'atagonie, d'après M. von lhering. 
Epoque actuel.le. - Plusieurs espèces ou variélés, sur les côtes australes de l'Amérique du Sud, d'après le Manuel de 'Tryon.

SGAPHELLA, Swainson, 1832.

SGapiella, sensu stricto.

Type: V. Junoniu, Hwass. Viv.

'Taille grande; forme ovoïde, allongée, atténuée aux deux bouts; spire relativement courte, subulée, obtuse au sommet; protoconche lisse, du type "scaphelloïde " (Dall), c'est-à-dire paucispirée, convexe, à nucléus obliquement redressé et se terminant par une pointe plus ou moins contournée; tours un peu convexes, peu nombreux, généralement lisses, ou ornés de très fines stries spirales qui disparaissent sur le dernier; celui-ci est très grand, ovale, à peine renflé en arrière, atténué ou excavé à la base, qui ne porte pas de bourrelet saillant sur le cou du canal. Ouverture allongée, anguleuse en arrière, sans gouttière, élargie au milieu, terminée en avant par un canal un peu long, légèrement infléchie, presque sans échancrure à son extrémilé; labre faiblement convexe, peu épais, lisse à l'intérieur, à peine sinueux ver's la suture; columelle excavée, tordue et rejetée vers l'extérieur à son extrémité supérieure, portant au milieu quatre plis également espacés el de même épaisseur, obliques à $45^{\circ}$ environ ; bord columellaire à peu près nul en arrière, peu calleux en avant.

Diagnosè refaite d'après l'espèce-lype, et d'après les plésiotypes fossiles: $r$ miocznica Fisch, et Tourn. (Pl. VI, fig. 5), de l'llelvétien de Manthelan; $Y$. Lamberli Sow. (I'I. VI, fig. 2), du Scaldisien d'Anvers; toutes deux de ma collection. Protoconche de Y. miocanica grossie (Fig. 19 ci-contre).

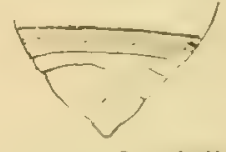

Fig. 19. - Scaphellı miocreenicu, Fisch. et Tourn.

Observ. - Il est surprenant que Fischer n'ait pas repris, dans son Manuel, ce Genre bien caractérisé, correctement élabli, et proposé bien antérieurement à Lovtes les divisions de Gray, des frères Adams et de 
Scaphella

Crosse; cette omission, jointe à l'absence d'un type bien défini pour le Genre Voluta, a pour effet de rendre tout à fait confuse et artificielle la classification des Voluta dans son Manuel. A ce point de vue done, - et abstraction faite de la théorie de la protoconche, - la rectilication faite par M. Dall, dans sa revision complète des Volutida, a une très grande importance, et je m'y associe entièrement.

Rapp. et diff. - Ce Genre est muni de quatre plis columellaires, comme Voluta; mais ces plis sont moins épais, plus écartés et un peu plus obliques; en outre, la protoconche est tout à fait différente, avec un aspect particulier, qu'on remarque aussi chez Eopsephxa; mais les autres caractères de la coquille ne permettent pas de placer ce dernier dans la même Sous-Famille que Scaphella.

\section{Répart. stratigr.}

Senonien. - Une espèce probable dans le "Groupe d'Arrialoor» de l'Inde méridionale : Melo piriformis Forbes, d'après la Monographie de Stoliczka.

Paleocene. - Une espèce bien certaine, dans les sables landéniens de Bracheux: V. Baudoni Desh., d'après la figure donnée par l'auteur. Une espèce dans le "Calcaire de Mons" : Cymba incequiplicala Briart et Cornet, d'après la Monographie de ces auteurs; une autre espèce dans les couches de Copenhague: V. crenistrix V. Koenen, d'après la figure. Une espèce dans les couches de Saratow, en Russie: Scaphella volginica Netschaew, d'après la Monographie de cet auteur.

Eocene. - Une espèce probable dans "l'Argile de Londres ": V. Wetherelli Sow., ma coll. Une espèce aux Etats-Unis: V. Showalteri Aldr., d'apres M. Dall. Trois espèces à protoconche obtuse, dans l'Australie du Sud : V.Mc-Coyi T. Woods, V. polila (1) et protowhysi Tate, ma coll.; autre espèce du même gisement, à protoconche normale: $V$. ellipsoidea Tate, ma coll.

Oligocexe. - Plusieurs espèces bien caractérisées dans l'Allemagne du Nord: V. Siemsseni Boll., coll. de l'Ecole des Mines; $V^{r}$ obtusa (2) $V$. Konen et $V$. longissima Giebel, toutes deux du Tongrien inférieur, d'après la Mlonographie de $\mathrm{Il}$. Von Kœenen.

Mrocene. - L'un des plésiotypes ci-dessus figurés, dans l'Helvétien du centre de la France, ma coll., dans le Burdigalien de l'A quitaine, coll. de l'Ecole des Mines, et dans le Tortonien du Portugal, d'après

(1) Cette espèce fait double emploi avec 1 . polita Conr., qui est un Caricella; il y a lieu de chnnger le nom de l'espèce nustralienne, et je propose en conséquence : Scaphella rictoriensis, nobis.

(2) Cetle espéce fait double emploi avec $\%$ ablusa Emmons, qui est un Aurinia; il y a lieu de changer le nom de l'espèce oligocénique d'Europe, et je propose en conséquence : Scaphella tongrica, nobis. 
Pereira da Costa; une espèce distincle, mais non figurée, dans le Tortonien du plateau de Cucuron: T. Fischeri font., d'après Fontannes; autre espèce plus étroite, dans le Tortonien des Landes : V. Tarbelliana Grat., d'après les figures de l'Atlas du Bassin de l'Adour. Une espèce certaine dans l'Allemagne du Nord: $Y$. Bolli Koch, d'après M. von Konen. Une espèce dans les couches de Maryland et de la Floride: V. Tremholmi Tuomey et IIolmes, d'aprés la figure donnée par M. Dall.

Pliocene. - Le second des plésiotypes ci-dessus figurés, dans le Crag d'Anvers et de Suffolk, ma coll. Une espèce costulée au sommet, dans les couches de la Floride : T. forilana Heilp., ma coll.

Epoque actúcle. - L'espéce-type sur les côtes de la Floride, ma coll.

Aurinia, H. el A. Adams, 1858. Type: V. dubia, Brod. Viv. (=Volutifusus, Conr. 1869.)

Taille grande; forme de Scaphella; spire conique, à tours généralement costulés et striés au début, lisses à l'âge adulte; protoconche scaphelloïde, à nucléus presque toujours détaché; dernier lour ovale, âssez étroit, excavé à la base, qui ne porte aucune trace de bourrelet. Ouverture en fuseau, tronquée sans échancrure à son extrémité antérieure; labre mince, presque vertical, à peine sinueux ver's la suture, lisse à l'intérieur' columelle peu excavée en arrière, droile et dépourvue de torsion en avant, portant au milieu deux plis assez obliques, très obsolètes quand la coquille est adulte; bord columellaire très mince, à peine visible.

Diagnose faite d'après un plésiotype du Miocène de la Virginie: I. virginiana Conr. (= Tolulifusus typus Conr.) (Pl. TH. Hig. 3), ma collection.

Rapp. et diff. - D'après Tryon, $r$. dubia n'est que le jeune âge de I. Junonia, qui est le type de Scaphella, de sorte qu'Aurinia serait synonyme de ce dernier Genre. M. Dall maintient, au contraire, Lurinia comme un Sous-Genre distinct, et il mentionne, it l'appui de cette opinion, la dégénérescence des plis columellaires, qui ne sont qu'au nombre de denx, même chez les jeunes individus; mais tous les autres carnctères sont semblables: protoconche, forme générale, mème fornementation des premiers tours, qui existe aussi chez certains Scaphelia. Aussi suis-je 
d'avis que la séparation à faire entre ces deux Groupes n'a tout au plus que la valeur d'une Section.

A ce propos, M. Dall fait remarquer que si, comme il le propose, le Genre Halia doit être classé dans, les Volutidx, il représenterait le stade extrême de la dégénérescence des plis columellaires, qui disparaissent complètement chez Hatia. Toutefois je remarque que la protoconche de ce dernier n'est pas du tout scaphelloïde; je possède, en effet, des Eralia très fraîchement conservés, dont le nucléus est tout à fait obtus, et dont les tours embryonnaires ne font aucunement la saillie caractéristique des Homcoplocinx; si donc $\mathrm{M}$. Dall attache une réelle importance à ce caractère, au point de vue du classement des Volutes, il est matériellement inadmissible de rapprocher Hatia de cette SousFamille. Je crois, en résumé, que la position systématique de Halia reste encore douteuse, et que le classement provisoire proposé par Fischer, près des Pleurolomidæx, à cause des caractères anatomiques de l'animal. est le plus satisfaisant, dans l'état actuel de nos connaissances.

\section{Répart. stratigr.}

Mrocene. - Outre le plésiotype ci-dessus figuré, deux autres espèces très voisines, dans la Floride: $Y$. obtusa Emmons et $V$. mutabilis Conr., d'après M. Dall; une autre espèce douteuse, dans le Tertiaire de Saint-Domingue: Scapha striata Gabb, d'après M. Dall. Deux espèces dans la formation santacruzienne de la Patagonie: $Y$. quemadensis V. Ihering, V. Philippiana Dall. (= V.gracilis Phil. non Swains.), d'après la Monographie de M. Von Ihering; cette dernière espèce également représentée dans le Tertiaire du Chili, d'après Philippi.

Purocene. - Une espèce dans la Caroline du Sud : V. simplex d'Orb., ma coll.; l'espèce-type de l'époque actuelle, dans le même gisement d'après 11 . Dall.

Epoque actuellz. - Outre le type, deux espèces sur lescôtes Sud des Etats-Unis: A. robusia et Gouldiana Dall, d'après les publications de cet auteur.

CARIGELLA, Conrad, 1835.

Caricerda, sensu stricto. Type: Turbinella piruloides, Conr. Eoc.

Taille parfois assez grande; forme piroïde, ventrue en arrière, très alténuée en avant; spire très courte, à galbe extraconique; protoconche lisse, paucispirée, obtuse au sommet, à nucléus à 
Caricella

peine saillant; tours peu nombreux, peu convexes, souvent ornés de filets spiraux qui disparaissent peu à peu; dernier tour très grand, généralement lisse, plus ou moins rentlé en arrière, rarement ridé vers la suture, obliquement déclive ou même excavé à la base, qui ne porte pas de bourrelet sur le cou, et sur laquelle reparaissent souvent des filets obliquement enroulés. Ouverture en fuseau, dépourvue de goutlière dans l'angle inférieur, rrítrécie en avant et terminée par un canal assez long, conlourné, à peine échancré à son extrémité; labre mince, dilaté, presque vertical en profil, non sinueux en arrière; columelle faiblement excavée en arrière, tordue et calleuse le long du canal, munic au milieu de quatre plis minces, saillants, assez écartés, dont l'obliquité diminue un peu d'avant en arrière; bord columellaire nul ou indistinct.

Diagnose faite d'après des échantillons dı Claibornien de l'Alabama : C. piruloides Conr. (Pl. V, fig. 7-8), ma coll. Protoconche grossie de la même espèce (Fig. 20 ci-contre).

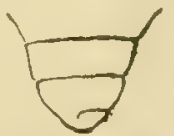

Fir. 20.- Curicelle biruloides, Conr.

Rapp. et diff. - Outre que la forme de l'embryon de Caricella n'est pas complètement scaphelloïde, comme celle de Scaphella; ce Genre s'en distingue par son galbe moins ovale, ressemblant à un Sycum, par son canal plus étroit et contourné comme celui des Turbinellita. M. Dall en fait seulement un Sous-Genre de Scaphella; mais les différences, que je viens de signaler, sont assez importantes pour justifier la séparation d'un Genre distinct, qui ne peut se confondre avec Aurinia, à cause de ses plis persistants, au nombre de quatre, à tout àge.

\section{Répart. stratigr.}

Sexonuen. - Une espèce dans le "Groupe d'Arrialoor ", de l'Inde méridionale: Melo piriformis Forbes, d'après la figure de la Monographie de Stoliczka.

Eocene. - Outre le type ci-dessus figuré, et sa variété bolaris Conr., plusieurs especes dans le Jacksonien du Mississipi : C. subangulata et polita Conr., ma coll.; C. doliala, prisca, demissa Conr., C. Heilprini Dall ( $=$ C. Baudoni Heilp. non Desh.), C. reliculata Aldr., C. Leana et podagrina Dall, d'après la Monographie de cet auteur sur le Tertiaire de la Floride. Une autre espèce aberrante, avec une couronne de rides sur le dernier tour et avec cincy plis columellaires, dans le Claibornien de l'Alabama : 1 . Cooperi Lea, ma coll. 


\section{VOLUTOGONUS, Crosse, 1871.}

Volutoconus, sensu stricto. Type : V.coniformis, Cox. Viv.

Taille au-dessous de la moyenne; forme un peu conique; spire très courte; à galbe conoïdal; protoconche lisse, en calotte déprimée, à nucléus très petit, un peu saillant, tout à fait central; tours très étroits, un peu convexes, séparés par des sutures rainurées; dernier tour très grand, formant presque toute la coquille, ovoïde et souvent ridé en arrière, subconique en avant, entièrement couvert de très fines stries spirales, qui deviennent flexueuses sur la base; celle-ci ne porte aucune trace de bourrelet sur le cou, du moins chez les plésiotypes fossiles. Ouverture très étroite et très longue, à bords à peu près parallèles, anguleuse sans goultière à la suture, tronquée en avant presque sans échancrure, chez les plésiotypes fossiles; labre mince, vertical, non sinueux vers la suture; columelle tout à fait droite, munie au milieu de quatre plis minces, égaux, obliques à $45^{\circ}$ et régulièrement espacés, légèrement tordue à son extrémité antérieure contre la troncalure basale : bord columellaire très mince, assez large, bien limité sur son contour extérieur.

Diagnose refaite d'après une espèce plésiotype de l'Eocène d'Australie: $V$. conoidea Tate (PI. VII, fig. 3 ), ma coll.

Rapp. et diff. - - insi que l'indique la diagnose ci-dessus, le plésiotype fossile que je rapporte à ce Genre diffère, en quelques points, de la figure de $V$.coniformis, dans le Manuel de Tryon; cette figure attribue, en effet, à l'espèce vivante, sans que le texte en fasse mention, une échancrure et un bourrelet basal qui n'existent pas sur le fossile; si cette échancrure existe réellement, et si elle est aussi profonde, avec un bourrelet basal, il est probable que l'espéce fossile qui a seulement l'ouverture tronquée en avant, et qui, par ce caractère ainsi que par ses plis, se rapproche complètement des Homooplocinz, ne pourra conserver le nom Volutoconus. Dans cette hypothèse, il serait alors nécessaire de créer, pour elle, un Genre distinct, attendu (qu'elle diffère de Scaphella par sa forme; par sa protoconche, et de Caricella, par l'absence de canal et par sá protoconche. 
Répart. stratigr.

Eocese. - Outre le plésiotype ci-dessus figuré, une autre espèce dans I'Australie: T. limbala Tate, d'après la figure publiée par cet auteur.

Epoque actuelle. - L'espèce-type dans les mers de l'Australie, sur les côtes Nord-Ouest, d'après le Manuel de 'Tryon.

FULGURARIA, Schumacher, 1817.

Taille souvent très grande; forme plus ou moins étroite et élancée; protoconche bulbeuse, parfois énorme, à nucléus latéralement enroulé sans saillie; ouverture plus ou moins dilatée, faiblement échancrée; labrénon rélléchi à l'extéricur; plis columellaires en nombre variable, peu obliques; pas de bourrelet basal.

Aсгтное, H. el A. Adams, 1858 . Type: V.pacifica, Sol. Viv.

Taille grande; forme parfois un peu ventrue, ovoïde; spire à galbe conique ou légèrement extraconique; protoconche bulbeuse, plus grosse que les premiers tours de la spire qui sont subconvexes, quelquefois ornés de costules; dernier tour très grand, renflé au milieu, atténué et excavé à la base qui est lisse, dépourvue de bourrelet sur le cou. Ouverture grande, assez large et dilatée, avec une goultière canaliculée dans l'angle inférieur', peu atténuée du côté antérieur, où elle est largement tronquée, avec une très faible échancrure; labre assez mince, à peu près vertical, faiblement rétrocurrent vers lasuture, lisse a l'intérieur ; columclle excavée au milieu, avec trois ou quatre plis épais, inéquidistants, obliques à $45^{\circ}$ environ, amincie et recourbée à son extrémité antérieure, ò elle forme un bec pointu au-dessus de l'échancrure; bord columellaire mince, très étalé sur la base. 
Diagnose refaite d'après un plésiotype vivant: $V$. fulgetrum Sow., ma coll.; et d'après un plésiotype fossile de l'Eocène de Table Cape, en Tasmanie: $V$. ancilloides Tate (PI. VII, fig.6), ma coll. Protoconche grossie (Fig. 21 ci-contre).

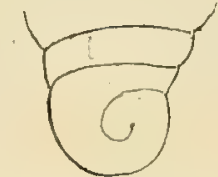

FIG. 21. - Alcithoe ancilloides, Tate.

Rapp. et diff. - Il y a, outre l'embryon bulbeux, une affinité incontestable entre Alcithoe el Fulguraria; cependant, lorsqu'on détaille les caractères distinctifs de ces deux formes, on trouve qu'ils sont assez nombreux et assez tranchés pour motiver au moins la séparation d'un SousGenre: d'abord l'ampleur de l'ouverture, de sorte que la coquille ne se termine pas en avant, chez Alcithoe, par un canal rétréci comme celui de Fulguraria; ensuite le nombre des plis columellaires qui, au lieu d'être égal à sept, comme chez $F$. rupestrìs, avec quelques plissements intercalaires, se réduit à trois ou quatre, et en outre, leur obliquité est plus grande; d'autre part, l'ornementation spirale disparaît complètement de la surlace; il ne reste, chez $A l$. pacifica, que des costules, comparables, il est vrai, à celles de Fulg. rupestris, et encore la plupart des Alcithoe sontils complètement lisses, comme $A$. fulgelrum ou comme notre plésiotype fossile; enfin le bord columellaire est très étalé sur la base chez Alcithoe, tandis qu'il est très élroit chez Fulguraria.

Dans son travail sur les fossiles australasiens du British Museum, M. Geo. Harris rapporte au Genre Scaphella, non seulement ce plésiotype ( $\boldsymbol{V}$. ancilloides), mais encore une espèce pliocénique de la NouvelleZélande, qui est citée sous le nom $V$. pacifica et qui, dans ce cas, serait précisément identique au type d'Alcithoe; or il suffit de jeter les yeux sur la protoconche de ces coquilles, pour se convaincre de l'impossibilité du rapprochement proposé par M. Harris, puisque le nucléus embryonnaire de Scaphella forme une pointe scaphelloïde, tandis qu'il est enroulé latéralement et sans saillie chez toutes les coquilles que j'ai groupées dans la Sous-Famille Volutobulbinæ.

\section{Répart. stratigr.}

Eocene. - L'espèce plésiotype ci-dessus figurée, dans l'Australie et la Tasmanie, d'après la figure d'un individu plus complet qué le mien, publiée par M. Tate.

Plocene, - Une espèce bien caractérisée dans les environs de Perpigran: $V$. pachytele Fontannes, d'après l'anteur. L'espèce-type de l'époque actuelle, dans les couches récentes de la NouvelleZélande, d'après M. Geo. Harris; autre espèce, ou variété de la précédente, dans le même gisement: V.gracilis Swainson, d'après la Monographie de M. Iutton. 


\section{Fulguraria}

Epoque actuelle. - Plusieurs espèces dans les mers australiennes, sur la côte orientale de l'Afrique, et au Brésil, d'après le Manuel de 'Tryon.

PTEROSPIRA, Geo. Harris, 1897.

Pterospira, sensu str. Type : V. Hamnafordi, Mc. Coy. Eoc.

Taille grande; forme fusoïde ou stromboïde; spire très courte, lisse, ou ornée de pelites costules et de filets spiraux, qui disparaissent sur le dernier toul; protoconche énorme, bulbiforme, lisse, composée d'un tour et demi, à nucléus complètement latéral et sans saillie, complitement confondu dans la sphire du premier tour embryonnaire dernier; lour très grand, dilaté. ()uverture large, avec une étroite goultière dans l'angle inférieur, atténuée sans échancrure à la base; labre curviligne, mince à son contour, réfléchi a l'extérieur par une expansion lamelleuse et auriforme, qui se prolonge en arrière jusqu'au milieu de l'avant-dernier tour'; " columelle excavée au milieu, et munie de trois plis larges, "égaux, proéminents" (fide Harris).

Diagnose complétée d'après un jeune indiyidu de l'espéce-type (Pl. VI, fig. (j), et d'après un fragment d'une espèce plésiotype: V. Mortoni Tate (Pl. VI, fig. 4), toutes deux de l'Eocène d'Australie, ma collection.

Rapp. et diff. - Ce Genre a été séparé, avec beaucoup de raison, de Fulguraria, non seulement parce que sa protoconche est encore plus volumineuse, mais encore parce que le nombre des plis columellaires est beaucoup moindre. Si on le compare à Alcilhoe, qui n'a que trois ou quatre plis, et dont l'ouverture est presque aussi large, on trouve qu'il s'en écarte par son labre réfléchi et auriforme. Il est fort possible que I'lerospira ne soit que le stade adulte de Mamillana, qui n'est représenté que par un individu incomplet et n'ayant pas atteint sa taille définitive; toutefois it me semble, d'après la figure de $\boldsymbol{M}$. mamilla, que cette dernière espèce a la spire à peu près réduite à la sphère embryonnaire, tandis que, che\% Pterospira, il y a toujours plusieurs tours apparents. Cependant, s'il était prouvé que Mamillana adulte a la spire plus développée, 
et qu'en outre, son labre se réfléchit à l'extérieur, il y aurait évidemment une complète identité entre ces deux formes, et Pterospira tomberait dans la synonymie de l'autre dénomination, qui est bien antérieure; il resterait alors, au point de vue de la phylogénie de ces formes, qui sont exclusivement australiennes, une lacune entre l'Eocène et l'Epoque actuelle.

\section{Répart. stratigr.}

Eocene. - Outre l'espèce-type et le plésiotype ci-dessus figurés, une autre espèce dans l'Australie du Sud : $V$. macroptera Mc. Coy, d'après MM. Tate et Geo. Harris.

\section{VOLUTILITHES, Swainson, 1840.}

Volutilithes, sensu str. Type : Voluta spinosa, Lamk. Eoc.

Taille assez grande; forme ovale, fusoide; spire relativement courte, à galbe conique; protoconche lisse, polygyrée, à nucléus généralement petit et aigu ; tours étagés, presque toujours couronnés d'épines plus ou moins saillantes, à la partie inférieure, costellés dans le prolongement de ces épines, ordinairement décussés par des plis spiraux et imbriqués, qui produisent des crénelures à l'intersection des côtes; ornementation disparaissant le plus souvent sur le milieu de la surface du dernier tour; qui est grand, ventru en arrière, atténué ou même excavé à la base; surface" dorsale portant quelquefois des traces de coloration, formées de linéoles spirales, à l'emplacement des plis, quand ceux-ci ont disparu ; sur la base reparaissent presque toujours des sillons obliques, qui s'enroulent, plus serrés, sur' le cou du canal.

Ouverture allongée, assez large en arrière, canaliculée, de ce côté, par une double gouttière, l'une dans l'angle inférieur, l'autre vis-à-vis la couronne d'épines, largement tronquée et peu profondément échancrée à la base; labre à peine oblique, parfois un peu épaissi par la dernière côte, lisse à l'intérieur, ou à peine lacinié par l'ornementation spirale; columelle calleuse, excavée à 
la partie inférieure, coudée du côlé antérieur, très obliquement tordue à cette extrémité, munie d'un pli principal à la hauteur de ce coude, et de trois ou quatre plis décroissants, souvent très obliques, au-dessous du premier; bord columellaire mince, très largement étalé sur la base, surtout en arrière.

Diagnose refondue d'après des échantillons de l'espèce-type, du Calcaire grossier de la tranchée de Villiers (PI. IV, fig. 25-26), ma coll. Protoconche grossie (Fig. 22 ci-contre). Autre espèce, à protoconche bulbiforme: $V$. antiscalaris $11 \mathrm{c}$. Coy (Pl. V, Frg. 22. - Volutilifig. 4), de l'Eocène de l'Australie du Sud, ma coll.

Observ. - Nous trouvons ici une nouvelle confirmation de l'impossibilité, oủ l'on est, de baser une classification des Volutidx, d'après la grosseur et la forme de l'embryon : en eflet, les deux plésiotypes ci-dessus figurés ne diffèrent exclusivement que par leur protoconche, et tous leurs autres caractères sont identiques; or il serait d'autant plus excessif de créer une nouvelle subdivision pour cette seule différence d'embryon que, ainsi que je l'ai déjà fait remarquor à plusieủrs reprises, et notamment dans les Coninie, la plupart des coquilles éocéniques de l'Australie ont une protoconche aberrante. Il ressort de là que la forme de la protoconche a plutôt une importance régionale qu'une signification phy̧logénétique, et par conséquent, que son utilité est tout à fait secondaire au point de vue de la division en Familles et en Sous-l amilles, voire même en Genres.

Dans mon "Catalogue illustré de l'Écène (IV, p. 196) ", j'ai indiqué $V$. abyssicola comme type vivant de ce Genre; c'est une erreur que j'ai reproduite d'après le Manuel de Fischer; en effet, l'espèce que Swainson avait en vue, quand il a créé Tolutilithes, est bien une coquille fossile ( $T$. spinosa), tandis que $V$. abyssicola s'écarte un peu de la forme typique, ainsi qu'on le verra ci-après.

Répart. stratigr.

Turonien. - Une espèce douteuse, dans les couches supérieures de Gosau: V. cristata Zekeli, d'après la figure publiée par cet auteur. Sexoniex. - Deux espèces dans les sables d'Aix-la-Chapelle: V. Orbignyana et Nöggerathi Müll. d'après les figures de la Monographie de M. Ilolzapfel; deux espèces dans les couches daniennes de Maëstricht: V. Debeyi et ventricosa (I) Kamliowen, dapres la Mono-

(1) Cette dénomination fait double emploi avec $V$. venlicosa Defr., de I'Eocène. Je propose, cn conséquence, pour remplacer le nom de l'espèce limbrutrgeoise : Volutilithes cretaceus, Vin. de lier. 
Volutilithes

graphie de cet auteur. Deux espèces dans le "Groupe d'Arrialoor " de l'Inde méridionale : $V$. latisepta et accumulata Stol., d'après la Monographịe de Stoliczka.

Paleocene. - Une espèce dans les couches de Copenhague $P$. nodifera von Kœnen; d'après la Monographie de cet auteur; deux espèces dans le "Calcaire de Mons ": V. cf. spinosa Lamk., V. graciosa Briart et Cornet, d'après la Monographie de ces auteurs. Une espèce dans les couches de Saratow, en Russie: $V$. completus Netschaew, d'après la Monographie de cet auteur.

Eocene. - Outre le type, nombreuses espèces caractéristiques, aux trois niveaux du Bassin anglo-parisien, dans le Cotentin et dans la Loire-Inférieure: $V$. bicorona Lamk., V. trisulcala Desh., V, amhigua Sol., $V$. elevata, luctalrix, suspensa, depauperata, scalaris et calva Sow., V. Bureaui Cossm., ma coll.; quelques autres formes anglo-parisiennes, un peu aberrantes, strombiformes, se rattachant cependant plutôt au type qu'aux Sections suivantes; $V$. depressa Lamk., $V$. athleta Sow., V. Solanderi Edw., V. strombiformis Desh., ma coll. Deux espèces dans les calcaires de la Vénétie: $V$. subspinosa Brongn., d'après la figure de l'ouvrage de Brongniart, et $V$. Fuchsi de Gregorio, d'après la Monographie inachevée de cet auteur. Plusieurs espèces dans le Claibornien des Etats-Unis : $V$. petrosus Say., V. symmetricus et Sayanus Conr., V. Dalli Gilb. Harr., $Y$. rugalus Conr., ma coll.; autres espèces dans le Texas: $V$. lisbonensis Aldr. et $T$. præcursor(') Dall, d'après les figures. Deux espèces dans les couches nummulitiques de l'Inde: $V$. dentata Sow. et $Y$. Sykesi d'Arch, d'après les figures de la Monographie de d'Archiac. Outre le plésiotype ci-dessus figuré, de l'Australie du Sud, une autre espèce du même gisement, à embryon bulbiforme : $V$. anticingulatus Mc. Coy, ma coll.

Oligocene. - Plusieurs espèces dans les environs d'Etampes, dans les Landes, dans l'île de Wight, en Belgique : $V$. Rathieri Hébert, $V$. subambigua d'Orb., V. geminata Sow., $V$. cingulata et suluralis Nyst, ma coll,; dans l'Allemagne du Nord : $V$. devexa Beyr., $V$. labrosa Phil., d'après la Monographie de M. Von Kœnen; dans le Vicentin: V.cf. elevala Sow., d'après les figures de la Monographie de M. Fuchs.

Mrocexe. - Plusieurs espèces dans les environs de Turin : V. multicostala, consanguinea Bell., $V$. apenninica Mich., d'après la Monographie de Bellardi.

P'rocene. - Une espèce confondue (à tort selon moi) avec l'espèce éocénique: V. luctatrix Sow., dans le "Crag rouge " d'Angleterre, d'après la Monographie de S. Wood.

(1) Dénomination déjả employée par Bellardi en 1887; je propose, pour l'espèce américaine : V. Wheelockensis, nobis. 


\section{Volutilithes}

Epoque actuelle. - Une espèce sur les côtes de l'Amérique septentrionale : $V$. Philippiana Dall, d'après cet auteur.

Volutocorbis, Dall, 1890. Type : V. limopsis, Conr. Eoc.

Taille moyenne; forme ovale, régulièrement atténuée aux deux bouts; spire assez courte, à galbe conoïdal; protoconche lisse, petite; tours non élagés, crénelés et réticulés; dernier tour peu ventru, entièrement orné, comme la spire, de costules axiales assez serrées, sur lesquelles des car’ues spirales découpent des crénelures régulières, jusque sur la base qui ne porte aucune trace de bourrelet. Ouverture fusiforme, peu lilatée, peu profondément échancrée en avant, canaliculée dans l'angle inférieur par une gouttière simple et bien évasée; labre peu oblique, assez épais, lacinié dans l'angle inférieur; columelle de Volutilithes.

\section{Diagnose complétée d'après un plésiotype du Calcaire grossier} de Parnes: $V$. crenulifer Bayan (Pl. V, fig.), ma coll.

Rapp. et diff. - L'utilité de cette Section est très contestable; elle ne diffère de Volutilithes que par sa forme générale et par son ornementation, par l'épaisseur de son labre, par l'absence d'épines et de gouttière labiale, correspondant à celte couronne d'épines chez Volutilithes. Or, parmi les nombreuses formes éocéniques, classées avec juste raison dans ce dernier Genre, il y en a plusieurs qui se rapprochent, par quelques-uns de leurs caractères, de Volutocorbis, de sorte qu'on peut hésiter à les placer plutôt dans un groupe que dans l'autre.

\section{Répart. stratigr.}

Senonien. - Deux espèces, l'une dans le "Groupe de Trichinopoly ", dans l’Inde méridionale, l'autre au Brésil : $V$. muricala fiorbes et $V$. radula Sow., d'après les figures des ouvrages de Stoliczlia et de Ch. White.

Eocene. - Deux espèces dans le Bassin anglo-parisien: $V^{\prime}$. scabricula Sol, et $V$. crenulifera Bayan ( $V$. crenulata Lamk. non Chemn.), ma coll. L'espèce-type dans le "Midway-Stagen des Etats-Unis, d'après M. Gilb. Harris.

Olrgocexe. - Une espèce de San Gonini (Vicentin), confondue avec $V$. crenulata Lamk., non tigurée, mais probablement distincte, d'après Brongniart. 
Epoque acturlle. - Une espèce au Cap de Bonne-Espérance: V. abyssicola Reeve, d'après la figure du Manuel de Tryon.

Neoathleta, Bellardi, 18\$\$. Type: V.affinis, Brocchi. Olig. $(=$ Volutopupa, I)all 1890)

Taille grande; forme plus ou moins ventrue; spire généralement courte; protoconche lisse, polygyrée, pupoïde, composée de tours convexes, à nucléus un peu saillant; tours costulés et couronnés de petites épines qui disparaissent quelquefois sur le dernier; ornementation composée de linéoles spirales rougeàtres, remplaçant les stries dans les intervalles lisses des côtes; dernier tour très grand et très ample, convexe en arrière, excavé à la base, qui porte des sillons imbriqués, obliquement enroulés sur le cou du canal. Ouverture grande, dilatée au milieu, assez large en arrière où elle est dépourvue de gouttière, peu rétrécie en avant où elle se termine par une troncature faiblement échancrée; labre mince, à peu près vertical, à peine sinueux à la suture, non lacinié à l'intérieur; columelle fortement excavée du côté postérieur, obliquement tordue et étroitement calleuse du côté antérieur, munie d'un pli épais et saillant, très oblique, au-dessous duquel il y a encore quatre plis parallèles, mais beaucoup plus lamelleux et plus petits; bord columellaire mince, souvent largement étalé sur la base en arrière.

Diagnose refaite d'après une espèce plésiotype: $V$. cithara Lamk. (Pl. V, fig. 3), et d'après sa variété $V$. ventricosa Defr. (PI.V, fig. 6), du Calcaire grossier de Grignon, ma coll. Protoconche grossie de la même espèce (Fig. 23 ci-contre).

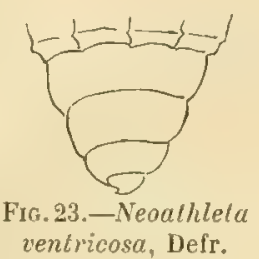

Observ. - Le type du Sous-Genre Volutopupa est désigné par M. Dall: $V$. cithara; or cetle espèce est génériquement identique au type de Neoathleta Bell., du Miocène inférieur, ou plutôt du Tongrien de la Ligurie; Neoathlela est certainement antérieur à Volutopupa, puisque Billardi est 
Volutilithes

mort en 1889; la livraison qui publie cette dénomination, u'a pu, il est vrai, être mise en vente qu'en janter 1890, par les soins de .1. Sacco; on s'explique done que M. Dall n'en ait pas eu encore connaissance, quand il a froposé l'ululopupa; mais, comme ce dernier nom n'a été publié qque dans le courant de l'année 1890, il n'y a pas de doute qu'il tombe dans la synonymie de Neoathleta, qui conserve la priorité.

Rapp. et diff. - Cette Section est extrêmement voisine de Volutitithes; Bellardi l'a séparée à cause des différences de la forme extérieure, M. Dall à cause de la disposition de l'embryon. J'y ajoute que l'ornementation a certainement un aspect distinct, et qu'en outre l'ouverlure n'a pas la mème disposition en arriere, sans aucune gonttiere, que le labre est plus mince et plus vertical, que la columelle est plus excavée du côté postérieur et moins coudée au milieu. Quant à la protoconche, il est évident qu'elle est beaucoup plus grosse que celle des Volutilithes s.s., tandis què la forme un peu plus ventrue, qui avait d'abord frappé Bellardi, n'est qu'un caractère bien fugitil. Dans ces conditions, je suis d'avis qu'il y a licu de conserver Neoathlela, à titre de simple Section; et encore y a-t-il des espèces, dépourvues de leur embryon, pour. lesquelles le doute subsiste, à cause des caractères mixtes qu’elles présentent.

\section{Répart. stratigr.}

Eockxe. - Outre le plésiotype ci-dessus, qui se trouve aussi en Angleterre, plusieurs autres espèces dans le Bassin de Paris: $V$. mulata, plicalella, lineolata Desh., I. lyra et bulbula Lamk., ma coll. Une espèce dans les couches nummulitiques de l'Inde: $T$. Sihesurensis d'Archiac, d'après la Monograplie de cet auteur.

Oligocexe. - Outre le type, plusieurs espèces dans le Tongrien de la Ligurie: N. obliqua et tricarinata Bell., V. Heberli(') Micht. Une autre espèce dans le Vicentin: $V$. Suessi liuchs, d'uprès la Monograplie de cet auteur.

Athleta, Conrad, 1853. 'Type: Voluta rarispina, Lamk. Mioc. (= Margovoluta, Sacco 1890)

'Test pesant. Taille moyenne; forme ventrue, ovoïdo-conique, cu plutôt strombiforme; spire très courte formant seulement une petite saillie extra-conique sur la croupe du dernier tour; proto-

(1) A propos de celte especee, M. Sacco relève un double emploi qui a échnppé à Deshayes, et il propose, pourlespéce parisienne, dénomméc à tort IY. Helserli, la nouvelle dénominalion: $V$. leshayesi. Mais ce double emploi avait déjả été enrrigé par Bayan, en 1875 : 1 . quinqueplicala; il y a donc lieu de supprimer $V$. Deshayesi. 


\section{Volutilithes}

conche lisse, paucispirée, turbinée, à nucléus en goutte de suif ; tours peu nombreux, crénelés, croissant d'abord lentement et s'élargissant d'une manière disproportionnée à partir de l'avant-dernier ; dernier tour très grand, formant presque toute la coquille, arrondi et couronné d'épines ou caréné à la partie inférieure, obtusément orné de sillons spiraux sur sa surface dorsale, très atténué à la base, sur laquelle les sillons sont plus serrés et plus profonds, et qui porte une sorte de bourrelet plissé aboutissant à l'échancrure antérieure.

Ouverture longue, peu large, avec une gouttière dans l'angle inférieur, et une échancrure assez profonde à son extrémité antérieure ; labre oblique, très épais, bordé à l'extérieur, irrégulièrement crénelé à l'intérieur, avec une légère inflexion à son contour antérieur; columelle épaisse, peu excavée, à peine coudée en avant, munie de trois plis presque égaux, assez saillants, peu obliques, et d'une ou deux rides inférieures, pliciformes, beaucoup plus petites que ces plis; bord columellaire extrèmement calleux, surtout en arrière où il s'étale largement jusque sur l'avant-dernier tour, souvent détaché en avant, et se terminant en pointe contre l'échancrure.

Diagnose refaite d'après un échantillon de l'espèce-type, du Burdigalien de Dax (PI. IV, fig. 24), et d'après un plésiotype du Claibornien de Woods-Blulf, dans I'Alabama: T. Tiıomeyi Conr. (Pl. V. fig. 5), ma collection.

Observ. - Je réunis à Athleta une coquille pour laquelle M. Sacco a proposé une nouvelle Section qu'il a classée, à tort d'après moi, dans le Genre Oniscia; autant que je puis en juger par la figure, Margovoluta Bellardii, qui est le type de ce Sous-Genre, et qui n'est représenté que par un seul échantillon mal conservé, est génériquement identique aux jeunes Alhleta; il en a l'ornementation, le labre épaissi, la callosité columellaire; quant à la plication, elle est incertaine sur l'individu-type, qui est engagé dans une gangue très dure; d'autre part, cet échantillon ne parait pas muni de l'échanerure basale des Cassididie, j'en conclus qu'il y a eu lieu de confondre cette coupe mal définie avec la Section Alhteta.

Rapp, et diff. - Au premier abord, il semble qu'Allteta doit être un 


\section{Volutilithes}

Genre complètement distinct de Volutilithes; l'énorme développement de la callosité basale, la brièveté de la spire, la différence des plis columellaires, la forme de la protoconche, le rudiment de bourrelet basal, paraissent, en effet, constituer des caracteres d'une importance suffisante pour motiver cette séparation. Toutefois, après un examen comparatif et très approfondi de ces deux formes, je persiste à penser qu'Athleta n'est pas un Genre distinct; car il y a des espèces éocéniques dont le classement générique donne lieu à de réelles hésitations ( $V$. alhleta Sow., $V$. strombiformis Desh., etc...), parce qu'elles participent à la fois aux caractères des deux groupes. D'ailleurs il ne faut pas perdre de vue que la forme ventrue et la forte callosité d'A thleta n'acquièrent toute leur importance que chez les individus complètement adultes, et que les jeunes ont une ressemblance complète avec les Volulilithes du même àge, sauf peut-être la protoconche qui permet de les distinguer, lorsqu'elle est conservée; d'autre part, il existe des espèces peu calleuses, mais strombiformes, telles que $V$. labrellus Lamk., chez lesquelles le second pli est, comme chez Athleta, presque aussi saillant que le pli antérieur, et dont l'embryon est turbiné. Pour tous ces motifs, il me parait plus prudent de n'admettre Athleta que comme une Section de Volutilithes.

\section{Répart. stratigr.}

Eocexe. - Une espèce un peu douteuse, dans le Bassin de Paris: V. labrellus Lamk, ma coll, ; une espèce typique dans le gisement de Bracklesham, en Angleterre: $V$. selseiensis J. Sow, coll. de l'Ecole des Mines. Le plésiotype ci-dessus figuré, dans le Claibornien des Etats-Unis, ma coll.

Oligocene. - Plusieurs espèces dans le Tongrien de la Iigurie: $V$. pygmieus, prxcursor, consanguineus Bell., d'après les figures de la Monographie de Bellardi; autre espèce douteuse : Margovoluta Bellardii Sacco, d'après la figure publiée par l'auteur. Une espèce à San Gonini, dans le Vicentin : V. italica Fuchs, d'après la figure.

Mrocexe. - L'espèce-type dans le Burdigalien de l'Aquitaine, ma coll., dans le Tortonien du Piémont, d'après Bellardi, dans le Bassin de Vienne, d'après R. Hoomes, et dans le Tortonien du Portugal, d'aprés Pereira da Costa. Une espèce voisine, dans le Tortonien des Landes et dans le Bassin de Vienne: V. ficulinaLamk., ma coll.; la même dans l'Helvétien du Piémont d'après Bellardi, et dans la Molasse de la Corse, d'après M. Locard, avec une autre espèce distincle : $\boldsymbol{V}$. Peroni Locard. Une autre espèce dans le Bassin de Vienne: T. Haueri M. Hornes, d'après la Monograplie de cet auteur. Une espèce probable dans les couches supérieures de Barma (Inde), identifiée avec $I$. dentata Sow., d'après M. Noetling. 
Liopeplum, Dall, 1890. Type: Athleta lioderma, Conr. Crét. (= Lioderma Conr. 1865, non Narseul 1857)

Taille assez grande; forme ovale; spire médiocrement allongée; protoconche petite, trochiforme; tours concavo-convexes, souvent costulés, séparés par des sutures bordées; dernier tour généralement lisse, avec une rampe postérieure concave au-dessus de la suture, ovale au milieu, atténué et légèrement excavé sur la base, qui porte en avant quelques sillons obliques. Ouverture assez grande,-à bords presque parallèles, peu dilatée au milieu, tronquée en avant par une très faible échancrure siphonale; labre mince, lisse à l'intérieur, oblique, un peu sinueux et rétrocurrent vers la suture; columelle faiblement excavée, munie de deux ou trois plis très obliques, à peine visibles à l'embouchure des individus adultes, et empâtés par la callosité du bord, qui forme en arrière un dẻpôt saillant, débordant sur l'avant-dernier tour, le long de la suture, et quelquefois sur le reste de la spire, comme cela a lieu chez Oliva.

Diagnose reproduite d'après celle de l'auteur (Tert. Flor., p. 73), et d'après la figure qu'il donne d'une espèce plésiotype : $L$. Spillmani Tuomey, du Crétacé supérieur du Mississipi. Copie de la figure originale (Fig. 24 ci-contre).

Rapp. et diff. - Cette Section, qui est évidemment l'ancêtre d'Athleta, s'en distingue par sa forme plus élancée, par sa callosité moins élalée sur la base, parfois enroulée en spirale, et par ses plis plus égaux, quoique très faibles. D'autre part, elle s'écarte de Volutilithes s. s. et de Volutocorbis par l'absence d'ornementation ou d'épines sur le dernier tour, par ses plis columellaires, par son énorme callosité; et, en outre, de Neoathleta par sa protoconche paucispirée.

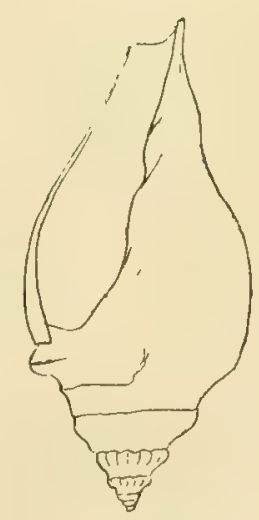

Fra. 24. - Jiopeplum lioderna, Conr.

Répart. stratigr.

SExoxnx. - Plusieurs espèces dans les "Couches de lipley ", appar- 
tenant an Crétacé tout à fait supérieur des Ėtats-Unis : $L$. lioderma Conr., Tolutilithes cretaceus Conr., L. Spillmani Tuom., V. subjugosa Gabb, d'après M. Dall.

Voumpomoria, Gabb, 1876. Type: V. Comradi, Gabb. Crét. (= Ptychosyca Gabb, fide Dall)

Taille très grande; forme élancée; spire courte ou médiocrcment allongée; protoconche lisse, petite, trochoïde (fide Dall); tours arrondis, souvent munis d'une rampe au-dessus de la suture; dernier tour très grand, ovale; arrondi cn arrière, atlénué et un peu excavé à la base, prolongé par un canal antérieur souvent assez élroit; surface ornée d'un treillis de côtes axiales et spirales, avec des granulations à leur intersection. Ouverture fusoïde, rétrécie sur le canal, paraissant dépourvue d'échancrure basale; labre mince, un peu sinueux, avec une légère entaille contre la suture (fide Dall); columelle excavée avec un fort pli principal et très oblique, du côté antérieur, les autres plis secondaires rarement visibles.

Diagnose traduite d'après la description d'un moule de l'espèce-type (in Whitfield, Gastr. lower green Marls New-Jersey, p. 71), et complétée d'après des indications fournies sur une espèce plésiotype avec test: $Y$. enraulensis Conr. (in Dall, 'I'ert. Flor., p. 73).

Rapp. et diff. - Èn réalité, je n'aperçois, entre Tolutomorpha et Volutilithes, aucune différence qui justifie la séparation d'une Section distincte; si l'on compare les deux diagnoses, on constate qu'elles sont à peu près identiques, sauf surquelques caractères de peu d'importance. Tontefois, comme je n’ai pu vérifier, sur les échantillons eux-mèmes, les rapports qui me paraissent exister entre ces deux Genres; comme, d'autre part, les figures que jai pu étudier sont seulement des moules internes ou des empreintes, daprès lesquels il est impossible de se faire une conviction cléfinitive; comme enfin M. Dall, dont la compétence, en matière de T'olulide surtout, est bien connue, conserve Volulomorpha comme un Genre distinct, intermédiaire entre Rostellites et Irolutilithes, probablement parce qu'il a reconnu des différences sérieuses sur les échantillons de $r$. eufau- 
Volutilithes

lensis ( ${ }^{1}$ Conr., munis de leur test, qui existent au Musée de Washington, je m’abstiens de supprimer cette Section jusqu'à plus ample informé ; en tous cas, d'après M. Dall, il paraît y avoir lieu d'y réunir Plychosyca Gabb, tandis que Piestochilus Gabb peut, à la rigueur, rester classé dans les Fasciolariidx, où nous le retrouverons.

Répart. stratigr.

Sexoxiex. - L'espèce-type, avec plusieurs autres formes voisines, dans la Craie supérieure de New-Jersey et du Missisșipi : $V$. ponderosa et Gabbi Whitf, d'après la Monographie de M. Whitfield; $V$. eufaulensis. Conr., V. delawarensis Gabb., d'après M. Dall.

PSEPHÆA, Crosse, 1871.

Protoconche mamelonnée; plis columellaires très inégaux, les inférieurs très enfoncés; échancrure un peu entaillée, avec un bourrelet basal plus ou moins visible.

Type: $V$. concinna, Brod. Viv.

Lopsephat, Fischer 1883. Type: V. muricina, Lamk. Eoc.

Test assez épais. Taille assez grande; forme étroite et longue ; spire allongée, épineuse ou costulée, à galbe conique; protoconche lisse, paucispirée, subcylindrique, à nucléus conique terminé par une petite pointe redressée ; tours subanguleux, ornés de costules pincées, qui se transforment sur l'angle en épines plus ou moins saillantes, et de fines stries spirales, parfois peu visibles; dernier tour grand, souvent couronné en arrière, généralement lisse au milieu, sauf le prolongement des costules jusque sur la base excavée; quelques filets noduleux sur le cou, qui porte un bourrelet obsolète, un peu plus saillant chez les individus très âgés.

Ouverture assez large el assez courte, avec une étroite gouttière

(1) La figure originale (au trait), publice par Conrad (Journ. Acad. Sc. nat., IV, p. 471, fig. 18), a complètement l'aspect d'un Volutilithes éocenique; le pli columellaire y est i peine indiqué, et l'ormenentation ressemble à celle de Volutilithes ambiguns Sow. 
anguleuse en arrière, terminée en avaut par une échancrure médiocrement profonde; labre peu épais, vertical, à peine sinueux entre la couronne d'épines et la suture, lisse à l'intéricur; columelle à peu près rectiligne, ou faiblement coudée, munie d'un pli principal, mince et oblique, au-dessous de la torsion antérieure, et de trois ou quatre plis plus faibles, très enfoncés à l'intérieur, invisibles à l'embonchure des individus complets et adultes; loord columellaire mince sur presque toute sa hauteur, calleux et appliqué sur la région ombilicale, jusque contre le bourrelet.

Diagnose refaite d'après des échantillons de l'espècetype du Calcaire grossier de la tranchée de Villiers (Pl. VI, fig. 1); et d'après un plésiotype des sables suessoniens de Saint-Gobain: $V$. angusta Deslı. (Pl. V, fig. 2), ma coll. Protoconche de $V$. mixla grossie (Fig. 25, ci-contre).

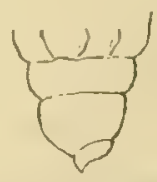

Fio.2:- Eopsephix mixla. Desh.

Rapp. et diff. - Ce Sous-Genre se distingue de Psephiea par son nucléus embryonnaire, qui forme un petit cône pointu, au-dessus des deux tours mamelonnés, dont se compose la partie cylindrique de la protoconche; en outre, la diagnose de Psephea, reproduite dans le Hanuel de Fischer, indique deux plis columellaires principaux, tandis qu'il n' $y$ en a qu'un chez Eopsephea, à moins que l'on ne compte comme un pli la torsion de la columelle, au-dessus du pli principal; quant au système d'ornementation, il est identique chez ces deux formes. Si on compare Eopsephea aux autres représentants de la mème Sous-Famille, par exemple à Volutitithes, dont il se rapproche par la plication de sa columelle, on trouve que la protoconche est bien plus développée, que l'échancrure est min peu plus profonde, et qu'elle donne lieu, par ses accroissentents, à la formation d'un bourrelet, dont on n'aperçoit jamais la trace chez Volutilithes; entin l'ornementation a un caractere tont à fait différent, et la spire est beaucoup plus élevée. Je crois inutile de rapprocher ce Sous-Genre des Tolulinie, qui sont aussi épineuses, mais dont les plis sont radicalement différents, et qui ont une échancrure beaucoup plus profonde, avec un bourrelet Lasal mieux marqué.

Répart. stratigr.

Turoviex. - Une espèce probable dans les grés d'Uchaux: $V$. Requieniana d'Orb., ma coll. et coll. de l'licole des Mines; antre espèce douteuse, dans les couches supérieures de Gosau: IT. acula Sow., d'après la figure de la Monographie de Zekeli. 
Sexonien. - Une espèce bien caractérisée, dans les sables de Vaals, près d'Aix-la-Chapelle: $V$. subsemiplicala d'Orb, d'après les figures de la Monographie de M. Holzapfel. Un fragment probable dans les couches daniennes de la Tunisie: $V$. Drui Thom. et Péron, d'après la figure publiée par M. Péron. Une espèce dans les couches crélaciques du Brésil: $V$. alticosta White, d'après cet auteur.

Paleocene. - Une espèce douteuse et mal conservée, dans le " Midway stage " de l'Alabama et de la Géorgie: V. Florencis Gilb. Harr., d'après la figure publiée par l'auteur.

Eоскке. - Nombreuses espèces outre le type, dans le Bassin angloparisien et en Belgique: $V$. Frederici et relicta Bayan, $Y$. Berlhic de Rainc., V. Goldfussi el angusta Desh., V. mixıa Chemn, V. torulosa Lamk., V.protensa et uniplicata Sow., ma coll. et diaprès la Monographie de F. Edwards. Une espèce dans la Tasmanie: I. Tateana Johnston, ma coll.

PTYGHORIS, Gabb, 1876.

Pтүсновis, s. str. Type: Voluta purpuriformis, Forbes, Grét.

Test un peu épais. Taille assez grande ; forme ovoïdo-conique, subbulbeuse, analogue à celle de Sycum; spire peu allongée, à galbe conique; protoconche papilleuse, paucispirée, à nucléus arrondi ; tours étroits, un peu convexes, séparés par des sutures bordées, spiralement sillonnés; dernier tour très grand, ventru, arrondi au milieu, alténué et subitement escavé à la base, terminé en avant par un canal buccinoïde et court, sur le cou duquel est un gros bourrelet obtus. Ouverture assez large, semilunaire, avec une étroite gouttière calleuse dans l'angle inférieur, faiblement échancrée à l'extrémité du canal; labı̀e un peu sinueux, épaissi et bordé à l'extérieur, lisse à l'intéricur' columelle courte, faiblement excavée, porlant tout à fait en avant cinq plis très rapprochés, obliques a $45^{\circ}$; bord columellaire calleux, avec une protubérance saillante à côté de la gouttière postérieure, el débordant même sur l'avant-dernier tour, comme chez Allileta. 
Diagnose refaite d'après le texte et la figure de l'espèce-type, dans l'ouvrage de Stoliczka (Cret. Gastr. South India, P.90, pl. VIII, fig. 4-7); copie réduite de cette figure (Fig. 26 ci-contre).

Rapp. et diff. - N'ayant pu éludier que les figures de ce Genre, il m'est impossible d'en fixer le classement définitif; s'il se rapproche d'Athlela par son ouverture calleuse et par son labre bordé, il paraît s'écarter absolument des Loxoplocince par sa plication columellaire, qui ne ressemble à celle d'aucune des formes de Volutidic. L'existence de cinq plis rapprochés dans le court espace qui sépare l'enroulement du bourrelet basal, sur

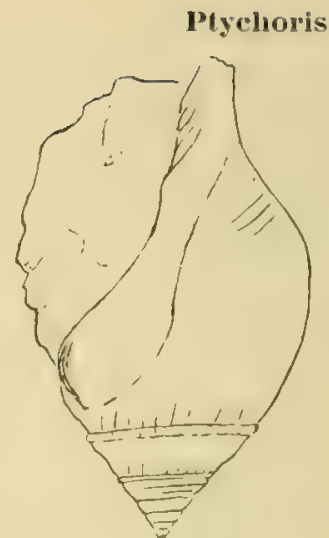

F16. 26. - Plychoris putpuriformis, Forbes.

la columelle, de l'extrémité antérieure du canal, me fait même douter que la figure soit exacte; d'autant plus que l'apparence r'est pas la même chez la scconde des espèces qui sont désignées comme appartenant à ce Genre (Athlela scrobiculala Stol.), et pour laquelle l'auleur indique trois plis presque égaux etmieux répartis sur toute la hauteur de la columelle. Il y a donc lieu d'attendre, avant de fixer le classement de Plychoris, que l'on ait pu étudier des matériaux plus certains que ceux dont on dispose actuellement. En tous cas, s'il est prouvé que la plication se rapproche de celle des Loxoplocinie, Plychoris se distinguera toujours d'Alhleta par sa protoconche papilleuse, par sa spire plus développée et par son bourrelet basal.

\section{Répart. stratigr.}

Turoxilex. - Deux espèces dans le "Groupe de Trichinopoly", de l'Inde méridionale, d'après Stoliczka.

\section{MIIIIJ).}

lorme variable, génélalement fusoïde; spire assez longue, ne dépassant pas cependant la moitié de la longueur tolale, rarement inférieure au tiers de celte longueur; protoconche lisse, pelite, saillante, ordinairement polygyrée, it nucléus parfois papilleux; surface lisse ou ornée. Ouverture assez étroite, anguleuse en arrière, ichancrie a la base par une entaille dont les accroissements forment un hourelet plus ou moins saillant: labre épais, tantôt lisse, tantit 
crénelé à l'intérieur, peu ou point sinueux; columelle droite, ou à peine excavée, portant plusieurs plis, dont l'épaisseur augmente toujours d'avant en arrière, l'antérieur souvent confondu avec la torsion columellaire; bord calleux el distinct de la base. Pas d'opercule.

Rapp. et diff. - On distingue cette Famille des Volutidæ: non seulement par la forme plus fusoïde de la coquille, mais surtout par la disposition inverse des plis columellaires, qui décroissent invariablement d'avant en arrière chez les Volutidæ, tandis que c'est précisément le contraire chez les Mitridæ. On ne peut tirer aucun critérium distinctif de la disposition de la protoconche, ou du moins on ne peut se baser absolument sur sa forme, attendu que certains Volutilithes ont un embryon de Mitra, tandis que certains Genres de Mitridx (par ex. I olvaria) ont une protoconche subglobuleuse. Il en est de même en ce qui concerne l'opercule.

Observ. - La classification des Genres de Milride ne présente pas les mêmes difficultés que celle des Volutidx, parce que la plupart des subdivisions qu’on y a faites présentent une réelle homogénéité, de sorte qu'on pourrait même, à la rigueur, se dispenser de diviser cette Famille en SousFamilles. Cependant Bellardi, se fondant presque exclusivement sur la présence oul'absence de plis à l'intérieur du labre, ainsi que sur le nombre des plis columellaires, a proposé (1886) trois Sous-Familles: Orthomitrinx, comprenant le Genre Mitra divisé en trois Sections non dénommées; Plesiomitrine, comprenant les genres Uromitra, Turricula, Pusia et Micromilia; Diplychomitrine, avec les deux Genres Clinomitra et Diptychomitra. Tout en adoptant ces dénominations, je leur ferai un reproche: c'est qu'elles m'obligent à les compléter, pour faire entrer dans la même classification les autres Genres fossiles et acluels, que Bellardi a laissés de côté, bornant son système aux Mitres du Piémont et de la Ligurie. Cette extension m'a mis dans la nécessité de recourir tantôt au labre, tantôt à la columelle, tantôt à la protoconche, pour me guider dans ce classement; c'est en m'inspirant de ces données éclectiques que j'ai dressé le tableau suivant, dans lequel j'ai interprété et élargi le sens des Sous-Familles de Bellardi.

Dans sa description des fossiles australasiens du British Museum, M. Geo. Harris a fait, à propos de Mitra multisulcata Geo. Harr., quelque: remarques intéressantes sur la formation successive des plis columellaires chez les Midridx; il a pu étudier la columelle de cette espèce sur une série d'individus, pris à diverses éponnes de leur croissance, et il a observé que le nombre des plis augmente à mesure que la coquille avance en âge ; ce nombre commence par d̂le de deux, et il finit par atteindre le chiffre de cinq; chez les adultes, ii se lorme souvent des plis subsidiaires 
entre les plis normaux. Il ressort de là que, dans la classification à élablir pour celte Famille, le nombre des plis doit toujours être complé sur les individus adultes.

Tableau des Genres, Sous-Genres et Sections.

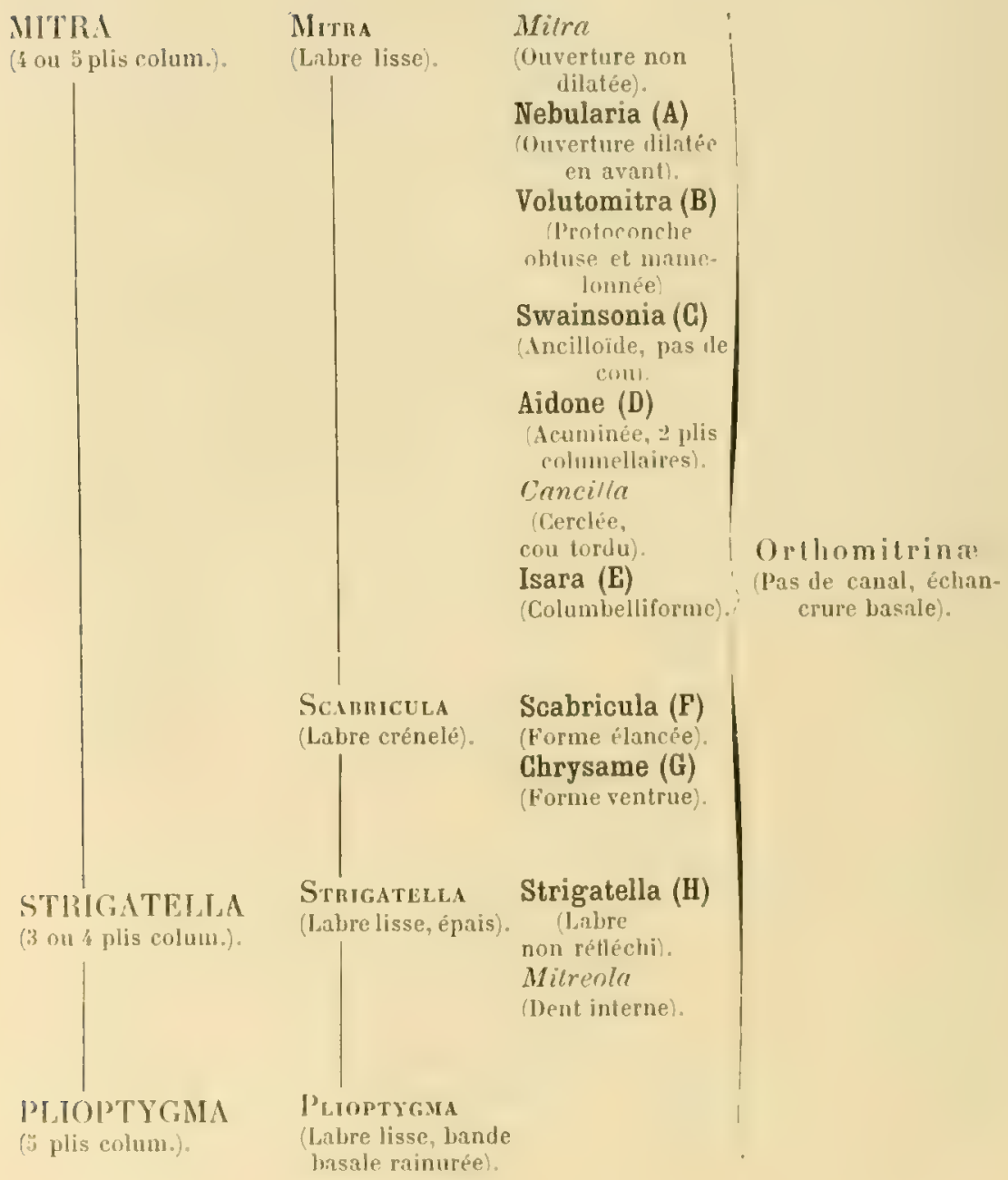




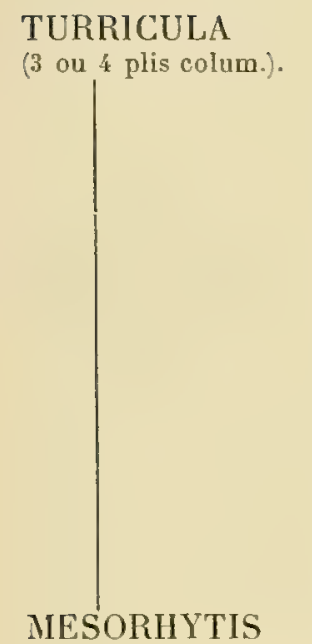

( 3 plis situés trẻs bas).

\author{
Tunicula \\ (Spire longue, \\ échancrure \\ profonde).
}

\section{Pusia (I)}

(Spire courte, échancrure faible).

\section{Fusmitra}

(Canal droit, échancrure faible)

$$
\text { | }
$$

UnOytra

(Canal contourné, protoconche polygyrée).

MesoIhHTIS

(Conal long, droit, sans échancrure).

\section{Coxonitra}

CONOMITRA

(4 plis colum.).

\section{MITROLUMNA}

(2 plis colum.).

\section{ZIERVOGELIA}

(3 ou 4 plis col., une dent pariétale).

\section{THALA \\ (4 plis colum.). \\ MUTYCA \\ (5 ou 6 plis colum.). \\ PERPIICARIA \\ (1 pli colum.).

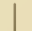 \\ DIBAPHUS}

(Pas de pli colum.).

Forme biconique).

Mitrolemia

(Forme olivoïde).

\section{Ziervogelia (J)}

(Formeglobuleuse).

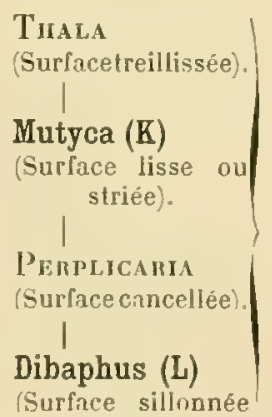

Surface sillonnee

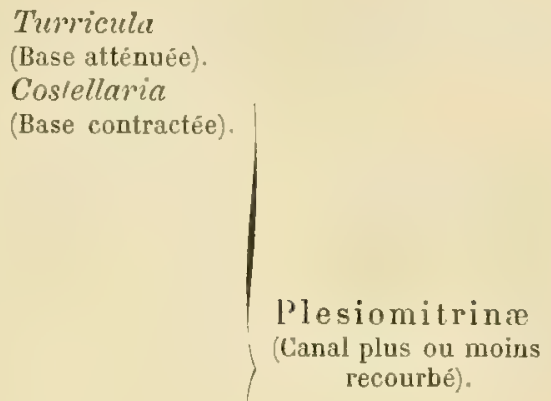

Semimitrinæ (Pas de canal ni d'échancrure basale).
Pseudomitrina

(Canal court, un peu échancré, labre plissé). 


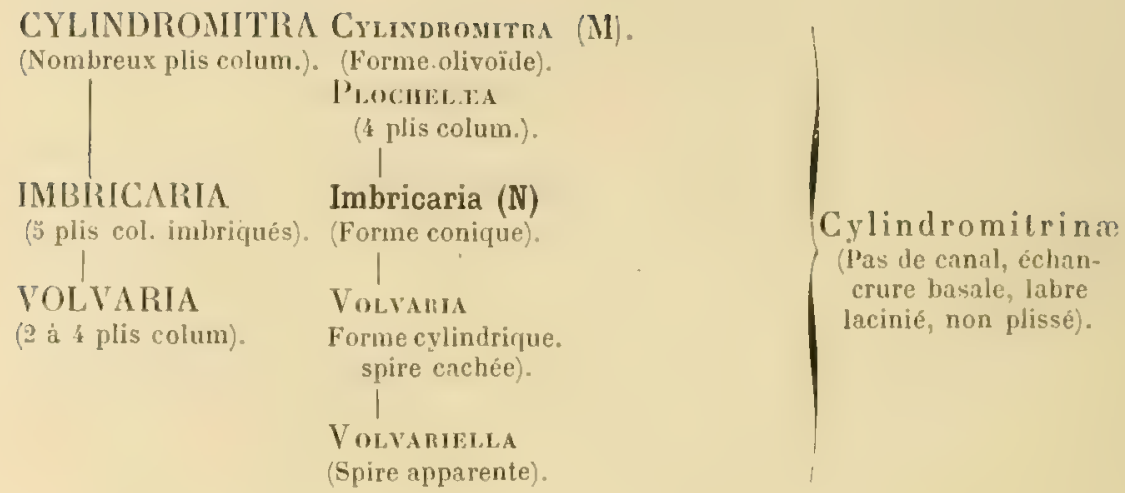

\section{Genres, Sous-Genres et Sections non signalés à l'état fossile.}

A. - Nebularia, Swainson 1840. - Type: M. abbalis Chemn. (= contracta Sw.). - Ce groupe ne differe de Mitra que par son ouverture plus dilatée en avant; la surface de la coquille est ornée de sillons spiraux, comme elle l'est chez un grand nombre de llitres typiques, et les autres caractères génériques sont, pour la plupart, identiques; je ne vois done pas bien la nécessité de cette Section, à laquelle appartiennent peut-êtro un cerlain nombre d'espèces fossiles, que les paléontologistes continuent a placer, avec raison, dans le Genre Mitra s. $s$.

B. - Volvtomrra, Gray 1847.- Type: Voluia groenlandica Beck. Ainsi que je l'ai fait observer à propos de la Famille Vohutida (p. 108), cette Section se rapproche de Mitra par tous les caractères de la coquille (quatre plis croissant d'avant en arrière, forme générale, labre simple, pas de canal, etc.); mais son sommet est obtus et submamelonné, et sa radule se rapproche de celle de Volula. Néanmoins je ne crois pas que ces dernières différences justilient le classement proposé par Fischer, et je persiste à penser que c'est tout an plus une Section de Mirra; Tryon l'a même complètement identifié avec ce Genre.

G. - Swansoxia, H. et $\Lambda$. Adams 18003 (= Mitrella Swainson 1838, non Risso, 1826). - Type: M. fissurata Lamk. Cette Section comprend des coquilles très voisines de Mitra $s$. $s$, et qui ne s'en distinguent que par leur forme olivacée ou ancilloïde, par l'absence complète de con, par la convexité de la base aboutissant à l'échancrure, sans aucune dépression excavée. La surface est imariablement lisse et polie. Je ne connais pas de fossile qui réponde exactement à ces caractères.

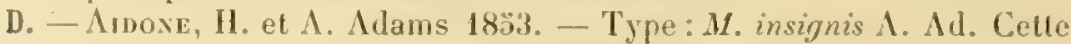
Section s'écarte un peu davantage des Mitres typiques, non seulement par 
sa spire plus acuminée, mais encore par ses plis columellaires, dont les deux postérieurs sont plus saillants, à la moitié de la hanteur de la columelle; les autres plis antérieurs sont à peine visibles, ou confondus avec la torsion columellaire; la surface est lisse et polie, l'ouverture est un peu dilatẻe en avant, comme celle de Nebularia.

E. - Isara, II. et A. Adams 1853. - Type: M. bulimoides Reeve. Cette coquille est tellement voisine de Mitra que j'hésite à l'admettre même comme une Section distincte; elle a seulement l'aspect colombelliforme, l'ouverture plus courte que la spire, le bord columellaire plus calleux; ce sont là, comme on le voit, des différences bien légères.

F. - Scarricula, Sivainson 1840. - Néotype: M. granatina Lamk. (sec. Fischer), ou $M$. lessellata Martynn (sec. Tryon). La forme générale et les plis sont les mêmes que chez Mitra s. $s$; mais, outre que l'ornementation se compose de côtes granuleuses, qui justifient la dénomination choisie par Swainson, le labre est crénelé à l'intérieur; d'autre part, la base étant excavée, le cou est bien isolé comme chez Cancilla. Pour ces motifs, j'admets Scabricula au rang de Sous-Genre.

G. - Chrysame, II. et A. Adams, 18ö3. - Néotype: $M$. coronata Lamk. (sec. Fischer), ou $M$. cucumerina Lamk. (sec. Tryon). Cette Section diffère de Scabricula par sa forme courte et ventrue, par ses plis columellaires plus transverses; l'ornementation est, en outre, moins granuleuse; elle se réduit, chez la plupart des espèces, à des côtes spirales, séparées par des sillons plus étroits : ce sont là des caractères qui ne justifient, tout au plus, que la séparation d'une Section.

H. - Strigatelua, Sivainson 1810. - Néotype : M. litterata Lamk. (sec. Fischer). C'est une forme ventrue, à trois plis columellaires, le quatrieme est confondu avec la torsion antérieure de la columelle; en outre, le labre est épaissi à l'intérieur par une callosité, qui est comme un indice précurseur (ou plutôt une dégénérescence) de la dent labiale de Mitreola. Pour ces motifs, je suis d'avis qu'on peut admettre Strigalella comme un Genre bien distinct de Mitra.

I. - Pusia, Sivainson 1840. - Néotype: $M$. microzonias Lamk. (sec. Fischer). Il n'y a pas, en apparence, de différences très importantes entre Pusia et Turricula, sauf la forme de la coquille, qui est plus courte et plus ventrue; la base est aussi régulièrement atténuée, les plis sont identiques, l'ornementation elle-même s'écarte peu de celle de Turricula; toutefois je constate, sur mes échantillons, que l'échancrure basale de Pusia est à peine entaillée, et que le canal est rudimentaire; en outre, le bord columellaire est mince el indistinct, comme chez Costellaria. Dans ces conditions, je considère que Pusia est un Sous-Genre de Turricula.

J. - Zienvogecia. Gray 1847 (Fisch. em. = Zierliana). - Type: $M$. Ziervogpliana Gray. Iutant (que l'on peut en juger d'apris lesfigures, cette coquille na ni canal, ni échancrure; quoiqu'elle soit plus globuleuse que Conomitra, elle s'en rapproche par sa forme, et par conséquent, il me semble que sa place est bien dans la Sous-Famille Semimitrinx; toutefois 
elle s'écarte de Conomitra par ses gros plis columellaires transverses, au nombre de trois, en général, car la présence d'un quatrième pli antérieur me paraît douteuse. Naïs elle est surtout caractérisée par l'énorme dent pariétale qui encombre l'angle inférieur de l'ouverture; outre qu'elle a toujours un pli de plus que Mitrolumna, eette dent l'en distingue neltement. Le nom de la personne à laquelle était dédié ce Genre (Ziervogel), ayant été complitement dénaturé par Gray, Fischer en a rétabli l'exacte latinisation.

K. - Mutrca, II. el A. Adams 1853 (= Milroidea Pease 1863 ; = Mauritia A. Adam 1869). - Type: M. Barclayi H. Adam (= M. mulliplicala Pease). Cette forme a beaucoup de ressemblance avec Thala; elles'en distingue, toutefois, non seulement par sa surface qui, au lieu d'être treillisée, est lisse, ou simplement ornée de stries spirales, avec quelques sillons obliques à la base; mais encore et surtout par le numbre des plis columellaires, quỉ est toujours supérieur à quatre, et parfois égal à six. Tryon a adopté la dénomination Mitroidea, quoiqu'elle soit bien postérieure, par le motif que la diagnose de Mulyca ne permet pas de reconnaître les deux espéces que les frères Adams y ont placées; je ne puis admettre cette opinion, qui est en contradiction formelle avec les rigles de la nomenclature.

L. - Dibapius, Philippi 1847. - Type: M. ectentula Swains. $(=D$. Philippii Crosse, sec Tryon). Ce Genre est caractérisé par l'absence complete de plis à la columelle, qui est simplement tordue à la base; l'extrímité antérieure est plutôt tronquée qu'échancrée; quant au labre, il est épaissi, rectiligne, et, ainsi que cela a lieu d'ailleurs chez tous les Pseudomitrinx, il n'est pas contracté en avant, de sorte que l'ouverture conserve à peu près la mème largeur, sur toute sa hauteur, de même que chez Clathurella; c'est principalement à cause de ce dernier caractire, que je considire les membres de cette Sous-Famille comme de "fausses Mitres" (Iseudo-Mitra).

M.-Crlnonomitra, Fischer 1884 =Cylindra Schum.1817, nan Cylinder, Montf. 1810), - Type : M. crenulata Chemn. Le type de ce Genre est caractérisé : non seulement par sa forme olivoïde et par l'absence de canal, mais surtout par le nombre de ses plis qui n'est pas inférieur à neuf', croissant régulièrement d'avant en arrière ; la troncature basale est assez profondément échancrée, avec un bourrelet obsoléte. I. R. Hornes indique une espice fossile (C. transylvanica) appartenant à ce Genre; mais, autant que je puis en juger par la figure, la détermination grénérique parait très douteuse, de sorte que je me borne à signaler cette citation, sans comprendre encore Cylindromitra dans le Catalogue détaillé des formes connues à l'état fossile.

N. - Imbncana, Schumacher 1817 (= Conoelix. Swains 1821). - Type: I. conica Schum. Coquille caractérisée: non seulement par sa forme conique, mais par ses cinf plis columellaires, qui ont une disposition imbriquée, peu fréquente chez les Mitridx; la troncature basale est pro- 
fondément échancrée, et ses accroissements forment un bourrelet un peu saillant; la protoconche a l'aspect légèrement styliforme, ou tout au moins mucroné.

\section{MITRA, Lamk. 1799.}

Coquille fusiforme ou ovale, solide; spire aiguë au sommet; quatre ou cinq plis columellaires; labre non réfléchi, lisse à l'intérieur.

Mitra, sensu stricto.

Type : M. episcopalis, Lamk. Viv.

(= Thiarella, Swains. 1840; = Mitraria, Rafin. 1815;

$=$ Mitrolithes; Krüg. 1823; sec. Tryon)

Test épais. Taille assez grande; forme fusoïde, étroite; spire allongée, généralementégale à l'ouverture, à galbe un peu conoïdal; protoconche lisse, polygyrée, conique, à nucléus obtus et faiblement dévié; tours plus ou moins convexes, lisses, ou ornés : soit de sillons ponctués par les accroissements, soit de plis d'accroissement; dernier tour très grand, ovale, excavé à la base, sur laquelle s'enroulent des sillons imbriqués, plus ou moins obsolètes, jusque sur le bourrelet obtus qui aboutit à l'échancrure antérieure.

Ouverture étroite, anguleuse en arrière, peu atténuée en avant, où elle est tronquée par une large el profonde échancrure; labre mince, presque vertical, un peu rétrocurrent vers la suture, généralement lisse à l'intérieur, quelquefois lacinié en avant; columelle oblique, peu ou point excavée, calleuse et terminée en pointe contre l'échancrure basale, munie de cinq plis équidistants, croissant d'avant en arrière, l'antérieur souvent peu visible; bord columellaire calleux, assez étroit, bien limité à l'extérieur, et sẹparé ou détaché du bourrelet basal par une dépression rainurée. 
Diagnose refaite d'après l'espèce-type, et d'après un plésiotype du Calcaire grossier de Mouchy : M. elongata Lamk. (Pl. VII, fig. 12-13), ma coll. Protoconche de M. Deluci Defr. grossie Fig. 27 "icontre).

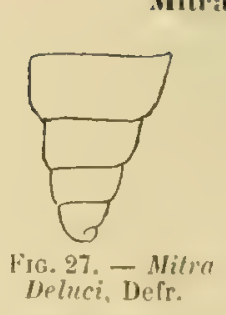

Observ. - Je n'ai pas de renseignements sur les trois dénominations, que Tryon indique comme synonymes de Mitra, et que Fischer n'a pas reprises dans son Manuel: Thiarella, Mitraria et Mitrolithes; je me borne donc à les enregistrer sans commentaires. Comme d'ailleurs Milra

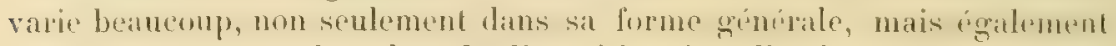
dans son ornementation, dans la disposition des plis, daus la longueur du cou formé par le bourrelet basal, et que, d'autre part, ces variations s'enchaînent graduellement d'une espèce à l'autre, souvent mème par l'intermédiaire des variétés d'une même espèce, j'imiterai la réserve de Bellardi, qui n'a pas jugé à propos de dénommer les Sections, simplement découpées par lui pour la commodité de la classification des nombreuses Mitres du Tertiaire supérieur. En conséquence, je n’ai pas appliqué aux formes fossiles la plupart des noms de Genres, créés avec profusion, par Swainson ou par les frères $\Lambda$ dams, pour de légères différences dans la forme extérieure de la coquille.

\section{Répart. stratigr.}

Eocraxe. - Outre le plésiotype ci-dessus figuré, plusieurs espèces dans le Bassin de Paris, dans la Loire-Inférienre, dans le Vicentin: M. Deluci Defr., M. plicatella, mixta, crebricosta Lamk., M. auversiensis Cossm., ma coll.; une espèce probable dans le nummulitique de Monte Postale (Vicentin): M. Marsalai de Gregorio, d'après la figure donnée par cetauteur.

Obicocene. - Plusieurs espèces dans l'Apennin: $M$. blandiu, semicostala, oligocinica, apenninica, cassinellensis, anceps, cxacula Bellardi, d'après la Monographie de cet auteur.

Mrocexe. - Très nombreuse's especes dans le P'iémont et l'llalie centrale, d'après la Monographie de Bellardi. P'lusicur's espèces dans le Burdigalien de I'Aquilaine: M. incognita Bast., M. Burgucli Grat., ma coll.; M. Dufiesnei Bast, d'après la figure publiée par Basterot; $M$. subelongata d'Orb. et $\boldsymbol{M}$. fusiformis Br., d'après le Catalogue de M. Benoist. Une espéce dans le Tortonien du ComtatVenaissin: $\boldsymbol{M}$. bathymophora Fontannes, d'aprés la figure publiéc par cet auteur. Plusieurs espèces typiques dans le Bassin de Vienne: M. fusiformis Br., M. Hilberi, Brusinai et Bellardii R. Hoernes, d'après la Monographie de MII. Iloernes et Auinger. Une espèce 
variable, dans le Tortonien du Portugal: $\boldsymbol{M}$. cf. fusiformis $\mathrm{Br}$., d'après la Monographie de Pereira da Costa.

Pliocexe. - Très nombreuses espèces dans le Piémont et l'Italie centrale, d'après la Monographie de Brocchi, de Bellardi, de Foresti, etc... L'une d'elles dans le Crag d'Angleterre: $M$. fusiformis Br., d'après la Monographie de S. Wood. Plusieurs autres espèces dans le Bassin du Rhòne : M. T'enayssina, bitenuala, Rhodanica, Escoffierx Fontannes, M. aperta Bell., d'après la Monographie de Fontannes. Epoque actuelle. - Très nombreuses espèces dans toutes les mers, d'après le Manuel de Tryon.

Cangilla, Swainson, 1840.

Néotype : M. filaris Linn. (sec. 'Tryon). Viv. (=Ziba, H. et A. Adams 1853)

Taille parfois grande; forme étroite, élancée; spire longue, acuminée, souvent un peu étagée, à galbe conique; protoconche lisse, petite, trochiforme, à nucléus pointu; tours convexes, ornés de bandelettes ou de carènes spirales, dont les interstices sont plus ou moins décussés par de fins plis d'accroissement; dernier tour fusiforme, rapidement alténué à la base, qui est généralement excavée, et qui se termine par un cou un peu allongé, tordu, et rejeté vers l'axe, avec un bourrelet peu saillant, formé par les accroissements successifs de l'échancrure antérieure. Ouverture très étroite, avec une gouttière calleuse dans l'angle inférieur, tronquée à l'extrémité supérieure par une échancrure assez profonde; labre peu épais, lisse à l'intérieur, simplement lacinié sur son contour par Jes côtes spirales, légèrement sinueux vers lá suture; columelle non excavée, munie de cinq plis, dont les trois antérieurs sont à peine saillants; bord columellaire étroit, calleux, se terminant en pointe effilée contre le bourrelet du cou.

Diagnose refaite d'après le néotype vivant, et d'après un plésiotype du Tortonien de Saubrigues: M. exornata Bell. (Pl. VIlI, fig. 16-17), ma coll.

Rapp. et diff. - Cette Section, qui correspond à la deuxième section de la classification de Bellardi, se distingue: non sculement par son orne- 
mentation composée de còtes spirales au lieu de sillons, mais encore el surtont par la disposition du cou, qui est un peu tordu; la forme générale de la coquille est d'ailleurs plus élancée que celle des Mitres typiques. Je considère Ziba comme synonyme de Cancilla; on ne l'en distingue, en effet, que par sa spire étagée et par ses carènes spirales plus saillantes : or ce sont là des caractères purement spécifiques.

\section{Répart. stratigr.}

Eocene. - Une espèce lisse sur les derniers tours des individus adultes, dans le Jacksonien du Mississipi : M. Millingloni Conr. ma coll. Une espèce à protoconche obtuse : Cancilla atracloides 'Tate, d'après M. Geo. Harris.

Mocene. - Outre le plésiotype ci-dessus figuré, plusieurs espices dans le Burdigalien, l'Helvétien et le Tortonien des Landes, du Portugal, du Piémont et du Bassin de Vienne: $\boldsymbol{M}$. planicostata Bell. ma coll., $M$. elegantissima Bell., M. separata, aculeala, puicherrima, eoscrobiculata Bell., d'apri's les Monographies de Bellardi, de da Costa et de R. Hornes. Deux espices confondues avec M. Bromi et scrobiculala, mais probablement différentes, dans le Tortonien du Bordelais, d'après le Catalogue de M. Benoist; une espéce dans le Tortonien des Landes: M. Grateloupi, d'Orb., d'apri's l'Atlas de Grateloup. Une espèce dans les " couches à silex " de la Floride: $M$. silicata Dall, d'après la Monographie de cet auteur.

Pliocene. - Plusieurs espèces ou variétés, dans le Plaisancien et l'Astien des Alpes-Maritimes, du Piémont et du Bassin du Rhône: M. scrobiculata Br., M. Bronni Micht., ma coll.; M. colligens, planicostala, transiens, conjungens, contiyua Bell.; M. fusulus Cocc., M. strialula Br., M. Massoli Font., daprès les Monographies de Bellardi et de Fontannes. Une espèce actuelle, dans les couches récentes de Karikal: $\boldsymbol{M}$. flammea Quoy, coll. Bonnet; la mêmo dans les couches récentes de Java, avec une autre espèce vivante: M. circula Kiener, d'après la Monographie de M. Martin.

Epoque actuelle. - Nombreuses espèces dans l'Océan Indien, les mers de Chine et l'Australasie, sur la côte Onest de l'Amérique centrale, et au cap Vert, d'apris le Manuel de Tryon.

STRIGATELLA, Swainson, 1840.

Forme ventrue; surface lisse ou nodoso-costulée; échancrure basale profonde, avec un gros bourrelet, sans cou distinct de la base: labre épais, calleux ou denté à l'intérieur; columelle un peu 
Strigatella

excavée en arrière munie au milieu de trois plis principaux, transverses et saillants, et en avant, d'un quatrième pli oblique, souvent obsolète, ou confondu avec la torsion columellaire.

Mrtreola, Stwainson, 1840. Type : M. labratula, Lamk. Eoc.

Taille moyenne; forme ovoïdo-conique, parfois un peu ventrue; spire égale à la hauteur de l'ouverture, à galbe conique ; protoconche lisse, paucispirée, à nucléus obtus; tours converes en avant, concaves en arrière, ternes, ornés de filets spiraux ou de costules écartées, subnoduleuses sur la convexité antérieure; sutures profondes, parfois bordées; dernier tour égal aux trois cinquièmes ou aux deux tiès de la longueur totale, lisse ou noduleux sur la convexité située au-dessus de la rampe suturale, ovale et peu excavé à la base; cou muni d'un bourrelet large et peu saillant, qui aboutit à l'échancrure antérieure.

Ouverture vernissée, peu large, à bords presque parallèles, munie d'une étroite gouttière dans l'angle inférieur, rétrécie en avant et très profondémenl échancrée; labrevertical, non sinueux en al'rière, un peu réfléchi et bordé à l'extérieur, épaissi à l'intérieur et généralement muni d'une dent postérieure; columelle peu excavée, munie de quatre plis équidistants, les trois inférieurs transverses et saillants, l'antérieur plus oblique, moins saillant, mais bien distinct de la torsion de la columelle, qui se recourbe et s'infléchit à droite, contre le bord de l'échancrure basale; bord columellaire large et calleux, bien limité à l'extérieur, quelquefois détaché du bourrelet du cou.

Diagnose faite d'après un échantillon de l'espèce-type, du Calcaire grossier de Mouchy (Pl. VIIJ, fig. 18-19), ma coll.

Rapp. et diff. - Cette Section ne se distingue de Strigatella que parsa dent labiale et par sa surface généralement noduleuse ou costulée; et encore y a-t-il des Mitreola à peu près lisses, dont la dent est presque eflacée, et des Strigatella ornés, dont la callosité interne s'épaissit au 
point de former presque une dent; aussi je ne comprends pas pourquoi Swainson a créé deux Genres distincts pour ces deux formes, car c'est tout au plus si la seconde, qui est exclusivement fossile, peut être distinguée de la première, qui est exclusivement vivante, ut qui succède ivilemment is lautre. Comparé à Mitras. s., Mitreola s'on disliwne par descaracteres importants, pui justifient la sepparalion du (imme slrigatella et de sa Section Mitreola: d'abord la dent labiale, puis le labre rélléchi, enfin les plis columellaires qui ne dépassent jamais le nombre de quatre; quant à la forme générale, il y a des Sections de Mitra (Volulomitra par ex.), qui ont exactement le galbe de Mitreola, de sorte qu'on ne peut en tirer aucune indication utile.

\section{Répart. stratigr.}

Paleocene. - Trois espèces dans le Montien de Belgique : $\boldsymbol{M}$. dilatata Br. et Corn., ma coll.; $\boldsymbol{M}$. brevis et vicina Briart et Cornet, d'après la Monographie de ces auteurs.

Eocrixe. - Outre l'espèce-lype ci-dessus figurée, nombreuses espèces dans le Calcaire grossier et les Sables moyens des environs de Paris: M. labiata Chemn., M. Lajoyei, obliquata, crassidens, labrosa Desh., M. monodonta Lamk., M. Bernayi Cossm., ma coll.; une autre espèce dans le Bassin de Nantes: $M$. Dumasi Cossm., coll. Dumas. Une espèce à Bracklesham: M. cf. labratula Lamk., el une autre à Barton : M. scabra Sow., d'après la Monographie de F. Edwards. Deux espèces douteuses, à labre incomplètement formé, dans l'Australie (Victoria) : $\boldsymbol{M}$. cassidea ct conoirlalis Tate, d'après les figures publiées par l'auteur; autre espèce australienne, à dent labiale non visible: $\boldsymbol{M}$. Dennanti Tate, ma coll.

Oligocexe. - Une espèce dans le Stampien des environs de Paris: M. Colleari Cossm. et Lamb., ma coll. Un fragment d'une espèce cerlaine, mais spréfifuement indelerminer, dans le Tongrion de l'Allemagne du Nord, d'après la Monographie de M. vou Koenen. Mrocexe. - Une esperentres incertane, dans le Burdigaliondes Iandes: $M$. ventricosa Grat., d'après la figure défectueuse el d'après la diagnose écourtée de l'Atlas de Grateloup.

PLIOPTYGMA, Conrad em. 1862.

Plioptyama, sensu str. Type: Mitra carolinensis, Conr. Mioc.

Taille très grande; forme fusoïde, assez étroite; spire longue, à galbe conique; protoconche lisse, paucispirée, à nucléus papil- 
Plioptygma

leux; tours cerclés par des carènes spirales, qui se transforment souvent en des rubans séparés par de profondes rainures, ou qui disparaissent même à l'àge adulte, sauf contre les sutures; dernier tour très long, ovale, peu ventru, à peine atténué à la base, sur laquelle s'enroulent obliquement des filets spiraux, jusqu'à une large bande rain urée, formée par les accroissements de l'échancrure antérieure; sur le cou, entre cette bande et le bord columellaire, il existe encore des filets obliques et onduleux.

Ouverture assez large, munie d'une étroite goultière dans l'angle inférieur, peu atténuée en avant, où elle est largement tronquée par une très profonde échancrure; labre peu épais, lisse à l'intérieur, presque vertical, à peine rétrocurrent contre la suture; columelle très peu excavée en arrière, droite en avant, se terminant en pointe effilée au bord de la troncature basale, munie de sept plis croissants, les cinq antérieurs obliques et obsolètes, les deux inférieur's plus écartés, plus transverses, et le dernier surtout plus saillant; bord columellaire calleux, assez large, bien limité à l'extérieur.

Diagnose faite d'après un échantillon de l'espèce-type, du Miocène de la Caroline du Nord (Pl. VIII, fig. 10), ma coll.; autre espèce voisine, dans le Pliocène de la Floride. M. Heilprini Cossm( ${ }^{1}$ ). (PI. VIII, fig. 11), ma coll.

Rapp. et diff. - Ce genre, dont la forme est analogue à celle de Mitras. s., s'en distingue facilement : non seulement par le nombre plus considérable de ses plis columellaires, mais encore par sa protoconche

(1) C'est l'espéce dénommée $\boldsymbol{M}$. lineolata Ifeilprin, qui fait double emploi avec celle de Bellardi. M. Dall, dans son Etude sur le Tertiaire de la Floride, estime que, la figure de la Monographie de Bellardi représentantune simple variété, il y a lieu de conserver lineolata pour l'espèce amérsaine. Je ne partage pas cette manière de voír, altendu que le choix du nom doit toujours se rédnire uniquement à une question de priorilé. Or le fascicule de Bellardi, dans lequel est décrit son M. lineolala, est signé " 15 janvier 1887 , tandis que le volume de «Trans. Wagner Free Inst. $x$, contenant le travail d'Heilprin, porte la date de mai 1887; il est vrai que la PI. Ill de Bellardi, représentant son espèce, n'a paru rue le for juin 1887 avec le second fascicule des Milridæ; mais il n'en est pas moins certain que le nom lineolata a été publié en texte par Bellardi avant Leilprin, qui aur.it pu en prendre connaissance. C'est pourquoi j'ai cru nécessaire et correct de changer le nom de celte espèce. 
Plioplygma

papilleuse, et aussi par sa rainure basale, remplaçant le bourrelet du cou de Mitra. La création de Conrad est donc tout à fait justifiée; il y a seulement à faire subir une légère rectification d'orthographe a la dénomination Pleioplygma, qu'il avait proposée: les diphtongues n'existant pas en latin, les mots d'étymologie grecque qui sont latinisés doivent subir l'élision d'une lettre, quand ils comportent une diphtongue; d'où la nécessité d'écrire Plioplygma en latin, bien que la première syllabe de ce mot soit tirée du mol grec $\pi \lambda . \varepsilon เ \circ$.

Répart. stratigr.

Mrocexe. - L'espèce-type ci-dessus figurée, dans la Caroline du Nord, ma coll.

Phiocene. - L'espèce plésiotype ci-dessus figurée, dans la Floride, ma coll.

\section{JURRIGULA, Klein, 1753. \\ (= Turris Montf. 1810; = Tiara Swains. 1810; \\ $=$ Vulpecula Blainw.1824)}

Surface plissée ou costellée; labre sillonné à l'intérieur; protoconche pancispirée, papilleuse, à nucléus dévié; quatre plis columellaires peu obliques.

T'urricula, sensu stricto. Type : $M$. vulpecula, Linn. Viv. (=Callithea Swainson 1840).

'T'aille moyenne ou assez petite; forme fusoïde, étroite, aciculée; spire longue, acuminée, à galbe conique; tours peu convexes, souvent étagés aux sutures, ornés de costules axiales parfois crénelées, et de sillons spiraux assez écartés; dernier tour ovoïde, peu ventru, régulièrement atténué à la base, qui est à peine excavée, et sur laquelle se prolongent les sillons, jusquau bourrelet formé par les accroissements de l'échancrure antérieure. Ouverture étroite, à bords parallèles, avec une goultière anguleuse en arrière, largement tronquée en avant par une échancrure médio- 
Tul'iculat

crement entaillée, et déviée vers l'axe par suite de la torsion du cou; labre droit, peu épais, intérieurement plissé à quelque distance du contour, non sinueux, ni rétrocurrent à la suture; columelle à peu près rectiligne, tordue en avant, munie de quatre plis régulièrement croissants, en saillie et en épaisseur; bord columellaire vernissé, assez large en arrière, portant quelquefois une callosité dentiforme dans l'angle inférieur, bien limité à l'extérieur, se terminant en pointe effilée à l'angle de l'échancrure basale.

Diagnose refaite d'après des échantillons de l'espèce-type, ma coll.; une espèce plésiotype dans Pliocène de Karikal : $T$. lirocoslata Cossm. (Pl. VIII, fig. 20-21), ma coll. (voir la description à l'annexe ciaprès); autre plésiotype du Tortonien de Stazzano: T. curla Bell. (Pl. VIlI, fig. 20), coll. du Musée de Turin, comm. par M. Sacco.

Observ. - Pour les trois dénominations indiquées comme synonymes de Turricula, j’ai simplement reproduit les citations du Manuel de Fischer, n'ayant pu en faire la vérification; quant à Callithea, c'est parce que le type (M. stigmataria Lamk.) est génériquement semblable à $M$. vulpecula, que je réunis Callithea comme synonyme de Turriculas.s.

Rapp. et diff. - Outre les caractères anatomiques de l'animal, qui sont différents de ceux de Milra, ce Genre s'en distingue non senlement par la forme générale de la coquille, qui est plus ornée, et qui se termine en avant par un canal plus distinct, mais encore et surtout par sa protoconche papilleuse, composée de deux tours au plus. Quant aux plis columellaires, ils ne foumissent pas un critérium bien certain, puisqu'il y a des Mitra à quatre plis, et des Turricula dont la torsion columellaire ressemble à un cinquième pli; toutefois il me semble que les plis de Turricula sont, en général, plus transverses. Le labre s'attuche à la suture d'une manière très différente dans ces deux Genres : rétrocurrent chez Mitra, un peu antécurrent, au contraire, chez Turricula; en outre, tandis que sa surface interne est lisse chez Mitra s. s., crénelée chez Scabricula, elle est sillonnée, ou plutôt plissée, dans toutes les subdivisions de Turricula. Je ne compare pas ce Genre avec Strigalella, ni avec Milreola, qui ont le labre calleux ou denté à lintérieur, et qui sont dépouvus de canal siphonal.

\section{Répart. stratigr.}

SEsoxinx. - Une espèce douteuse, dans le "Groupe d'Arrialoor " de l'Inde méridionale: Voluta citharina liorbes (milreola sec. Stoliczka), d'après la Monographic de ce dernicr auteur. 
Paleocene. - Deux espèces douteuses dans les couches montiennes de Copenhague : M. xquicosta et densistria von Kœnen, d'après la Monographie de cet auteur.

Eocene. - Une espèce à peu près certaine, dans le Bassin de Nantes: $T$. hemiconoides Cossm., ma coll.; autre espèce un peu douteuse, à la Close (Loire-Infér.): 'T' genotixformis Cossm., coll. Dumas. Une espèce ambiguë, dans le Nummulitique des environs de L'au: M. cincta (1) A. Rouault, d'après la figure publiée par cet auteur; autre espèce probable dans les couches nummulitiques de Biarrit\%: M. scalarina d'Archiac, d'après la figure publiée par cet auteur.

Obıgocexe. - Une espèce probable dans le Vicentin: M. regularis Schaur., d'après la Monographie de M. Fuchs.

Mrocexe. - La seconde espèce plésiotype ci-dessus figurée, dans lo Tortonien du Piémont, d'après Bellardi.

Pliocene. - Outre la première des espèces plésiotypes ci-dessus figurées, dans l'Inde française, plusieurs espèces dans les couches récentes de la Nouvelle-Lélande: T. rubiginosa, marginala, planala, Ilutton, d'après les diagnoses de l'auteur. Plusieurs espèces dans les couches récentes de Java: T. vulpecula, balcicana, Jackeri, Javana, gembacana, Callithea rajaensis Martin, d'après la Monographie de cet auteur.

Epoque actuelle. - Nombreuses espèces dans l'Océan Indien, les mers de Cline et l'Australie, d'après T'ryon.

\section{Costellaria, Swainson, 1840.}

Néotype: M. semifasciata, Lamk. (sec. Fischer) Viv.

'Taille assez pelite; forme fusoïde; un peu pupoide; spire médiocrement allongée, généralement élagée aux sutures, à galbe conoïlal; protoconche lisse, paucispirée, à nucléus obtus, à peine papilleux; tours convexes, généralement bordés par une rampe au-dessus de la suture inférieure, ornés de côtes axiales peu courbées, parfois subépineuses, sur l'angle de la rampe postérieure, et de sillons spiraux, plus ou moins visibles dans les intervalles des côtes; dernier tour à peu près égal à la moitié de la longueur totale, orné comme la spire, contracté et excavé à la

(1) M. Newton a catalogué, en 1891, avec le même nom (Ełwards mss.), une Mitre qui tombe nécessajrement dans la synonymie de celle de llouault, qui cst bien antérieure: il y a lieu de changer le nom de la coquille oligncénique des couches de lleaJon, et je propose en conséquence: M. Newtoni, nobis. 
Turricula

base, qui porte des chaînettes obliquement enroulées, jusqu'au cou et même sur le bourrelet très obsolète et peu saillant, correspondant aux accroissements de l'échancrure antérieure.

Ouverture courte, rhomboïdale, avec une étroite gouttière dans l'angle inférieur, peu dilatée au milieu, subitement rétrécie en avant, et terminée par un canal court, dévié vers l'axe, avec une échancrure assez prolonde sur le cou; labre un peu épais, faiblement curviligne, un peu antécurrent à sa jonction avec la suture, orné à l'intérieur de plis allongés, parallèles et peu saillants ; columelle droite, oblique en arrière et au milieu, tordue et incurvée à son extrémité antérieure, munie de quatre plis régulièrement croissants, les deux antérieurs minces et un peu obliques, les deux postérieurs transverses, aplatis; une côte pariétale existe souvent dans l'angle inférieur, près de la gouttière; bord columellaire assez mince, à peine distinct.

Diagnose faite d'après des échantillons d'une espèce vivante, voisine du type: $M$. mililaris Reeve, et d'après un plésiotype de l'Eocène d'Australic : M. paucicostata Tate (Pl. VIII, fig. 3), ma coll.

Rapp. et diff. - Costellaria est incontestablement très voisin de Turricula, et ne s'en distingue que par quelques caractères fugitifs, qui justifient tout au plus la séparation d'une Section : d'abord l'excavation de la base, qui isole le cou d'une manière très nette, de sorte que le canal paraît plus contracté; ensuite la protoconche plus obtuse; enfin le bord columellaire moins bien limité et moins calleux. Néanmoins j'ai constaté que, pour quelques espèces intermédiaires entre ces deux groupes, on éprouve une réelle liésitation; ce qui prouve qu'en définitive Turricula passe graduellement à Costellaria.

Répart. stratigr.

Eocexe. - Une espèce bien caractérisée, dans le Bassin de Nantes: Turr. intortella Cossm. (Pl. VIII, fig. 26), ma coll. Plusieurs espèces dans l'A ustralie du Sud, outre le plésiotype ci-dessus figuré : $M$. exilis, leptalea, semilirvis (1), cilharelloides, clathwella Tate, ma coll.

'Le nom de cette espèce doit être changé, pour cause de double emploi avec l'espèce de F. Edwards; je propose, en conséquence, pour l'espèce australienne: M. Tatei, nobis. 


\section{Turpicula}

Mıcexe. - Une espẻce cortaine, désignée comme Uromitra par Bellardi, dans le Tortonien de la Toscane: M. decipiens Bell., ma coll.; plusieurs espèces dans l'Helvétien ét le Tortonien du Piémont: M. subglobosa, avellana, cognata, consimilis, canaliculata, ornata, turita Bell., etc., d'après la Monographie de Bellardi. Une espèce dans l'Aquitanien du Bordelais: M. Parlschi Horn., ma coll. Nombreuses espèces dans le Bassin de Vienne: $M$. intermiltens R. IInern., M. recticosta et Borsoni Bell., etc. d'après la Monographie de MM. Hœrnes et Auinger. Deux espèces dans l'Australie du Sud: $M$. terebricformis el sordida Tate, ma coll. Une espèce à la Jamaïque et à Saint-I Jomingue : M. Henelieni Sow., d'après la figure publiée par Guppy.

Pliocrase. - Deux espèces dans l'Astien des Alpes-Maritimes : M. crassicosta Bell., M. corrugata Defr. (Pl, VIII, fig. 28), ma coll. Plusieurs espèces désignées comme Uromitra, dans le Plaisancien et l'Astien du Piémont: U.subcoronala, leucozona, frumenum Bell., d'après la Monographie de Bellardi. Deux espèces dans la Floride : M. Holmesi et Wilcoxi Dall. d'après les figures publiées par cet auteur.

Éropue actuelle. - Nombreuses espèces ou variétés, dans l'Océan Indien, les mers de Chine, la Polynésie, l'Australie et la mer Rouge, d'après le Manuel de 'Tryon.

Fusimitra, Conrad, 1865. Type: M. cellulifera, Conr. Olig.

'Taille petite; forme très étroite, aciculée, en tarière; spire longue, à galbe conique; protoconche lisse, paucispirée, à nucléus papilleux ou tectiforme; tours un peu convexes, lisses ou costulés, parfois ornés de fines stries spirales dans les intervalles des colles, sifrarés par des sutures profondes, ondulées et généralement bordées par un bourrelet; dernier tour égal ou inférieur à la moitić de la longueur tolale, ovale en arrière, subitement excavé à la base, qui porte des cordonnets enroulés sur le cou, sans aucune trace de bourrelet.

Ouverture très courte, rhomboïdale, dépourvue de gouttière postérieure, rétrécie en avant, où elle se termine par un canal qui paraît contourné, quand on l'examine de face, mais dont le cou est vertical dans l'axe de la coquille; échancrure basale à peine entaillée, presque nulle; labre mince, un peu oblique, à peine sinueux vers la suture, à laquelle il aboutil presque orthogonale- 
Turricula

ment, plissé à l'intérieur; columelle droite, peu ou point incurvée en avant; munis de trois plis principaur, qui sont généralement dans le prolongement des cordonnets de la base; un quatrième pli antérieur, souvent confondu avec la torsion de la columelle, et peu visible quand l'ouverture n'est pas mutilée; bord columellaire peu distinct, limité par une légère rainure qui sépare les plis columellaires du cou.

Diagnose refaite d'après un échantillon de l'espèce-type (Pl. VIII, fig. 30), ma coll. ; et d'après deux plésiotypes de l'Eocène des environs de Paris: $M$. terebellum Lamk., du Calcaire grossier de Villiers (Pl. VIII, fig. 31), ma coll., M. extranea Desh., du Suessonien de Cuise (Pl. VIIl, fig. 29), ma coll. Protoconche de la première, grossie (Fig. 28 ci-contre).

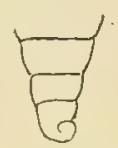

FIG. 28. - Fusimitra terebellum, Lamk.

Observ. - D’après l'avis de Tryon et de M. Dall (Tert. Flor.; I, p. 49), ce Genre n'aurait aucune valeur, non seulement parce qu'il n'a pas été suftisamment caractérisé, mais encore parce que Conrad y comprenait un certain nombre de formes très diverses; M. Geo. Harris (Austral., p. 124) a adopté cette opinion et a rapporté au Genre Cromitra la plupart des espèces d'Australie, qui sont d'ailleurs des Costellaria, comme on l'a vu ci-dessus. Or, en étudiant $M$. cellulifera, qui est la première espèce citée par Conrad dans son Genre Fusimitra, et en la comparant avec un groupe d'espèces parisiennes, $\mathrm{j}$ 'ai constaté qu'clle leur est identique, et que foutes ces formes présentent des caractères distinctifs, qui justifient la séparation d'un Sous-Genre différent, non seulement de Turricula et de Costellaria, mais même d'Uromitra Bell., que j'avais d'abord réuni à Fusimitra comme synonyme. Par conséquent il n'y a pas de motif pour rejeter la dénomination proposée par Conrad, qui ne caractérisait aucun de ses Genres, et il suffit d'y donner l'interprétation restreinte que j'ai déjà faite en 1889.

Rapp. et diff. - Fusimilra se distingue de Turricula: non seulement par son canal plus allongé, mais surtout par l'absence presque complète d'échancrure basale; trois des plis colımellaires se prolongent jusque sur le cou, comme cela a quelquefois lieu chez Costellaria, mais Fusimitra a le cou plus droit que Costellaria et n'a pas l'échancrure qui existe dans ce dernier Genre; enfin l'embryon est plus obtus, le labre moins droit, peu ou point antécurrent vers la suture. J'estime que ce sont là des diflérences d'une importance sulfisante pour justifier la séparation d'un Sous--Genre. 
Répart. stratigr.

Paleocene. - Une espèce bien caractérisée, dans le Montien de Belgique, et dans le Londonien du Bassin de Paris: M. Wateleti Br. et Corn., na coll.; trois autres especes dans le grisement de Mons: M. Koeneni, dentata et Gosseleti, Briartet Cornet, l'après Ia Monographie de ces auteurs; une espèce probable dans les couches de Copenlıague: M. semilwvis(') von Koenen, d'aprèsla figure publiée pal cet auteur.

Eocene. - Outre les deux plésiotypes ci-dessus figurés, plusicurs espèces dans le Bassin de Paris et dans la Loire-Inférieure: M. aizyensis et Barbieri Desh., M. Gaudryi de Rainc., M. Bouryi et telraptycla Cossm., M. cancellina Lamk., ma coll., M. diasticla Cossm., coll. Bourdot. Une espèce dans le Bartonien d'Angleterre: M. volutiformis F. Edw., ma coll. Trois espèces dans le Claibornien de l'Alabama : M. minima et lineata Lea, M. perexilis Conr., ma coll., une autre espèce dans le Maryland: M. marylandica Clark, d'après la figure publiée par cet auteur.

Origocene. - L'espèce-type dans le Vicksburgien du Mississipi, ma coll.; une autre espèce dans l'Alabama : $M$. conquisila Conr., ma coll. Deux espèces dans le Tongrien de l'Allemagne du Nord: M. impressa von Kœnen, M. circuncisa Beyr., d'après les figures publiées par M. von Konen.

Uromitra, Bellardi, 1886 (restr. sensu).

Type: M. cupressina, Br. Plioc. (=Eumitra, Tate 1888)

'I'aille moyenne ou petite; forme turriculée, étroite; spire longue, acuminée, à galbe conique; protoconche lisse, polyryrée, conique, à nucléus extrêmement petil et à peine papilleux; lours un peu converes, généralement costulés au moins au début, le plus souvent ornés de sillons spiraux qui traversent les costules, séparés par des sutures profondes et ondulées par les costules, rarement munis d'une rampe spirale au-dessus de la suture; dernier lour égal ou un peu inférieur à la moitié de la longueur totale,

(1) Le now de cette esjèce, bien postérieur à la dénomniation proposée par F. Edwarls. doit ètre changé. de mème que j'ai déjà corrigé le double emploi qui a échanpé à M. Tate, voir Costellaria, p. 16\%). Je propose, en conséquence, pour l'espèce du Danemark: F. danensis, nobis. 
quelquefois lisse, arrondi et excavé à la base, sur laquelle s'enroulent des sillons obliques, et qui se termine par un cou allongé, tordu, sans bourrelet, portant seulement quelques filets obliques.

Ouverture étroite, contournée, à bords parallèles, dépourvue de gouttière en arrière, rétrécie en avant, où elle se termine par un canal long et infléchi, sans aucune échancrure à l'extrémité ; labre assez mince, plissé à l'intérieur, un peu sinueus, peu ou point antécurrent à la suture; columelle en $S$, portant quatre plis, l'antérieur à peine visible, le second très peu saillant, les deux inférieurs plus proéminents et plus transverses, correspondant souvent au prolongement des filels du cou; bord columellaire très mince et indistinct.

Diagnose refaite d'après des échantillons de l'espèce-type, du Plaisancien de Bologne (Pl. VIII, fig. 32), ma coll. ; et d'après un plésiotype du Plaisancien de Biot, dans les Alpes-Maritimes: M. Michelottii Hoern. (PI. VIII, fig. 15), ma coll.

Observ. - Le nom Eumitra a été donné, par M. Tate, sans aucune diagnose générique, à une espèce australienne, qui a un canal allongé, presque droit, comme celui de Fusimitra, mais dont la protoconche est identique à celle d'Uromitra; M. Géo. Harris compare cette espèce à M. scrobiculata, parce que ses tours, plans et subulés, sont sillonnés comme ceux de cette dernière espèce. Malgré ces caractères un peu hybrides, je ne crois pas qu'il y ait lieu de conserver Eumitra comme une Section distincte, et puisque cette dénomination est postérieure de deux années à Uromilra, je l'y réunis comme synonyme.

Rapp. et diff. - Contrairement à l'opinion que j’ai précédemment émise (Ann. géol., 1887, p. 1107), Uromilra doit être définitivement séparé de Fusimilra, malgré la similitude apparente des deux coquilles; en effet, le canal est beaucoup plus tordu, et surtout la protoconche est absolument différente, beaucoup plus allongée et plus conique chez Uromitra, terminée par un nucléus microscopique qui n'a aucun rapport arec le nucléus papilleux de Fusimitra; les plis columellaires et l'ornementation se ressemblent beaucoup; cependant il semble que les costules d'Uromitra sont plus sinueuses, et que le labre est, par conséquent, moins rectiligne. Il résulte de cetle comparaison qu'il y a lieu de restreindre beaucoup la diagnose un peu vague de Bellardi, qui comprenait dans son Genre Uromitra des formes appartenant évidemment à d'autres groupes, et qui désignait, d'une manière trop générale, sous ce nom, toutes les Mitres 
Turricula

allongées, ayant des plis à l'intérieur du labre. Si on compare Uromitra avec Turricula, on trouve que c'est un Sous-Genre bien distinct, ì canse de la forme de la coquille, de son canal contourné, de l'absence d'une échancrure basale, et surtout à cause de sa protoconche non papilleuse; les mêmes différences existent entre Uromitra et Coslellaria, sauf en ce qui concerne l'excavation de la base, qui est également creuse chez ces deux coquilles.

Répart. stratigr.

Eocrase. - Une espèce, à canal peu contourné, dans l'Australie du Sud: M. alokiza Ten. Woods, ma coll. P'rotoconche grossie de cette espèce (Fig. 29 ci-contre).

Mrocene. - Nombreuses espèces ou variétés, dans l'llelvétien et le Tortonien du Piémont: U. antegressa, belliata, similis, clathurata, cincta, dissimilis, paucicostala Bell., ete., d'après la Monographie de Bellardi; dans le Bassin de Vienne: M. Bonellii Bell. ( = M. cupressina Iloern, non Br.), ma coll.; la mème espèce dans le P'émont, d'après Bellardi. Une espèce dans les couches d'Edeghem : M. acicula Nyst., ma coll. Plusieurs autres espèces dans le Bassin de Vienne: M. Michelollii M. Ioern., M. Fuchsi R. Iloern., d'après la Monographie de MM. Hornes et $\Lambda$ uinger. Deux espèces dans le Tortonien du Bordelais: M. cf. pyramidella $\mathrm{Br}$. et $M$. cf. strialula $\mathrm{Br}$., d'après le Catalogue de M. Benoist.

Plocene. - Outre les types et plésiotypes ci-rlessus figurés: Milra pyramidella Br., recticosta Bell., plicalula Br., U. eoebenus Bell., dans le Plaisancien des Mlpes-Maritimes et du Bolonais, ma coll. ; nombreuses espèces dans le P'iémont. Y. soror, nilida, bifaria Bell., etc., d'après la Monographie de Bellardi; une espèce dans le Messinien de la l'oscane: M.turrita Foresti, d'après la figure publiće par cet auteur; une espèce dans le Crag d'Angleterre: M. ebenus, var. uniplicala Wood, d'après la Monographie de S. Wood.

MESORHY'IS, Meek, 1876.

Mesorhyts, sensu str. Type : F'ascrolaria gracilenta, Meek. Crét.

'Taille moyenne; forme très étroite, aciculée; spire longue, acuminée, à galbe conique; protoconche lisse, polygyrée, conique, pointue, ả nucléus très petit ; tours généralement costulés ct ornés de filets spiraux rarement lisses, séparés par des sutures 
profondes et crénelées par les côtes; dernier tour égal aux trois cinquièmes de la longueur totale, orné comme la spire, régulièrement atténué à la base, qui porte, lorsqu'il est lisse, des sillons obliquement enroulés jusque sur le cou; pas de bourrelet basal. Ouverture étroite, lancéolée, avec une gouttière anguleuse en arrière, terminée en avant par un canal long et droit, sans aucune échancrure à son extrémité; labre un peu sinueux, comme les costules axiales, paraissant lisse à l'intérieur; columelle droite, non tordue en avant, portant à la partie inférieure trois plis croissants, peu obliques, les deux inférieurs taillés carrément, ou même divisés par une rainure spirale; bord columellaire peu distinct.

Diagnose faite d'après une espèce plésiotype du Turonien de Provence : M. cancellata Sow. (PI. VIII, fig. 12-13), ma coll.; et d'après un autre plésiotype du Paléocène de Smithville, dans le Texas: M. polita Gabb. (Pl. VIII, fig. 14), ma coll.

Rapp. et diff. - Meek a lui-même indiqué (Invert. Pal. Upper Missouri, p. 364) les affinités de ce Genre avec les Mitridæ, plutôt qu'avec les Fasciolariidx, près desquels les auteurs ont l'habitude de le placer. Il me paraît d'ailleurs évident qu'il doit être classé dans la même Sous-Famille que Fusimitra; toutefois il s'en écarte : non seulement par la longueur de son canal, mais encore et surtout par la position de ses plis columellaires, qui sont placés plus en arrière que chez la plupart des Mitridx; ce dernier caractère a même motivé le choix du nom de ce Genre. Il est difficile d'étudier ces plis, d'une manière très précise, sur les échantillons crétaciques qui sont généralement dans un état de conservation très défectueux; mais je rapporte au même Genre une espèce de Paléocène du Texas, qui m'a été envoyée sous le nom Fusimitra polita Gabb., et qui, quoique à peu près lisse, a bien le galbe des Mesorhylis; or, sur ces échantillons, les plis ont un aspect tout à fait particulier, qui répond complètement à la diagnose publiée par Meek, et qui est bien distinct de ce qu'on observe sur la columelle de Fusimitra. Enfin la protoconche, allongée et pointue, est semblable à celle d'Uromitra, et par conséquent, absolument différente de celle de Fusimitra, qui a un embryon papilleux et paucispiré.

Répart. stratigr.

Cexomasiex. - Une espèce dans le Var: $\boldsymbol{M}$. cassisiana d'Orb, ma coll.; la même, plus douteuse, à l'île d'Aix, coll. Joly.

Tunosiex. - La première des espèces plésiotypes ci-dessus figurées, 
dans le Mornasien du Var, ma coll., et à Gosau dans le Tyrol, d'après la Monographie de \%ekeli; une autre espèce probable, dans les Grès d'Uchaux: Voluta Gasparini d'Orb., ma coll.

Srinxiex. - L'espèce-type dans les conches du Groupe "Fox llills" (Missouri), d'après Meek. Une espèce voisine de $M$. cancellala, probablement distincte, dans le Santonien supérieur des Corbières, coll. de Grossouvre. Une espèce dans le "Groupe d'Arrialoor " de l'Inde méridionale : Turricula arrialoorensis Stoliczka, d'apries la Monographie de cel auteur.

Paleocene. - L'espèce plésiotype ci-dessus figurée, dans le "Midway stage " du Texas, ma coll.

CONOMITRA, Conrad, 1865.

Conomitra, sensu stricto.

Type: $M$. fusoides, Lea. Loc.

Taille petite; forme ovale ou biconique, également atténuée aux deux bouls; spire assez courte, à galbe subconoïdal; protoconche lisse, petite, subglobuleuse, composée d'un tour et demi, à nucléus obtus ou à peine papilleux; tour's lisses ou plissés, parfois décussés par des sillons spiraux, dont un seul persiste souvent au-dessus de la sulure, qui est profonde et marginée; dernier tour généralement supérieur aux deux tiers de la longueur totale, ovoïde, un peu ventru, régulièrement alténué à la hase, sur laquelle se prolonge parfois l'ornementation de la spire, on bien sur laquelle reparaissent des sillons spiraux, quand le dernier tour est lisse ; cou à peu près nul, pas de bourrelet basal.

Ouverture étroite, à bords presque parallèles, peu dilaté au milieu, avec une étroite gouttière dans l'angle inférieur, rétrécie sans contraction en avant, dépourvue de canal, tronquée sans échancrure, à son extrémité antérieure; labre peu épais, crénclé à l'intérieur, presque vertical; columelle peu incurvée, munie de quatre plis croissant régulièrement et peu obliques, terminée en pointe droite pris de la troncature basale; bord columellaire mince, bien distinct. 
Diagnose refaite d'après des échantillons de l'espècetype, provenant de Claiborne dans l'Alabama (Pl. VIII, fig. 1), ma coll.; et d'après un plésiotype du Bartonien du Ruel, dans les environs de Paris: M. Vincenti Cossm. (Pl. VIII, lig. 2), ma coll. Protoconche de $M$. fusellina Lamk., grossie (Fig. 30 ci-contre).

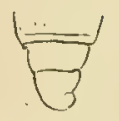

Rapp. et diff. - Ce genre s'écarte complètement de Turricula ; quoique Fischer en fasse seulement un Sous-Genre de ce dernier, je suis d'avis de le classer dans une Sous-Famille bien distincte, à cause de l'absence de canal et d'échancrure basale, à l'extrémité antéricure de son ouverture. La protoconche est, il est vrai, plus voisine de celle des Plesiomitrina que de celle des Orthomitrinæ; mais on a pu remarquer déjà ci-dessus que l'embryon varie beaucoup dans les Genres et mème dans les SousGenres d'une mème Sous-Famille de Mitridæx. Je ne puis d'ailleurs reprendre, pour l'appliquer à cette troisième Sous-Famille, le nom Diplychomitrinix, qu'a proposé Bellardi pour deux des Genres que jy classe (Diplychomitra et Clinomitra, qui n'ont que deux plis columellaires), attendu qu'elle comprend d'autres formes à quatre plis, telles que Conomitra, par exemple; j'ai donc adopté le nom S'emimitrinæe, qui indique que les coquilles à y classer ne sont que la moitié des Mitres des deux autres groupes, parce qu'il leur manque un des deux caractères essentiels.

\section{Répart. stratigr.}

Paleocese. - Une espèce certaine dans les "sables de Bracheux " aux environs de Paris: $M$. prisca Desh., d'après mon Catal. illustré de l'Eocène des environs de Paris.

Eocexe. - Plusieurs espèces aux trois niveaux du Bassin de Paris : M. hordeola Desh., M. rusellina, graniformis et marginala Lamk., M. inaspecta Desh., M. Vincenti Cossm., ma coll.; dans le Bassin de Nanles et dans le Cotentin : $M$. fusellina Lamk., $M$. conuliformis Cailliaud, M. tenuiplicata Vass., M. namnetica, et hypermeces Cossm., ma coll. Une espéce dans le Nummulitique des environs de Pau : $M$. Delbosi $\Lambda$. Rouault, d'après la figure publiée par cet auteur. Dans le Bartonien d'Angleterre: $M$. parva Sow., ma coll.; deux autres espèces dans le Bassin anglais: M. porrecta et obesa F. Edwards, d'après la.Monographie de cet autenr. Quatre espèces dans l'Australie du Sud: $M$, othone T. Woods, M. Dennanti, ligala et conoirlalis Tate, ma coll. L'espèce-type dans le Claibornien des EtatsUnis, ma coll.

Oligocexz. - Une espece dans le Tongrien de Belgique: $\boldsymbol{M}$. suluralis Bosq., ma coll.; une espece dans le Stampien d'Etampes et de 


\section{Conomitrai}

Nayence: $\mathbf{M}$. perminuta Braun, ma coll.; une espece it Gaas, dans les Landes, ma coll. Une autre espèce dans le Brunswick: $M$. Süllingensis Speyer, d'apris la tigure publiée par cet auteur.

Mrocexe, - Une espèce un peu aberrante, dans l'Helvétien de Touraine: 11. oliveformis Duj., ma coll.

MiTroLUMNA, Bucq. Daut\%. Dolli. 1882.

Mtroluma, sensu stricto. T'ype: M. olivoidea, Cantr. Viv. (= Clinomitra el Diptychomitra, Bell. 1888)

Taille petite; forme ovoïde, souvent un peu ventrue; spire courte, subulée, à galle subconoïdal; proloconche lisse, petite, stibglobuleuse, à nucléus obtus; tours peu convexes, séparés par des sutures linéaires, généralement treillissés; dernier tour supéricur aux deux tiers de la longueur totale, régulièrement atténué à la base, qui porte des sillons obliques; pas de cou ni de bourrelet dorsal. Ouverture très étroite, à bords presque parallèles, avec une petite gouttière dans l'angle inférieur, à peine rétrécie en avant, tronquée à l'extrémité antérieure, sans canal ni échancrure; labre épaissi par une varice externe, crénelé à l'intérieur vis-à-vis de cette varice, vertical et rectiligne, sans aucune sinuosité vers la suture; columelle droite, munie au milieu de deux plis, dont l'inférieur est le plus épais et le plus saillant; bord columellaire mince, se terminant en pointe un peu en deçà de la troncature basale.

Diagnose complétée d'aprìs des échantillons de l'espice-type, provenant du Pleistocene de l'alerme(Pl. VIII, fig. I), ma coll.; autre plésiotype provenant du Miocene de Colli Torinesi: Clinomitra Rovasende Bell. (Pl. VIII, fig. 24), coll. du Musée de Turin, communiqué par II. Sacco.

Observ. - Je n'hésite pas à réunir avec ce Genre, comme synonymes, les deux Genres Clinomitra et Diplychomitra, que Bellardi a respectivement proposés pour $C$. Rovasendie Bell, et pour D. eximia Bell. : tout d'abord, l'auteur avoue lui-mème qu'il n'y a d'autres différences, entre ses 
Mitrolumna

deux Genres, que la forme pupoïdale et la surface partiellement lisse de la première de ces espèces, tandis que les coquilles qu'il désigne sous le nom Diptychomitra sont plutôt biconiques et treillissées; or c'est un critérium manifestement insulfisant pour servir de base à une distinction générique, d'autant plus que tous les échantillons-types qu'il a figurés sont incomplets, probablement roulés. D'autre part, en comparant minutieusement l'une de ses espèces de Clinomitra, j'ai constaté l'identité générique la plus complete avec Mitra olivoidea Cantraine, type du Genre Mitrolumna, institué dans le premier volume des "Mollusques du Roussillon ", en 1882, c'est-à-dire six ans avant la création des deux Genres de Bellardi; cette constatation entraîne la disparition complète de ses deux dénominations, de même que le classement de Mitrolumna dans la même Sous-Famille que Conomitra, a pour conséquence, comme je l'ai déjà fait remarquer ci-dessus, la disparition des Diptychomitrinx qui ne sont qu'un cas particulier des Semimitrinæ.

Rapp. et diff. - Mitrolumna se distingue de Conomitra: par ses deux plis médians, au lieu de quatre plis antérieurs; par ses crénelures labiales plus grosses, par son galbe plus olivoïde, moins biconique. MM. Bucquoy, Dautzenberg et Dollfus indiquent l'existence de trois plis columellaires; mais, sur aucun échantillon récent, ni fossile, je n'ai pu constater l'existence de ce troisième pli, ni même celle d'une torsion antérieure de la columelle; il y a là une petite inexactitude qu'íl convenait de rectifier, d'autant mieux qu'elle a pu être cause des doubles emplois de Bellardi; chez Clinomitra Rovasendæe, ces deux plis sont mème extrêmement épais et taillés carrément, celui du bas est presque deux fois aussi large que l'intervalle qui le sépare du premier.

Répart. stratigr.

Mrocexe. - Huit espèces ou variétés, dans l'Helvétien du Piémont: Clinomitra Rovasendæ Bell., ci-dessus figuré; Diptychomitra eximia, filifera, canaliculata, sublxvis, subovalis et clathrata Bell., d'après la Monographie de Bellardi; Diptychomitra Michaudi Bell., coll. du Musée de Turin, communiqué par M. Sacco.

Preistocexe. - L'espèce-type ci-dessus figurée, dans les terrains modernes de la Sicile.

Époque actuelle. - L'espèce-type, avec plusieurs variétés, dans la Méditerranée, d'après MII. Bucquoy, Dautzenberg et Dollfus. 
'I'HALA, H. et A. Adams, 1853.

'T'hala, sensu stricto.

Type: $M$. mirifica, Reeve. Viv. (= Micromitra, Bell. 1888)

Taille petile; forme étroite, pupoïdale ou subcylindrique; spire plus ou moins allongée, à galbe conoïdal ou subconique; protoconche lisse, petite, très obtuse; tours un peu convexes, subulés, séparés par des sutures peu profondes, treillissés par des plis axiaux très serrés et par des tilets spiraux moins saillants que les plis, et surtout visibles dans leurs interstices; dernier tour grand, orné comme la spire, ovale el peu ventru, contracté à la base, sur laquelle les filets deviennent plus gros et les côtes cessent, jusqu'au cou qui est largement gonflé, mais dépourvu d'un véritable bourrelet basai.

Ouverture très étroite, avec une goultière un peu échancrée dans l'angle inférieur, un peu contractée en avant, terminée par un canal très courl, Ironqué à son extrémilé, sans échancrure distincte; labre épaissi en dehors par une varice obsolète, muni de petites crénelures internes, à peu près vertical, ou à peine sinueux vers l'échancrure de la gouttière suturale; columelle droite, munie de quatre plis situés assez bas et très inégaux, les deux antérieurs petits, les deux postérieurs plus saillants et plus transverses; bord columellaire mince, limité vers la base par une petite rainure ou dépression peu profonde.

Diagnose refaite d'après un plésiotype des Faluns de Pontlevoy: M. pupa Duj. (Pl. VIII, fig. 3 ); et de l'Aquitanien de Mérignac (PI. YIII, fig. 6); tous deux de ma coll.

Observ. - Je suis encore ici contraint de supprimer un Genre de Bellardi : Micromilra, que je considere comme absolument identique à Thala. Il est surprenant que cel auteur, qui connaissait a fond les formes vivantes, n’ait pas été frappé de la similitude que présentent, avec Thala, 
les fossiles qu'il a séparés, avec raison, des autres groupes de Mitridæ. La plupart des auteurs, notamment Fischer et Tryon, tout en classant ce Genre dans la Famille Mitridæ, ont fait remarquer l'affinité de la coquille avec certaines formes de Pleurotomidx, particulièrement avec Clathurella et Mangitia; toutefois il n'y a pas, chez Thala, de véritable sinus, et, en ontre, sa protoconche est bien différente. En présence de ces caractères hybrides, je propose une nouvelle Sous-Famille : Pseudomitrinx, qui comprendra ce Genre, et les Genres voisins, dont la forme s'écarte complètement de celle des autres Mitridæ.

Répart. stratigr.

Eocene. - Une espèce probable, dans l'Australie: M. escharoides Tate, d'après la figure publiée par cet auteur.

Miocene.-Outre le plésiotype ci-dessus figuré, septespèces ou variétés dans l'Helvétien et le Tortonien du Piémont: M. taurinia, propinqua, granosa, abbreviata, seminuda, intermedia et pusilla Bell., d'après la Monographie de Bellardi. Plusieurs espèces dans le Bassin de Vienne: 1 . lapugyensis, Neugeboreni, Sturi R. Hoern., d'après la Monographie de MM. Hoernes et Auinger.

Pliocexa. - Deux espèces dans le Plaisancien de la Ligurie : $M$. obsoleta $\mathrm{Br}$., $M$. mangilixformis Bellardi, d'après la Monographie de cet auteur; la première de ces deux espèces, dans le Bassin du Rhône, d'après Fontannes.

Epoque actuluxe. - Plusieurs espèces ou variétés dans la Polynésie, l'Australasie, l'Océan Indien, et une seule à Panama, d'après le Manuel de Tryon.

Perplicaria, Dall, $1890 . \quad$ Type $: P$. perplexa, Dall. Plioc.

Taille petite; forme étroite, pupoïdale; spire un peu allongée; protoconche lisse, petite, paucispirée, à nucléus involvé; tours peu nombreux, élevés, croissant rapidement, convexes, à sutures profondes, cancellés par des carènes spirales el par des plis axiaux, qui forment des crénelures à leur intersection; dernier tour égal aux trois quarts de la longueur totale, ovoïdo-cylindrique, orné comme la spire, à peine atténué à la base, qui ne porte aucune trace de bourrelet sur le cou. Ouverture semilunaire, dilatée au milieu, non contractée en avant; avec une gouttière dans l'angle inférieur, terminée du côté antérieur par 
Thala

une large troncature à peine sinueuse; labre presque rectiligne, épaissi à l'extérieur par une varice obsolète, plissé à l'intérieur; columelle peu excavée, munie de deux plis très obliques et rapprochés; bord columellaire mince, assez larire, surtout vis-àvis des plis.

Diagnose reproduite d'après le texte et la figure copiće (Fig. 31 ci-contre) de l'espèce-lype, dans la Monographie de M. Dall (Tert. Flor., pp. 90 et 228. Pl. III, fig. 1, et PI. XIII, fig. 4).

Rapp. et diff. - Lorsque M. Dall a créé ce Genre, il n'avait encore à sa disposition qu'un seul individu mutilé, qu'il comparait à un Daphnella, sans sinus et à columelle plissée; et il l'a d'abord classé entre les Volutidx et les Fasciolariid $x$; toutefois il inclinait plutôt à le rapprocher de Volutocorbis, à cause de son ornementation, et de Volutomorpha, à cause de sa forme élancée; le pli très oblique, que porte la columelle de cet individu

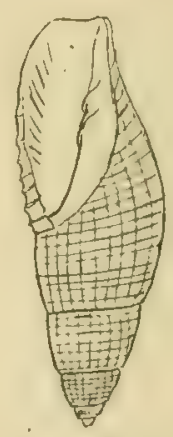

Fis.31. - Perplicavia perplexa, Dall. mutilé, a en effet l'aspect du pli principal des Loxoplocinx.

Mais, deux ans après, dans la seconde partie de sa Monographie, M. Dall ayant un exemplaire parfait de cette singulière coquille, l'a rapprochée de Mutycr, et surtout du Dibaphus, qu'elle rappelle complètement par son extrémité antérieure tronquée et à peine échancrée; l'ornementation cancellée a quelque analogie avec celle des Thala, quoique ces derniers ne soient cependant treillissés que dans les intervalles des plis axiaux. C'est done bien dans la Sous-Famille Pseudomitrine qu'il y a lieu de classer Perplicaria, qui complète ainsi la série des variations de la plication columellaire, de 0 pli à 6 plis.

Répart. stratigr.

Pliocexe. - L'espèce-type dans les couches de Caloosahalchie (Floride), d'après l'auteur.

GYLINDROMITRA, Fischer, 1884.

Plochel жa, Gabb., 1872. Type: P. crassilabra, Gabb. Tort.

"Coquille olivoïde; sutures presque obsolètes, comme chez "Ancilla; ouverture linéaire, obliquement tronquée à la base, 
Cylindromitra

" comme chez Dibuphus; bord externe épaissi à l'intérieur, vers " le milieu; bord interne calleux, muni de plusieurs plis trans" verses, dont le supérieur est le plus petit; columelle étroitement

"recourbée à la base."

Diagnose traduite d'après le "Manual of Conchology" de Tryon, et copie de la figure assez défectueuse, reproduite dans ce Manuel (Fig. 32 ci-contre).

Observ. - Le type de ce Genre, insuffisamment caractérisé, est une coquille du Tertiaire supérieur des $A n$ tilles, dont la figure est probablement reproduite d'après un dessin peu exact, et dont je n'ai pu me procurer aucun échantillon, la coquille étant unique dans la collection de l'Académie des Sciences de Philadelplie. Tryon classe ce Genre dans la Famille Olividx; mais le seul fait d'avoir une forme d'Oliva et une spire d'An-

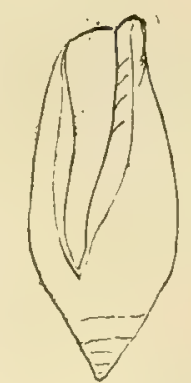

Fra. 32. - Plochelæu crassilabra, Gabb. cilla ne me parait pas suffisant pour justifier ce classement. Quoique les plis columellaires aient été tracés, sur la copie de la figure originale, par un dessinateur inhabile ou peu familiarisé avec la Conchyliologie, l'indication contenue dans la diagnose me suggère l'idée que cette plication a plutôt de l'analogie avec celle des Milridie, et comme la coquille a presque la forme de Cylindromitra, avec une troncature basale peu ou point échancrée, je suis persuadé que Plochelæa est mieux à sa place, comme Sous-Genre de Cylindromitra, que dans la Famille Olividæ. En résumé, ce ne sont là que des hypothèses, et il faut évidemment attendre que des renseignements plus précis ou de nouveaux matériaux nous permettent de confirmer le classement proposé pour ce Genre, ou bien d'affirmer que ce n'est (comme je le crains) qu'un échantillon fruste d'un Genre déjà connu.

Répart. stratigr.

Mrocene. - L'espèce-type dans le Tertiaire de Saint-Domingue, d'après Gabb.

VOLVARIA, Lamarck, 1801.

$(=$ Volvarius Montf. 1810)

VOLVARIA, sensu stricto.

Type: V. bulloides, Lamk. Eoc.

Taille au-dessous de la moyenne; forme cylindracée; spire cachée et involvée; protoconche tantôt involvée dans l'ombilic 
Volvaria

apical, tantôt visible dans cet ombilic, et alors lisse, composée d'un bouton saillant el globuleux, à nucléus pelit et un peu obtus; dernier tour enveloppant toute la spire, presque cylindrique, arrondi au sommet autour de l'ombilic apical, un peu atténué en avant, orné de sillons spiraux, finement ponctués par les accroissemenls; base à peine distincte du cou, qui est légèrement gonflé, plutôt que muni d'un véritable bourrelet.

Ouverture très étroite, presque linéaire en arrière, un peu ćlargeie à son extrémité antéricure, où elle est largement tronquée et faiblement échancrée en demi-cercle; labre assez mince, lisse à l'intérieur, lacinié à son contour, arrondi en demi-cercle en avant, vertical au milieu, non sinueux en arrière, formant, à son extrémité inférieure, une gouttière prolongée en bec aigu, et masquant parfois partiellement l'ombilic apical; columelle courte, munie de quatre plis minces, obliques et croissants, non tordue à la base; bord columellaire indistinct, sauf à l'extrémité lout à fait inférieure de la région pariétale, où il s'épaissit un peu pour former, avec le labre, la gouttière ci-dessus mentionnée.

Diagnose faite d'après un échantillon de l'espèce-type, du Calcaire grossier de Grignon (PI. VIII, fig. 22), ma coll.; et d'après une espèce voisine, à nucléus mucroné, des Sables moyens de Narines : V. acutiuscula Sow. (PI. YIII, fig. 23), ma coll.

Observ. - J'ai précédemment indiqué (Essais Pal. comp., I, p. 44) pour quels motifs il me paraît inadmissible de classer Volvaria dans les Opisthobranches, auprès d'Aclieon, dont il se rapproche peut-être par ses sillons ponctués et par sa forme de Bullidx; mais, outre que son embryon homøostrophe ressemble à celui des Volutidx, ses plis columellaires n'ont aucun rapport avec ceux des Actronide ou des Bullide, et ils ont, au contraire, beaucoup d'analogie avec ceux des Mitridx. Comme la forme et l'ornementation de la coquille de Volvaria ressemblent à celles de Cylindromitia, et que la protoconche peut se comparer à celle d'Imbricaria, comme enfin le labre est vertical et lacinié, ainsi que cela a lieu chez ces deux Genres, je crois en définitive que l'opinion de Gray est la mieux fondée, et qu'il y a lieu, par conséquent, de placer Volvaria dans la Sous-Famille Cylindromitrine'.

Rapp. et diff. - I'olvaria se distingue de Cylindromilra et d'Imbri- 
caria: non seulement par sa forme plus cylindrique, mais encore par ses plis columellaires moins nombreux, non imbriqués, par son échancrure basale moins entaillée, et par conséquent, par l'absence presque complète de bourrelet sur le cou.

\section{Répart. stratigr.}

Eocene. - Les deux espèces-type et plésiotype ci-dessus figurées, dans le Bassin anglo-parisien, rna coll.; l'espèce-type dans le Bruxellien la Belgique, d'après Nyst. Une espèce dans le Claibornien de l'Alabama : V. alabamiensis, Cossm., ma coll.

Mrocène. - Une espèce du mẻme groupe que $V$. acutiuscula, dans l'Inde (Upper Burma): V. birmanica Nœetling, d'après la figure donnée par cet auteur.

Volvarielia, Fischer, 1883. Type: V. Lamarcki, Desh. Eoc.

Taille petite; forme cylindracée; spire très courte, à galbe extraconique; protoconche lisse, globuleuse, à nucléus planorbulaire, déprimé ; tours à peine convexes, séparés par des sutures subcanaliculées, sillonnés; dernier tour formant presque toute la coquille, à peu près cylindrique sur presque toute sa hauteur, un peu ovalisé en arrière, atténué et légèrement convexe en avant, orné de stries spirales subonduleuses, rapprochées, très finement ponctuées par les accroissements; base un peu obliquement déclive, absolument dépourvue de cou et de bourrelet ou de gonflement dorsal. Ouverture très étroite en arrière, graduellement dilatée en avant, dépourvue de gouttière postérieure, largement tronquée à son extrémité antérieure, sans aucune trace d'échancrure; labre mince, curviligne, lisse à l'intérieur; columelle légèrement excavée, portant deux plis très obliques, écartés, à peu près égaux, l'antérieur confondu avec la torsion de la columelle, et se raccordant avec le contour de la troncature basale; bord columellaire indistinct. 
Diagnose faite d'après un rare échantillon de l'espèce-type, du Suessonien d'Hérouval (Pl. VIII, fig. 27), coll. Pezant; cet échantillon a malheureusement été brisé au moment de la reproduction photographique.

Rapp. et diff. - C'est avec raison que Fischer a séparé ce Sous-Genre de Tolvaria, non seulement à cause du caractìrequ'il indique brièvement, dans son Manuel: spire saillante; mais encore à cause de la plication columellaire qui est tout à fait différente; en outre, le nucléus embryonnaire est plus déprimé, l'échancrure basale a totalement disparu; enfin le labre est plus arqué, et il aboutit obliquement à la suture, au lieu gu'il est perpendiculaire chez Volearia. L'individu de ma collection provenant de Liancourt, d'après lequel j'ai refait et complété cette diagnose, n'était pas complètement adulte ; et il a été brisé de même que celui d'Ilérouval, que m’a communiqué M. Pezant; il est possible qu'en vieillissant le labre devienne lacinié sur son contour, comme celui des autres $C y l i n d r o m i t r i n e$.

Répart. stratigr.

Eocene. - Ontre le type ci-dessus figuré, une autro espèce (ou variété ?) dans le Suessonien des environs de Paris : $V$. Dienvali de Raincourt, d'après la figure donnée par cet auteur. Une espèce aux Etats-Unis: $V$. alabamiensis( $\left.{ }^{1}\right) \Lambda$ ldrich $(\Lambda$ ne pas confondre avec mon V.alabamiensis), d'après la figure publiée par l'auteur.

(1) M. Aldrich ayant publiẻ son espèce sous le nom Volvaria, bien que ce soit, en réalité, un Volvariella, il n'est pas possible de lui conserver cette dénomination, postérieure à la-mienne. Je propose, én conséquence: V. Alarichi, nobis, pour l'espèce de lolvariella décrite par notre confrère. 


\title{
ANNEXE
}

\author{
$1^{\circ}$ NOTES COMPLÉMENTAIRES \\ RELATIVES AUX DEUX PREMIÈRES LIVRAISONS \\ Première livraison.
}

\section{OPISTHOBRANCHIATA.}

Pseudatena, Sacco, 1896. Type: P. tauroglandula Sacc. Mioc.

Sous-Genre séparé de Tornatina, à cause de sa forme utriculoïde, de sa spire complètement involvée par le dernier tour; la surface est ornée de fines stries spirales et de plis axiaux au sommet; la columelle, régulièrement arquée, est simple, légèrement tordue en avant. Les figures, que M. Sacco a données des trois espèces qu'il classe dans ce nouveau Sous-Genre, sont trop indistinctes pour que je puisse les reproduire; les échantillons, insuffisamment éclairés, sont mal venus en photographie; ce n'est donc que d'après le texte très écourté qu'on peut se faire une opinion sur cette nouvelle subdivision, qui comprendrait, dans les mers actuelles, deux espèces des fonds fangeux : Utriculus spatha et oliviformis Watson.

Mnestocyliahnella, Oppenheim, 1896.

Type : Bulla magnifica, Oppenh. Eoc.

Forme olivoïde, intermédiaire entre Mnestia et Cylichnella, couronnée d'une carène apicale, comme le premier de ces Genres, à bord columellaire largement étalé, et muni de deux plis, comme chez Cylichnella; en outre, la surface porte des plis d'accroissement réguliers et serrés, croisés par de très fines stries spirales.

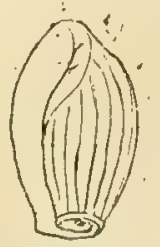

Fig. 33. - Mnestocylichnella mainifica, Upph.

(Fig. 33 ci-contre, copie de la figure publiée par l'auteur, Colli Berici, p. 79, Pl. II, fig. 5). 
Cyrichnella. - A ajonter :

Oligocene. - Une espèce dans les couches de Gaas: Bulla marginala Grat., d'après M. Benoist.

Ringiculella. $-\Lambda$ ajouter :

Eocexe. - Deux espèces probables aux États-Unis : $R$. lisbonensis et claibornensis Aldrich, d'après les figures publiées par cet auteur.

\section{SPIRIGELLA, Rang, 1828.}

Coquille très aplatie, allongée, arquée; nucléus sénestre, placé en arrière et à gauche; à l'intéricur une petite cavité correspond à la spire; impression musculaire peu distincte. Type : $S$. unguiculus, Rang. Mioc.

Observ. - A la suite de cette diagnose que je reproduis textuellement, d'après le Manuel de Conchyliologie (p. 70̃3), Fischer ajoute: le nucléus des Spiricella les rapproche des Umbrella Rang. Cependant il classe ce Genre dans les Capulidx, à cause de ces relations très obscures. Or notre confrère M. Benoist, dans une leltre relative à quelques omissions de la $1^{\text {re }}$ livraison des Essais, m'écrit le renseignement suivant que j'extrais textuellement: “... Genre Spiricella Rang. (Actes Soc. linn. Bordeaux, "II, PI. 5, p. 228), représenté dans les Faluns de Mérignac(Burdigalien), " par $S$. unguiculus Desm. et quelques fragments de celte espèce ont été "recueillis par moi au Moulin de l'Eglise, à Satucats. Le type doit se " trouver dans la collection de Rang. " Je n'ai pu, bien entendu, savoir ce qu'était devenue cette collection, afin de vérifier, par l'inspection de l'impression musculaire, si Spiricella doit être réellement rapproché d'Umbrella; mais il est certain que l'embryon hétérostrophe, désigné par lang comme le principal caractère de son nouveau Genre, plaide en laveur du classement qu'il proposait, plutôt que près des Capulus, qui n’ont pas de nucléus sénestre. C'est pourquoi je préfère ne pas attendre l'époque, peut-être lointaine, où j'aborderai l'étude des Capulidx, pour combler la lacune probable de la $1^{\text {re }}$ livraison de nes Essais, en indiquant, dès à présent, qu'il y a lieud'ajouter, à la page 132 , ce qui précède.

UMBRELLA. - $\Lambda$ ajouter :

Mrocene. - Une espèce dans le Burdigalien de l'Aquitaine: U. girondica Benoist in litt., coll. du Musée de Bordeaux.

Carinaria. $-\Lambda$ ajouter:

Mrocene. - Une espèce dans le Tertiaire des Antilles : C. caperata Guppy, d'après M. Dall. 


\section{Deuxième livraison.}

\section{ENTOMIO'TANIATA.}

La publication toute récente, dans les "Mémoires de Paléontologie de la Société géologique de France ", d’un second Mémoire, relatif aux Entomotæniata, a nécessité, de ma part, l'examen d'un grand nombre de Nérinées jurassiques de la France; de l'étude de ces matériaux, dont je n'avais qu'un petit nombre à ma disposition, quand j'ai écrit la seconde livraison de mes "Essais ", il résulte quelques rectifications ou additions, pour le détail desquelles le lecteur pourra se reporter au Mémoire précité, mais qu'il importe de signaler dans cette troisième livraison, afin de tenir notre publication à jour.

Sequania. $-\Lambda$ ajouter :

Rauraciex. - Une espèce dans l'Oolite corallienne de la Meuse: Cerith. moreanum Buv., d'après la figure de l'Atlas de Buvignier; une autre espèce nouvelle, dans l'Oolite blanche de l'Indre : $S$. nodifera Cossm., ma coll.

Fibula. - Il y a lieu de placer dans ce Sous-Genre: Cerith. Pellati de Lor. que j'avais d'abord placé dans le Genre Pseudonerinea.

Phaneroptyxis. $-\Lambda$ ajouter :

Bathosiex. - Une espèce nouvelle dans le Portugal : P. Choffali, coll. de la Comm. des Travanx géologiques.

Nerinella. - A ajouter:

Toanciex. - Une espèce dans le Lias supérieur de Vicinaberg (Autriche) : $N$, atava Schmid, d'après la figure publiée par cet auteur.

Endiatrachelus, Cossmann, 1898.

Type: Nerinea Erato, d'Orb. Portl.

Section nouvelle, qui se distingue de Nerinella s. s.: non seulement par sa base ovale et sans cou, mais encore par ses tours non évidés, sans 
arêtes saillantes aux sutures, qui sont bordées par une rampe ou par une rainure très oblique. L'ouverture ressemble à celle de Pseudonerinea, avec un bec échancré ou sinueux à la base; le labre porte, à l'intéricur, un large ruban spiral, plus ou moins saillant; quant à la columelle, qui est très excavée, elle est munie, tout à fait en avant, d'un bourrelet pliciforme qui borde l'échancrure basale; enfin un pli pariétal aigu existe en arrière. Cette Section est, par rapport à Nerinella, ce qu'est Mclanioptyxis par rapport à Nerinea; mais elle s'écarte de Melanioptyxis par son bourrelet et par l'absence de cou, ainsi que par son large ruban labial.

\section{Répart. stratigr.}

Raubaciex. - Une espèce dans l'Oolite corallienne de la Meuse et de l'Yonne: $N$. subcylindrica d'Orb., coll. Cotteau.

Sequaxiex. - La même espèce dans la Haute-Marne et le Boulonnais, d'après M. de Loriol.

Kinmerndgrix. - Deux espèces bien distinctes: $N$. monsbeliardensis Cont., dans le Doubs, d'après Contejean; E. Pellati Cossm., dans le Jura, coll. Pellat.

Portlandien. - L'espèce-type dans la Franche-Comté, coll. Pellat.

Aptyxiella. - $\Lambda$ la suite d'une nouvelle vérification, la plupart des Aptyxiella cités dans notre seconde livraison appartiennent à d'autres Genres; d'autre part, il y a des espèces que j'ai dû classer dans ce Genre, et dont je n'avais pas fait mention. En résumé, la répartition stratigraphique est à rectifier de la manière suivante:

Rauraciex. - Une espèce dans l'Yonne: A. coltaldina d'Orb., coll. Coltean.

Sequariex. - Trois espèces dans la Charente-Inférieure: A. sexcostata, rupellensis et inornata d'Orb.; coll. Beltrémieux; l'une d'elles (sub. nom. exarala Cont.), dans le Doubs, coll. de la Soc. d'Emul. de Montbéliard.

Kimmeridgiex. - L'une des trois espèces séquaniennes, dans le llanovre : A. rupellensis d'Orb., ma coll.

Porthandien. - Trois espèces, dont l'une est douteuse, soit dans l'Yonne: Nerinea vallonia de Lor.; soit dans le Boulonnais : Turr. Sæmanni de Lor. et Cerith. pseudoexcavatum de Lor., coll. P'ellat. Neocomen. - (Comme précédemment.)

Aphanotania, Gossmann, 1898.

'Type: Nerinea strigillata, Gredn. Séq.

Coquille térébriforme, aciculée, à galbe conique; tours subulés ou un peu étagés, ornés de plis obliques, non rétrocurrents vers 
la suture. Ouverture étroite, échancrée à la base; columelle excavée, avec un pli tordu qui limite le bec antérieur près de l'échancrure; labre oblique, incliné à gauche de l'axe, du côté antérieur, avec un pli interne.

Observ. - Cette coquille n'est ni un Nerinea, ni un Nerinella; il me paraît même douteux qu'on puisse continuer à la laisser dans le SousOrdre Entomotæniata, car je n'ai pu distinguer aucune trace d'un sinus dans la direction des stries d'accroissement, qui ont une obliquité en sens inverse de la direction des stries des Nerineidx. En outre, je n'ai constaté l'existence d'un pli pariétal sur aucun des échantillons examinés; le bec basal de l'ouverture a plus d'analogie avec l'échancrure de Pseudonerinea et surtout d'Endiatrachelus, qu'avec le pseudo-canal de Nerinella. Enfin le caractère tout spécial de l'ornementation est déjà un indice différentiel d'une grande importance. Cependant, comme je n'ai pu étudier l'ouverture bien entière, ni vérifier qu'il n'y a absolument aucune entaille, même linéaire, à la partie postérieure du labre, je ne puis encore affirmer définitivement que ce Genre doit être éliminé des Enlomotæniata. D'autre part, la présence d'une lame spirale à l'intérieur du labre, ainsi que l'absence d'un véritable canal siphonal, ne permettent pas de rapprocher A. strigitlata des Cerithidæ; je le classe done provisoirement à la suite de Nerinella, dont il se rapproche par son galbe général.

Répart. stratigr.

Sequarien. - L'espèce-type dans la Haute-Marne, coll. de Gézincourt; dans le Boulonnais, coll. Pellat, Legay et Rigaux.

Kinnerrogiex. - La même dans le Ptérocérien de l'Ain, coll. Pellat; dans le Hanovre, d'après la figure publiée par M. Struckmann.

\section{PRosobranchita.}

Erratum à corriger à la page 46 : TOXOGLOSSA, au lieu de Trenioglossa.

Pusionella. - Ajouter:

Eocexe. - Une espèce probable dans le Texas: Fusus Marmodei Ileilp., d'après la figure publiée par. M. Aldrich (Bull. Americ. Pal. 1897, n 8). 


\section{PLEUROTOMIDA}

A ajouter au tableau (p. 60 et 61 ) deux omissions : Donovanis et Sinistrella.

Hempleurotoma. - Il y a lieu de faire remarquer que la dénomination Coronia de Greg., que je considere comme synonyme, n'aurait pu, en tous cas, être conservée, attendu qu'elle fait double emploi avec un Genre bien antérieur d'Ehrenberg.

Ficulopsis, Stoliczlia, 1867.

Type : Pyrula pondicherriensis, Forbes. Crét.

Taille grande; forme piroïde, étroite, allongée; spire très courte, presque nulle, mucronée au sommet; dernier tour formant presque toute la coquille, ovale-arrondi en arrière, atténué et à peine excavé à la base, entièrement treillissé par des carènes spirales et par des plis axiaux, moins saillants que les carènes, mais formant avec elles des mailles à peu près carrées. Ourerture un peu dilatée, subanguleuse du côté postérieur, peu rétrécie à son extrémité antérieure, oì elle se termine par une troncature à peine échancrée; labre mince, presque droit, muni d'un sinus sutural, dont l'entaille forme, par ses accroissements, de petites écailles curvilignes le long de la suture; columelle calleuse, épaisse, munie de cinq plis décroissants, l'antérieur oblique el mince; bord columellaire étroit, épais, bien limité à l'extérieur.

Diagnose traduite d'après le texte, et complétée d'après la figure de l'ouvrage de Stoliczka (Cret. Gastr. South India, p. 84, pl. VI, fig. 10-11). Reproduction réduite de cette figure(Fig. 34 ci-contre).

Rapp. et diff. - Ainsi que Stoliczka l'a fait observer, ce Genre, représenté par une seule espèce peu rare et munie de son test, a une intime analogie avec Pirula (= Ficula), même par son ornementation, dans laquelle prédominent les carénes spirales; mais il s'en distingue essentiellement par sa columelle calleuse et plissée, tandis que celle des Pirules est mince 
et dénuéc de plis. En outre, il ne se termine pas en avant par un véritable canal; sa base est moins excavée, et enfin il paraît posséder, contre la suture, l'entaille caractéristique des Pholidotominæ; Stoliczka fait mention de ce sinus dans le texte de la diagnose de l'espèce-type, et la figure, qui donne la vue, en plan, du sommet de la spire, reproduit les accroissements de ce sinus, avec le même aspect écailleux que sur la figure de Gosavia: il me parait donc évident que ces deux formes appartiennent à la même SousFamille.

Quant au classement des Pholidotominx, ainsi que je l'ai indiqué dans les observations relatives à la Famille Volutidx, il ne paraît pas encore définitif; l'addition de ce nouveau genre Ficulopsis contribue à donner aux Pholidolominx une composition tout à faithétérogène, en ce qui concerne la forme extérieure, qui est successivement: fusoïde, buccinoïde, volutoïde, conique, ou ficuloïde; si l'on éliminait le caractère commun de l'entaille suturale, que je considère comme ayant une importance capitale, surtout à cause de ses accroissements écailleux, on serait obligé, en

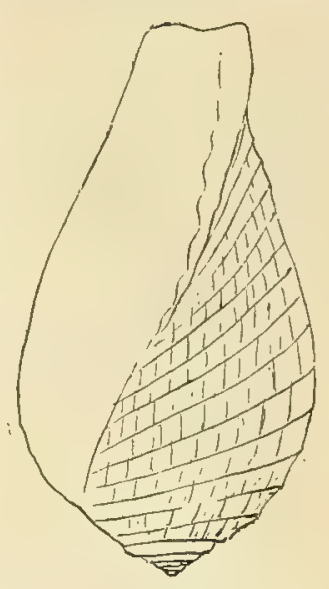

FIG. 34. - Ficulopsis pondicherriensis, Forbes. tenant compte soit de la forme de la coquille, soit de ses plis columellaires, de répartir les cinq Genres de cette SousFamille dans des groupes absolument distincts. Je crois que cette conclusion serait contraire aux véritables affinités de ces formes crétaciques; il est d'ailleurs probable que, lorsqu'on connaitra mieux les protoconches de ces cinq Genres, on constatera qu'elles présentent la même homogénéité que pour le sinus sutural, avec une forme petite et trochoïde, analogue à celle de Volutilithes.

\section{Répart. stratigr.}

Turonies. - L'espèce-type dans les " Groupes de Valudayur et de Trichinopoly w, de l'Inde méridionale, d'après Stoliczka.

\section{BORSONIA Bellardi.}

EuchilodoN, Heilprin (em.), 1880.

Type: E. crenocarinatus, Heilp. Eoc.

Taille moyenne; forme fusoide, étroite, turriculée; spire probablement longue, un peu ćlagée; tours anguleux, munis d'une 
rampe excavée au-dessus de la suture, ornés de carènes spirales, dont deux sont finement crénelées, celle sur l'angle et celle qui borde la suture; dernier tour grand, orné comme la spire, excavé à la base, sur laquelle s'enroulent obliquement des cordomets un peu plus serrés que les carènes des tours de spire. Ouverture étroite, un peu trigone et squalène en arrière, terminée en avant par un canal long et droit, sans échancrure à son extrémité antérieure; labre épaissi, muni de crénelures oblongues a l'intérieur, vraisemblablement sinueux sur l'angle du dernier tour; columelle à peu près rectiligne, faisant un angle extrêmement ouvert avec la base de l'avant-dernier tour, munie en arrière de sept ou huit plissements à peu près égaux: bord columellaire mince, étroit, terminé en pointe effilée le long du canal.

Diagnose faite d'après la figure de l'espèce-type, publiée par M. Aldrich dans le Bull, of. Amer. Pal. $n^{0} 8, \mathrm{pl}$. IV, fig. 1. Reproduction de cette figure (Fig. 35 ci-contre).

Observ. - Je n'ai pas eu connaissance de ce Genre, quand j'ai publié la seconde livraison de mes "Essais ", n'ayant reçu qu'un an plus tard le fascicule du Bulletin dans lequel M. Aldrich a repris et fait figurer un certain nombre d'espèces éocéniques, décrites en 1880 par Heilprin, dans les "Proc, of the nat. Mus.". D'après celte figure, la coquille, qui a servi de type au Genre Euchilodon (non Eucheilodon, le latin ne comportant pas de diphtongues), est un Pleurotomidx, qui doit probablement être rapproché de Rouaultia, mais avec un plus

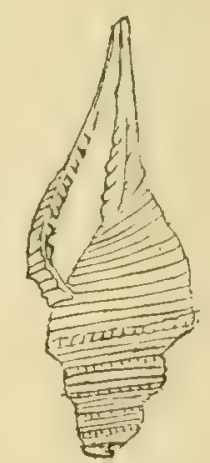

Fig. $35 .-$ Euchilodon crenocarinatus, lleilp. grand nombre de plis à la columelle, et avec des crénelures à l'intérieur du labre.

Répart. stratigx.

Eockxe. - L'espèce-type dans le gisement Jackson(Mississipi), d'après M. Aldrich.

Hatia. - Voir, dans la présente livraison (p. 129), les observations relatives à ce Genre, que M. Dall a récemment proposé de classer dans la Famille Volutidie. 
BELA, Leach.

Teleochilus, Geo. Harris, $1897\left({ }^{1}\right)$.

Type: Daphnella gracillima, T. Woods. Eoc.

Taille assez grande; forme étroite, élancée, fusoïde; spire relativement courte, à galbe conoïdal; protoconche lisse, paucispirée, déprimée en goutte de suif, à nucléus tout à fait obtus; tours convexes, assez élevés, sillonnés, séparés par des sutures subcanaliculées; dernier tour très grand, un peu ovoïde en arrière, avec une rainure spirale au-dessus de la suture, excavé à la base, et portant, ainsi que celle-ci, des sillons spiraux, qui s'enroulent obliquement sur le cou du canal. Ouverture longue, peu dilatée au milieu, à peine atténuée en avant, où elle se termine par une large troncature un peu échancrée sur son contour externe; labre mince, presque vertical, non sinueux en arrière; columelle peu excavée du côté postérieur, légèrement bombée au milieu, incurvée à droite du côté antérieur, se terminant en pointe à l'angle de la troncature basale; bord columellaire lisse, mince, uu peu étalé en arrière, étroit et plus calleux à son extrémité antérieure.

Diagnose refaite d'après des échantillons de l'espèce-type de Muddy Creek (Pl. VIII, fig. 4), ma coll.

Rapp. et diff. - J'ai classé (Essais, II, p. 93) cette coquille, non sans hésitation, dans la Section Daphnobela, quoiqu'elle s'écarte de Bucc. junceum, type de cette Section, par son labre non sinueux, par sa protoconche en calotte déprimée, sans nucléus saillant. M. Geo. Harris, dans l'étude qu'il a entreprise des fossiles australasiens du British Museum, a proposé pour elle un nouveau Genre, dont le classement lui parait embarrassant, et qu'il rapproche à la fois de Daphnella dans la Famille Pleurotomida, et de Dibaphus dans la l'amille Mitridz. J'admets, à la rigueur, qu'on sépare Teleochilus de Daphnobela, mais simplement comme une Section nouvelle de Bela, dont le sinus est presque nul et dont l'embryon a quelque analogie avec celui de $D$. gracillima; mais il n'y a aucun rapport entre cette coquille et Dibaphus, qui a une ornementation can-

(1) «The Australasian tert. Moll. » Brit. Mus., 1897, 407 p., 8 pl. 
cellée, une onverture bien différente, et une columelle incurvée vers l'axe à son extrémité antérieure. C'est donc bien dans les Pleurotomide qu'il y a lieu de classer Teleochihus, et c'est pourquoi je ne catalogue celte Section que dans l'annexe de la présente livraison.

Répart. stratigr.

Eocene. - L'espèce-type en Australie (Victoria).

Agathotoma Cossmann, nom mut. (Revue critique de Paléozool., $3^{\text {e }}$ année, I, 1899). (= Ditoma Bell. 1875, non Ill. 1807, Col.

Je me borne à enregistrel celte correction de nomenclature, précédemment faile dans la "Revue critique ", et qui avail échappé à mes investigalions antérieures.

\section{$2^{\circ}$ DESGRIPTION DES ESPÈCES INÉDITES, CITÉES DANS GETTE LIVRAISON.}

Sveltia colpodes, nov. sp.

Pl. II, fig. 18-19.

Taille moyenne ; forme fusoïle, étroite, allongée ; spire à galbe conique; protoconche globuleuse, turbinée, composée de trois tours lisses, à nucléus très petit, à peine saillant; les autres tours converes, séparés par des sutures linéaires, qui sont ondulées par huit costules axiales, obliques, formant une pyramide tordue, persistant jusqu'au dernier lour', crénelées par trois filets spiraux et obsolètes, presque tolalement effacés dans les intervalles des côtes, avec un filet intercalaire encore plus fin. Dernier tour un peu supérieur à la longueur de la spire, ovoïde, atténué à la base, sur laquelle se prolonge régulièrement l'ornementation, el qui est imperforée, complètement dépourvue de bourrelet.

Ouverture très courte, en forme de palme, arrondie et dépourvue de gouttière à la partie inférieure, subanguleuse avec un bec court à son extrémité antérieure; labre oblique, épaissi à l'intérieur, avec six crénelures obluses el allongées; columelle à peu près rectiligne, oblique, légìrement infléchie à droite près du bece, munie de deux plis un peu obliques, assez saillants et d'une lor- 
sion antérieure qui simule un troisième pli, au point où elle s'infléchit à droite; bord columellaire assez large, très calleux, hermétiquement appliqué sur la base.

Dis. - Longueur : 14 mill.; diamètre : 6 mill.

Rapp. et difF. - Cette espèce ressemble beaucoup à $S$. parvoturila Sacco, du Tortonien du Piémont; mais elle est plus étroite, ses tours ne sont pas aussi anguleux que paraissent l'être, d'après la figure, ceux de la coquille italienne, qui n'est, d'ailleurs, elle-même qu'une variété de S. laurinix.

Loc. - Saubrigues (Landes); plusieurs individus donnés par M. Dumas (Pl. II, fig. 18-19), ma coll. — Miocène supérieur.

Brocehinia rissoireformis, nov. $s p$.

Pl. II, fig. 15.

Taille très petite; forme de Rissoia, ovoïdo-conique; spire assez courte, à galbe conoïdal ; protoconche lisse, paucispirée, subglobuleuse, à nucléus petit, un peu saillant; quatre tours converes, légèrement déprimés en arrière vers la suture qui est peu profonde, ornés d'environ dix filets spiraux, fins et serrés, très réguliers, et de quelques plis d'accroissement peu visibles, très obliques. Dernier tour égal aux sept onzièmes de la longueur totale, arrondi à la base, qui est imperforée, et qui atteint l'échancrure, sans l'intermédiaire d'aucun bourrelet, ni de cou. Ouverture semilunaire, munie d'une gouttière peu visible dans l'angle inférieur, terminée en avant par un bec extrêmement court, presque réduit à l'échancrure qu'il produit sur le contour supérieur, à droite de l'axe de la coquille; labre un peu épais, très obliquement incliné à gauche de l'axe, du côté antérieul', muni à l'intérieur de costules parallèles; columelle à peu près rectiligne en arrière, infléchie à droite vers le bec, munie de deux plis courts, épais, transverses, très rapprochés au milieu de sa hauteur; bord columellaire étroit, assez calleux.

Dis. - I.ongueur : 5 \$/2 mill.; diamètre: $23 / 4$ mill.

RAPP. IT DIFF. - Cette petite coquille ressemble à $B$. avara Word sp., du Crag d'Angleterre; mais elle est plus courte et plus finement ornée; 
par tous ses caracteres, elle se rapporte exactement au Genre Brocchinia Jouss., quoiqu'elle s'écarte spécifiquement du type (B. mitrxformis) par son bec moins canaliculé, et par son galbe plus court, rissoïforme.

Loc. - Gourbesville (Manche); unique (1'l. Il., fig. 15), ma coll. Pliocine.

Sveltella Dumasi, nov. $s p$.

Pl. II, fig. 12 .

Taille petite; forme étroite, fusoïde; spire longue, pointue, à galbe conique; protoconche lisse, paucispirée, globuleuse, à nucléus peu saillant; six tours convexes, subanguleux, dont la hauteur égale les trois cinquièmes de la largeur, séparés par des sutures profondes, non canaliculées; ornés de huit à dix filets spiraux, équidistants, médiocrement saillants, et de dix costules axiales, se succédant plus ou moins régulièrement d'un toul à l'autre, plus ou moins saillantes selon les individus. Dernier tour égal à la moitié de la longueur totale, ovale à la base, qui est perforée d'une fente étroite à la place de l'ombilic, et qui est munie d'un bourrelet très obtus, sur lequel se prolongent les filets et cessent les côtes. Ouverture courte, ovale, avec une goutlière obsolète dans l'angle inférieur, et avec un bec presque droit, à peine échancré à son extrémité antérieure; labre épaissi par la dernière côte, sinueux et antécurrent en arrière, lisse à l'intérieur ; columelle à peu près verticale, munie de deux plis minces, obliques et peu saillants; bord columellaire calleux, élargi en arrière, rétréci en pointe du côté antérieur.

Dıм. - Longueur: 71,2 mill. ; diamètre: $31 / 2$ mill.

RAPr. ET DIFF. - Beaucoup plus étroite que la plupart de ses congénères, d'une taille un peu moins petite, elle s'en distingue, en outre, par son ornementation et par l'obliquité de ses plis.

Loc. - Saubrigues (Landes); trois individus donnés par M. Dumas (11. II, fig. 12), ma coll. - Miocène supérieur.

Glabella oligoptycha, nov. sp.

Pl. III, fig. 29-30.

Taille moyenne; forme d'Oliva: spire presque nulle; à bouton 
embryonnaire un peu pointu; trois ou quatre tours un peu convexes, séparés par des sutures déprimées, recouverts d'un enduit vernissé; dernier tour formant presque toute la hauteur de la coquille, peu ventru, ovale, ayant sa convexité maximum vers le tiers postérieur de sa hauteur, atténué à la base qui en forme le prolongement continu, sans aucune inflexion. Ouverture très allongée, étroitement canaliculée dans l'angle inférieur, un peu resserrée en arrière et au milieu, plus dilatée du côté antérieur, arrondie à son contour supérieur, qui est à peine sinueux lorsqu'on l'examine en plan; labre un peu oblique en avant, convexe vers le tiers inférieur, lisse à l'intérieur, bordé par un large bourrelet aplati, un peu réfléchi en dedans vers le tiers de sa hauteur; columelle un peu sinueuse en $S$, munie de quatre plis épais, les deux antérieurs ayant une tendance à se souder, les deux autres plus minces et plus écartés; bord columellaire peu calleux, presque nul en arrière, mieux limité en avant à partir des plis, se reliant au rebord externe du contour supérieur.

Din. - Longueur : $151 / 2$ mill.; diamètre : 8 mill.

Rapp. ET DIFF. - Cette espèce se distingue de $G$. prunum par sa forme plus étroite, par sa base non sinueuse, par ses deux plis presque soudés ; elle s'écarte de $G$. marginata par sa callosité moins étalée, par son bourrelet labial moins prolongé sur la spire; elle est moins ventrue que $G$. curla, et elle a la spire plus courte; elle est plus élancée que $G$. gibbosa Jouss, et elle a les plis plus inégaux.

Loc. - Karikal, plusieurs individus (Pl. III, fig. 29-30), coll. Bonnet; ma coll. - Couches récentes cénozoïques, attribuées au Pliocène.

Gibberula tectiformis, nov. sp.

Pl. IV, fig. 18-19.

Taille assez petite; forme ovale et courte; spire sans aucune saillie, formant un toit aplati el calleux, circonscrit par une arête émoussée; protoconche rétuse, dans une minuscule excavation au centre de la callosité; dernier tour ovoïde, ventru, formant toute la coquille, obliquement atténué à la base, qui porte un limbe assez étroil el bien limité, correspondant aux accroissements de l'échan- 
crure. Ouverture étroite, aussi haule que le dernier tour, à bords parallìles, entaillée en arrière par une étroite gouttière, profondément échancrée à son extrémité antérieure; labre oblique, presque rectiligne, rétrocurrent en arc de cercle vers la suture, peu épais, non bordé à l'extérieur, rétléchi vers l'ouvertnre, muni a l'intérieur de petites crénelures peu saillantes: columelle convexe, portant six ou sept plis, qui décroissent et s'amincissent d'avant en arriere; bord columellaire assez large, calleux, surtout sur la région pariétale, où le callus forme une gibbosité axiale eı arrière des plis.

Diм. - Longueur: $81 / 2$ mill.; diamètre : 引 1/2 mill.

Rapp. ext DIFF. - Je ne connais, parmi les espèces vivantes du mème groupe, aucune coquille qui ait, comme celle-ci, la spire aplatie et couronnée à la périphérie; sa taille est bien plus grande que celle de $G$. $A n$ gasi Brazier, qui a aussi la sphire aplatie, mais qui est tout à fail piriforme.

Loc. - Karikal, peu commune (PI. IV, fig. 18-19), coll. Bonnct. Couches récentes cénozoïques, attribuées au Pliocène.

'Turicula lirocostata, nov. sp. Pl. VIII, fig. 20-21.

Taille petite; forme fusoïde; spire longue, à galbe un peu conoïlal: protoconche d'un tour et demi, formant un petit bouton lisse, saillant, à nucléus papilleux et dévié; tours un peu conrexes, dont la hauteur égale la inoitié de la largeur, séparés par de profondes sutures et légèrement étagés, ornés de costules axiales, droites, qui se succèdent régulièrement d'un tour à l'autre; dans les intervalles de ces côtes, on distingue de profonds sillons spiraux, séparant des cordonnets d'une largeur égale à celle de ces sillons. Derniel tour égal à la moitié de la longueur totale, un peu ovale, à peine excavé à la base, sur laquelle se prolonge l'ornementation, jusqu'au bourrelet du cou, qui est isolé par un cordon crénelé, et qui porte des crochets formés par les accroissements de l'échancrure. Ouverture très courte, avec une goultiere étroite dans l'angle inférieur, à bords presque parallèles, 
tronquée en avant par une profonde échancrure; labre presque vertical, épaissi par la dernière côte; portant une dizaine de plis internes el minces; columelle munie de quatre plis: l'antérieur oblique, les trois autres plus épais, plus saillants, et de plus en plus transverses; une dent pariétale près de la goultière postérieure; bord columellaire assez large, calleux, bien linité.

Dis. - Longueur : 8 mill.; diamètre : 3 mill.

RAPP. ET DIFF. - L'espèce vivante, à laquelle celle-ci ressemble le plus, est T. modesta Reeve, des Philippines ; toutefois elle s'en distingue par sa forme plus étroite et plus pupoïde, par son canal moins isolé ; d'ailleurs T. modesta est placé, par Tryon, dans la Section Costellaria, tandis que notre fossile me paraît ètre un Turricula bien caractérisé:

Loc. - Karikal, rare (Pl. VIII, fig. 20-21), coll. Bonnet, ma coll. Couches récentes cénozoïques, attribuées au Pliọène. 



\section{TABLE ALPHABÉTIQUE}

DES

FAMILLES, GENRES, SOUS-GENRES, ETC.

Les noms en italiques sont ceux des synonymes.

\begin{tabular}{|c|c|c|c|}
\hline \multicolumn{3}{|c|}{$\begin{array}{l}\text { Pages. } \\
\text { Page }\end{array}$} & \multirow{2}{*}{$\begin{array}{r}\text { Pages. } \\
32\end{array}$} \\
\hline Admete ....................... & 31 & 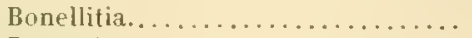 & \\
\hline Admetopsis................... & 7 & 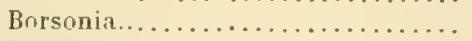 & 189 \\
\hline 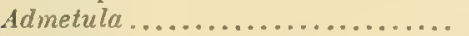 & 32 & 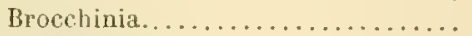 & 18 \\
\hline 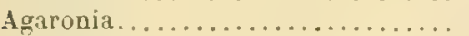 & 50 & Buccinella.................. & 10 \\
\hline 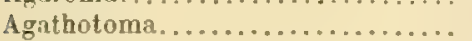 & 192 & 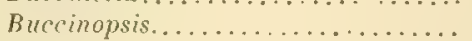 & 76 \\
\hline Aidone. & 152 & Bullata $\ldots \ldots \ldots \ldots \ldots \ldots \ldots \ldots \ldots \ldots$ & \\
\hline 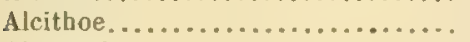 & 132 & & \\
\hline Alocospira................... & 62 & 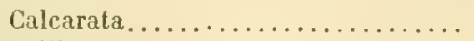 & 21 \\
\hline 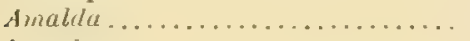 & 58 & 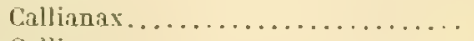 & \\
\hline 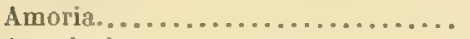 & 119 & Callipara................... & 106 \\
\hline acia................... & 45 & Callithea ..................... & 162 \\
\hline$l(u x \ldots \ldots \ldots \ldots \ldots \ldots \ldots$ & 58 & ispira. ................ & 81 \\
\hline 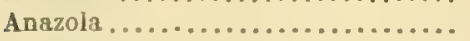 & 44 & Cancellaria......................... & 10 \\
\hline 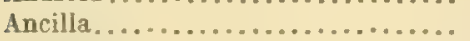 & 58 & C.MYCELLARUo & \\
\hline llaria................... & 58 & 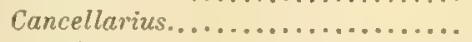 & 10 \\
\hline Ancillarina.................... & 67 & Cancilla.................... & 157 \\
\hline ina.................... & 65 & Caricella ................... & 129 \\
\hline lopsis.................... & 45 & 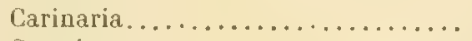 & 184 \\
\hline llus.................... & 58 & ione..................... & 44 \\
\hline stoma.................. & 23 & Chiloptygna.................. & 44 \\
\hline 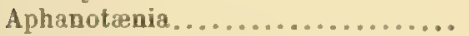 & 186 & Chrysame ................... & 153 \\
\hline$\ldots \ldots \ldots \ldots \ldots \ldots \ldots \ldots$ & 17 & 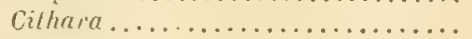 & 73 \\
\hline 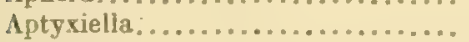 & 186 & 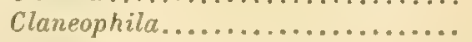 & 49 \\
\hline 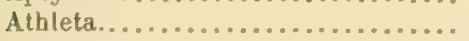 & 140 & 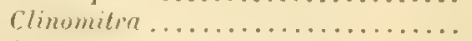 & 17.4 \\
\hline a...................... & 106 & $\ldots \ldots \ldots \ldots \ldots \ldots \ldots \ldots \ldots$ & 81 \\
\hline 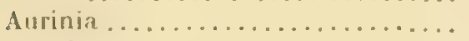 & 128 & 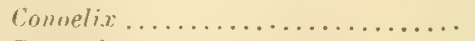 & 154 \\
\hline 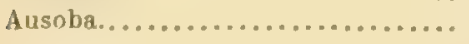 & 107 & itra................ & 172 \\
\hline & & & \\
\hline Babylonella... & 35 & 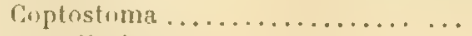 & 34 \\
\hline 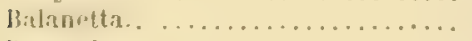 & 81 & 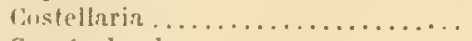 & 164 \\
\hline Baryspirn.................... & 64 & Cryptochorda.................. & it \\
\hline$\ldots \ldots \ldots \ldots \ldots \ldots \ldots \ldots \ldots \ldots$ & 191 & 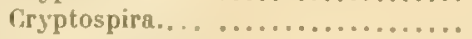 & 9. \\
\hline 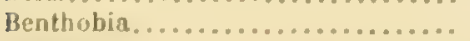 & 6 & 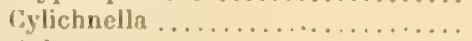 & $18 i$ \\
\hline 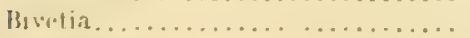 & 8 & rylimblra $\ldots \ldots \ldots \ldots \ldots \ldots \ldots \ldots$ & 178 \\
\hline Bierropsin................... & 8 & Gylindromitra $\ldots \ldots \ldots \ldots \ldots \ldots \ldots$ & $1: i 4$ \\
\hline
\end{tabular}




\begin{tabular}{|c|c|c|c|}
\hline \multirow{2}{*}{ Cymba. } & Pages. & \multicolumn{2}{|r|}{ Pages. } \\
\hline & 106 & Lapparia $\ldots \ldots \ldots \ldots \ldots \ldots \ldots$ & 111 \\
\hline Cigmbancillat.................. & 4; & 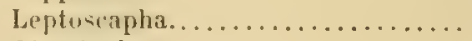 & 120 \\
\hline 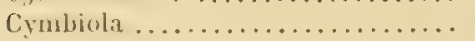 & $12 t$ & dintricula................. & 49 \\
\hline 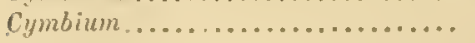 & 106 & Liopeplum .................. & 143 \\
\hline \multirow[t]{2}{*}{ 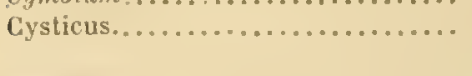 } & 81 & 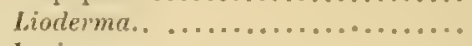 & 43 \\
\hline & & Lyria......................... & 113 \\
\hline Dactylidia. & 34 & & \\
\hline 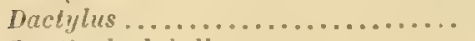 & $4: i$ & 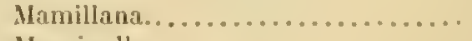 & 117 \\
\hline Denticuloylabella............... & 87 & 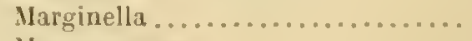 & 83 \\
\hline 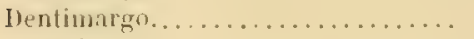 & 90 & 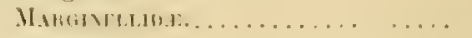 & 79 \\
\hline 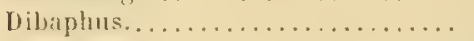 & $15 i$ & 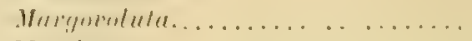 & 140 \\
\hline 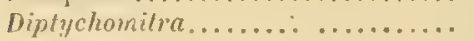 & $17 t$ & 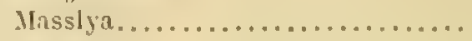 & 39 \\
\hline \multirow{2}{*}{ 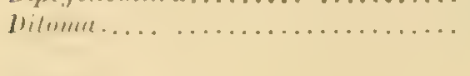 } & 193 & 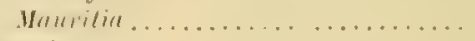 & 1 iit \\
\hline & & $\ldots \ldots \ldots \ldots \ldots \ldots \ldots \ldots$ & 106 \\
\hline$\ldots \ldots \ldots \ldots \ldots \ldots \ldots$ & $\therefore$ & $\ldots \ldots \ldots \ldots \ldots \ldots \ldots \ldots \ldots$ & 13 \\
\hline$n \pi \ldots \ldots \ldots \ldots \ldots \ldots \ldots \ldots$ & 91 & 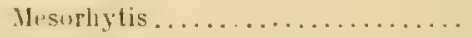 & 170 \\
\hline 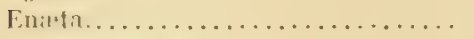 & 10:i & ${ } \ldots \ldots \ldots \ldots \ldots \ldots \ldots \ldots \ldots \ldots$ & 82 \\
\hline irachelus. .............. & Is:i & 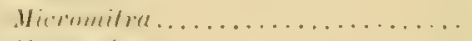 & 170 \\
\hline otæniata................. & lisi: & yivu $\ldots \ldots \ldots \ldots \ldots \ldots \ldots \ldots$ & $96 \mathrm{i}$ \\
\hline$\ldots \ldots \ldots \ldots \ldots \ldots \ldots$ & $7:$ & Microvoluta ........... s. et & 108 \\
\hline 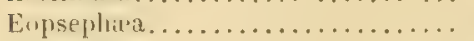 & $14: i$ & 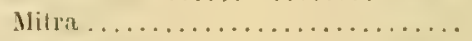 & $15:$. \\
\hline$\ldots \ldots \ldots \ldots \ldots \ldots \ldots \ldots$ & 82 & Hitraria ..................... & $15: \%$ \\
\hline$\ldots \ldots \ldots \ldots \ldots \ldots \ldots$ & 87 & $(\iota, \ldots \ldots \ldots \ldots \ldots \ldots \ldots \ldots$ & 1.72 \\
\hline un................... & 189 & $\ldots \ldots \ldots \ldots \ldots \ldots \ldots$ & $1: ?$ \\
\hline$\ldots \ldots \ldots \ldots \ldots \ldots \ldots \ldots \ldots$ & 10 & : $\ldots \ldots \ldots \ldots \ldots \ldots \ldots \ldots$ & 148 \\
\hline iba....................... & 123 & iclea ..................... & 154 \\
\hline 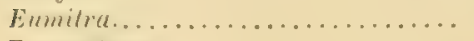 & 168 & lithes.................... & Lii; \\
\hline \multirow{2}{*}{ 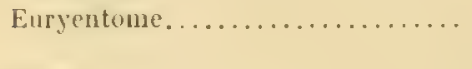 } & $9: 3$ & na................. & $17 t$ \\
\hline & & chnella............... & 183 \\
\hline & \$' & $1, \ldots \ldots \ldots \ldots \ldots$ & il \\
\hline$\ldots \ldots \ldots \ldots \ldots \ldots \ldots \ldots$ & $18 \%$ & . $\ldots \ldots \ldots \ldots \ldots \ldots \ldots$ & 6 \\
\hline pphi...$\ldots \ldots \ldots \ldots \ldots$ & 116 & (n, & 109 \\
\hline 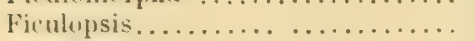 & 188 & Mutyea.................. & $15 t$ \\
\hline 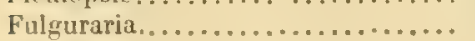 & 107 & & \\
\hline \multirow[t]{2}{*}{ Fusimitra $\ldots \ldots \ldots \ldots \ldots \ldots \ldots \ldots$} & 166 & & \\
\hline & & $\ldots \ldots \ldots \ldots \ldots \ldots \ldots \ldots$ & 152 \\
\hline & 44 & leta ..................... & 139 \\
\hline ia $\ldots \ldots \ldots \ldots \ldots \ldots \ldots \ldots$ & 16 & lindrus................. & 46 \\
\hline a....................... & & raria .................... & 81 \\
\hline Glabella............... 84 et & 91 & 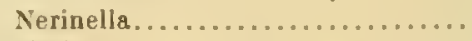 & 185 \\
\hline 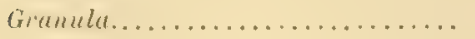 & 96 & Nevia............................... & 13 \\
\hline \multirow[t]{2}{*}{ 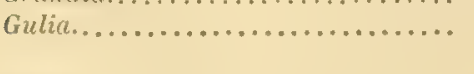 } & 26 & & \\
\hline & & & $4 \%$ \\
\hline & 190 & illaria................. & 49 \\
\hline$\ldots \ldots \ldots \ldots \ldots \ldots \ldots \ldots \ldots$ & 73 & $11 \mathrm{n} \ldots \ldots \ldots \ldots \ldots \ldots \ldots \ldots$ & 52 \\
\hline H & 72 & 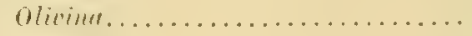 & 52 \\
\hline 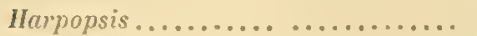 & 76 & 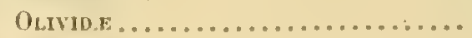 & 41 \\
\hline$\ldots \ldots \ldots \ldots \ldots \ldots \ldots \ldots$ & $11 \ddot{3}$ & 1 it........................ & 70 \\
\hline Ilemipleurotıma............... & $18 s$ & 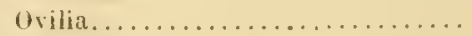 & 28 \\
\hline \multirow[t]{2}{*}{ 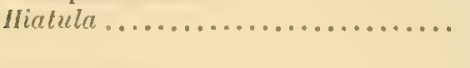 } & 50 & & \\
\hline & & & 82 \\
\hline & $1 \because 1$ & & 177 \\
\hline & 153 & . $\ldots \ldots \ldots \ldots \ldots \ldots \ldots \ldots$ & 96 \\
\hline \multirow[t]{2}{*}{ Inviliulin } & t.i & plyvis . . . . . . . . . . . & $18: i$ \\
\hline & & Plesiocerithiuu................. & \\
\hline Lituprudomil. & 56 & Pleniotritun..................... & \\
\hline
\end{tabular}


DES FAMILLES, GENRES, SOUS-GENRES, ETG.

\begin{tabular}{|c|c|c|c|}
\hline & 'ages. & & Pages. \\
\hline Plevrotonid.................... & 188 & 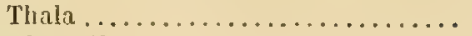 & 176 \\
\hline Plicaria....................... & 10 & Thiurella...................... & 135 \\
\hline Plioptygma..................... & 160 & Tiara...................... & 162 \\
\hline Plochelrea..................... & 178 & 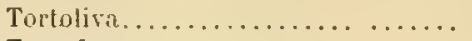 & 62 \\
\hline Porcellanu.............. 83 et & 91 & 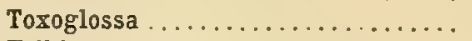 & 1 \\
\hline 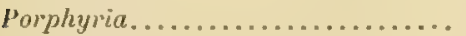 & 43 & 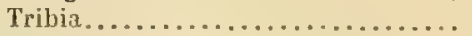 & $1 \geq \underline{2}$ \\
\hline 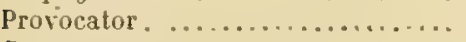 & 108 & Tortoliva... ................. & 67 \\
\hline 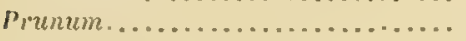 & 91 & Trigonostoma................ & 24 \\
\hline Psephrea...................... & 107 & Turbinopsis ................. & 8 \\
\hline ena................. & 183 & Turricula.................... & 162 \\
\hline mbium............... & 108 & Turris..................... & 162 \\
\hline$\ldots \ldots \ldots \ldots \ldots \ldots \ldots \ldots \ldots$ & 131 & & \\
\hline$\ldots \ldots \ldots \ldots \ldots \ldots \ldots$ & 147 & 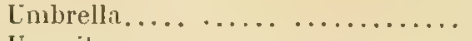 & $18 s^{\prime}$ \\
\hline$c a \ldots \ldots \ldots \ldots \ldots \ldots \ldots$ & 144 & $\operatorname{tra} \ldots \ldots \ldots \ldots \ldots \ldots \ldots \ldots \ldots \ldots$ & 168 \\
\hline .................... & 153 & 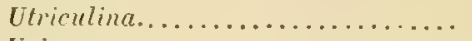 & 49 \\
\hline 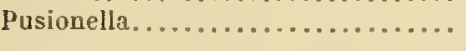 & 187 & 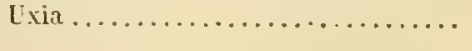 & 37 \\
\hline 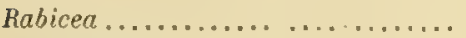 & 98 & & 26 \\
\hline la. ......................... & 56 & Vespertilio ................. & 117 \\
\hline Rhachiglossa ................. & 41 & 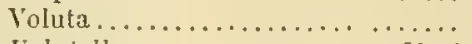 & 109 \\
\hline Ringiculella.................... & 184 & 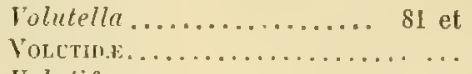 & $\begin{array}{r}107 \\
99\end{array}$ \\
\hline$\ldots \ldots \ldots \ldots \ldots \ldots \ldots \ldots$ & 58 & $f u s u s \ldots \ldots \ldots \ldots \ldots \ldots \ldots$ & 128 \\
\hline cula................... & 153 & Volutilithes .............. & 135 \\
\hline$\ldots \ldots \ldots \ldots \ldots \ldots \ldots \ldots \ldots$ & 15 & Volutoconus.................. & 131 \\
\hline 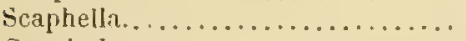 & 126 & Volutocorbis................ & 138 \\
\hline Scaphula...................... & 49 & vlyria.................. & 109 \\
\hline 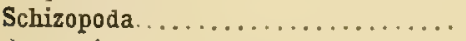 & $\{1$ & 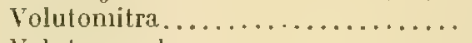 & 108 \\
\hline 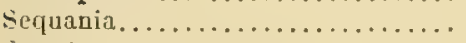 & 185 & 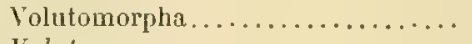 & 144 \\
\hline 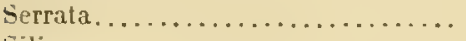 & 86 & 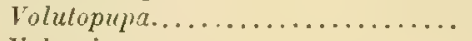 & 139 \\
\hline 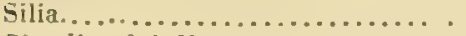 & 78 & 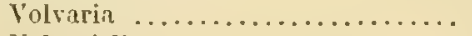 & 179 \\
\hline Simplicoglabella................. & 83 & iella.................. & 181 \\
\hline$\ldots$ & 11 & $\ldots \ldots \ldots \ldots \ldots \ldots \ldots \ldots$ & 92 \\
\hline$\ldots \ldots \ldots \ldots \ldots \ldots \ldots$ & 61 & 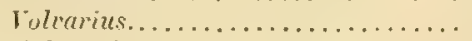 & 179 \\
\hline ................. & 68 & 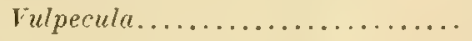 & $16 \geq$ \\
\hline$\ldots \ldots \ldots \ldots \ldots \ldots \ldots$ & 184 & & \\
\hline 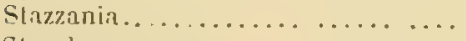 & 88 & Wyzillea................ & $10 \mathrm{~S}$ \\
\hline 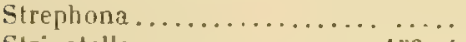 & 48 & & \\
\hline Strigatella............ 153 et & 158 & Yetus... & 123 \\
\hline Sveltella...................... & 29 & & \\
\hline Sreltia .................. & 19 & Ziba ... & 157 \\
\hline 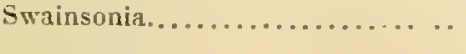 & 152 & $\ldots \ldots \ldots \ldots \ldots \ldots \ldots$ & 107 \\
\hline 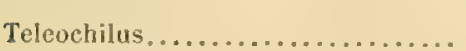 & 191 & Zierrogelia . & 153 \\
\hline
\end{tabular}



TOURS

IMPRIMERIE DESLIS FRERES

6, Rue Gambetta, 6 




\section{PIANCHE I}

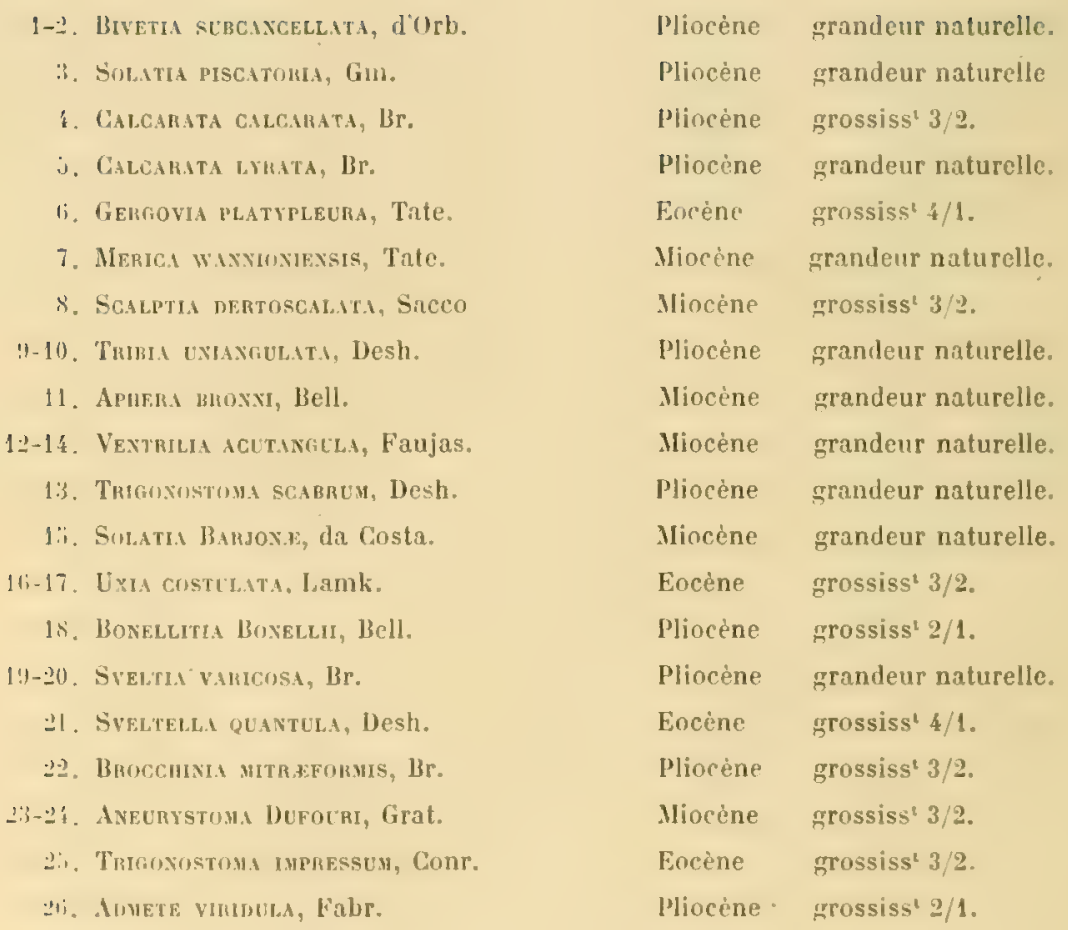



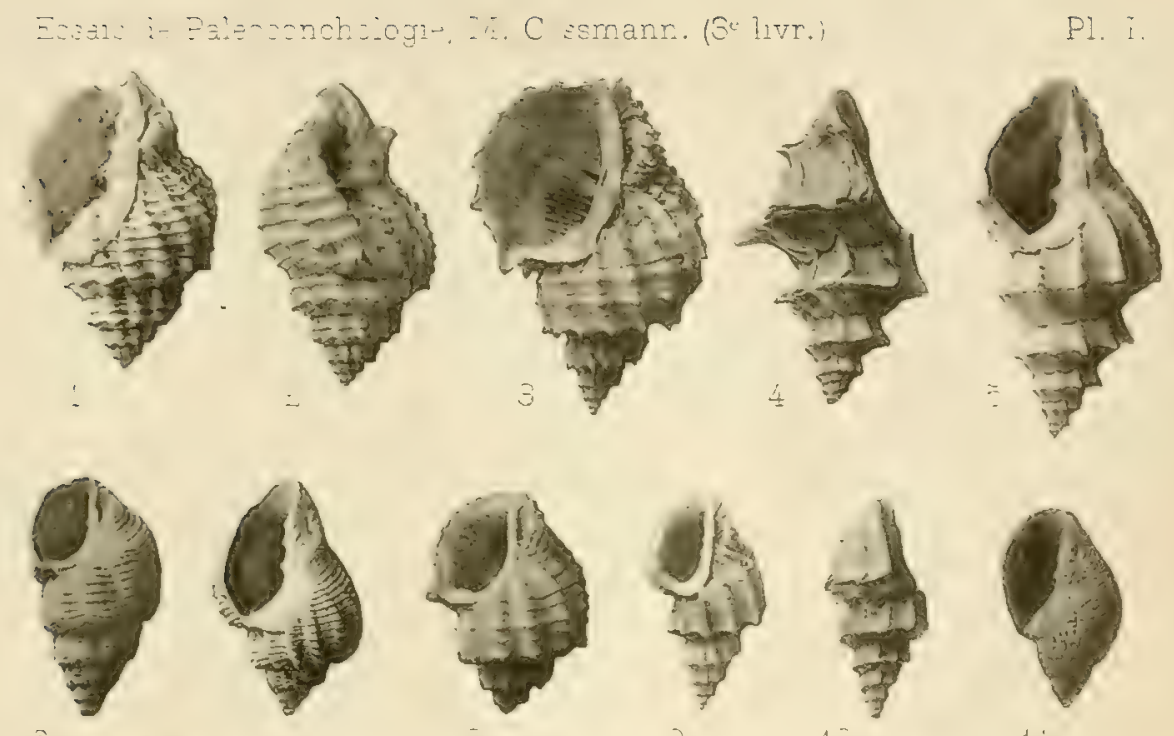

$\hat{c}$
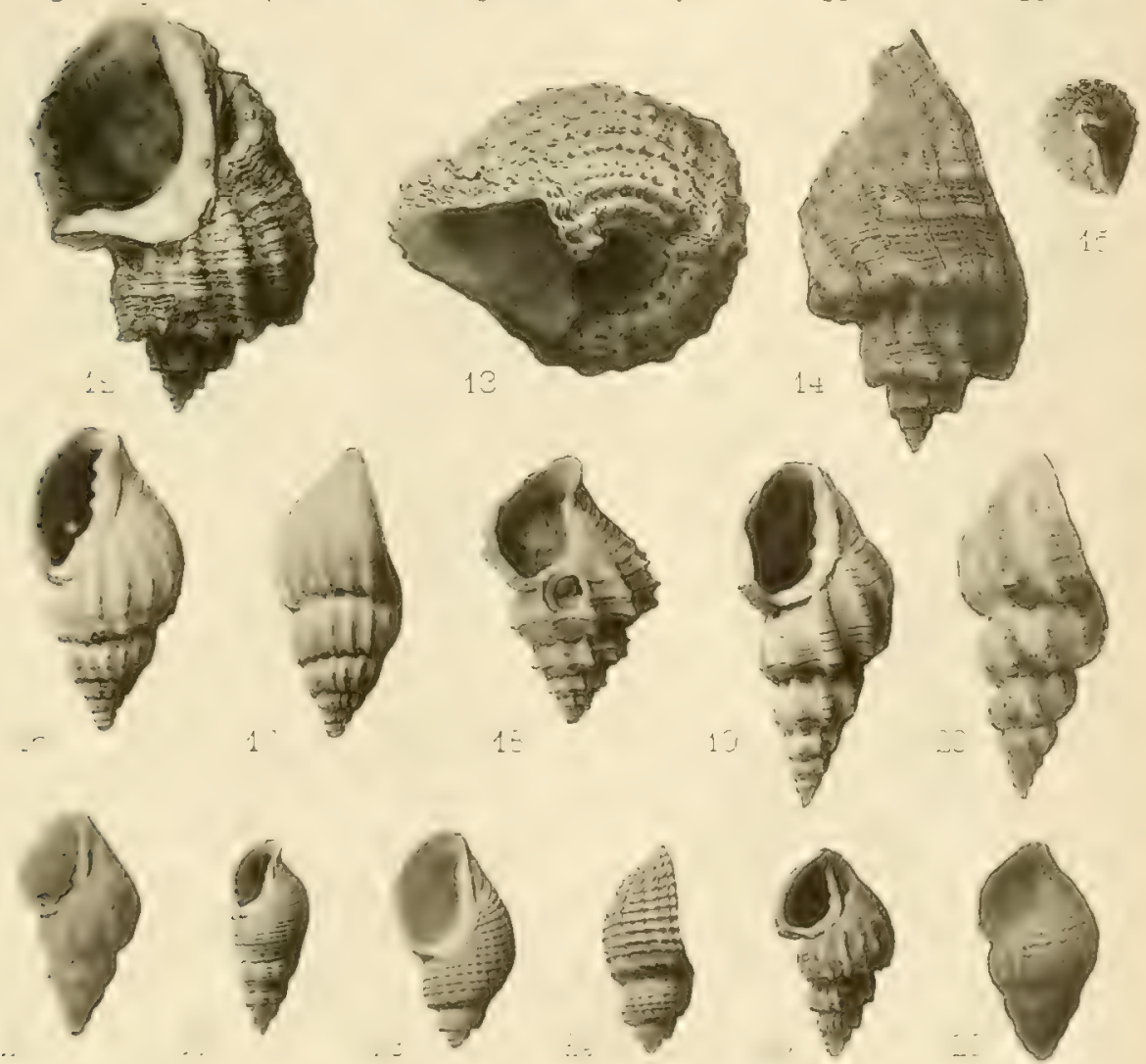




\section{PLANCHE II}

\footnotetext{
1-2. Tugoxostona inatlicite, $\mathrm{Br}$.

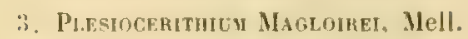

f-̈. Orilia doliolinis, Bast.

li-7. Boxelitita evtLs., Sol.

s. Babylonella elevati, Lea.

y-10. Coptostom Quidritur, Sow.

11. Conptristona chicssyexse. Cossm.

12. Syeltelli Diaisi, Cossm.

13-11. Massi.y Launexst, Grat.

13. Brocchisin hissorizomis, Cossm.

16. Moned CATCerhari, Conr.

17. Anmetopsis subusirorms, Meek.

1S-19. Sveltia colpodes, Cossm.

20-24. Neocylixdrus cimolixexsis, Conr.

21-2:3. Arimosia Bistenotina, Defr.

22. Arimoxid Denemssoxi. Vass.

$2 \because-26$. Dactroiura mutica, Say.

27. Cilluandix Braxoem, Sow.

2x. LAMPhonoma strclavtza, d'Orb.

:?, STHEPHoxi Flamelita, Lamk.

30-31. Negcylixbuts Derheswei, Bast.
}

Pliocène grandeur naturelle,

Eocene grossiss $4 / 1$.

Miocène grandeurnaturelie.

Eocéne grandeur naturelle.

Eocene grossiss' $2 / 1$.

Encène grossiss' $3:$.

Eocène grossiss $3 / 2$.

Miocène grossisst $2 / 1$.

Miocène grossiss $2 / 1$.

Pliocene grossiss $4 / 1$.

Sénon. grandeur naturelle.

sénon. grandeur naturelle.

Miocène grandeur naturelle.

Miocene grandeur naturclle.

Miocène grandeur naturelle.

Eocene grandeur naturelle.

Vivante grossiss $3 / 1$.

Eocène grandeur naturelle.

lliocène grandeur naturelle,

Miocène grossiss' $3 / \mathbf{2}$.

Miocène grandeur naturelle. 
Essais de Paléoconchologie, M. Cossmann (je livr.)

P1. II.

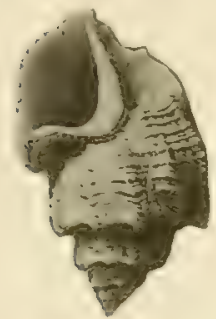

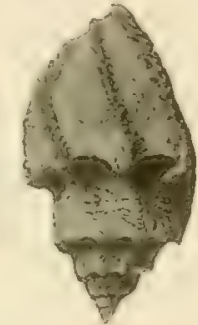

$\cdot 2$

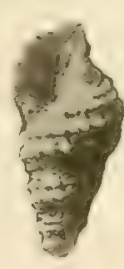

3

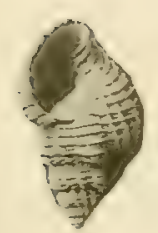

$\overline{6}$

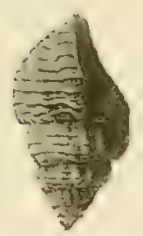

$-$

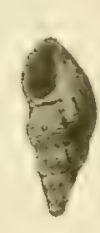

s

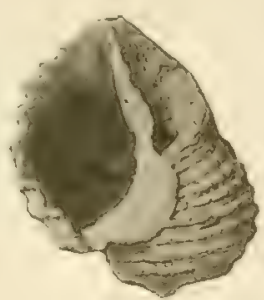

4

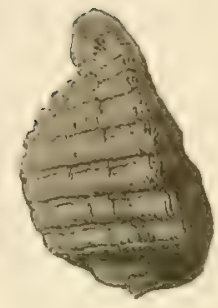

5

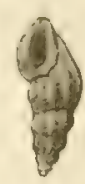

12
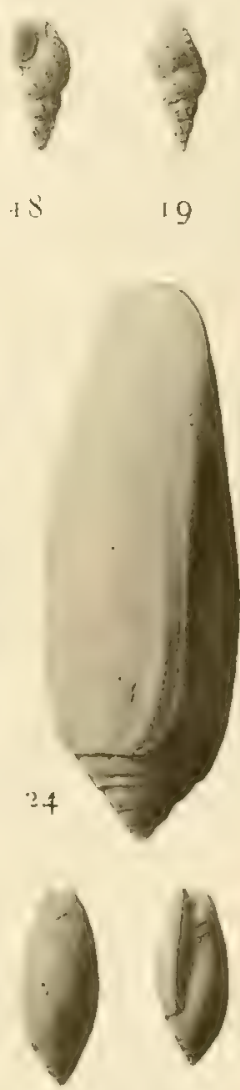

$31, \quad 31$ 



\section{PIANCHE III}

1-f. Baryspira giannforms, Lamk.

i-li. Axchlo biccinornes, Jamk.

7. Sparella debi, Desh.

¿-9. Alocospiza papredata, Tate.

10-11. Octucle stimisea, Conr.

12. Sparelia Aperta, Yass.

13. SPABELLA OBSOLFTA, Br.

1: 1ii. Olvficta mpressi, Vass.

16-1i. Tortoliva canaljena, Lamk.

18. Ancildia pesilda, Fuchs.

19. Cunlopryam extgua, Sow.

afi-21. Spareluiva cimorda, Lamk,

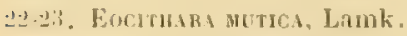

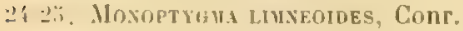

24i. Gibrerlua ovati, Lea.

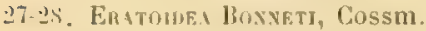

2y-30. Grabelta olagoptraila, Cossm.

31. Marginetia Stephiside, da Costa.

$\begin{array}{ll}\text { Miocène } & \text { grandeur naturelle. } \\ \text { Eocène } & \text { grandeur naturelle. } \\ \text { Eocène } & \text { grandeur naturelle. } \\ \text { Miocène } & \text { grandeur naturelle. } \\ \text { Encène } & \text { grandeur naturelle. } \\ \text { Eocène } & \text { grandeur naturelle. } \\ \text { Miocène } & \text { grandeur naturelle. } \\ \text { Eocène } & \text { grandeur naturelle. } \\ \text { Eocène } & \text { grandeur naturelle. } \\ \text { Miocène } & \text { grossiss' } 3 / 1 . \\ \text { Vivante } & \text { grossiss } 3 / 2 . \\ \text { Pliocène } & \text { grossiss' } 3 / 2 . \\ \text { Eocène } & \text { grandeur naturelle. } \\ \text { Eocène } & \text { grossiss' } 3 / 1 . \\ \text { Eocène } & \text { grossiss' } 3 / 2 . \\ \text { Pliocène } & \text { grossiss' } 2 / 1 . \\ \text { Pliocène } & \text { grossiss' } 3 / 2 . \\ \text { Miocène } & \text { grandeur naturelle. }\end{array}$



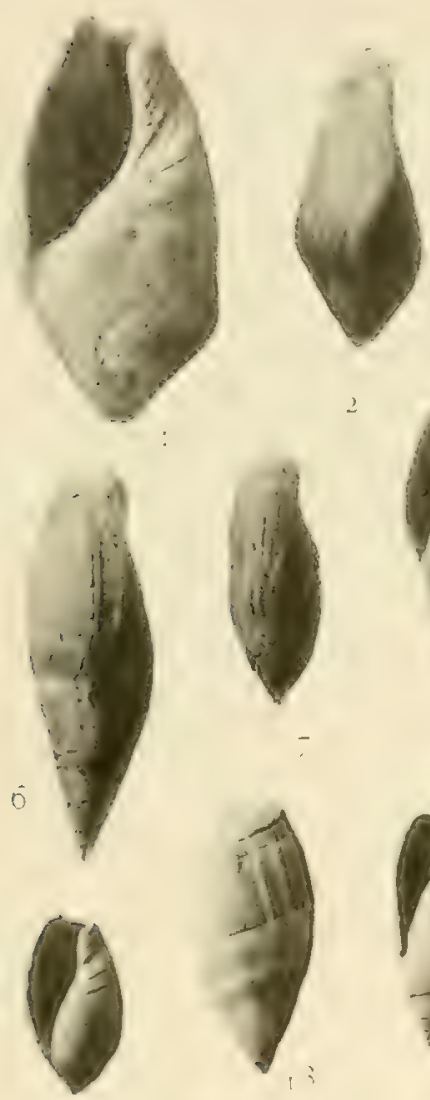

(1)
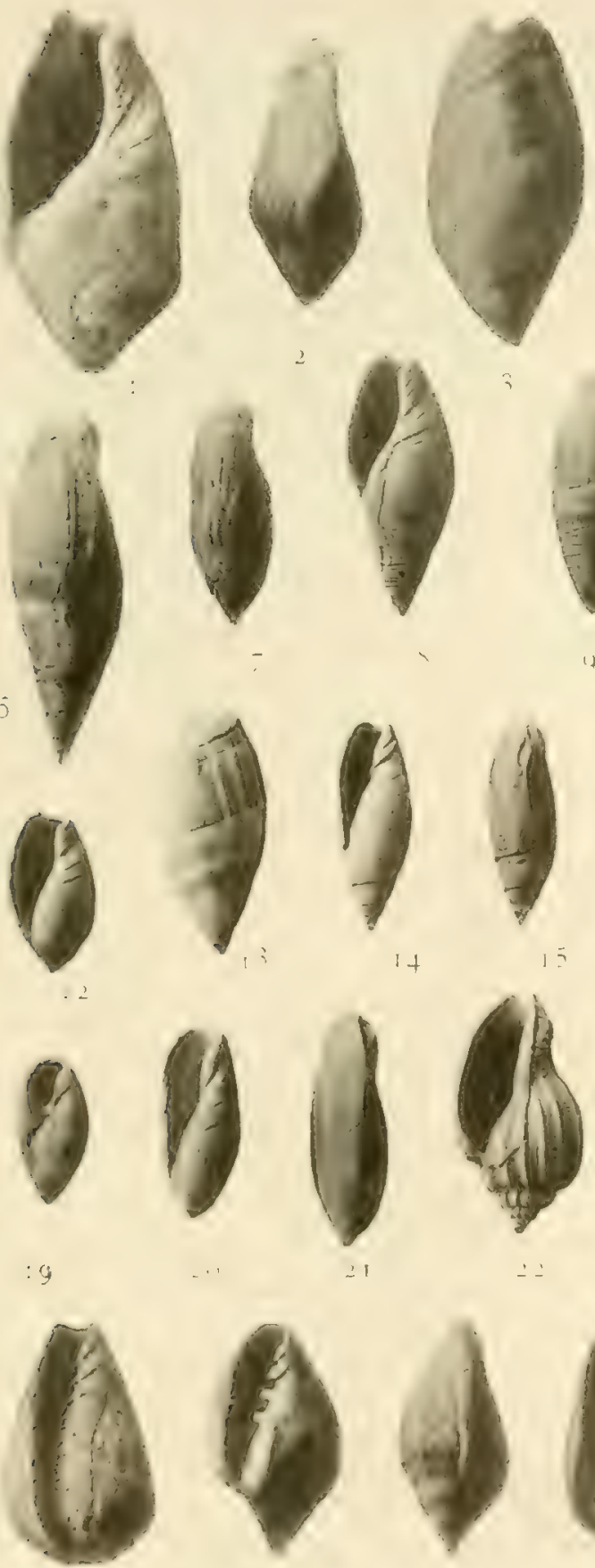

is

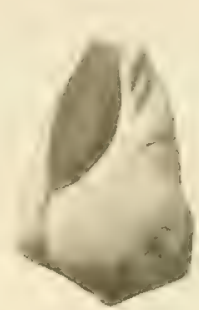

$+$
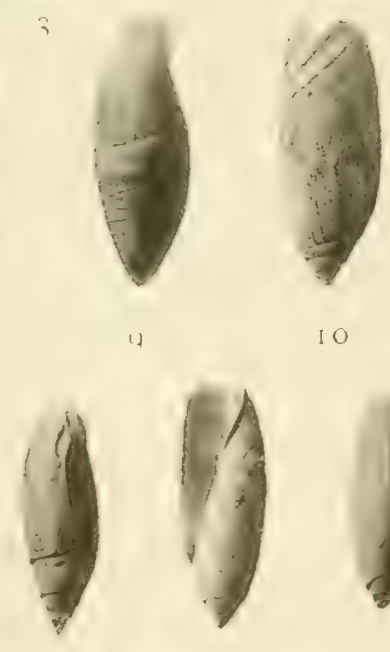

10
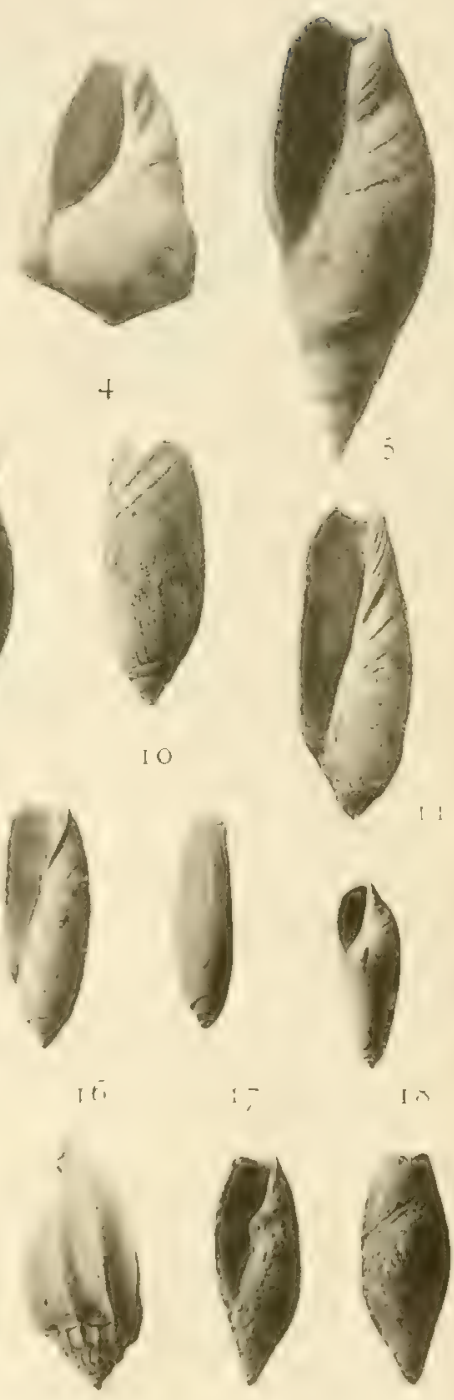

$\therefore$
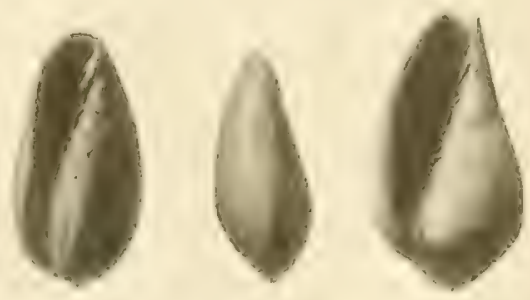

$\therefore$ 




\section{PI.ANCHE IV}

\author{
1-4. Chyptochond stnowbones, llermann. \\ $\therefore$ Mabrinella iunis-lfports, Br. \\ 3. Ilarei Brochoni, Benoist. \\ i. Stazinia emingrata, Bon. \\ 6-7. Faba cissidfonms, Tate. \\ 8. Stizzini dichotomoptycha, Cossm. \\ 9-10. Eunvextone chussilabra, Conrad. \\ 11. Sembata propixqua, Tate \\ 12-13. Grbberula ovllita, Lamk. \\ 14. Fabi puseoles, Brongn. \\ 13. Destimargo dentifera, Lamk. \\ 16. Persictla angystom, Desh. \\ 17. Pensicula Goossexsi, Cossm. \\ 18-19. Ginbercen tectifonms, Cossm. \\ 20. Stazzaxia nichotoxoptren, Cossm. \\ 21. Volvami obloweata, Bon. \\ 2.2. Serhata Wixklem, Tate. \\ 23. Vespertilio Wecd, T. Woods. \\ if. Atmleta Rarispin, Lamk. \\ 2:i-21i. VouUtILItIES sprioses, Lamk.
}

\begin{tabular}{|c|c|}
\hline Eocène & grandeur naturelle. \\
\hline l'liocène & grandeur naturelle. \\
\hline Miocène & grandeur nalurelle. \\
\hline Miocène & $\operatorname{grossiss}^{\mathrm{t}} 3 / 2$. \\
\hline Eocène & grossiss $^{\mathfrak{5}} 5 / 1$ \\
\hline Eocène & grossiss' $3 / 1$. \\
\hline Eocene & grossiss' 2/1. \\
\hline Eocène & grossiss' 2/1. \\
\hline Eocène & grossiss $2 / 1$ \\
\hline Eocène & grandeur naturelle. \\
\hline Eocène & grossiss $3 / 1$. \\
\hline Encène & grossiss $2 / 1$ \\
\hline Eocène & 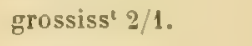 \\
\hline Pliocène & grossiss' $3 / 1$ \\
\hline Eocène & grossiss' $3 / 1$ \\
\hline Miocẻne & grossiss $3 / 2$ \\
\hline Eocène & grossiss $2 / 1$. \\
\hline Eocène & grandeur naturelle. \\
\hline Miocène & grandeur naturelle. \\
\hline Eocène & grandeur naturell \\
\hline
\end{tabular}


Essais de Paléoconchologie, M. Cossmann (30 livr.)

PI. IV
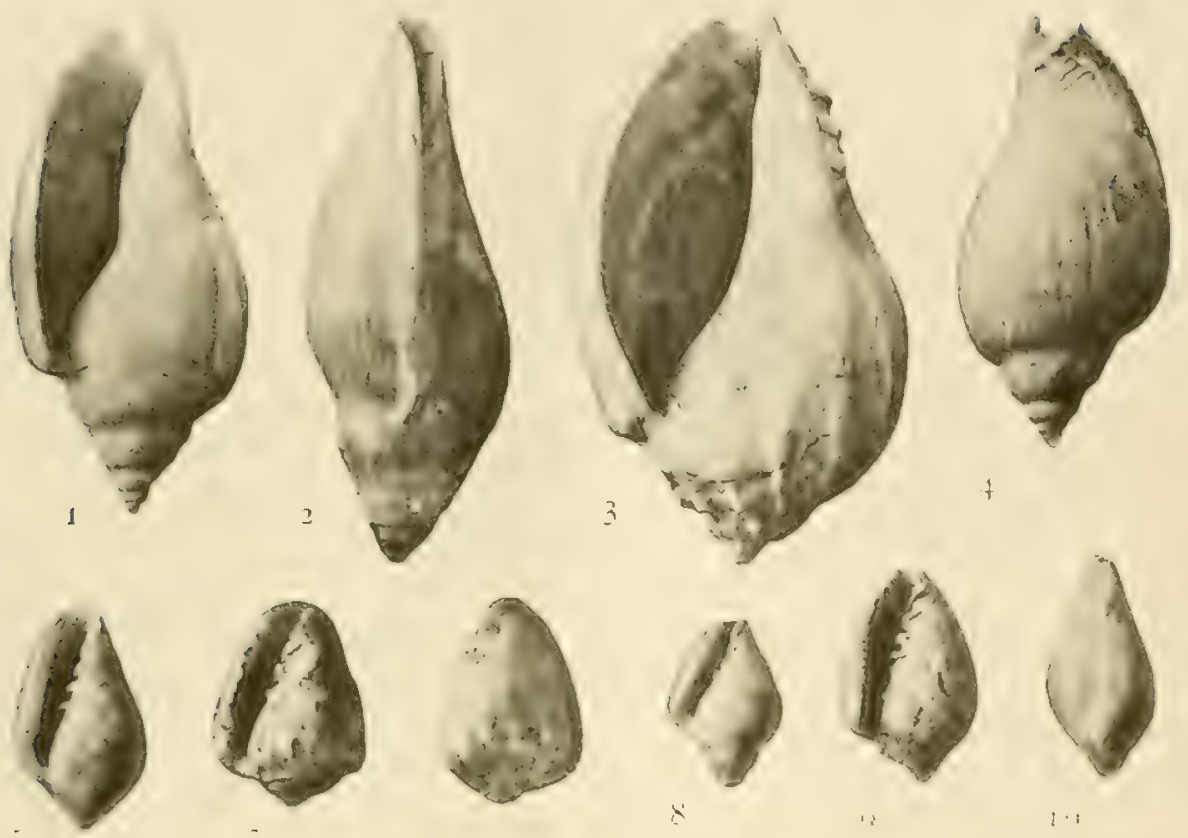

j

i)
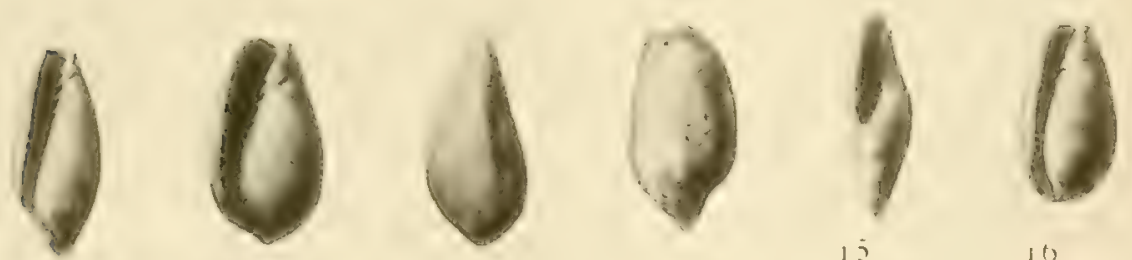

II

12

13

14
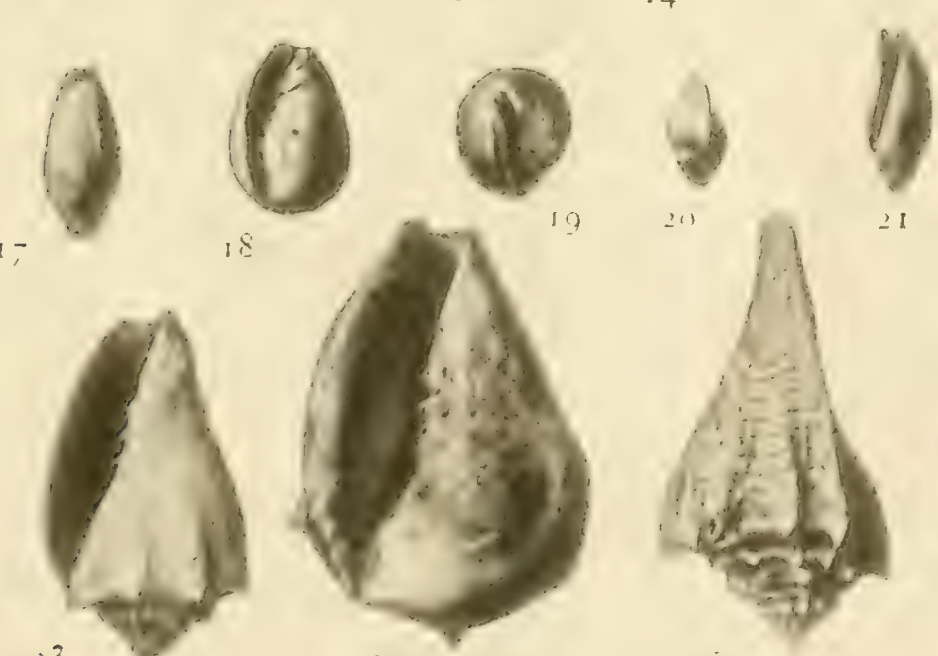

$\therefore$

10
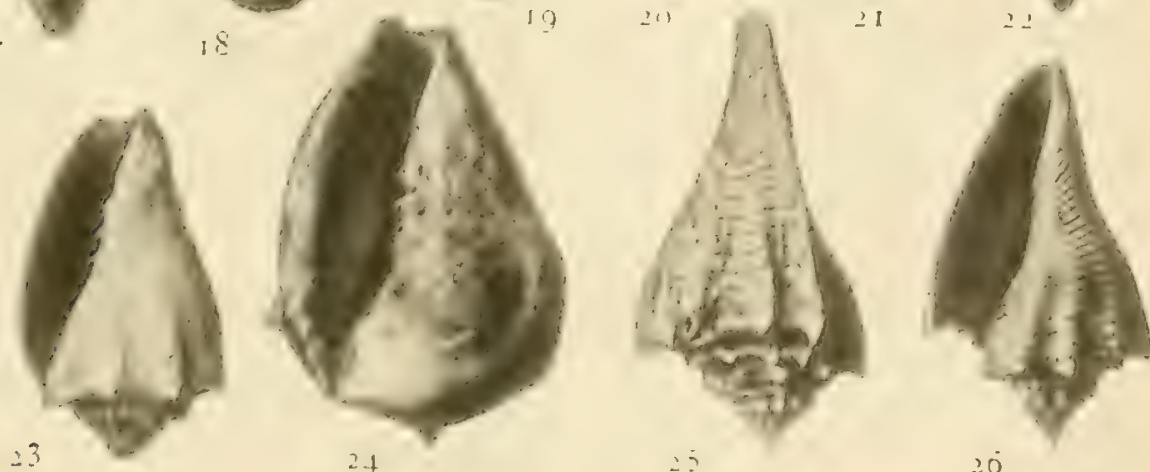

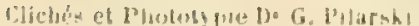






\section{PLANCHE V}

1. Volutocoris chexulifera, Bayan.

2. Eupserhali angusta, Desh.

3. Neontmeeta cithaba, Lamk.

4. Volumithes axtiscalanis, Mc. Coy

5. Aтnleti Thoney, Conrad.

6. Neoithleti ventricosi, Defr.

7-8. Citbicella pinchoides, Conrad.

9. Lyih tuligidula, Lamk.

10. Anomi Masoxi, Tate.
Eocène grandeur naturelle.

Eocène grandeur naturelle.

Eocene grandeur naturelle.

Eocène grandeur naturelle.

Eocine grandeur naturelle.

Eocéne grandeur naturelle.

Eocène grandeur naturelle.

Eocène grandeur naturelle.

Miocène grandeur naturelle. 

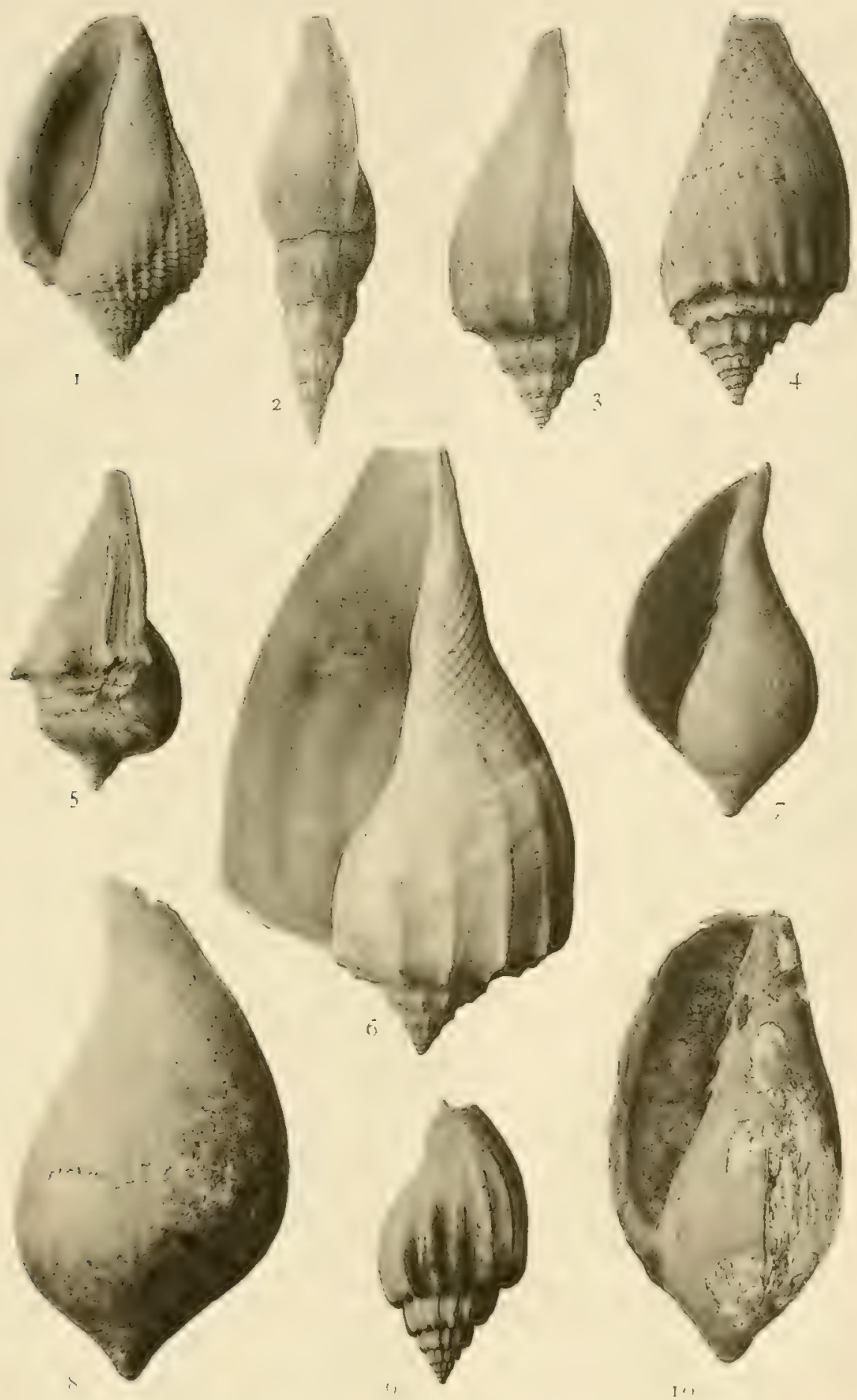




\section{PLANCHE VI}

1. EOPSEPHEA MURICINA, Lamk.

Eocène grandeur naturelle.

2. Scaphella Lambeiti, Sow.

Pliocène grandeur naturelle.

3. Aunwa viginians, Conrad.

Miocène grandeur naturelle.

4. Pterospira Mortoni, Tate.

Eocène grandeur naturelle.

5. Scaphelat mochica, Fisch, et Tourn.

Miocène grandeur naturelle.

6. Pterosplis Hixxafond, Mc. Coy.

Eocène grandeur naturelle.

7. Amohra Masoni, Tate.

S. Vespertilio Welni, T. Woods.

Eocène grandeur naturelle.

9-10. Lyta napuli, Lamk.

Eocène

Eocène grandeur naturelle. grandeur naturelle. 
Essais de Paléoconchulogic, M. Cossmann (3e livr.)

PI. VI

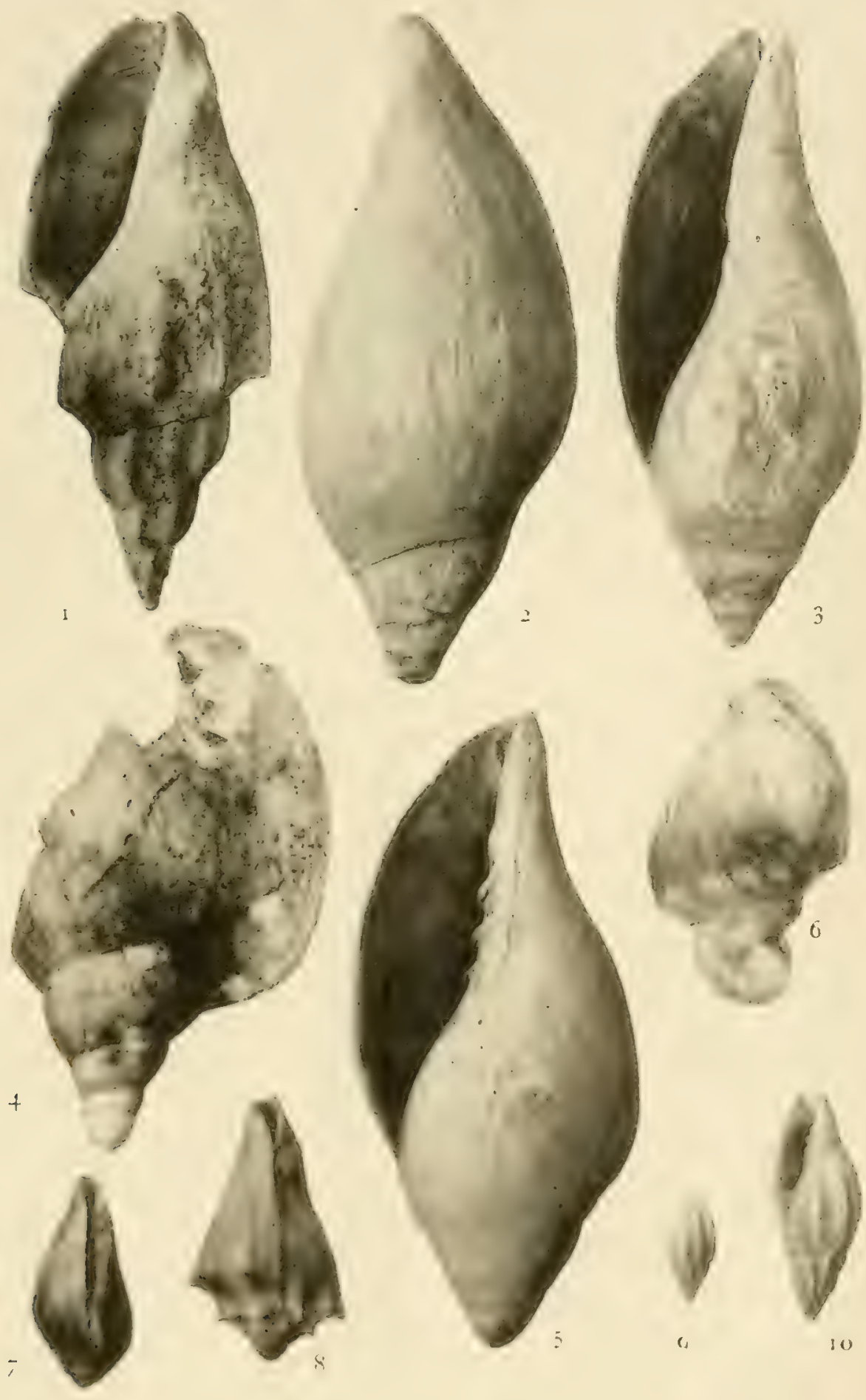





\section{PLANCHE VII}

1-2. Leptoscaphi vinctlosi, Lamk.

3. Voutoconts Coxuders, Tate.

4-5. Volnta micsicilis, Lamk.

6. Alcithoe axcillomes, Tate.

7-8. HarPLA MTHEOL., Lamk.

9. Yetus proboscmilis, Lamk.

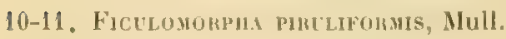

12-13. Mitra elosgata, Lamk.

$\begin{array}{ll}\text { Eocène } & 3 / 2 \\ \text { Eocène } & \text { grandeur naturelle. } \\ \text { Eocène } & \text { grandeur naturelle. } \\ \text { Eocène } & \text { grandeur naturelle. } \\ \text { Eocène } & 3 / 1 . \\ \text { Vivante } & \text { grandeur naturelle. } \\ \text { Sénonien } & 3 / 2 . \\ \text { Eocène } & \text { grandeur naturelle. }\end{array}$



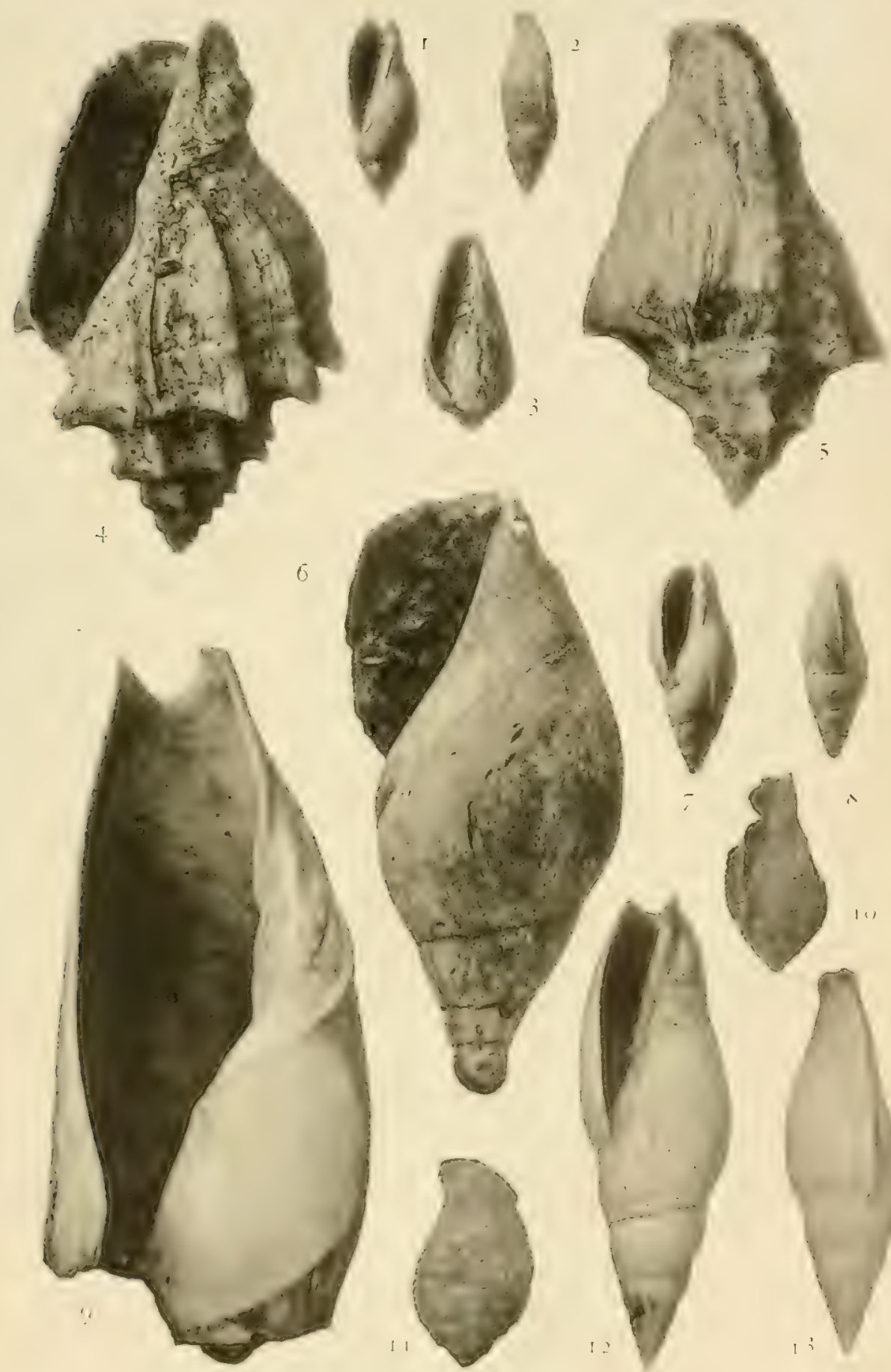

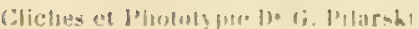
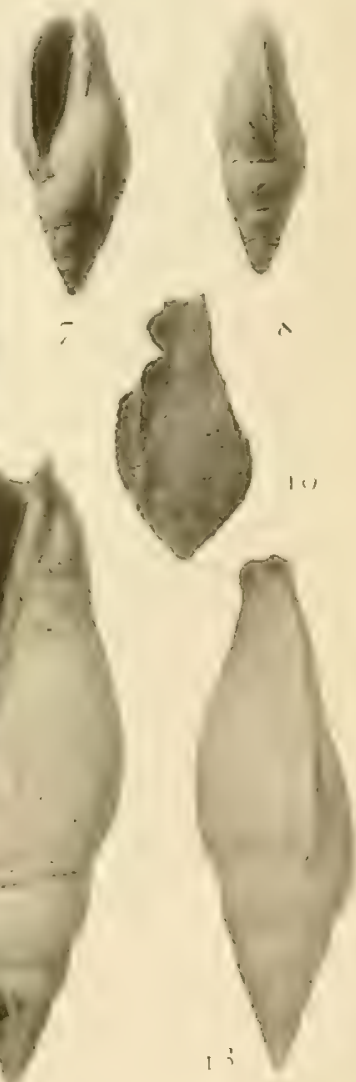

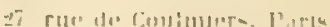






\section{PLANCHE VIII}

1. Coxomitri fisotdrs, Lex.

2. Coxinitma vixcexti, Cossm.

3. Costelluir pilcienstata, Tate.

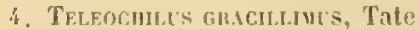

5-6). Tirala pita Dujard.

7. Mithosizy olivoldes, Cant.

8. Lupromit nemest, Cont.

1. Luppant Mnumeixi, Galib.

10. Phoptyam canolinexse, Conr.

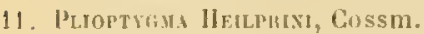

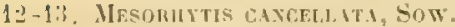

1'. Mesonuyts rolita, Gabb.

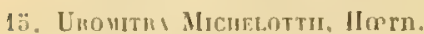

16-17. Caxchla exorxit., Bell.

18-19. Мrtheoi.i labbittia, Lamk.

20-21. Terbictia tumocostita, Cossm.

ㄱ-2 Vocvmis вгthomes, Lamk.

23. Vulvaha act tuserta, Sow.

zi. Mitrolingi Rovasenon. Boll.

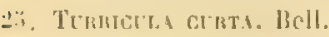

2ti. Conthlahina inturtelda, Cossm.

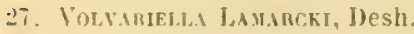

2.'. Costellama comegata, Defr.

"2. Fismitri extraxen, Desh.

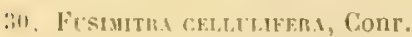

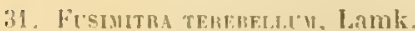

::- Unomitra cichasesis. Brocchi.
Encène grossiss $3 / 1$.

Eocène renssiss' $3 / 1$.

Eocène grossiss $3 / 1$.

Focine grandeur naturelle.

lliocène grossiss' 31.

Pleistocène grossiss' $3 /$.

Eocène grandeur naturelle.

Paléocène grindeur naturelle.

Miocène rêd. 1/2.

Plincene grandeur naturelle.

Turonien grandeur naturelle.

Paléocène grandeur naturelle.

plincène grossiss 3,2 .

Mincène grandeur naturelle.

Encène grossisst $3 / 2$.

Pliocene grossiss $3 / 1$.

Encene grossiss 32.

Eocène grossiss $3: 2$.

Miocéne grandeur naturalle.

Ilincène grandeur naturelle.

Eorène grossiss' 2/1.

Eocene grandeur naturelle.

Plincène grossisst $2 / 1$.

Vincene grossiss' $3 / 2$.

Oligrocéne grossiss 32.

Encenc urossisst 32.

Pliocine granleur naturelle. 
Essais de Paléoconcholuctie, M. Cossmann (3e livr.)

Pl. VIII.

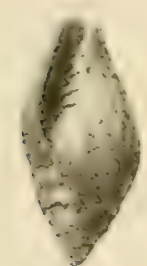

1

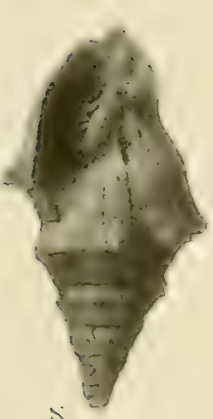

2
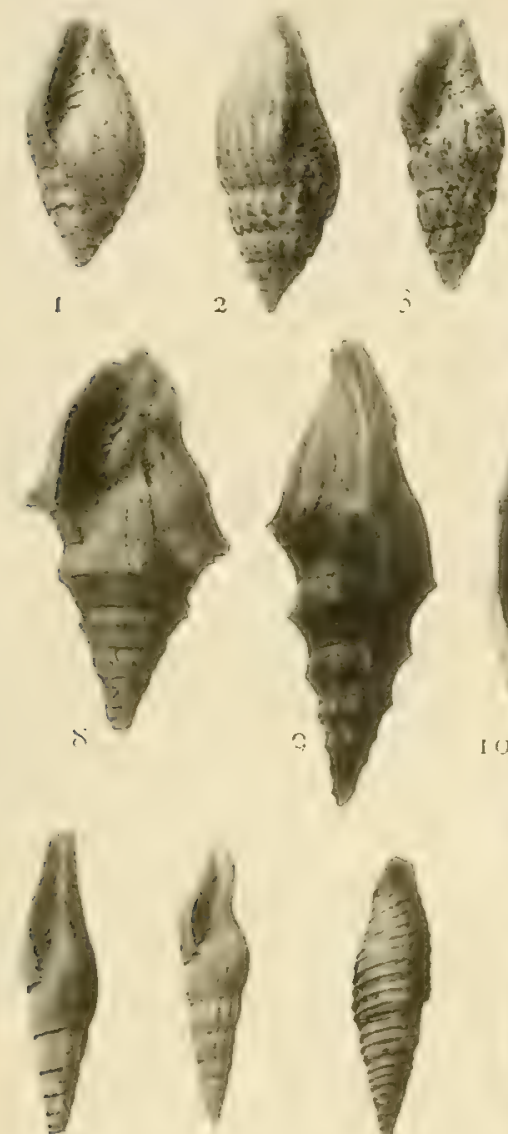

I 1
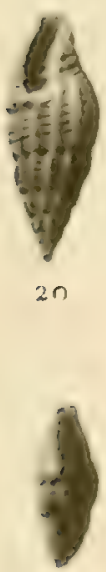

1

26
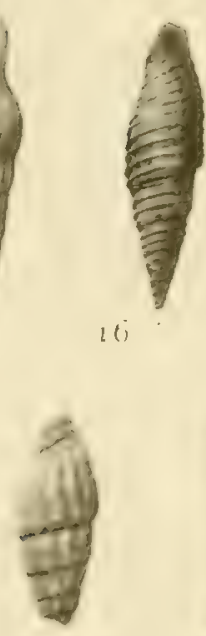

21

$2-$
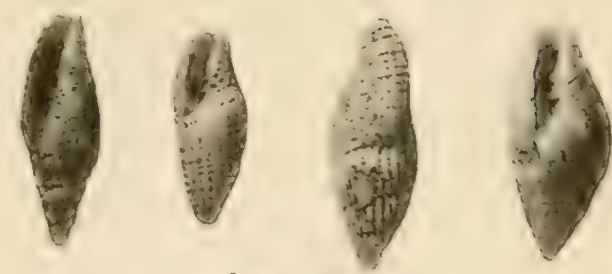

$+$
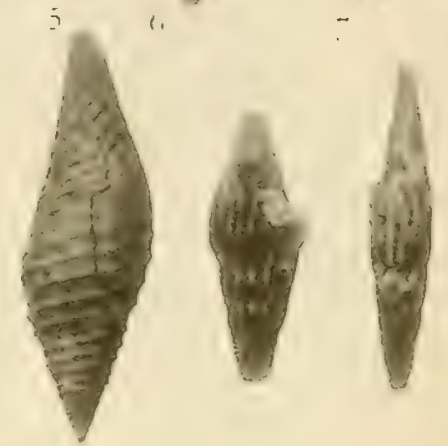

11

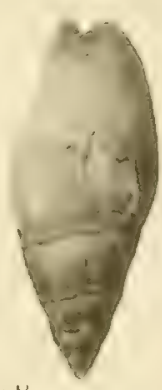

is

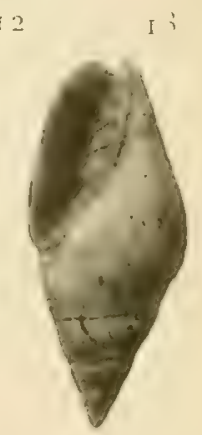

19
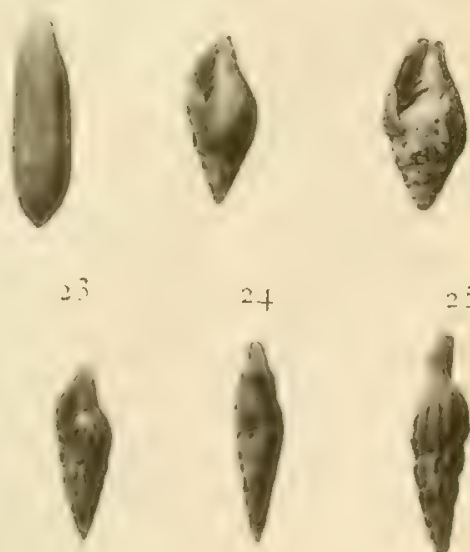

$\because 9$

is

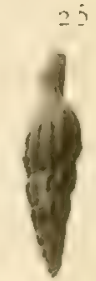

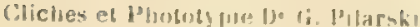














\section{(anamas $3908800560 \quad 4392$

A howhah

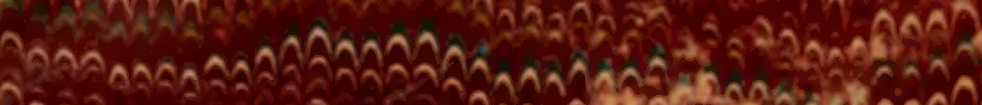
WMTMAMA

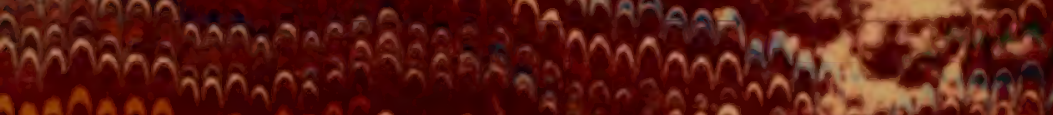

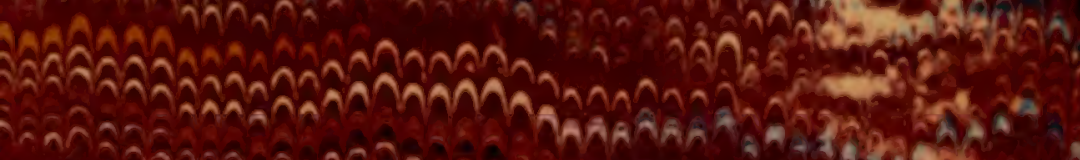

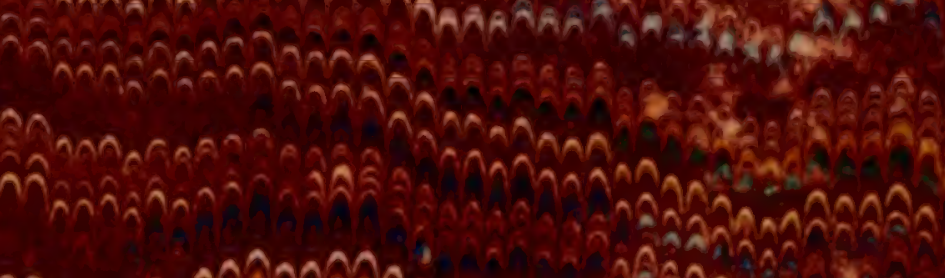

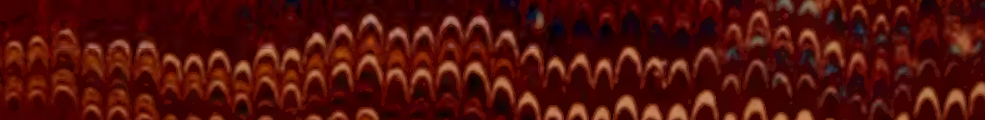
267)

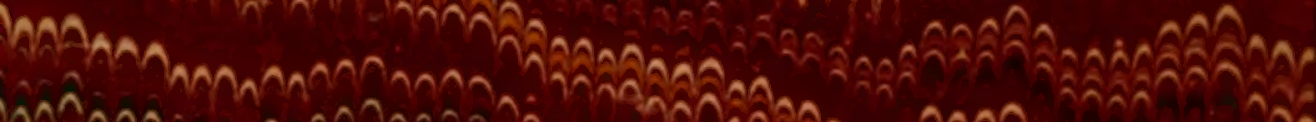

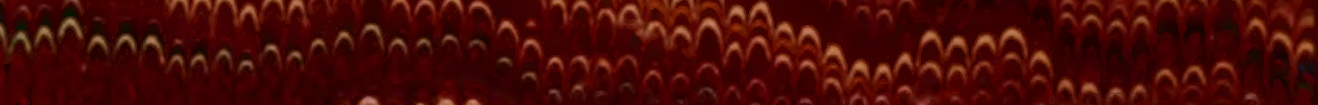

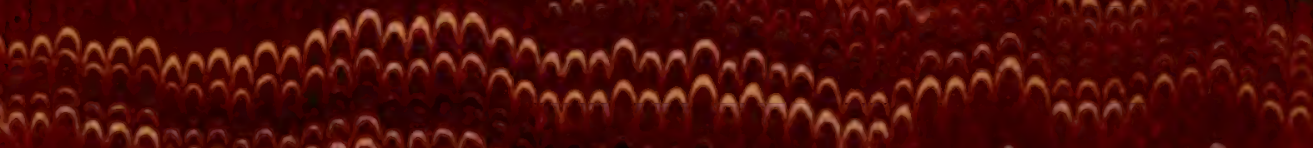
MANATANATAMNATA

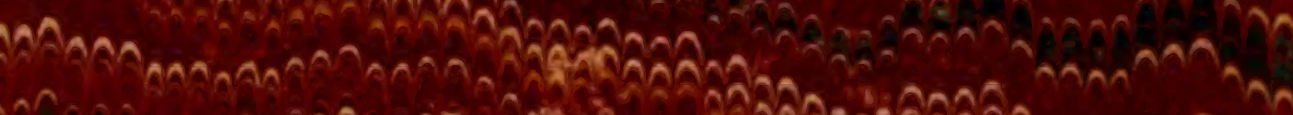

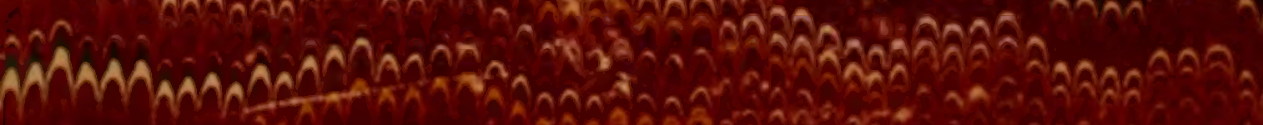

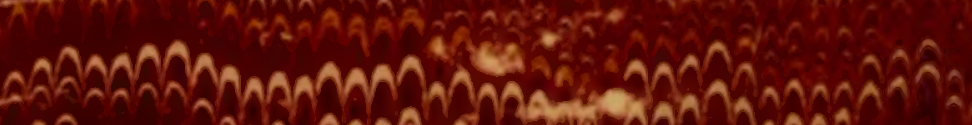
AWW ŴA

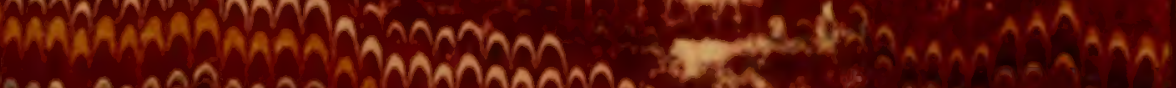
TAMAPA जि

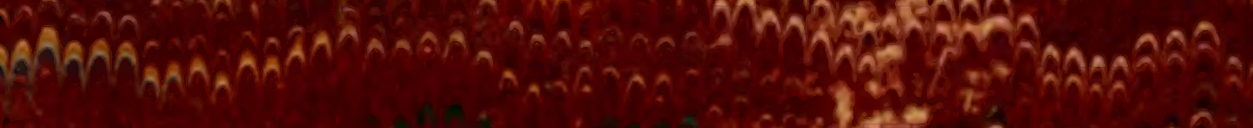

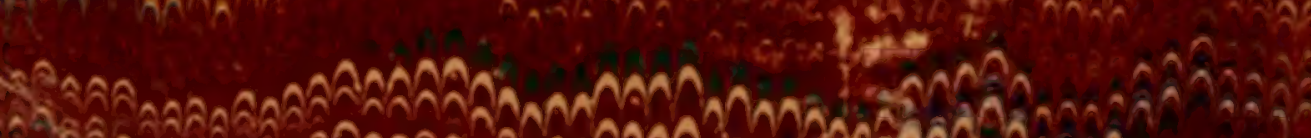

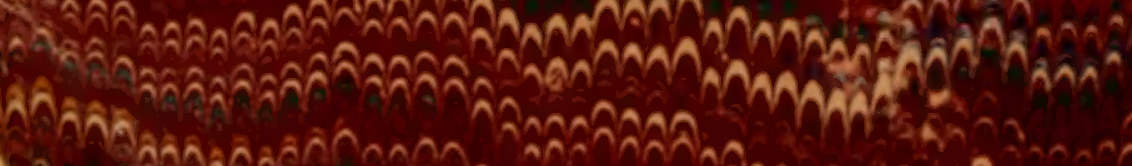
AMWWAN

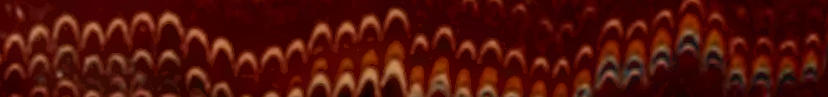
GतN NAMAOAARAA 